\title{
METAMORPHISM AND THE $P$-T $T$ HISTORY OF ALPINE SCHIST FROM THE NEWTON RANGE, SOUTHERN ALPS, NEW ZEALAND
}

Dave B. Murphy

A thesis submitted to

Victoria University of Wellington,

in partial fulfilment of the requirements for the degree of

$$
\begin{gathered}
\text { Master of Science } \\
\text { in Geology }
\end{gathered}
$$

School of Geography, Environment and Earth Sciences

Victoria University of Wellington 


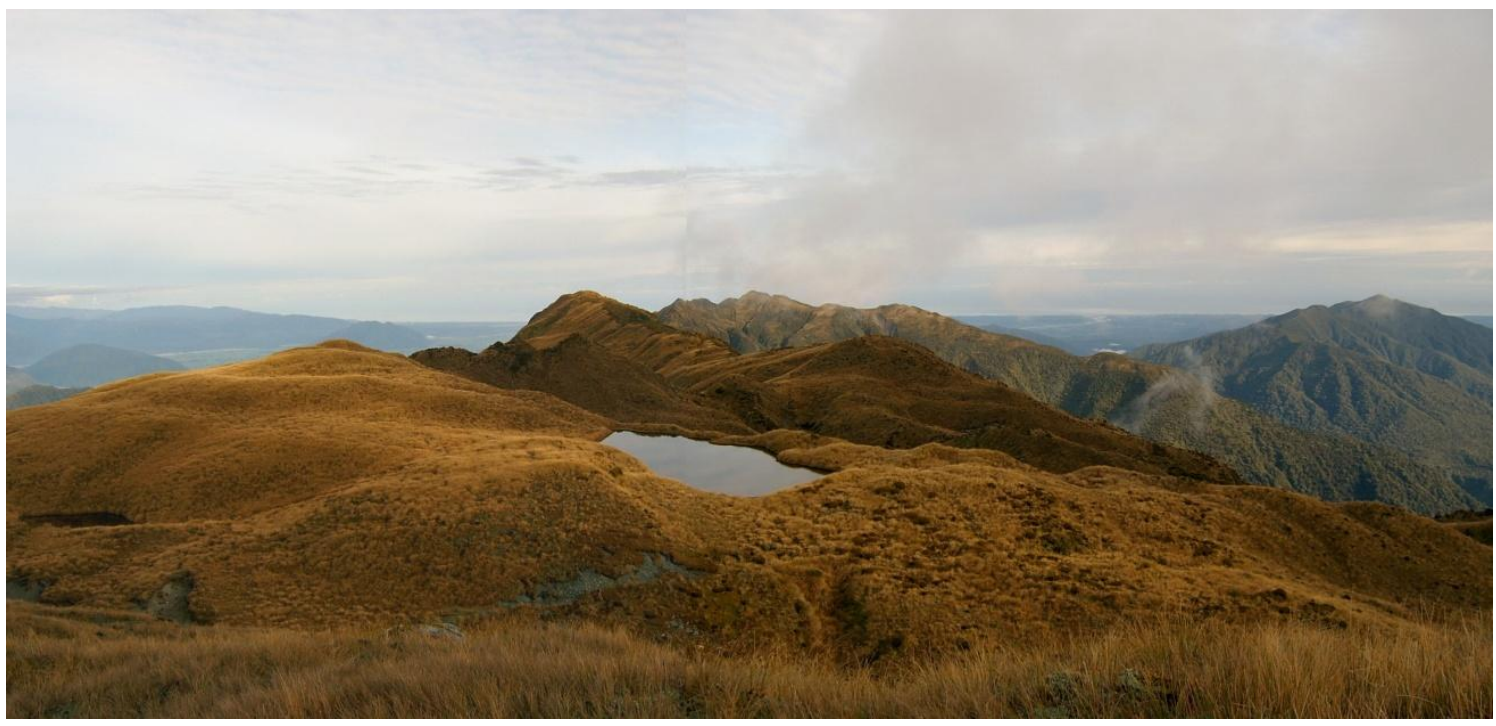

Frontpiece. The tussocky ridge atop the Newton Range, seen through a rare break in the clouds. Photo is taken in the centre of the SE section, looking westward to the NW section (farthest most hilltops in centre of picture). 


\section{ABSTRACT}

Metamorphic rocks have the potential to record in their mineral assemblages, mineral compositional zoning, and textures, information about geological changes and processes that occur during tectonic events. Interpretations of metamorphic pressure-temperature (P-T) records have traditionally relied on results of geothermobarometry studies, but that approach is not suitable in every case. Metamorphosed greywacke, which makes up $~ 95 \%$ of the New Zealand Southern Alps, has long proven problematic for traditional geothermobarometry because it develops intractable mineral compositions and/or assemblages, especially at relatively low temperature (greenschist facies) conditions. An alternative forward modelling approach using the computer program THERMOCALC was recently used to extract the first detailed P-T history (P-T path) from such previously intractably difficult "greyschist" rocks from a single site in the New Zealand Southern Alps. The present study is the first attempt to apply those new methods to rocks from another study area, and is the first detailed geological study of the Newton Range in the New Zealand Southern Alps.

The Newton Range is a $\sim 15 \mathrm{~km}$-long, east-west trending range located $\sim 30 \mathrm{~km}$ southeast of the town of Hokitika, $\sim 110 \mathrm{~km}$ northeast of the Franz Josef-Fox Glacier region, and immediately to the east of the Alpine Fault in the Southern Alps, South Island, New Zealand. The rocks in the Newton Range are mainly derived from Torlesse Terrane accretionary prism greywacke and argillite (Alpine Schist, greyschist), together with a large pods of ultramafic rock (part of the Pounamu Ultramafic Belt (PUB)) and minor associated metabasic layers (greenschist), all metamorphosed to greenschist facies conditions. The dominant mineral assemblage in the greyschist $(\mathrm{Qtz}+\mathrm{Ms}+\mathrm{Bt} \pm \mathrm{Chl} \pm \mathrm{Ep} \pm$ $\mathrm{Pl} \pm \mathrm{Ilm} \pm \operatorname{Ttn} \pm$ Grt \pm Zrn \pm Tur \pm Ap \pm Cal), much like that found elsewhere in the Southern Alps.

As elsewhere in the Southern Alps, the dominant high-grade metamorphic mineral assemblages in the Alpine Schist in the Newton Range are inherited. The mineral assemblages, compositions, and some textures thus record evidence of processes that took place during tectonic events, presumably mainly in Cretaceous time, prior to the formation of the modern Southern Alps, which are forming today by the ongoing oblique continent-continent collision of the Pacific Plate against the Australian Plate at the Alpine Fault. 
Compositional zoning in garnet from the greyschist is an important record of the metamorphic P-T path traversed by the host rock as the garnet grew. Occasionally, garnet from the study area contains an inmost core (stage 0) of unusual (anomalously high- or low-MnO) composition. The cores with extremely low $\mathrm{MnO}$ are possibly detrital in origin, and those with extremely high $\mathrm{MnO}$ may perhaps have grown in the early tectonic episode that formed the Otago Schist. Typically, garnet shows the following core- to rim zoning sequence. Stages $1 \& 2$ show a progressive decrease in $\mathrm{MnO}$ and increase in $\mathrm{FeO}$ from core to rim, with higher $\mathrm{MnO}$ cores present in rocks with higher whole-rock $\mathrm{MnO}$ compositions. Stage 3 is characterised by a gradual decrease in $\mathrm{CaO}$ and signifies the growth of Ca-bearing oligoclase late in the garnet growth history. Stage 4 is a discontinuous overgrowth characterised by an abrupt increase in $\mathrm{CaO}$. Such overgrowths have in the past been attributed to garnet growth accompanying the development of the Alpine Fault mylonite zone in the late Cenozoic. In the Newton Range they were only observed on garnet adjacent to the main outcrop of the PUB at $\sim 4.5 \mathrm{~km}$ from the Alpine Fault, far from the mylonite zone, so local element availability during decompression (and possibly fluid flow and/or metasomatism) may have played a part in the growth of these rims.

A P-T path for Alpine Schist from the Newton Range has been estimated using detailed garnet composition data measured along core-to-rim transects across individual garnets, together with predicted garnet compositions and P-T pseudosection results calculated using THERMOCALC. The P-T path starts at $\sim 3.5 \mathrm{kbar} / 400^{\circ} \mathrm{C}$, where both garnet and albite coexist, and increases in pressure and temperature to $\sim 6.5 \mathrm{bar} / 500^{\circ} \mathrm{C}$ where garnet coexists with both albite and oligoclase. The estimated peak metamorphic conditions probably correspond to peak metamorphic pressures, unlike in the Franz Josef-Fox Glacier region where peak conditions $\left(\sim 9.2 \mathrm{kbar}\right.$ and $\left.620^{\circ} \mathrm{C}\right)$ probably coincided with peak metamorphic temperatures. 
ABSTRACT

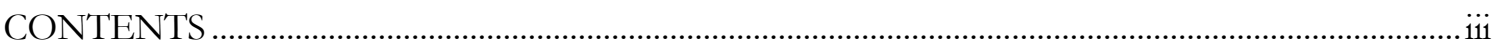

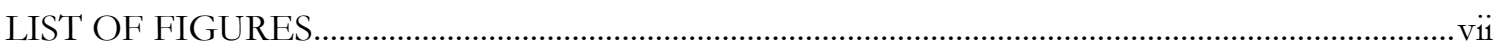

LIST OF TABLES ………………………………………..........................................................

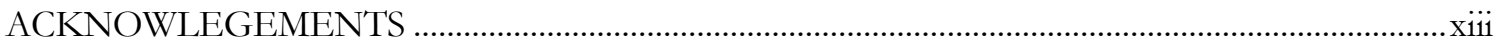

\section{1: PREAMBLE}

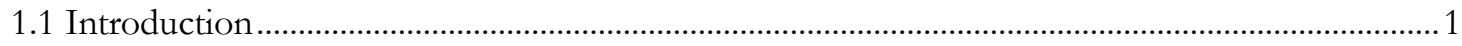

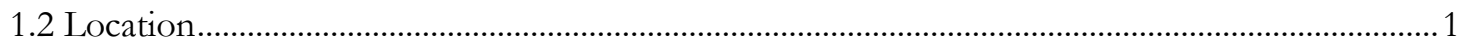

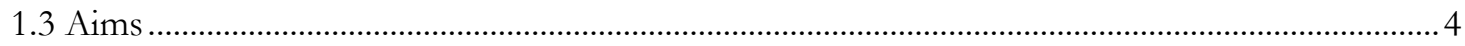

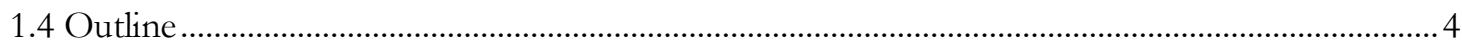

\section{2: BACKGROUND \& TECTONIC SETTING}

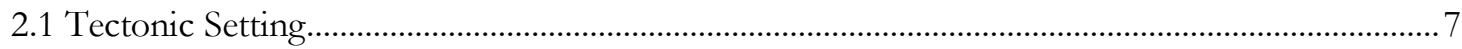

2.2 Haast Schist Overview ................................................................................................................10

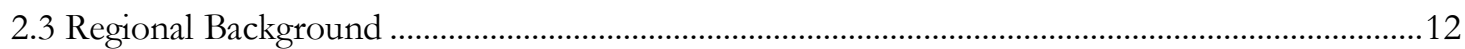

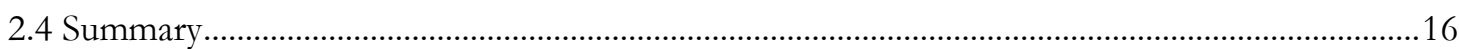

\section{3: FIELD OBSERVATIONS}

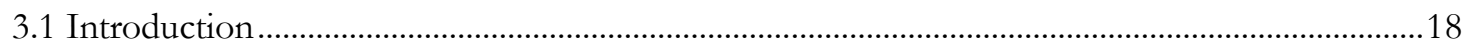

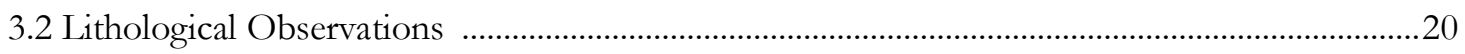

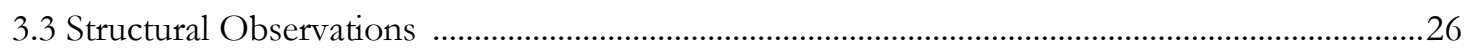

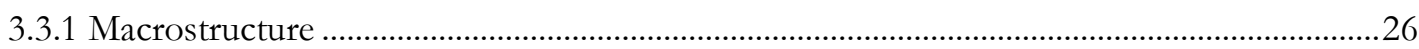

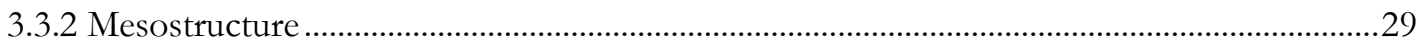

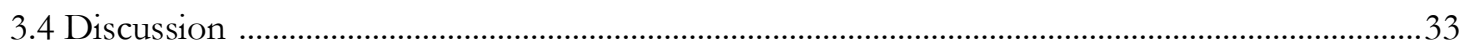

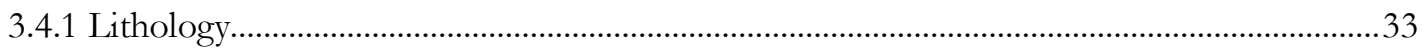

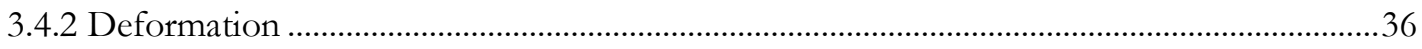

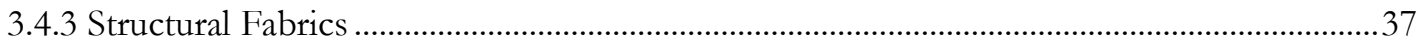

3.4.4 Role of PUB in Deformation of the Dominant Foliation .......................................................38

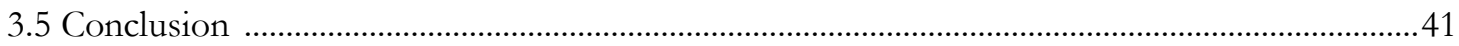




\section{4: PETROGRAPHY \& MICROSTRUCTURE}

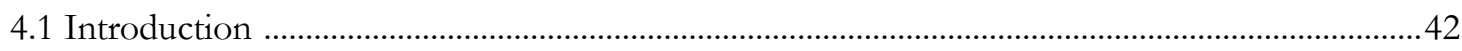

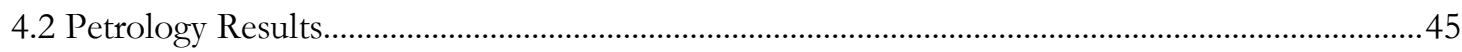

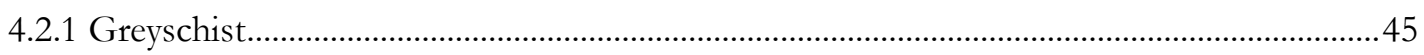

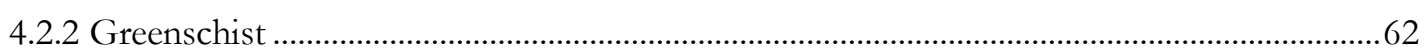

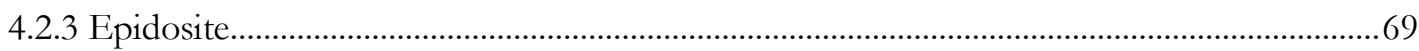

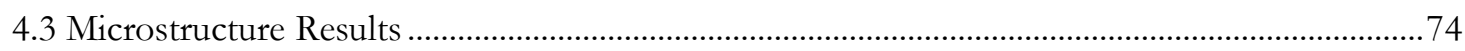

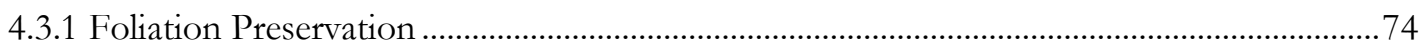

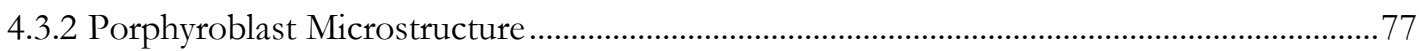

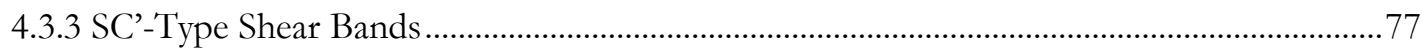

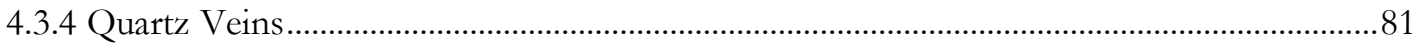

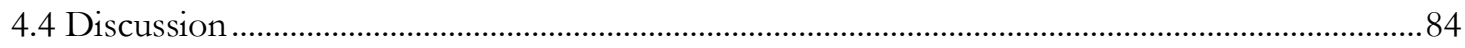

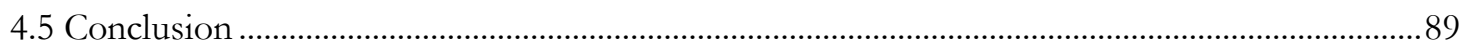

\section{5: WHOLE-ROCK GEOCHEMISTRY \& TERRANE AFFINITY}

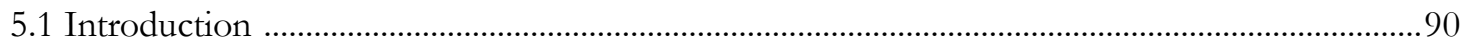

5.2 Haast Schist Protolith Terranes ................................................................................................... 90

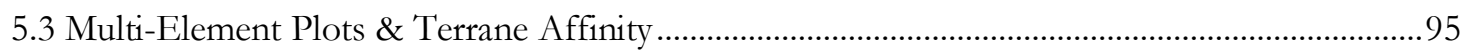

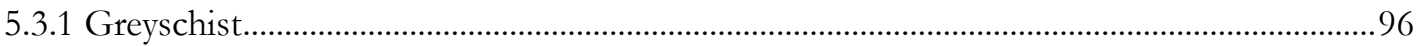

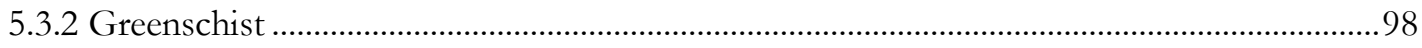

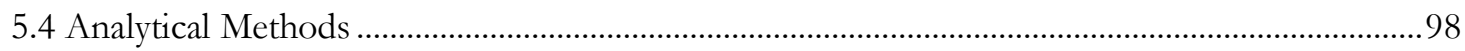

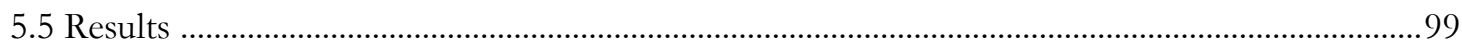

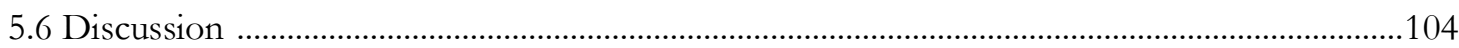

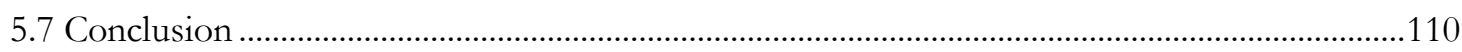

\section{6: MINERAL CHEMISTRY}

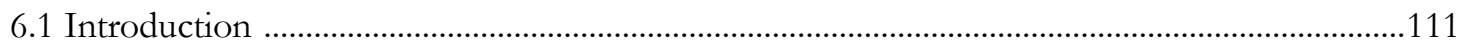

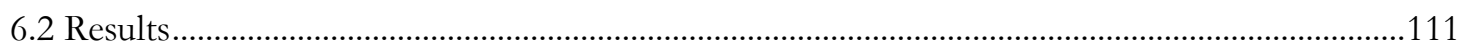

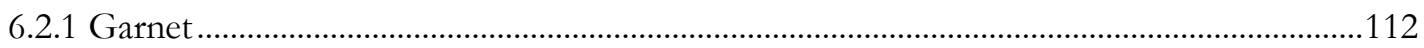

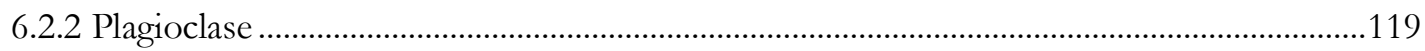

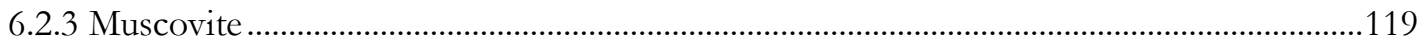

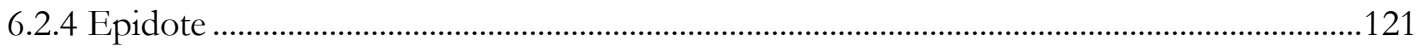

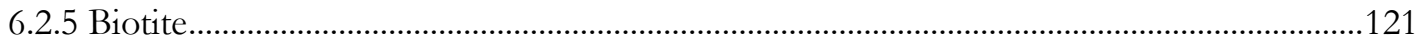

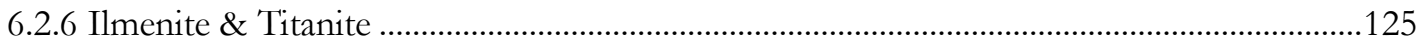

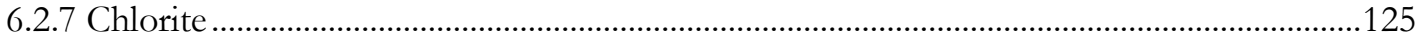




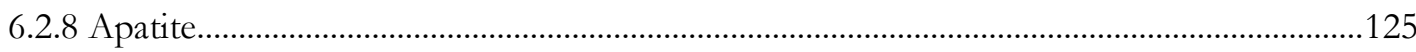

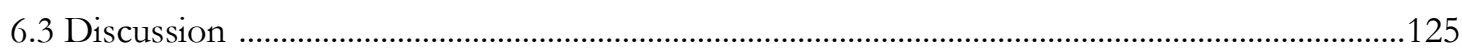

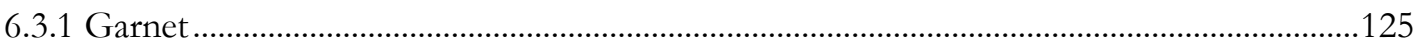

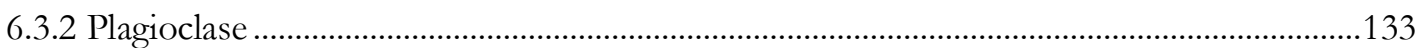

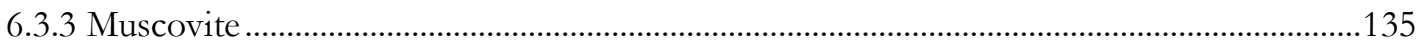

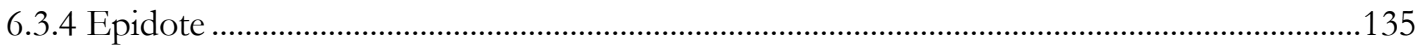

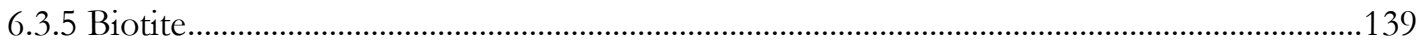

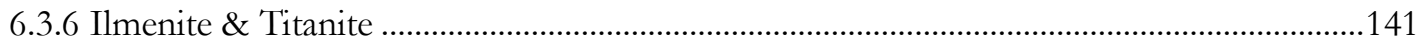

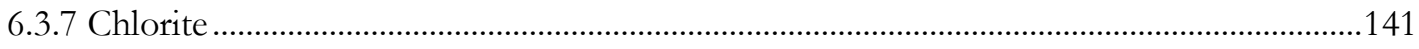

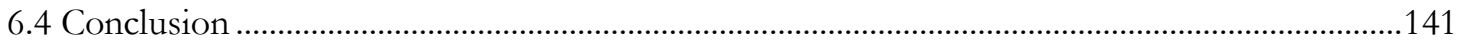

\section{7: THERMOCALC \& P-T PATHS}

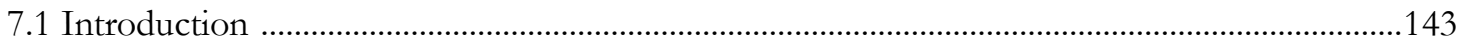

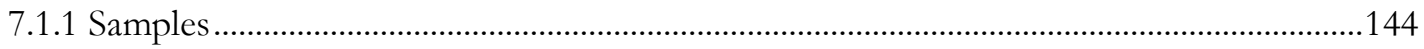

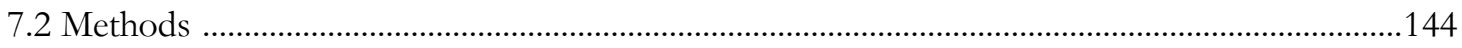

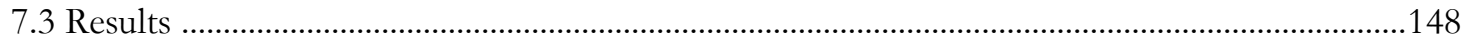

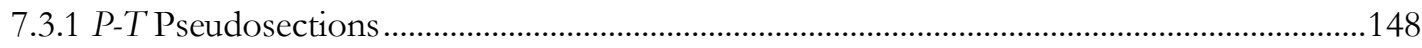

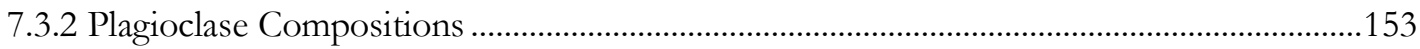

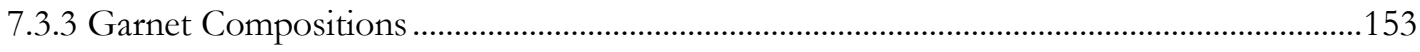

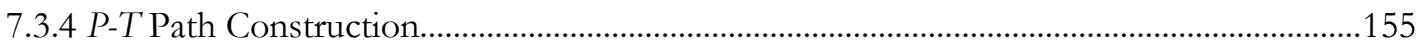

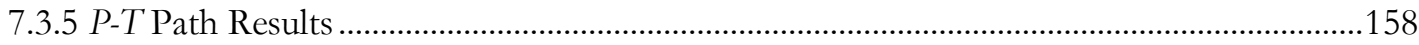

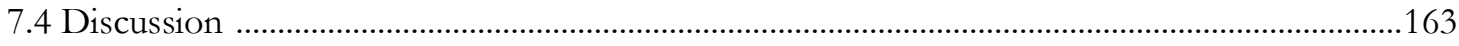

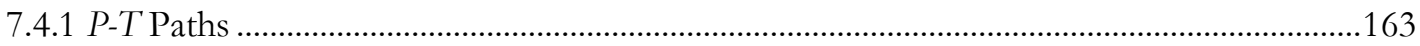

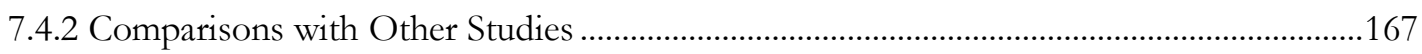

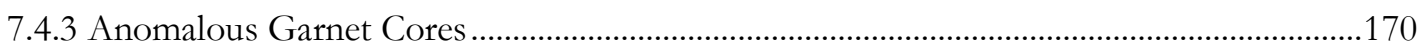

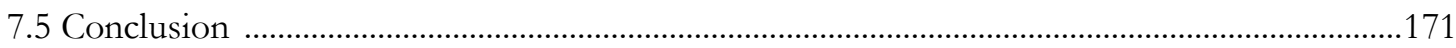

\section{8: SUMMARY \& SUGGESTIONS FOR FUTURE RESEARCH}

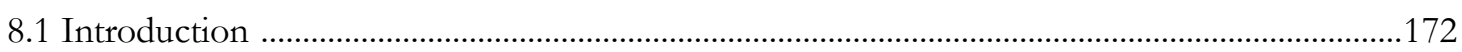

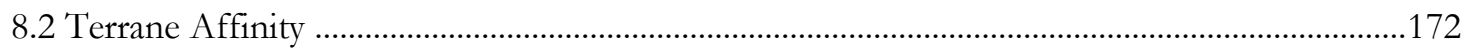

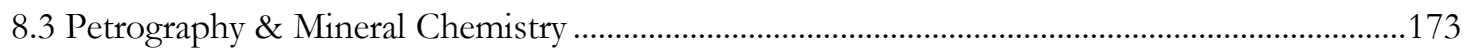

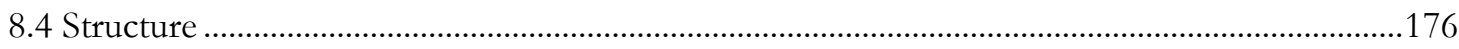

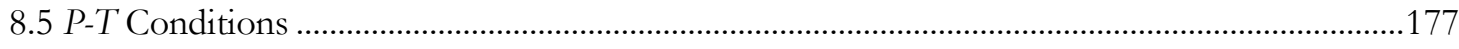

8.6 Variations in Metamorphic Grade - Tectonic Implications .........................................................178

8.7 Future Research.......................................................................................................................179 


\section{APPENDICIES}

A1.1: Structural observation and sample location data .194

A1.2: Outcrop-scale fold and fault data .195

A2.1: Mineral assemblage information for all 108 samples .196

A2.2: Orientation of SC'-type shear bands .197

A3.1: Microprobe Analyses of Garnet .199

A3.2: Microprobe Analyses of Plagioclase .223

A3.3: Microprobe Analyses of Muscovite .226

A3.4: Microprobe Analyses of Epidote .228

A3.5: Microprobe Analyses of Biotite .231

A3.6: Microprobe Analyses of Titanite, Ilmenite and Apatite .234

A3.7: Microprobe Analyses of Chlorite .235

A4.1: Activity-composition models .236

A4.2: Activity-composition model input file. .237

A4.3: Chapter seven mineral abbreviations .241 


\section{LIST OF FIGURES}

\section{1: INTRODUCTION}

1.1 Map of the South Island and north Westland region showing major faults . .2

1.2 Map of the area surrounding the Newton Range …………………………..................................

1.3 Map of numbered sample locations .....................................................................................

\section{2: BACKGROUND \& TECTONIC SETTING}

2.1 Regional tectonic setting and metamorphic grade of the Haast Schist, South Island . .8

2.2 P-T conditions of garnet growth in Alpine Schist from north Westland ....................................14

2.3 Map of north Westland showing the location of previous studies 15

\section{3: FIELD OBSERVATIONS}

3.1 Map of sample locations and lithologies 19

3.2 Photo of pelitic and psammitic layering in greyschist ...................................................................21

3.3 Photos of greyschist samples from different textural zones .........................................................21

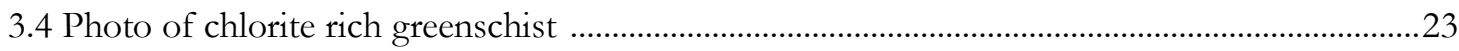

3.5 Photo of banded epidosite and chlorite rich greenschist ................................................................23

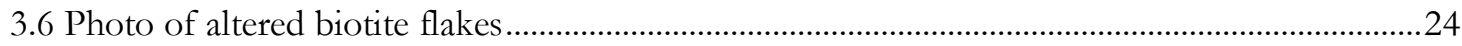

3.7 Photo of an outcrop of greyschist with necked quartz veins .......................................................24

3.8 Photo showing a $\sim 1 \mathrm{~m}$ thick quartz vein .......................................................................................25

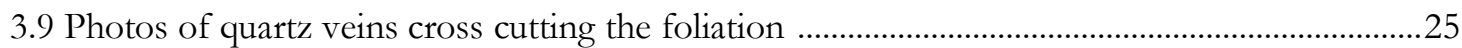

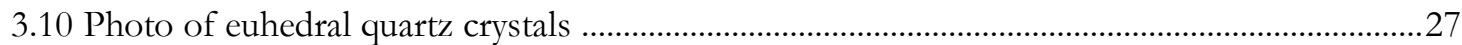

3.11 Map of locations of Pounamu Ultramafic Belt outcrops in the South Island ..........................27

3.12 Photo of the $\sim 350 \mathrm{~m}$ outcrop of the PUB on the ridge of the Newton Range ........................28

3.13 Alpine Schist foliation orientations from the Newton Range ....................................................28

3.14 Basic structural map of the Newton Range ..........................................................................30

3.15 Basic structural cross section of the Newton Range ....................................................................31

3.16 Photos, schematic representations and equal-area stereonet of outcrop-scale folding ............32

3.17 Photos of different types of lineations in greyschist ....................................................................34

3.18 Equal-area stereonet of lineation measurements .........................................................................35

3.19 Map showing active faults in the region surrounding the Newton Range ................................35 
3.20 Photos showing the S2/S3 crenulation fabric seen in the Franz Josef-Fox glacier region and inferred in the Newton Range

3.21 Map and schematic cross section of macroscopic folding of the PUB, Noisy Creek area .....40

3.22 Table summarizing the size, extent and location of PUB proximal to the Newton Range ....40

\section{4: PETROGRAPHY \& MICROSTRUCTURE}

4.1 Map of locations and lithologies of samples collected from the Newton Range .43

4.2 Schematic diagram explaining thin section orientation and labeling styles ..................................44

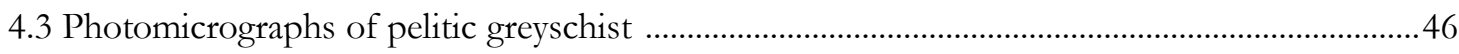

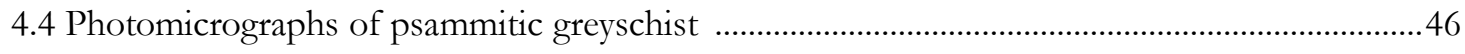

4.5 Photomicrographs of greyschist with alternating pelitic and psammitic layers ...........................46

4.6 Photomicrographs of textural changes in quartz with increasing metamorphic grade .............48

4.7 Photomicrographs of textural changes in muscovite with increasing metamorphic grade ......49

4.8 Photomicrographs of different biotite porphyroblasts in greyschist ..............................................50

4.9 Photomicrographs of biotite crack-fill textures ...........................................................................51

4.10 Photomicrographs of biotite veins crosscutting the foliation ....................................................... 51

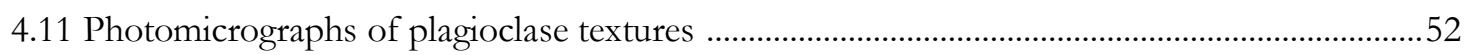

4.12 Photomicrographs of different forms of chlorite in greyschist ...............................................54

4.13 Photomicrographs of chlorite crack-fill and pseudomorph textures .........................................55

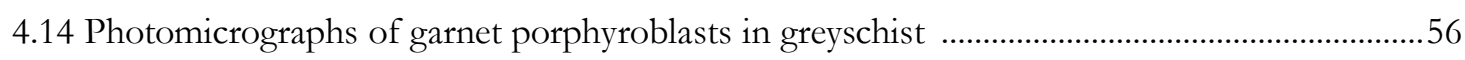

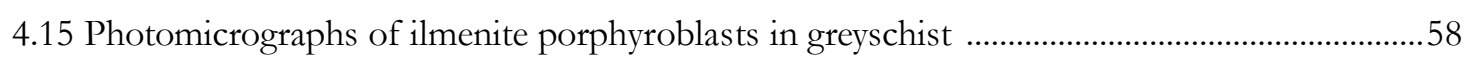

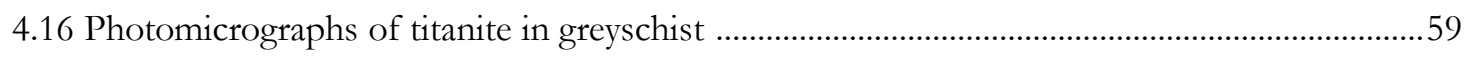

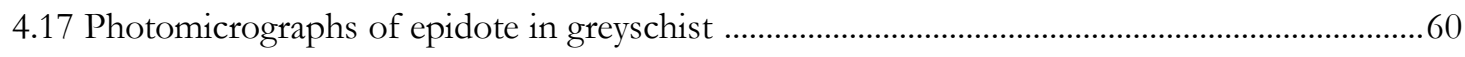

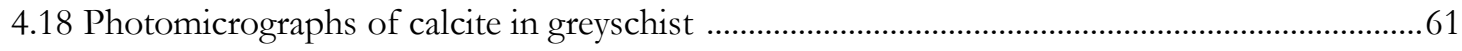

4.19 Photomicrographs of zircon, tourmaline and apatite in greyschist ............................................63

4.20 Photomicrographs of the different chlorite textures in greenschist ............................................64

4.21 Photomicrographs of different amphibole textures in greenschist ..............................................66

4.22 Photomicrographs of different forms of epidote in greenschist ...............................................67

4.23 Photomicrographs of different types of biotite in greenschist.......................................................68

4.24 Photomicrographs of quartz in greenschist...........................................................................68

4.25 Photomicrographs of ilmenite and titanite in greenschist..........................................................70

4.26 Photomicrographs of calcite in greenschist............................................................................

4.27 Photomicrographs of magnetite porphyroblasts in greenschist....................................................71

4.28 Photomicrographs of a red oxide ( hematite) in greenschist .....................................................71

4.29 Photomicrographs of quartz texture in epidosite .......................................................................72 
4.30 Photomicrographs of different forms of epidote in epidosite 72

4.31 Photomicrographs of magnetite in epidosite ...........................................................................73

4.32 Photomicrographs of biotite and chlorite porphyroblasts in epidosite …...............................73

4.33 Photomicrographs of microgarnet in epidosite ......................................................................75

4.34 Photomicrographs of large amphibole porphyroblasts in epidosite .......................................75

4.35 Photomicrographs of rare isoclinal intrafolial folds in Alpine Schist......................................76

4.36 Photomicrographs of a weak crenulation foliation in low grade Alpine Schist........................78

4.37 Photomicrographs of a strong crenulation foliation in high grade Alpine Schist....................78

4.38 Photomicrographs of different types of inclusion trails preserved in garnet...........................79

4.39 Photomicrographs of curved trails in garnet ..............................................................................8

4.40 Photomicrographs of a biotite porphyroblast with domino-type fragmentation.....................80

4.41 Photomicrographs of SC'-type shear bands in both low and high grade Alpine Schist...........82

4.42 Schematic representation of SC'-type shear band orientations relative to thin section cuts ..83

4.43 Equal-area stereographic projection of C'-type shear bands and S foliation planes ................83

4.44 Photomicrographs of asymmetrically folded quartz vein crosscutting the foliation ................85

4.45 Photomicrographs of mixed quartz/chlorite veins crosscutting the foliation...........................85

\section{5: WHOLE-ROCK GEOCHEMISTRY \& TERRANE AFFINITY}

5.1 Map of basement terranes in the South Island 91

5.2 Map of metamorphic grades of Haast Schist in the South Island ............................................93

5.3 Map of the location and lithology of samples analysed for whole-rock geochemistry ............100

5.4 Major element oxide plots from Mortimer \& Roser (1992) ......................................................105

5.5 Trace element plots from Mortimer \& Roser (1992) and Roser \& Cooper (1990) .................106

5.6 Trace element plots from Mortimer \& Roser (1992) and Roser \& Cooper (1990) .................107

5.7 Trace element plots of greenschists and metabasites from throughout the Southern Alps ...108

\section{6: MINERAL CHEMISTRY}

6.1 Summary of garnet growth stages in each sample

6.2 BSE garnet images and corresponding compositional transects, incl. schematic.

6.3 BSE garnet images and corresponding compositional transects .....

6.4 BSE garnet images and corresponding compositional transects.....

6.5 Ternary diagram of garnet stage compositions .....

6.6 Ternary diagram of plagioclase compositions (core and rim).

6.7 BSE image of albite overgrown by oligoclase

6.8 BSE and schematic images of epidote zoning 
6.9 Plot of zoned epidote $100 \cdot \boldsymbol{X}_{\mathrm{Fe}}$ compositions vs. distance from garnet-in isograd 123

6.10 Images of biotite core, rim and fill textures..... 124

6.11 Plot of biotite compositions in the ideal biotite plane. 126

6.12 BSE image of ilmenite overgrown by titanite 126

6.13 Plots of chlorite compositions plotted over diagrams of metamorphosed pelite..... 127

6.14 Ternary diagrams of garnet compositions from the Newton Range, McArthur Range,

Alpine Schist and Otago Schist...... 130

6.15 Ternary diagrams of stage 0 garnet compositions (Newton Range) and Torlesse terrane detrital and source garnet compositions

6.16 Schematic plagioclase $\boldsymbol{X}_{\mathrm{An}}$ - temperature solvus for the Newton Range . .134

6.17 Muscovite compositions plotted over fields of Alpine Schist and Otago Schist .136

6.18 Epidote $100 \cdot \boldsymbol{X}_{\mathrm{Fe}}$ compositions plotted against metamorphic grade . 138

6.19 Ti in biotite geothermometry results 140

6.20 Plot of results from two chlorite geothermometers.

\section{7: THERMOCALC \& P-TPATHS}

7.1 Map showing locations of the nine samples used in the THERMOCALC study 145

7.2 11-component P-T pseudosections for DNMR-27 showing mineral assemblage fields.

7.3 11-component P-T pseudosections for DNMR-27

7.4 11-component P-T pseudosections for DNMR-01, 05, 07, and 20.

7.5 11-component P-T pseudosections for DNMR-51, 80, 90, and 93

7.6 Schematic examples of methods used to calculate $P-T$ paths of garnet growth

7.7 11-component P-T pseudosections and P-T paths of garnet growth for

DMNR-01 and 05

7.8 11-component P-T pseudosections and P-T paths of garnet growth for

DMNR-07 and 20 160

7.9 11-component $P-T$ pseudosections and $P-T$ paths of garnet growth for

DMNR-27 and 51 . .161

7.10 11-component P-T pseudosections and P-T paths of garnet growth for

DMNR-80 and 93 162

7.11 11-component P-T pseudosections and P-T paths of garnet growth for DMNR-90.

7.12 Summary of P-T paths of garnet growth for all nine samples.

7.13 Photos and P-T paths of DMNR-93, $20 \& 27$ showing effects of titanite 168

7.14 Summary of P-T paths for different parts of the Haast Schist 


\section{8: SUMMARY \& SUGGESTIONS FOR FUTURE RESEARCH}

8.1 Schematic diagrams showing how different $P-T$ paths and peak metamorphic conditions can control different mineral assemblages and isograd sequences in a rock

8.2 Map of active faults in the surrounding area and schematic diagram of differential exhumation between the Newton and McArthur Ranges. 


\section{5: WHOLE-ROCK GEOCHEMISTRY \& TERRANE AFFINITY}

5.1 Coefficients for the discriminant function diagram from Roser \& Korsch (1988) . .96

5.2 Whole rock major element oxide ( $w \mathrm{t} \%)$ XRF geochemical analyses .101

5.3 Whole rock trace element ( $\mathrm{ppm}$ ) XRF geochemical analyses. .102

5.4 Major and trace element ratios for greyschist in the Newton Range .103

5.5 Typical trace element ratios in New Zealand greywacke terranes compared to greyschist from the McArthur Range and Newton Range

\section{6: MINERAL CHEMISTRY}

6.1 Representative analyses of garnet. .113

6.2 Representative mineral analyses. . .118

6.3 Epidote zone compositions

\section{7: THERMOCALC \& P-T PATHS}

7.1 Whole-rock major element oxide data of greyschist used to make $P$ - $T$ pseudosections .147

7.2 Whole-rock major element oxide data used for input into THERMOCALC to make P-T pseudosections 


\section{ACKNOWLEGEMENTS}

First and foremost I would like to thank my supervisor Dr. Julie Vry. The finishing of this thesis has been a long time coming, and you have helped me immensely with your endless patience for me, and passion for your work.

I would like to thank Bruce Dando for flights into the Newton Range. This thesis is dedicated to your pride and joy, which unfortunately is no longer with us.

To my field assistants Jodi Williams, Dan Bassett and James Marsh. Thank you for your bravery in the wet and cold and your enthusiasm towards repetitive sunrise excursions through wet tussock. I am thankful for permission granted by the Mawhera Incorporation, South Pacific Forest Holdings, and the Department of Conservation to carry out sampling and fieldwork in the Newton Range.

I am grateful to VUW, who has in part financed my tuition with the Victoria Graduate Award and the J.L. Stewart Postgraduate Scholarship. A big thank you to the SGEES technical staff, in particular Stuart Bush for thin section preparation, John Patterson for help on the now extinct electron microprobe and Gillian Ruthven for her help in the library wading through stacks of journals and maps. To Mike Hannah and Joel Baker, thank you for helping me throughout my time at VUW, I have a great deal of respect for the both you. Thank you to Ben Gillam and A. Prof. Tim Little for helpful discussions regarding the structural fabrics of the Alpine Schist in the Franz JosefFox glacier region, albeit veiled behind a month of strenuous (yet rewarding) field work.

To my fellow postgraduates that I have had the honor of sharing the floors of Cotton with over the last few years: Rach, Boots, Pepe, Herman, Dan, Kim, Jules, Mearn, Katie, Aidan, George, Ben, Hannu, Chris T, the pre-existing and recent influx of geology postgraduates, and all of those who I have mistakenly forgotten in this long sentence. I will always remember friendships we have formed and the great times I have had with you all.

Thank you to my non-geology friends for providing me with non-geology entertainment. I am sorry for talking about rocks in the process. To my flatmates over the years, thank you for putting up with my eccentric behavior, irregular sleeping hours and occasional inattention to the cleaning roster.

A special thank you to Jodi Williams, whose endless enthusiasm and constructive edits have helped immensely throughout the writing of this thesis. Bubbles, possum, always.

A final thank you to my all of my family - Michelle, Jo and especially Mum and Dad. You are all constantly there for me even though my visits to you may have become increasingly infrequent. Your constant patience and love has kept me going throughout my time at university. 


\section{Chapter One}

\section{PREAMBLE}

\subsection{Introduction}

Metamorphic pressure-temperature $(P-T)$ paths are an integral part of interpreting the metamorphic history of any tectonic orogen. This study examines the metamorphism of the Alpine Schist in the Newton Range, using various tools to decipher the complex, variably overprinted metamorphic history preserved in the Alpine Schist in north Westland. Lithological and structural observations were recorded in the field and oriented schist samples were collected, later cut into $30 \mu \mathrm{m}$ thick thin sections for petrographic and structural analysis. Selected samples were also analysed an electron microprobe to gain insights into how the mineral chemistry varies within individual crystals, as well as between samples as variations in mineral composition are significantly affected by changes in pressure and temperature during metamorphism. Whole rock geochemical data is used to interpret the protolith for Alpine Schists, and is also fundamental for calculating $P$-T pseudosections with the aid of the computer program THERMOCALC 3.33. THERMOCALC is a powerful tool which enables forward modelling of complex mineral phase relationships, and phase compositions for various P-T conditions, as opposed to traditional geothermobarometry where typically only a single point in the P-T history can be obtained. In combination with detailed core-to-rim compositional transects of garnet, THERMOCALC can be used to produce detailed $P$-T paths, enabling a considerably more complete metamorphic history for the Alpine Schist to be constructed than was previously attainable with traditional methods.

All of these tools were used to interpret the history of Alpine Schist from the Newton Range. The results, used in conjunction with other studies from various locations in the Southern Alps, further highlights along-strike differences in the metamorphic history of the Alpine Schist.

\subsection{Location}

The Newton Range is located in the northern section of the Southern Alps (west coast of the South Island), $\sim 25 \mathrm{~km}$ southeast of the township of Hokitika (Figs. $1.1 \& 1.2$ ). The southern most splays of 


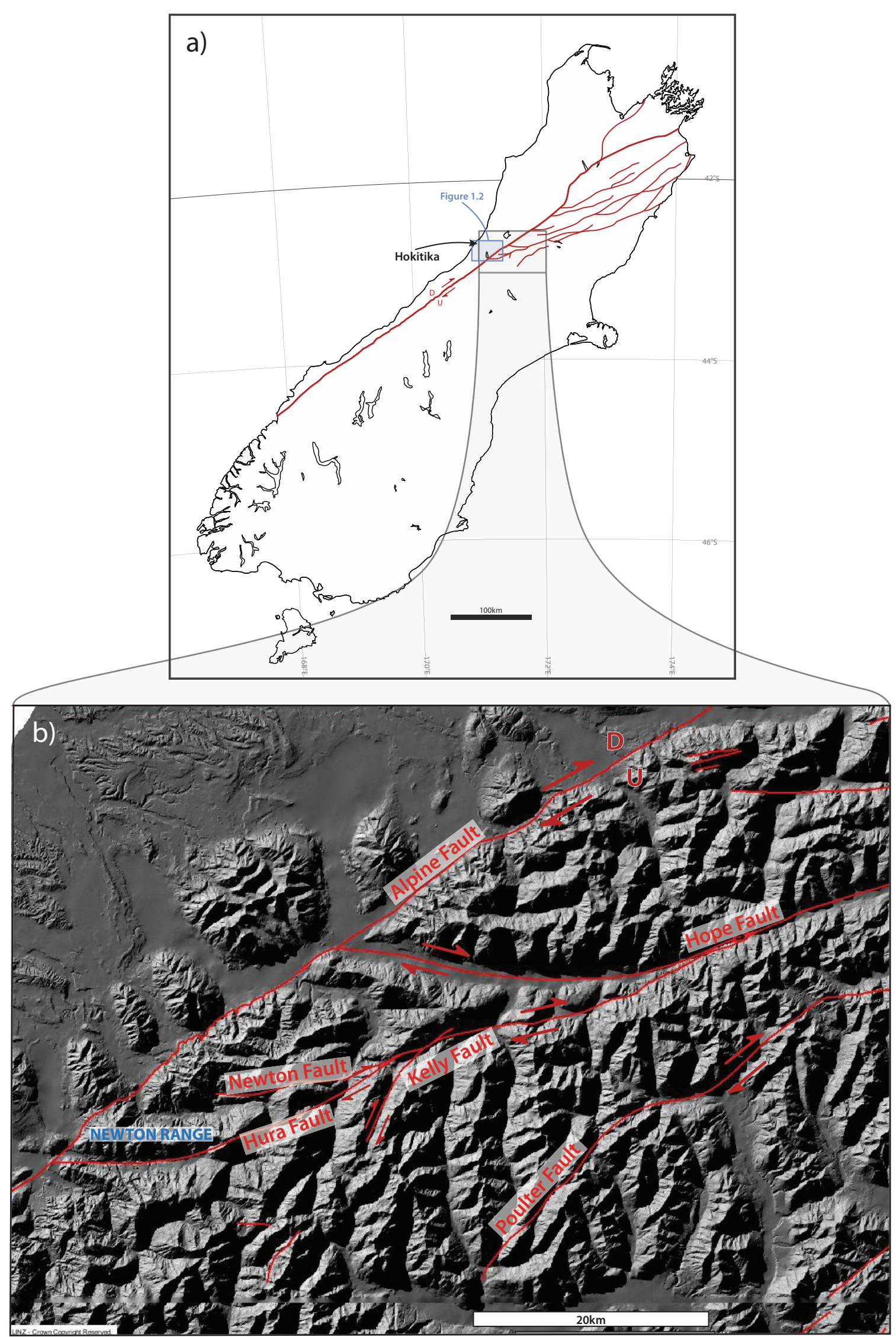

Figure 1.1. a) Map of the South Island, with major active faults (red lines). Blue box outlines the location of figure 1.2. b) Map of the north Westland region with major active faults and the Newton Range labelled. DEM data and major fault locations (1:100,000 scale) are from the New Zealand Active Faults Database (GNS, 2010). 


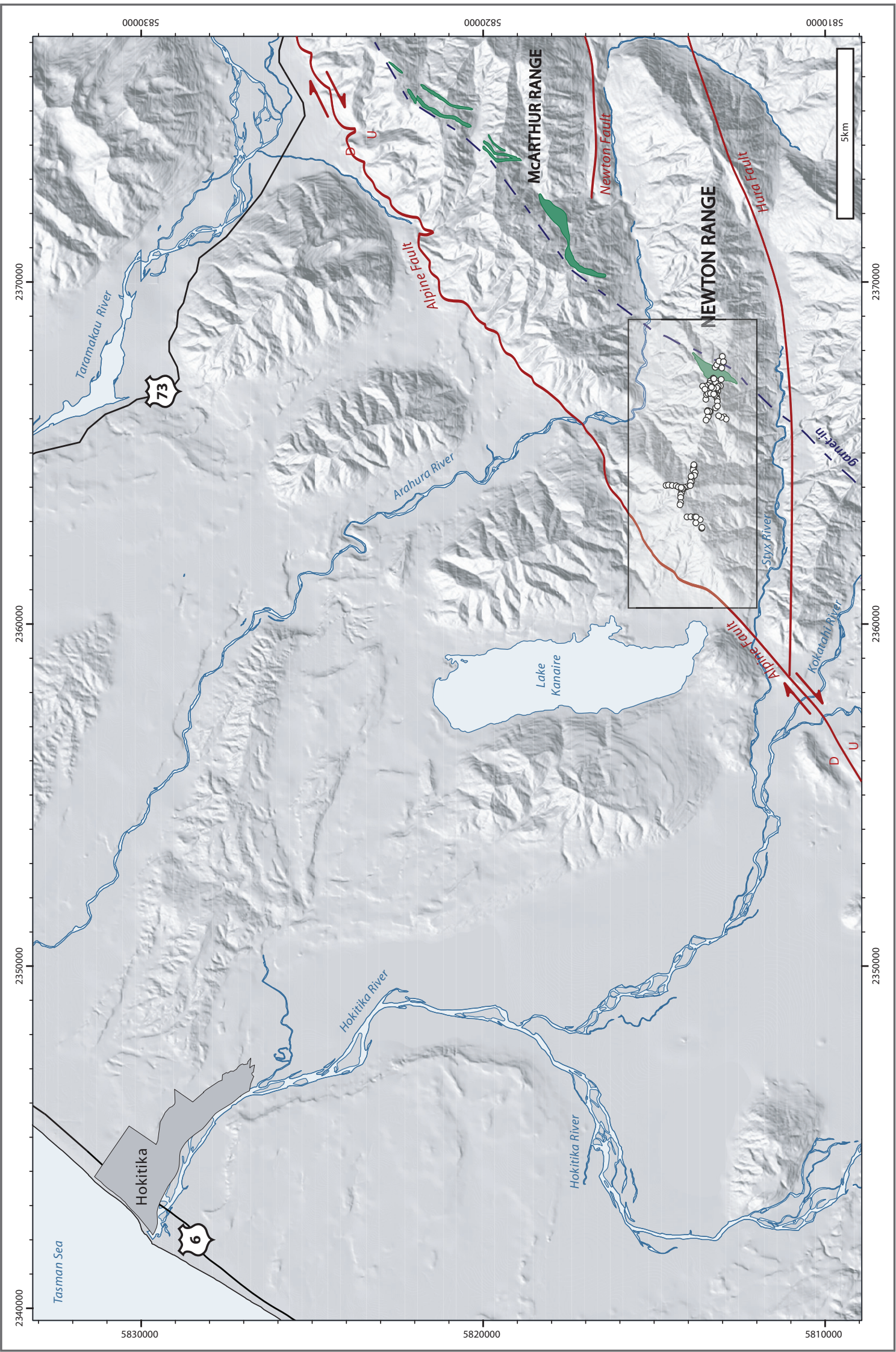

Figure 1.2. Map of the area surrounding the Newton Range. Grey box denotes the area of figure 1.3, which has sample locations numbered (white circles). Fault locations (red lines) from Nathan (2002) and GNS (2010). Approximate garnet-in isograd from this study and Williams (2006). New Zealand Map Grid showing coordinates in metres in terms of the Geodetic Datum 1949, 1:50,000 topographic map sheets J33 \& K33. Green polygons are outcrops of the Pounamu Ultramafic Belt from this study and MacKenzie (1984). 
the active Marlborough Fault System intersect the Alpine Fault both north and south of the Newton Range (Hope Fault, Kelly Fault, Newton Fault and Hura Fault). The main ridge crest of the Newton Range runs approximately east to west, bordered by the Alpine Fault and Lake Kaniere to the west and the upper reaches of the Arahura River to the east. The Arahura and Styx rivers are located immediately north and south of the range respectively.

The study area is comprised of two sections, where samples were collected during two field seasons. These areas are located in the northwest and southeast of the range (NW Section and SE section respectively) separated by an inaccessible, densely vegetated razorback ridge (Fig. 1.3). Outcrop of schist is typically isolated to small patches, surrounded by dense tussock vegetation, on the edge of and above the bushline, $1000-1300 \mathrm{~m}$ in elevation.

\subsection{Aims}

This thesis provides the first detailed geological study of the Alpine Schist from the Newton Range. The aim is to gain insights into the complex, variably overprinted metamorphic history of the Alpine Schist through detailed observations of the petrology, structural fabrics, mineral chemistry and whole rock geochemistry of the rocks from the Newton Range. Succinct interpretations of these observations subsequently allow the study to be put into a wider context, through comparisons with other studies of the Alpine Schist throughout the Southern Alps.

\subsection{Outline}

The thesis is comprised of eight chapters and additional appendices, and is structured as follows:

- A concise introduction into the Haast Schist belt and tectonic setting of the Southern Alps. Other studies of the petrography and structure of the Alpine Schist are briefly presented.

- Observations collected during fieldwork are presented including lithological information and deformation fabrics. Interpretations of the macro and meso structure of the field area are made.

- Optical microscopy is used for detailed petrographic and microstructural observations. Comparisons to deformational fabrics of other studies of the Alpine Schist are also made. 

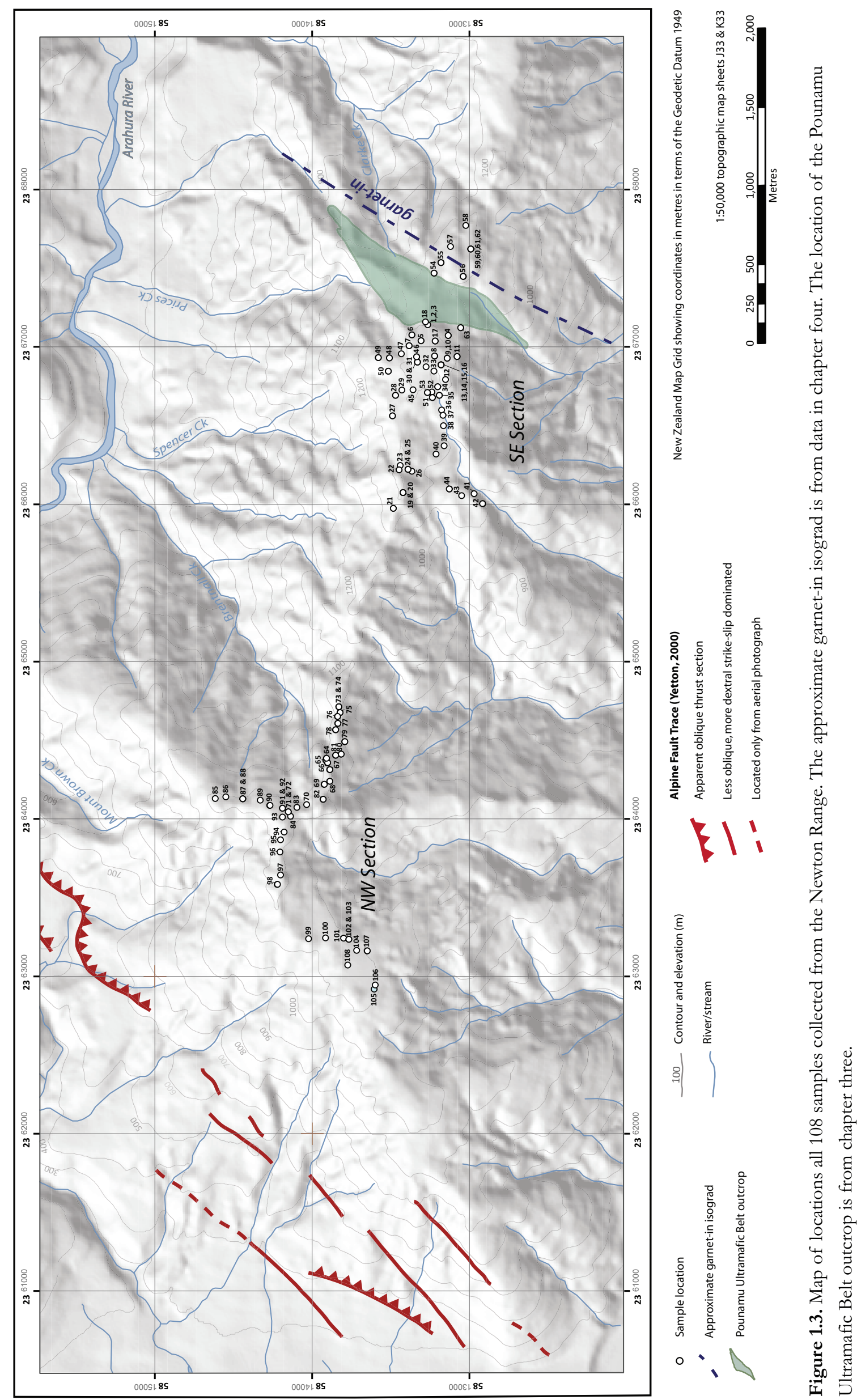
- Whole-rock major and trace element geochemical data is presented to gain insights into the protolith of both greyschist and greenschist.

- Variations in mineral composition gained from electron microprobe analyses are presented to gain insights into the growth history of selected minerals in greyschist, notably garnet. Compositional zoning can therefore provide information regarding the polymetamorphic history of the Alpine Schist. Detailed core to rim transects of garnet are produced for use in chapter seven.

- $\quad P-T$ pseudosections are calculated using whole-rock geochemical data and the computer program THERMOCALC 3.33. Detailed compositional transects of garnet are used together with the THERMOCALC results to extract $P$ - $T$ path information for individual samples.

- A synthesis of discussions of different chapters is presented. Brief conclusions regarding the implications of this thesis and ideas for future research are also presented.

- Several appendices of sample information, mineral chemistry analyses and THERMOCALC activity-composition models are presented. 


\section{Chapter Two}

\section{BACKGROUND \& TECTONIC SETTING}

\subsection{Tectonic Setting}

New Zealand is located astride a zone of transpressive collision between the Pacific and Australian tectonic plates. The dynamics of the plate boundary change from north to south, depending on the type of colliding lithosphere (continental or oceanic), and the direction of relative motion between the plates. East of the North Island, oceanic lithosphere of the Pacific Plate subducts beneath the Australian Plate along the west dipping Hikurangi subduction zone (fig 2.1a). Subduction ceases southward adjacent to thick continental crust of the Chatham Rise, and the plate boundary transitions into a zone of predominantly dextral strike-slip faults (Marborough Fault System - MFS) (Walcott, 1998). The MFS is truncated in the central South Island by the southeast dipping dextralreverse Alpine Fault, a structure which accommodates the oblique collision of Pacific and Australian Plate continental lithosphere. The Alpine Fault continues offshore off the coast of Fiordland where slip is partitioned into a series of smaller thrust faults to accommodate the transition back to subduction (Barnes, et al., 2005), with oceanic lithosphere of the Australian Plate underthrusting the Pacific Plate in the Fiordland subduction zone.

The boundary between the Pacific and Australian Plates developed at $\sim 45 \mathrm{Ma}$. Plate motion was initially transtensional and diffuse, with deformation dispersed over a zone up to $200 \mathrm{~km}$ wide (Sutherland, 1995, Sutherland, 1999). An increase in the proportion of margin-parallel motion at $\sim 25 \mathrm{Ma}$ resulted in the formation of the Alpine Fault (Cooper, et al., 1987, Sutherland, 1995). Motion on the Alpine Fault remained predominantly strike-slip until more margin-convergent plate motion in the late Miocene transformed the fault into a dextral-reverse structure, resulting in the uplift of the Southern Alps (Cande \& Stock, 2004, Sutherland, 1995, Walcott, 1998). Since its inception the Alpine Fault has accommodated $\sim 90 \mathrm{~km}$ of shortening (Walcott, 1998) and produced a apparent dextral displacement of $440-480 \mathrm{~km}$ depending on what offset geological marker is used (Sutherland, 1999, Wellman, 1955).

The modern rate of plate motion between the Pacific Plate relative to the Australian Plate is $\sim 38 \mathrm{~mm} / \mathrm{yr}$ with a bearing of $\sim 073^{\circ}$ (using Nuvel 1A angular velocities from DeMets, et al. (1994), 


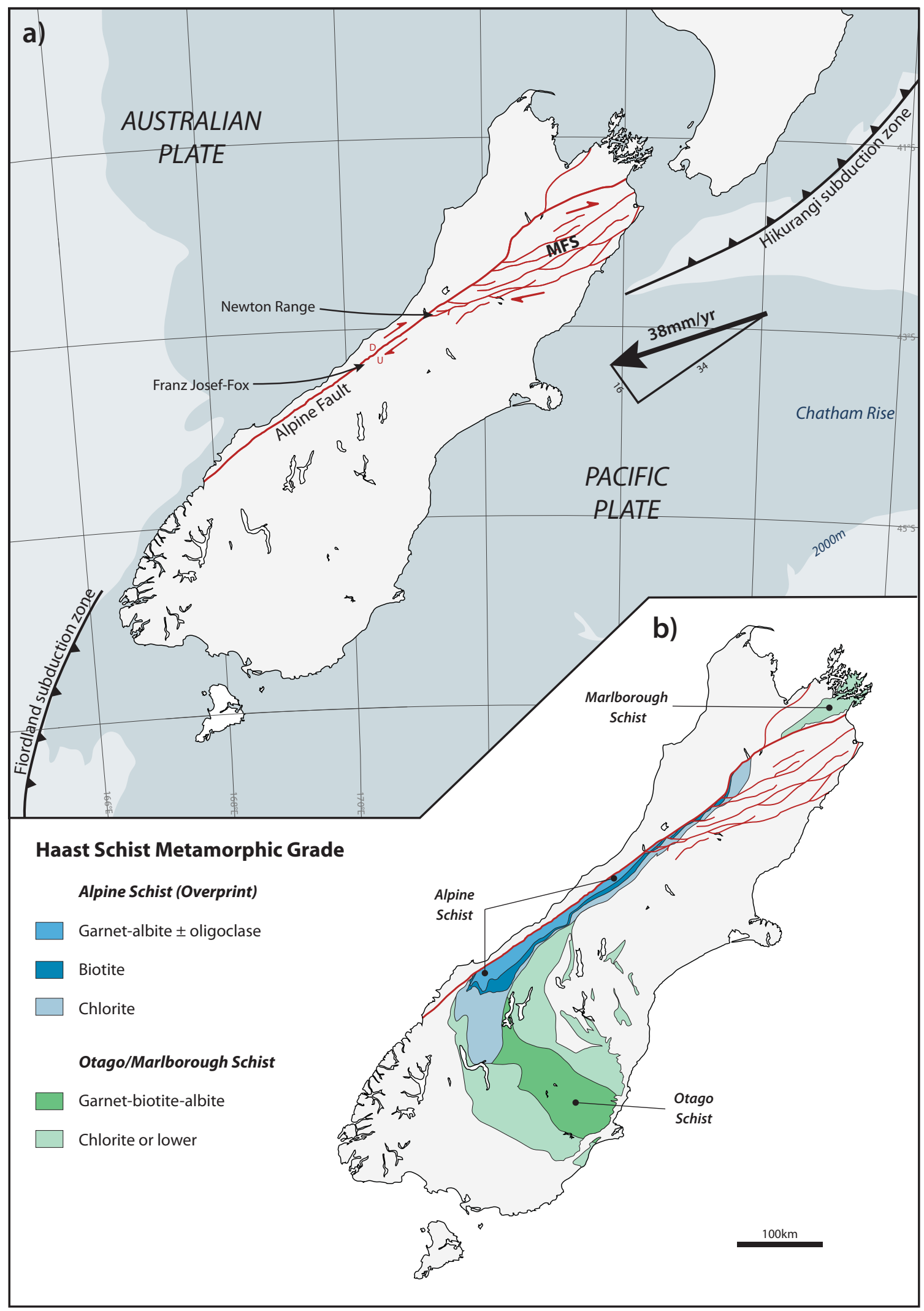

Figure 2.1. a) Regional tectonic setting of the South Island of New Zealand showing the modern rate of plate motion between the Pacific Plate relative to the Australian Plate (using Nuvel 1A angular velocities from DeMets, et al. (1994), and the Alpine Fault trace at the foot of the Newton Range as a reference point), with normal and parallel motion with respect to the Alpine Fault. MFS - Marlborough Fault System. 2000m - bathymetric contour. b) Map showing metamorphic grade and divisions of the Haast Schist. Data is from N.Z. Geological Survey Map (1972), Mortimer (1993), Mortimer (2000) and Coombs et al., (2000). 
and the Alpine Fault trace at the foot of the Newton Range as a reference point) which can be partitioned into two separate components of normal and parallel motion with respect to the Alpine Fault $(34 \mathrm{~mm} / \mathrm{yr}$ and $16 \mathrm{~mm} / \mathrm{yr}$ respectively). The oblique nature of convergence (as well as the propagation of fault structures to the surface from a ductile fault zone) results in the segregation of the Alpine Fault into alternating segments of east-northeast striking dextral faults and northnortheast striking oblique thrust faults (Norris \& Cooper, 1995, Sibson, et al., 1981). The scale and regularity of these segments decreases in north Westland, compared to the central Southern Alps (Yetton \& Nobes, 1998). The Alpine Fault accommodates $60-80 \%$ of the plate motion in the central South Island (Berryman, et al., 1992, Norris \& Cooper, 2001, Sutherland \& Norris, 1995).

The average strike of the Alpine Fault is $055^{\circ}, \sim 16^{\circ}$ anticlockwise of the plate motion vector (Norris \& Cooper, 1995) whilst in north Westland south of the Hope Fault the strike is $\sim 50^{\circ}, \sim 23^{\circ}$ anticlockwise of the plate motion vector.. The Alpine Fault has a variable southeast dip. In the central Southern Alps the Alpine Fault dips between $30^{\circ}$ and $50^{\circ}$ (Kleffmann, et al., 1998), and in north Westland dips $\sim 58-60^{\circ}$ (Langridge, et al., 2010, Nathan, et al., 2002).

Uplift varies considerably along strike with the highest uplift rates of $8-12 \mathrm{~mm} / \mathrm{yr}$ recorded in the central Southern Alps, near the Franz Josef-Fox Glacier region, decreasing significantly to the north and south (Norris \& Cooper, 2001). Southeast of Hokitika, and immediately south of the study area of this thesis, uplift rates decrease to 6-8mm/yr (Norris \& Cooper, 2001, Yetton \& Nobes, 1998). $\sim 25 \mathrm{~km}$ to the northeast of the Newton Range vertical slip rate decreases even further to $\sim 3 \mathrm{~mm} / \mathrm{yr}$ (Langridge, et al., 2010). The decrease in uplift rates south of the central Southern Alps is attributed to fault motion having a greater strike-slip component (Sutherland, et al., 2006, Sutherland \& Norris, 1995). Northward decreases in uplift rates are due to partitioning of slip into the MFS, with $\sim 52 \%$ of plate motion accommodated by the MFS northward of the intersection of the Hope and Alpine Faults (Langridge, et al., 2010). The MFS acts as a transition zone between uplift of the Pacific Plate in the South Island, and the subduction of the Pacific Plate to the north. Increased slip rates on the southern strands of the MFS (i.e. Hope Fault) and southward propagation of new faults, reflect a southward migration of the MFS as the plate boundary evolves (Little \& Jones, 1998, Walcott, 1998).

This complex deformational regime, along with high erosion rates, has exhumed a large amount of rock from the Pacific Plate, from depths of 25-30km in the central Southern Alps (Wellman, 1979). This has produced varying exposures of basement rocks along the Alpine Fault, most notably the Haast Schist belt (Fig. 2.1b), which preserves a large portion of the metamorphic history of New Zealand. 


\subsection{Haast Schist Overview}

In the South Island the Haast Schist ranges in metamorphic grade from prehnite-pumpellyite to amphibolite facies and is divided into units with regards to their geographic location and mineral assemblages into the Alpine, Otago and Marlborough Schists in the South Island (Fig. 2.1b), the Kaimanawa Schist in the North Island and the Chatham Schist in the Chatham Islands (Brown, 1967, Grapes \& Watanabe, 1992, Mason, 1962, Mortimer, 1993a, Mortimer, 2000, Nathan, et al., 2002). The Haast Schist is the metamorphosed equivalent of several sedimentary basement terranes. Fossils in un-metamorphosed parts of the protolith terranes close to the boundaries of the Haast Schist range in age from late Palaeozoic to late Triassic (Campbell \& Warren, 1965, MacKinnon, 1983, Mortimer, 2000). A detailed discussion of the formation and source of basement terranes metamorphosed by the Haast Schist is provided in chapter four.

\section{Otago and Marlborough Schists}

The Otago Schist is exposed as a gentle arch $\sim 150 \mathrm{~km}$ wide, orientated approximately northwest southeast, located in the southern South Island in the Otago and southern Westland regions. The highest grade schist is greenschist facies, garnet-biotite-albite grade and is exposed in the core of the arch. Metamorphic grade gradually decreases towards the arch flanks to prehnite-pumpellyite facies rocks (Mortimer, 2000). Estimates for the timing of peak metamorphism from K-Ar and Ar-Ar dating of metamorphic mica are Jurassic in age (Adams, et al., 1985, Gray \& Foster, 2004, Little, et al., 1999), with $P-T$ estimates for peak metamorphism in the range of of $350-400^{\circ} \mathrm{C}$ and $8-10 \mathrm{kbar}$ (Mortimer, 2000).

The Marlborough Schist consists of low-grade schist (chlorite zone and lower grade) located in the Marlborough region and is bounded on all sides by splays of the MFS (Mortimer, 1993a). The Marlborough Schist represents the northern equivalent of the Otago Schist, having been displaced along the Alpine Fault during the late Cenozoic (Mortimer \& Johnston, 1990). 


\section{Alpine Schist}

The Alpine Schist is exposed as a narrow, southeast-northwest oriented band stretching much of the length of the Alpine Fault in the Southern Alps. The Alpine Schist progressively increases in metamorphic grade westward, from prehnite-pumpellyite facies metagrewacke east of the Main Divide, to upper greenschist and amphibolite facies within 1-2km of the Alpine Fault (Grapes, 1995, Grapes \& Watanabe, 1992, Nathan, et al., 2002).

This increase in metamorphic grade is a product of exhumation of rocks from greater crustal depths with increasing proximity to the Alpine Fault. The deepest rocks are from crustal depths of $\sim 30 \mathrm{~km}$, where the Alpine Fault reaches a decollement, where the Pacific Plate delaminates away from the lower crust and subsequently tilts and thrusts up the fault ramp (Little, et al., 2005, Norris, et al., 1990, Wellman, 1979). This exhumation of different crustal depths has exposed rocks with different deformational structures and mineral assemblages (Grapes, 1995, Grapes \& Watanabe, 1992, Little, et al., 2002a). Uplift of the Alpine Schist along the Alpine Fault has also formed a thin band of mylonitised Alpine Schist 1-2km thick directly adjacent to the eastern side of the fault (Little, et al., 2002a, Sibson, et al., 1981).

The Alpine Schist has peak metamorphic conditions of $420-620^{\circ} \mathrm{C}$ and $5.2-9.2 \mathrm{kbars}$ (Grapes, 1995) lower in pressure and higher in temperature than peak metamorphism of the Otago Schist. Recent estimates for the timing Alpine Schist metamorphism come from Sm-Nd \& Lu-Hf dating of a garnet porphyroblast in north Westland and indicate that the metamorphism began at $\sim 100 \mathrm{Ma}$, with a major episode of high grade mineral growth at $~ 86 \mathrm{Ma}$ (Vry, et al., 2004) most likely coinciding with the oblique collision of the Hikurangi Plateau with the Gondwana margin. Other age estimates range from: $\sim 68 \mathrm{Ma}$ from U-Pb monazite and SHRIMP ion-probe zircon analyses (Chamberlain, et

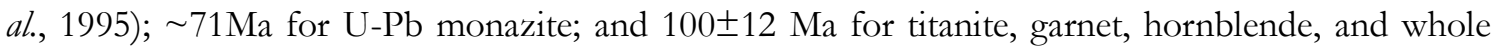
rock fractions from a Haast River amphibolite (Mortimer \& Cooper, 2004). Alpine Schist metamorphism has erased most evidence for the earlier Otago event, but evidence of a metamorphic overprint of chlorite grade Alpine Schist over garnet-albite Otago Schist does exist in northwest Otago (Mortimer, 2000).

Metamorphism in the late Cenozoic synchronous with the uplift of the Southern Alps (Little, et al., 2002a, Little, et al., 2002b) resulted in the exhumation and further deformation of the Alpine Schist after peak metamorphism. The late Cenozoic event overprinted earlier metamorphic fabrics and formed the $\sim 1-2 \mathrm{~km}$ thick zone of mylonitic Alpine Schist that is exposed in the hanging wall of the Alpine Fault. 
Most studies of the Alpine Schist have focussed on the region surrounding the Franz-Josef and Fox Glaciers, approximately $\sim 110 \mathrm{~km}$ southwest of the Newton Range (Grapes, 1995, Grapes \& Otsuki, 1983, Grapes \& Watanabe, 1992, Grapes \& Watanabe, 1994, Little, et al., 2002a, Little, et al., 2002b). These studies have primarily focussed on the changes in: mineral compositions and assemblages; deformation textures; and $P-T$ conditions using traditional geothermobarometry methods, with respect to increasing metamorphic grade (see chapters four, six and seven). Structural fabrics have been extensively studied and support a multi-phase deformational history (structural fabrics and development are discussed in detail in chapters three, five and eight).

\subsection{Regional Background}

Early geological work in north Westland primarily focussed on large scale regional mapping and exploration of economic deposits (i.e. Bell \& Fraser, 1906, McKay, 1893, Morgan, 1908). Later work had more of a focus on localised regional mapping including geochemical analyses of schist and ultramafic rocks (Pounamu Ultramafic Belt - PUB) and the separation of the schist into various subunits based on textural observations and metamorphic grade (i.e. Coleman, 1966, Gregg, 1964, Warren, 1967). More recent studies of the PUB are discussed in more detail in chapter three.

Due to the majority of studies of the Alpine Schist being conducted in the Franz-Josef Fox Glacier region, relatively little is known of the Alpine Schist in other locations, notably in the north Westland, leading to the general assumption that metamorphism of the Alpine Schist is relatively homogenous throughout the Southern Alps. Recent studies in the north Westland have significantly contributed to the understanding of the metamorphic history of the Alpine Schist, and highlighted the along-strike differences in mineral assemblages and $P$-T conditions. These studies were primarily B.Sc. Honours and M.Sc. theses (Cavanagh, 2004, Dixon, 2001, Parish, 1998, Pepper, 2000, Storkey, 1999, Thurlow, 1999, Williams, 2006) as well as associated papers developed out of, and drawing on the body of work produced by these (Vry, et al., 2001, Vry, et al., 2004, Vry, et al., 2008).

\section{Mineral Assemblages}

A recent study in the McArthur Range (Williams, 2006), $7 \mathrm{~km}$ north of the Newton Range, found that garnet coexisted with only one plagioclase, (Na-bearing albite), for much of the metamorphic history, with oligoclase (Ca-bearing plagioclase) developed late in the metamorphic history as rims 
on some albite porphyroblasts. This differs from the sequence reported for the Franz Josef-Fox Glacier region where oligoclase-in isograd appears before the garnet-in isograd. This discovery resulted in the identification of a new metamorphic zone in the Alpine Schist in north Westland, the garnet-albite-biotite zone.

\section{$P$-TConditions of Garnet Growth}

The majority of the recent studies in north Westland attempted to gain estimates of $P$ - $T$ conditions of garnet growth using traditional geothermometers and barometers (GTB). However a Ca-bearing plagioclase is needed to obtain realistic $P$ - $T$ estimates for garnet growth, yet oligoclase only occurs as rims on albite porphyroblasts. As growth of garnet and oligoclase were only in equilibrium during the formation of the garnet rims, $P-T$ estimates for the growth of garnet cores remained poorly understood. Estimated P-T conditions for garnet growth from recent studies in north Westland are summarised in figure 2.2, locations of which are presented in figure 2.3.

$P-T$ conditions obtained from traditional GTB methods have yielded estimates grouping in the range of $400-600^{\circ} \mathrm{C}$ and $6-10 \mathrm{kbars}$, with a few outlying estimates higher in pressure. Based on the $P$ $T$ estimates, along with changes in mineral chemistry and textures, these studies have attributed garnet growth to several different events in the metamorphic history.

Parish (1998) obtained core and rim P-T estimates for three mylonite zone garnets. Differences in pressure estimates of the three cores, $(7.6,7.3$, and 12.0kbar), lead to the suggestion that growth of the lower P garnets occurred during late Cenozoic uplift along the Alpine Fault, whilst growth of the higher P garnet occurred much earlier, possibly during subduction in the Mesozoic.

Storkey (1999) attained results for the cores and rims of three garnets from Alpine Schist that all showed core-to-rim increases in temperatures and decreases in pressures. One garnet core from the Styx River had notably lower temperature and higher pressure than two other garnets from Macpherson Creek, although all garnets had similar rim P-T estimates. From this it was inferred that the garnet core from the Styx River possibly represented an earlier event than the higher temperature/lower pressure rims.

Thurlow (1999) attributed growth of garnet in greyschist from the Kokatahi River to the Alpine Schist metamorphic event and obtained P-T conditions for garnet rims of $\sim 490-560^{\circ} \mathrm{C}$ and $\sim 8 \mathrm{kbar}$. 


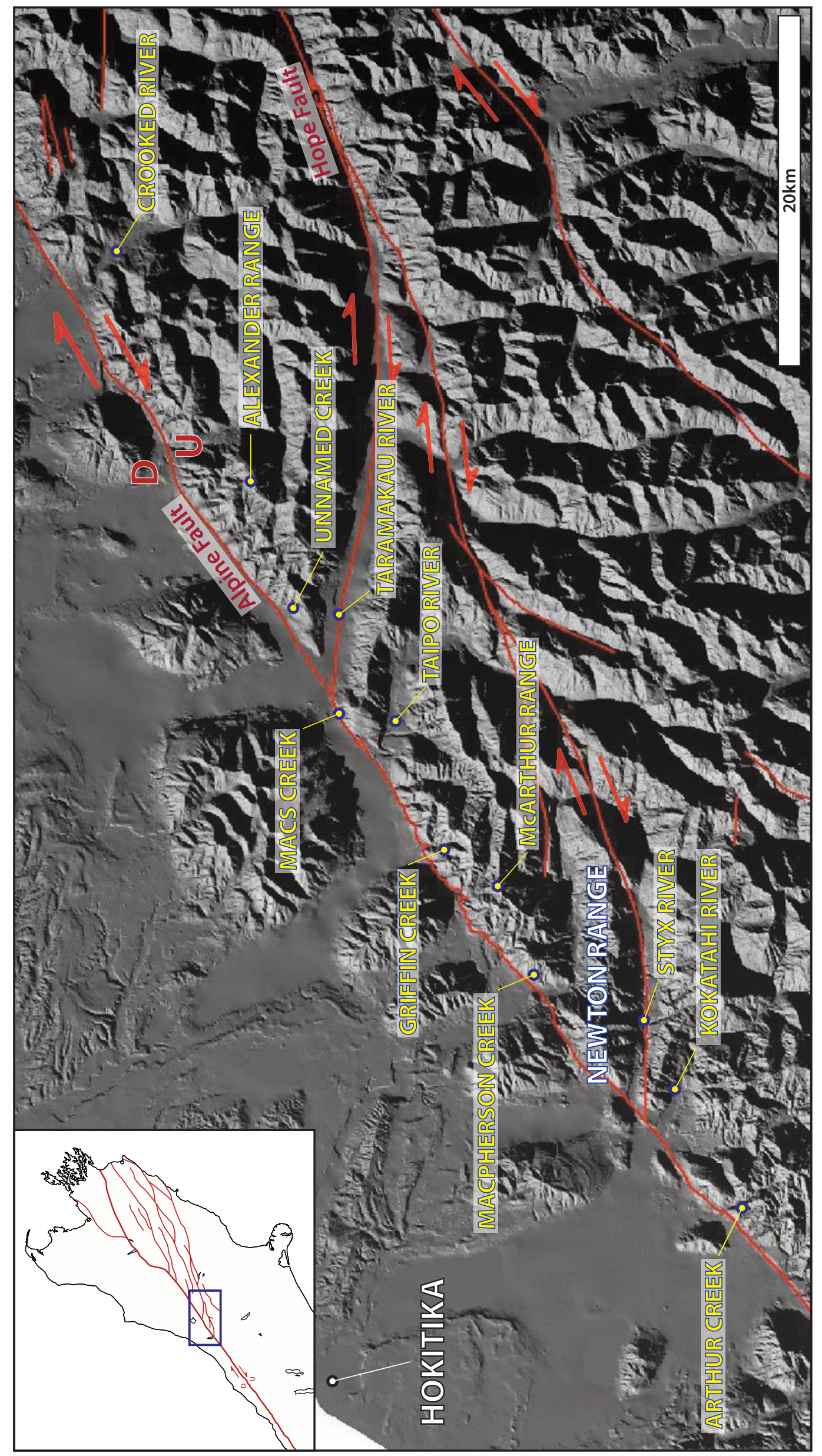




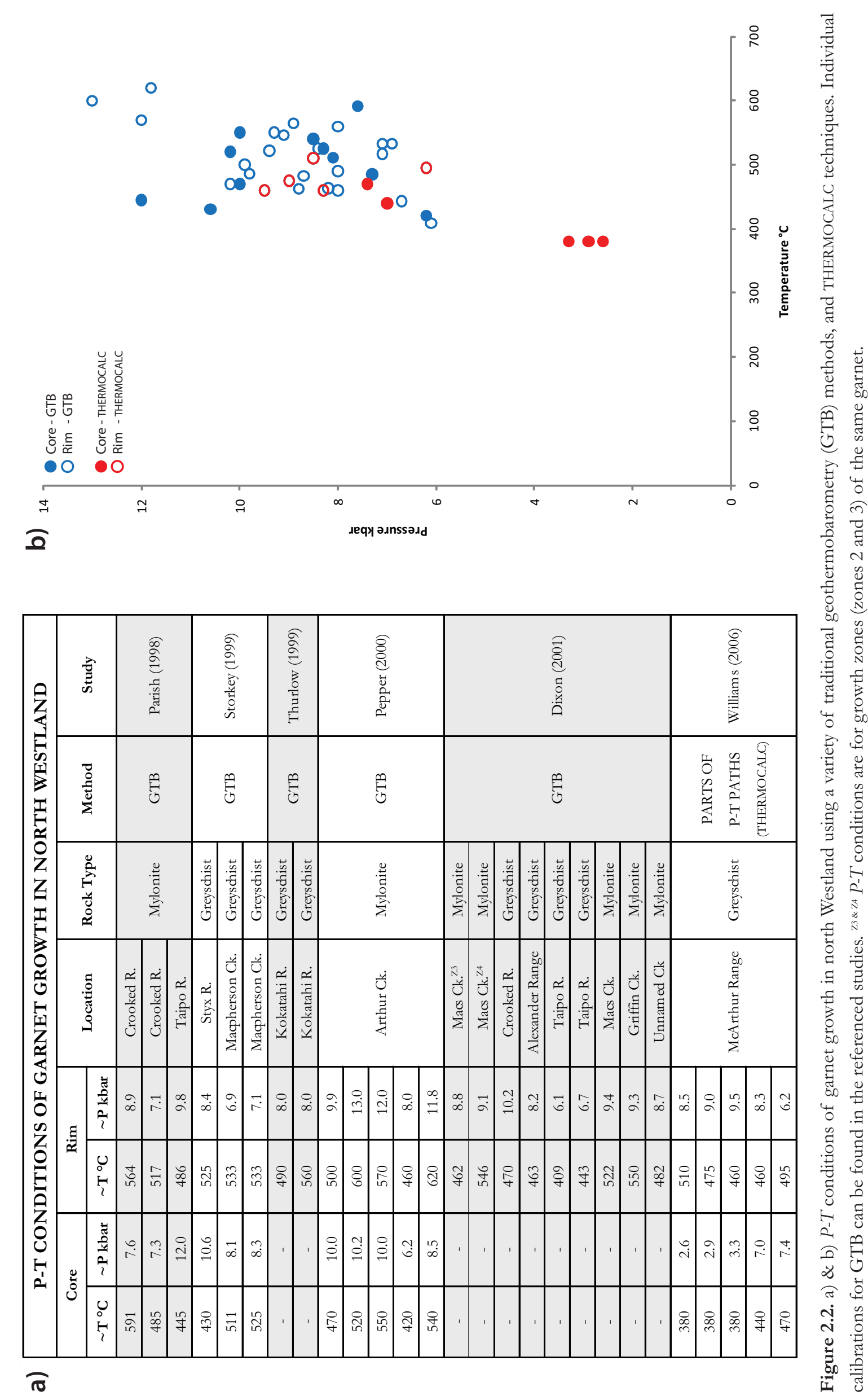


Pepper (2000) obtained core and rim P-T estimates for five garnets from mylonitised Alpine Schist. Based on the mineral chemistry and core and rim P-T results Pepper (2000) inferred that garnet growth occurred during two different stages of metamorphism, though did not specify which metamorphic events the garnet growth occurred in.

As previously mentioned $P-T$ estimates for garnet cores in north Westland are not reliable due to the absence of a Ca-bearing plagioclase for much of the metamorphic history, and the combined results from these GTB studies in the region show no clear agreement in $P$-T conditions of garnet growth. Therefore the interpretations that garnet growth occurred during several different metamorphic events, primarily based on differences in core-rim $P-T$ results, are dubious at best when garnet cores were most likely not in equilibrium with paired minerals used in GTB analyses.

Dixon (2001) investigated Alpine Schist north and south of the Taramakau River, and, aware of the uncertainty of GTB analyses on garnet cores, obtained P-T estimates for the rims only for nine garnets from mylonitised and non-mylonitised Alpine Schist, ranging from $410-550^{\circ} \mathrm{C}$ and 6.1 10.2kbar. Lu-Hf and Sm-Nd dates for a large polyphase garnet in mylonitised schist (from Dixon (2001)) show core to rim ages of $\sim 100 \mathrm{Ma}$ to $\sim 12 \mathrm{Ma}$ (Vry, et al., 2004). Dates from the most extreme rim were unattainable, but as these rims overprint the surrounding mylonitic foliation an age of $\sim 5$ 6Ma was estimated, associated with the late Cenozoic uplift of the Southern Alps.

The first investigation into the P-T conditions of Alpine Schist using the computer program THERMOCALC (a method used in this study), was in the McArthur Range (Vry, et al., 2008, Williams, 2006). P-T paths calculated with the aid of THERMOCALC can obtain P-T estimates for multiple points of the core-to-rim garnet growth history, as opposed to GTB methods that only yield reliable $P-T$ estimates for growth of garnet rims (see chapter seven for a more comprehensive discussion of this). The core and rim P-T estimates for five garnets from Alpine Schist from the McArthur Range are shown in figure 2.2 , with the intermediate points from the complex paths removed for visual clarity.

Studies from the McArthur Range (Vry, et al., 2008, Williams, 2006) found that in samples with higher $\mathrm{MnO}$ whole-rock compositions, garnet grew at lower P-T conditions at the start of the P-T path. P-T paths for garnet in samples higher in $\mathrm{MnO}$ were at higher $P-T$ conditions, near the maximum pressures, where the ends of many $P-T$ paths overlap. $P-T$ conditions start at $380^{\circ} \mathrm{C} / 2.6 \mathrm{kbar}$, reach peak conditions at $\sim 490^{\circ} \mathrm{C} / 9.0 \mathrm{kbar}$, with garnet growth continuing during decompression to $\sim 500^{\circ} \mathrm{C} / 6 \mathrm{kbar}$. The peak conditions are noticeably lower in temperature than 
Franz Josef-Fox Glacier region, highlighting along strike differences in the metamorphic history of the Alpine Schist.

\subsection{Summary}

The Alpine Schist has a complex variably overprinted metamorphic history and shows along strike variation in the P-T history, from north to south. Best estimates of the evolving metamorphic conditions are from $P-T$ paths produced of the Alpine Schist in the McArthur Range $\sim 7 \mathrm{~km}$ to the northeast (Vry, et al., 2008, Williams, 2006) which used similar methods to ones used in study. This thesis examines a previously unstudied area (the Newton Range) and compares observations of petrography, structure, mineral/whole-rock compositions, and interpreted $P-T$ paths created using THERMOCALC, to previous studies from throughout the Haast Schist, notably from the Franz JosefFox Glacier region and north Westland. 
Chapter Three

\section{FIELD OBSERVATIONS}

\subsection{Introduction}

This chapter presents lithological and structural data collected in the field from the Newton Range, Southern Alps, New Zealand. The purpose of the field work was to obtain rock samples and gather data that could be used to help interpret the metamorphic pressure-temperature $(P-T)$ history of the Alpine Schist and put it into a wider context, comparing this study to other studies of Alpine Schist throughout the Southern Alps.

Structural fabric information was collected in order to identify any changes in orientation of foliation, lineation and folding, which may have resulted from changing deformation regimes or multiple deformation events. The data presented here is used in combination with microstructural observations (chapter four) to interpret the sequence and nature of deformation in the study area. The relationship of the deformation events to the well studied sequence of events of the Alpine Schist in the Franz Josef-Fox Glacier region is discussed in detail in the discussion section of this chapter and chapter four.

The Alpine Schist in the Newton Range consists mainly of greyschist (pelite and psammite), with lesser amounts of chlorite rich greenschist, and minor epidosite and quartz veins. A discontinuous $\sim 350 \mathrm{~m}$ wide band of the Pounamu Ultramafic Belt (PUB) is present near the southeast most samples collected in the range, oriented sub-parallel to the strike of the dominant foliation of the surrounding greyschist. The focus of the present study is on the Alpine Schist.

\section{Methods}

Work was undertaken during two field seasons, each in different $\sim 2 \mathrm{~km}$ long sections (SE and NW) of the range (Fig. 3.1). The locations of the study areas were selected to document any variation in metamorphic grade with increasing structural distance away from the Alpine Fault. A $\sim 1.4 \mathrm{~km}$ long section of ridge crest between the two sections was inaccessible by foot due to difficult terrain and 


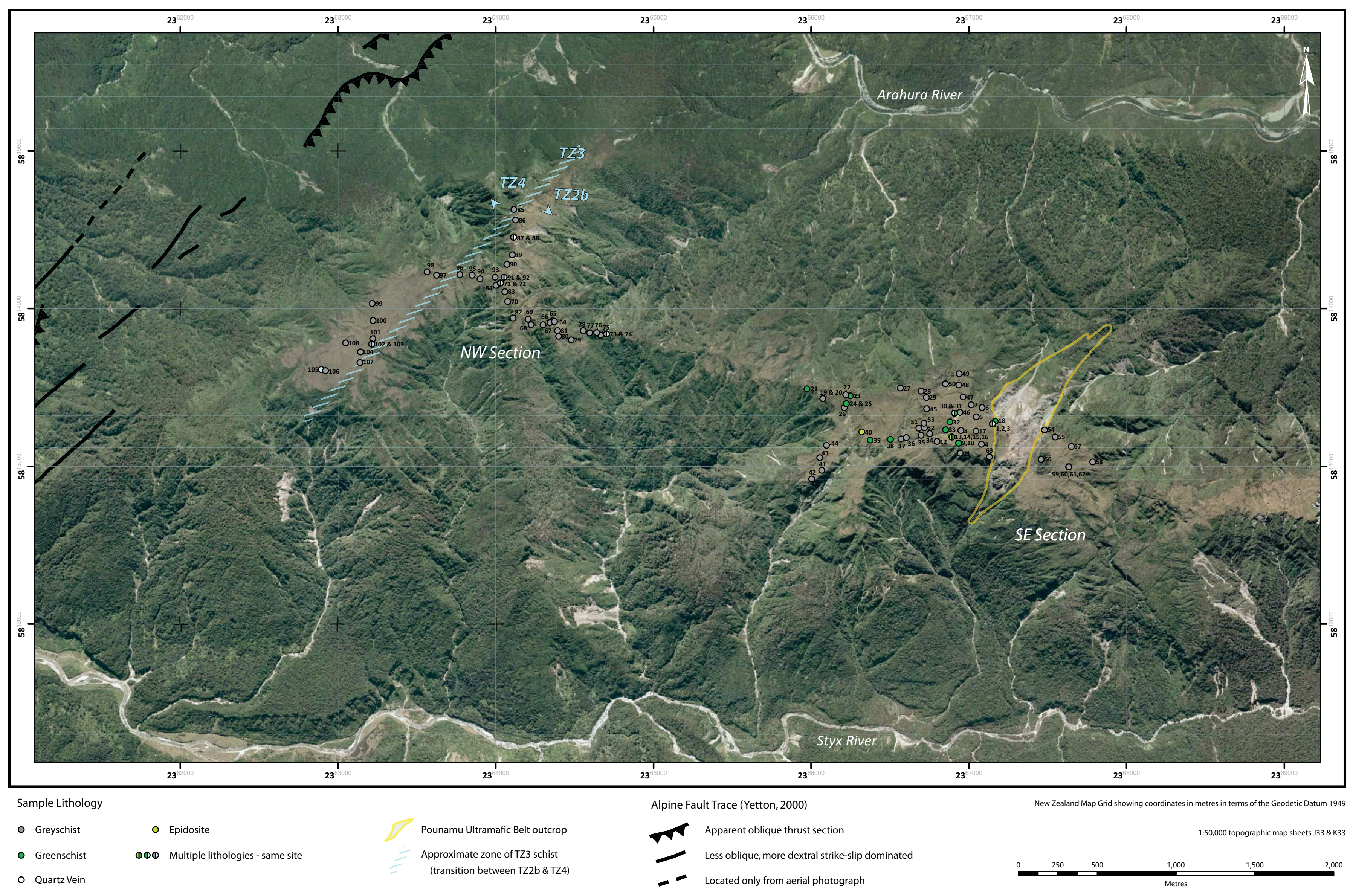

Figure 3.1. Map of sample locations and lithologies of all 108 samples collected from the Newton Range. The background image is an aerial photograph taken in summer conditions, enabeling much of the Pounamu Ultramafic Belt outcrop to be identifed by the lack of vegetation. Numbered sites refer to the suffix of the location numbers DMNR-\#\#. 
vegetation. 108 samples of greyschist, greenschist, quartz veins and epidosite were collected from accessible outcrops of in situ rock, which are typically located along ridges, spurs and in incised stream headwaters. All but two samples collected were in situ; the two samples that were not collected in situ were located on the main ridge crest, and are therefore still useful for textural and mineralogical observations. Oriented samples were collected where possible, and unoriented samples were collected in cases where the rock was extremely fragile, or where the accessibility of the outcrop was limited due to topography and/or adverse weather conditions. All sample locations were recorded using a handheld GPS unit with $\pm 5 \mathrm{~m}$ accuracy, and are presented in figure 3.1 and appendix A.1.1. Structural observations were taken at each sample site as well at other locations between samples.

\subsection{Lithological Observations}

\section{Greyschist}

The dominant lithology in the Newton Range is strongly foliated planar greyschist that ranges from textural zone (TZ) TZ2b to TZ4 on the basis of segregated quartz layer thickness in hand sample observations (Turnbull, et al., 2001). Most outcrops consist of either pelitic or psammitic schist although compositionally banded outcrops of pelitic and psammitic layers, ranging in thickness from $0.5-5 \mathrm{~cm}$, are common in the SE section of the study area (Fig. 3.2). Thin quartz layers or segregations in the pelitic schists become more numerous and thicker with increasing proximity to the Alpine Fault, corresponding to a change in textural grade from TZ2b to TZ4 at the northwestern-most edge of the sample collection area (Fig. 3.3). The transition between textural zones TZ2b and TZ4 is rather abrupt, with a thin zone of TZ3 schist apparent in a few samples reflecting the transition. The lack of a large zone of TZ3 schist is comparable to the Whitcombe River watershed $\sim 30 \mathrm{~km}$ to the southwest (Cooper \& Reay, 1983).

The rocks are very fine grained, so thin-section petrography is required for detailed documentation of the mineral assemblages and textures (see chapter three - petrography and microstructure). Minerals identifiable in hand sample include: small elongated ilmenite porphyroblasts $(\sim 0.7 \mathrm{x}$ $0.3 \mathrm{~mm})$; flakes of unaltered black and altered bronze coloured biotite $(\sim 1 \mathrm{~mm}$ in diameter) and multiple orientations of microcrystalline quartz layers and veins ranging from $>1 \mathrm{~mm}-1 \mathrm{~m}$ in thickness. No garnet is seen in hand sample. 


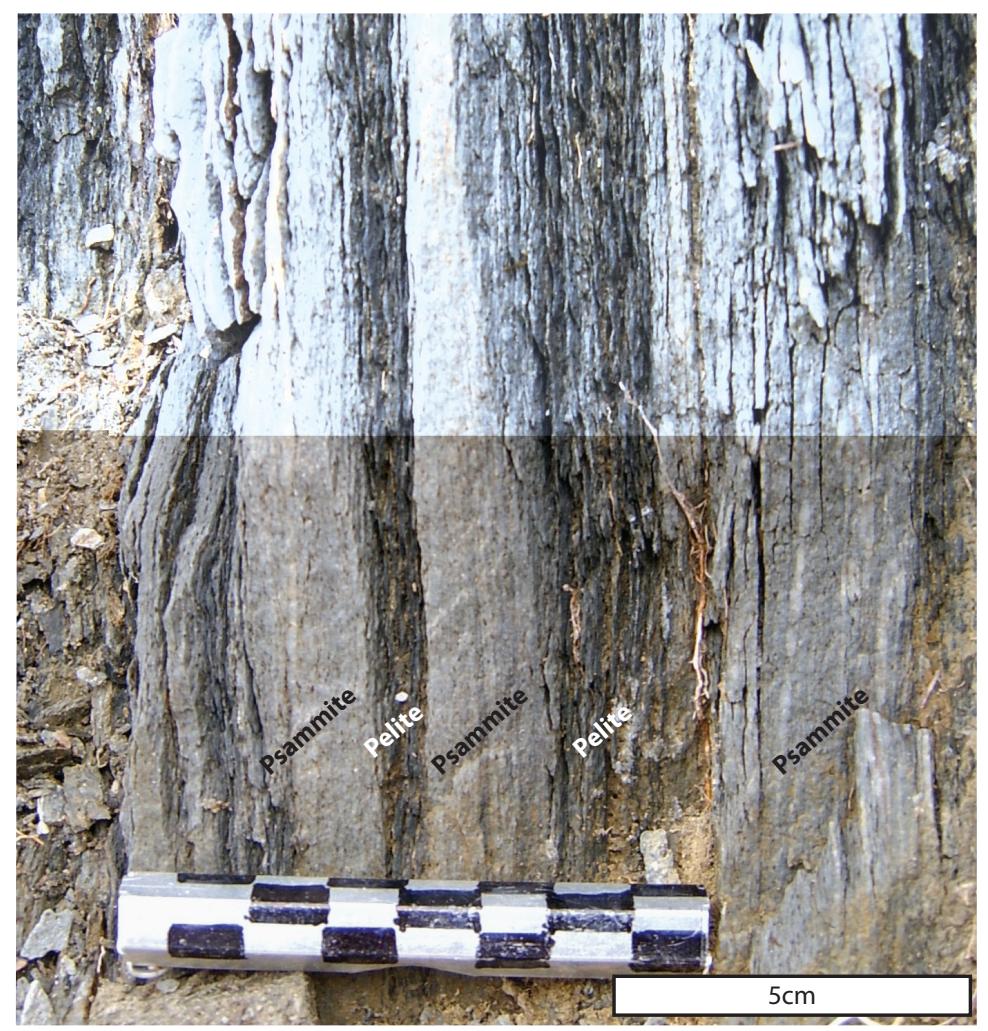

Figure 3.2. Photo of pelite and psammite layering in greyschist. Sample location DMNR-01.

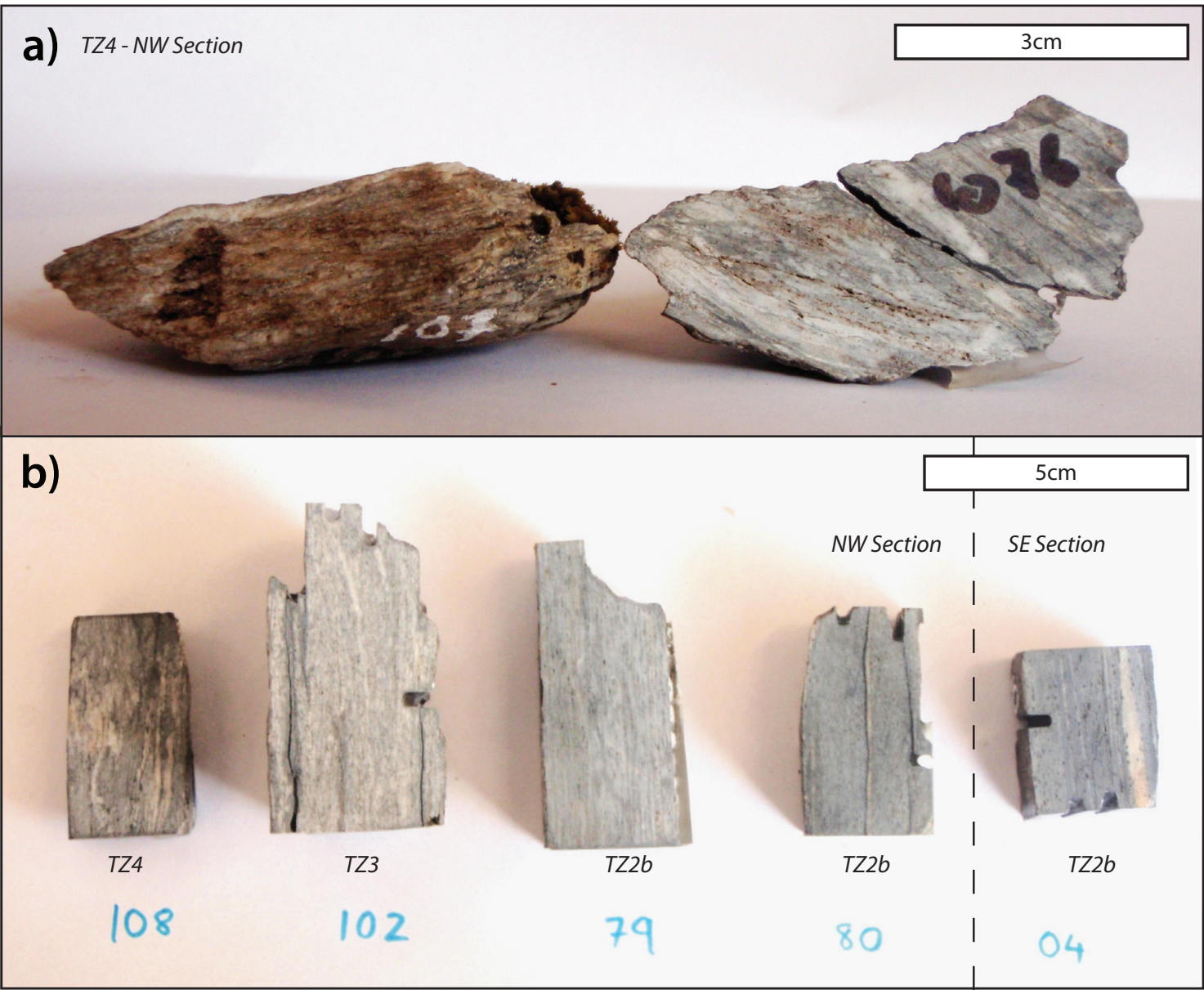

Figure 3.3. Photos of greyschist samples from different textural zones. a) Lowest TZ4 segregated greyschist. The sample on the left shows how it is hard to identify segregation on an uncut surface. b) Progression of textural grade from low TZ4 (left) to high TZ2 (right). Textural zone transition through TZ3 occurs in a thin zone, (see fig. 3.1) including DMNR-102. 


\section{Greenschist}

Greenschist comprises $\sim 15 \%$ of all outcrop in the SE section of the Newton Range but was not observed in the NW section. Greenschist is strongly foliated and typically highly fissile, making large oriented samples difficult to obtain. Greenschist is chlorite rich, giving it a distinctive forest green colour and commonly contains necked quartz veins $1 \mathrm{~mm}-2 \mathrm{~cm}$ thick (Fig. 3.4). Fine $<1 \mathrm{~cm}$ long tremolite/actinolite needles occur in some greenschists. Streams commonly incise preferentially where outcrops of weak greenschist occur, highlighting $\sim 5-20 \mathrm{~m}$ thick discontinuous bands sub parallel to the dominant foliation.

\section{Epidosite}

Several outcrops of greenschist contain minor amounts of epidote and biotite rich rock, generally occurring as $5-20 \mathrm{~cm}$ thick bands. These zones are commonly heavily crushed, occurring between equally friable bands of chlorite rich greenschist (Fig. 3.5a). The epidote rich rock has a distinctive lime green colour and is typically intermixed with microcrystalline quartz layers (Fig. 3.5b). Layers rich in gold coloured altered biotite flakes (up to $1.2 \mathrm{~cm}$ ) are associated with all epidosite outcrops (Fig. 3.6).

\section{Quartz Veins}

Multiple generations of quartz veins occur in both greyschist and greenschist; the veins range in thickness from $<1 \mathrm{~mm}-\sim 1 \mathrm{~m}$ in the SE section and $1 \mathrm{~mm}-10 \mathrm{~cm}$ in the NW section of the study area. The orientation of quartz veins is typically sub-parallel to the dominant foliation but occasionally has a crosscutting relationship. Many thinner sub-parallel veins are necked, whilst less common larger veins are planar and continuous along strike (Figs. $3.7 \& 3.8$ ). Three contain veins that perpendicularly crosscut the dominant foliation (Fig. 3.9a). Thinner veins $(<1.5 \mathrm{~mm}$ thick) are occasionally oriented sub-perpendicular to the foliation and are asymmetrically folded (Fig. 3.9b). One vein in the $\mathrm{SE}$ section has an open cavity texture containing euhedral quartz crystals $<2.5 \mathrm{~cm}$ in length (Fig. 3.10). The wide range in quartz vein texture and orientation is evidence for a complex, multi-stage fluid flow history in Newton Range which clearly warrants further investigation in future studies. 

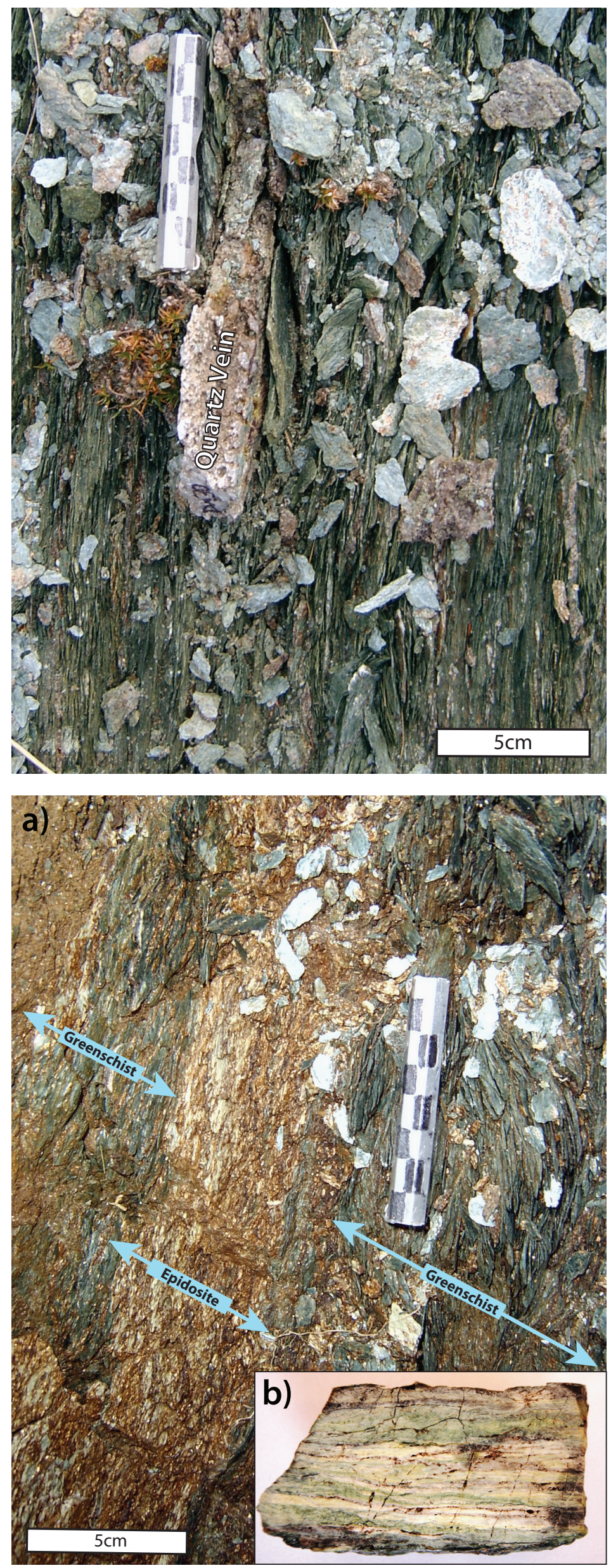

Figure 3.4. Photo of chlorite rich greenschist with a necked quartz vein sub-parallel to the dominant foliation. Note the fissile nature of the rock. Sample location DMNR-13.

Figure 3.5. a) Photo of banded epidosite and chlorite rich greenschist. Note the crushed nature of the epidosite. b) Cut and polished hand specimen of epidosite showing epidote and quartz layers (sample is $4 \mathrm{~cm}$ thick) Sample location DMNR16. 

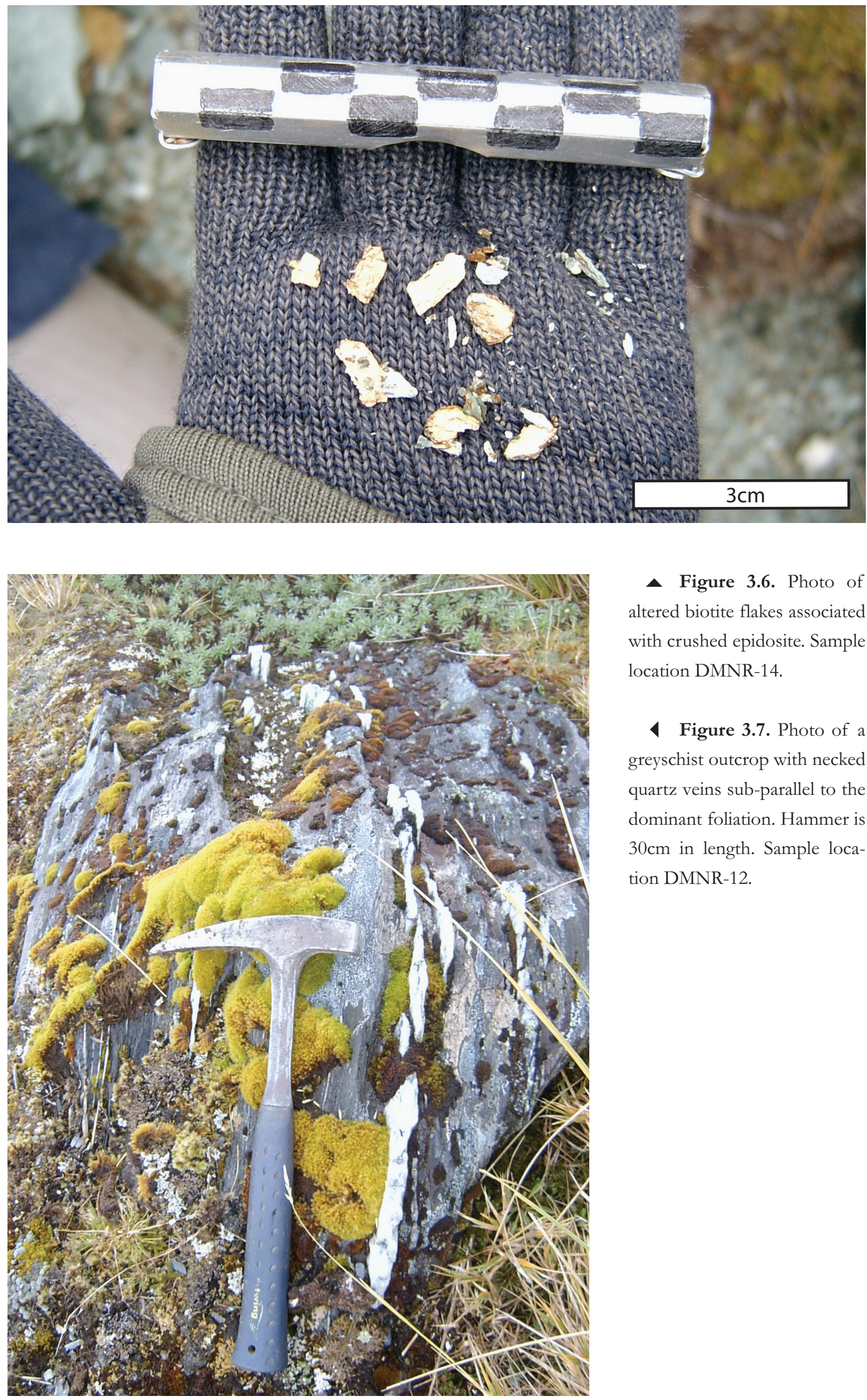

- Figure 3.6. Photo of altered biotite flakes associated with crushed epidosite. Sample location DMNR-14.

4 Figure 3.7. Photo of a greyschist outcrop with necked quartz veins sub-parallel to the dominant foliation. Hammer is $30 \mathrm{~cm}$ in length. Sample location DMNR-12. 


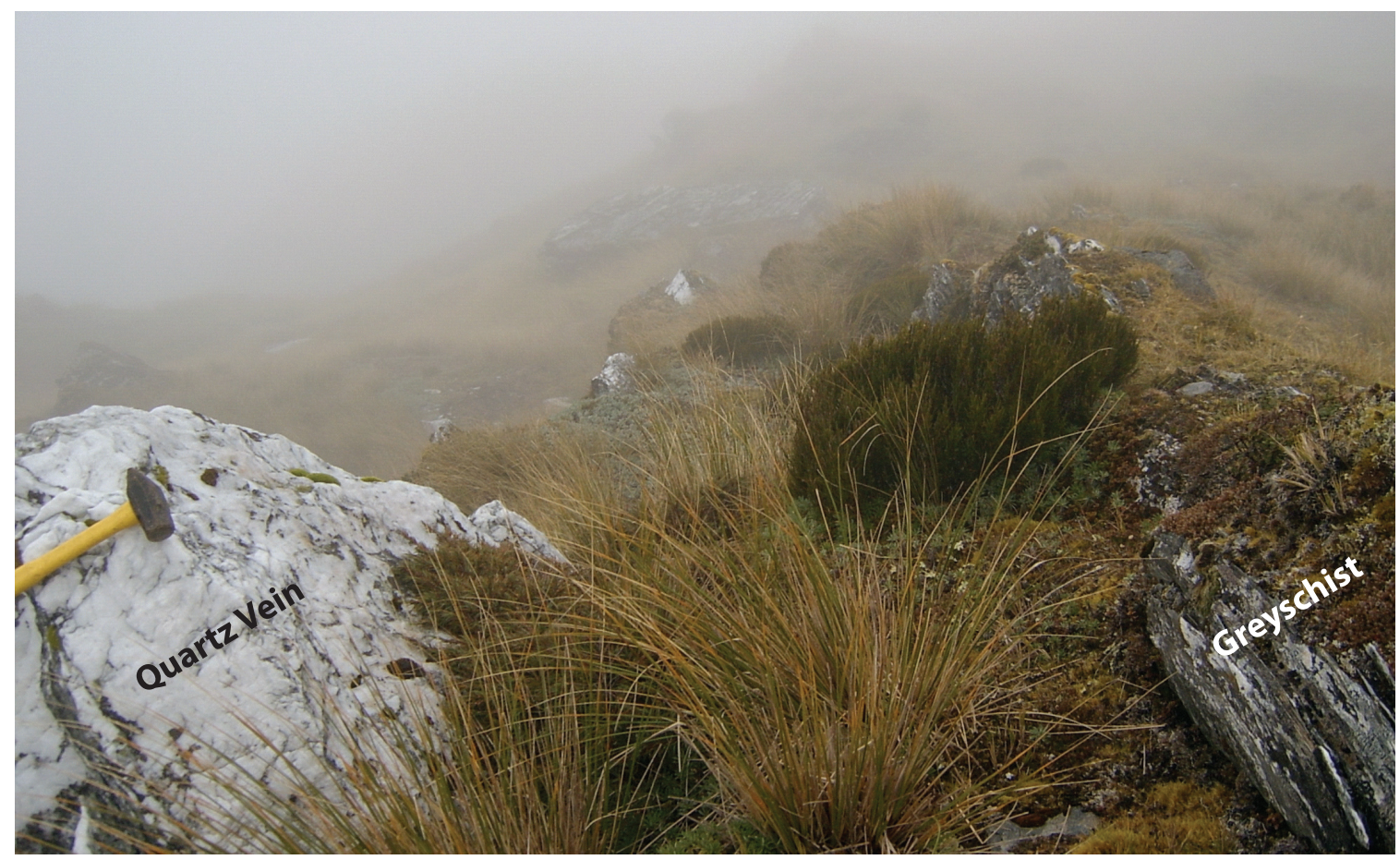

Figure 3.8. Photo showing a $\sim 1 \mathrm{~m}$ thick quartz vein oriented sub-parallel to the foliation of the surrounding greyschist. Photo is taken facing SSW, with $30 \mathrm{~cm}$ long hammer as scale. Location $\sim$ DMNR-04.

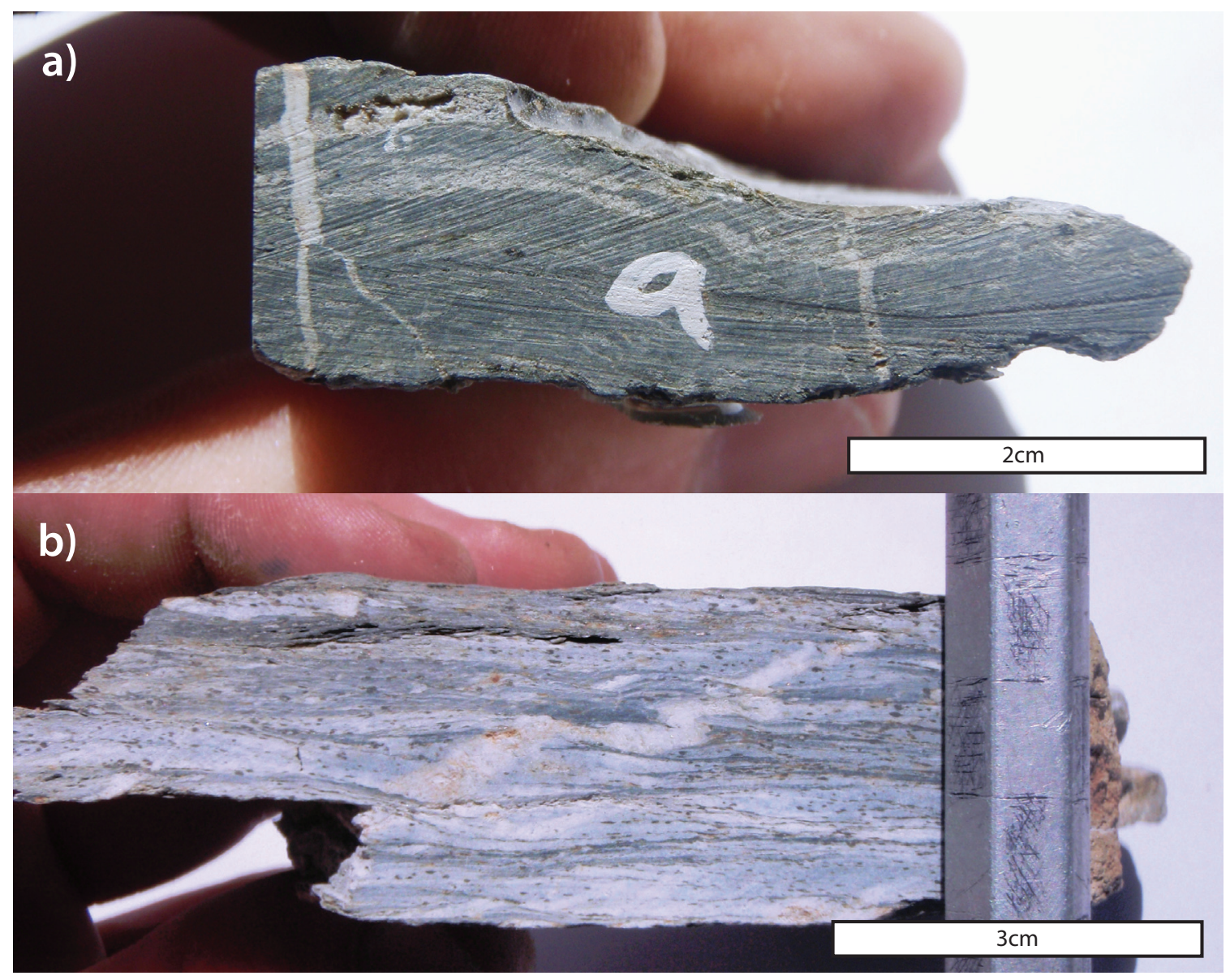

Figure 3.9. Photos of quartz veins differing in orientation with respect to the dominant foliation. a) Relatively undeformed quartz veins perpendicularly cross-cutting the dominant foliation (DMNR-92). b) An asymmetrically folded quartz vein oblique to the dominant foliation (DMNR-52). 


\section{Pounamu Ultramafic Belt}

The PUB consists of a series of metamorphosed/metasomatised tectonic slices of an ophiolite sequence, which were thrust into Torlesse Terrane sediments prior to the metamorphism of the Haast Schist Belt (Cooper \& Reay, 1983). The slices of PUB were further dismembered and dissected during Haast Schist metamorphism to form discontinuous pods that outcrop at ridge crests in north Westland, from the Waitaha River in the south to Mill Stream in the north (Fig. 3.11). Cooper \& Reay (1983) infer that the PUB continues through Otago, with a gap of $\sim 100 \mathrm{~km}$ between Jacobs River and Waitaha River where the belt has been cut by the Alpine Fault, whist other studies infer the ultramafic rocks in Otago to be a separate formation from the PUB (Cooper \& Lovering, 1970, Roser \& Cooper, 1990).

In the Newton Range, the PUB trends approximately parallel to the strike of the surrounding greyschist with a steep apparent dip to the southeast. Based on a brief lithological investigation, the rocks consist mainly of serpentinite, with associated talc, tremolite/actinolite, chlorite and magnetite. The Newton Range PUB pod has been briefly mapped and sampled (Beck, 1965, MacKenzie, 1984) and was part of a local study of the PUB, also including the McArthur and Griffin Ranges (Koons, 1978). Maps from these studies, in combination with aerial photograph interpretation and field observations, define a pod bulging to $\sim 350 \mathrm{~m}$ at its thickest at the top of the ridge, and pinching out $\sim 500 \mathrm{~m}$ down incised stream headwaters on the flanking slopes (Figs. 3.1 \& 3.12). The PUB has a complex emplacement, metamorphic and deformational history (Cooper, 1976, Cooper \& Reay, 1983, Ireland, 1981, Ireland, et al., 1984, Koons, 1978) but as the focus of this study is on the metamorphic history of the surrounding Alpine Schist, acquisition of samples and detailed structural and lithological observations of the PUB was not undertaken.

\subsection{Structural Observations}

\subsubsection{Macrostructure}

The dominant foliation of the Alpine Schist in the Newton Range strikes $\sim$ NE-SW and is predominantly SE dipping. All outcrops in the NW section dip SE and have a mean orientation of 37/SE/51 (Fig. 3.13a). In the SE section 49 out of 73 outcrops dip SE with a general strike of 005$020^{\circ}$ (Fig. 3.13b). There is a large scatter in foliation orientation in the SE section due to macro and mesoscale folding/overturning of the schist. Structural data is shown in the structural map (Fig. 3.14) and the structural cross section (Fig. 3.15). As seen in figure 3.14, there are domains of 


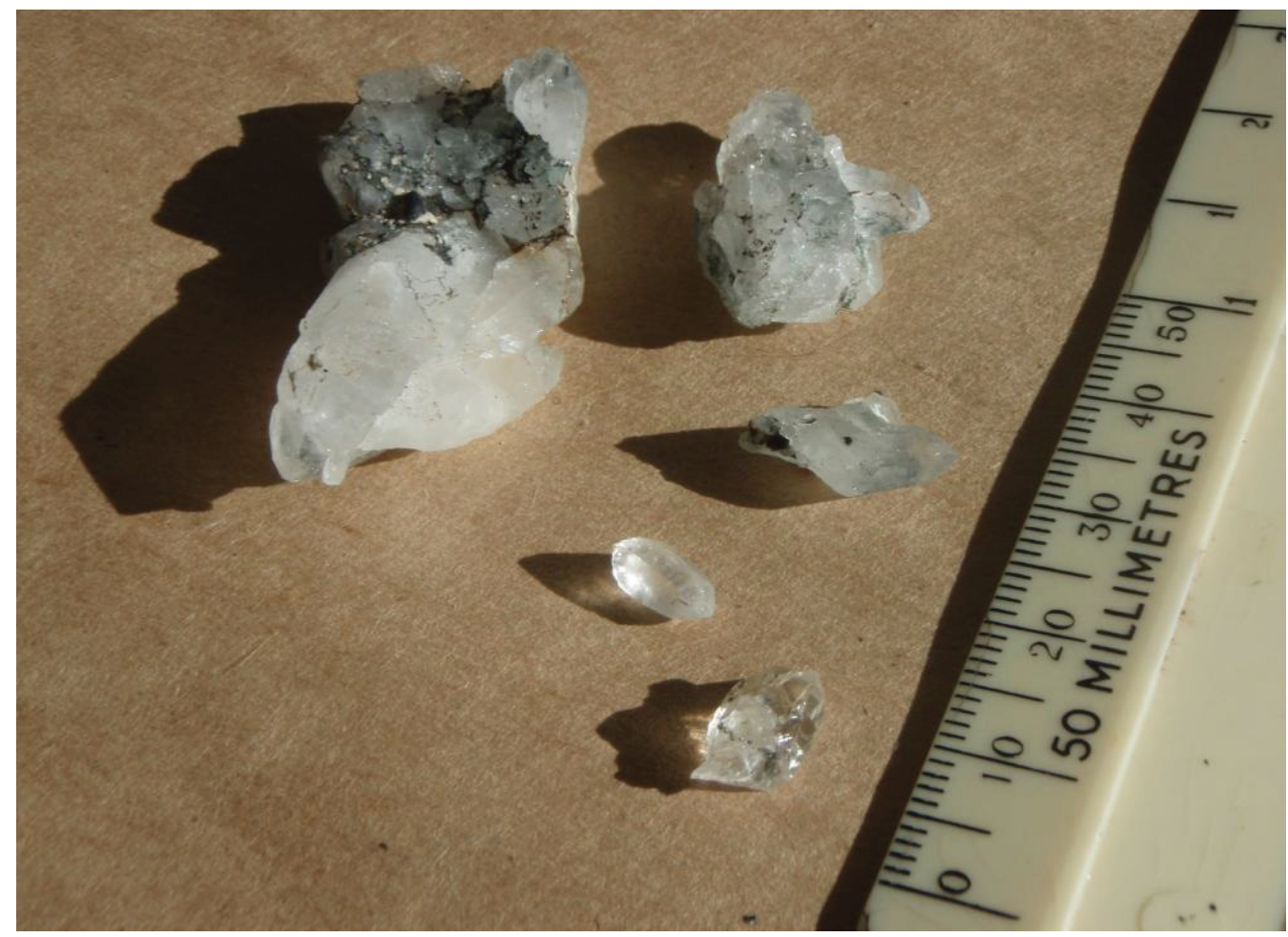

Figure 3.10. Photo of euhedral quartz crystals found in an open cavity vein. Location $\sim$ DMNR-50.

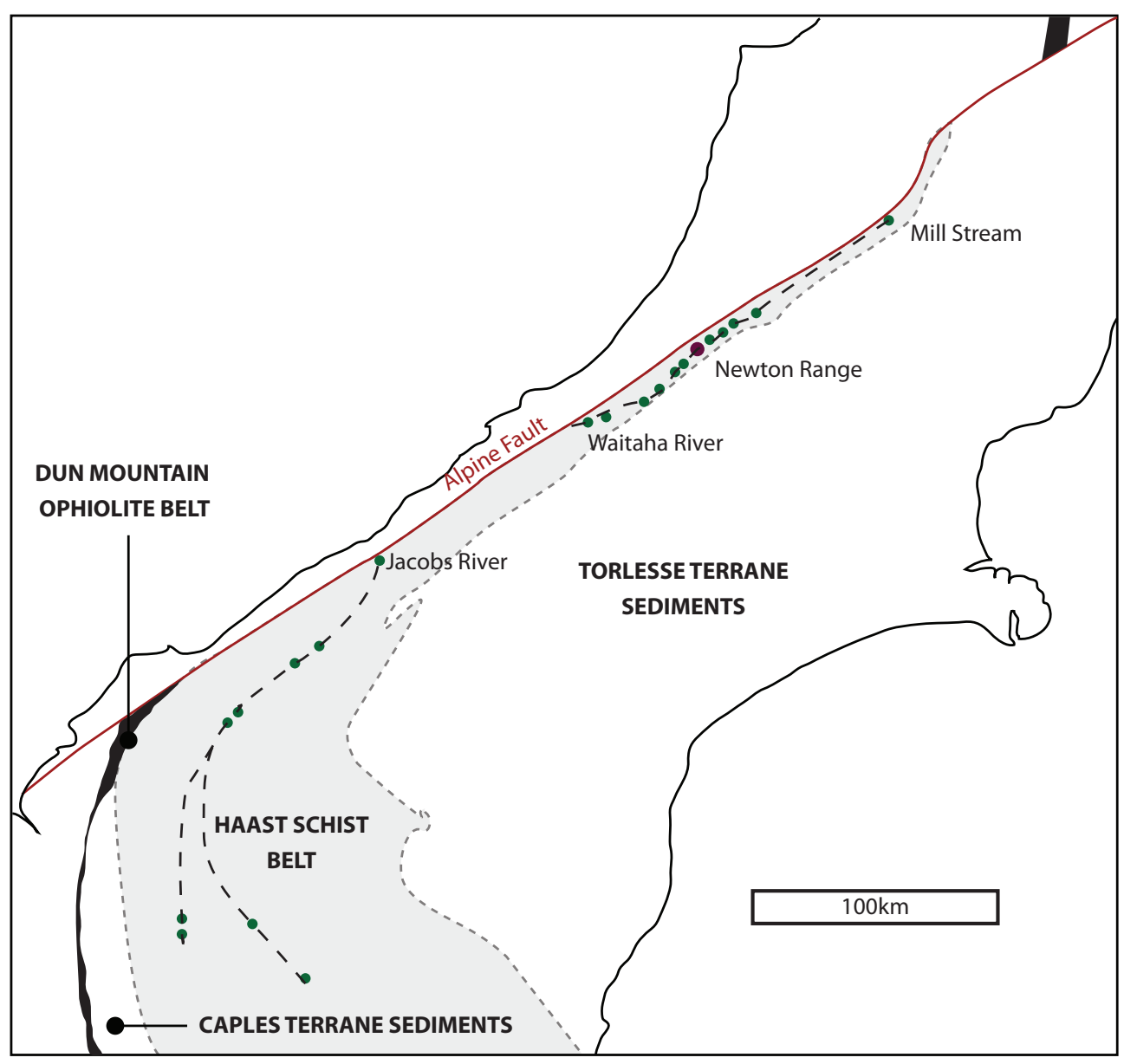

Figure 3.11. Map of locations of Pounamu Ultramafic Belt outcrops in the South Island, New Zealand (green filled circles). The belt (black dashed line) is cut by the Alpine Fault between the Waitaha and Jacobs Rivers. Modified from Cooper \& Reay (1983). 


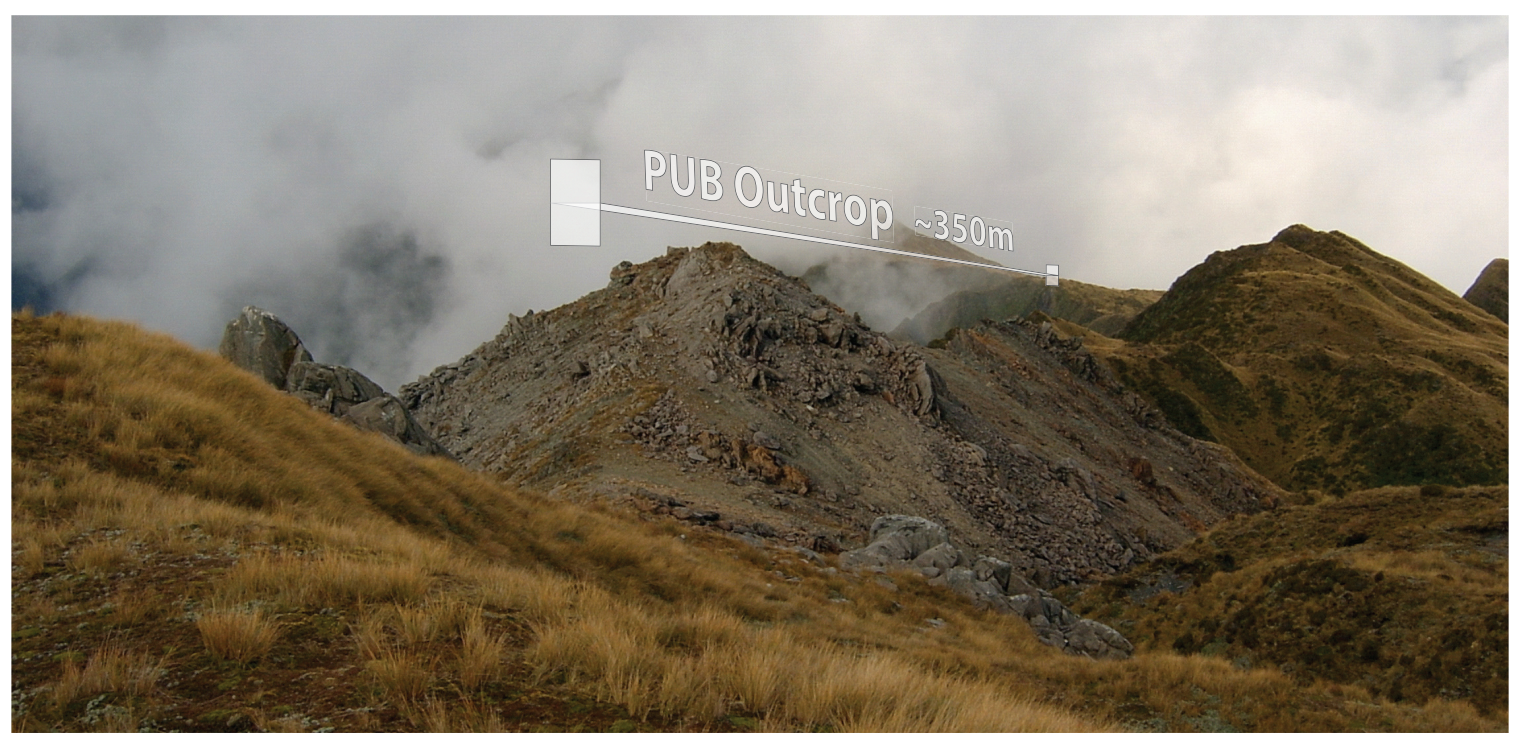

Figure 3.12. Photo of the $\sim 350 \mathrm{~m}$ wide outcrop of the Pounamu Ultramafic Belt on the ridge of the Newton Range. The surrounding vegetated slopes are greyschist. Photo facing ENE.

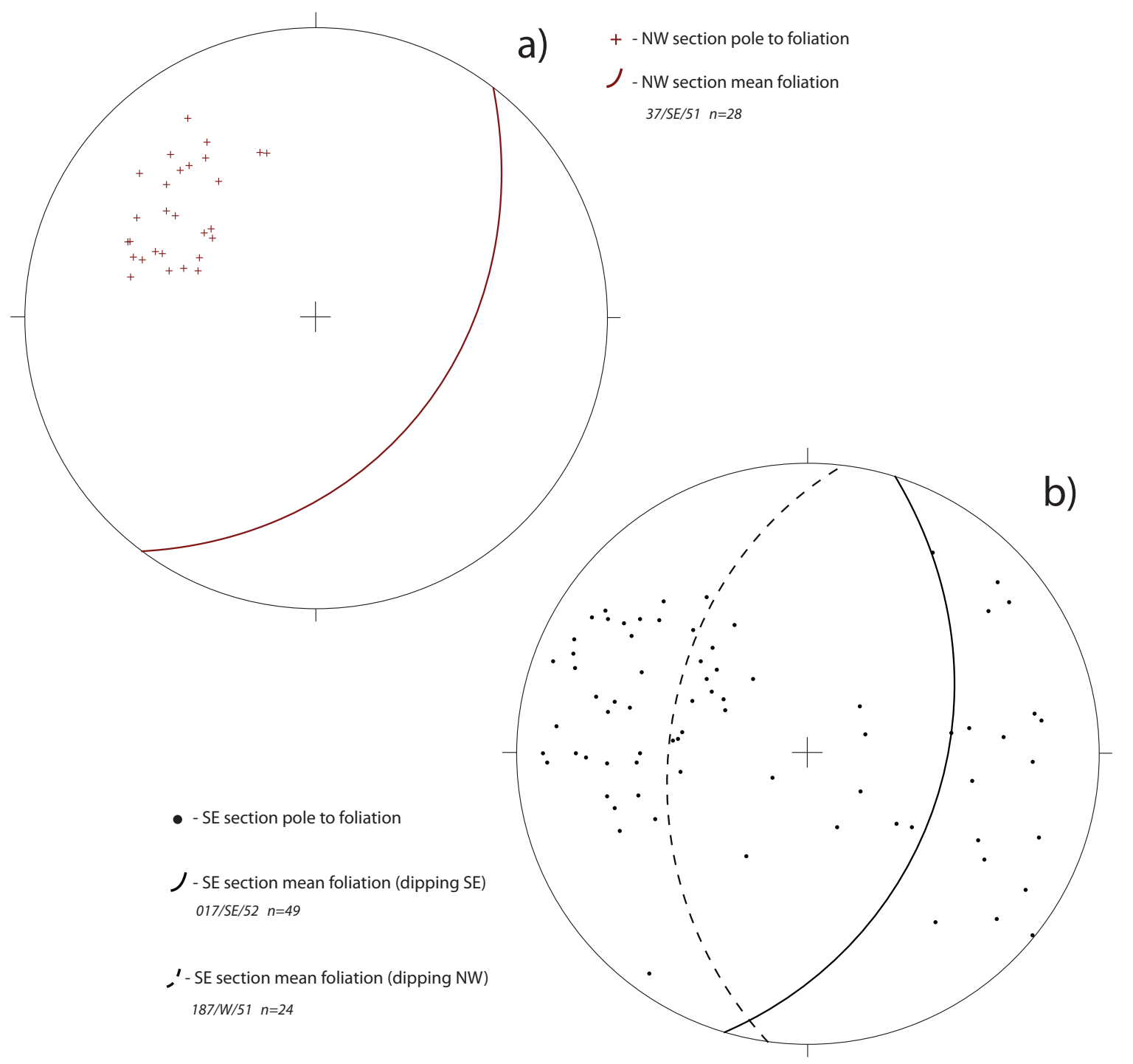

Figure 3.13. Lower hemisphere equal-area stereographic projections of Alpine Schist foliation orientations from the Newton Range. a) All NW section foliation data. b) SE and NW dipping planes from the SE section. 
alternating $\mathrm{SE} / \mathrm{NW}$ dips which line up along the strike of the mean foliation. A possible interpretation of the alternating dip domains and the scattered SE section dips is large scale folding of the schist. This interpretation infers large scale folds with axial traces sub-parallel to the strike of the dominant foliation, linked along strike where the dip domain switches from NW to SE or vice versa. However this is just one interpretation, and such a pattern in foliation scatter could also be created by variably overturned/not overturned schist. Due to the sparse nature of outcrop and lack of structural fabric in most samples (both crenulation and cleavage), the orientation and location of these folds are inferred, and further investigation may be warranted to find a more appropriate explanation for the variable dips in the SE section.

\subsubsection{Mesostructure}

\section{Outcrop-Scale Folding}

Two localities of greenschist and two of greyschist in the SE section contain outcrop-scale folding. The greyschist outcrops are located 20 and $250 \mathrm{~m}$ east of the PUB, and both greenschist outcrops are both $\sim 900 \mathrm{~m}$ east of it. The folds have a brittle kink like appearance with one folded outcrop containing a band of brittlely deformed epidosite (Fig. 3.16). The fold hinges have shallow plunges $\left(1-32^{\circ}\right)$ and trend NE or SW (mean $=026 / 11$ ) (Fig. 3.16c). This trend is similar to the northwestsoutheast orientation of the mean foliation, and trace of the Alpine Fault. The axial planes of these folds are sub horizontal and greatly differ in orientation compared to the near vertical inferred axial planes of the antiforms and synforms presented in figures 3.13 and 3.15 .

\section{Lineations and Crenulations}

24 samples of greyschist contained lineations which can be broadly split into two types. The most common is a preferred mineral alignment lineation of biotite and/or ilmenite (Fig. 3.17a). This mineral alignment lineation has the same orientation as, and occasionally occurs simultaneously with a lineation that has a rodding like appearance on the foliation surface (Figs. 3.17b \& 3.17c). This rodding lineation is similar in appearance to the S2/S3 intersection lineation seen in non-mylonitic schists in the well-studied Franz-Josef Fox Glacier region. However, in most samples with the rodding lineation, n thin sections cut perpendicular or near-perpendicular to the lineation show no evidence of a crenulation. Only cut surfaces of three oriented samples contain a crenulated fabric where $\mathrm{mm}$ scale layers of psammite and pelite are near-isoclinally folded on a sub-cm scale to form a 


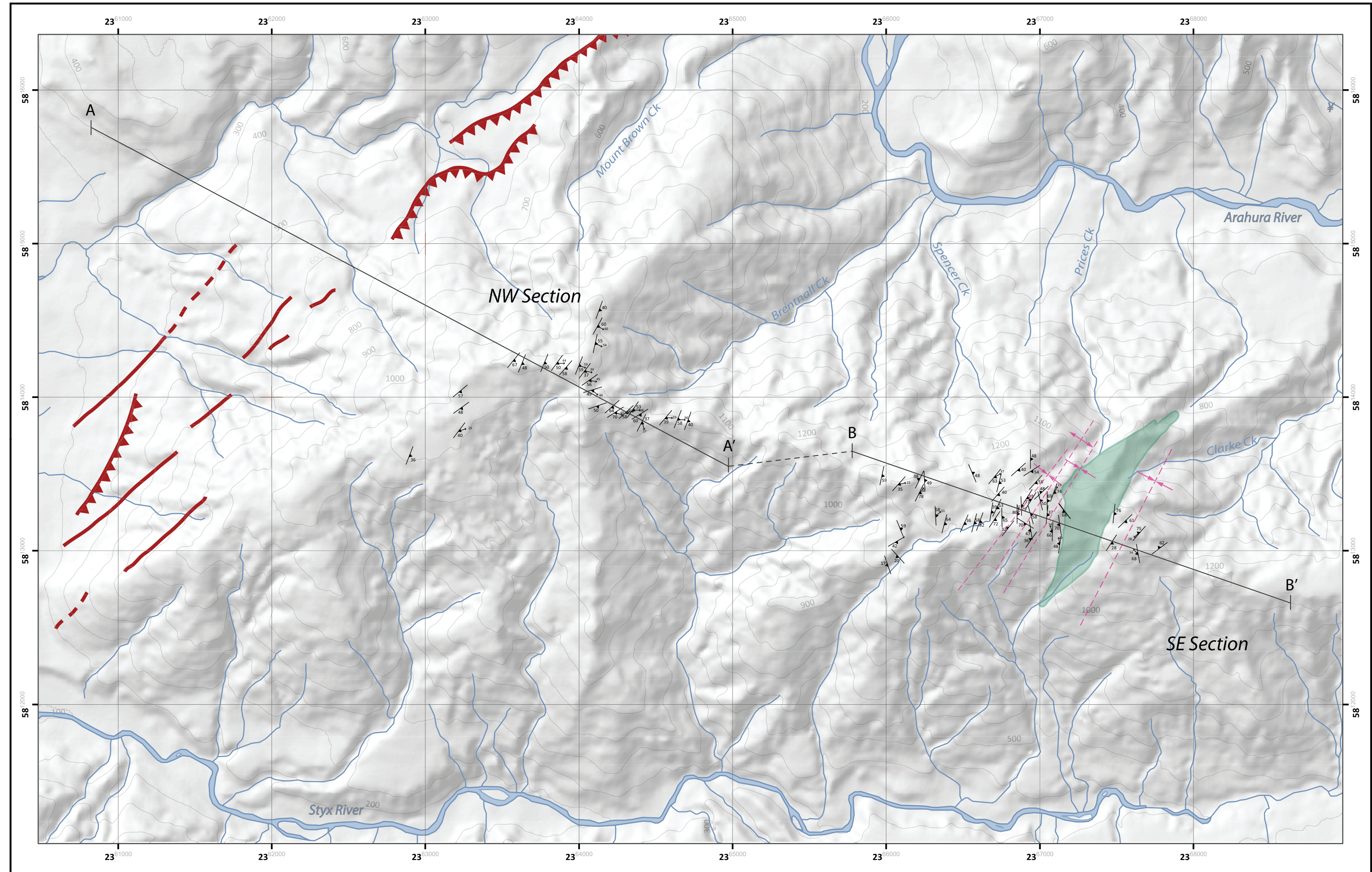

Lo Foliation orientation 7 inferred antiform axial trace 100 Contour and elevation $(m) \quad$ Pounamu Ultramafic Belt Alpine Fault Trace (Yetton, 2000) L Less oblique, more dextral strike-sip dominated

New Zealand Map Grids row

Figure 3.14. Map of the Newton Range showing foliation and lineation measurements and inferred macroscale fold axial traces. Some data is omitted for visual clarity.

1:50,000 topographic map sheets 333 \& $к 33$ 


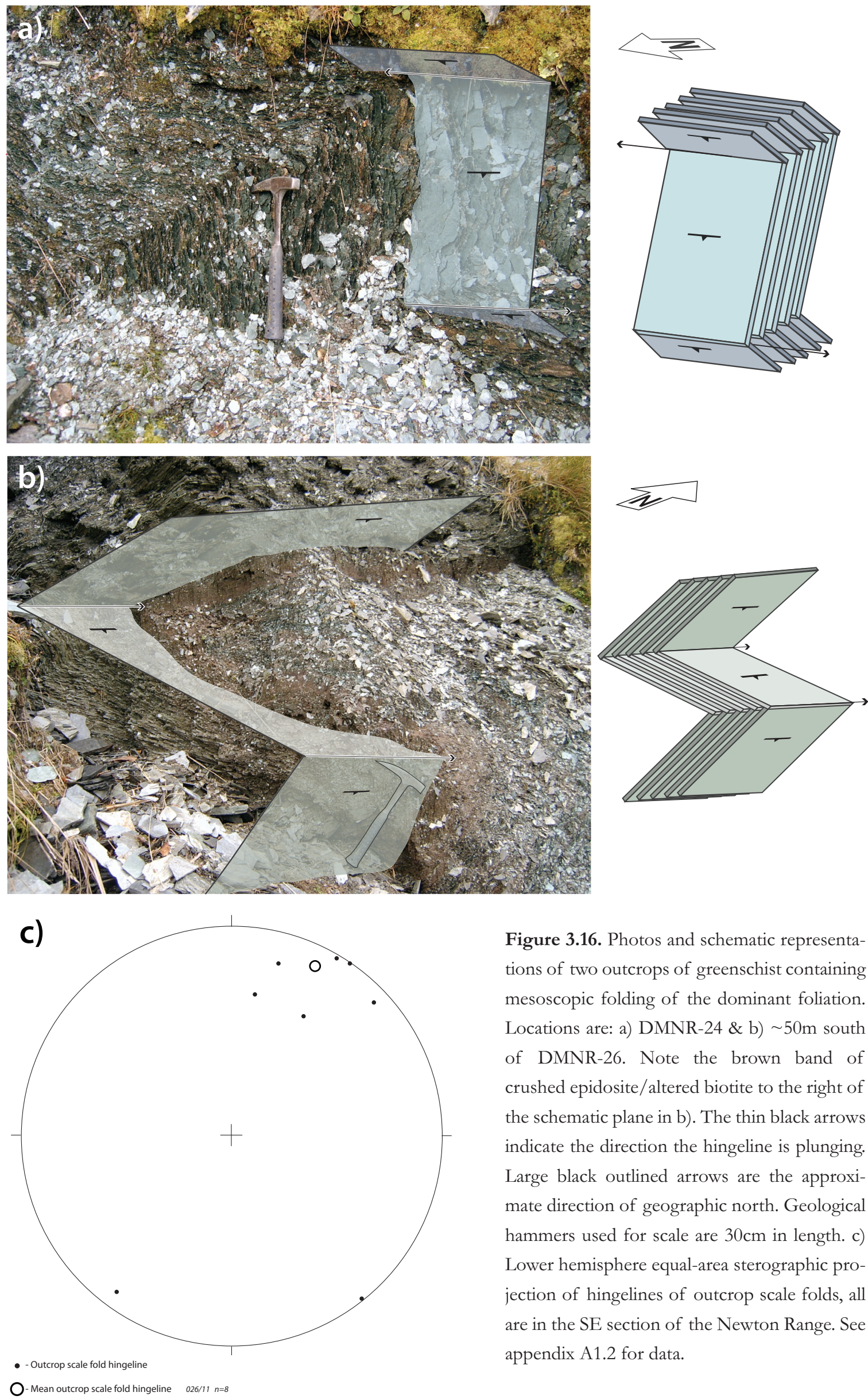

Figure 3.16. Photos and schematic representations of two outcrops of greenschist containing mesoscopic folding of the dominant foliation. Locations are: a) DMNR-24 \& b) 50m south of DMNR-26. Note the brown band of crushed epidosite/altered biotite to the right of the schematic plane in b). The thin black arrows indicate the direction the hingeline is plunging. Large black outlined arrows are the approximate direction of geographic north. Geological hammers used for scale are $30 \mathrm{~cm}$ in length. c) Lower hemisphere equal-area sterographic projection of hingelines of outcrop scale folds, all are in the SE section of the Newton Range. See appendix A1.2 for data. 
wavy crenulation intersection lineation (Fig. 3.17e). This folding is not visible until the rock is cut. For the remaining samples without a crenulation it may be inferred that the other rodding lineations are the same as this crenulation intersection lineation and hence forth will be referred to as the "intersection lineation". The absence of a visible crenulation can probably be attributed to a poor expression of folding in relatively thin samples $(\sim 1.5 \mathrm{~cm}$ thick) of homogeneous schist compared to samples containing thin alternating bands of pelitic and psammitic where identifaction of folds is much easier. This intersection lineation appears to become tighter with increasing proximity to the Alpine Fault, where smaller scale intrafolial folds can be seen, than in samples from the SE section of the study area (Fig. 3.17f).

It is difficult to identify the type of lineation in the field alone, with limited outcrop availability, and subsurface folded quartz veins occasionally creating a lineation similar in appearance to the intersection lineation (Fig. 3.17d). Lineation data for samples with such folded subsurface quartz were found to have a random scatter (corresponding to the variability of the original orientation of the quartz veins before folding) and was discarded from the presented dataset once rocks were cut and the folded quartz veins were visible. The presented lineation dataset has a larger scatter in the SE section mainly because the same type of lineation occurs on both SE and NW dipping planes (Fig. 3.18). In the NW section the lineation pattern has less scatter and is centred at 102/48 ( $\mathrm{n}=14)$. Lineations on SE dipping planes generally contain a NNE plunging lineation, whereas NW dipping planes contain a NNW plunging lineation. These lineations may be analogous to the SE dipping plane lineations but have been flipped post formation during folding/overturning of the schist to form an apparent new orientation.

\section{Faulting}

One small outcrop-scale fault was seen in the NW section of the field area at sample site DMNR-74 oriented $057 / \mathrm{NW} / 48$. A cross-cutting quartz vein marker, oblique in orientation to the exterior foliation had an apparent northwest side up (reverse) offset of $25 \mathrm{~cm}$, however with the absence of further markers no clear evidence of the absolute sense of slip was available. Active large scale faults in the surrounding region include the Alpine Fault and southernmost extent of the Marlborough Fault System (MFS). The Alpine Fault is situated $\sim 1 \mathrm{~km}$ northwest of the western-most collected samples and has an approximate strike of $\sim 045^{\circ}$ (wider regional strike is $\sim 050^{\circ}$ ). Yetton (2000) mapped the Alpine Fault into sections of oblique thrust and dextral strike-slip segments with the fault trace at the foot of the Newton Range containing both of these types of segments. $\sim 25 \mathrm{~km}$ 

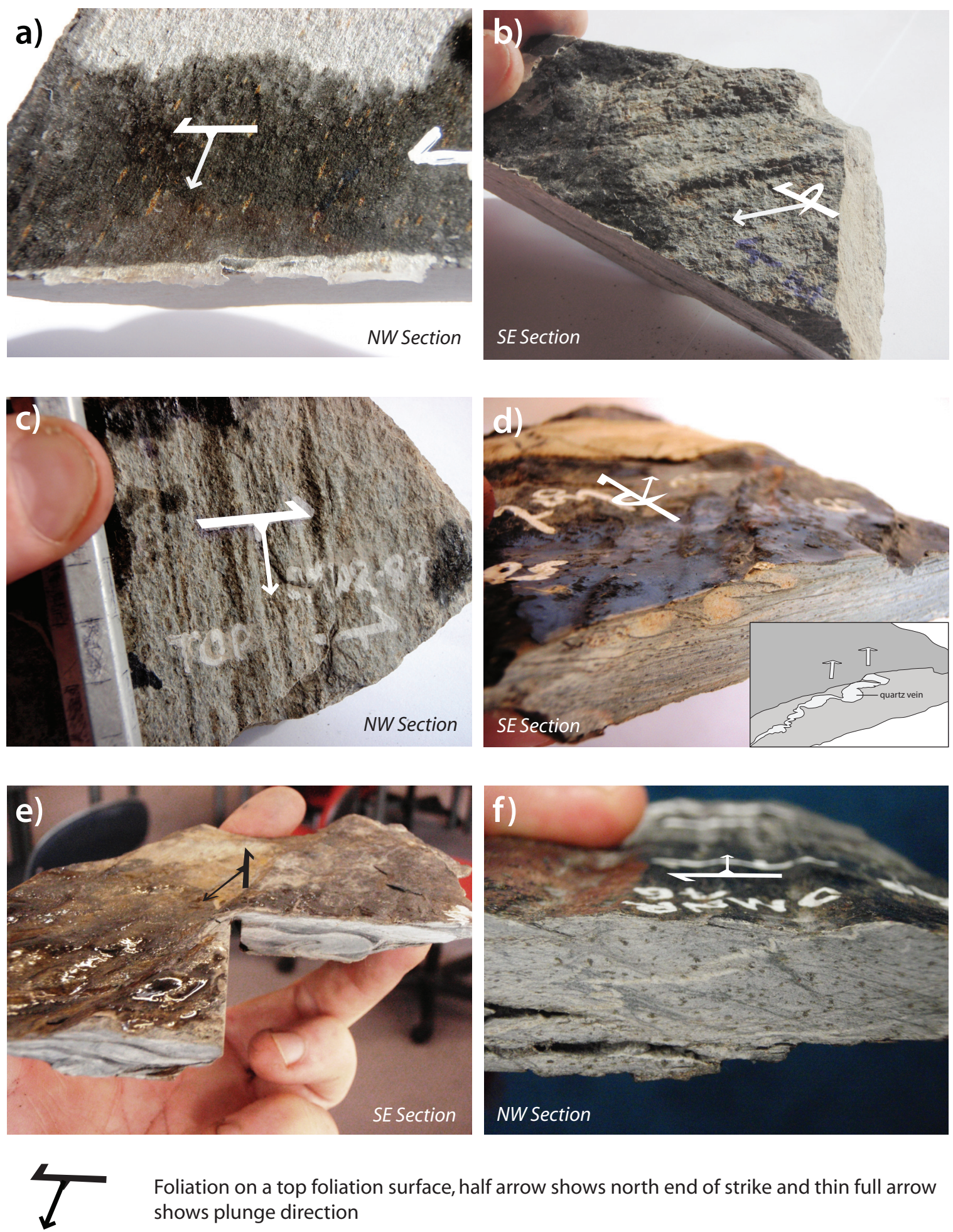

Foliation on a top foliation surface, half arrow shows north end of strike and thin full arrow shows plunge direction

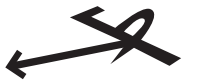

Foliation on a bottom foliation surface, half arrow shows north end of strike and thin full arrow shows plunge direction

Figure 3.17. Photos of different types of lineations in greyschist from the Newton Range. a) preferred mineral alignment lineation of biotite (DMNR-72), b) intersection lineation with a rodding like appearance, with no folding seen in the cut face (DMNR-52), c) intersection lineation and preferred mineral alignment lineation in the same orientation (DMNR-87), d) subsurface quartz vein which falsely appears to be tan intersection lineation as in b) \& c). e) intersection lineation caused by folds of pelite/psammite layering (DMNR-57), f) tightly spaced intersection lineation coinciding with apparent small scale psammite pelite folding, (NW section, DMNR-76). 
northeast of the Newton Range the Hope Fault of the MFS intersects the Alpine Fault (Fig. 3.19). $\sim 50 \mathrm{~km}$ east of this intersection the Hope Fault splits southward into the Kelly, Newton and Hura Faults which border the Newton Range immediately to the north and south.

\subsection{Discussion}

\subsubsection{Lithology}

Lithological differences between samples of Alpine Schist reflect variations in protolith lithology. Psammitic and pelitic greyschists formed in an accretionary wedge complex off the Gondwana supercontinent, most probably as part of the Torlesse Terrane in the late Triassic, with compositional layering analogous to turbidite sequences in a distal submarine fan complex (Adams, et al., 2007, Foley, et al., 1988, George, 1992, Leverenz, 2000, MacKinnon \& Howell, 1984, MacKinnon, 1983) (see chapter five). Greenschist and epidosite are derived from other protoliths, with two possible sources being volcanogenic sediments within the Torlesse Terrane, or altered schists associated with the PUB. Greenschist is largely restricted to the border of the PUB pod in the Newton Range and are chlorite/tremolite rich (Koons, 1978). Greenschist from the McArthur Range $\sim 7 \mathrm{~km}$ to the northeast is quartz and chlorite rich, often containing garnet and trace amounts of calcite (Williams, 2006). Epidosites similar to ones found in the Newton Range have been seen in both the PUB and throughout the Haast Schist (Cooper \& Reay, 1983). To further interpret the protolith of schist in the Newton Range, petrological and geochemical investigation of both greyschist and greenschist is required, and is discussed further in chapters four and five.

\subsubsection{Deformation}

In the Newton Range the sparse and typically overgrown nature of outcrop does not allow a full structural history to be constructed, although parallels may be drawn to other studies of the Alpine Schist (i.e. Little, et al., 2002a, Little, et al., 2002b), aiding the identification of the source of deformational structures seen. In the Whitcombe River watershed/Diedrich Range relict graded bedding with younging directions, and multiple outcrops containing folds with vergence, allow full structural interpretations to be made (Cooper \& Reay, 1983, Ireland, 1981, Ireland, et al., 1984). 


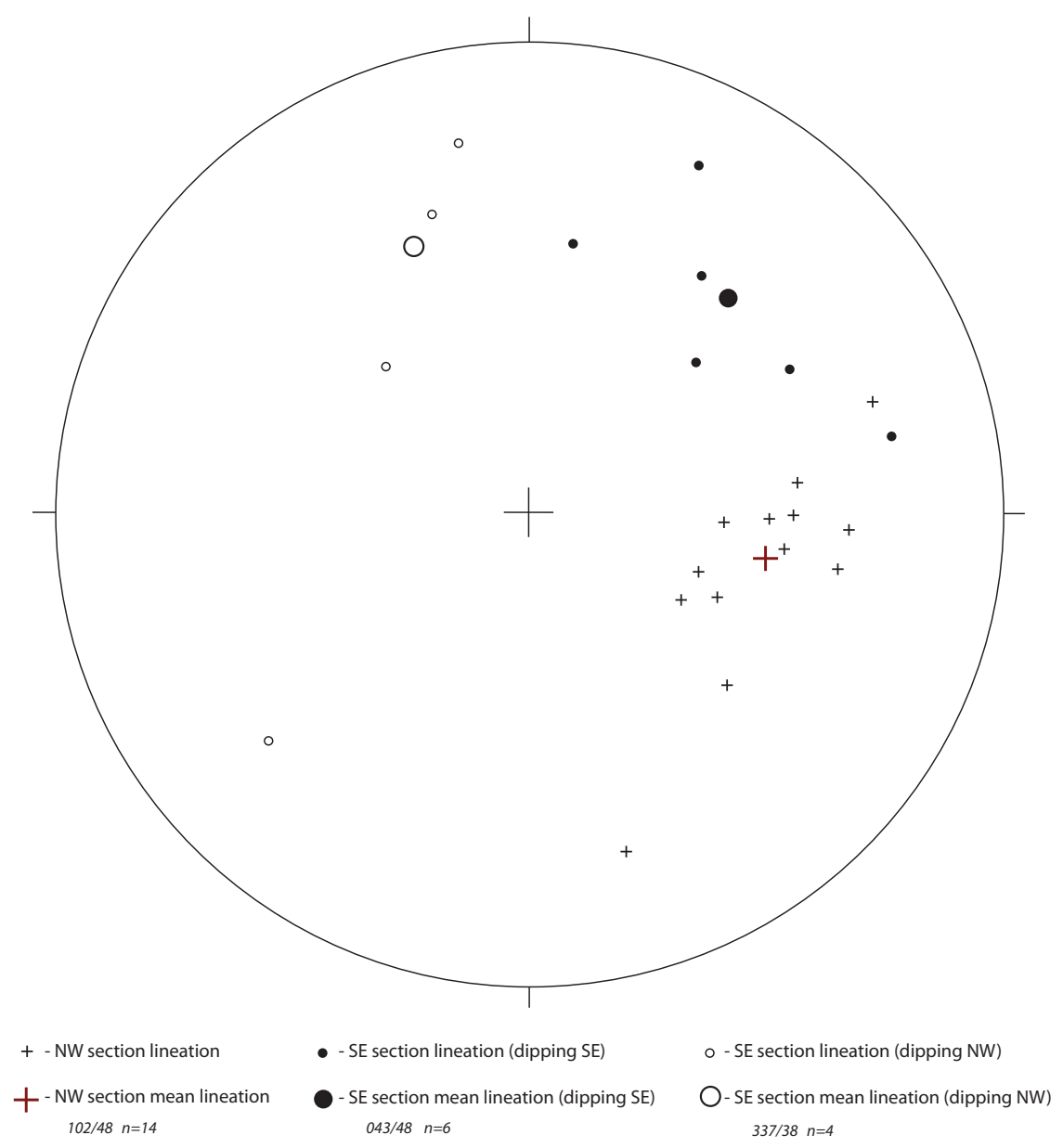

Figure 3.18. Lower hemisphere equal-area sterographic projection of lineation measurements in schist from both the NW and SE sections.

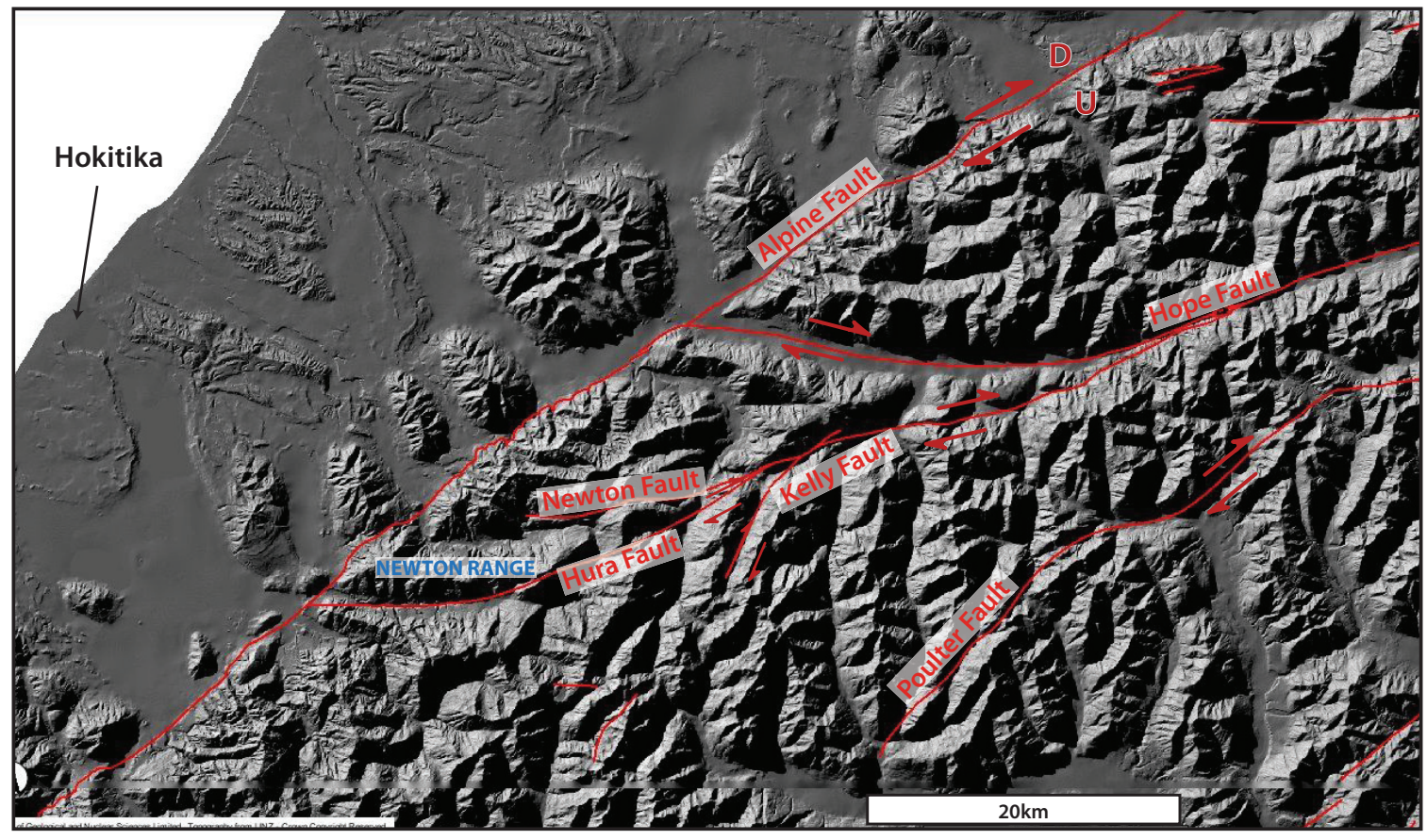

Figure 3.19. Map showing active faults in the region surrounding the Newton Range. The Kelly fault splits off the Hope Fault $\sim 55 \mathrm{~km}$ NE of the Newton Range and the Hope Fault intersects the Alpine Fault $\sim 25 \mathrm{~km}$ to the north. Fault locations from the New Zealand Active Faults Database (GNS, 2010). 


\section{Outcrop-Scale Folding}

Outcrop-scale folding is inferred to be post-metamorphic, based on the brittle style of kink folding seen in greyschists and greenschists. These brittle kink folds are analogous to post mylonitic folds reported from: Alpine Schist mylonite in Samuel Spur Stream and Weir Stream, 4.5km southeast and $7 \mathrm{~km}$ north-northeast of the Newton Range respectively (Storkey, 1999); schist adjacent to the PUB in the McArthur Crags (Koons, 1978); and in the Whitcombe River watershed (Cooper \& Reay, 1983). Koons (1978) inferred this folding to be related to late stage uplift along the Alpine Fault and slip on east-west striking faults, which were interpreted as possible extensions of the MFS. The characteristic shallow plunge of outcrop-scale fold hinge lines are similar in orientation to hinge lines noted by Storkey (1999) and Cooper \& Reay (1983).

\subsubsection{Structural Fabrics}

Structural fabrics of Alpine Schist in the Franz Josef-Fox Glacier region have been well studied (Little, et al., 2002a, Little, et al., 2002b) where multiple fabrics or surfaces (S\#) corresponding to different deformation events (D\#) have been identified. These fabrics from youngest to oldest are; S0, S1, S2, S3, Sm, with a general trend of the youngest fabrics becoming stronger closer to the Alpine Fault, overprinting older, pre-existing fabrics. S0 is the original compositional bedding of the schist protolith and is seen as either a dominant fabric in low grade semi-schists near the main divide, or as compositional layering in schists closer to the Alpine Fault, commonly reinforced by S2. S1 is only seen as crenulated trails in biotite porphyroblasts and as rare isoclinal fold hooks, folded during D2. The S2 fabric is the dominant fabric in the schist and occurs as reinforced compositional banding in TZ2b schists and as segregated layers in TZ3 and TZ4 schists. D3 has formed a fabric that either crenulates or reinforces the pre-existing S2 foliation. This crenulation/reinforcement is separated into three zones in the Franz Josef-Fox Glacier region called the western folded zone, main planar zone, and eastern folded zone, which occur because the overprinted pre-existing S2 fabric was not homogenous in orientation prior to D3. Folded zones contain a crenulated S2/S3 fabric which verge towards the main planar zone. The main planar zone represents schist which had a pre-oriented S2 foliation similar to S3, hence any D3 deformation only reinforces the existing fabric. Sm is the most recent mylonitic foliation occurring in mylonites adjacent the Alpine Fault. The Sm fabric typically unfolds the S2/S3 crenulation fabric so that there is one planar foliation. $\mathrm{Dm}$ has formed SC'-type shear bands in proto-mylonitic schist immediately east of the mylonite zone. 


\section{S2/S3 Intersection Fabric in the Newton Range}

The Alpine Schist from the Newton Range has one dominant planar foliation. Evidence for a fabric like the S2/S3 crenulation, recognised in the Franz Josef-Fox Glacier region is very limited, and was observed in a total of five samples, and only after they were cut and polished. However the presence of an intersection lineation in many samples (even though a crenulated fabric was not observed) suggests further evidence for a poorly preserved S2/S3 intersection fabric. The lack of this intersection fabric in most samples is consistent with a reinforced S2/S3 fabric analogous to the main planar zone in the Franz Josef-Fox Glacier region. This implies that the orientation of S2 was relatively homogeneous and was steepened prior to D3. Figure 3.20 shows an example of the S2/S3 crenulation fabric from the Franz Josef-Fox Glacier region, seen in Tatere Stream and the Whataroa River catchment from the western and eastern folded zones respectively for comparison to two crenulated samples from the Newton Range. Another fabric identifiable in the Newton Range is the S0 compositional layering (Fig. 3.2). For the most part this is parallel to the reinforced S2/S3 fabric but becomes less apparent with increasing textural grade until it is nearly inconspicuous in the western-most samples.

\subsubsection{Role of PUB in Deformation of the Dominant Foliation}

Throughout the Southern Alps mesoscale folding and macroscale "flipping" of the dominant foliation commonly occurs in greyschist immediately adjacent to PUB pods, with larger pods generally associated with more intense/widespread folding and the more sparsely distributed thinner pods associated with less intense deformation (Fig. 3.22). Data from this study shows the flipping of the dominant foliation is restricted to the area immediately east and west of the PUB, and not in the NW section. Similar changes in foliation dip direction in other studies are generally attributed to synmetamorphic deformation of the PUB through the matching of younging directions of surrounding graded beds coupled with the identification of a repeating sequence in the pods of metasomatised ophiolite (Cooper \& Reay, 1983). The folding forms recognisable patterns in each PUB pod, the complexity of which depends on how much of an anticlinal core outcrops, with larger pods indicative of deeper exhumation of the ophiolite sequence. The Newton Range PUB pod has been interpreted to represent such an anticline core (Koons, 1978). The large scale folds in the Whitcombe River watershed/Diedrich Range have amplitudes of up to $20 \mathrm{~km}$, with multiple pods (exhumed anticline cores) outcropping over a band 1-2 km wide. A detailed map and schematic cross section (Fig. 3.21) is presented from the Whitcombe River watershed to show how separation 

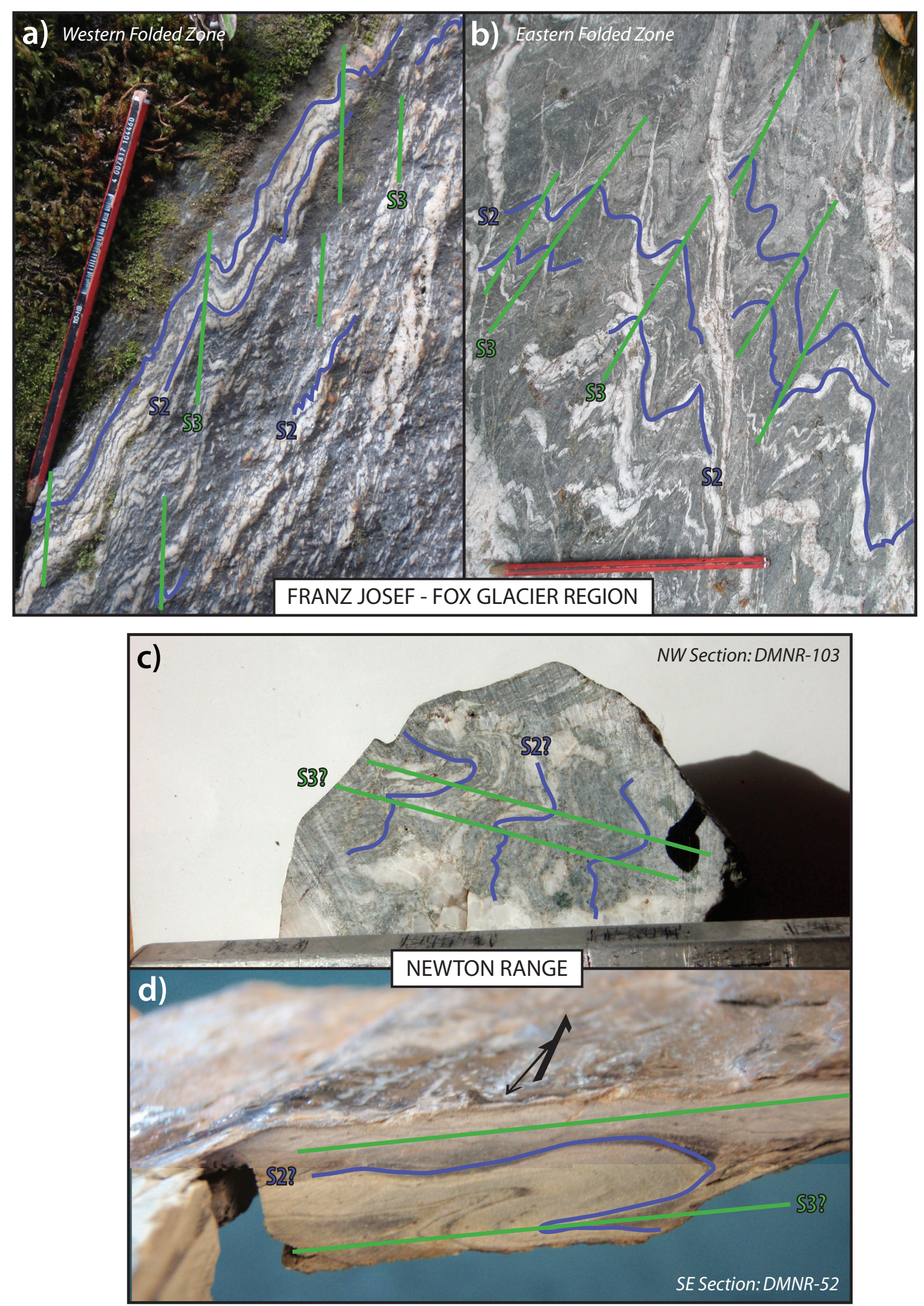

Figure 3.20. Photos showing the S2/S3 crenulation fabric seen in the Franz Josef-Fox Glacier region and inferred in the Newton Range. a) well segregated TZ4 western folded zone greyschist from Tatere Stream. b) TZ2 eastern folded zone greyschists with folded pelite and psammite layering from the Whataroa River catchment. Pencil is $16 \mathrm{~cm}$ long. (Photos courtesy of B. Gillam, VUW). c) Segregated TZ4 folded greyschist. Sample is not oriented and is $\sim 4.5 \mathrm{~cm}$ across. (DMNR-103). d) Folded psammite and pelite layering inferred to be a similar $\mathrm{S} 2 / \mathrm{S} 3$ fabric as seen in b). Sample is $1 \mathrm{~cm}$ thick. (DMNR-52). 


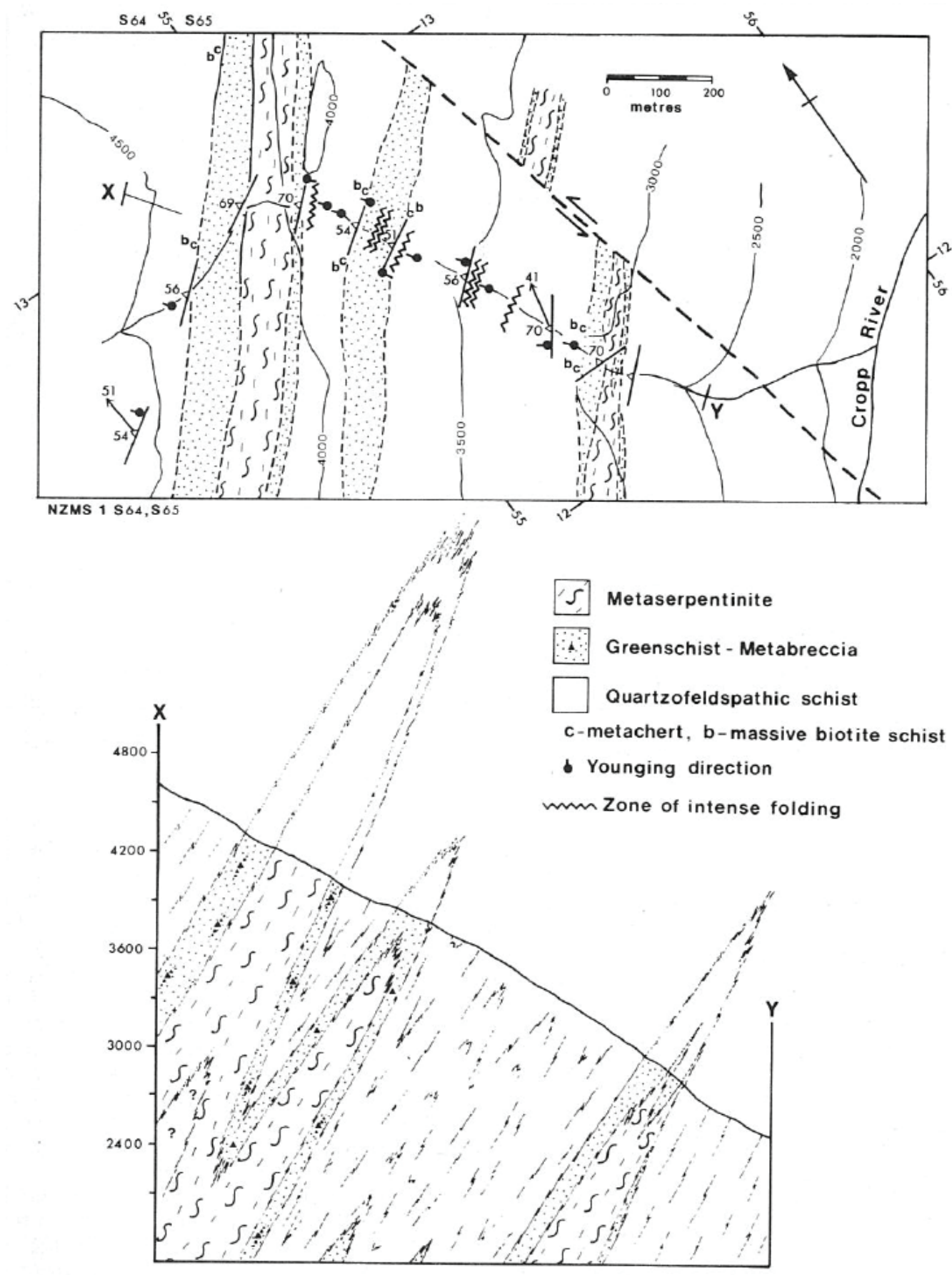

Figure 3.21. Map and schematic cross section of macroscopic folding of the Pounamu Ultramafic Belt in the Noisy Creek area from Cooper \& Reay (1983). Pods will contain a different sequence depending on what part of the anticline is exposed i.e. metaserpantine is only exposed when the deepest part of the anticline core is exposed. Note the zones of intense folding between pods denoted by the zig zag lines.

\begin{tabular}{|l|c|c|c|c|l|}
\hline Location & Distance to Alpine Fault & PUB belt width & No. of pods & Avg. pod thickness & References \\
\hline Griffin Range & $\sim 3.5 \mathrm{~km}$ & $800 \mathrm{~m}$ & 2 & $20 \mathrm{~m}$ & Koons (1978) \\
\hline McArthur Range & $\sim 4.5 \mathrm{~km}$ & $550 \mathrm{~m}$ & $2-3$ & $20 \mathrm{~m}$ & Williams (2006), Koons (1978) \\
\hline Mc Arthur Crags & $\sim 4.5 \mathrm{~km}$ & $250-500 \mathrm{~m}$ & $1-2$ & $250 \mathrm{~m}$ & Koons (1978) \\
\hline Newton Range & $\sim 5.5 \mathrm{~km}$ & $350 \mathrm{~m}$ & 1 & $350 \mathrm{~m}$ & This Study \\
\hline Diedrich Range & $\sim 5-6.5 \mathrm{~km}$ & $1.5 \mathrm{~km}$ & $3-4$ & $70 \mathrm{~m}$ & Ireland (1981), Ireland et al. (1984) \\
\hline Whitcombe/Hokitika River & $\sim 7-9 \mathrm{~km}$ & $1-2 \mathrm{~km}$ & $3-4$ & $110 \mathrm{~m}$ & Cooper \& Reay (1983) \\
\hline
\end{tabular}

Figure 3.22. Table summarizing the size, extent and location of PUB proximal to the Newton Range. Data is sourced from in text and geological maps. 
of two to four $\sim 100 \mathrm{~m}$ thick pods over a distance of $1-2 \mathrm{~km}$ may be inferred (Cooper \& Reay, 1983). Also note how there are zones of intense mesoscale folding between individual pods.

Mesoscale folds in the Newton Range are likely to postdate metamorphism and folding of the PUB as the folds have a brittle-style, kinked appearance, with some including folded crush zones (Fig. 3.16). The differing rheology of the PUB pod may have acted as a relatively rigid indentor, forcing deformation of the surrounding weaker schist, possibly during late stage compression and uplift of the Southern Alps along the Alpine Fault in the late Cenozoic. The dissimilarity in mesoscale fold axes (sub horizontal) and macroscale fold orientations (inferred sub vertical) suggest the different styles of folding were created during different deformation events. This study is unable to interpret the timing of the "flipping" of the dominaint foliation.

\subsection{Conclusion}

Field observations from the Newton Range show that greyschist has similar lithological characteristics to Alpine Schist from throughout the Southern Alps, but has less common and generally weaker structural fabrics. This may in part be due to the sparse nature of outcrop and lack of recognisable structural fabrics in the field before rocks are cut. The field data from the Newton Range shows evidence for the part of the complex history seen in the Franz Josef-Fox Glacier region, with a crenulations foliation and intersection lineations analogous to a S2/S3 intersection fabric. Brittle-style mesoscale kink folds are interpreted to have formed during the latest deformation event associated with the uplift of the Southern Alps, and are analogous to folds seen overprinting the mylonitic foliation in Samuel Spur and Weir Streams, and in TZ2b greyschists in the Whitcombe River watershed. It is postulated that the PUB may play some part in this deformation due to its different rheological nature, acting as relatively rigid indentor, pushing against and subsequently deforming the surrounding schist late in the metamorphic history. 


\section{Chapter Four}

\section{PETROGRAPHY \& MICROSTRUCTURE}

\subsection{Introduction}

This chapter presents a synthesis of petrographic and microstructural observations based on comprehensive examination of thin sections from 108 samples of schist collected from the Newton Range. Observations of mineral textures and relationships to other minerals shed light on the complex, variably overprinted metamorphic history of the Alpine Schist, and are of use in other facets of this thesis, providing guidance for electron microprobe compositional analyses, and underpinning $P$ - $T$ pseudosection and $P$ - $T$ path modelling using THERMOCALC. Interpretations of $P$ $T$ conditions made using THERMOCALC relate to the dominant mineral assemblage in the rock, therefore petrographical observations of mineral textures are important in the relative timing of mineral growth. Microstructural observations yield important insights into the deformation history unable to be seen in outcrop or hand sample, primarily providing information regarding the development and preservation of multiple foliations.

This chapter will describe the inter-sample variability for each of the different lithologies found in the Newton Range (Fig. 4.1), as well as discussing the changes in mineral texture with increasing proximity to the Alpine Fault, a proxy for an increase in metamorphic grade.

\section{Methods}

$30 \mu \mathrm{m}$ thick thin sections of 108 samples were prepared at Victoria University of Wellington. Oriented thin sections were cut when possible at directions perpendicular to the foliation, both parallel-to and perpendicular-to strike (st \& d orientations respectively) (Fig. 4.2a). Sample orientations are indicated by the symbol in the top right of microphotographs when applicable (Fig. 4.2). Microphotographs were taken using an Olympus BX51 petrographic microscope with $4 \mathrm{x}, 10 \mathrm{x}$ and 40x magnification UplanFl lenses using an Olympus DP70 mountable camera and associated bundled software. 

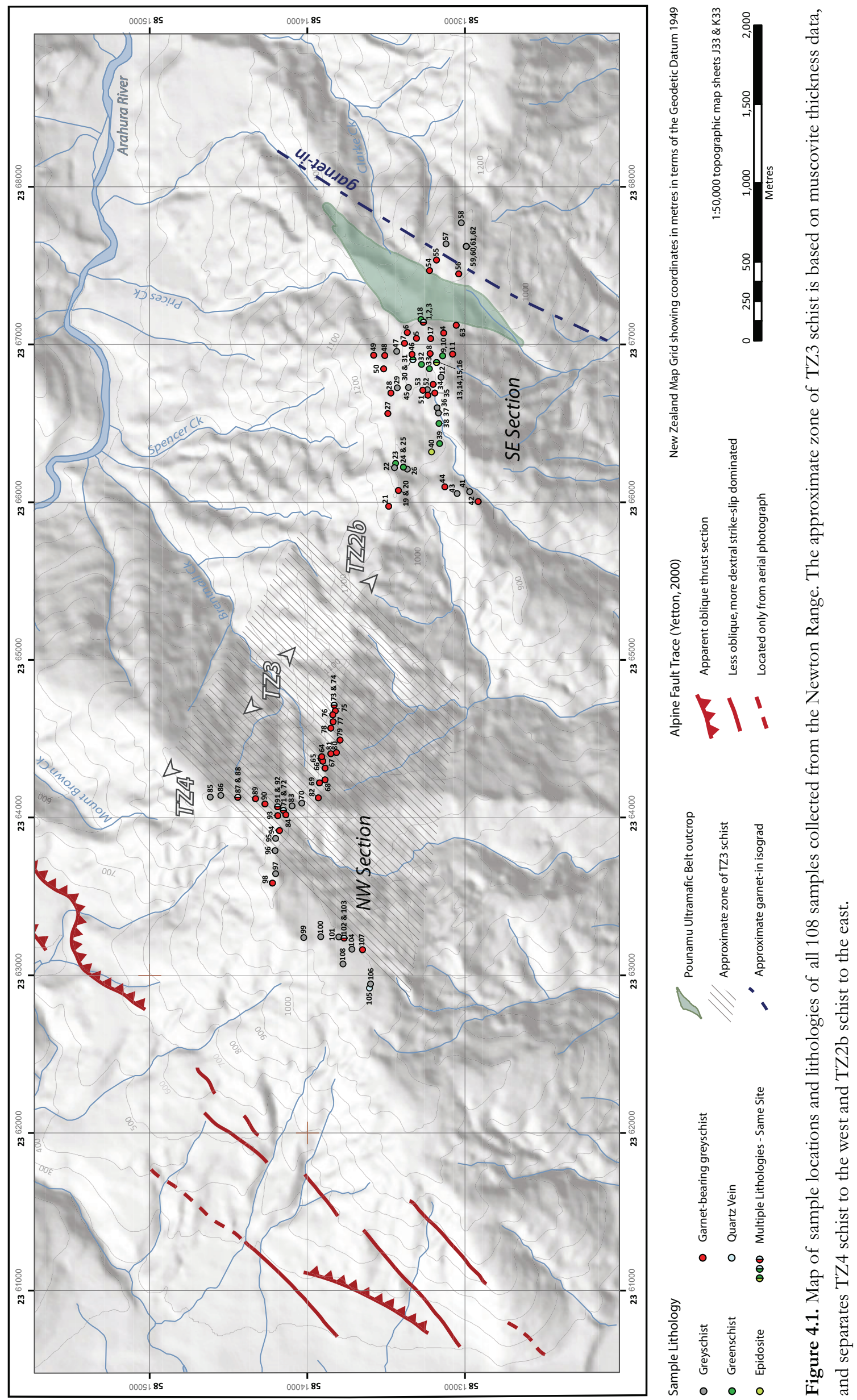

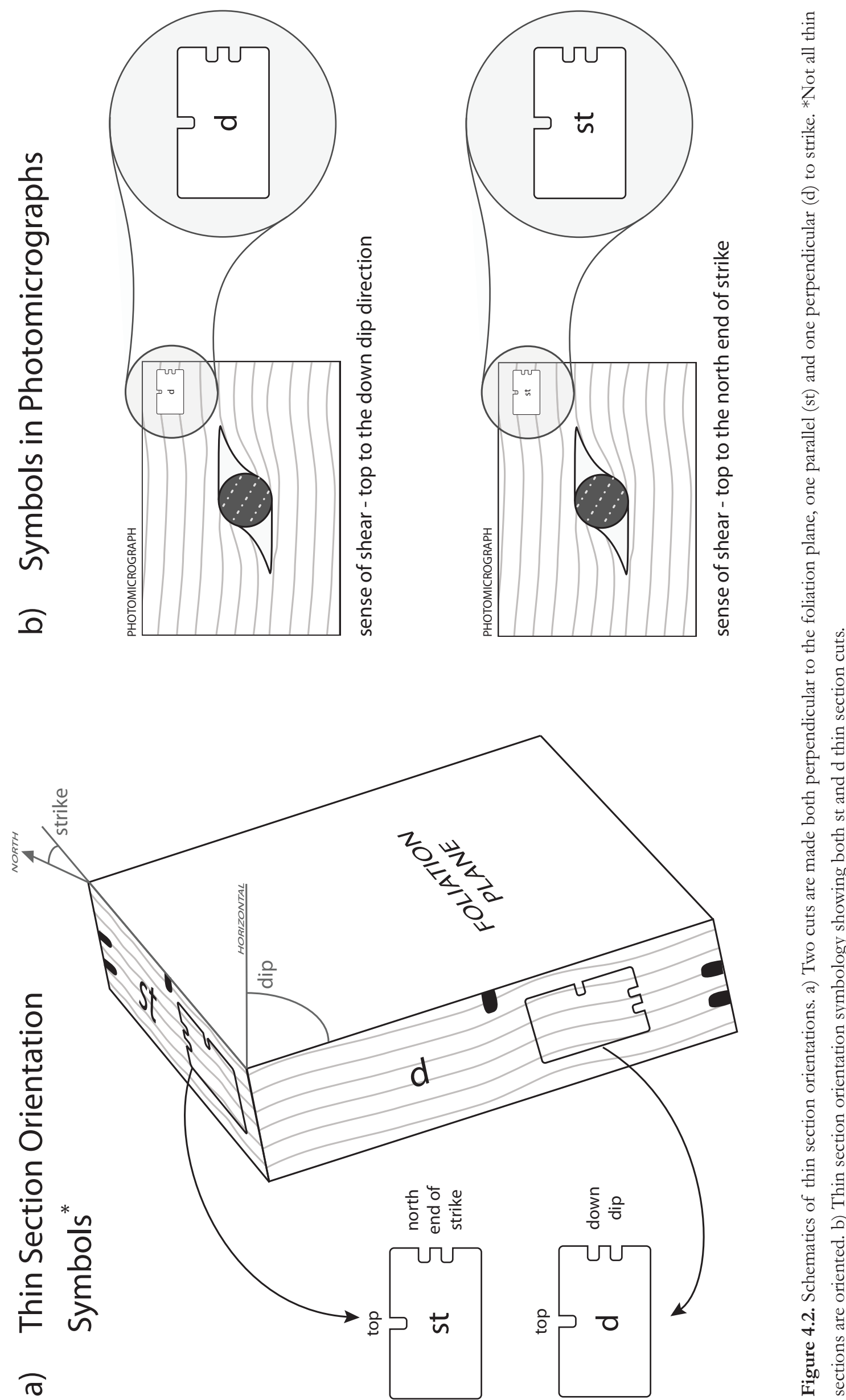


\subsection{Petrology Results}

\subsubsection{Greyschist}

Greyschist (quartzofeldspathic schist) is the dominant lithology in the Newton Range $85 \%$ of samples). Both pelitic and psammitic samples were collected and have the following mineral assemblage:

$$
\mathrm{Qtz}+\mathrm{Ms}+\mathrm{Bt} \pm \mathrm{Chl} \pm \mathrm{Ep} \pm \mathrm{Pl} \pm \mathrm{Ilm} \pm \operatorname{Ttn} \pm \mathrm{Grt} \pm \mathrm{Zrn} \pm \operatorname{Tur} \pm \mathrm{Ap} \pm \mathrm{Cal}
$$

Complete mineral assemblages for all greyschist samples are shown in appendix A2.1. Mineral abbreviations used are from Kretz (1983). There is variability in the relationship of minerals to the exterior foliation between samples and within individual thin sections. This is because mineral growth has occurred at different times in the polymetamorphic history, where deformation events pre and post mineral growth have overprinted old, and developed new structural fabrics. Such microstructural fabrics include crenulation of the dominant foliation, development of SC'-type shear bands, and rigid-body rotation and matrix mantling of porphyroblasts. Different microstructures are present in microphotographs in the following petrography sections, but in an effort to separate the petrographic observations of the different lithologies (greyschist, greenschist and epidosite), microstructures are described in a separate section following the petrographic observations.

Pelitic samples are rich in both quartzofeldspathic and phyllosilicate minerals, whereas psammitic samples are dominated by a quartzofeldspathic matrix with only sparse phyllosilicate minerals (Figs. 4.3 \& 4.4). Many samples contain both pelitic and psammitic layers alternating on a millimetre to decimetre scale. With increasing metamorphic grade (towards the Alpine Fault) the schist becomes more segregated, containing distinct layers of alternating phyllosilicate minerals and quartz layers, ranging between $100 \mu \mathrm{m}-3 \mathrm{~mm}$ thick (Fig. 4.5). Occasional bimineralic lenses containing only quartz and feldspar are observed in both pelitic and psammitic samples. It is important to note that "pelitic greyschist", is a relative term, as and no true pelites are present in the Newton Range.

\section{Quartz}

Quartz is the most abundant mineral in the greyschist and is present in all 90 greyschist samples. It occurs predominantly as a matrix mineral and also as common inclusions in garnet, biotite and chlorite porphyroblasts. Quartz veins are also present in many samples, described further in section 4.2.5. As a matrix mineral quartz is typically anhedral and varies in size from $5-500 \mu \mathrm{m}$ (Figs. 4.6a \& 


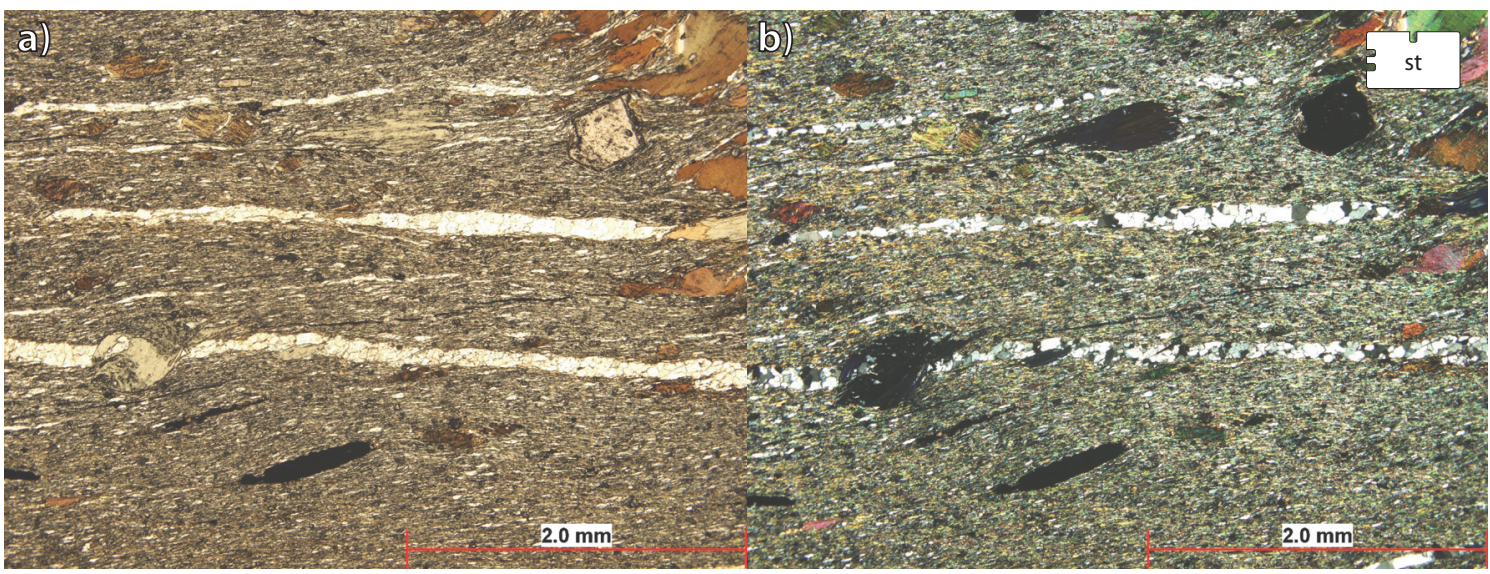

Figure 4.3. Photomicrograph of pelitic greyschist comprised of quartzofeldspathic and phyllosilicate minerals. a) PPL, b) CPL. Sample DMNR-05st.

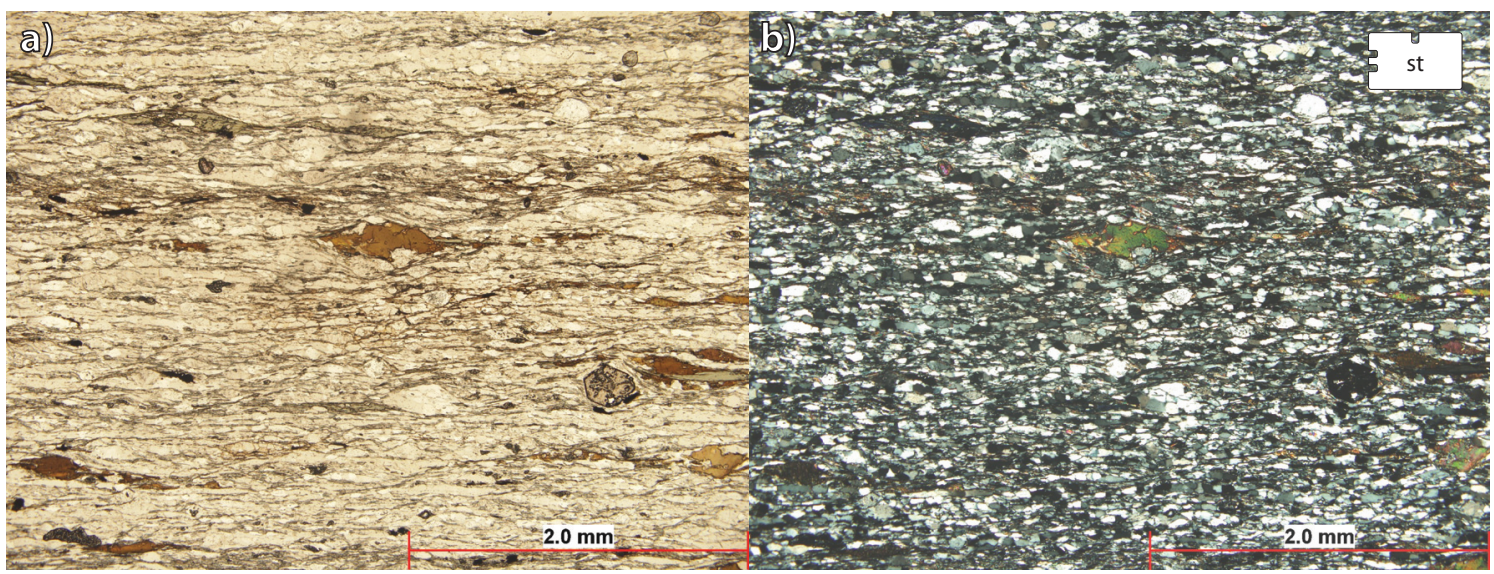

Figure 4.4. Photomicrograph of psammitic greyschist comprised primarily of quartzofeldspathic minerals. a) PPL, b) CPL. Sample DMNR-01st.

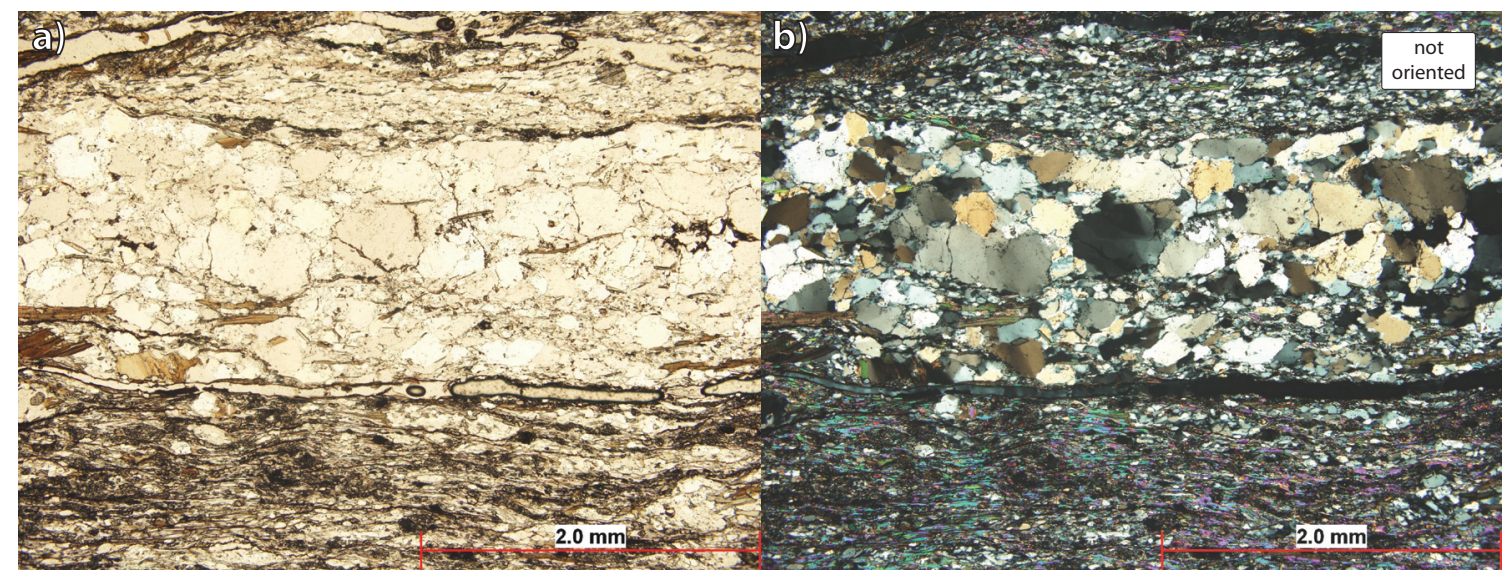

Figure 4.5. Photomicrographs of greyschist with distinct pelitic and psammitc layers. a) PPL, b) CPL.

DMNR-107a. 
b). In the lowest grade samples quartz often has an equigranular, polygonal to interlobate texture, occurring as isolated lenticular boudins up to $1 \mathrm{~cm}$ long within a mixed quartzofeldspathic/ phyllosilicate matrix (Figs. 4.6c \& d). Dynamic recrystallization of quartz become more ubiquitous with increasing metamorphic grade, with the highest grade samples containing completely interlobate and seriate quartz crystals (Figs. 4.6e, $\mathrm{f} \& \mathrm{~g}$ ).

\section{Muscovite}

Muscovite is present in all but one greyschist sample. It is typically a common matrix mineral (second only in abundance to quartz), however several samples contain only rare muscovite. Muscovite also occurs as rare inclusions in garnet porphyroblasts. The majority of crystals are 1$10 \mu \mathrm{m}$ in thickness with rare crystals in samples more proximal to the Alpine Fault reaching up to $50 \mu \mathrm{m}$ thick and $500 \mu \mathrm{m}$ long. This represents an increase in metamorphic grade from textural zone (TZ) TZ2b, through TZ3, to TZ4 (Turnbull, et al., 2001) (Fig. 4.7). Pelitic samples contain significantly more muscovite than psammitic samples.

\section{Biotite}

Biotite occurs in all but two greyschist samples in varying abundance. It occurs predominantly as porphyroblasts, as well as inclusions in garnet, infill of deformed garnet and ilmenite, and rare veins crosscutting the dominant foliation. Biotite porphyroblasts are $20 \mu \mathrm{m}-2 \mathrm{~mm}$ in length and typically occur as anhedral, elongate ribbon-like crystals, or occasional subhedral tabular porphyroblasts (Figs. $4.8 \mathrm{a}$ - d). In low grade samples biotite porphyroblasts are commonly anhedral and slightly poikiloblastic and/or tabular in texture, and generally become finer and more ribbon like with increasing metamorphic grade (Fig. 4.8). Crack-fill biotite textures within biotite, ilmenite and garnet porphyroblasts are more common in lower grade (Fig. 4.9). Biotite veins diagonally crosscut the dominant foliation in multiple directions, sometimes within the same thin section (Fig. 4.10).

\section{Plagioclase}

Plagioclase occurs in $85 \%$ of greyschist samples. It is identified by twinning or distinctive inclusion patterns, and occur more commonly in psammitic schist than pelitic schist (Fig. 4.11). Crystals are 

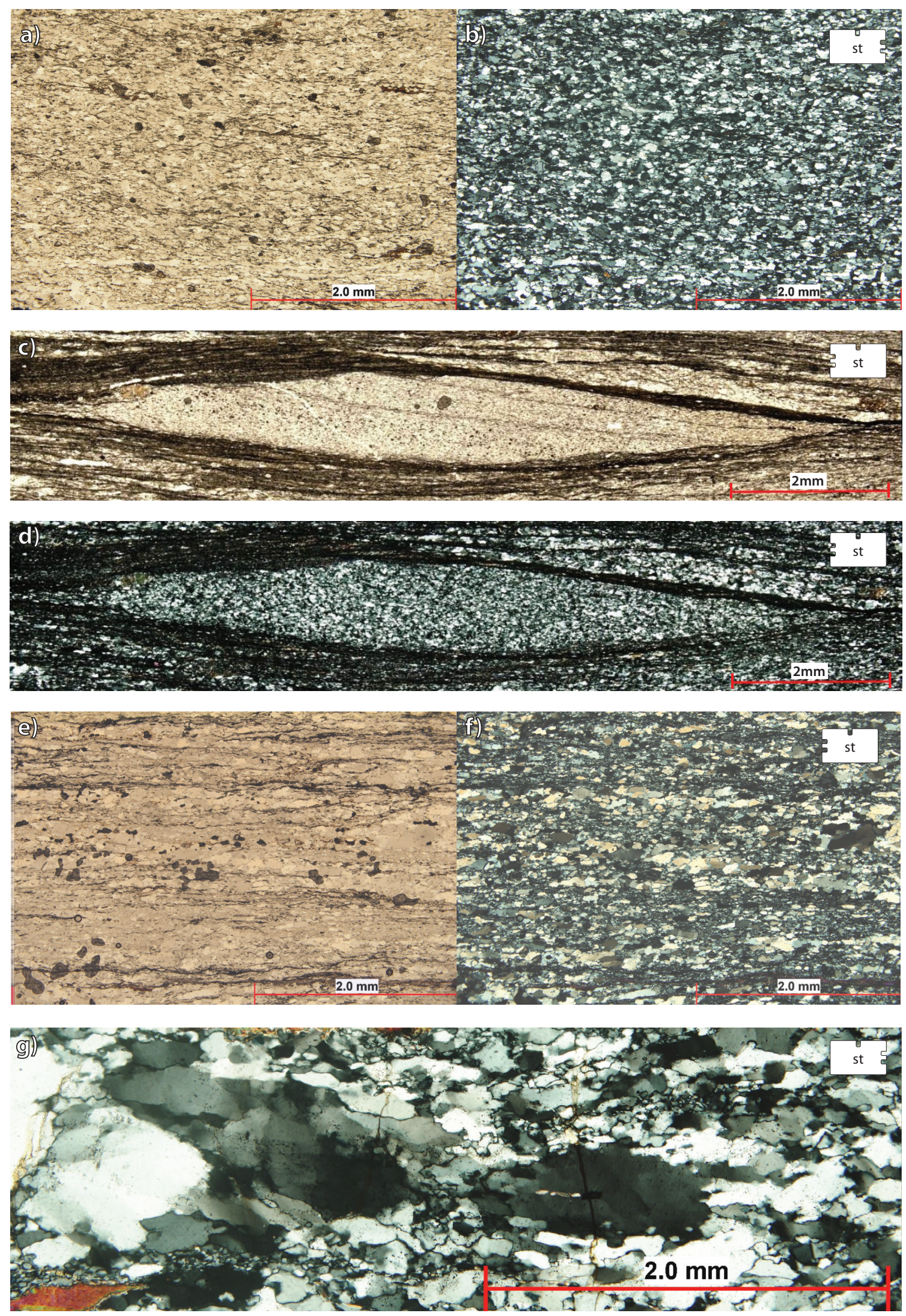

Figure 4.6. Photomicrographs of textural changes in quartz with increasing metamorphic grade. a) \& b) PPL \& CPL of low grade greyschist with a fine equigranular quartzofeldspathic matrix. DMNR-57st. c) \& d) PPL \& CPL of discontinuous lens of equigranular, polygonal quartz grains. DMNR 58st. e) \& f) PPL \& CPL of high grade greyschist showing an increase in the size of quartz crystals compared to lower grade samples. DMNR37st. g) CPL of a heavily dynamically recrystallised quartz crystal in high grade greyschist. DMNR-49st. 

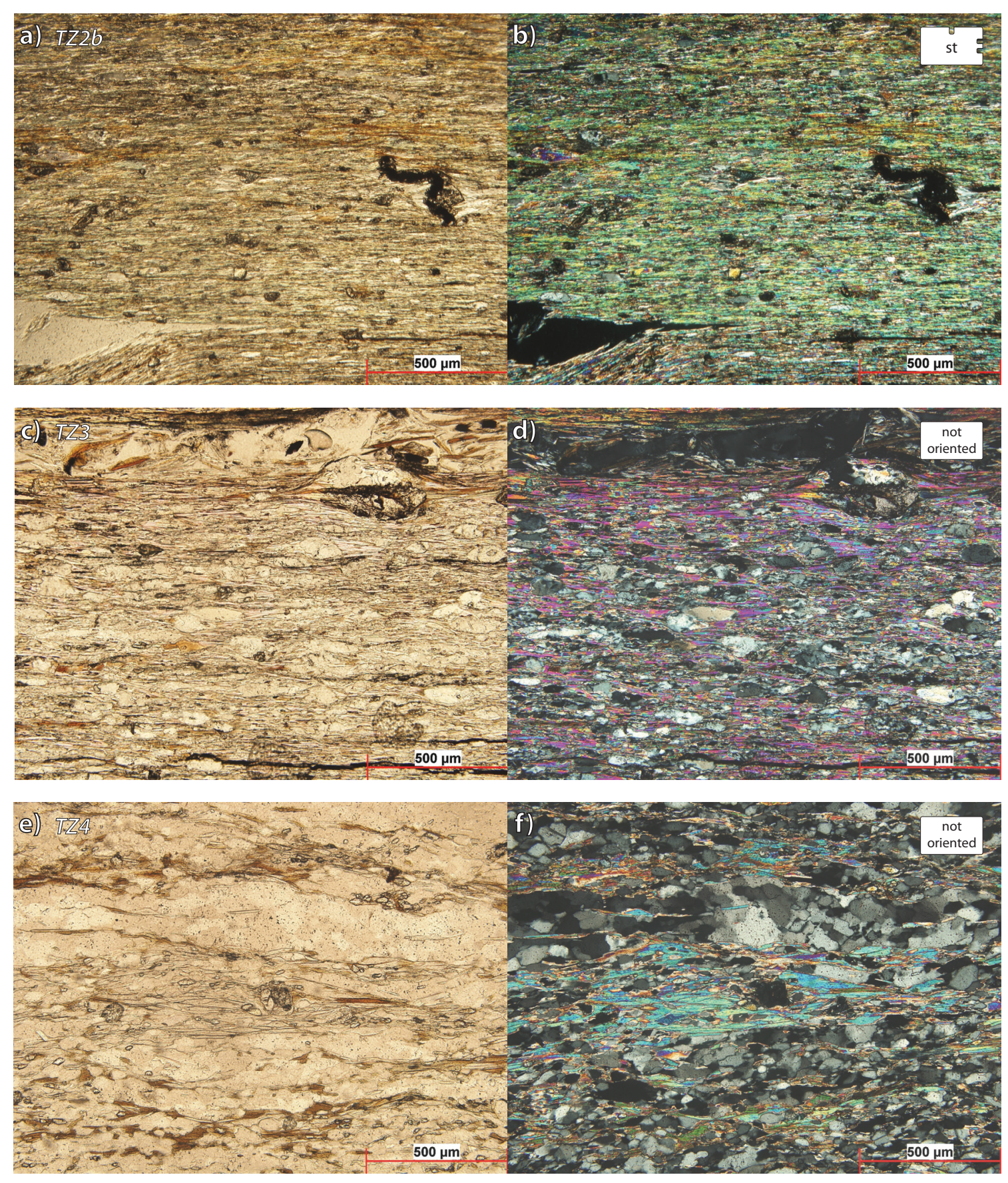

Figure 4.7. Photomicrographs of three greyschist samples showing textural changes in muscovite with increasing metamorphic grade. The increasing thickness of muscovite grains categorises the rocks into different textural zones (TZ) (Turnbull et al., 2001). a) \& b) PPL \& CPL of fine muscovite $<15 \mu \mathrm{m}$ thick in low grade greyschist (TZ2b). DMNR-57st. c) \& d) PPL \& CPL of muscovite 15-25 $\mu$ m thick in medium grade greyschist (TZ3). DMNR-84. e) \& f) PPL \& CPL of coarse muscovite up to $50 \mu \mathrm{m}$ thick in high grade greyschist (TZ4). DMNR-100b. 

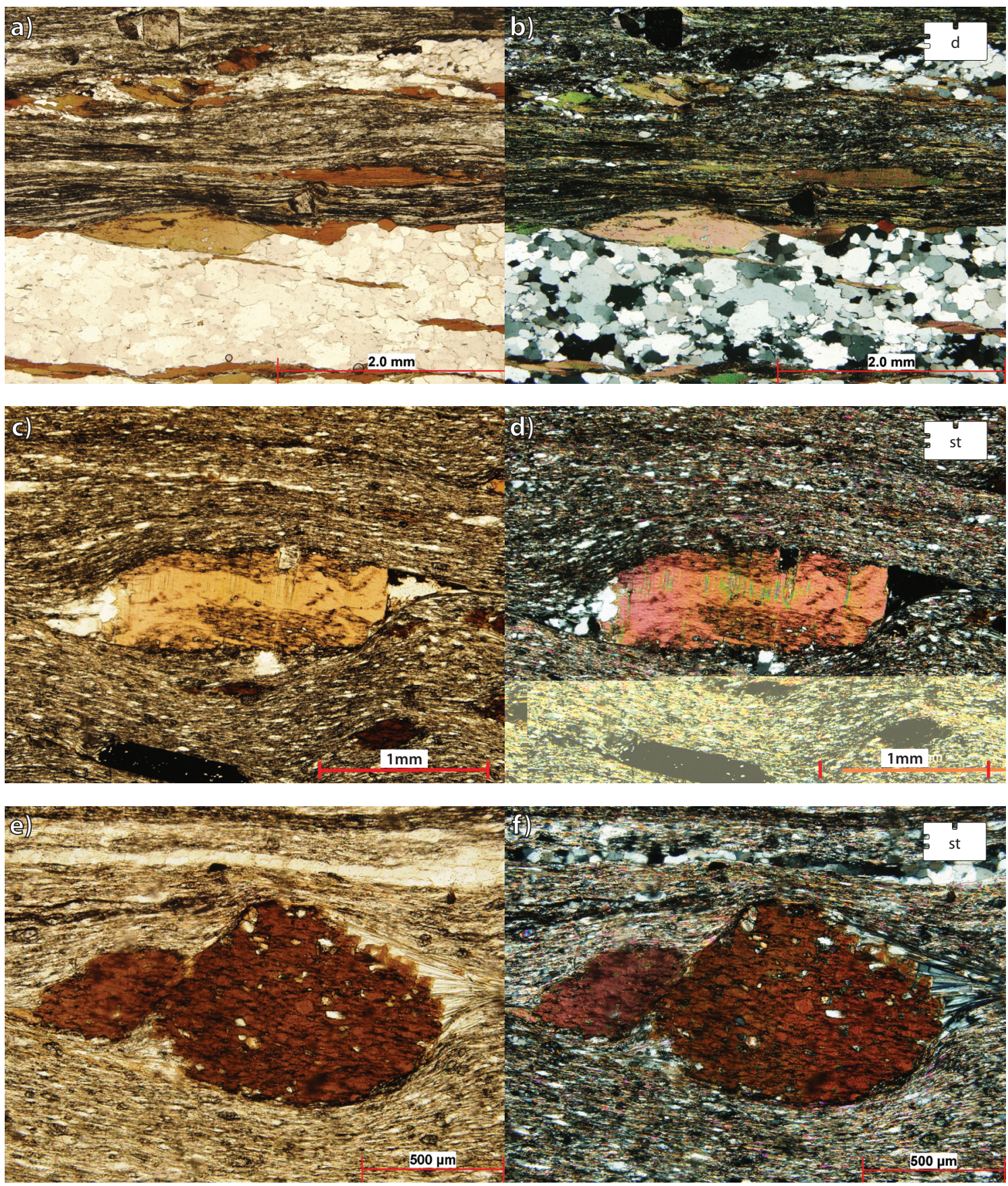

Figure 4.8. Photomicrographs of the different types of biotite porphyroblasts present in greyschist samples. a) \& b) PPL \& CPL of elongate ribbon-like biotite porphyroblasts. DMNR-19d. c) \& d) PPL \& CPL of tabular biotite porphyroblast. DMNR-63st. e) \& f) PPL \& CPL of poikiloblastic biotite porphyroblasts common in low grade samples. DMNR-63st. 

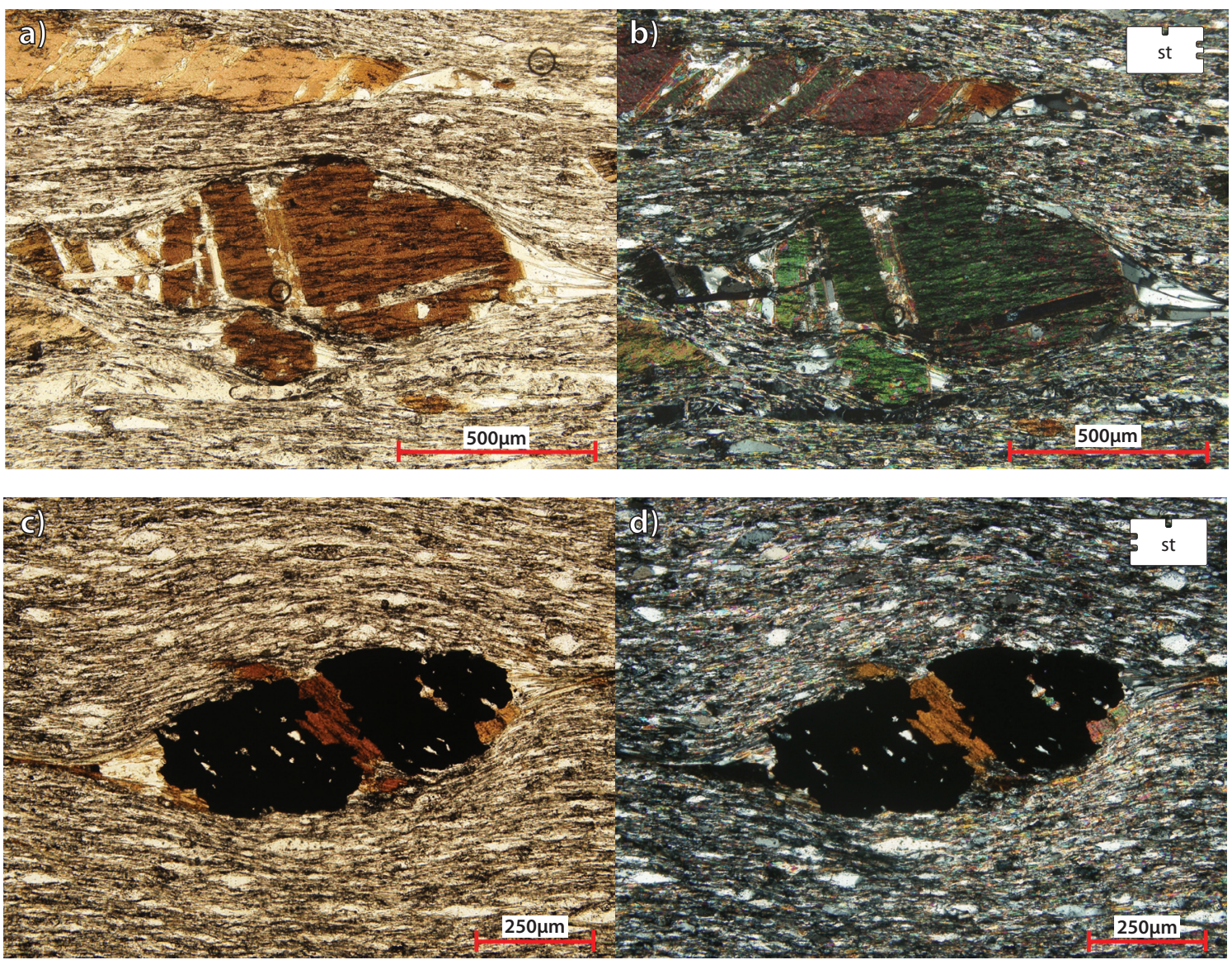

Figure 4.9. Photomicrographs of biotite crack-fill textures. a) \& b) PPL \& CPL of crack-fill in a biotite porphyroblast. DMNR-08st. c) \& d) PPL \& CPL of crack-fill in an ilmenite porphyroblast. DMNR-63st.

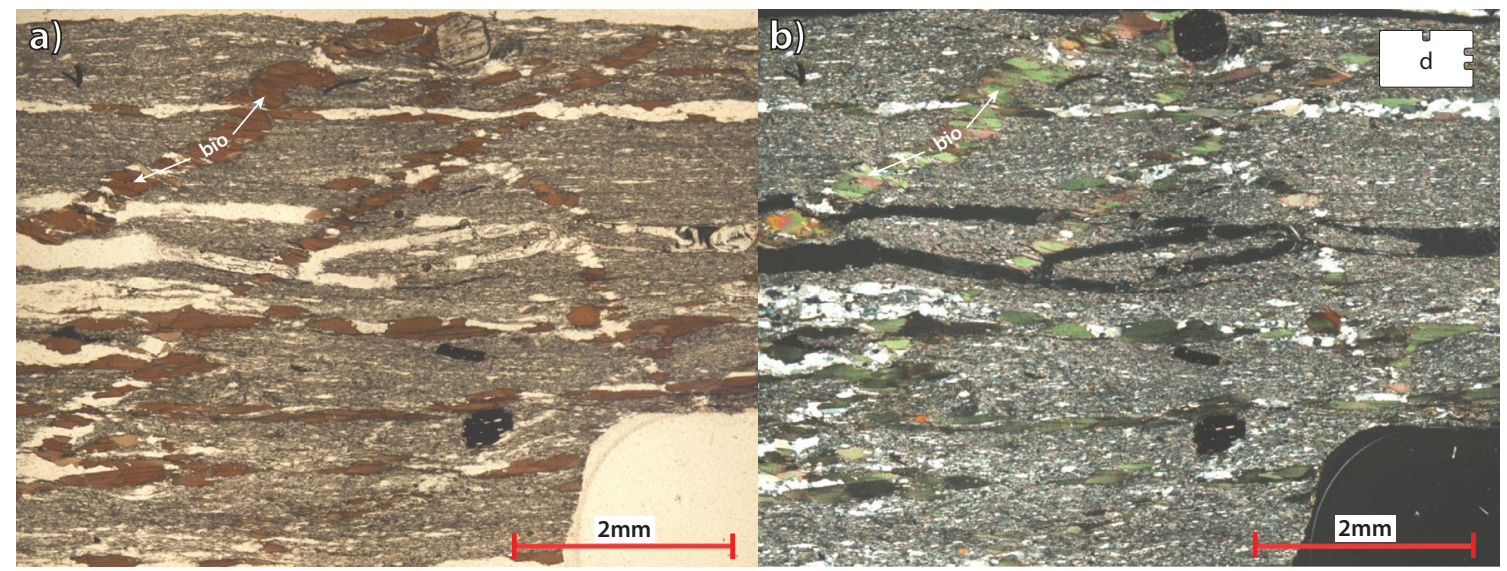

Figure 4.10. Photomicrographs of biotite veins crosscutting the dominant foliation. a) PPL, b) CPL.

DMNR-51d. 

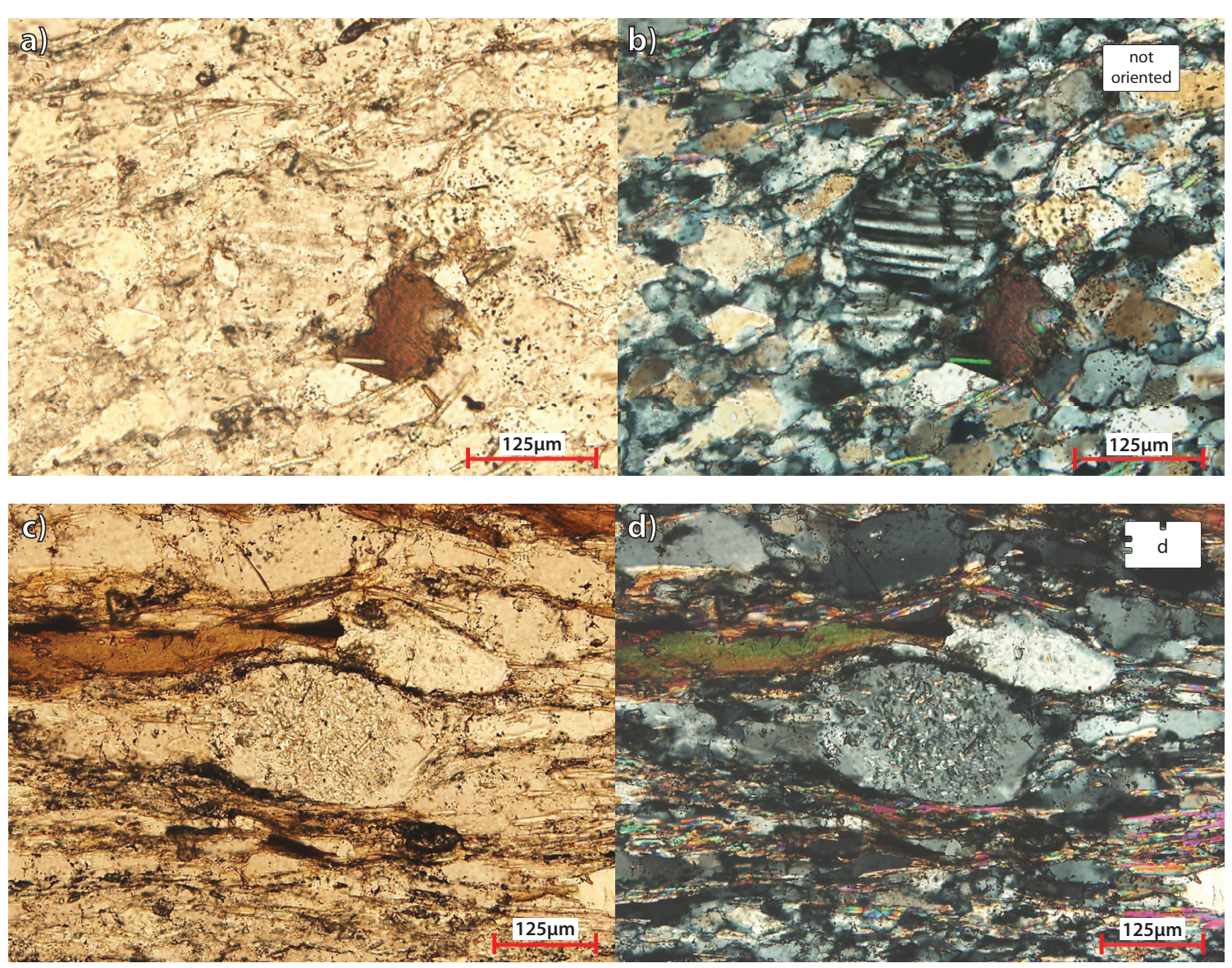

Figure 4.11. Photomicrographs of plagioclase textures present in greyschist samples. a) \& b) PPL \& CPL of a plagioclase grain with multiple twinning. DMNR-84. c) \& d) PPL \& CPL of an inclusion rich plagioclase. DMNR-93d. 
only observed as anhedral matrix minerals or small porphyroblasts, ranging in size from $50-500 \mu \mathrm{m}$. Abundance varies from rare to common ( 1-60 per thin section), and increases closer to the Alpine Fault, mainly due to a reduction in the amount of pelitic schist in the NW section.

\section{Chlorite}

Chlorite is present in $91 \%$ of greyschist samples. It occurs as porphyroblasts (Figs. $4.12 \mathrm{a}-\mathrm{d}$ ), rare, fine platelets in the matrix (Figs. 4.12e \& f), as infill and pseudomorphs of biotite and garnet porphyroblasts (Fig. 4.13), and also occurs as mixed quartz/chlorite veins, which perpendicularly crosscut the dominant foliation (see section 4.2.5). Chlorite porphyroblasts are 10-600 $\mu \mathrm{m}$ in size and are predominantly anhedral and ribbon-like, but occasionally occur as subhedral tabular crystals. With increasing grade chlorite porphyroblasts become less common, and finer, more ribbon-like chlorite as well as chlorite infill and pseudomorph textures, become more common.

\section{Garnet}

Garnet occurs in $60 \%$ of samples and is rare to common in abundance (1-100 per thin section, 1-5 average). Garnet occurs only as porphyroblasts and ranges in size from 50-1200 $\mu \mathrm{m}(\sim 200-500 \mu \mathrm{m}$ average). Garnet is typically euhedral, but rare subhedral/anhedral porphyroblasts with corroded rims are also present (Figs. $4.14 \mathrm{a}-\mathrm{c}$ ). Garnet abundance within a particular sample does not rely on metamorphic grade, however, average garnet size does increase slightly with increasing metamorphic grade. Garnet occurs in both phyllosilicate and quartzofeldspathic rich layers, although when both are present, growth more often occurs in the phyllosilicate layers. The majority of porphyroblasts are rich in quartz inclusions, and also contain occasional inclusions of epidote, ilmenite, apatite and zircon. Rare porphyroblasts have star shaped inclusion patterns typical of growth in highly graphitic schist (Burton, 1986) (Fig. 4.14d). Garnet inclusion patterns and their relationship to the exterior foliation are further described in section 4.2.4. Zoning is apparent in rare porphyroblasts as distinct patterns of either inclusion rich cores and inclusion poor rims, or inclusion poor cores and inclusion rich rims (Figs. 4.14e \& f). 

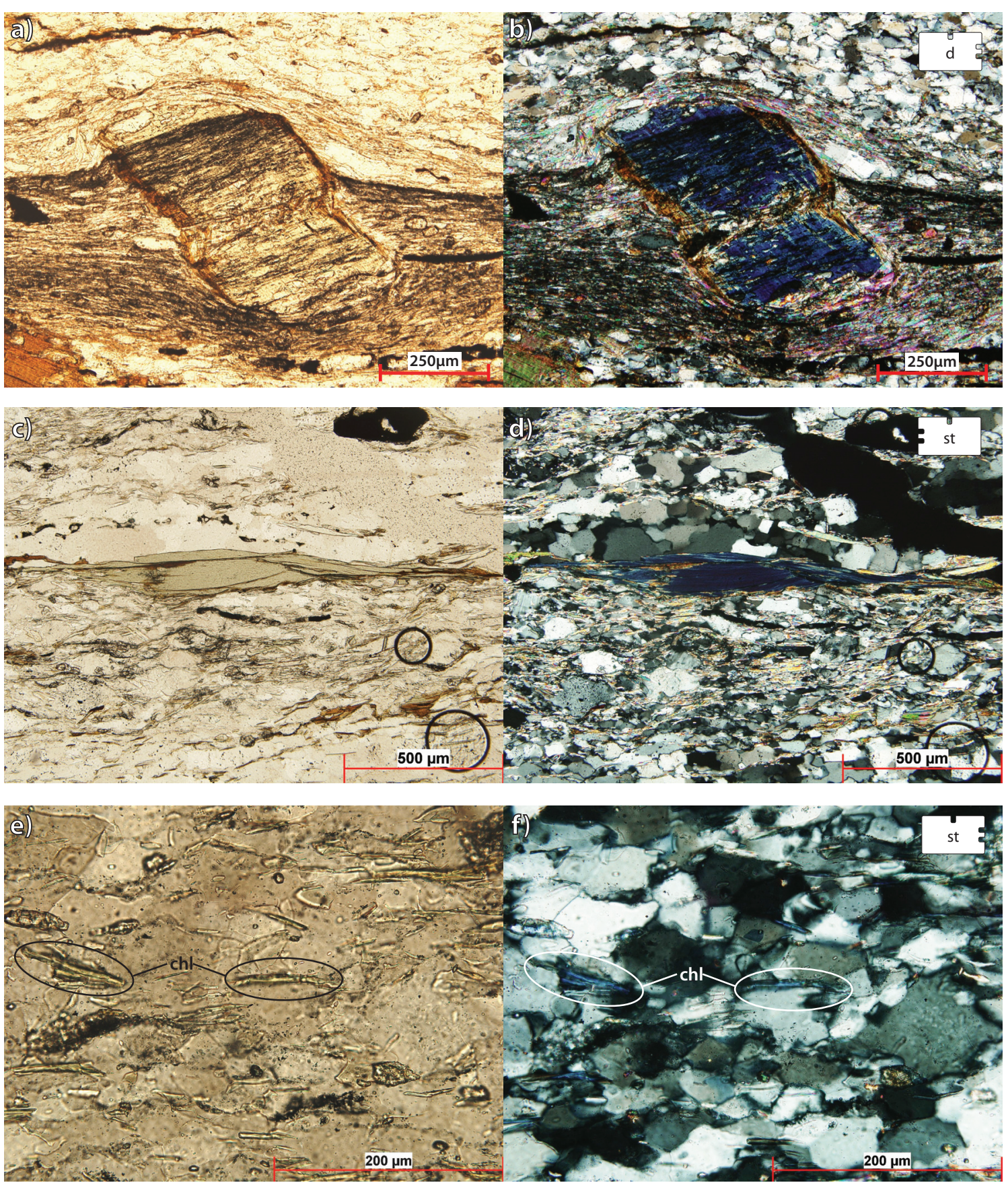

Figure 4.12. Photomicrographs showing the different forms of chlorite in greyschist samples. a) \& b) PPL \& CPL of a tabular chlorite porphyroblast. The brown discontinuous rim has the same chloritic composition as the rest of the porphyroblast (not biotite). DMNR-01d. c) \& d) PPL \& CPL of a ribbon-like chlorite porphy- 

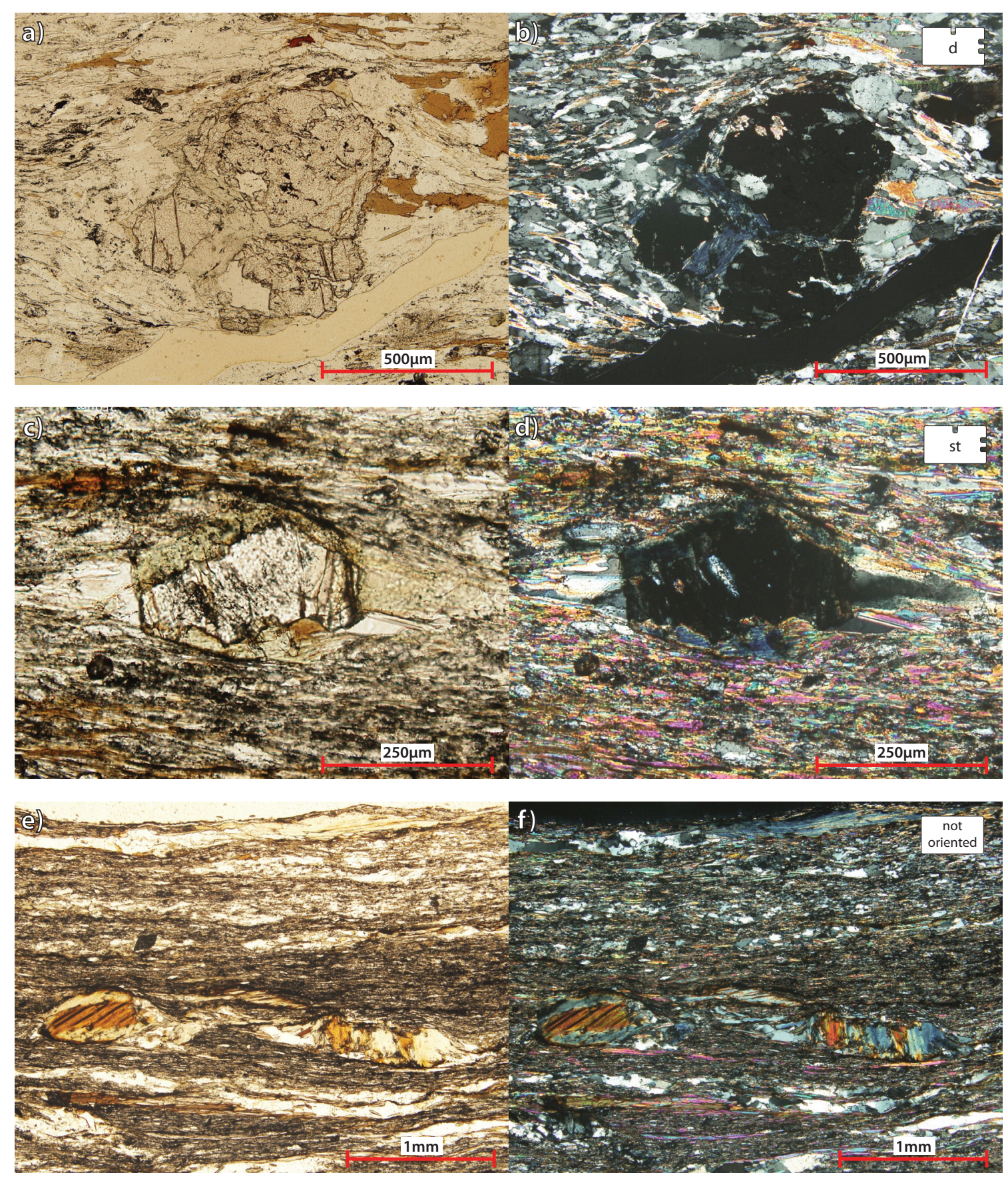

Figure 4.13. Photomicrographs showing crack-infill and pseudomorph textures of chlorite in greyschist samples. a) \& b) PPL \& CPL of crack-infill of a garnet porphyroblast by chlorite. DMNR-83d. c) \& d) PPL \& CPL of a garnet porphyroblast pseudomorphed by chlorite. DMNR-69st. e) \& f) PPL \& CPL of biotite porphyroblasts with crack-infill and pseudomorhed by chlorite. DMNR-92b. 

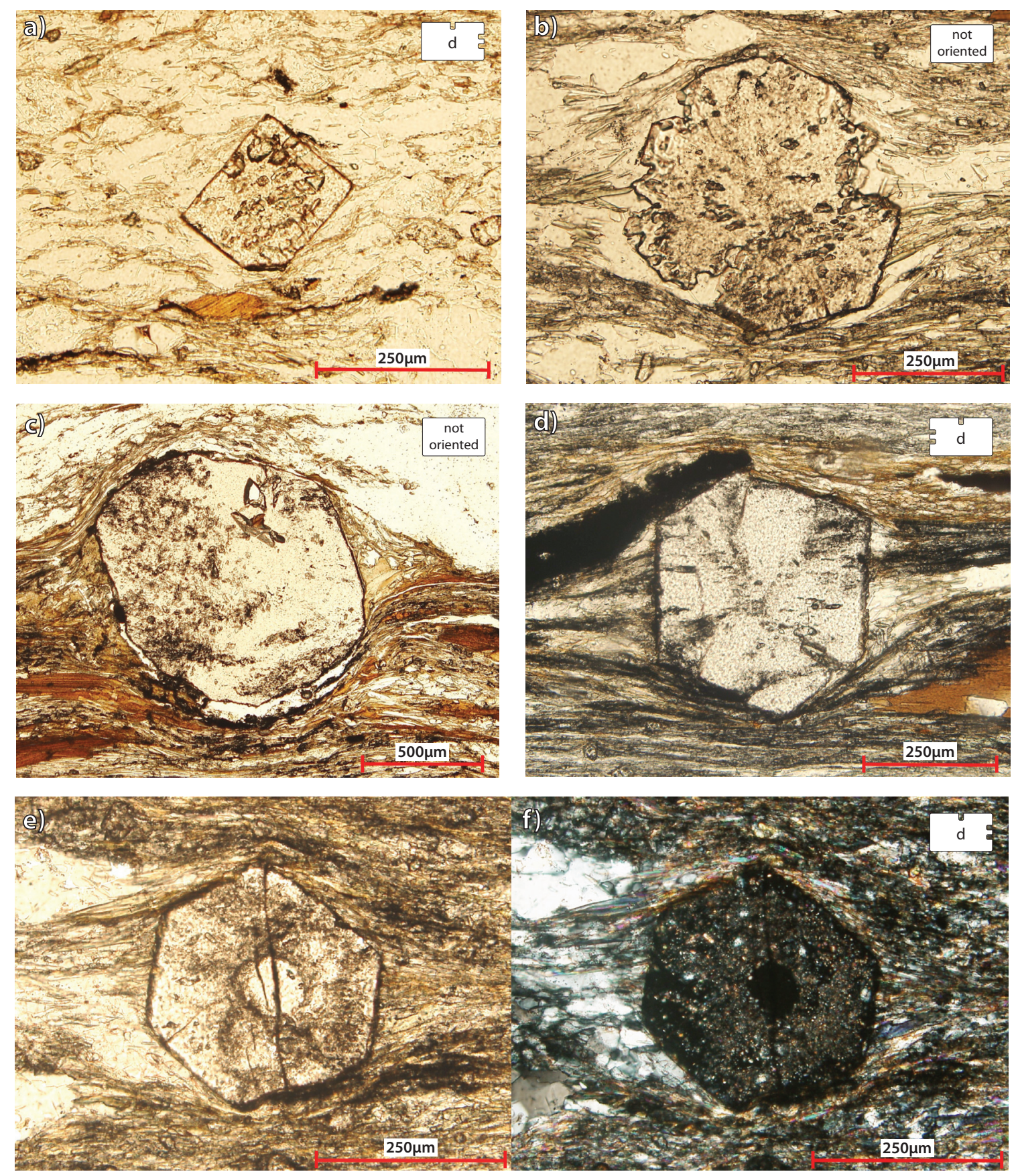

Figure 4.14. Photomicrographs of garnet porphyroblasts in greyschist samples. a) PPL of a typical euhedral garnet porphyroblast. DMNR-01d. b) PPL of a garnet porphyroblast with corroded rims. DMNR-20a. c) PPL of an anhedral garnet porphyroblast. DMNR-98b. d) PPL of a garnet with a star shaped inclusion pattern. DMNR-19d. e) \& f) PPL \& CPL of a garnet porphyroblast with a distinct inclusion free core. DMNR-27d. 


\section{Ilmenite}

Ilmenite is present in $87 \%$ of samples. It occurs as porphyroblasts and rare inclusions in garnet. Porphyroblasts are typically elongate but occasionally occur as stubby anhedral crystals and range in

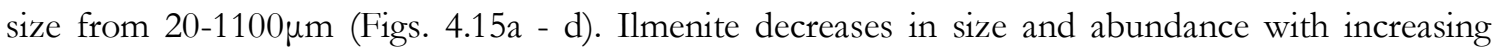
metamorphic grade. Ilmenite porphyroblasts are often rimmed by titanite in lower grade samples, and are almost completely replaced by titanite in the highest grade samples (Figs. $4.15 \mathrm{e}-\mathrm{f}$ ).

\section{Titanite}

Titanite occurs in $67 \%$ of samples in varying abundance. It occurs as euhedral to subhedral porphyroblasts, rare inclusions in garnet, small accessory minerals, and as rims on ilmenite porphyroblasts. Porphyroblasts are $50-500 \mu \mathrm{m}$ in size but decrease in size with increasing metamorphic grade. Euhedral porphyroblasts are more common in lower grade samples (east of the PUB) compared to higher grade samples (NW section) where titanite often occurs as sporadic, fine anhedral porphyroblasts (Figs. 4.16a - d). Titanite rims many ilmenite porphyroblasts and partially or completely pseudomorphs ilmenite in many higher grade samples, resulting in anhedral titanite with remnant ilmenite cores (Figs. 4.16e \& f).

\section{Epidote}

Epidote occurs in $92 \%$ of samples in varying abundance. It is a common accessory mineral and also occurs as rare inclusions in garnet. Epidote is typically small $(\sim 40-80 \mu \mathrm{m})$, with occasional large crystals up to $200 \mu \mathrm{m}$ (Fig. 4.17). Epidote is anhedral and occurs both as individual crystals as well as clusters of microcrystals $(<10 \mu \mathrm{m})$ (Fig. $4.17 \mathrm{a}-\mathrm{d})$. Some crystals show zonation patterns represented by core to rim changes in birefringence (Fig. 4.17 e \& f). Epidote becomes more common in higher grade samples where it more commonly occurs as a pervasive microcrystalline phase.

\section{Calcite}

Calcite is present in one greyschist sample as rare strain fringes on biotite porphyroblasts and in mixed quartz/calcite veins (Fig. 4.18). Crystals are anhedral to subhedral and are $50-300 \mu \mathrm{m}$ in diameter. 

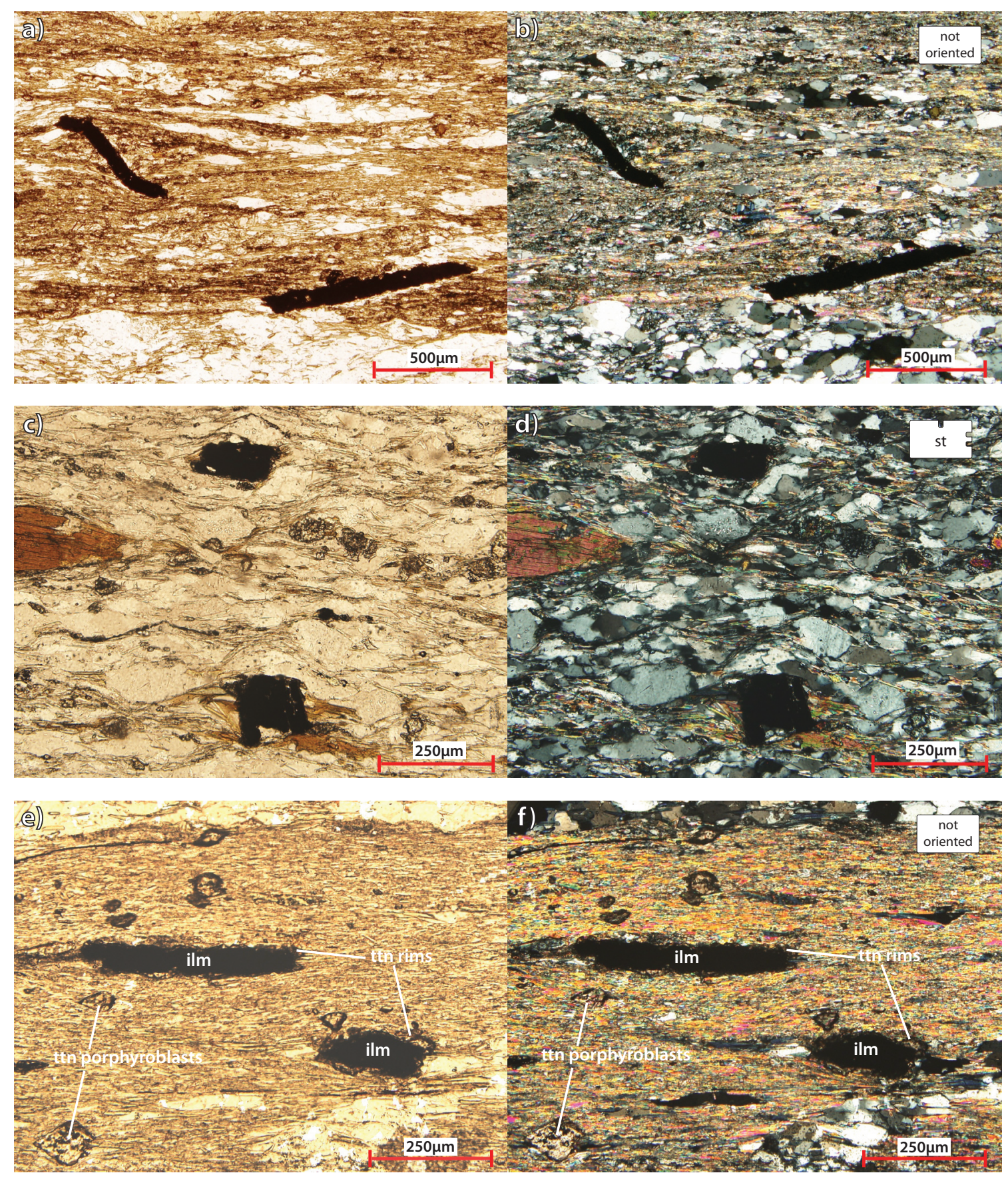

Figure 4.15. Photomicrographs of ilmenite (black) in greyschist samples. a) \& b) PPL \& CPL of a typical elongate ilmenite porphyroblast. DMNR-20a. c) \& d) PPL \& CPL of a stubby ilmenite porphyroblast. DMNR56st. e) \& f) PPL \& CPL of ilmenite rimmed with titianite in lower grade schist. DMNR-20a. 

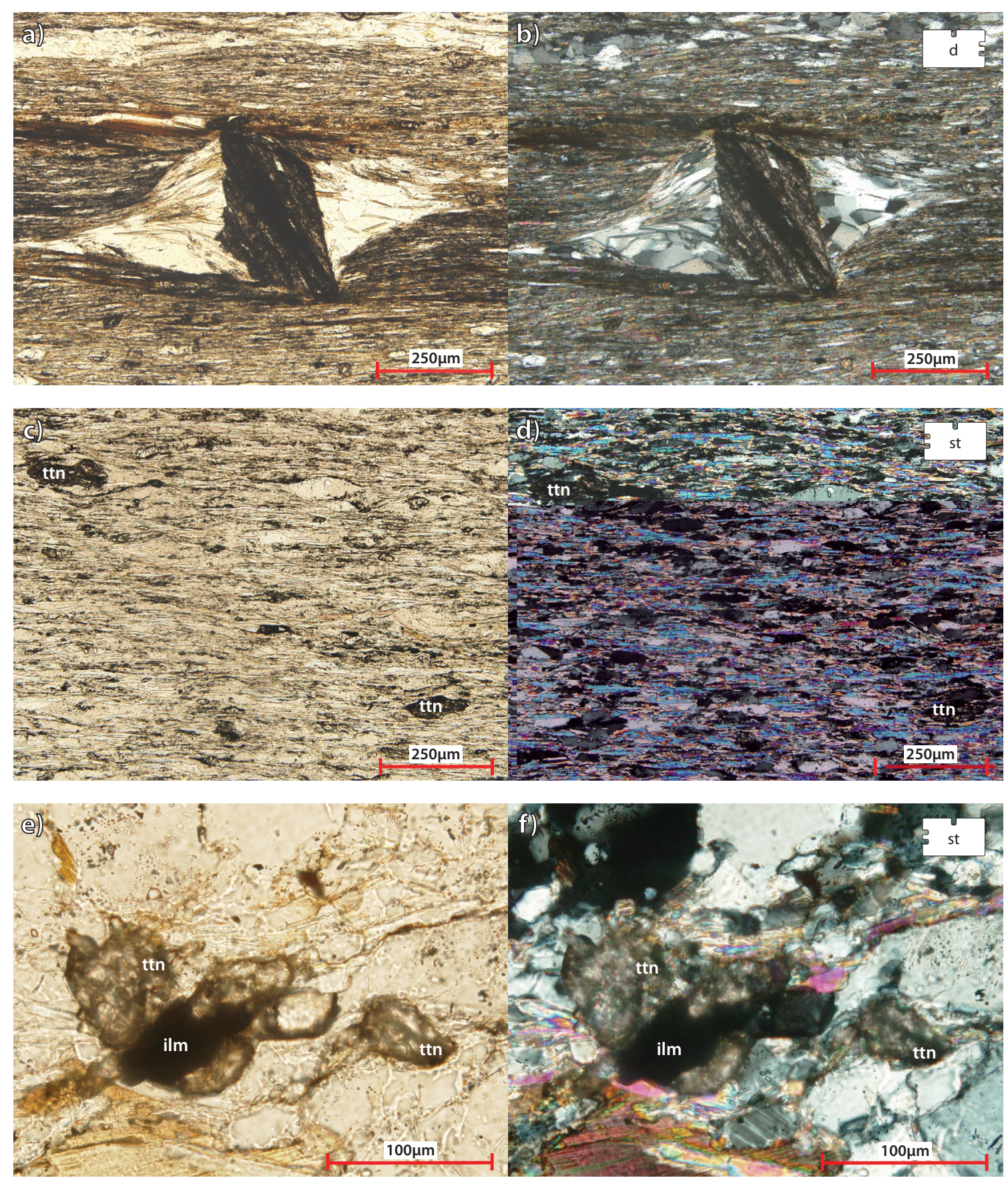

Figure 4.16. Photomicrographs of titanite in greyschist samples. a) \& b) PPL \& CPL of an euhedral titanite porphyroblast. DMNR-59d. c) \& d) PPL \& CPL of fine, sporadic anhedral titanite. DMNR-82st. Note photomicrographs a-d are to the same scale. e) \& f) PPL \& CPL titanite almost completely replacing ilmenite in high grade schist. DMNR-93st. 

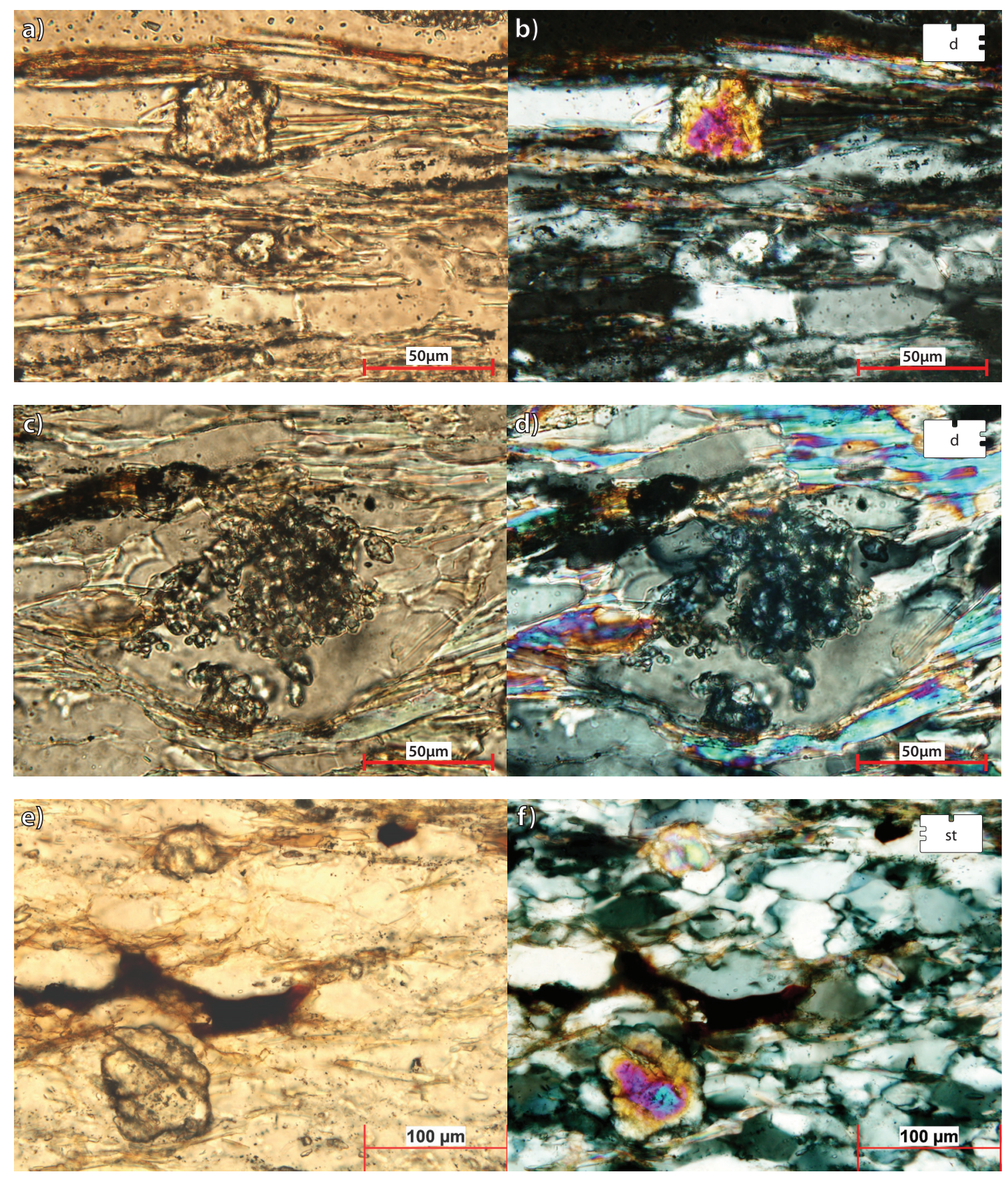

Figure 4.17. Photomicrographs of epidote in greyschist samples. a) \& b) PPL \& CPL of a typical anhedral epidote cyrstal. DMNR-73d. c) \& d) PPL \& CPL of an epidote microcrystal cluster. DMNR-69d. e) \& f) PPL \& CPL of a zoned epidote (represented by distinct changes in birefringence). DMNR-52st. 

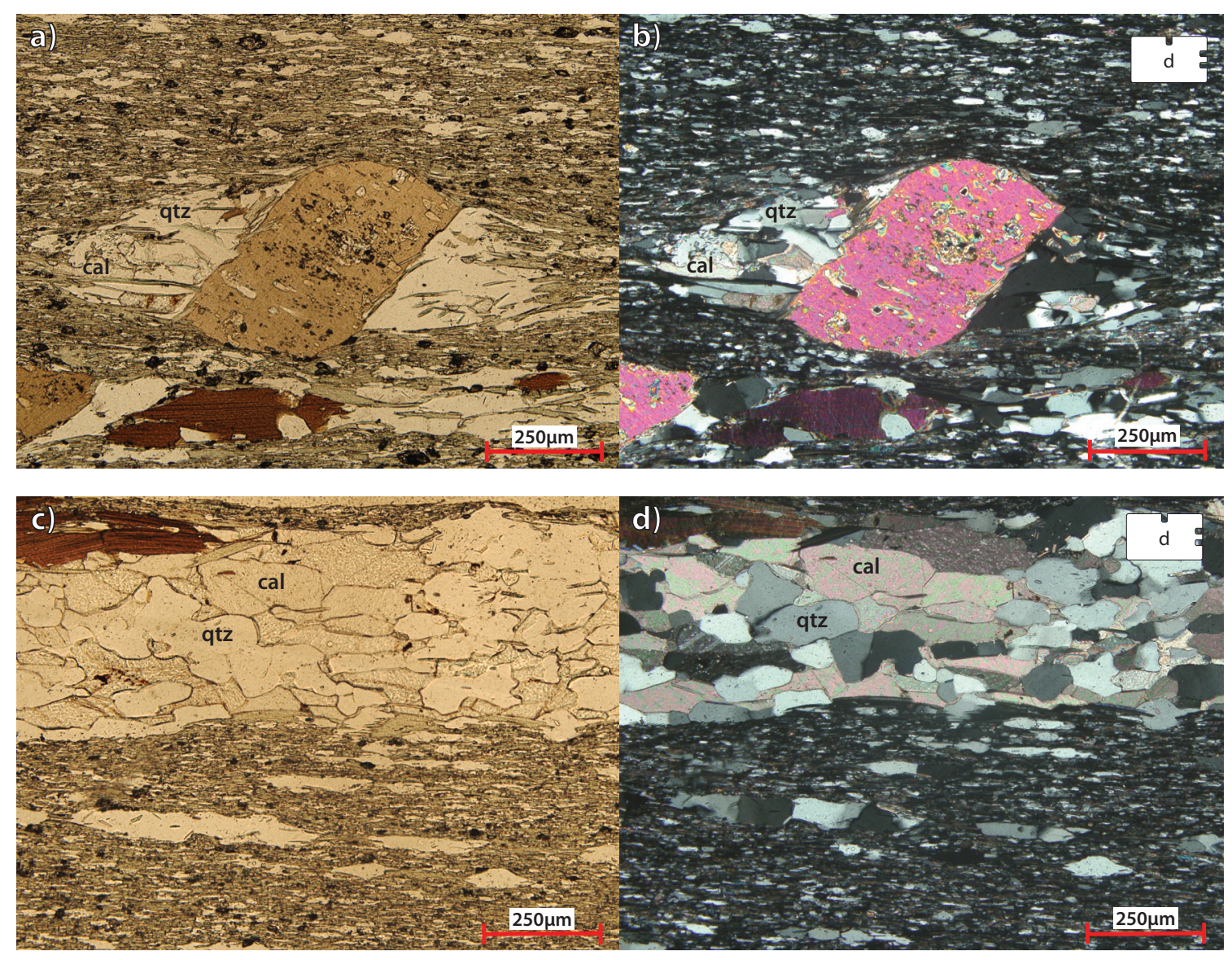

Figure 4.18. Photomicrographs of calcite in greyschist samples. a) \& b) PPL \& CPL of calcite forming in the the strain shadows of a biotite porphyroblast. DMNR-22d. c) \& d) PPL \& CPL of a mixed calcite/quartz vein. DMNR-22d. 


\section{Accessory Minerals (Zircon, Tourmaline, Apatite)}

Zircon, tourmaline and apatite are found sporadically throughout greyschist samples as accessory minerals ranging in size from $30-100 \mu \mathrm{m}$ (Fig. 4.19). Apatite and zircon are also present as rare inclusions in garnet porphyroblasts. Tourmaline is the most common accessory mineral occurring in $\sim 34 \%$ of the samples. It is certain that more samples than documented contain these accessory minerals but due to their fine, sporadic nature they may fail to be noticed during petrographic observations.

\subsubsection{Greenschist}

Greenschist accounts for $12 \%$ of the samples collected in the field area and have the general mineral assemblage:

$$
\mathrm{Chl}+\mathrm{Amp}+\mathrm{Ep}+\mathrm{Bt}+\mathrm{Qtz} \pm \mathrm{Ilm} \pm \mathrm{Ttn} \pm \mathrm{Cal} \pm \mathrm{Mag} \pm \mathrm{Pl} \pm \mathrm{Tur}
$$

Greenschists are defined by high concentrations of chlorite and amphibole and proportionately less quartz ,in comparison to greyschists. All greenschist samples are dominated by a fine chlorite and amphibole foliated matrix. Microcrystalline epidote is also a common matrix mineral in several samples. The majority of the greenschist samples have a pervasive matrix with little segregation of quartz layers compared to greyschist, however, some greenschist samples have occasional segregated

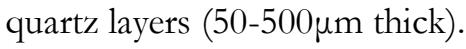

\section{Chlorite}

Chlorite occurs in all samples as a matrix mineral and is often the main component of the matrix (Figs. $4.20 \mathrm{a} \&$ b). Some quartz rich samples have occasional fine chlorite platelets located along quartz grain boundaries (Figs. 4.20c \& d). Many biotite porphyroblasts have partially retrogressed into chlorite (Figs. 4.20e \& f).

\section{Amphibole}

Amphibole is present in all but two greenschist samples in moderate to high abundance. It commonly occurs as a matrix mineral, as well as porphyroblasts. Two types of amphibole are 

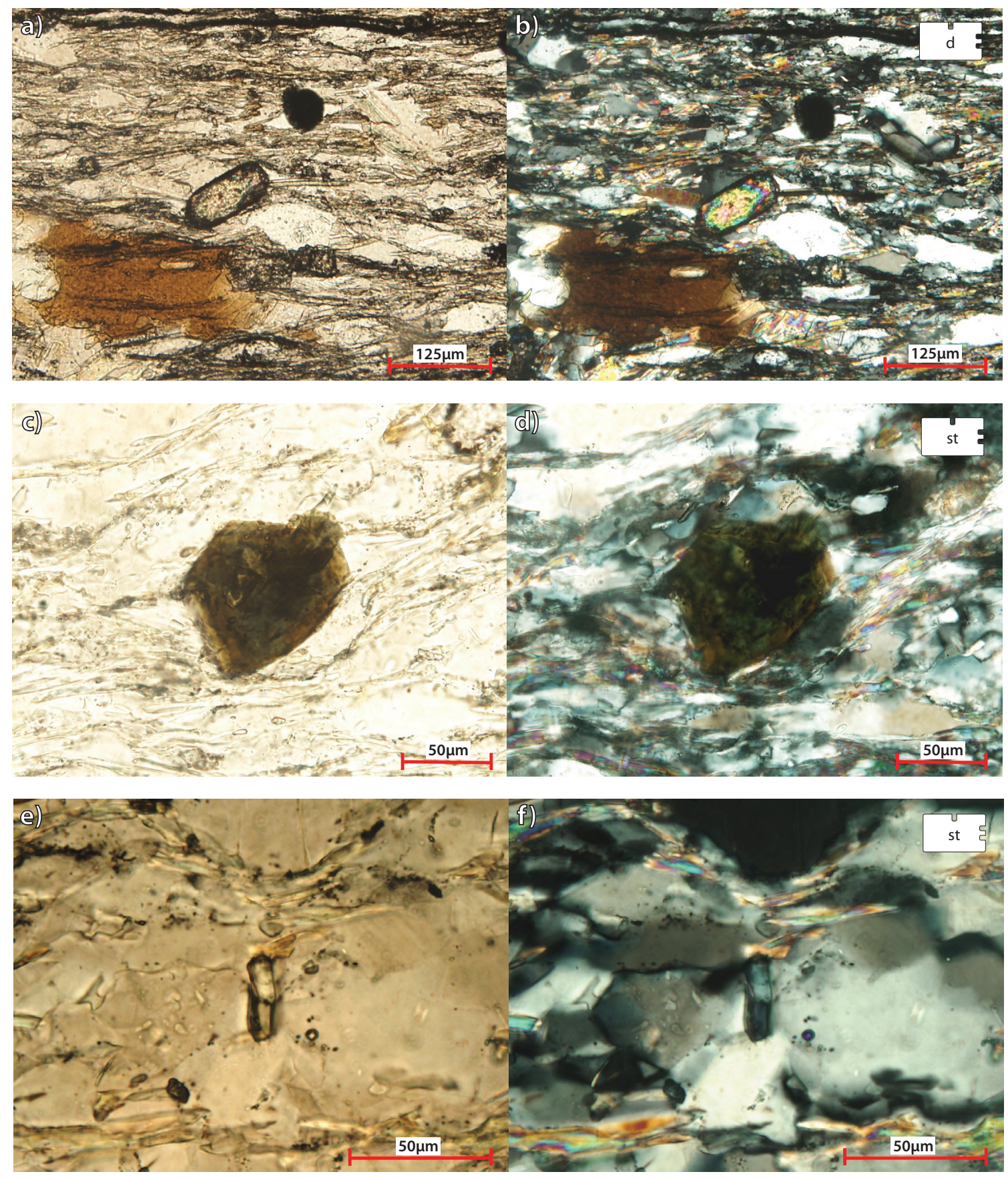

Figure 4.19. Photomicrographs of accessory minerals in greyschist samples. a) \& b) PPL \& CPL of a zircon crystal. DMNR-11d. c) \& d) PPL \& CPL of a tourmaline crystal. DMNR-56st. e) \& f) PPL \& CPL of an apatite crystal. DMNR-46st. 

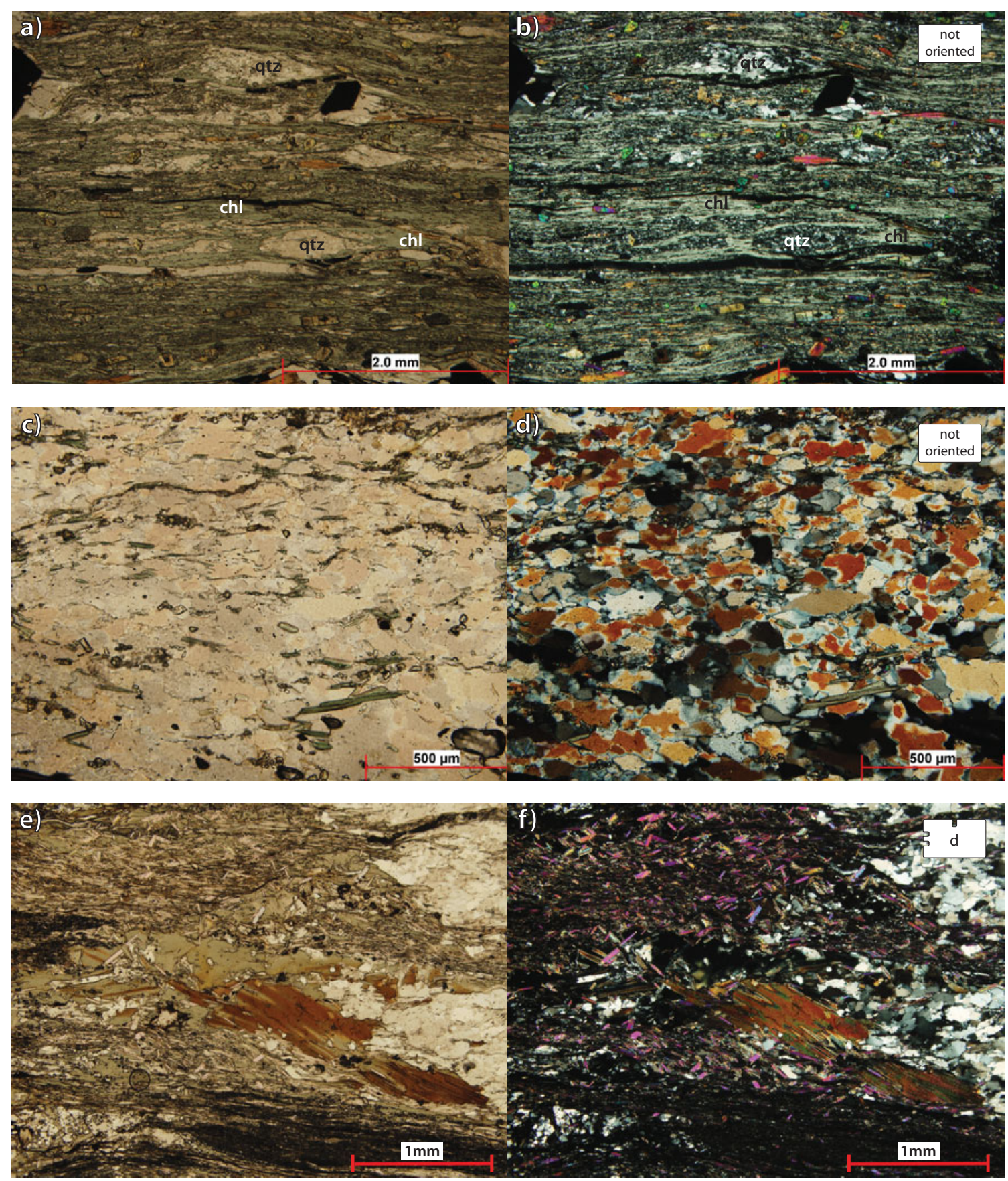

Figure 4.20. Photomicrographs of the different chlorite textures in greenschist samples. a) \& b) PPL \& CPL of chlorite as the predominant matrix mineral. DMNR-31a. c) \& d) PPL \& CPL of fine chlorite platelets in the matrix. DMNR-10a. e) \& f) PPL \& CPL of a biotite porphyroblast partially retrogressed to chlorite. DMNR$33 \mathrm{~d}$. 
observed, both of which exhibit inclined extinction: small matrix crystals that are colourless or exhibit very pale green to yellow pleochroism and second order green to pink birefringence (Figs. $4.21 \mathrm{a}-\mathrm{d}$ ); and large elongate porphyroblasts up to $6 \mathrm{~mm}$ in length that exhibit green pleochroism and low second order birefringence (Figs. 4.21e \& f). Amphibole is very acicular and often forms a fibrous texture akin to tremolite/actinolite textures. The abundance and size of amphibole porphyroblasts varies greatly throughout greenschist samples and has no apparent relationship to metamorphic grade.

\section{Epidote}

Epidote is present in $86 \%$ of greenschist samples as a microcrystalline matrix mineral, large porphyroblasts, and as an accessory mineral. In 30\% of samples, microcrystalline epidote is equal in proportion to both chlorite and amphibole (based on visual estimates) (Figs. 4.22a \& b). Epidote porphyroblasts are euhedral to anhedral with a maximum diameter of $500 \mu \mathrm{m}$ and sometimes exhibit core to rim birefringence zonation (Figs. $4.22 \mathrm{c} \& \mathrm{~d}$ ). Euhedral epidote occasionally overgrows ilmenite porphyroblasts (Figs. 4.22e \& f).

\section{Biotite}

Biotite occurs in $86 \%$ of greenschist samples as large porphyroblasts or as uncommon ribbons within the matrix (Figs. 4.23a - d). Three samples contain large (up to $4 \mathrm{~mm}$ ) altered porphyroblasts, either oxidised or chloritised, in high abundance. Many of these porphyroblasts are slightly poikiloblastic. Matrix biotite are often heavily altered or completely replaced by chlorite.

\section{Quartz}

Quartz is present in all but one greenschist sample in subordinate amounts. It occurs as segregated layers/lenses of interlobate, inequigranular to seriate crystals (see Fig. 4.20). One quartz rich sample has a highly deformed, extremely seriate quartz crystal matrix (Figs. 4.24a - b). 

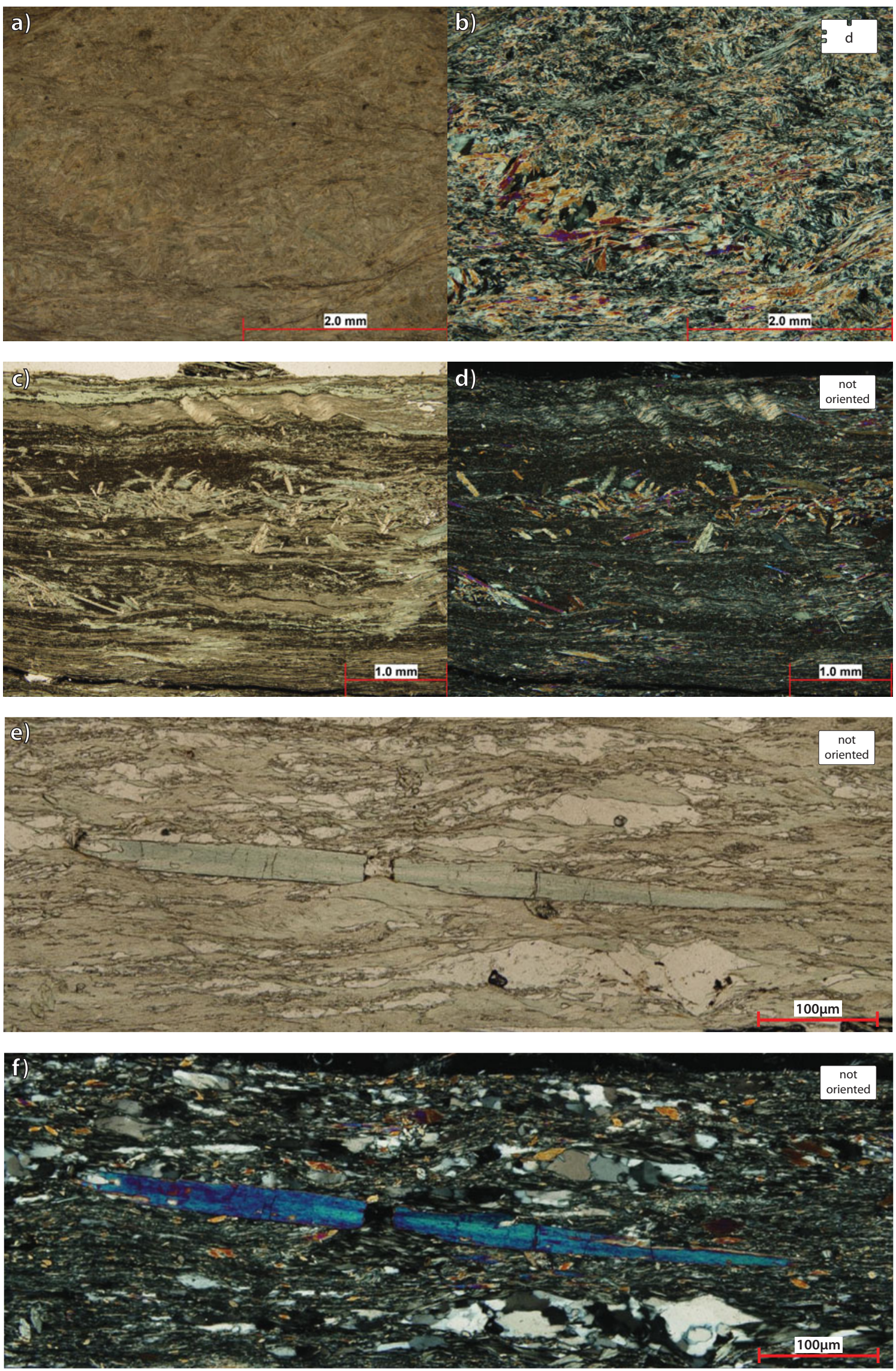

Figure 4.21. Photomicrographs of amphibole in greenschist samples. a) \& b) PPL \& CPL of greenschist with a predominantly amphibole matrix. DMNR-18d. c) \& d) PPL \& CPL of greenschist with a mixed amphibole/chlorite matrix. DMNR-32b. e) \& f) PPL \& CPL of a large amphibole porphyroblast. DMNR-13a. 

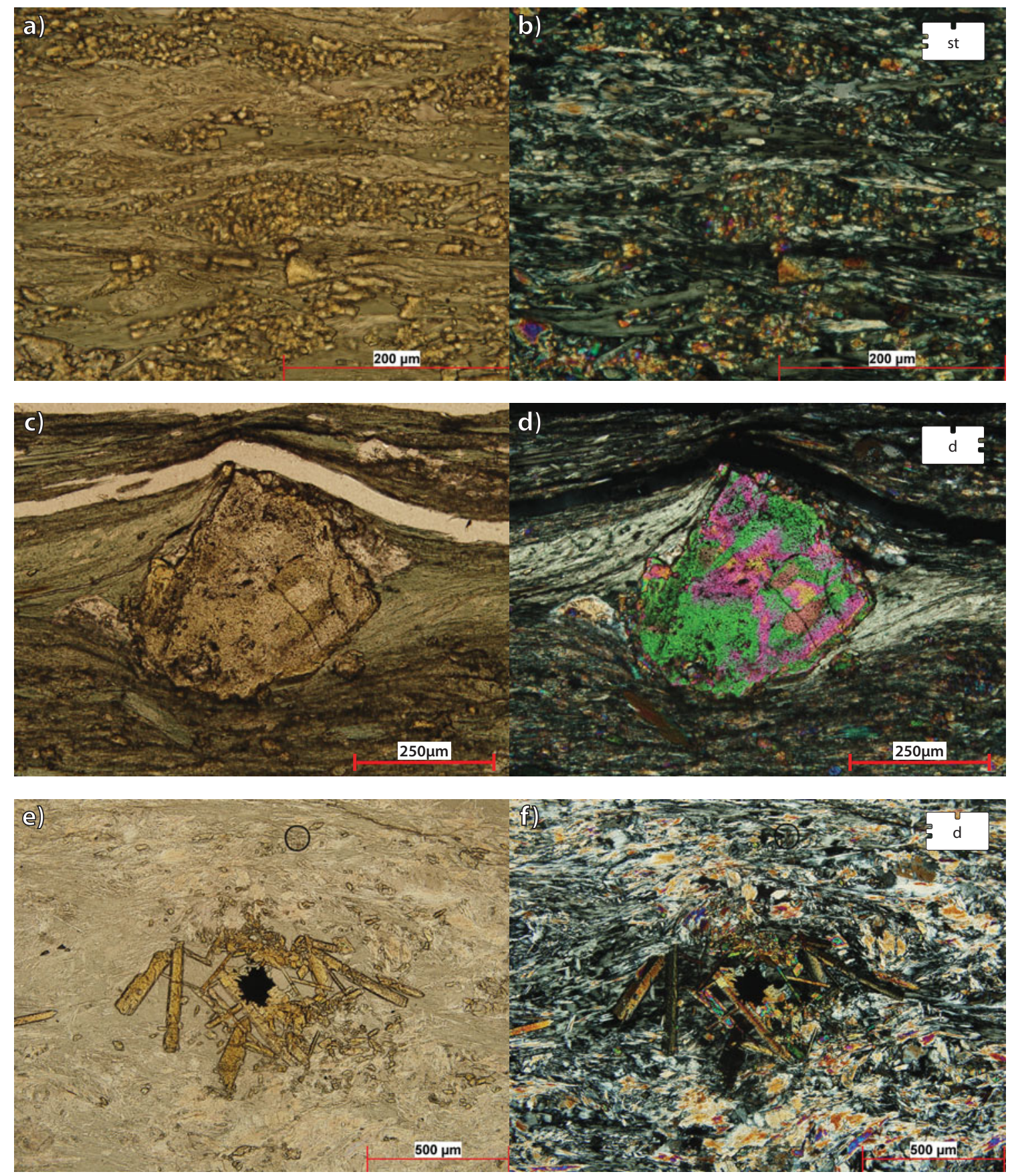

Figure 4.22. Photomicrographs of epidote in greenschist samples. a) \& b) PPL \& CPL of greenschist with a microcrystalline epidote matrix. DMNR-24st. c) \& d) PPL \& CPL of a large epidote porphyroblast. DMNR09d. e) \& f) PPL \& CPL of euhedral epidote overgrowing ilmenite. DMNR-18d. 

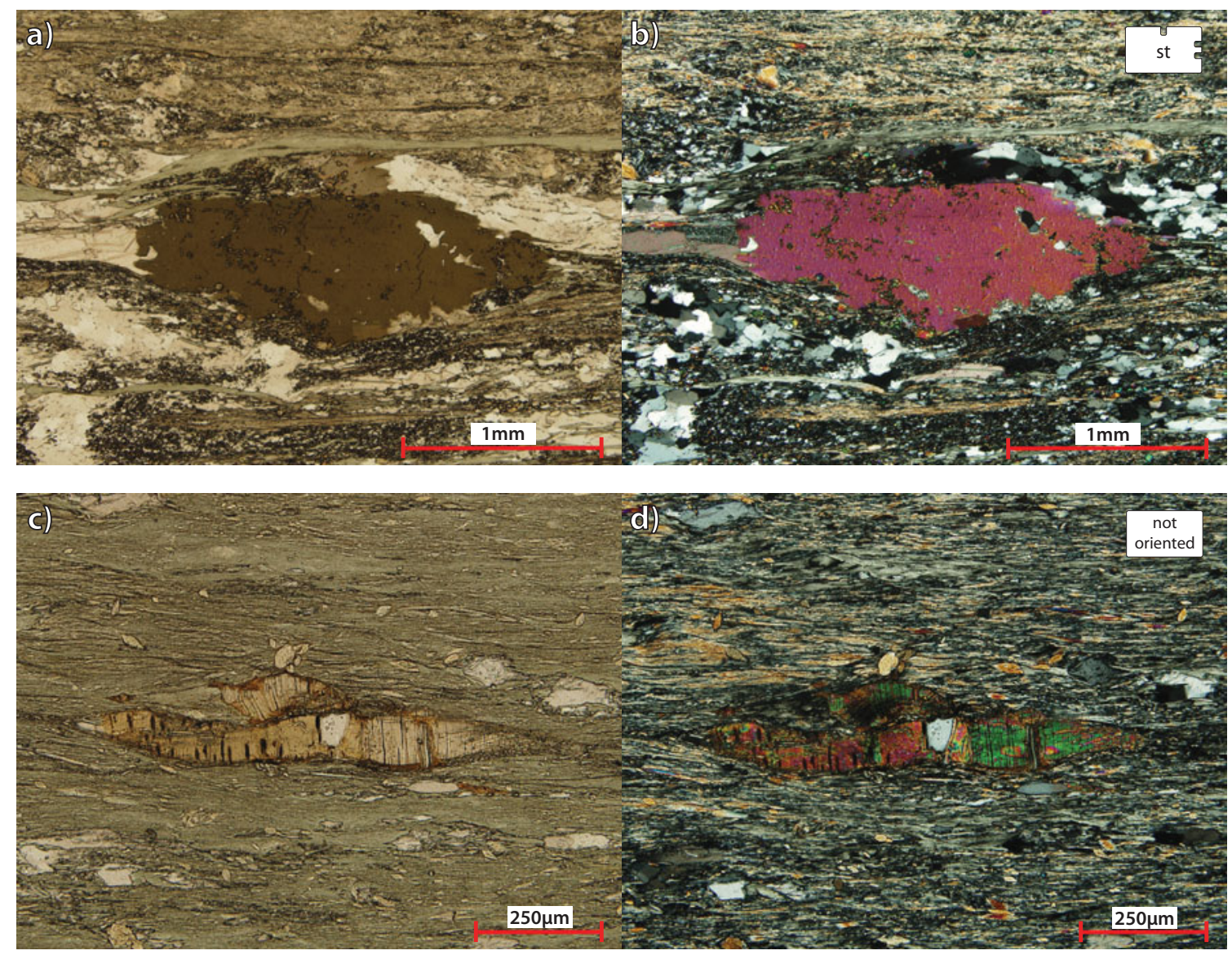

Figure 4.23. Photomicrographs of biotite in greenschist samples. a) \& b) PPL \& CPL of a large biotite porphyroblast. DMNR-24st. c) \& d) PPL \& CPL of a ribbon-like biotite porphyroblast. DMNR-13a.

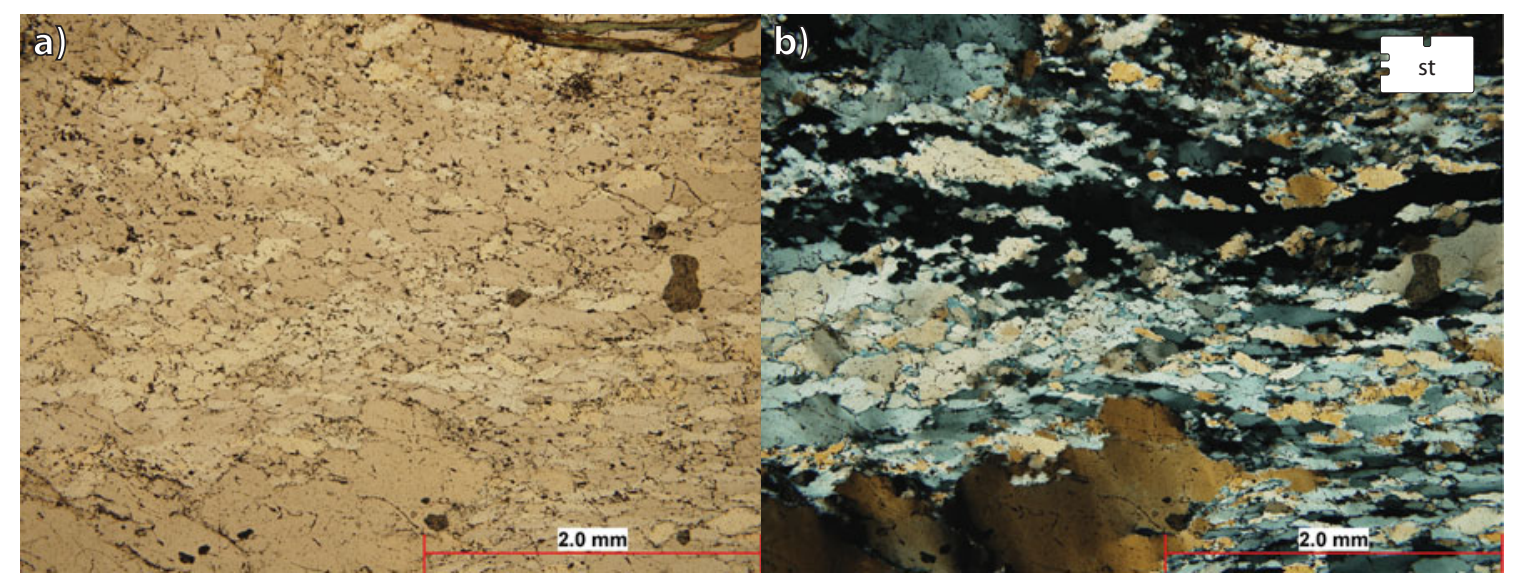

Figure 4.24. Photomicrographs of quartz in greenschist samples. a) \& b) PPL \& CPL of the seriate quartz matrix observed in one greenschist sample. DMNR-30st. 


\section{Ilmenite and Titanite}

Ilmenite is present as rare small porphyroblasts in four greenschist samples. One sample contains ilmenite with rims of euhedral epidote crystals. Titanite is observed in one sample as small $<20 \mu \mathrm{m}$ anhedral crystals, forming on the rims of ilmenite (Fig. 4.25). No porphyroblasts of titanite are observed.

\section{Other Minerals (Calcite, Magnetite, Hematite and Accessory Phases)}

Calcite is present in two samples associated with quartz, as a matrix mineral, and as coarse crystalline veins (Fig. 4.26). The maximum crystal size is $1.5 \mathrm{~mm}$. Magnetite occurs in two greenschist samples as common euhedral porphyroblasts $\sim 50-200 \mu \mathrm{m}(\max 3 \mathrm{~mm}$ ) (Fig. 4.27). A dark red oxide (possibly hematite) occurs along the grain boundaries of quartz, generally restricted to coarse crystalline quartz veins/layers parallel to the exterior foliation (Fig. 4.28). Muscovite, tourmaline and plagioclase occur as uncommon accessory phases in some greenschists.

\subsubsection{Epidosite}

Five samples of epidosite were collected in the Newton Range, all occurring within outcrops of greenschist. Epidosite has a similar mineral assemblage to greenschists, but differ in relative proportions of minerals. Samples consist primarily of quartz and epidote with lesser amounts of chlorite, biotite and magnetite. Only one sample contains amphibole. A dark red oxide with the appearance of hematite is common in crosscutting quartz filled cracks/veins. Quartz is inequigranular and in places heavily dynamically recrystallised (Fig. 4.29).

Microcrystalline, anhedral epidote defines the foliation in all epidosite samples, and also forms large clusters with the appearance of large $(>1 \mathrm{~mm})$ anhedral porphyroblasts (Figs. 4.30a \& b). Smaller subhedral epidote porphyroblasts are also common, $\sim 50-200 \mu \mathrm{m}$ in diameter (Figs. 4.30c \& d). Small $(>200 \mu \mathrm{m})$ magnetite porphyroblasts define the foliation in one sample, occasionally rimming epidote (Fig. 4.31).

Biotite occurs as large porphyroblasts with crack fill textures (up to $1.5 \mathrm{~mm}$ ) and as altered ribbon like porphyroblasts (Fig. 4.32). Chlorite occurs as a ribbon-like matrix mineral (Fig. 4.32). Garnet is 


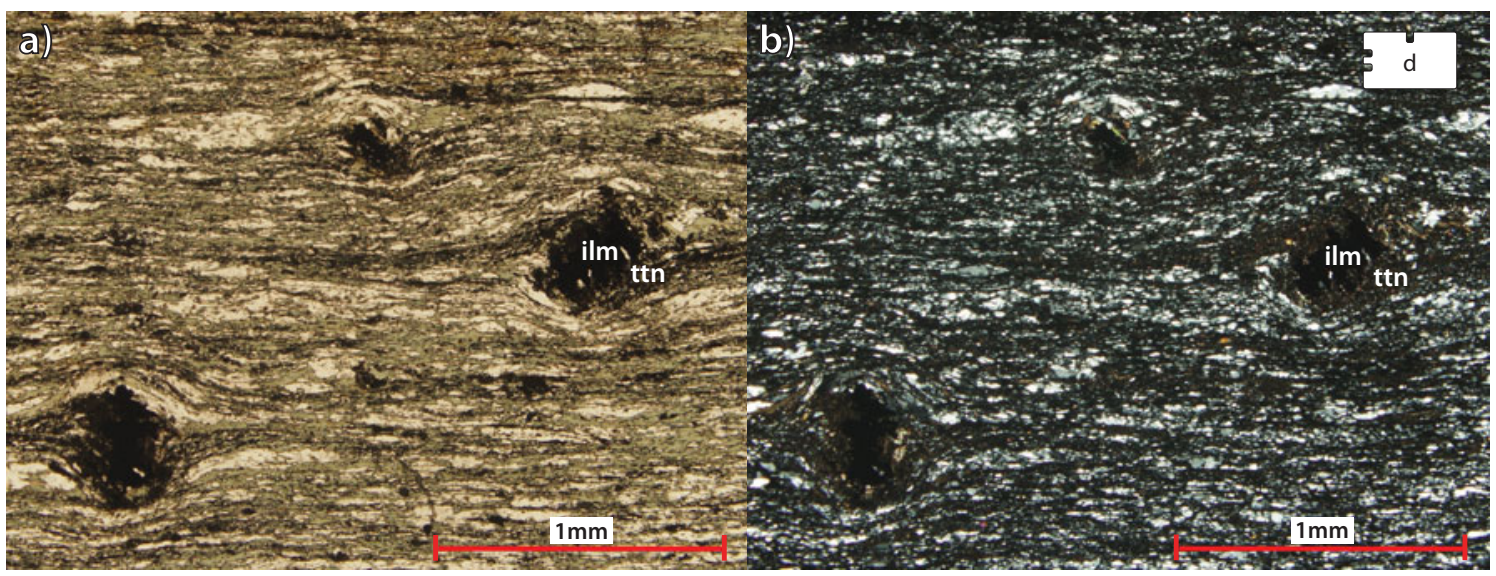

Figure 4.25. Photomicrographs of ilmenite and titanite in greenschist samples. a) \& b) PPL \& CPL of titanite rims on ilmenite porphyroblasts. DMNR-39d.
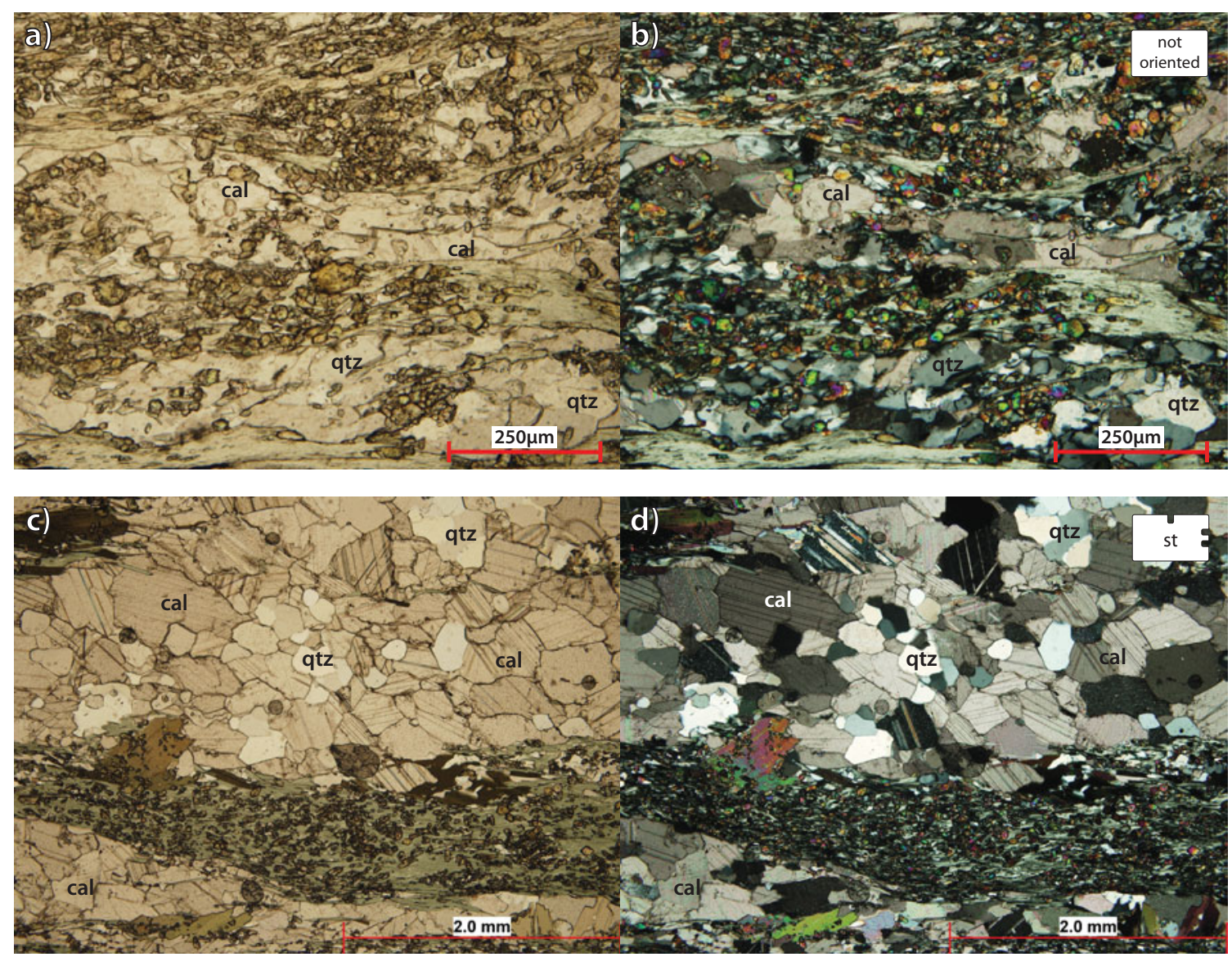

Figure 4.26. Photomicrographs of calcite in greenschist samples. a) \& b) PPL \& CPL of calcite forming part of the matrix. DMNR-25a. c) \& d) PPL \& CPL of coarse calcite/quartz veining. DMNR-24st. 


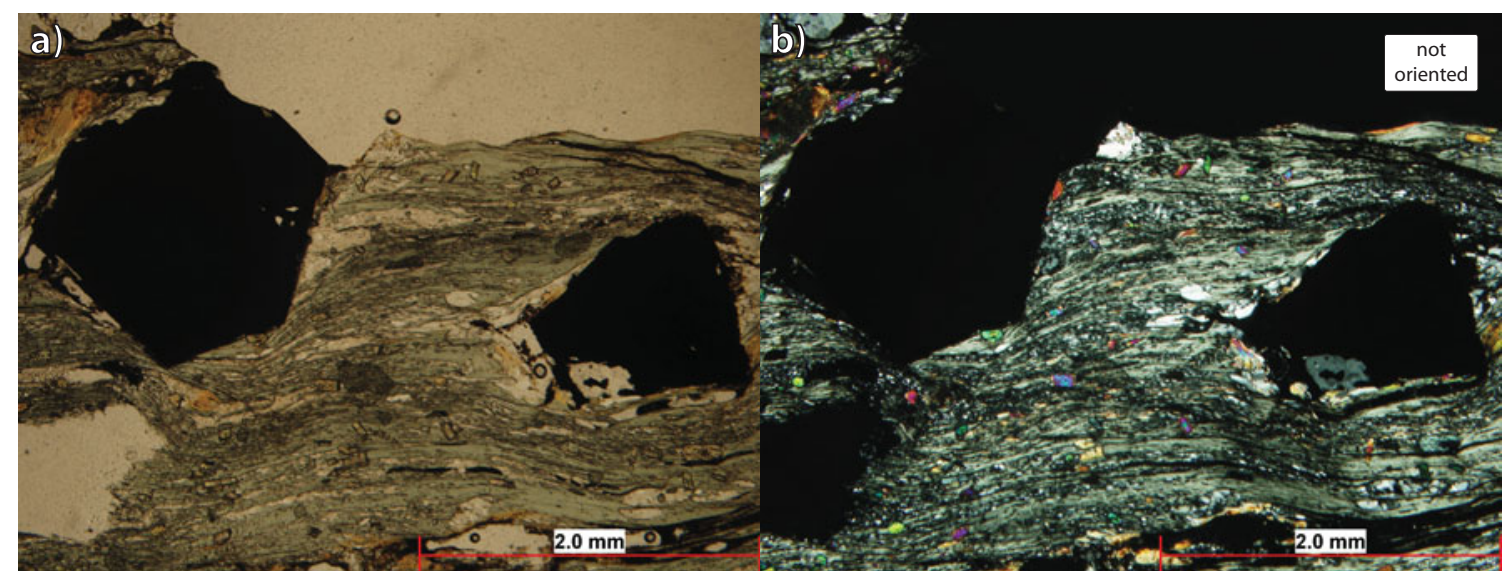

Figure 4.27. a) \& b) PPL \& CPL Photomicrographs of euhedral magnetite porphyroblasts. DMNR-31a.

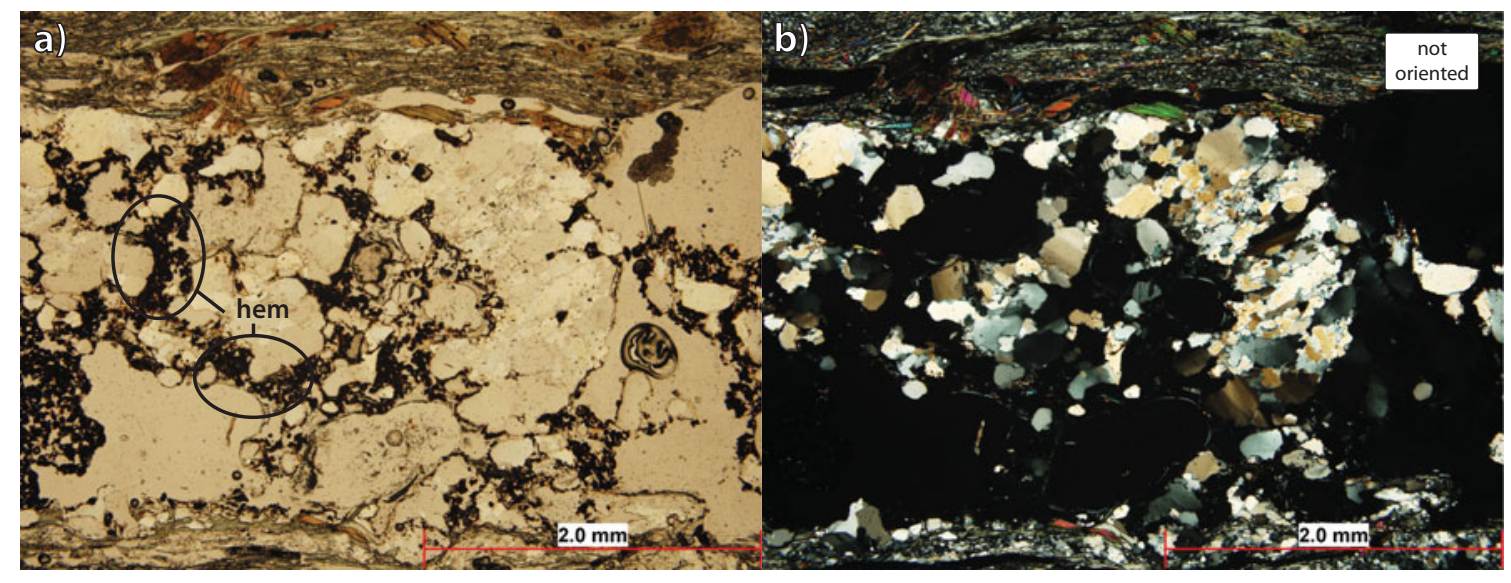

Figure 4.28. a) \& b) PPL \& CPL Photomicrographs of a red oxide (likely hematite) located along grain boundaries in a coarse crystalline quartz vein. DMNR-31b. 


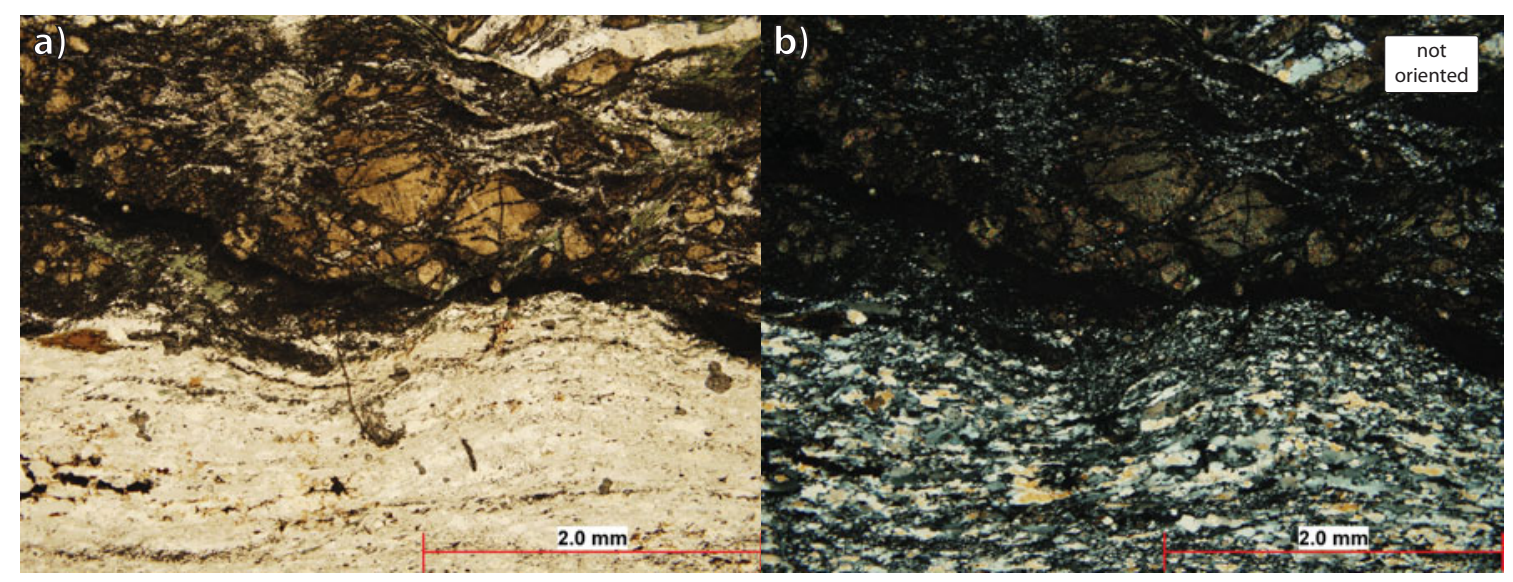

Figure 4.29. a) \& b) PPL \& CPL photomicrographs of seriate, dynamically recrystallised quartz in epidosite samples. DMNR-16.
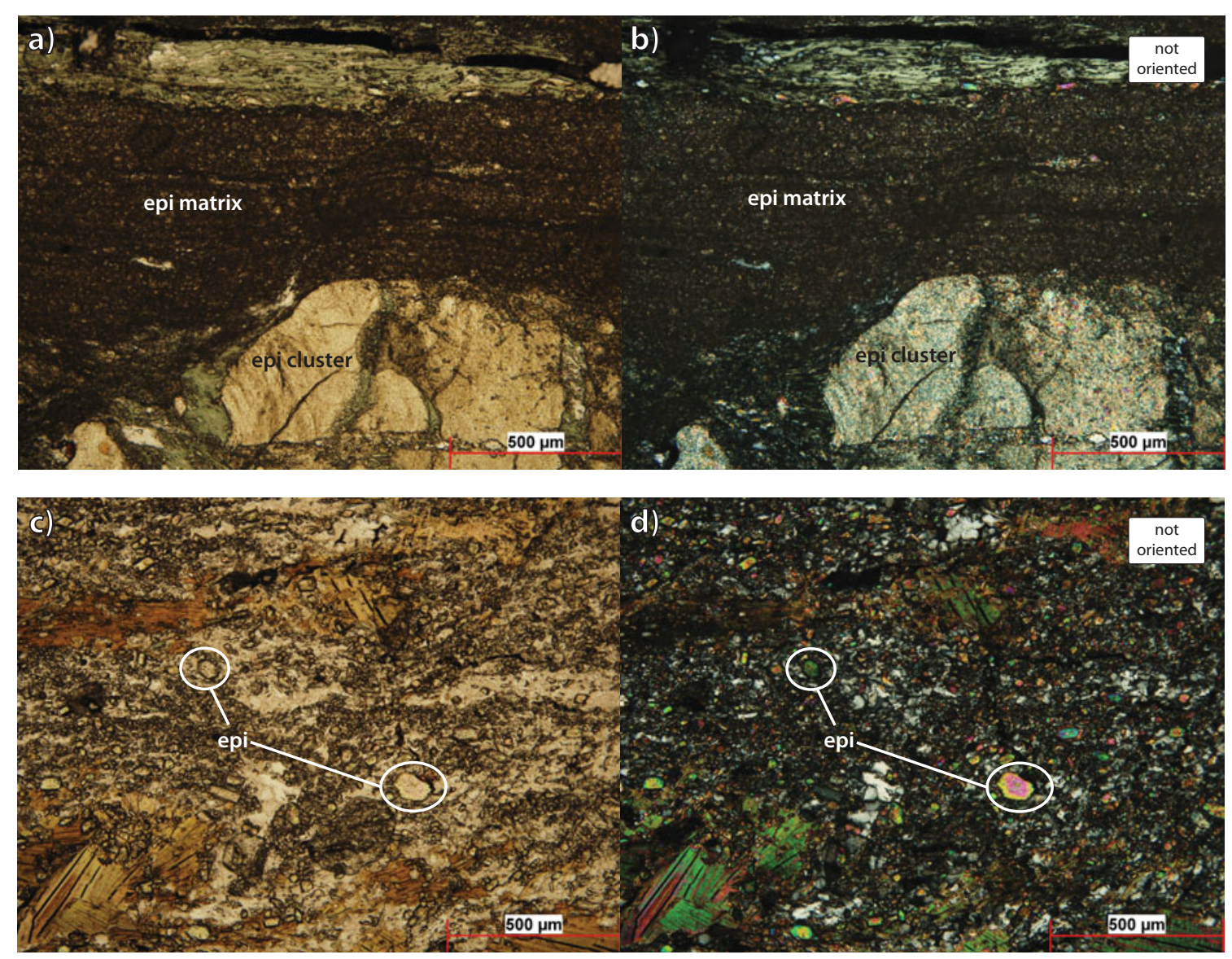

Figure 4.30. Photomicrographs of epidote in epidosite samples. a) \& b) PPL \& CPL of microcrystalline epidote forming both large clusters as well as the surrounding matrix. DMNR-16. c) \& d) PPL \& CPL of individual anhedral epidote porphyroblasts. DMNR-14a. 

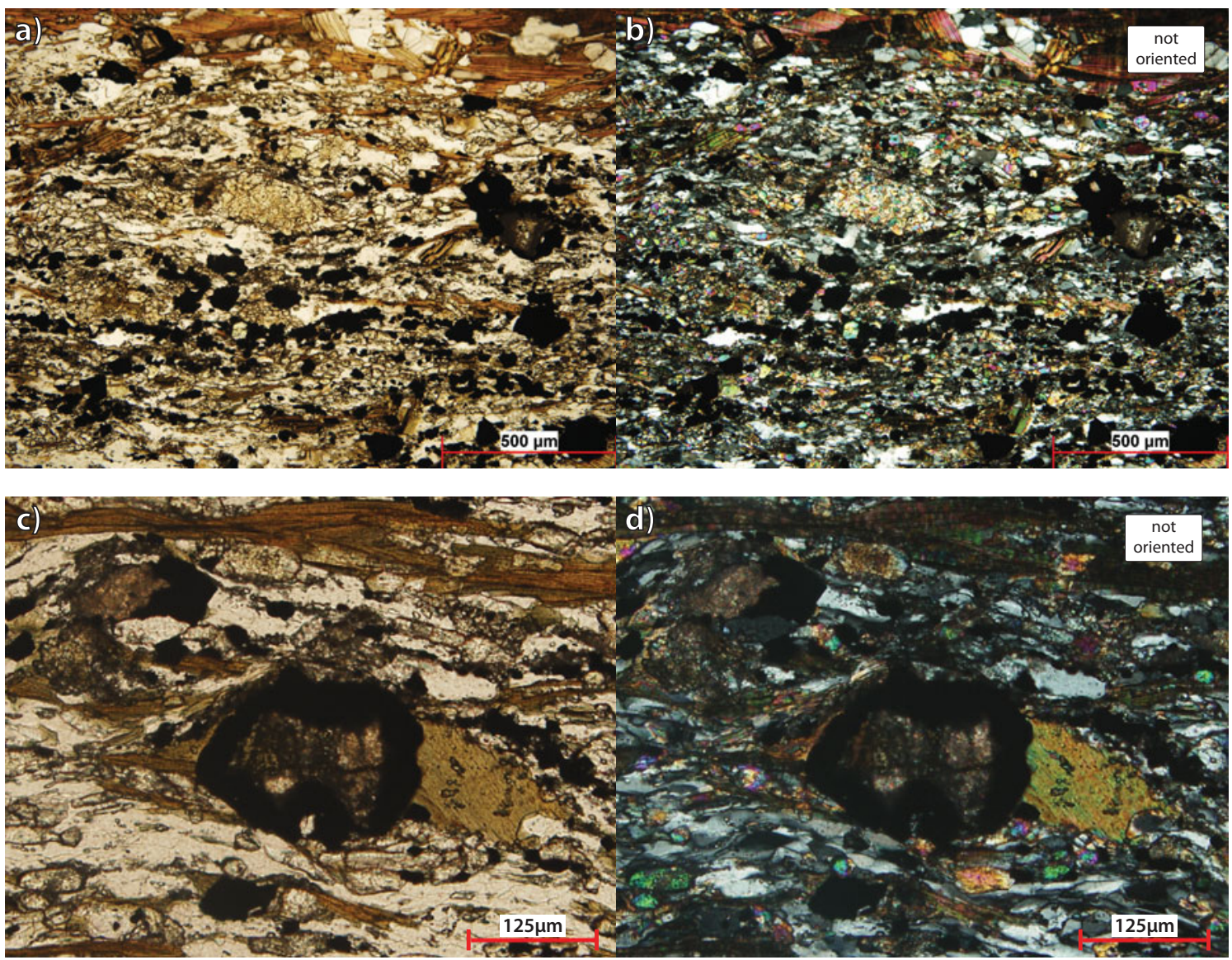

Figure 4.31. Photomicrographs of magnetite in epidosite samples. a) \& b) PPL \& CPL of small magnetite crystals that define the foliation. DMNR-38b. c) \& d) PPL \& CPL of magnetite rimming epidote. DMNR-38b.

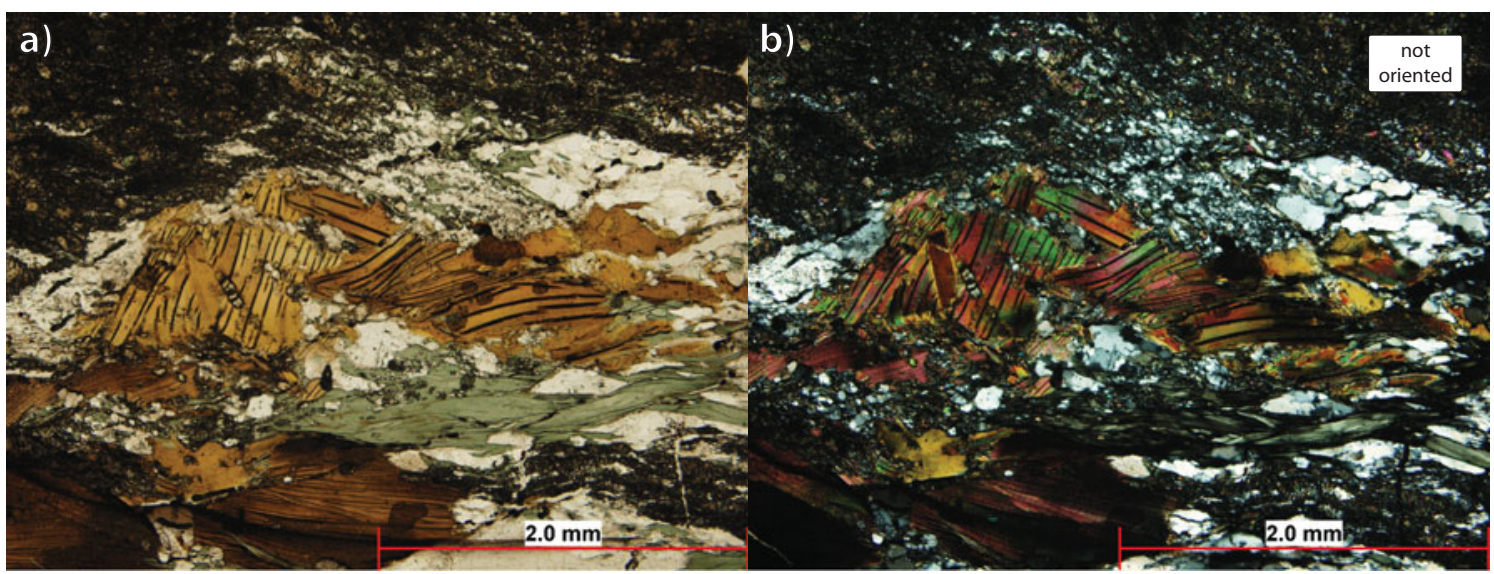

Figure 4.32. a) \& b) PPL \& CPL photomicrographs of large biotite porphyroblasts and ribbon-like chlorite porphyroblasts in epidosite samples. DMNR-16. 
present in one epidosite sample as hundreds of tiny $>10 \mu \mathrm{m}$ crystals (Fig. 4.33). Amphibole occurs in one sample as large acicular porphyroblasts up to $5 \mathrm{~mm}$ long (Fig. 4.34).

\subsection{Microstructure Results}

\subsubsection{Foliation Preservation}

The Alpine Schist in the Newton Range has a complex, variably overprinted history and hence interpreting relict foliations is often difficult. Three distinct foliations are observed in rocks from the Newton Range.

\section{Pre-Dominant (Early) Foliation}

An early foliation is present in the lowest grade unsegregated samples. It occurs as rare, discontinuous layers of equigranular quartz that have either been isoclinally folded, or stretched to form isolated lenticular boudins. The folds are symmetric in shape and have limbs parallel to the dominant foliation, and are often comprised of the same equigranular quartz as the lenticular boudins (Fig. 4.35). The lenses and discontinuous layers consist of fine equigranular quartz that is noticeably different in texture from quartz in the surrounding matrix, which is generally more interlobate and inequigranular (see Figs. 4.6c \& d).

\section{Dominant Foliation}

The dominant foliation is planar and is represented by the separation of greyschist into phyllosilicate/quartzofeldspathic layers as well as the alignment of phyllosilicate minerals (muscovite, biotite, and chlorite) in both greyschist and greenschist. The segregation of phyllosilicate/ quartzofeldspathic layers becomes more distinct with an increase in metamorphic grade (see Figs. $4.4-4.6)$. 

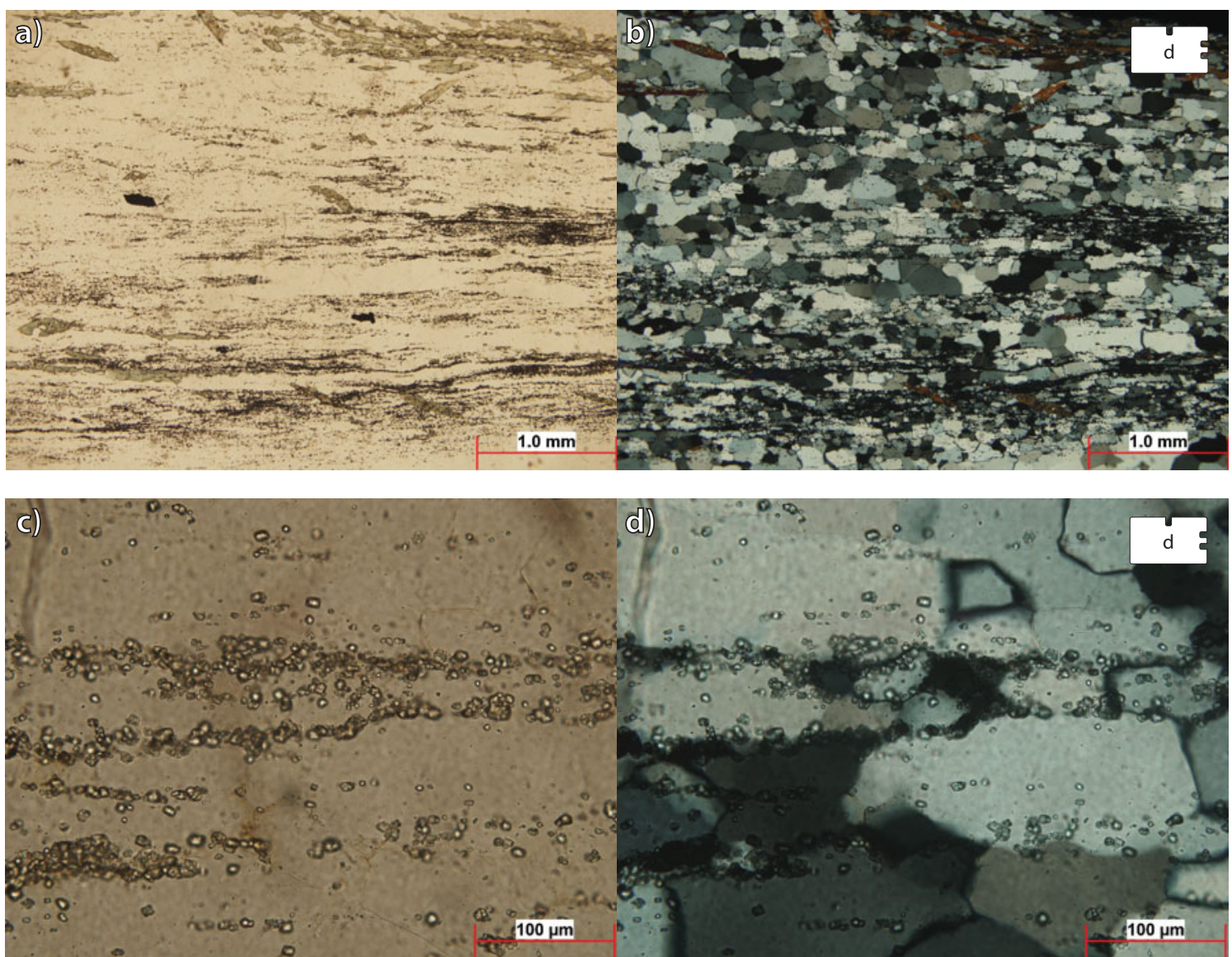

Figure 4.33. a) to d) PPL \& CPL photomicrographs of microgarnet that define the foliation in one epidosite sample (due to their small size the microgarnet do not appear isotropic in cross polarised light). DMNR-40d.

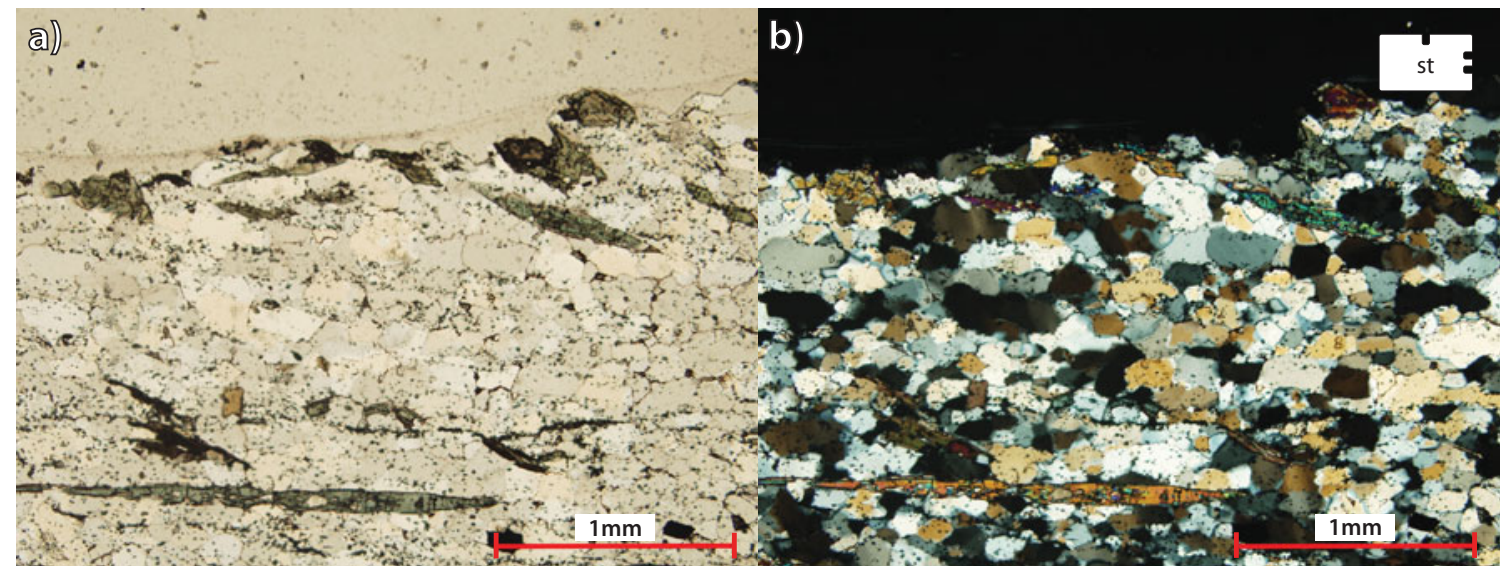

Figure 4.34. a) \& b) PPL \& CPL photomicrographs of large amphibole porphyroblasts observed in one epidosite sample. DMNR-40st. 

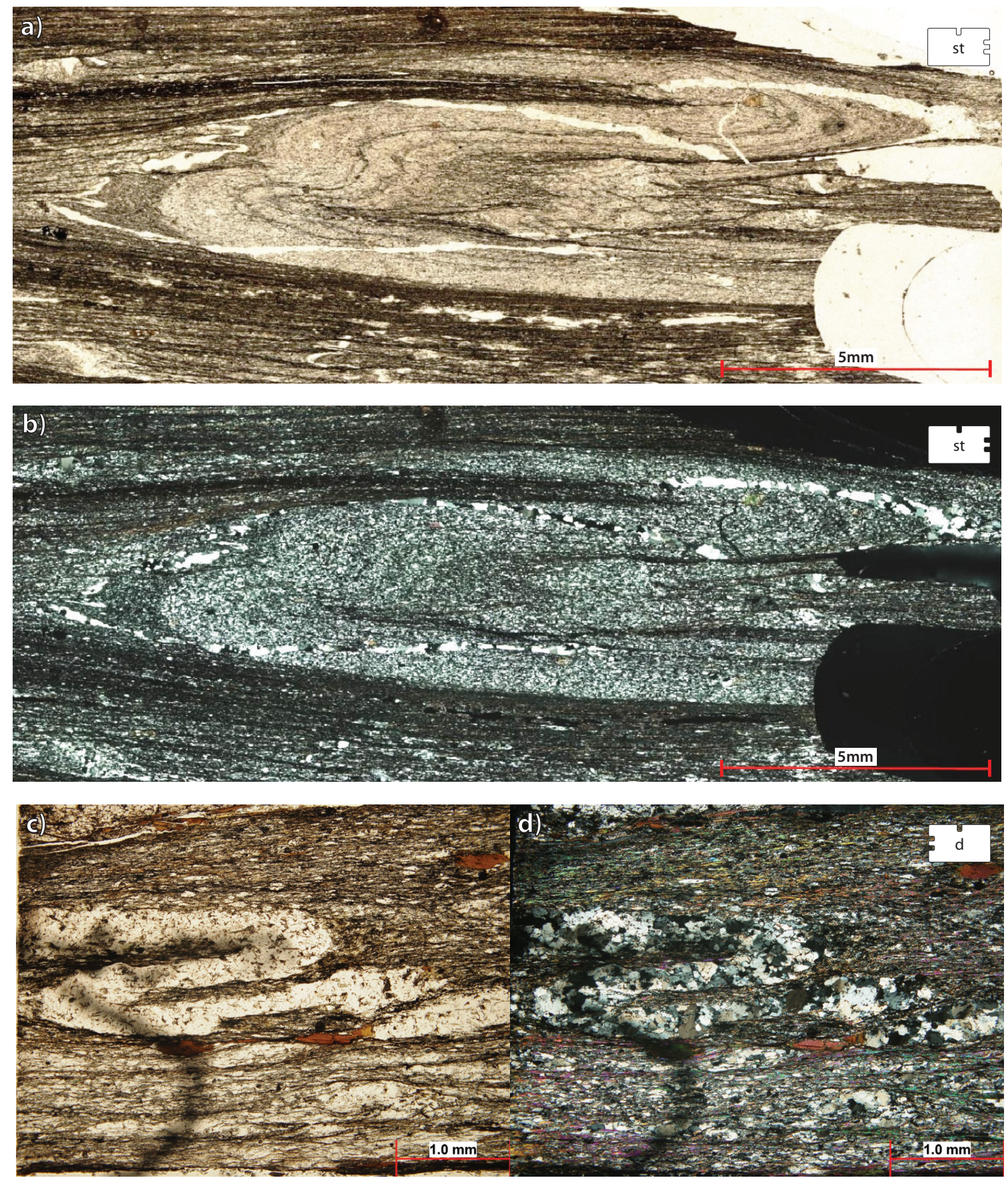

Figure 4.35. Photomicrographs of rare isoclinal intrafolial folds in Alpine Schist that represent a pre-dominant foliation. Note hinglelines of the isoclinal folds are parallel to the dominant foliaiton. a) \& b) PPL \& CPL of a discontinuous, interlobate quartz layer. Note the thin quartz vein within the quartz layer which has also been folded and consequentially disected into discontinuous segments. DMNR-58st, c) \& d) PPL \& CPL of a thin quartz layer/vein. DMNR-75d. 


\section{Crenulation}

Some samples $(\sim 7 \%)$ show crenulation of the dominant foliation. In low grade samples crenulations are typically weak $(<100 \mu \mathrm{m}$ amplitude) and are isolated to phyllosilicate layers, whilst in higher grade rocks both quartzofeldspathic and phyllosilicate layers are highly crenulated ( $500 \mu \mathrm{m}$ amplitude) (Figs. $4.36 \& 4.37$ ). One oriented sample in the SE section has a crenulation seen in both st and doriented thin sections. The axial plane of the crenulation is calculated by converting the pitch of the crenulation axial trace of both st and d-oriented thin sections into trends and plunges and calculating the plane on which two axial traces lie. The orientation of the axial plane of crenulations in sample DMNR-54 is 012/SE/46, comparable to the mean orientation of southeast dipping schist in the SE section (017/SE/52 - see chapter three), implying the dominant foliation may be a crenulation fabric.

\subsubsection{Porphyroblast Microstructure}

Inclusion trails are present in biotite, ilmenite, chlorite, titanite and garnet porphyroblasts, in a variety of orientations with respect to the exterior foliation. The majority of inclusion trails are straight, but differ in orientation with respect to the exterior foliation between different samples and within individual thin sections (Figs. 4.38a \& b). Occasional porphyroblasts have curved inclusion trials that are continuous to the exterior foliation (Fig. 4.39). The exterior foliation symmetrically wraps most porphyroblasts, which often have weakly developed asymmetric strain shadows (not exceeding the original porphyroblast diameter in length). Domino-type fragmented porphyroblasts of biotite and chlorite are common in the SE section but seldom contain inclusion trails traceable to the exterior foliation (Fig. 4.40).

The apparent rotation of porphyroblasts (with respect to the orientation of the exterior foliation) can in many cases be explained by apparent rigid-body rotation of inequant porphyroblasts postgrowth, where coaxial strain (pure shear) is a significant contributor to the amount of total deformation in the rock. The original aspect ratio of the mineral and the amount and nature of deformation are both controls on the final orientation of the porphyroblast (Figs. 4.38e \& f).

\subsubsection{SC'-Type Shear Bands}

Evidence for non-coaxial strain (and the sense of simple shear), is seldom present in rocks from the Newton Range, with the best indicators being weakly developed SC'-type shear bands. The majority 

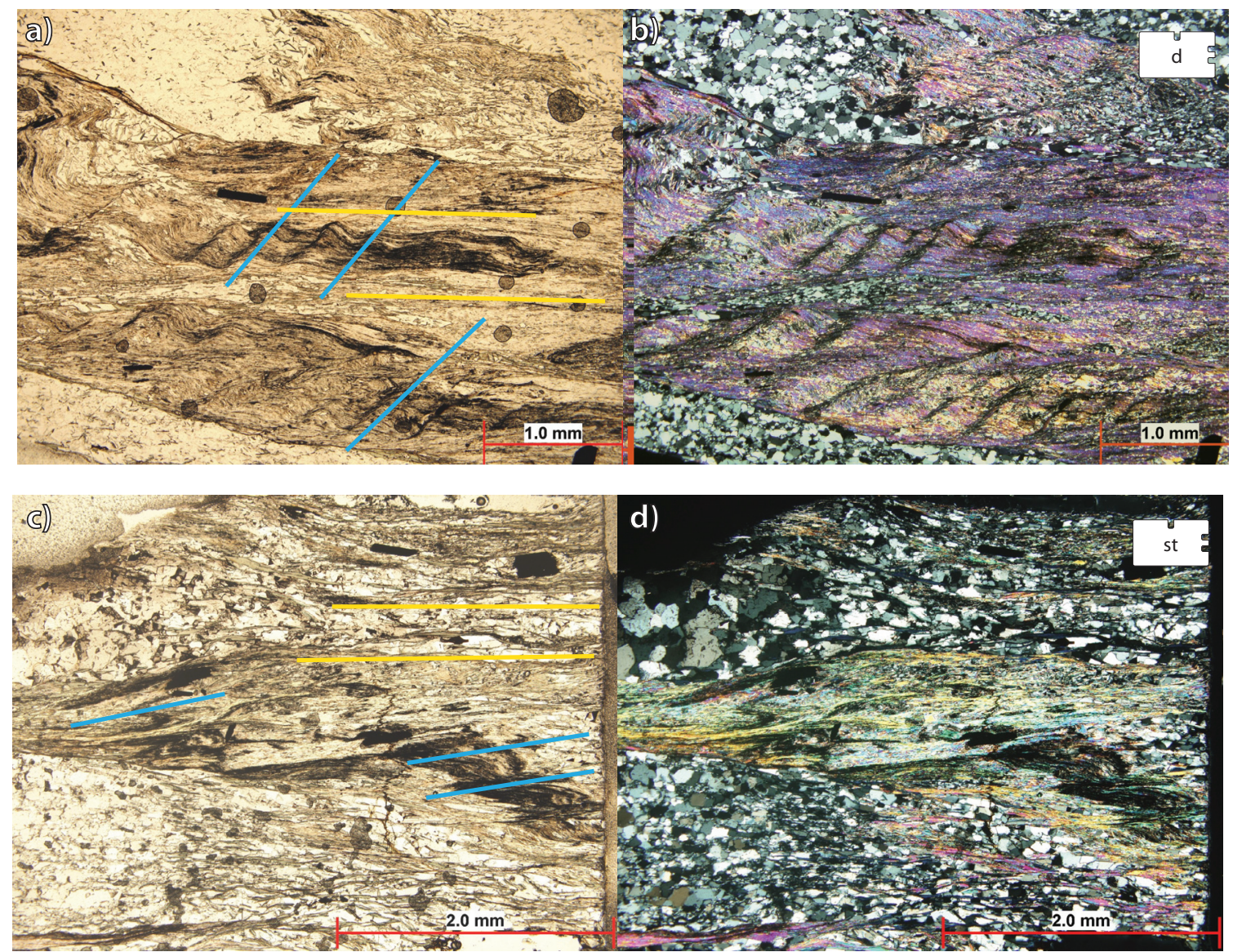

Figure 4.36. Photomicrographs of a weak crenulation foliation seen in different orientations of the same sample of low grade Alpine Schist. a) \& b) PPL \& CPL showing crenulation axial trace (blue) at a moderate angle to the dominant foliation (yellow). DMNR-54d. c) \& d) PPL \& CPL showing crenulation axial trace near parallel to the dominant foliaiton. DMNR-54st.

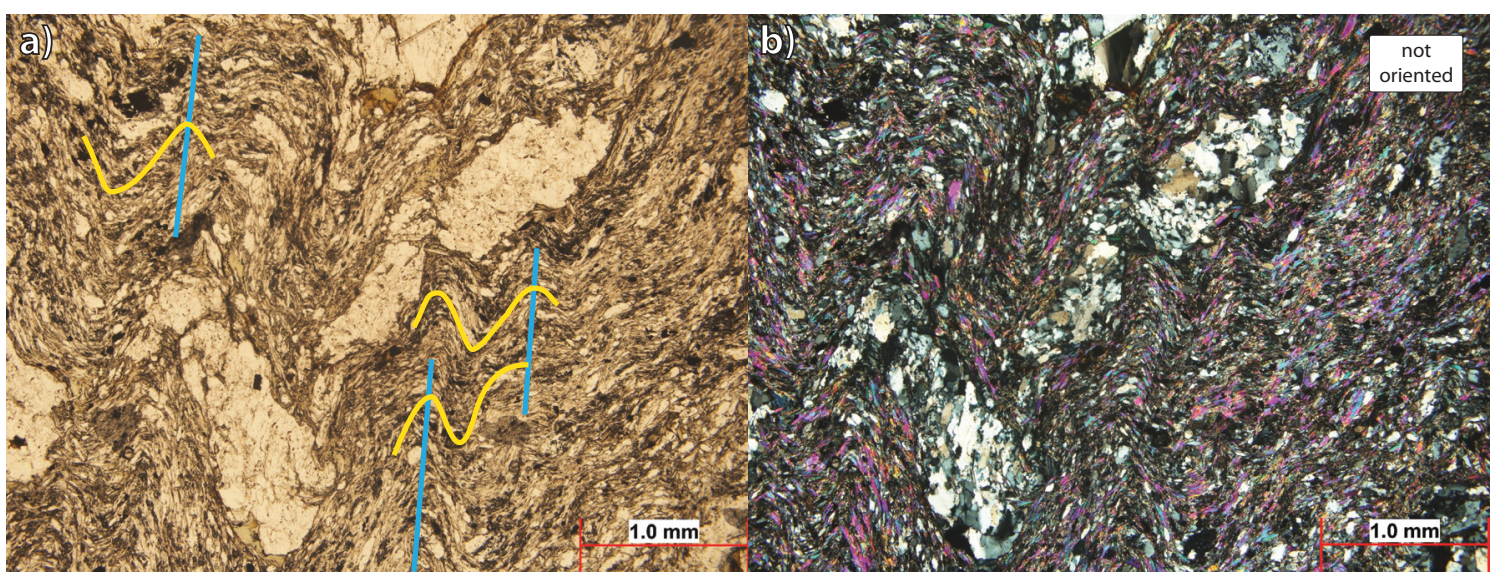

Figure 4.37. e) \& f) PPL \& CPL photomicrographs of a strong crenulation foliation in high grade greyschist. Yellow and blue lines represent the folded foliation and axial trace of the crenulation respectively. DMNR-103c. 

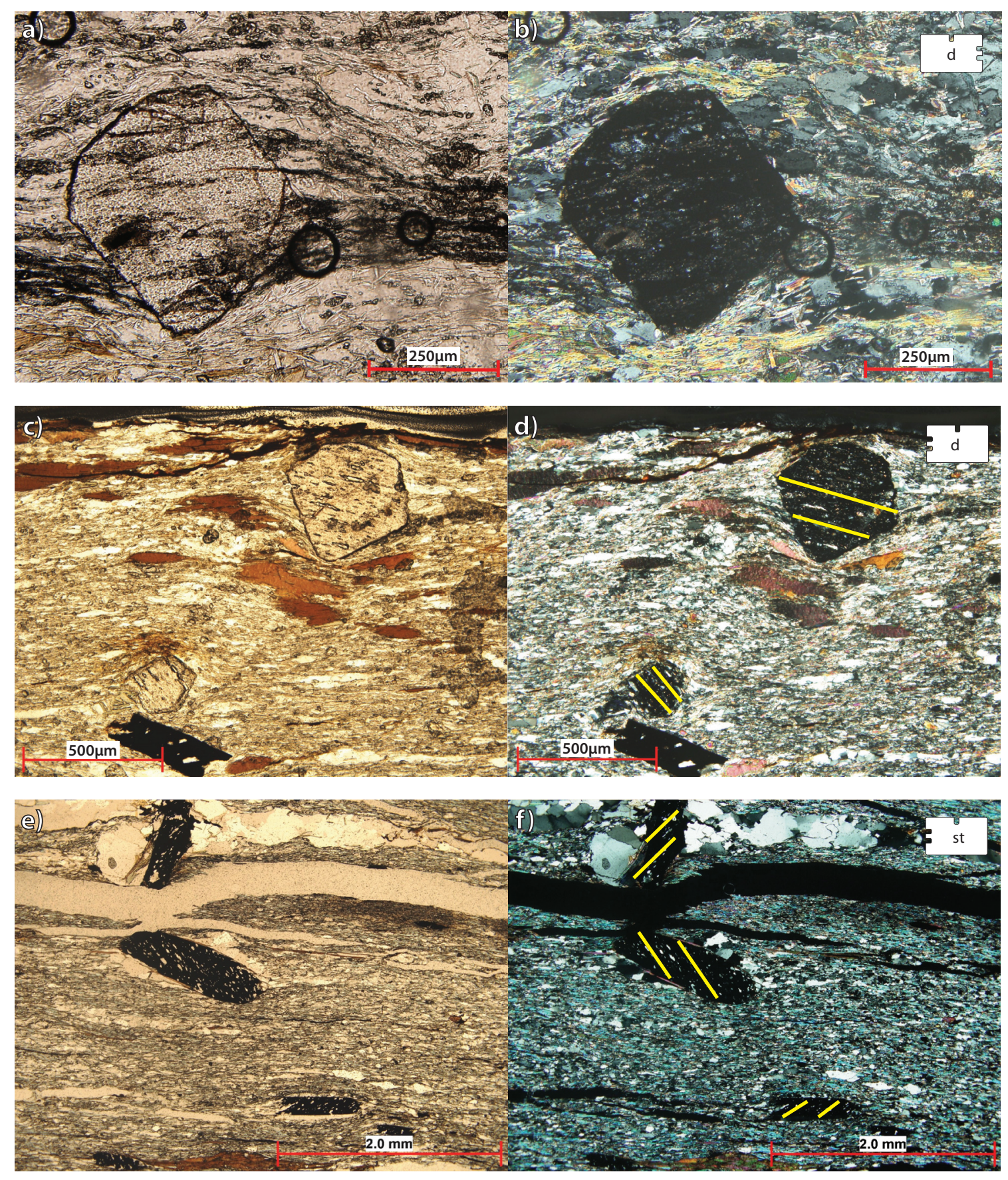

Figure 4.38. PPL \& CPL photomicrographs showing the different orientations of straight inclusion trails (yellow lines) with respect to the dominaint foliation. a) \& b) straight trails parallel to and continuous with the exterior foliation in garnet. DMNR-34d. c) \& d) straight trails in garnet with varying angles to the exterior foliation. DMNR-51d. e) \& f) straight trails in ilmenite with varying orientations of inclusion trails and the porphyroblast long axis with repect to the exterior foliation. DMNR-70st. 


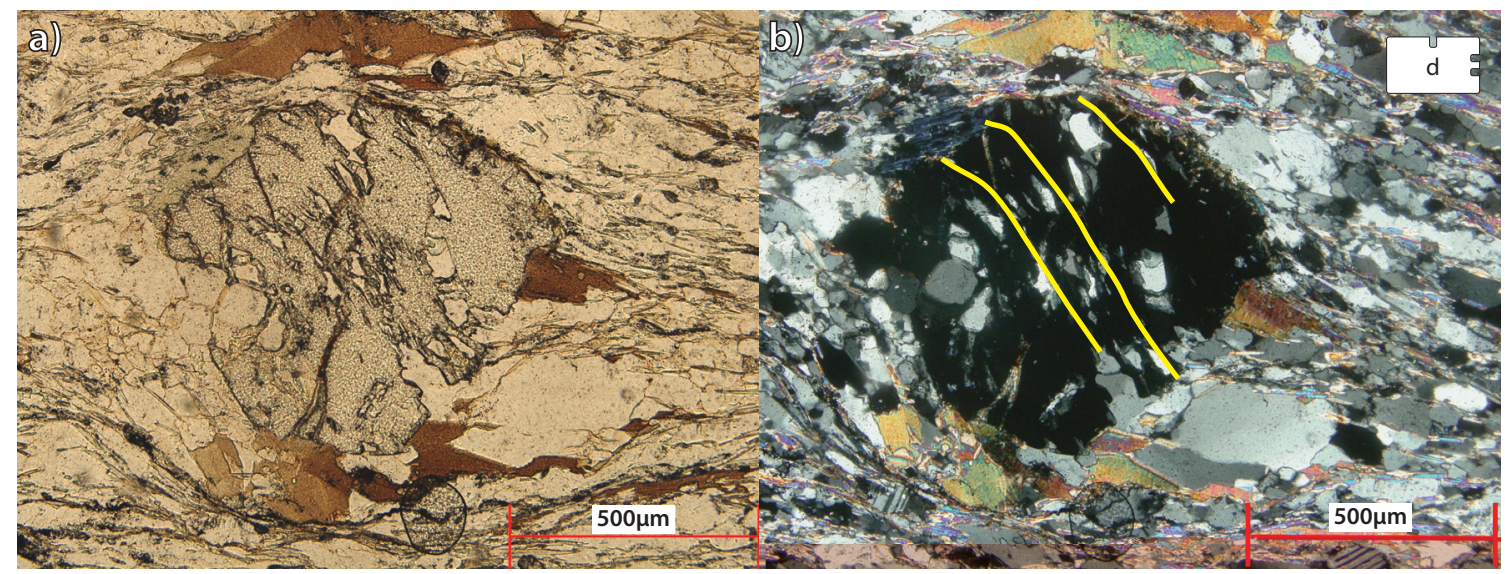

Figure 4.39. a) \& b) PPL \& CPL photomicrographs of curved trails in garnet (yellow lines) traceable into the exterior foliation. DMNR-67d.

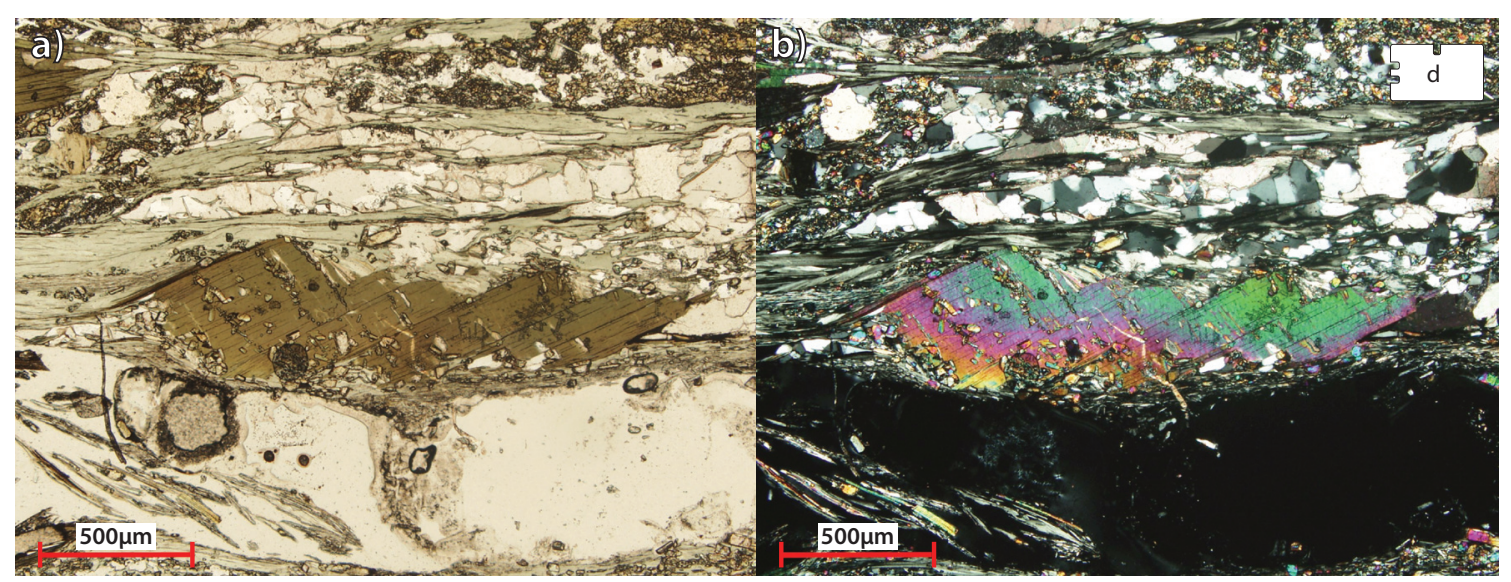

Figure 4.40. a) \& b) PPL \& CPL photomicrographs of a biotite porphyroblast with domino-type fragmentation. DMNR-24d. 
of these shear bands occur in the NW section of the study area. In samples in the SE section where a sense of shear is obtainable, there is not a recognisable pattern between shear sense, dip direction nor proximity to the Alpine Fault.

Weakly developed SC'-type shear bands are present in 13 samples in the NW section, and 3 in the SE section (Fig. $4.41 \&$ appendix A.2.2). These bands are only observable in thin section, the orientations of which may be calculated in the following manner, when observed in both st and dorientated thin sections. See figure 4.43 for a schematic representation.

The pitch of the C' band is taken off an oriented thin section and converted into trend and plunge. The plane that contains the C' lineations from both the st and d-oriented thin sections is the C' shear band. As the S plane is inferred to be parallel to the shear zone boundary in SC'-type shear bands, a bulk shear direction is represented by the line perpendicular to the intersection of the $C^{\prime}$ and $\mathrm{S}$ planes. This is calculated as the line pitching $90^{\circ}$ northward along the $\mathrm{S}$ plane. Such a method for bulk shear calculation is typically used for mylonites and proto-mylonites (e.g. Little, et al., 2002b) where the S plane is subparallel to the shear zone boundary. So for non-mylonitic samples from the Newton Range this method is imperfect, as the shear zone boundary (S) is not perfectly represented by the foliation orientation. The calculated slip directions are therefore a best guess only. Calculations are completed using the software GeoCalculator v4.9.2 (Holcombe, 2009).

SC'-type shear band orientations generally strike $\sim \mathrm{E}-\mathrm{W}$ and dip $\sim 40-50^{\circ} \mathrm{S}$. Bulk shear directions are to the east-northeast with a mean slip direction of $063^{\circ}$ (Fig. 4.42). This is $13^{\circ}$ anticlockwise of the $<5.9 \mathrm{Ma}$ plate motion vector $\left(076^{\circ}\right)$, calculated for the Newton Range using the <5.9Ma PAC-AUS (Pacific \& Australian tectonic plates) finite rotation parameter from Walcott (1998).

\subsubsection{Quartz Veins}

Multiple generations of quartz veins occur in schist from the Newton Range. Their relationship is typically sub-parallel to the dominant foliation, but many crosscut the dominant foliation and are asymmetrically folded (see chapter three).

The earliest quartz veins are dismembered by and subsequently folded within isoclinal intrafolial folds (Fig. 4.35). Other generations of quartz veins are oblique in orientation to the dominant foliation and are strongly asymmetrically folded, some of which are overgrown by porphyroblasts (Fig. 4.44). 


\section{Low Grade (SE section)}

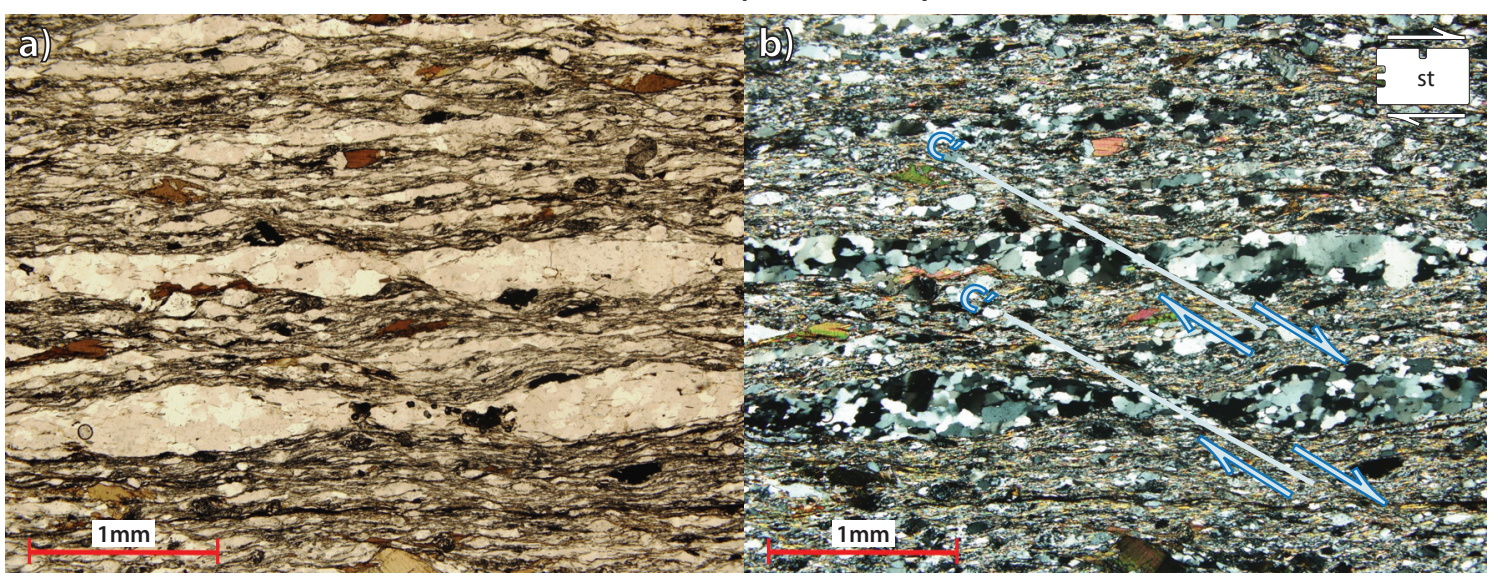

\section{High Grade (NW section)}
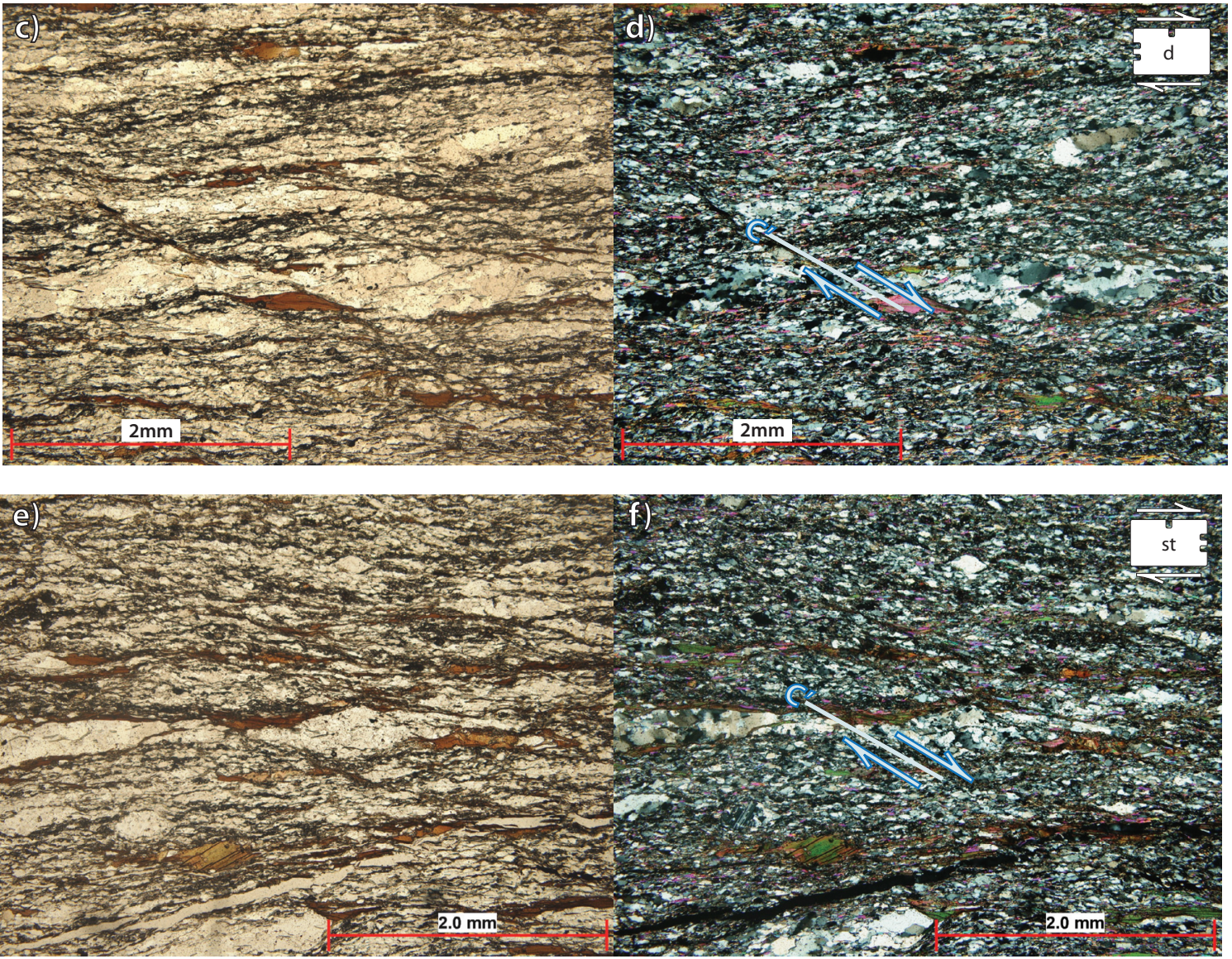

Figure 4.41. PPL \& CPL photomicrographs of SC'-type shear bands. Photomicrographs are taken with the $\mathrm{S}$ plane parallel to the top edge of the photomicrograph. a) \& b) low grade. DMNR-28st. c) - f) high grade (DMNR-86d \& 86st). When SC'-type shear bands are observed in both st and d-oriented thin sections in the same sample, the orientation of the C' plane can be calculated (see text and fig. 4.43). 


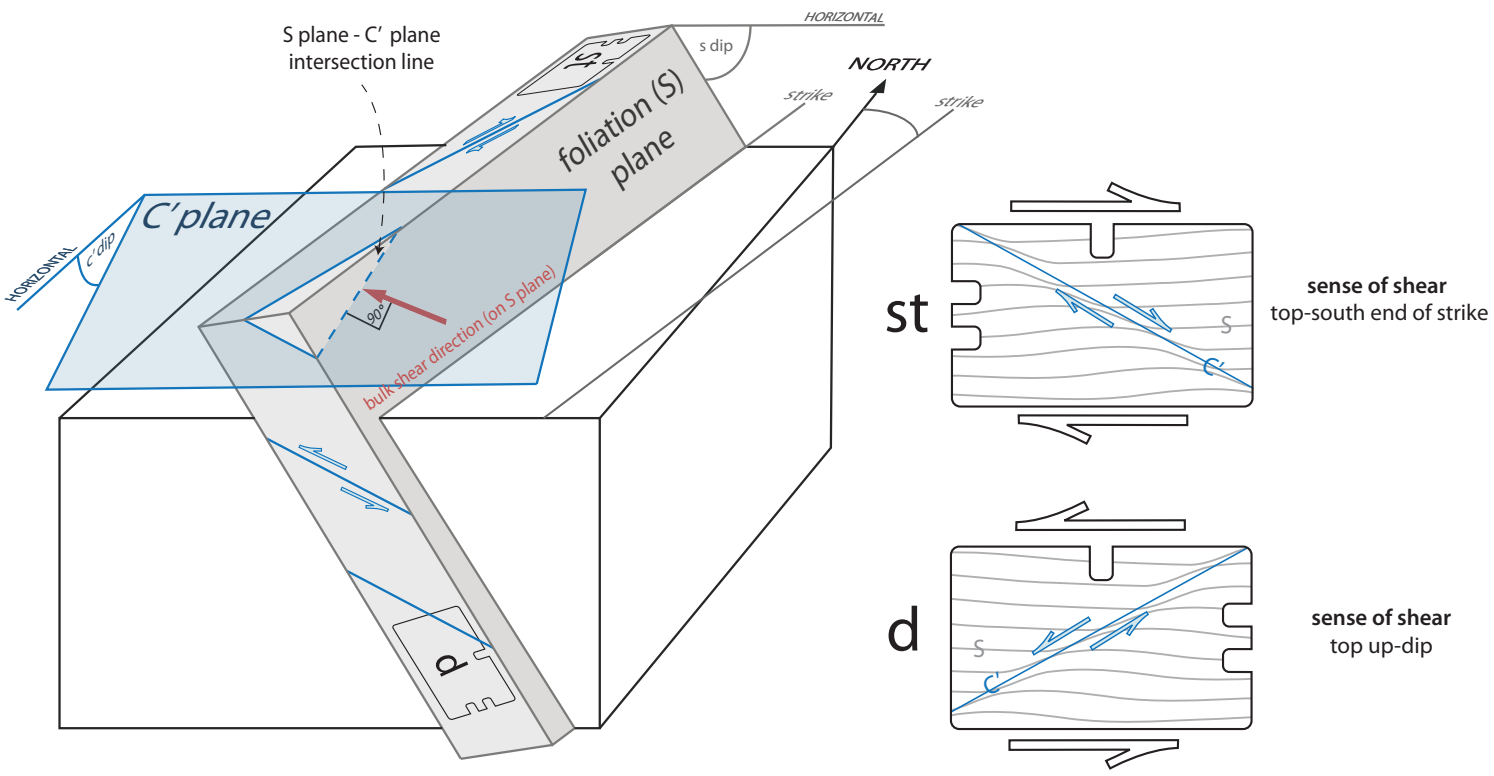

Figure 4.42. Schematic representation of the orientation of SC'-type shear bands and corresponding thin section cuts, with sear sense indicatiors (blue half arrows) for the $C^{6}$ plane. The $S^{\prime}$ plane (shaded blue) contains both the apparent dips of the C' band in st and d-oriented thin sections. The bulk shear direction is calculated as the perpendicular line to the S-C' intersection line (dashed blue) which lies on the S plane. For an explanation of thin section orientation see text and figure 4.2.

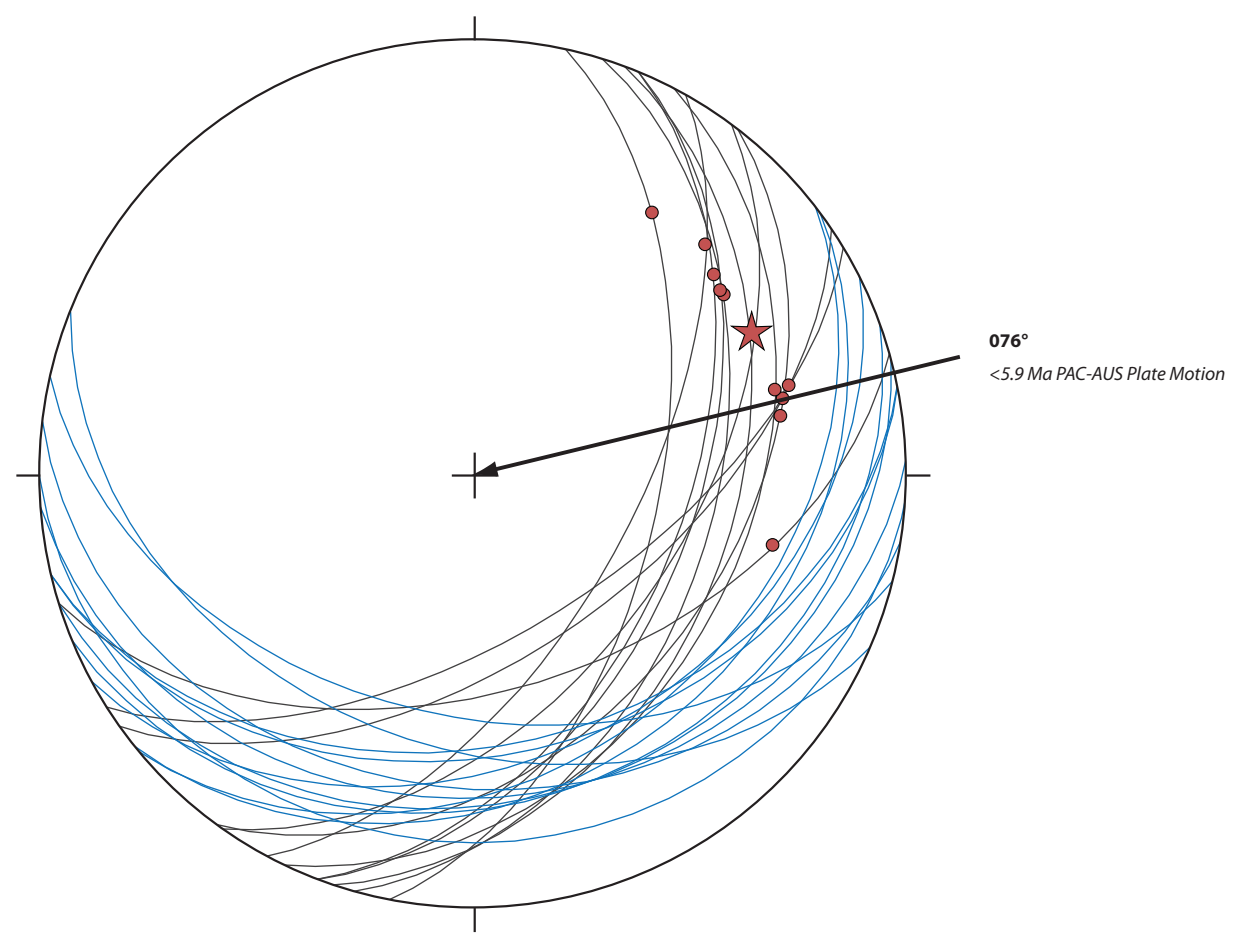

Figure 4.43 Equal-area stereographic projection of C'-type shear bands (blue) and corresponding S (foliation) planes (black). Red filled circles show the bulk shear direction for individual samples. Red star indicates the mean slip direction (063-29, $\mathrm{n}=13)$. The <5.9 Ma PAC-AUS plate motion direction is the finite rotatation parameter from Walcott (1998). 
The most recent quartz veins perpendicularly crosscut the dominant foliation and often have a mixed quartz/chlorite mineralogy (Fig. 4.45). Such veins occur in both the NW and SE sections.

\subsection{Discussion}

\section{Metamorphic Grade}

With increasing proximity to the Alpine Fault there are notable changes in the texture and mineralogy of Alpine Schist from the Newton Range. Phyllosilicate layers become less apparent and the schist is generally more quartzofeldspathic. Muscovite progressively becomes coarser with individual crystals up to $50 \mu \mathrm{m}$ thick apparent in the highest grade samples. Biotite becomes less tabular, finer and more ribbon like, oriented subparallel to the dominant foliation (Fig. 4.8). Quartz becomes more interlobate and seriate, providing evidence of dynamic recrystallization. Ilmenite and chlorite become far less abundant and when present, typically smaller in size. Small pervasive titanite is common, often rimming small, rare ilmenite porphyroblasts. Epidote becomes more common in higher grade samples, primarily occurring as a pervasive microcrystalline phase. The garnet-in isograd is located $\sim 100 \mathrm{~m}$ to the east of the PUB, with the most eastward occurrence of garnet. Garnet size increases slightly with increasing proximity to the Alpine Fault.

These observations show an overall increase in metamorphic grade, consistent with observations of Alpine Schist throughout the Southern Alps (Grapes \& Otsuki, 1983; Grapes \& Watanabe, 1984; Grapes, 1995; Little, et al., 2002a; Williams, 2006). Segregated quartz layers increase in number and thickness with increasing grade (see chapter three) from textural zone TZ2b to TZ4. The progressive increase in muscovite thickness represents a change from TZ2b to TZ4 with the intermediate TZ3 zone encompassing much of the NW section. This zone of TZ3 schist is far more extensive than the zone of TZ3 schist presented in chapter three when only the thickness of segregated quartz layers was used as a TZ proxy. This shows the relationship between segregated quartz layers and white mica thickness is not the same as in other areas of the Haast Schist, where both white mica and segregated quartz layers coincide with textural zones boundaries (see Turnbull, et al., 2001). 


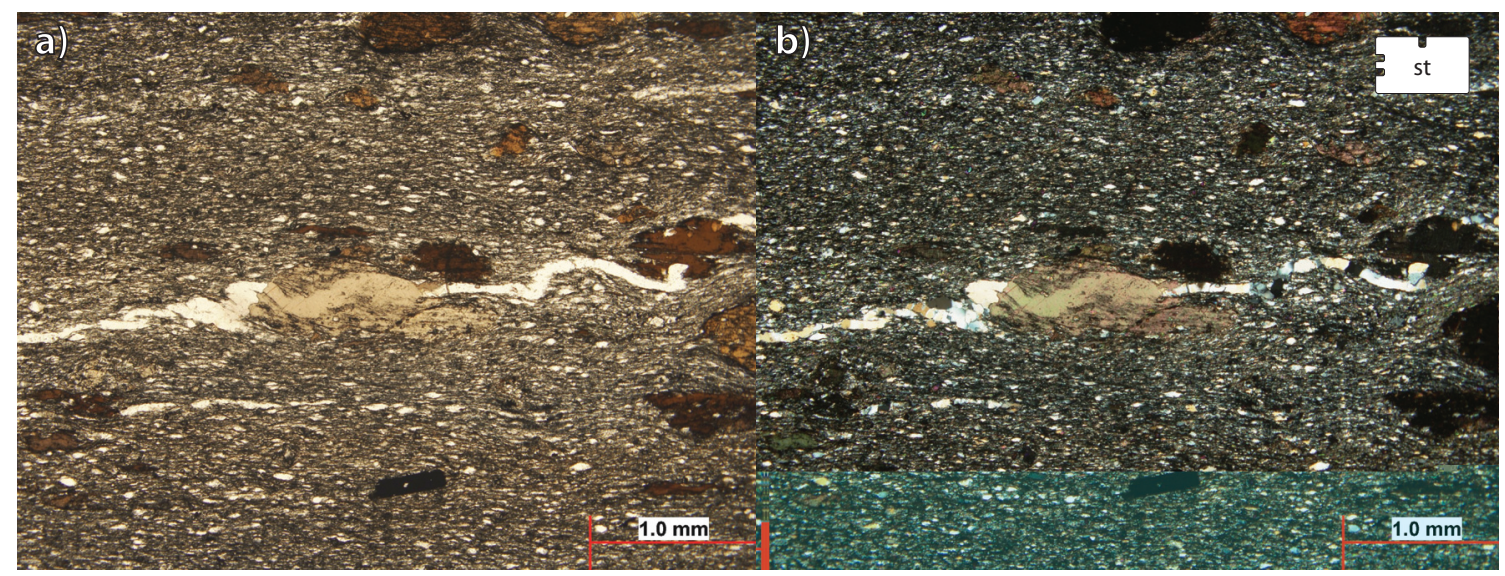

Figure 4.44. a) \& b) PPL \& CPL photomicrographs of an asymmetrically folded crosscutting quartz vein, overgrown by a biotite porphyroblast. The folded inclusion train pattern suggests biotite growth took place after folding of the vein. DMNR-63st.
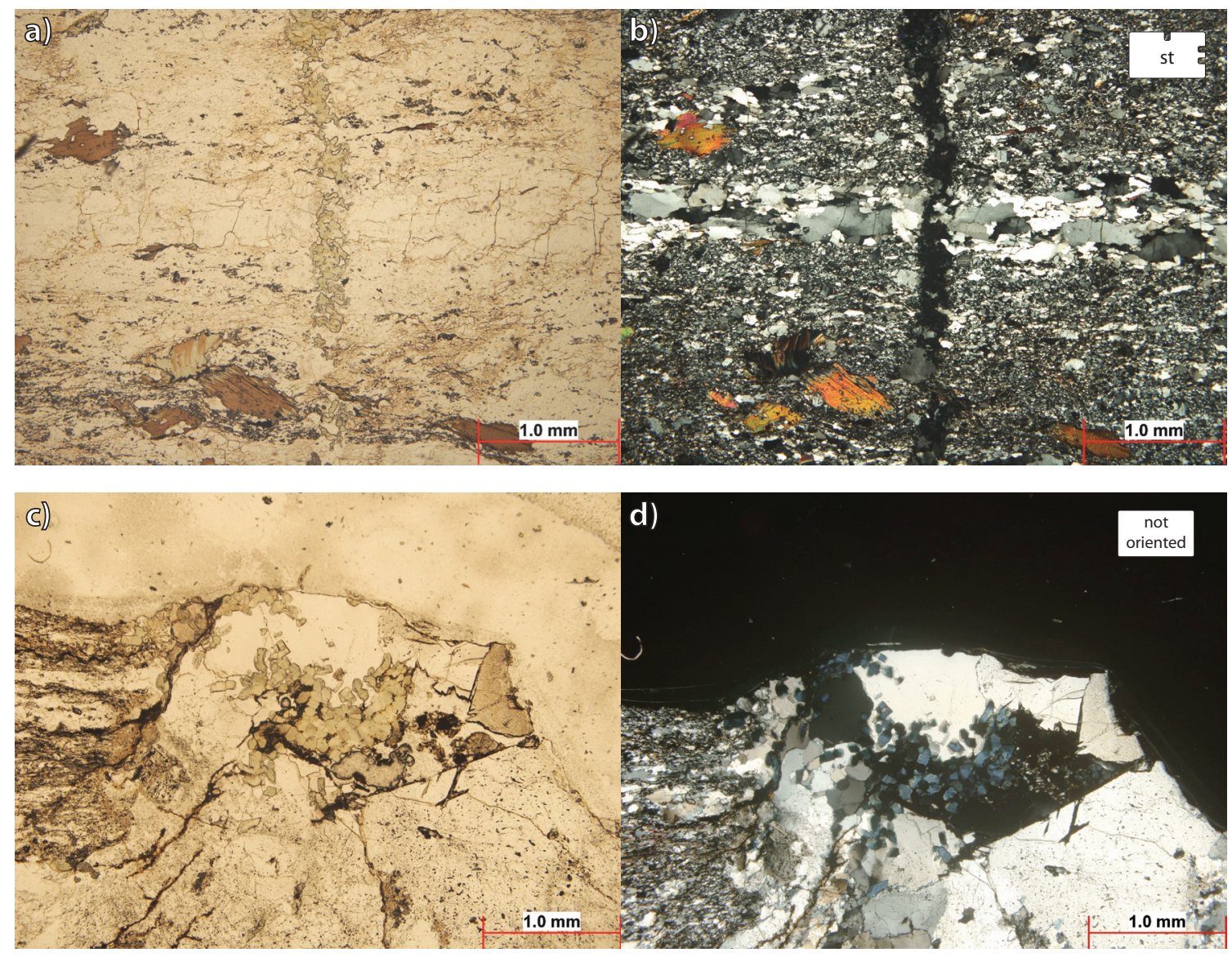

Figure 4.45. PPL \& CPL photomicrographs of mixed quartz/chlorite veins perpendicularly crosscutting the dominant foliaton. a) \& b) low grade. DMNR-48. c) \& d) high grade. DMNR-88d. 


\section{Foliation Development}

A sequence of deformation events (D1, D2, D3, Dm) and corresponding structural fabrics (S1, S2, S3, Sm) has been well developed for Alpine Schist in the Franz Josef-Fox Glacier region (Little, et al., 2002a; Little, et al., 2002b). These fabrics have been defined in chapter three (section 3.4.3), and in the following section, the different foliations recognised in the Newton Range are related to the fabrics described by Little, et al. (2002a; 2002b).

Isolated lenticular boudins and dismembered layers of fine equigranular quartz in low grade samples are inferred to represent relict sedimentary bedding (S0), possibly first reinforced by a metamorphic event (D1), which have later been isoclinally folded by subsequent metamorphic events (D2 \& D3). The relict bedding would have been oriented at a high angle to the direction of subsequent compression, to enable such tight folding of the equigranular quartz layers.

The dominant foliation is for the most part planar, with only $\sim 7 \%$ of samples having a crenulation foliation. The crenulation suggests the overprinting of a younger foliation, possibly analogous to the crenulation of S2 by S3 in the Franz Josef-Fox Glacier region, explained in depth in chapter three (Little, et al., 2002a; Little, et al., 2002b). If the dominant foliation has been created by two major deformation events (D2 \& D3), the lack of a crenulation fabric in the majority of samples suggests that in non-crenulated schist, the dominant foliation is the product of the younger event (D3) reinforcing (rather than obliquely overprinting) the older fabric (S2). The dominance of a reinforced planar fabric in most schist samples in the Newton Range may represent a northern equivalent of the main planar zone in Alpine Schist from the Franz Josef-Fox Glacier region.

\section{Porphyroblast Growth}

The orientation of inclusion trails are a function of the orientation and nature of the foliation the porphyroblasts overgrew, and the subsequent deformation/reorientation of the exterior foliation and/or porphyroblast. Straight inclusion trails traceable into the exterior foliation signify porphyroblast growth after the development of the dominant foliation. As a planar foliation is inferred to represent S2 reinforced by S3, the relative timing of the growth of such porphyroblasts can either be attributed to late D2, or early D3, where in either case the porphyroblast has overgrown the previously developed S2 foliation. Minerals with this relationship to the exterior foliation include ilmenite, biotite, chlorite, garnet and titanite and signifies all of these minerals, for at least part of their growth history, grew during the dominant porphyroblast growth event. 
When trails are curved, and traceable into the exterior foliation, it is possible that porphyroblasts overgrew a weakly crenulated or actively deforming fabric. This suggests these porphyroblasts grew during early D3. The lack of crenulations in the surrounding matrix is a possible result of post-D3 flattening in the late Cenozoic. There is seldom evidence for curved inclusion trails, but this could easily be attributed to the limited orientation of thin section cuts, as the three-dimensional nature of curved trails will appear straight in some thin section orientations.

As non-mylonitic Alpine Schist has a large component of pure shear and has a poly-deformational history, interpretations regarding the relative contribution and sense of simple shear in the Newton Range are uncertain at best. The relative rotation of porphyroblasts with inclusion trails cannot be explained by simple shear alone as flattening of the exterior foliation and rigid-body rotation of preoriented inequant porphyroblasts play an important role in the angle of inclusion trails to the surrounding fabric.

For porphyroblasts with inclusion trails at a high angle to the exterior foliation two basic endmembers may explain their current orientation with respect to the exterior foliation. One option is that growth during an earlier metamorphic event (prior to formation of the dominant foliation) has preserved an early foliation no longer present in the surrounding matrix. Subsequent overprinting by a new fabric at a different orientation to the early foliation preserves the trails at a high angle to the current exterior foliation, assuming the porphyroblasts have not rotated (e.g. Bell, 1985). The opposite interpretation of high-angle trails would be that porphyroblasts have overgrown the current exterior foliation, but have since been rotated to different angles (with respect to the exterior foliation) without rotation of the exterior fabric.

In reality, nether of these options does not fully explain the inherent complexities surrounding the relative deformation of both the exterior fabric and the porphyroblasts (i.e. the original orientation of fabric and the reference point of which porphyroblast and/or fabric rotation is relative to). Explanations regarding the relative contributions of coaxial and non-coaxial strain in the rotation of porphyroblasts are complex (i.e. Holcombe \& Little, 2001), and without multiple cuts of the threedimensional inclusion trails (only st and d orientations were cut in this study), and a limited structural dataset, in depth analysis is beyond the scope of this study. 


\section{Post Dominant Foliation Deformation}

Crack fill textures show that growth of low grade metamorphic minerals (biotite and chlorite) has occurred synchronous with layer parallel extension, possibly in the late Cenozoic metamorphic event, associated with the formation of Alpine Fault mylonite and uplift of the Southern Alps. Some samples contain mixed quartz/chlorite veins perpendicularly crosscutting the dominant foliation. This suggests fluid flow during the late Cenozoic and/or decompression history of the rocks was at high enough P-T conditions for chlorite to form.

Weakly developed SC'-type shear bands are a possible eastward extension of a distal mylonite zone into non-mylonitic Alpine Schist. Shearing is most probably related to the late Cenozoic metamorphic event and shows a top-west-southwest sense (dextral-reverse), analogous to shear fabrics in other parts of the Southern Alps proximal to the Alpine Fault (Little, et al., 2002a; Little, et al., 2002b). As no mylonitic samples could be collected in the study area, the extent of SC'-type shear bands, and relationship to the mylonite zone as seen in the Franz Josef-Fox Glacier region is unknown. SC'-type shear bands are also present in the SE section of the study area, where they are isolated to a few samples immediately west of the PUB. As there is a lack of SC'-type shear bands in schist from the SE section not adjacent to the PUB, a possibility is that the differing rheology of the adjacent PUB pod may act as a relatively rigid indentor during deformation, effectively forcing deformation of the surrounding schist (see chapter three, section 3.4.4). This hypothesis is highly speculative and clearly more in-depth structural analysis of the PUB and surrounding schist is needed to gain further insights regarding the role of the PUB during deformation.

The SC'-type shear bands observed in the NW section of the Newton Range could be of interest in future studies regarding the westward extent of the distal mylonite zone and the relative roles of simple and pure shear during the late Cenozoic metamorphic event. The angle of C' bands relative to the shear zone boundary $(\mathrm{S})$ is a product of the relative proportion of coaxial and non-coaxial strain, and are progressively rotated (flattened) towards $\mathrm{S}$ with increasing proportions on noncoaxial strain (Kurz \& Northrup, 2008) (i.e. increasing proximity to the Alpine Fault and associated mylonite zone). Hence the C' shear bands occurring in rocks on the eastern most margin of the Alpine Fault shear zone may be important with regards to the initial inception angle of the SC'-type shear bands, and the associated roles of pure and simple shear during the late Cenozoic metamorphic event.

Such a study would require a transect of samples to be collected towards the mylonite zone (unable to be collected from the ridge tops and flanking slopes in this study). Possible locations of which 
might outcrop in the streams draining the NW section, which also cross the Alpine Fault, i.e. Mt Brown Creek. The shear zone boundary would also need to be adequately defined (currently only foliation orientation is used) so that C' - S angles could be accurately calculated. Such study would require a much larger sample suite and hence is beyond the scope of this current study.

\subsection{Conclusion}

Petrographic observations show an increase in metamorphic grade with increasing proximity to the Alpine Fault from TZ2b biotite grade schist in the most eastward samples to TZ4 garnet grade schist in the most westward samples. The zone of TZ3 schist calculated from muscovite thicknesses is far more extensive when calculated using segregated quartz layer thickness as a TZ proxy. SC'type shear bands are present in many samples in the NW section showing a top to the westsouthwest bulk shear direction. Foliation development is comparable to the well studied fabrics of the Franz-Josef Fox Glacier region where multiple deformation events and corresponding fabrics are observed (S0/S1, S2 \& S3). The Alpine Schist in the Newton Range is analogous to the main planar zone of the Franz Josef-Fox Glacier region where S2 has a steep planar pre-orientation, later reinforced during D3 by S3. Sporadic crenulation fabrics suggest possible oblique overprinting of S2 by $\mathrm{S} 3$ in some samples. 
Chapter Five

\section{WHOLE-ROCK GEOCHEMISTRY \&}

TERRANE AFFINITY

\subsection{Introduction}

This chapter presents whole-rock XRF ( $\mathrm{x}$-ray fluorescence) major element oxide and trace element data for ten greyschist and four greenschist samples from the Newton Range. The full geochemistry results are then used to identify the sedimentary protolith and terrane affinity of greyschist, and to provide insights into the origins of greenschist.

The major element compositions of individual greyschist samples are also essential input data for calculating P-T (pressure-temperature) pseudosection diagrams using the computer program THERMOCALC (chapter seven). The results of the P-T pseudosection calculations include calculated mineral composition data that is used in combination with measured garnet compositions to extract a detailed interpretation of the metamorphic $P$-T path followed by the sample. The whole-rock XRF data presented in this chapter is thus fundamental for interpreting the assembly and the complex metamorphic history of the Newton Range.

\subsection{Haast Schist Protolith Terranes}

The basement rocks of New Zealand are comprised of several sedimentary protolith terranes (Adams, et al., 1998, Adams, et al., 2007, Bishop, et al., 1985, MacKinnon, 1983, and references therein) (Fig. 5.1). Each of these terranes have separate sedimentary sources, depositional environments and correspondingly different geochemical signatures. The Haast Schist belt in the South Island contains the metamorphosed equivalents of three of these: the Torlesse, Caples and Waipapa terranes (Fig. 5.2) (Coombs, et al., 2000, Mortimer, 1993b, Mortimer, 2000, New Zealand 


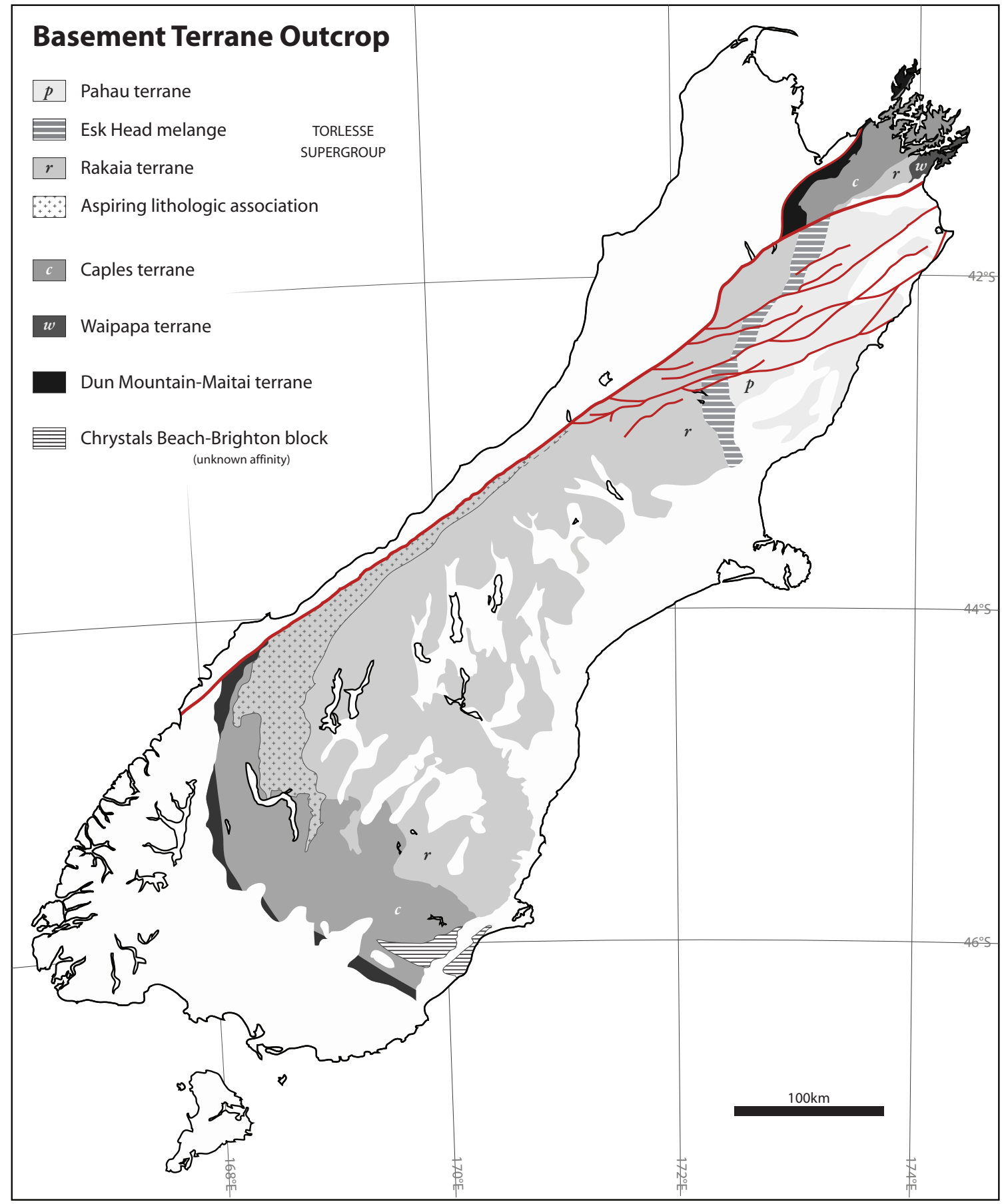

Figure 5.1. Map of the South Island, New Zealand showing some of New Zealand's basement terranes. Data is from N.Z. Geological Survey Map (1972), Adams et al., (2007), Mortimer (1993), Mortimer (2000), Bierlein \& Craw (2009) and Coombs et al., (2000). The northern extent of the Aspiring lithologic association is inferred. 
Geological Survey, 1972). The Waipapa terrane is only observed in the eastern-most Marlborough Schist and hence is not further discussed in this chapter. The Haast Schist also contains another sub-terrane: the Aspiring terrane or Aspiring lithologic association (Craw, 1984, Mortimer, 1993b, Norris \& Craw, 1987). For the purpose of clarity in this chapter the name Aspiring lithologic association is used, as defined by geochemical analyses in Mortimer \& Roser (1992). The geochemistry of New Zealand basement terranes not part of the Haast Schist have also been extensively studied (e.g. Roser \& Coombs, 2005, Roser, et al., 2002) and are only referred to in this chapter when describing fields of previously developed multi-element discrimination plots.

Schist in the Newton Range increases in metamorphic grade westward from Torlesse terrane sediments at the main divide to mylonite adjacent to the Alpine Fault. The Pounamu Ultramafic Belt (PUB) lies in the middle of this grading sequence in TZ2b schist, and as the PUB has in some cases been inferred to represent the basement of the Torlesse terrane (Ireland, et al., 1984, Reay \& Cooper, 1984), this poses the question: if the PUB is the basement to the Torlesse terrane and Torlesse terrane sediments are located to the west, what terrane are the schists east of the PUB sourced from? This chapter will focus on the differentiation between the Torlesse terrane, Caples terrane, and the Aspiring lithologic association through the analysis of major element oxides and immobile trace element concentrations.

\section{Torlesse Terrane}

The Torlesse terrane is interpreted to represent an accretionary prism complex consisting of marginal marine/submarine turbidite facies rocks that were deposited in a trench/slope or borderland basin setting from Permian to early Cretaceous time (Adams \& Graham, 1996, Barnes \& Korsch, 1990, Bradshaw, et al., 1981, MacKinnon \& Howell, 1984, MacKinnon, 1983). The rocks of the Torlesse terrane consist almost entirely of a mix of sand and interbedded muds, with minor amounts of mafic material and other rare rock types including ferruginous chert and limestone, which are evidence for some periodic distal volcanogenic/marine sediment input (MacKinnon, 1983). The Torlesse is broadly divided into the Rakaia terrane and the later-deposited Pahau terrane; these are separated by the tectonic slices and belts of broken formation that make up the Esk Head melange (Adams \& Graham, 1996, MacKinnon, 1983).

The Torlesse sediments were sourced from a predominantly felsic, continental volcano-plutonic part of the evolving Gondwana supercontinent (MacKinnon, 1983, Mortimer \& Roser, 1992, Roser \& Cooper, 1990, Roser \& Korsch, 1988). A sediment source in the present New England fold belt of 


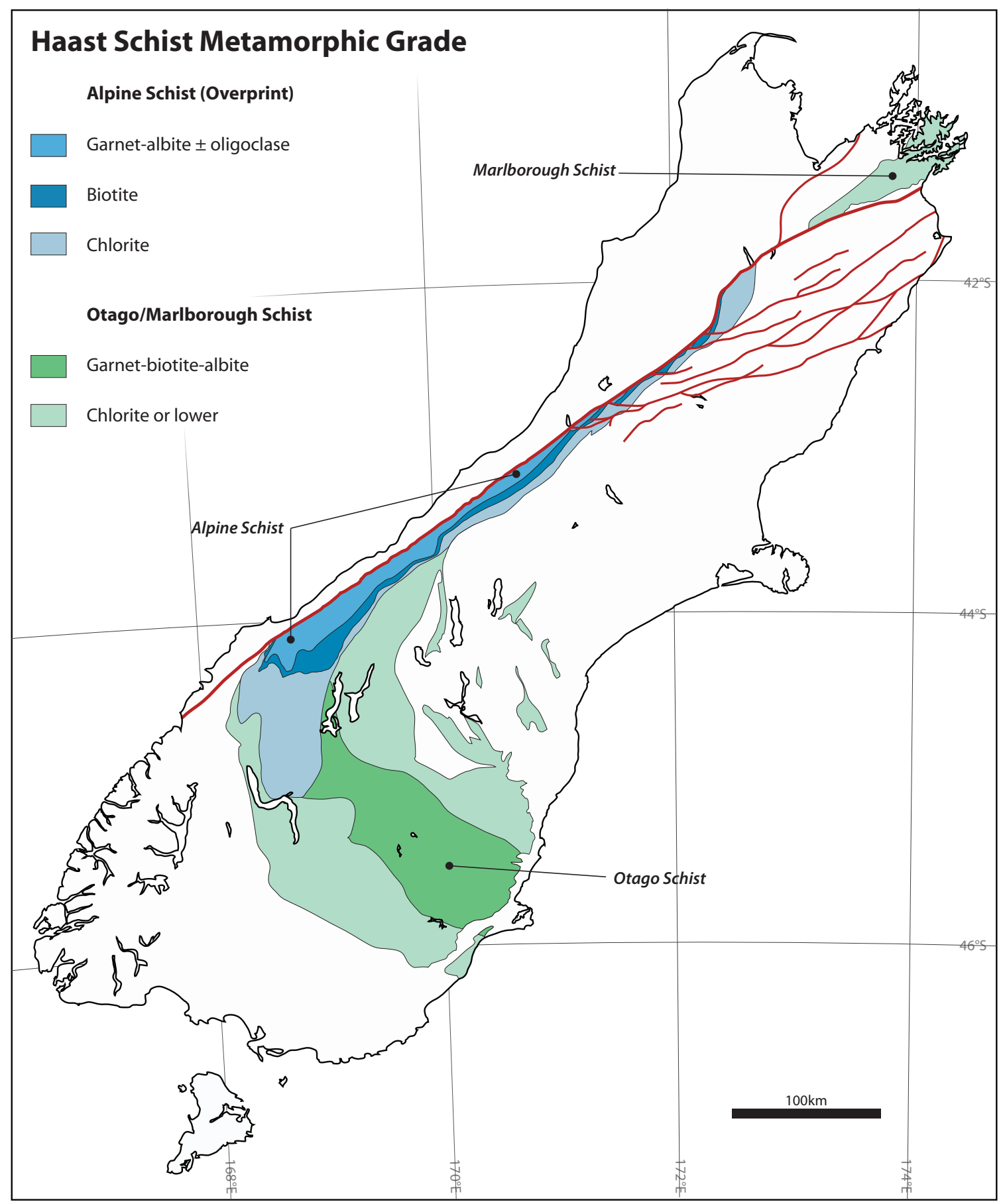

Figure 5.2. Map of the Haast Schist showing metamorphic grade and divisions of the Alpine, Otago and Marlborough Schists. Data is from N.Z. Geological Survey Map (1972), Mortimer (1993), Mortimer (2000) and Coombs et al., (2000) 
southeast Queensland has been suggested on the basis of Triassic zircon populations (Adams, et al., 2007, Korsch \& Wellman, 1988, Wysoczanski, et al., 1997). An Antarctica source has also been suggested, with igneous clast compositions in Rakaia sub-terrane sediments consistent with Permian to Triassic plutons and volcanics from the Amundsen and Ross provinces of Marie Byrd Land (Wandres, et al., 2004).

The closest age estimate of un-metamorphosed Torlesse sediments proximal to the Newton Range is late Triassic from Torlessia mackayi tube fossils found in greywacke from the Harman-Styx track, $>10 \mathrm{~km}$ to the east-southeast (Campbell \& Warren, 1965, MacKinnon, 1983). Geographically the study area lies in the older Torlesse (Rakaia terrane) with the Esk Head melange and Pahau terrane rocks outcropping far from the study area.

\section{Caples Terrane}

The Caples terrane has a volcanogenic, distal arc provenance, and is dominated by volcanic/volcaniclastic submarine fan deposits, with more basalt, chert and limestone than the Torlesse terrane (Roser, et al., 1993, Turnbull, 1979). The Caples terrane was sourced from an actively evolving calc-alkaline arc system, with compositions grouping in fields of intermediate igneous rocks, but do range in composition from dacitic to basaltic (Roser \& Korsch, 1988, Roser, et al., 1993).

\section{Aspiring Lithologic Association}

The Aspiring lithologic association outcrops as a discontinuous band along the boundary of the Torlesse and Caples terranes in the Haast Schist of northwest Otago/south Westland. The Aspiring lithologic association disappears in central Otago near Cromwell (Fig. 5.1) (Craw, 1984, Grapes, 1999, Mortimer, 2000, Norris \& Craw, 1987), where the Caples/Torlesse contact continues as a sinuous, sharp, tectonically bound contact, defined by Mortimer \& Roser (1992) by means of multielement discriminant plots.

The Aspiring lithologic association may represent a part of the Torlesse terrane that received a more distal oceanic component of sediment than the more typical trench/slope/borderland basin sediments. The Aspiring lithologic association contains both volcanogenic and continental derived sediments but is primarily comprised of relatively pelitic greyschist. The Aspiring lithologic 
association is distinguished from the Caples and Torlesse terranes based on the common occurrence of metabasic greenschist, and associated thin horizons of marble, chert and ultramafic rock. (Craw, 1984, Grapes, 1999, Mortimer, 2000, Norris \& Craw, 1987).

\section{Pounamu Ultramafic Belt}

The PUB consists of a series of metamorphosed/metasomatised tectonic slices of an ophiolite sequence, which were thrust into Torlesse terrane sediments prior to the metamorphism of the Haast Schist belt (Cooper \& Reay, 1983). Further dismemberment and deformation during the subsequent metamorphic history has produced discontinuous pods that outcrop at ridge crests in North Westland, from the Waitaha River in the south to Mill Stream in the north. The dominant lithology is serpentine but pods also contain associated greenschist talc, tremolite/actinolite, chlorite and magnetite. Greenschist typically occurs on the border of serpentine pods but also outcrops as discontinuous bands adjacent to pods, parallel to the strike of surrounding schist.

\subsection{Multi-Element Plots \& Terrane Affinity}

Analysis of geochemical data can be invaluable for constraining or identifying the sedimentary sources of metamorphosed rocks, as typical techniques used for un-metamorphosed samples such as QFL diagrams or lithic composition analysis can be rendered unsuitable due to deformation, recrystallization, and fluid-mediated element transport during metamorphism. As discussed briefly above, the rocks that make up the extensive greywacke-schist terranes of New Zealand were derived from different source areas, and as a consequence differ in their geochemical signatures. Geochemical data from rocks of the Haast Schist belt can help identify different sub-terranes in the precursor greywacke rocks, and thus can be a key line of evidence for deciphering the original complex tectonic geometry and later tectonic evolution of the New Zealand microcontinent.

Many studies have aimed to differentiate the sediment source and chemistry of New Zealand terranes, using both major element oxide and trace element data from large suites of metamorphosed and un-metamorphosed rocks throughout New Zealand (Coombs, et al., 2000, Grapes \& Palmer, 1984, Mortimer \& Roser, 1992, Roser \& Coombs, 2005, Roser, et al., 2002, Roser \& Cooper, 1990, Roser \& Korsch, 1986, Roser \& Korsch, 1988, Roser, et al., 1993). This chapter presents new data overlain on selected plots from these studies to aid identification of the 
sedimentary protolith of Newton Range schists. Multi-element discriminant plots used in this study are described in the following sections.

\subsubsection{Greyschist}

\section{Major Element Oxide Discriminators}

Roser \& Korsh (1986 \& 1988) use a conceptually simple plot of $\mathrm{K}_{2} \mathrm{O} / \mathrm{Na}_{2} \mathrm{O}$ vs. $\mathrm{SiO}_{2}$ to discriminate between island arc and active continental margin sediment sources, an ideal separator between the Torlesse and Caples terranes. However, as this simple discriminant does not allow for compositional changes with grain size variation (psammites will contain more quartz and feldspar than mica rich pelites) the more detailed discriminant function plot of Roser \& Korsh (1988) is more useful. This uses seven major element oxides shown to be good discriminators between sediment sources. The discriminant functions (F1 \& F2) are calculated using discriminant function coefficients (table 5.1) to separate samples into four different groups (P1, P2, P3 and P4), characteristic of four New Zealand sedimentary terranes (Maitai, Caples, Torlesse and Greenland Group). As previously mentioned, the most important terranes to distinguish between in this study are the Torlesse and Caples terranes. The four groups defined by Roser \& Korsch (1988) are:

\begin{tabular}{ccc}
\hline & $\mathrm{F} 1$ & $\mathrm{~F} 2$ \\
\hline $\mathrm{TiO}_{2}$ & -1.773 & 0.445 \\
$\mathrm{Al}_{2} \mathrm{O}_{3}$ & 0.607 & 0.070 \\
$\mathrm{Fe}_{2} \mathrm{O}_{3}$ & 0.760 & 0.250 \\
$\mathrm{MgO}$ & -1.500 & -1.142 \\
$\mathrm{CaO}$ & 0.616 & 0.438 \\
$\mathrm{Na}_{2} \mathrm{O}$ & 0.509 & 1.475 \\
$\mathrm{~K}_{2} \mathrm{O}$ & -1.224 & 1.426 \\
$\mathrm{Constant}$ & -9.090 & -6.861 \\
\hline
\end{tabular}

Table 5.1. Coefficients for the discriminant function diagram from Roser \& Korsh (1988). F1 and F2 values for each sample are derived by first multiplying each oxide by the corresponding coefficient value, then summing these values and the constant together.

P1 - Mafic and lesser intermediate igneous provenance, characteristic of New Zealand volcanogenic terranes including the Maitai terrane and parts of the Caples terrane (Roser \& Korsch, 1988). The inferred source is volcaniclastic and volcanic rocks, most probably sourced from the earlier deposited Brook St terrane, currently exposed in south Otago/Southland (Roser \& Korsch, 1988). 
P2 - Intermediate igneous provenance represented by Caples terrane sediments. Volcanogenic greywacke and argillite represented by andesitic lithic fragments, deposited in a forearc basin environment.

P3 - Felsic igneous (volcanic and plutonic) represented by the Torlesse terrane. Early Torlesse material reflects a silicic volcanic source (MacKinnon, 1983) with later Torlesse material reflecting some cannibalistic reworking of earlier Torlesse deposits. QFL plots reveal a dissected magmatic arc tectonic setting (Dickinson, et al., 1983, Roser \& Korsch, 1988).

P4 - Quartzose or mature continental provenance poor in feldspar and rich in quartz represented by the Greenland group. Nathan (1976) defined these types of sediments as polycyclic sand fractions from pre-existing sedimentary terranes, with a wide range of possible primary sources including volcanic, active continental margin or previously recycled sediments.

\section{Trace Element Discriminators}

Immobile trace elements are particularly useful in analysis of the sedimentary source of metamorphosed rocks as they are resistant to redistribution during metamorphism. Bhatia \& Crook (1986) differentiated between different sources of Palaeozoic greywackes in eastern Australia by comparing immobile trace element concentrations ( $\mathrm{La}, \mathrm{Ce}, \mathrm{Nd}, \mathrm{Th}, \mathrm{Zr}, \mathrm{Nb}, \mathrm{Y}, \mathrm{Sc}$ ). Four endmember sedimentary sources/tectonic settings were inferred: oceanic island arc; continental island arc; active continental margin and passive margin (see Bhatia \& Crook for definitions of these settings).

Roser \& Cooper (1990) used ratios of immobile trace elements to differentiate Caples and Torlesse terrane sediment sources in Haast schist from the western Southern Alps. Caples terrane sediments were found to be enriched in Sc, Ti, V, Y and relatively depleted in $\mathrm{Ca}, \mathrm{La}, \mathrm{Nb}$, Th and $\mathrm{Zr}$ relative to Torlesse terrane rocks, resulting in respective sources of ocean island arc and active continental margin to be inferred. Mortimer \& Roser (1992) expanded on this premise and accurately defined the boundary of the Caples and Torlesse terranes in the Otago Schist through analysis of a large suite of both psammitic and pelitic samples. Selected multi-element plots from this are used for comparison to greyschist from the Newton Range in the results section.

Analyses of samples from the Aspiring lithologic association range in composition and generally group on the boundary between the Torlesse and Caples terranes (Mortimer \& Roser, 1992, Roser \& Cooper, 1990) reflecting a mixed continental and volcanogenic sediment source. This mixed 
source allows the Aspiring lithologic association to be defined as a distal component of the Torlesse terrane, and not a separate terrane (Mortimer \& Roser, 1992). The distal, more volcanogenic source of the Aspiring lithological association accounts for the more common metabasite, metachert and marble compared to the Caples and Torlesse terranes.

Plots used in this study are:

Ti/Zr vs. La/Sc and Y/Nb vs. Th/Sc - Developed by Roser \& Cooper (1990) to overcome the problems veining and dilution effects created when using major element oxide discriminant diagrams. Preliminary studies of Haast Schist in this study largely grouped samples into the Torlesse terrane.

$\mathbf{Y} / \mathbf{N b}$ vs. Ti/V and Ce/V vs. La/Y - Developed by Mortimer \& Roser (1992), these plots distinguish between continent derived sediments rich in $\mathrm{Nb}$, La and $\mathrm{Ce}$, and oceanic arc derived sediments enriched in Ti, Y and V. These plots have been used for Haast Schist metamorphosed equivalents of the Caples and Torlesse terranes.

\subsubsection{Greenschist}

Greenschist/metabasite in the Southern Alps could represent tectonic slices of igneous material and/or periods of sedimentation with a high volcanogenic input (Grapes \& Palmer, 1984). The magma type of the metabasite source can be inferred through multi-element plots (Grapes \& Palmer, 1984, Pearce \& Cann, 1973, Winchester \& Floyd, 1976). Grapes \& Palmer (1984) gathered analyses of metabasite from throughout the Southern Alps and found a predominantly tholeiitic basalt source similar in composition to ocean floor and intraplate basalts. Samples of kyanite-bearing metabasic mylonite from Kini Creek, South Westland, differ in composition to other Southern Alps data, containing low Ti, $\mathrm{Zr}$ and $\mathrm{P}_{2} \mathrm{O}_{5}$, and considerably higher $\mathrm{Cr}$ and $\mathrm{Ni}$ (Cooper \& Lovering, 1970, Grapes \& Palmer, 1982, McClintock \& Cooper, 2003).

There is little trace element data for PUB-sourced greenschist. Taylor (1955) partitions PUB greenschist from the Kokatahi River into two groups: group 1 greenschist similar in composition to other Southern Alps metabasite; and group 2 with ultramafic characteristics of elevated $\mathrm{Cr}$ and $\mathrm{Ni}$, similar to serpentenite from the main PUB pod. A small set of samples from Weir Stream/Lynch Creek (Storkey, 1999) show compositions comparable to tholeiitic basalt-sourced metabasite. 


\subsection{Analytical Methods}

Samples (10 greyschist, 4 greenschist, Fig. 5.3) were cleared of all weathered material and pen marks then oven dried overnight at $110^{\circ} \mathrm{C}$ prior to crushing using a TEMA tungsten carbide swing mill into fine rock powders at Victoria University of Wellington. Quartz veins were not included in whole-rock powders so as not to overestimate $\mathrm{SiO}_{2}$. XRF analyses of major element oxide and trace element concentrations were carried out by SpectraChem Analytical Ltd in Lower Hutt, Wellington. The L.O.I. (loss on ignition) determinations were carried out at $1000^{\circ} \mathrm{C}$ for $1 \mathrm{hr}$ on $2-4 \mathrm{~g}$ subsamples. Major oxides were measured sequentially in glass discs fused with a lithium borate flux, using a Siemens SRS303AS X-ray spectrometer fitted with a $3 \mathrm{~kW}$ rhodium end window tube $(125 \mu \mathrm{m} \mathrm{Be}$ window). Concentrations were derived using Spectraplus software from matrix-corrected measured intensities against linear regression calibrations for individual oxides. Measuring times for individual oxides are optimised to achieve a practical lower limit of measurement of $0.01 \%$ for routine analysis.

\subsection{Results}

All analyses of schist from the Newton Range are presented in tables 5.2 and 5.3. Greyschists are enriched in $\mathrm{SiO}_{2}, \mathrm{Al}_{2} \mathrm{O}_{3}, \mathrm{TiO}_{2}, \mathrm{Na}_{2} \mathrm{O}$ and $\mathrm{K}_{2} \mathrm{O}$, and are depleted in $\mathrm{P}_{2} \mathrm{O}_{5} \mathrm{Fe}_{2} \mathrm{O}_{3}, \mathrm{MgO}, \mathrm{MnO}$ and $\mathrm{CaO}$, relative to greenschist. Both greenschist and greyschist have concentrations of $\mathrm{SO}_{3}$ below detection limit. For trace elements, greyschists are enriched in $\mathrm{Ba}, \mathrm{Ce}, \mathrm{Cu}, \mathrm{Ga}, \mathrm{La}, \mathrm{Nb}, \mathrm{Pb}, \mathrm{Rb}, \mathrm{Sr}$, Th, $\mathrm{Y}$ and $\mathrm{Zr}$, and depleted in $\mathrm{Cr}, \mathrm{Ni}, \mathrm{Sc}$ and $\mathrm{V}$, relative to greenschist. Trace elements near or below detection limit in both grey and greenschists include As, $\mathrm{U}$ and Zn. Trace elements Ce, La, $\mathrm{Nb}, \mathrm{Th}$, and $\mathrm{Y}$ are in very low concentrations or below detection limit in greenschist alone.

\section{Greyschist}

Table 5.4 shows all element ratios used for plots of greyschist. Comparisons of trace element ratios from the Caples, Torlesse and Maitai terranes (Roser, et al., 1993) and greyschist from the Newton Range and nearby McArthur Range (Williams, 2006) are presented in table 5.5. Greyschist from the Newton Range is very similar in composition to greyschist from the nearby McArthur Range (Williams, 2006).

All Newton Range greyschist samples plot in the active continental margin setting on a $\mathrm{K}_{2} \mathrm{O} / \mathrm{Na}_{2} \mathrm{O}$ vs. $\mathrm{SiO}_{2}$ plot, (Fig. 5.4a). In the multi-element discriminant diagram from Roser \& Korsch (1988), 

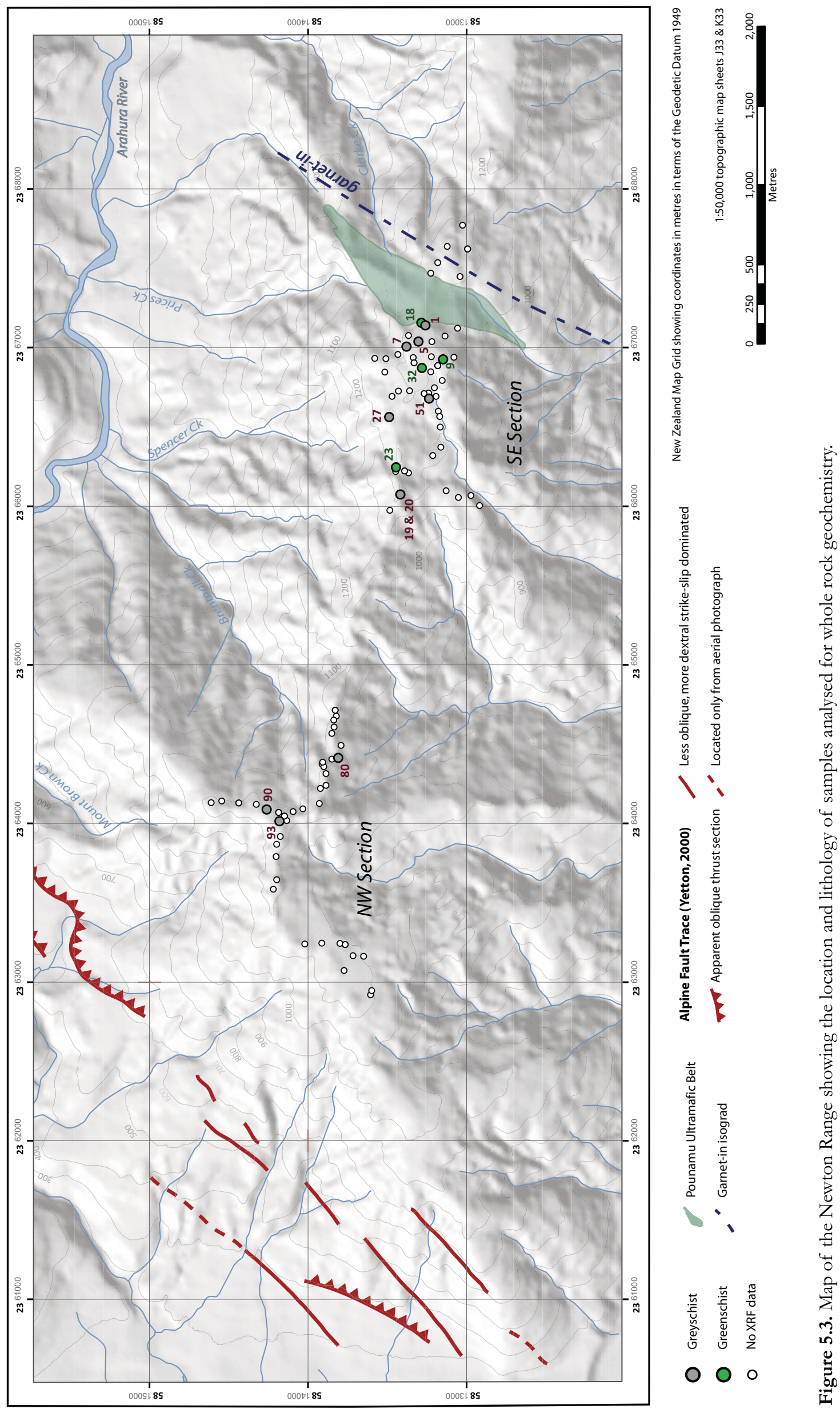


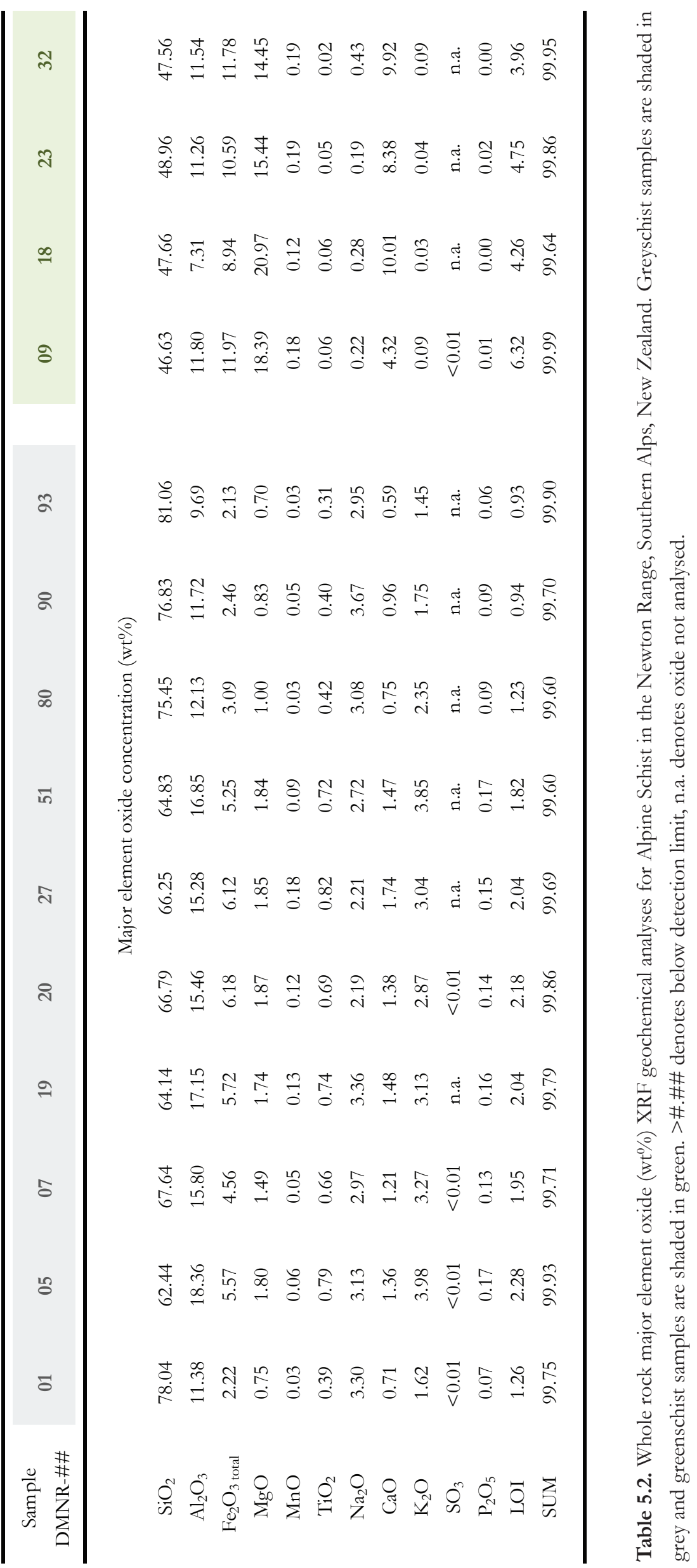




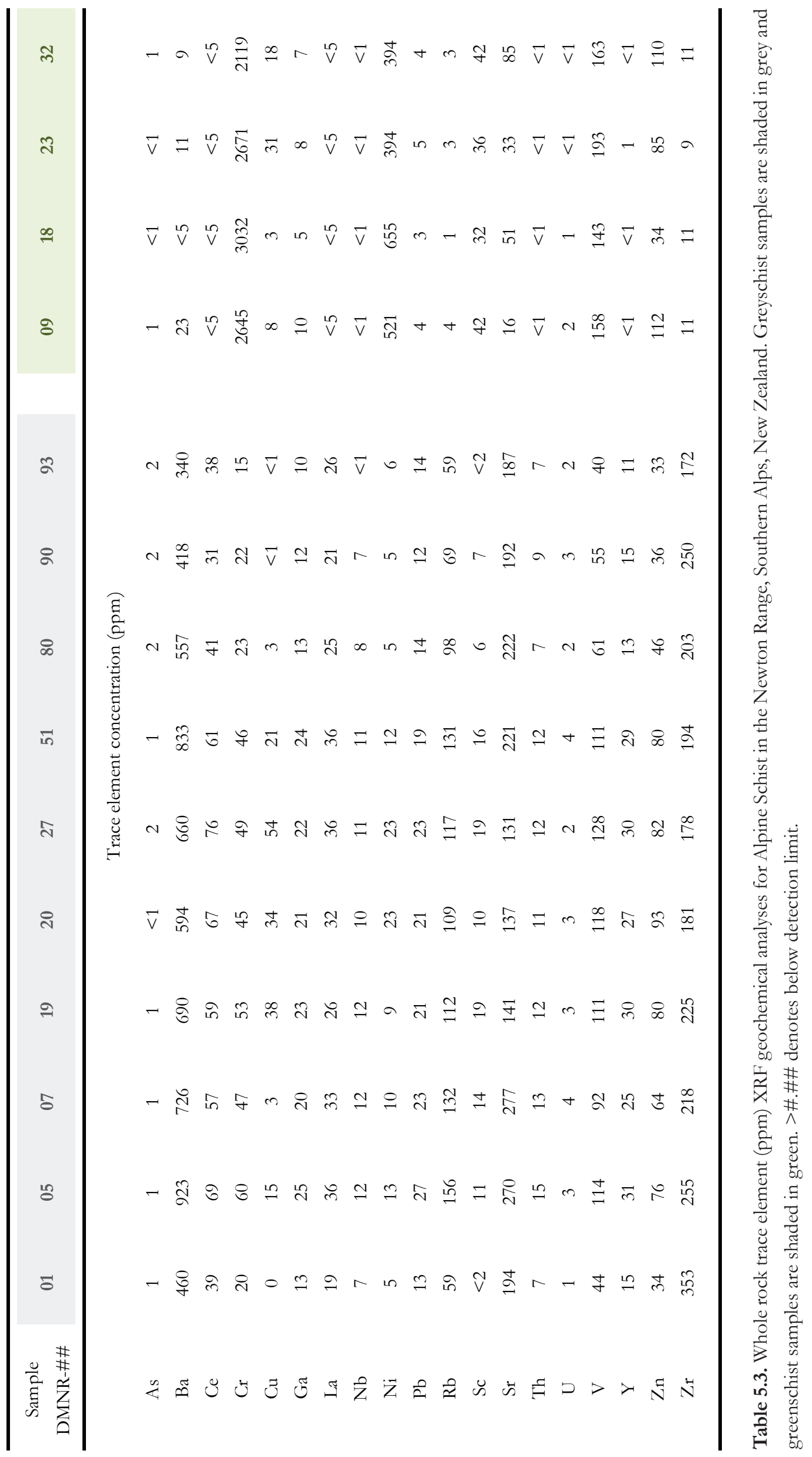




\begin{tabular}{|c|c|c|c|c|c|c|c|c|c|c|}
\hline $\begin{array}{c}\text { Sample } \\
\text { DMNR-\#\# }\end{array}$ & 01 & 05 & 07 & 19 & 20 & 27 & 51 & 80 & 90 & 93 \\
\hline \multicolumn{11}{|c|}{ Calculated major and trace element ratios for greyschist } \\
\hline $\mathrm{K}_{2} \mathrm{O} / \mathrm{Na}_{2} \mathrm{O}$ & 0.49 & 1.27 & 1.10 & 0.93 & 1.31 & 1.37 & 1.42 & 0.76 & 0.48 & 0.49 \\
\hline $\mathrm{F}^{+}$ & -2.18 & -0.25 & -1.18 & 0.55 & -0.58 & -0.93 & -1.33 & -2.47 & -1.75 & -3.09 \\
\hline $\mathrm{F}^{+}$ & 0.18 & 2.22 & 1.26 & 1.32 & -1.22 & -0.71 & 1.37 & 0.47 & 0.90 & -0.69 \\
\hline $\mathrm{Ti} / \mathrm{Zr}$ & 6.67 & 18.59 & 18.06 & 19.63 & 22.88 & 27.76 & 22.22 & 12.41 & 9.64 & 10.65 \\
\hline $\mathrm{La} / \mathrm{Sc}$ & $>9.5^{*}$ & 3.27 & 2.36 & 1.37 & 3.20 & 1.89 & 2.25 & 4.17 & 3.00 & $>13^{*}$ \\
\hline $\mathrm{Ce} / \mathrm{V}$ & 0.89 & 0.61 & 0.62 & 0.53 & 0.57 & 0.59 & 0.55 & 0.67 & 0.56 & 0.95 \\
\hline $\mathrm{La} / \mathrm{Y}$ & 1.27 & 1.16 & 1.32 & 0.87 & 1.19 & 1.20 & 1.24 & 1.92 & 1.40 & 2.36 \\
\hline $\mathrm{Y} / \mathrm{Nb}$ & 2.14 & 2.58 & 2.08 & 2.50 & 2.70 & 2.73 & 2.64 & 1.63 & 2.14 & $>11 *$ \\
\hline $\mathrm{Th} / \mathrm{Sc}$ & $<3.5^{*}$ & 1.36 & 0.93 & 0.63 & 1.10 & 0.63 & 0.75 & 1.17 & 1.29 & $<3.5^{*}$ \\
\hline $\mathrm{Ti} / \mathrm{V}$ & 53.53 & 41.57 & 42.80 & 39.80 & 35.10 & 38.60 & 38.84 & 41.31 & 43.81 & 45.79 \\
\hline $\mathrm{Ce} / \mathrm{Sc}$ & $>19.5^{*}$ & 6.27 & 4.07 & 3.11 & 6.70 & 4.00 & 3.81 & 6.83 & 4.43 & $>19 *$ \\
\hline $\mathrm{V} / \mathrm{La}$ & 2.32 & 3.17 & 2.79 & 4.27 & 3.69 & 3.56 & 3.08 & 2.44 & 2.62 & 1.54 \\
\hline
\end{tabular}

Table 5.4. Major and trace element ratios for greyschist in the Newton Range for use in chapter five figures and table 5.3. * One element is below detection and therfore the corresponding ratio is either a maximum or minimum (these values are not used in plots). ${ }^{+}$Formula for ratio presented in table 5.4.

\begin{tabular}{ccccc}
\hline & $\mathrm{Ti} / \mathrm{Zr}$ & $\mathrm{Th} / \mathrm{Sc}$ & $\mathrm{Ce} / \mathrm{Sc}$ & $\mathrm{V} / \mathrm{La}$ \\
\hline Caples & $18-48$ & $<0.2-1.06$ & $<1-4$ & $7-25$ \\
Maitai & $45-80$ & $<0.2$ & $<1$ & $18-80$ \\
Torlesse & $10-22$ & $0.75-2.50$ & $4-15$ & $5-10$ \\
& & & & \\
McArthur Range & $6.3-26.4$ & $<0.11^{*}-2.4$ & $3-17$ & $2-4.5$ \\
Newton Range & $\mathbf{6 . 7 - 2 7 . 8}$ & $\mathbf{0 . 6 3 - > 3 . 5 *}$ & $\mathbf{3 . 1}->\mathbf{1 9 . 5 *}$ & $\mathbf{1 . 5}-\mathbf{4 . 3}$ \\
\hline
\end{tabular}

Table 5.5. Typical trace element ratios in New Zealand greywacke terranes after Roser, 1987 and Roser et al. 1993, compared to greyschist from the McArthur Range (Williams, 2006) and the Newton Range (this study). 
90\% of samples plot as P3 with a Felsic/Torlesse provenance (Fig. 5.4b). The one sample that plots in $\mathrm{P} 4$ (quartzose recycled) has higher $\mathrm{SiO}_{2}(\sim 81 \%)$ than all other greyschist samples.

In the trace element plots (Figs. 5.5 \& 5.6), greyschist from the Newton Range generally plots in the fields of Torlesse terrane sediments (Mortimer \& Roser, 1992, Roser \& Cooper, 1990). There is a slight overlap with Caples terrane sediments in the two plots containing Sc (Figs. 5.5a \& 5.5b). This is because of a slight enrichment (16-19ppm) of Sc in three samples: DMNR-19, $27 \& 51$. Note in these diagrams the underlying data also has a similar overlap between Torlesse and Caples terranes. In the two other plots not containing Sc, (fig 5.6) there is a 100\% correlation of greyschist from the Newton Range with Torlesse derived sediments. Greyschist from the study area is also comparable to the Torlesse terrane in having depressed $\mathrm{Ti} / \mathrm{Zr}$ and $\mathrm{V} / \mathrm{La}$ and elevated $\mathrm{Th} / \mathrm{Sc}$ and $\mathrm{Ce} / \mathrm{Sc}$ compared to samples from the Caples and Maitai terranes (Table 5.5).

\section{Greenschist}

Element discriminant diagrams for greenschist are presented in figure 5.7, plotted with other data from metabasite/greenschist in the Alpine Schist (Grapes \& Palmer, 1982, McClintock \& Cooper, 2003, Storkey, 1999, Taylor, 1955, Williams, 2006). Greenschist from the Newton Range is compositionally unlike most metabasite from the Alpine Schist, containing extremely low levels of $\mathrm{Zr}$, Ti and $\mathrm{P}_{2} \mathrm{O}_{5}$ and extremely elevated levels of $\mathrm{Cr}$ and Ni. Other samples from the Southern Alps with similar compositions to Newton Range greenschist include kyanite-bearing mylonites from Kini Creek (McClintock \& Cooper, 2003) and group 2 greenschist from the PUB outcrop in the Kokatahi River (Taylor, 1955). Group 1 greenschist from the Kokatahi River have considerably less $\mathrm{Cr}$ and $\mathrm{Ni}$ than group 2 samples, more akin to the majority of metabasite found throughout the Southern Alps. Greenschist from the nearby McArthur Range (Williams, 2006) and Weir Stream/Lynch Creek (Storkey, 1999) have compositions unlike those in the Newton Range, and more similar to the majority of Southern Alps metabasite.

\subsection{Discussion}

\section{Greyschist}

Both major element oxide and trace element plots show that greyschist from the Newton Range has an overwhelming similarity to Torlesse terrane sediments. Three samples that plot out of the 

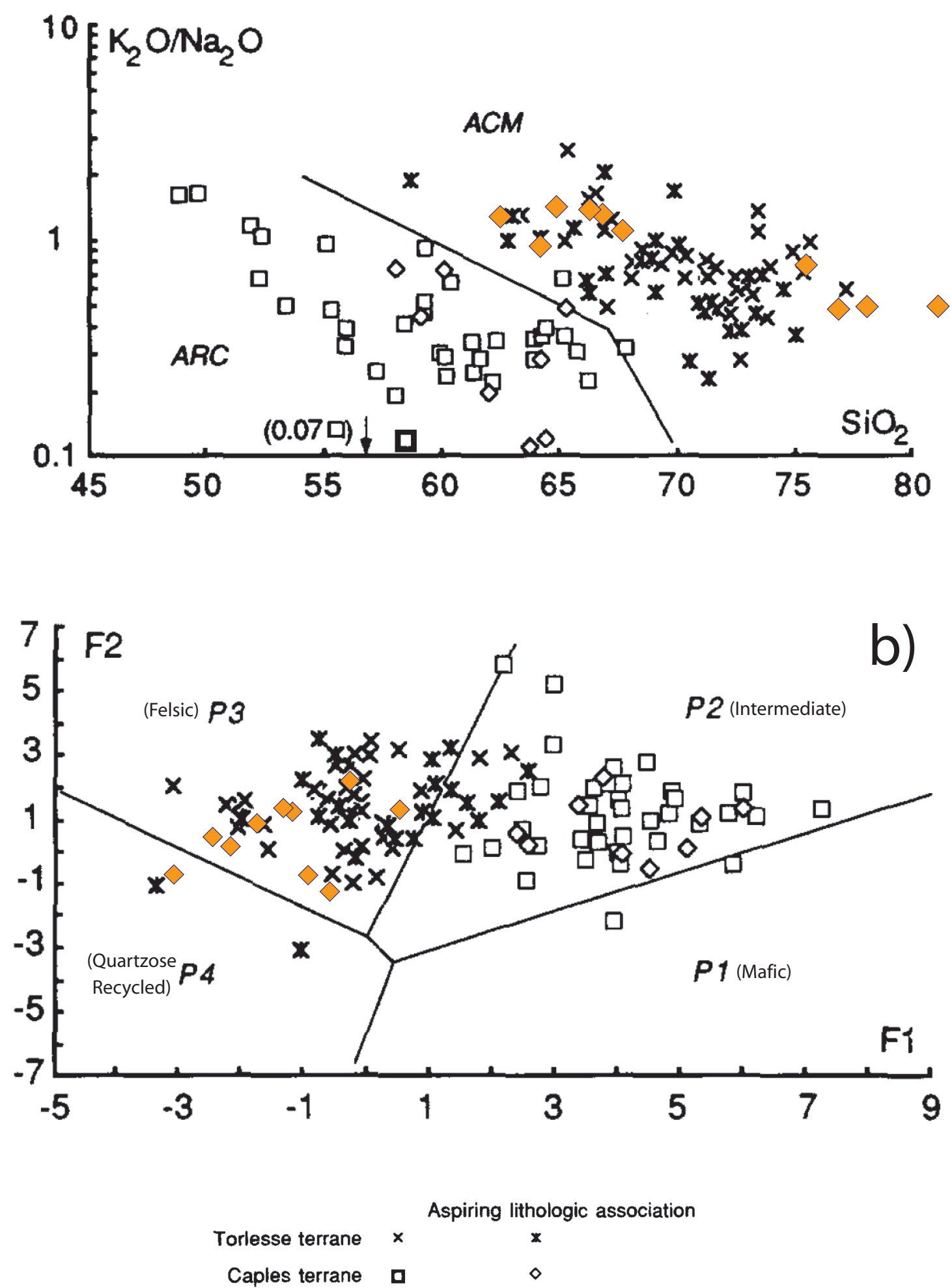

Figure 5.4. Major element oxide discriminant plots with data from this study (orange diamonds) plotted over data from Mortimer \& Roser (1992). a) $\mathrm{K}_{2} \mathrm{O} / \mathrm{Na}_{2} \mathrm{O}$ vs $\mathrm{SiO}_{2}$, showing differentiation between active continental margin (ACM) and oceanic island arc (ARC) derived sediments. b) Discriminant function diagram after Roser \& Korsh (1988). 

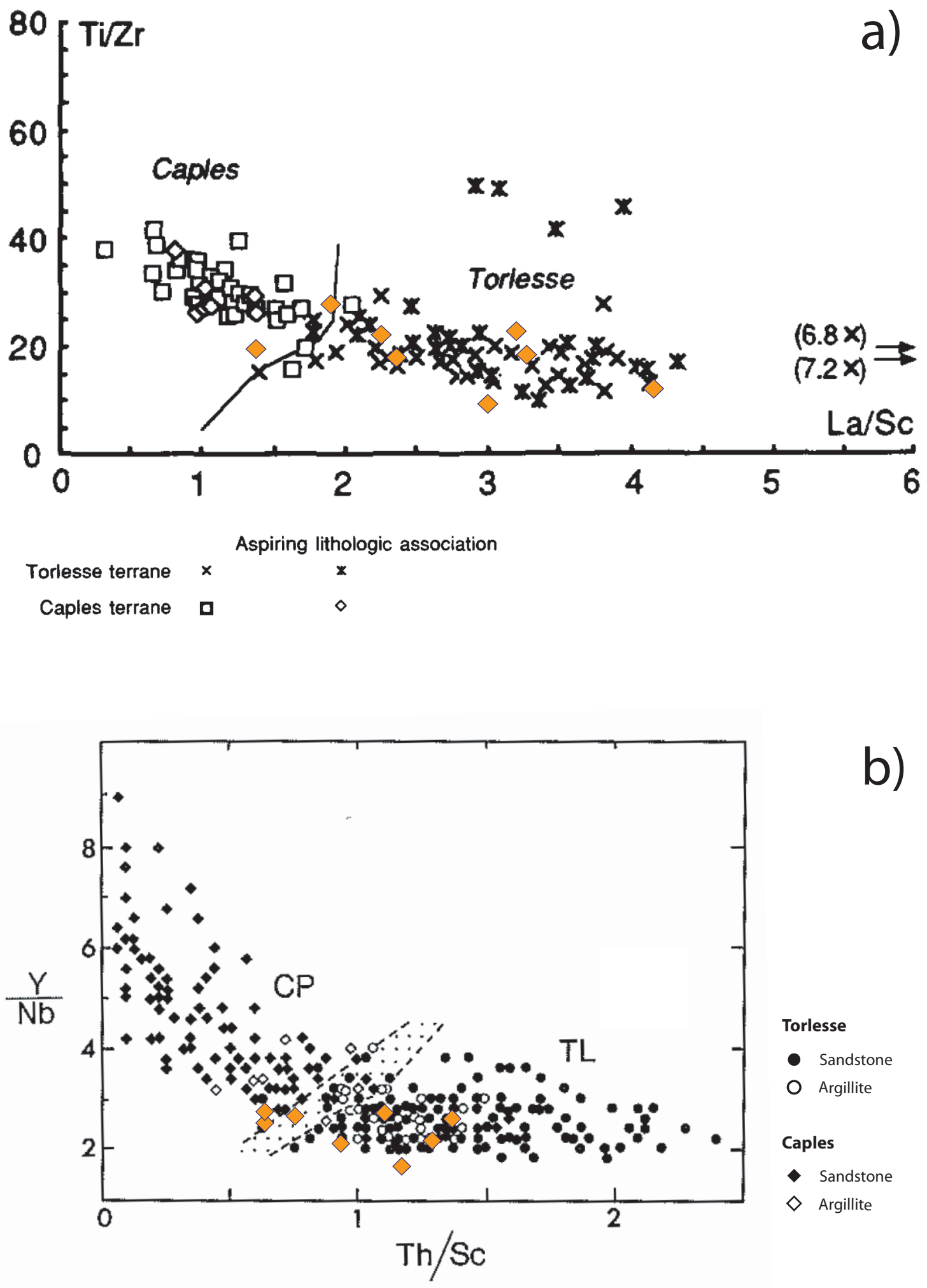

Figure 5.5. Trace element discriminant plots with data from this study (orange diamonds) plotted over data from Mortimer \& Roser (1992) (a) and Roser \& Cooper (1990) (b). a) La/Sc vs Ti/Zr, solid line represents approximate boundary between Torlesse and Caples terrane sediments. Offscale samples are marked by arrows with ordinate values in brackets. b) Th/Sc vs Y/Nb plot for low-grade Torlesse (TL) and Caples (CP) sediments. Stippled area outlines the overlap zone between Torlesse and Caples terranes. 

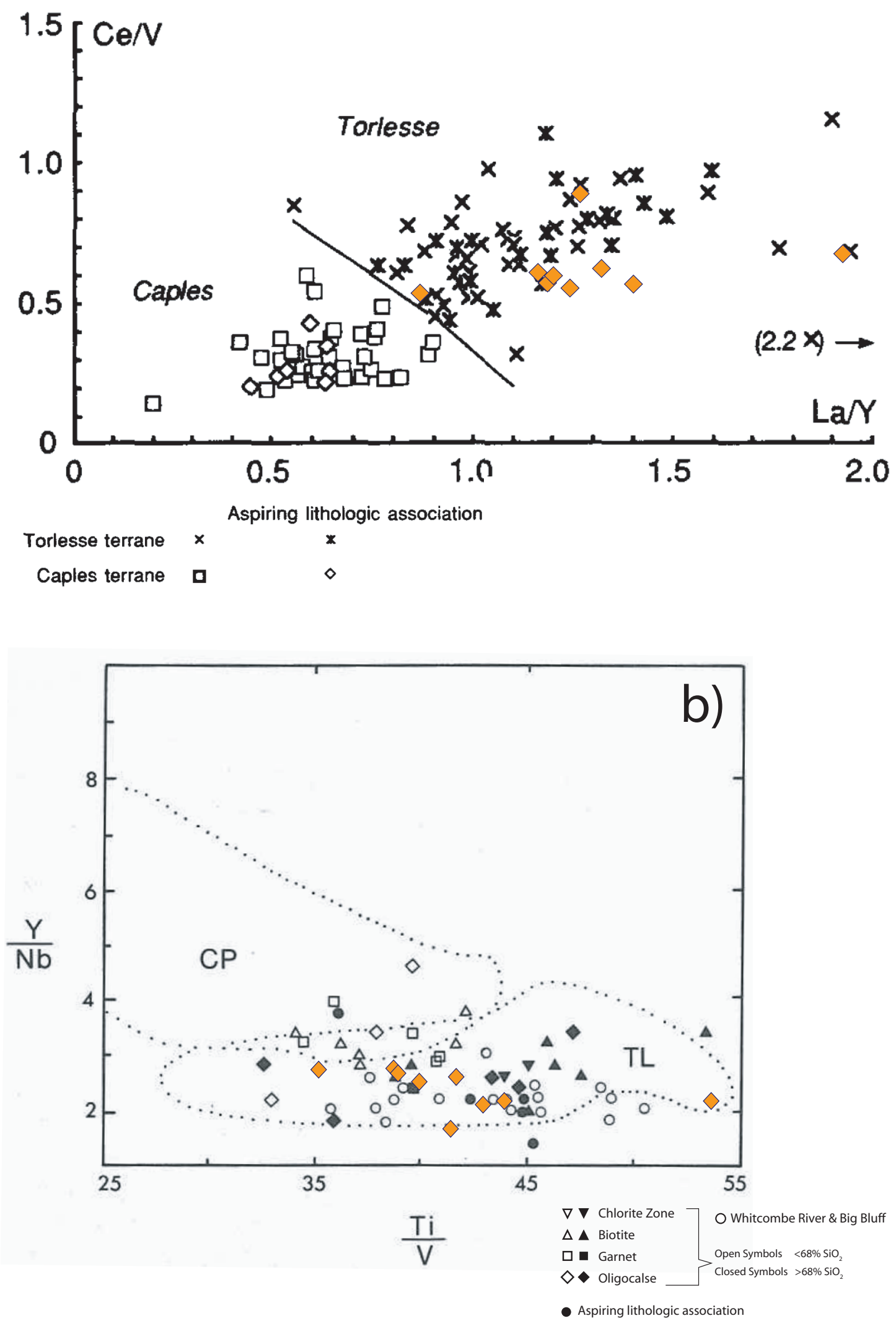

Figure 5.6. Trace element discriminant plots with data from this study (orange dimonds) plotted over data from Mortimer \& Roser (1992) (a) and Roser \& Cooper (1990) (b). a) Ce/V vs La/Y, with solid line representing the approximate boundary between Torlesse and Caples terrane sediments. Offscale samples are marked by arrows with ordinate values in brackets. b) Y/Nb vs Ti/V plot of schists from the Franz Josef-Fox glacier region, and Whitcombe River/Big Bluff. Dotted fields are Caples (CP) and Torlesse (TL) Terrane fields. 

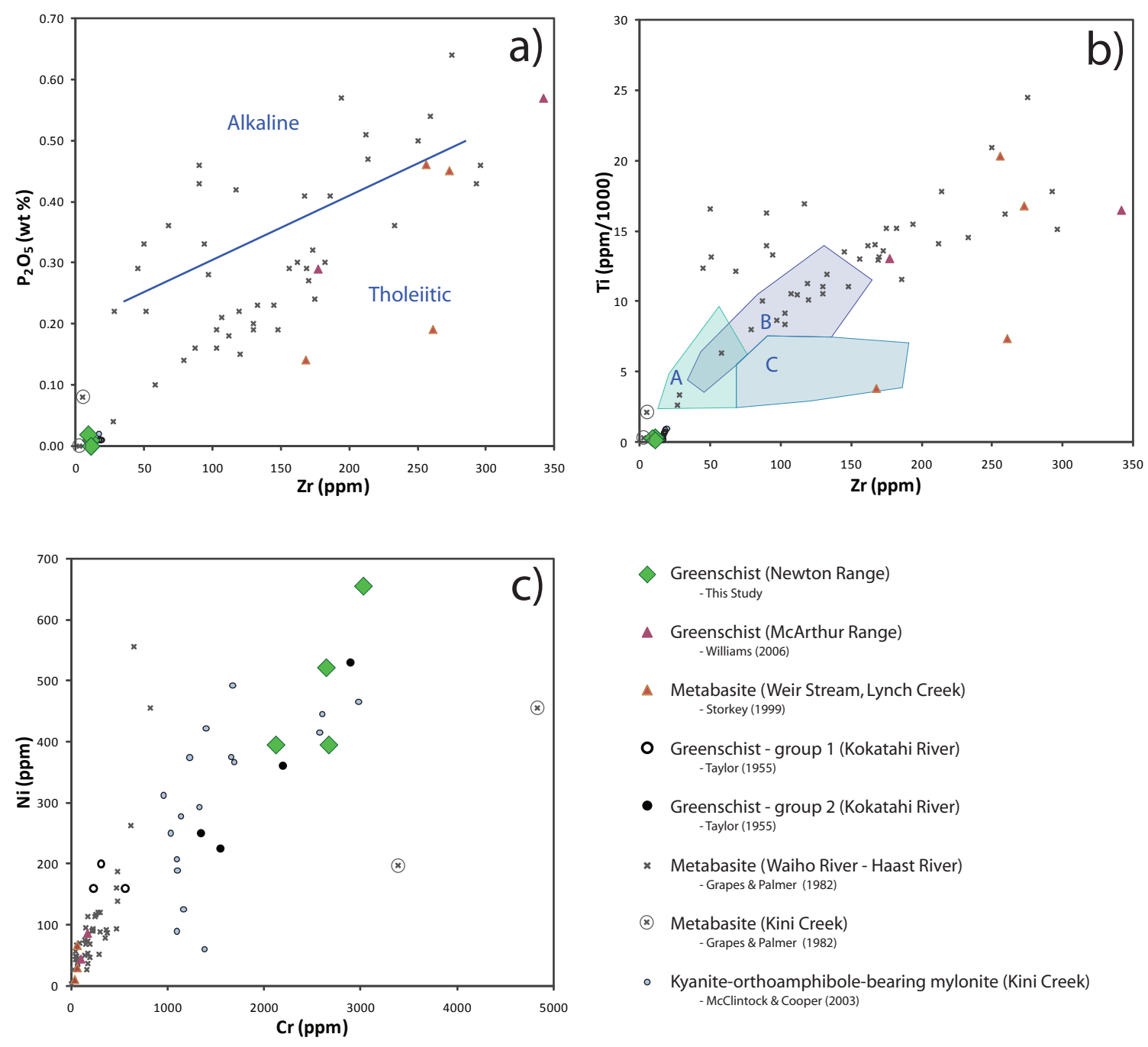

Greenschist (Newton Range) - This Study

$\Delta$ Greenschist (McArthur Range) - Williams (2006)

- Metabasite (Weir Stream, Lynch Creek) - Storkey (1999)

- Greenschist - group 1 (Kokatahi River) -Taylor (1955)

- Greenschist - group 2 (Kokatahi River) - Taylor (1955)

$\times$ Metabasite (Waiho River - Haast River) - Grapes \& Palmer (1982)

※) Metabasite (Kini Creek) - Grapes \& Palmer (1982)

- Kyanite-orthoamphibole-bearing mylonite (Kini Creek) - McClintock \& Cooper (2003)

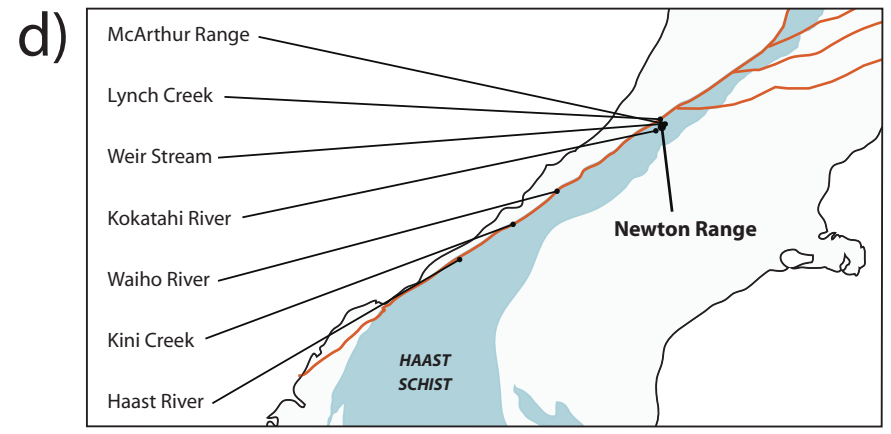

Figure 5.7. Trace element discriminant plots with data from greenschists and metabasites throughout the Southern Alps. a) $\mathrm{P}_{2} \mathrm{O}_{5}$ vs Zr with fields of tholeiitic and alkaline basalts after Winchester \& Floyd (1976) and Grapes \& Palmer (1984), b) Ti vs Zr with basalt fields after Pearce \& Cann (1973) and Grapes \& Palmer (1984). A - island arc tholeiites, B - ocean floor basalts, C - calcalkali basalts. c) Cr vs Ni. Note how the Newton Range greenschists are similar in composition to samples from Kini Creek and group 2 from the Kotatahi River. Greenschists from the nearby McArthur Range, Weir Stream and Lynch Creek all group closer to metabasites found throughout the Southern Alps from Waiho River south to Haast River. Kokatahi River samples all have Zr below detection limit so are not plotted in b) \& c). Garnet amphibolite and talc-tremolite rocks from McClintock \& Cooper (2003) are not plotted. d) Basic location map of the South Island, New Zealand, showing locations of greenschist plotted in a) - c). 
Torlesse grouping can be explained by either elevated $\mathrm{Sc}$ or $\mathrm{SiO}_{2}$. The unusually high $\mathrm{SiO}_{2}$ content in one sample (DMNR-93) is attributable to sampling of a relatively resistant quartz-rich rock, possibly containing quartz veins/segregations. Elevated Sc may be due to a weak, more mafic sediment input during deposition, which is not uncommon in the Torlesse terrane (MacKinnon, 1983).

\section{Greenschist}

Greenschist from the Newton Range have higher $\mathrm{Cr}$ and $\mathrm{Ni}$, and thus are more ultramafic in character, than most other greenschist in the Alpine Schist. The most likely source is the PUB, a source also favoured by McClintock \& Cooper (2003) for ultramafic mylonite in Kini Creek, south Westland.

DMNR-18 is located directly beside the PUB pod in the Newton Range (Fig. 5.1) and is most probably the same pod bordering greenschist observed by Koons (1978), therefore it is not unusual that this sample would have an ultramafic composition. Other greenschist occurs as thin discontinuous bands $(<20 \mathrm{~m})$ sub-parallel to strike and are situated up to $2 \mathrm{~km}$ from the major outcrop of the PUB. These may represent partially exposed anticline cores of PUB pods, as has been suggested in the Whitcombe River watershed and Diedrich Range (Cooper \& Reay, 1983, Ireland, et al., 1984). However the occurrence of such anticlinal cores cannot be fully inferred due to the lack of structural data available from outcrop in the Newton Range (see chapter three).

\section{Evidence for the Aspiring Terrane}

Studies of the Alpine Schist mylonite zone in north Westland (Dixon, 2001, Storkey, 1999) have proposed that a narrow ( $\sim 1 \mathrm{~km}$ wide) slice of the Aspiring lithological association, identifiable based on the presence of metabasite and metachert, extends northward into north Westland along the eastern side of the Alpine Fault. Grapes (1999) suggested the transition from Torlesse terrane sediments to the Aspiring lithologic association with increasing proximity to the Alpine Fault may be recognised through increasing concentrations of $\mathrm{V}, \mathrm{Sc}, \mathrm{MnO} \& \mathrm{Fe}_{2} \mathrm{O}_{3}$, an observation also favoured by Dixon (2001).

This study found no evidence of the Aspiring lithologic association in the Newton Range, although the possibility that a narrow band of those rocks might occur under the heavy vegetation cover 
immediately adjacent to the Alpine Fault cannot be ruled out. In the present study area, greenschists are more ultramafic in character, and thus unlike, the typical greenschist that occurs in the Aspiring lithologic association, and marble and metachert are either extremely rare, or absent. There is also no increase in $\mathrm{V}, \mathrm{Sc}, \mathrm{MnO}$ or $\mathrm{Fe}_{2} \mathrm{O}_{3}$ with increasing proximity to the Alpine Fault. The greyschist in the Newton Range is interpreted to be derived from Torlesse terrane sediments, an interpretation also favoured by Williams (2006) based on her study of rocks in the McArthur Range $7 \mathrm{~km}$ to the north.

\subsection{Conclusion}

Greyschist plots with overwhelming similarity to Torlesse terrane sediments. An overlap with Caples terrane sediments is due to a slight enrichment in Sc in three samples. Greenschist shows an ultramafic signature (elevated $\mathrm{Cr}$ and $\mathrm{Ni}$ ) and are inferred to represent outcrops of the PUB and not volcanogenic parts of the Torlesse terrane or Aspiring lithological association. No geochemical evidence for the Aspiring lithologic association is observed in the Newton Range. The inferred protolith of Alpine Schist in the Newton Range is Torlesse Terrane sediments deposited in the late Triassic off the Gondwana supercontinent in a trench slope, borderland basin setting, probably as part of a developing accretionary prism complex. 


\section{Chapter Six}

\section{MINERAL CHEMISTRY}

\subsection{Introduction}

This chapter documents the chemistry and compositional zoning of minerals in samples of Alpine Schist greyschist from the Newton Range, Southern Alps, New Zealand. Results are presented for garnet, plagioclase, biotite, muscovite, epidote, ilmenite, titanite and apatite. Detailed compositional zoning profiles and backscattered electron (BSE) images of garnet are presented in this chapter and are used in chapter seven to interpret changes in metamorphic pressure-temperature (P-T) conditions during the garnet growth. For minerals other than garnet, insights into mineral compositional zoning were obtained by analysing cores, rims, and other areas of interest identified on the basis of thin-section microscopy and/or BSE imaging. The mineral chemistry data and BSE imaging results obtained in this chapter are discussed in comparison with results of previous studies of mineral chemistry in rocks of the Haast Schist group.

\section{Methods}

Electron microprobe analyses were carried out using wavelength dispersive methods at Victoria University of Wellington. The minerals were analysed in standard polished thin sections that had been coated with a $25 \mathrm{~nm}$ film of carbon. The analyses were performed on the JEOL JXA-733 SuperProbe, using Moran Scientific software that incorporates modified ZAF and Bence-Albee matrix corrections. The accelerating voltage was $15 \mathrm{kV}$, the beam current was $12 \mathrm{nA}$, and a beam diameter of $1-10 \mu \mathrm{m}$ was used, depending on the mineral analysed. Anhydrous minerals were analysed using a $1 \mu \mathrm{m}$ beam, and hydrous minerals typically analysed with a wider beam ( 5 or $10 \mu \mathrm{m})$.

\subsection{Results}

Representative results of mineral analyses are presented in tables 6.1 and 6.2. All other analyses are presented in appendices A3.1 - A3.7. 


\subsubsection{Garnet}

Garnet size ranges from $180-1200 \mu \mathrm{m}$. The main compositional mixing in the garnet involves Fe, $\mathrm{Ca}$, and $\mathrm{Mn}$. MgO contents are low and constant at $\sim 1 \mathrm{wt} \%$ and $\mathrm{Cr}_{2} \mathrm{O}_{3}$ and $\mathrm{TiO}_{2}$ contents are always $<0.5 \mathrm{wt} \%$ (table 6.1). Figure 6.1 summarises results obtained from detailed analyses of a 28 garnets in ten different rock samples. The samples were selected to provide data from typical garnet-bearing Alpine Schist greyschists collected from across the available range of metamorphic grade in the study area, and to include a range of bulk-rock $\mathrm{MnO}$ contents. The five stages of garnet growth that are identified in figure 6.1 are shown on a schematic garnet compositional zoning profile in figure 6.2a. BSE images of representative individual garnets and detailed compositional zoning profiles, with the interpreted garnet growth stages identified, are presented in figures 6.2, 6.3 and 6.4. No individual garnet shows all five growth stages.

Three garnets from the study area contain a core (stage 0 ) that is characterised by anomalously high or low $\mathrm{MnO}$ content compared to the more typical garnet core compositions (here designated stage 1 or 2). The transition from the stage 0 core to the garnet that overgrows it (stage 1 or 2 ) is marked by a sharp compositional change that is visible in BSE images. Sample DMNR-27 has a low MnO core (Fig. 6.3a), samples DMNR-80 and DMNR-90 have high MnO cores (figs. 6.3d, \& 6.4b).

In general, the compositional profiles for the remaining garnet show a gradual decrease in $\mathrm{MnO}$ and increase in $\mathrm{FeO}$ from core to rim (figs. 6.1, 6.2, 6.3 \& 6.4). Stage 1 garnet occurs in relatively $\mathrm{MnO}$ rich rocks, and is marked by contents of $\mathrm{MnO}(\sim 17 \mathrm{wt} \%)$ that are higher than $\mathrm{FeO}(13-15 \mathrm{wt} \%)$. The transition from stage 1 to stage 2 is gradual and is here defined by equal amounts $(\sim 15 \mathrm{wt} \%)$ of $\mathrm{FeO}$ and $\mathrm{MnO}$. All garnet shows stage 2 growth, which involves either gradual decreases in $\mathrm{MnO}$ from $\sim 15 \mathrm{wt} \%$ to $\sim 7 \mathrm{wt} \%$, as $\mathrm{FeO}$ increases to $\sim 25 \mathrm{wt} \%$, or near-constant $\mathrm{MnO}$ contents at $\sim 10 \mathrm{wt} \%$. Where stage 3 is present, $\mathrm{CaO}$ gradually decreases by $\sim 3-4 \mathrm{wt} \%$ from typical core values near $8-10$ $\mathrm{wt} \%$, as $\mathrm{FeO}$ and $\mathrm{MnO}$ gradually increase (by $\sim 2-4 \mathrm{wt} \%$, and $\sim 0-1 \mathrm{wt} \%$, respectively). The abrupt transition to an outermost rim (stage 4) is marked by a sharp increase in $\mathrm{CaO}$, and concomitant decreases in $\mathrm{FeO}$ and $\mathrm{MnO}$. The resulting garnet is similar in composition to garnet in stage 2, but has $\sim 1-2 \mathrm{wt} \%$ lower $\mathrm{CaO}$, and $\sim 1-2 \mathrm{wt} \%$ higher $\mathrm{MnO}$. Compositions of garnet stages $1-4$ are presented in figure 6.5 . 


\begin{tabular}{|c|c|c|c|c|c|c|c|}
\hline Garnet & $\begin{array}{c}\text { Stage } 0 \\
\text { Low } \mathrm{MnO} \text { core }\end{array}$ & $\begin{array}{c}\text { Stage } 0 \\
\text { High } \mathrm{MnO} \text { core }\end{array}$ & $\begin{array}{c}\text { Stage } 1 \\
\mathrm{MnO}>\mathrm{FeO}\end{array}$ & $\begin{array}{c}\text { Stage } 1-2 \text { Transition } \\
\mathrm{FeO} \approx \mathrm{MnO}\end{array}$ & $\begin{array}{c}\text { Stage } 2 \\
\mathrm{FeO}>\mathrm{MnO}\end{array}$ & $\begin{array}{c}\text { Stage } 3 \\
\mathrm{CaO} \text { Drop }\end{array}$ & $\begin{array}{l}\text { Stage } 4 \\
\text { CaO Rise }\end{array}$ \\
\hline Sample DMNR-\#\# & 27 & 90 & 27 & 27 & 05 & 05 & 05 \\
\hline \multirow{3}{*}{$\begin{array}{l}C \text { Coding for garnets }(C \#, G \#) \\
\text { G } \\
\text { Analysis No. }\end{array}$} & 1 & 3 & 1 & 1 & 1 & 1 & 1 \\
\hline & 1 & 1 & 1 & 1 & 2 & 2 & 2 \\
\hline & 14 & 10 & 10 & 6 & 2 & 8 & 11 \\
\hline \multicolumn{8}{|l|}{$\mathrm{wt} \%$ oxides } \\
\hline $\mathrm{SiO}_{2}$ & 37.74 & 37.83 & 38.24 & 38.22 & 37.63 & 37.38 & 37.88 \\
\hline $\mathrm{Al}_{2} \mathrm{O}_{3}$ & 21.23 & 21.33 & 20.67 & 21.45 & 19.68 & 19.80 & 20.04 \\
\hline $\mathrm{FeO}^{t}$ & 25.65 & 5.44 & 13.33 & 15.74 & 24.89 & 27.64 & 25.09 \\
\hline $\mathrm{MgO}$ & 0.82 & 0.06 & 0.16 & 0.24 & 0.61 & 0.92 & 0.71 \\
\hline $\mathrm{MnO}$ & 7.04 & 24.03 & 16.15 & 15.71 & 8.17 & 9.22 & 8.79 \\
\hline $\mathrm{TiO}_{2}$ & 0.21 & 0.30 & 0.17 & 0.21 & 0.16 & b.d. & 0.20 \\
\hline $\mathrm{Cr}_{2} \mathrm{O}_{3}$ & n.a. & n.a. & n.a. & n.a. & b.d. & b.d. & 0.12 \\
\hline $\mathrm{CaO}$ & 10.85 & 12.46 & 12.78 & 12.27 & 7.78 & 4.15 & 6.78 \\
\hline Total & 103.53 & 101.45 & 101.49 & 103.84 & 98.93 & 99.11 & 99.61 \\
\hline \multicolumn{8}{|l|}{ Normalised on an 8 cation basis } \\
\hline $\mathrm{Si}$ & 2.926 & 2.981 & 3.014 & 2.950 & 3.074 & 3.068 & 3.076 \\
\hline $\mathrm{Al}$ & 1.940 & 1.981 & 1.921 & 1.952 & 1.895 & 1.916 & 1.919 \\
\hline $\mathrm{Fe}^{t}$ & 1.663 & 0.358 & 0.879 & 1.016 & 1.700 & 1.897 & 1.704 \\
\hline $\mathrm{Mg}$ & 0.095 & 0.007 & 0.019 & 0.028 & 0.075 & 0.113 & 0.085 \\
\hline $\mathrm{Mn}$ & 0.462 & 1.603 & 1.078 & 1.027 & 0.565 & 0.641 & 0.605 \\
\hline $\mathrm{Ti}$ & 0.012 & 0.018 & 0.010 & 0.012 & 0.010 & b.d. & 0.012 \\
\hline $\mathrm{Cr}$ & n.a. & n.a. & n.a. & n.a. & b.d. & b.d. & 0.008 \\
\hline $\mathrm{Ca}$ & 0.901 & 1.052 & 1.080 & 1.015 & 0.681 & 0.365 & 0.590 \\
\hline \multicolumn{8}{|l|}{$(\mathrm{Mg}+\mathrm{Fe})-\mathrm{Ca}-\mathrm{Mn}$ Diagram } \\
\hline $\mathrm{Mg}+\mathrm{Fe}$ & 56.33 & 12.09 & 29.38 & 33.83 & 58.76 & 66.65 & 59.96 \\
\hline $\mathrm{Mn}$ & 14.80 & 53.08 & 35.29 & 33.28 & 18.71 & 21.26 & 20.26 \\
\hline $\mathrm{Ca}$ & 28.87 & 34.83 & 35.34 & 32.89 & 22.53 & 12.09 & 19.78 \\
\hline \multicolumn{8}{|l|}{ Mole Fractions } \\
\hline $\boldsymbol{X}_{\mathrm{sps}}$ & 0.15 & 0.53 & 0.35 & 0.33 & 0.18 & 0.19 & 0.19 \\
\hline$X_{\mathrm{grs}}$ & 0.29 & 0.35 & 0.35 & 0.33 & 0.22 & 0.14 & 0.21 \\
\hline $\boldsymbol{X}_{\mathrm{alm}}$ & 0.53 & 0.12 & 0.29 & 0.33 & 0.57 & 0.63 & 0.57 \\
\hline $\boldsymbol{X}_{\mathrm{prp}}$ & 0.03 & 0.00 & 0.01 & 0.01 & 0.02 & 0.04 & 0.03 \\
\hline
\end{tabular}

Table 6.1. Representative analyses of garnet. Garnet codes C \& G are used to differentiate individual garnets within a particular sample. For a full description of stages $0-4$ see text and figures 6.1 \& 6.2 a. b.d. = below detection limit, n.a. $=$ not analysed.

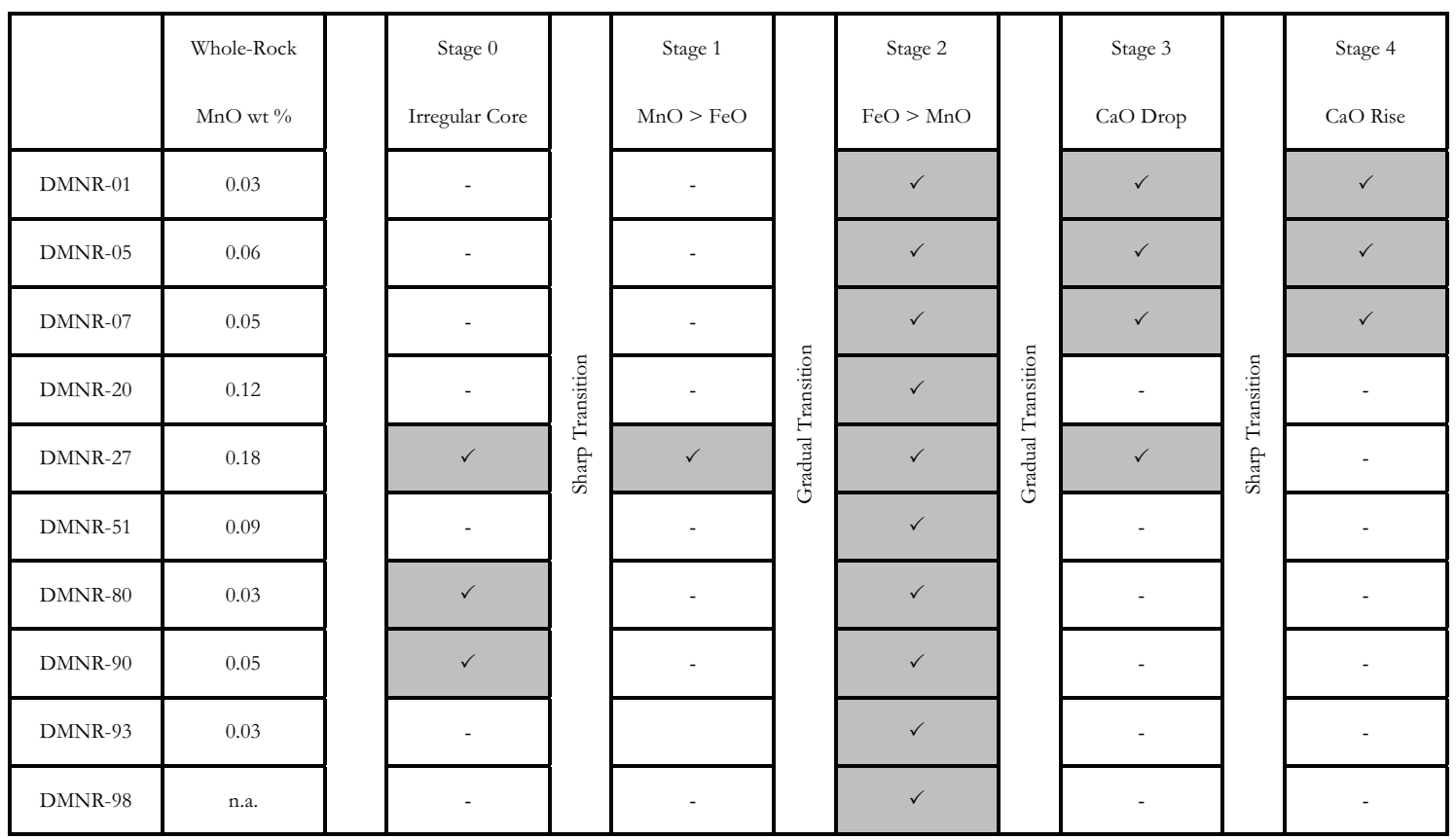

Figure 6.1. Summary of garnet growth stages seen in each sample. Whole-rock $\mathrm{MnO}$ composition is presented if available (n.a. = not analysed). Shaded boxes with ticks indicate the garnet growth stage is present in a particular sample. 
ALL STAGES SCHEMATIC

a)
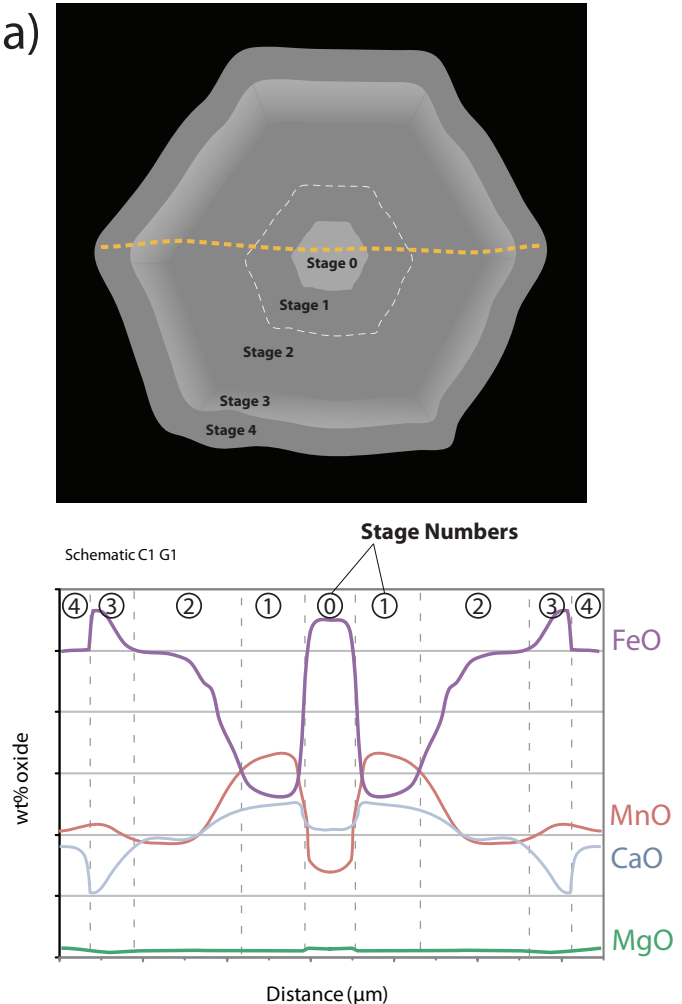

DMNR-05

C)
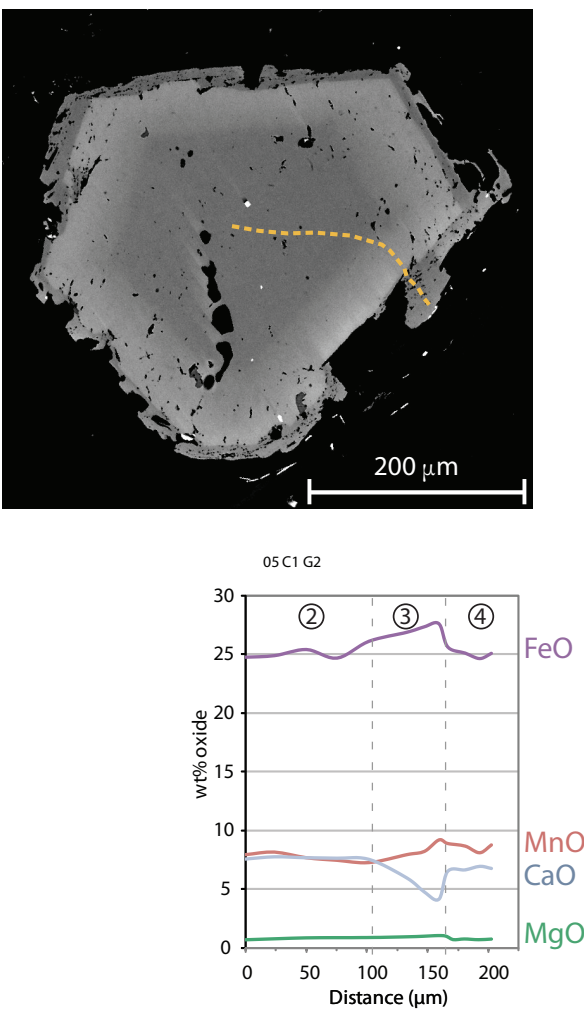

DMNR-01

b)

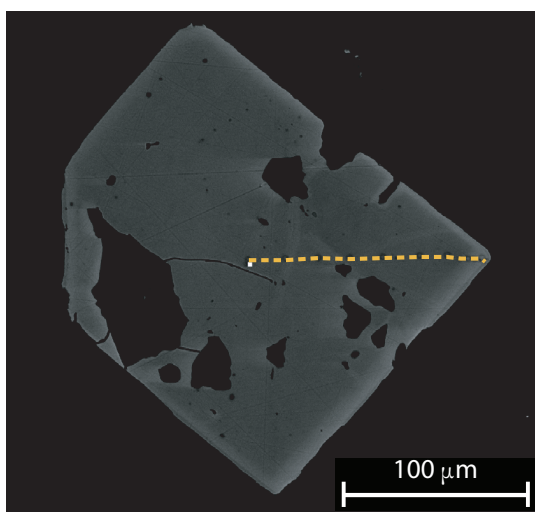

$01 d C 5$ G1

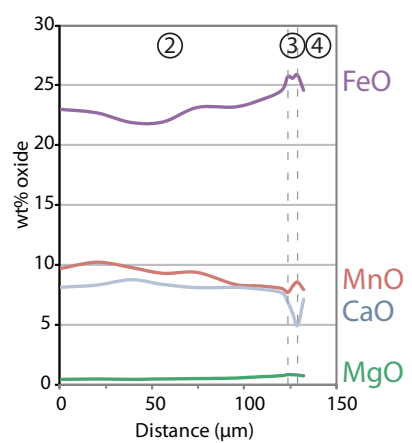

DMNR-07

d)

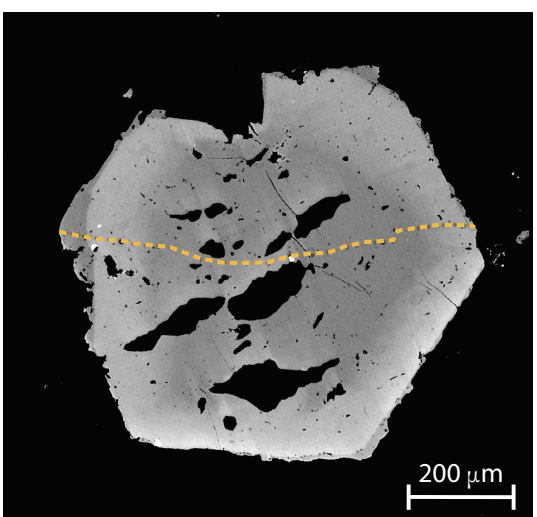

07dC10 G1

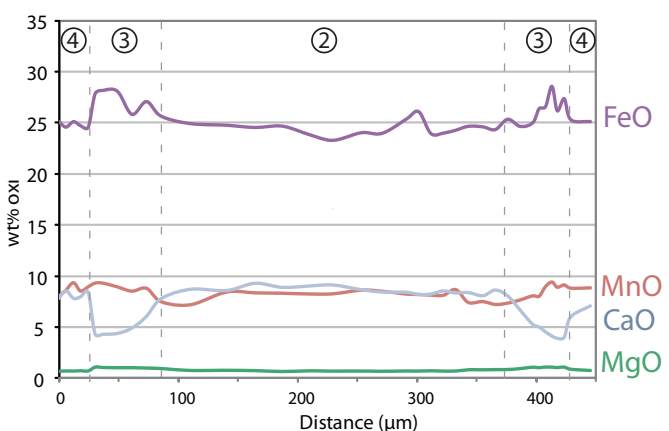

Figure 6.2. a) Schematic BSE image and compositional transect showing the general composition of each of the interpreted garnet growth stages. b) - d) BSE garnet images showing transect line (orange) and corresponding compositional transects. Vertical dashed grey lines and circled numbers superimposed on the garnet zoning profiles mark the interpreted stages of garnet growth seen in a) and explained in the text. 
DMNR-20

a)

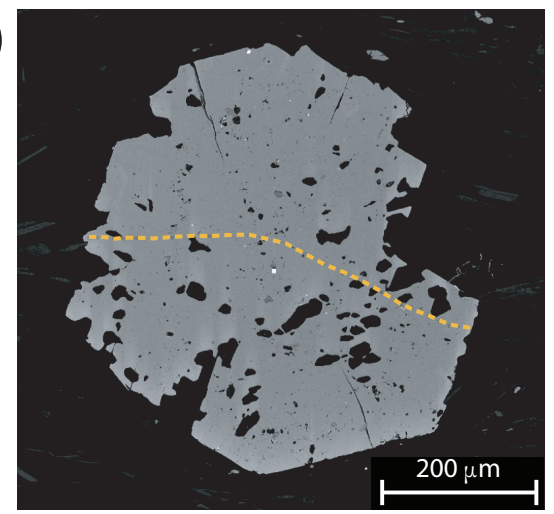

$20 a C 5 b$ G1

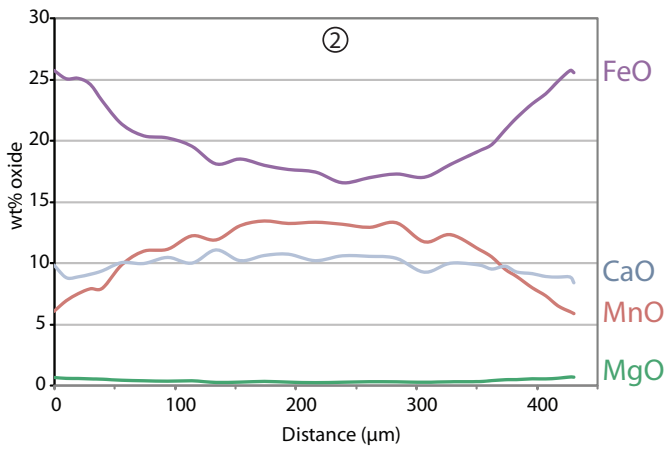

DMNR-51

c)

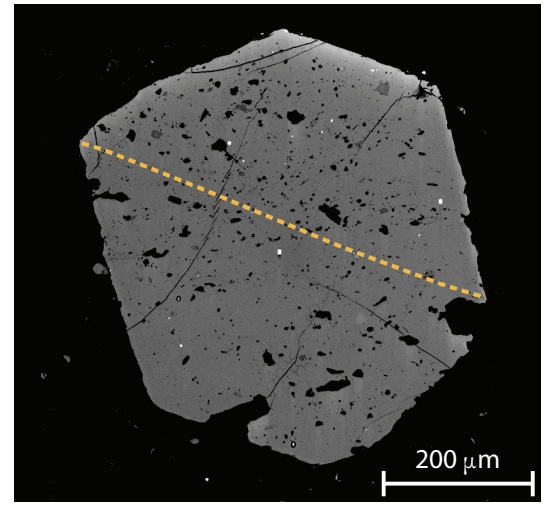

$51 \mathrm{CBG}$

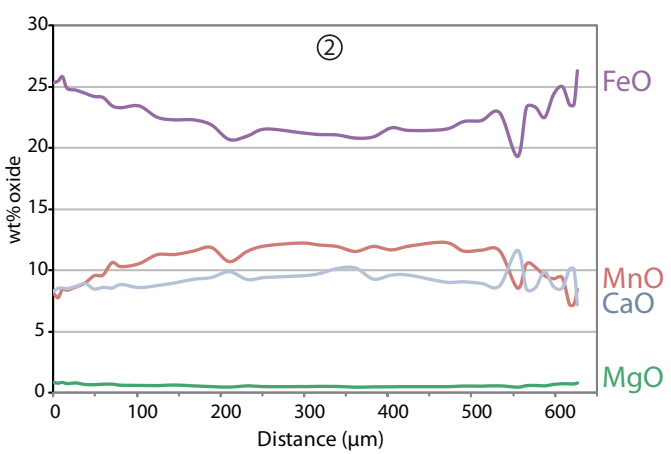

DMNR-27

b)
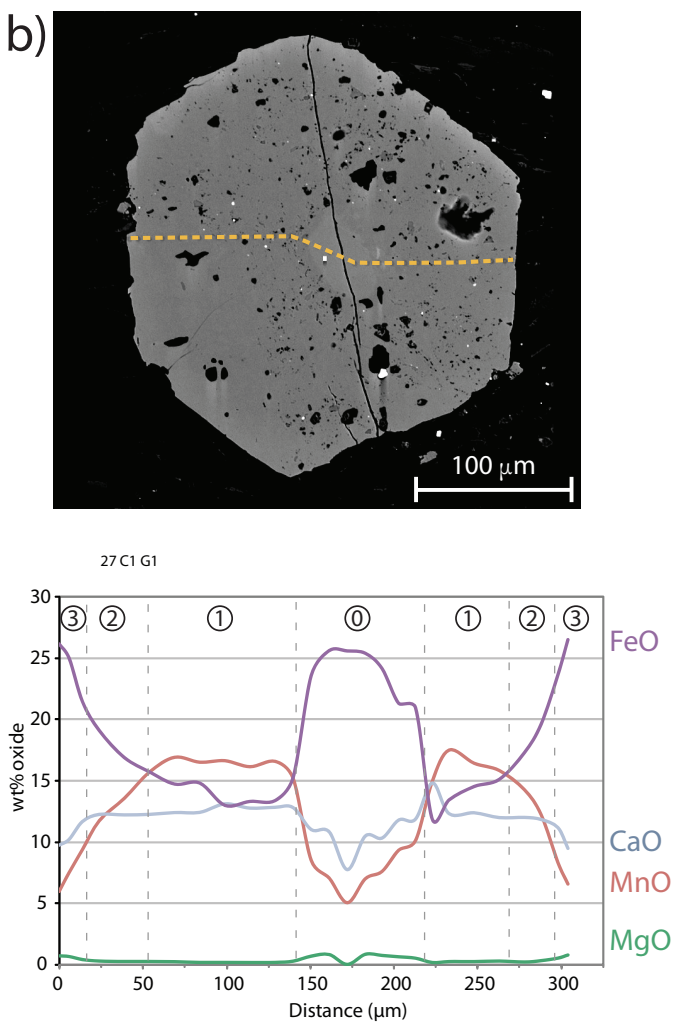

DMNR-80

d)

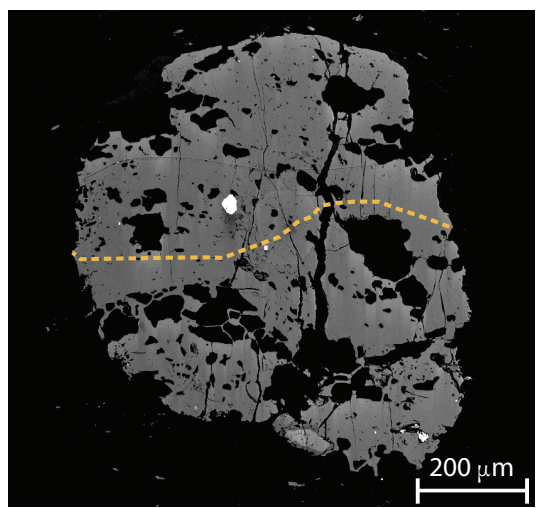

$80 \mathrm{C1}$ G1 Transect 1

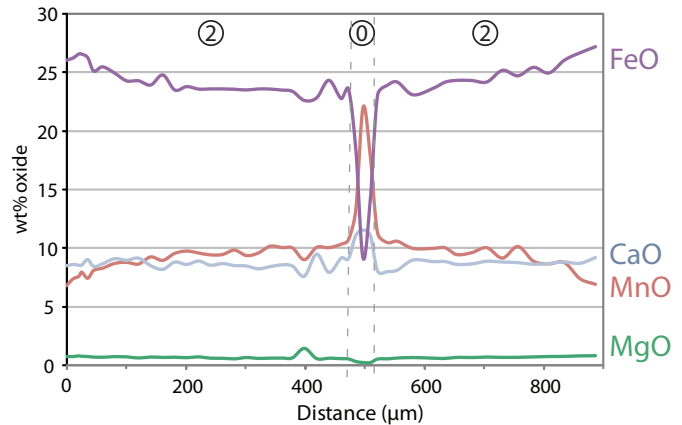

Figure 6.3. BSE garnet images showing transect line (orange) and corresponding compositional transects. Vertical dashed grey lines and circled numbers superimposed on the garnet zoning profiles mark the interpreted stages of garnet growth seen in $6.2 \mathrm{a}$ ) and explained in the text. 


\section{DMNR-90 \#1}

a)

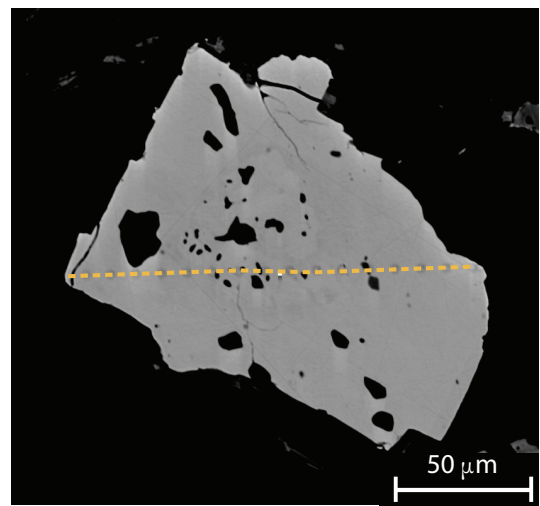

$90 \mathrm{C} 1 \mathrm{Gl}$

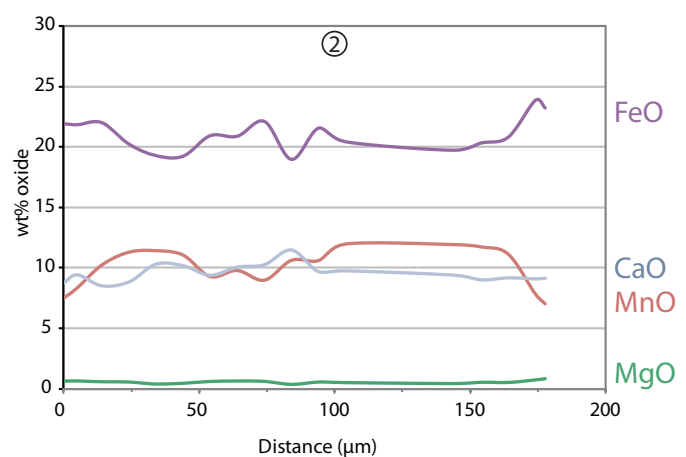

DMNR-93

d)
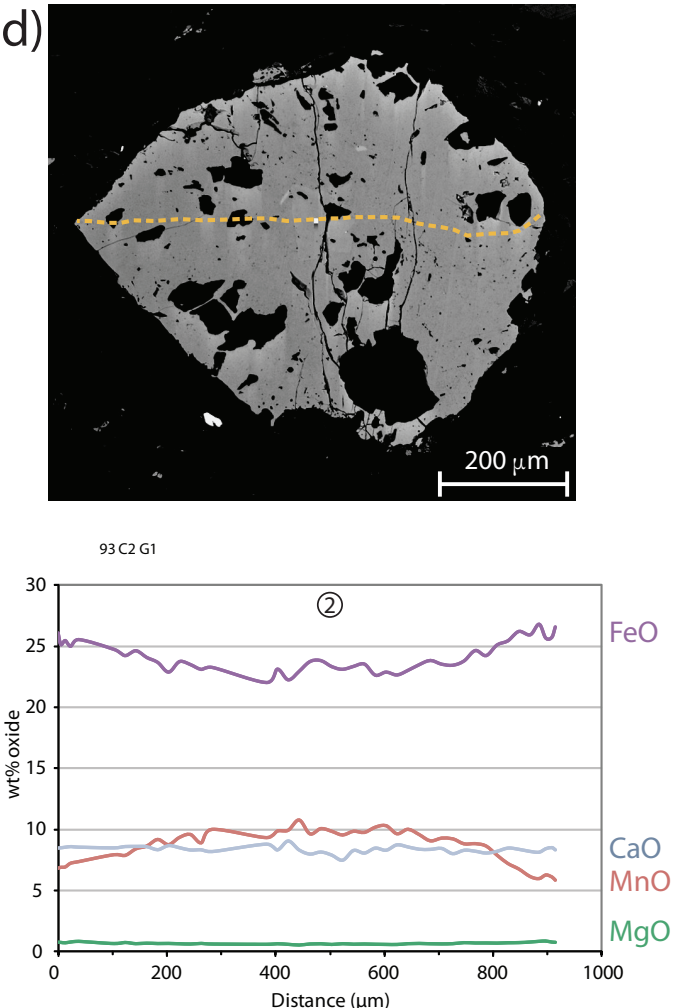

DMNR-90 \#2

b)
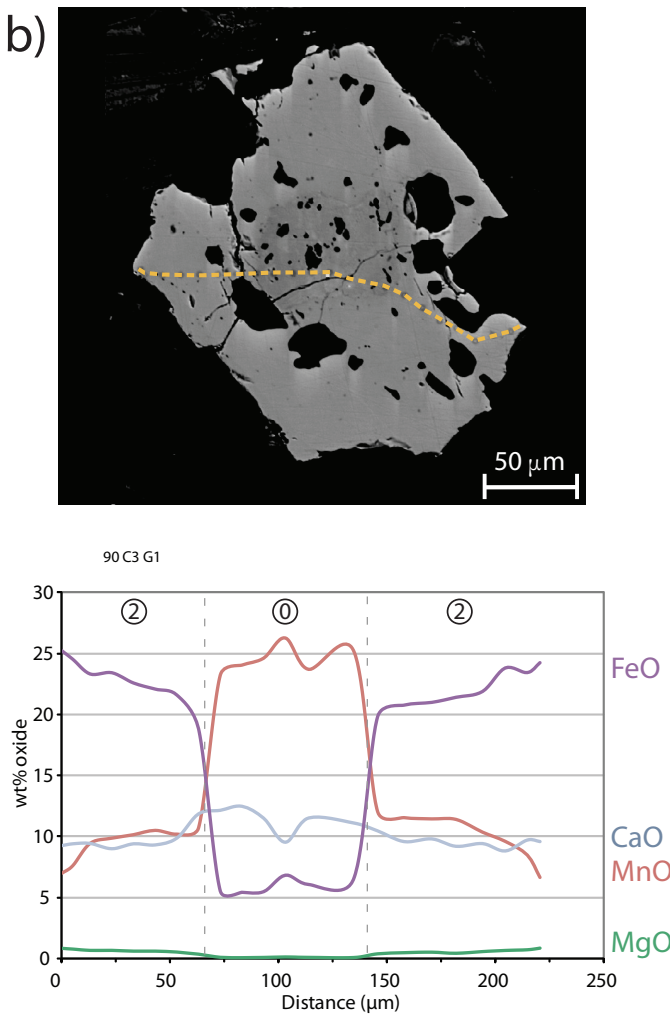

DMNR-98

c)

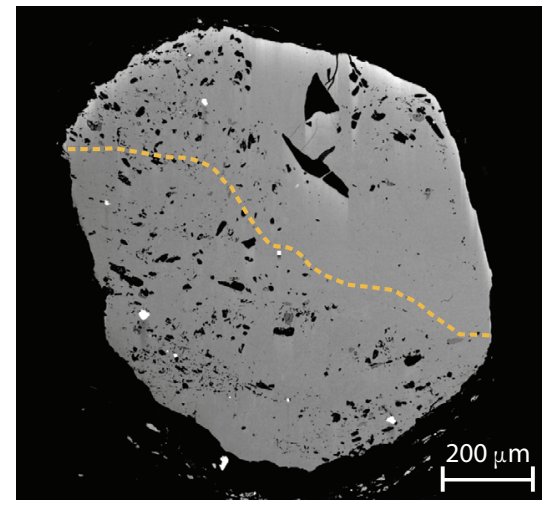

$98 \mathrm{C} 1 \mathrm{G}$

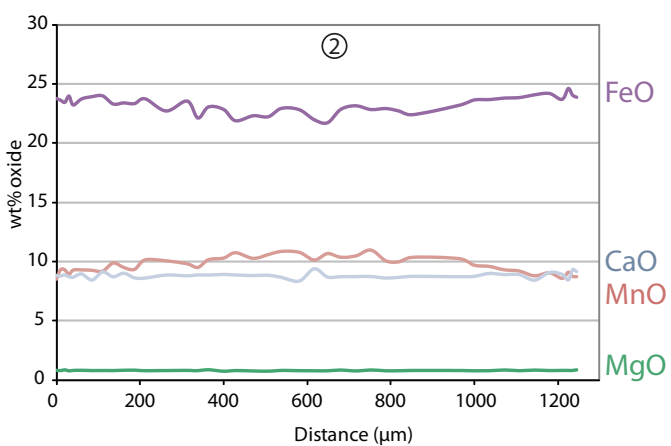

Figure 6.4. BSE garnet images showing transect line (orange) and corresponding compositional transects. Vertical dashed grey lines and circled numbers superimposed on the garnet zoning profiles mark the interpreted stages of garnet growth seen in $6.2 \mathrm{a}$ ) and explained in the text. 


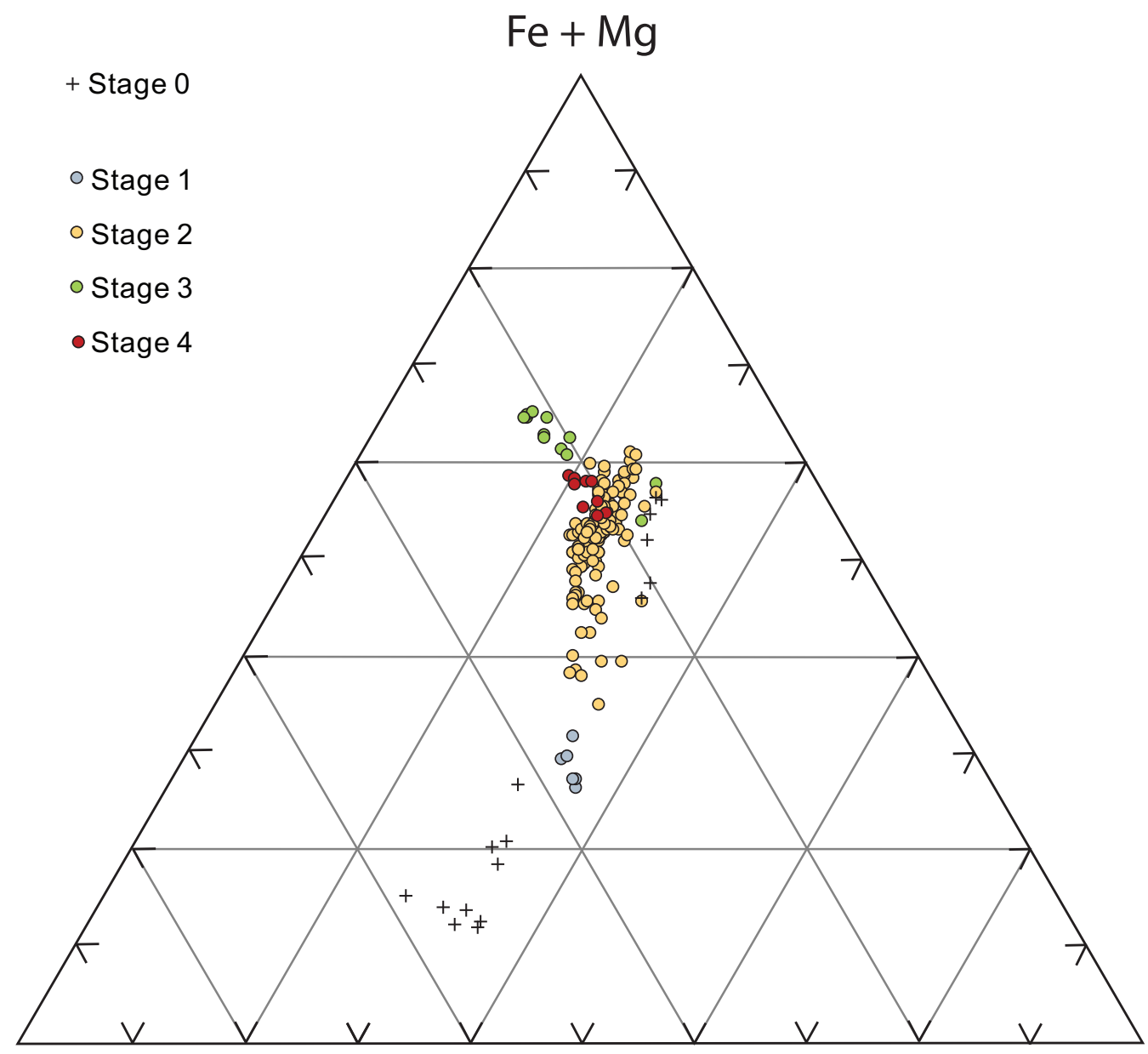

$\mathrm{Mn}$

Figure 6.5. Ternary diagram of garnet $(\mathrm{Fe}+\mathrm{Mg})$ - $\mathrm{Mn}$ - Ca compositions (mole proportions on an 8 cation basis). Each stage is reflected by a different colour. Note the general trend of decreasing Mn from stage 0 to stage 4 and the drop in Ca from stage 2 to stage 3. 


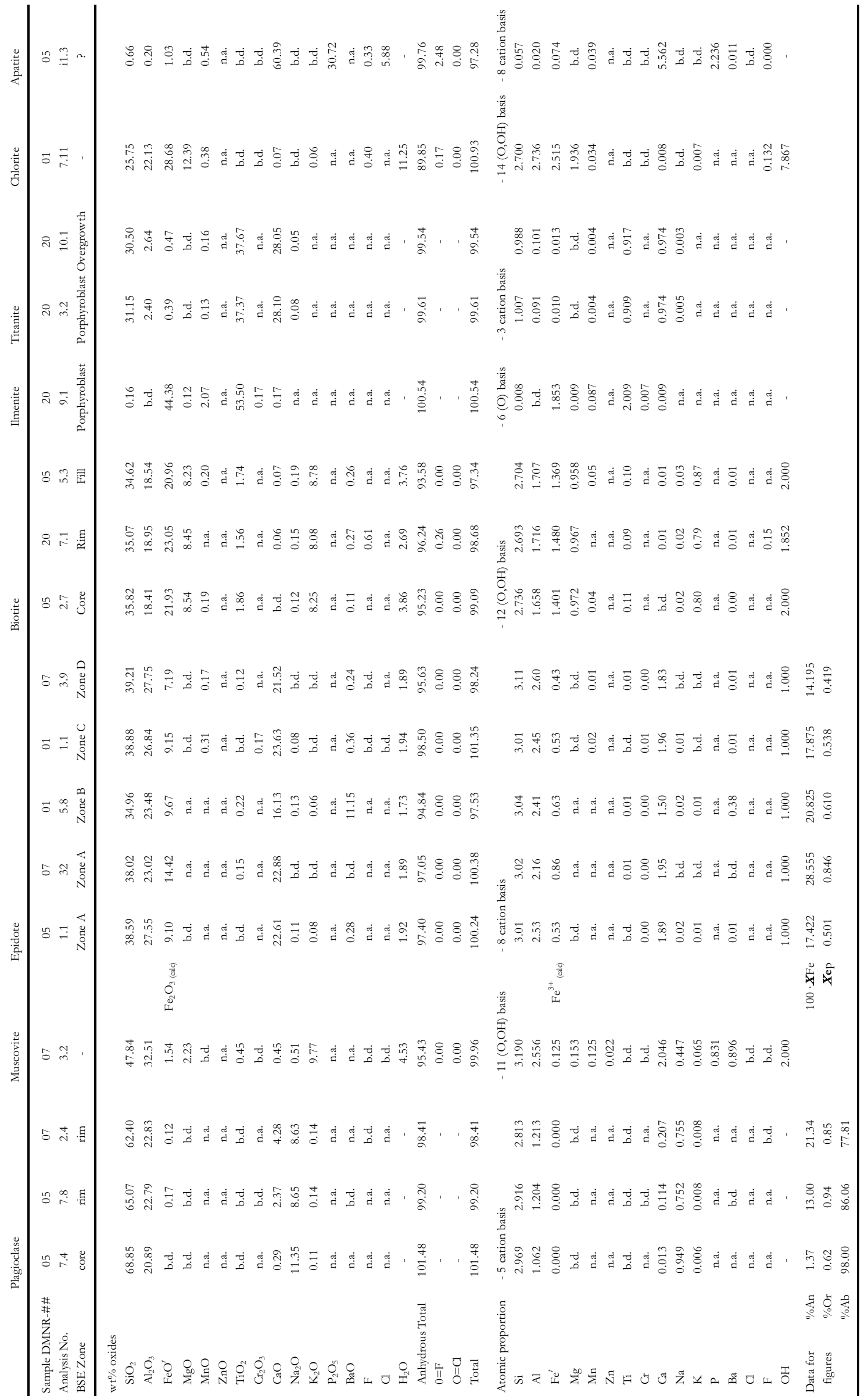

Table 6.2. Representative mineral analyses. b.d. = below detection limit, n.a. = not analysed, - = not applicable. 


\subsubsection{Plagioclase}

The results of 44 analyses of plagioclase from eight different samples are presented in table 6.2 and appendix A3.2 and are shown on a feldspar ternary diagram (Fig. 6.6). The $\mathrm{K}_{2} \mathrm{O}$ contents are consistent and low, with typical percent orthoclase near $\mathrm{Or}_{0.8}$. Most of the plagioclase is albite, which occurs as small porphyroblasts $\sim 150 \mu \mathrm{m}$ in diameter. Some of these porphyroblasts have overgrowths of oligoclase that show up as brighter areas in BSE imaging (see Fig. 6.7). Although detailed compositional zoning profiles were not obtained, the albite in the porphyroblasts is zoned. The measured percent anorthite values in 32 analyses of albite range from $A_{0.55-4.30}$ and show no obvious relationship in terms of proximity to the Alpine Fault. Three analyses of albite show higher calcium contents at $\mathrm{An}_{6.88}, \mathrm{An}_{8.73}$ and $\mathrm{An}_{9.41}$.

Results of BSE imaging show that the development of oligoclase can be patchy and typically develops in areas of low strain at the tips and within cracks of some albite porphyroblasts (Fig. 6.7). The results of 17 analyses of oligoclase range between $\mathrm{An}_{10.9}-\mathrm{An}_{23.9}$ with a gap in data between $\mathrm{An}_{13-}$ $\mathrm{An}_{17.49}$.

\subsubsection{Muscovite}

White mica occurs as a typically fine $(<10-50 \mu \mathrm{m}$ thick) matrix mineral in greyschist, where it typically defines the dominant foliation (textural zones TZ2b, TZ3 \& TZ4 (Turnbull, et al., 2001)). The dioctohedral micas in the study area are slightly phengitic, with compositions that can be described in terms of some limited mixing (solid solution) involving the following compositional end-members:

$$
\begin{array}{ll}
\text { Muscovite } & \mathrm{K} \mathrm{Al}_{2} \mathrm{AlSi}_{2} \mathrm{O}_{10}(\mathrm{OH})_{2} \\
\text { Celadonite } & \mathrm{K} \mathrm{MgAl} \mathrm{Si}_{4} \mathrm{O}_{10}(\mathrm{OH})_{2} \\
\text { Fe-celadonite } & \mathrm{K} \mathrm{FeAl} \mathrm{Si}_{4} \mathrm{O}_{10}(\mathrm{OH}) \\
\text { Paragonite } & \mathrm{Na} \mathrm{Al}_{2} \mathrm{AlSi}_{3} \mathrm{O}_{10}(\mathrm{OH})
\end{array}
$$

For ten analyses of white mica from five samples, $\mathrm{Na} /(\mathrm{Na}+\mathrm{K})$ is 0.04 to 0.11 on a molar basis, $\mathrm{Si}$ is 3.15 to 3.28 atoms per formula unit (apfu on 11 oxygen basis), and $(\mathrm{Mg}+\mathrm{Fe})$ is 0.21 to $0.40 \mathrm{apfu}$. 
a)

b)

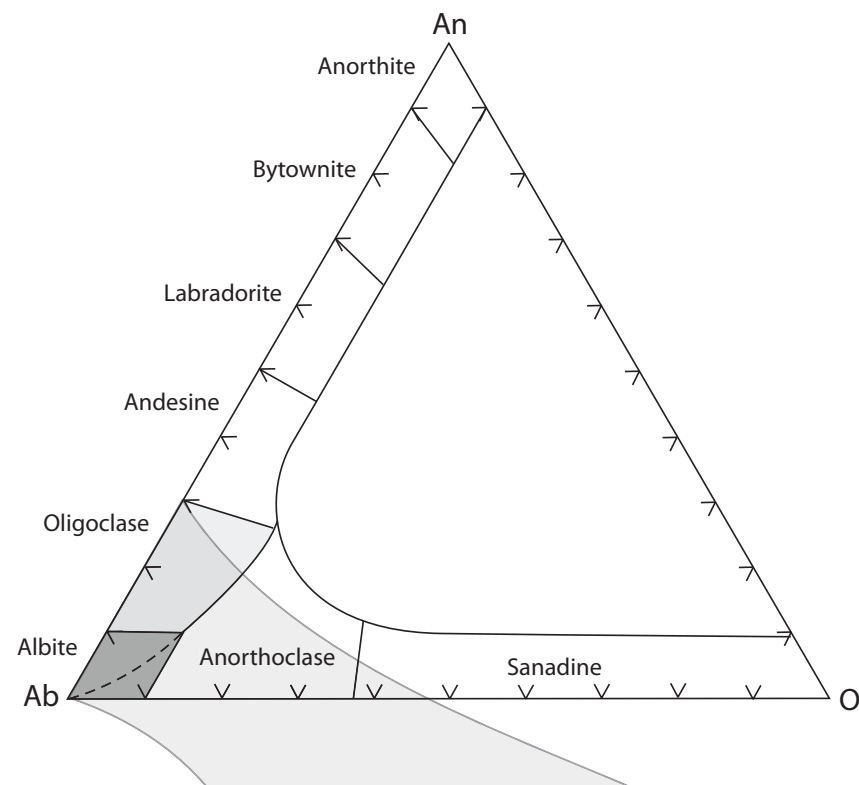

- Cores

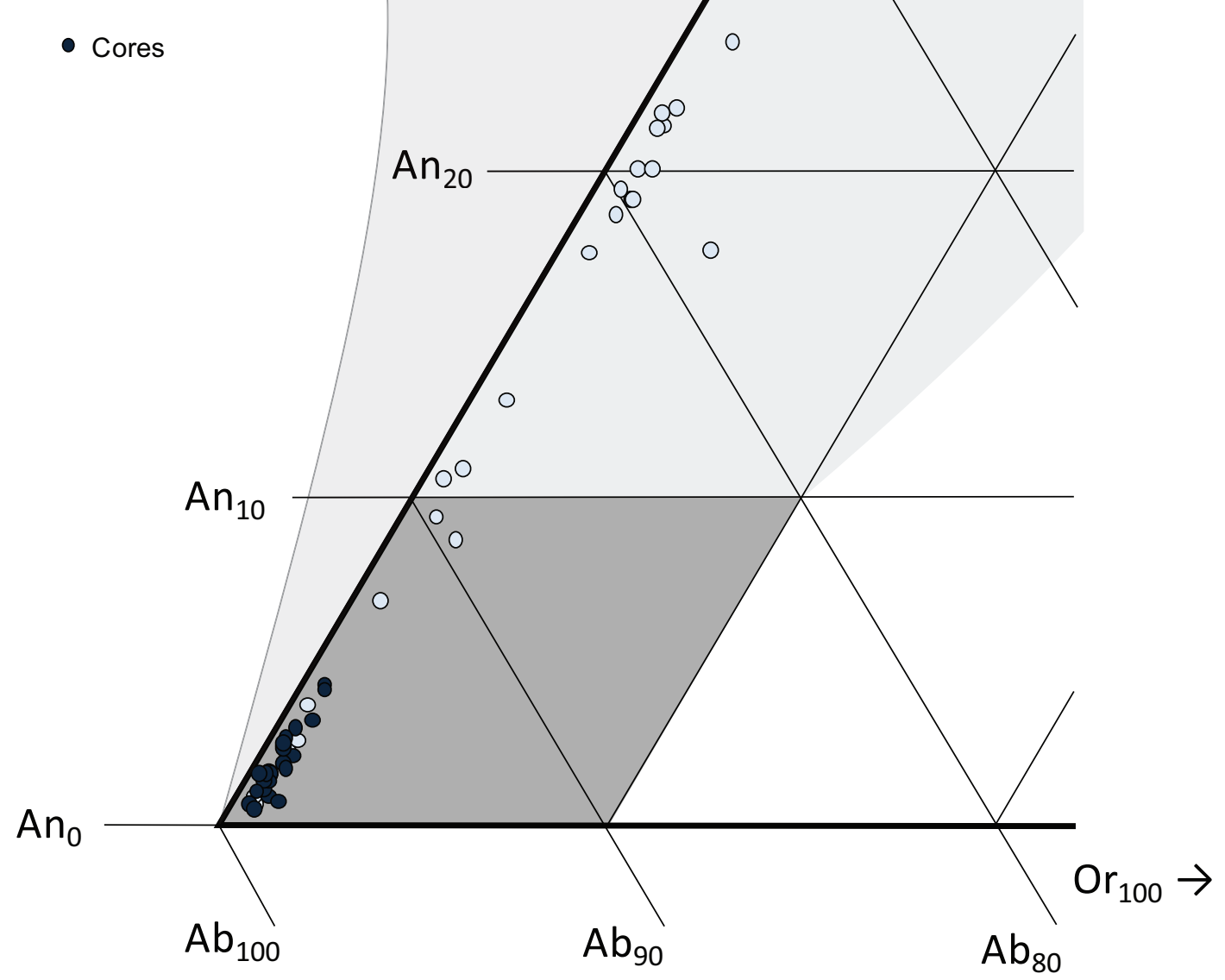

Figure 6.6. a) Solid solution nomenclature of feldspars plotted on a ternary diagram of endmembers from Deer (1966). Note the shaded albite and oligoclase fields also presented in b). b) Plagioclase analyses from this study ranging from $\mathrm{An}_{0.5-25}, \mathrm{Ab}_{99.5-75}$. 


\subsubsection{Epidote}

The epidote-group minerals have a formula A1A2 M1M2M3 $\mathrm{Si}_{2} \mathrm{O}_{7} \mathrm{SiO}_{4} \mathrm{O}(\mathrm{OH})$, where A1 is a smaller alkali site, A2 is a larger alkali site that can accommodate $\mathrm{REE}^{3+}$ and large divalent cations such as Sr \& Ba, and M1, M2 \& M3 are occupied by $\mathrm{M}^{3+}$ cations (Armbruster, et al., 2006). Epidote in the study area is strongly zoned, visible both in BSE images and chemical composition (Figs. 6.8 \& 6.9, tables $6.2 \& 6.3)$. Epidotes with this zonation pattern are also seen as inclusions inside some garnet porphyroblasts.

The epidote compositions fall between the following endmembers (Armbruster, et al., 2006):

$$
\begin{aligned}
& \text { epidote } \mathrm{Ca}_{2} \mathrm{Al}_{2} \mathrm{Fe}^{3+} \mathrm{Si}_{2} \mathrm{O}_{7} \mathrm{SiO}_{4} \mathrm{O}(\mathrm{OH}) \text { and } \\
& \text { clinozoisite } \mathrm{Ca}_{2} \mathrm{Al}_{3} \mathrm{Si}_{2} \mathrm{O}_{7} \mathrm{SiO}_{4} \mathrm{O}(\mathrm{OH})
\end{aligned}
$$

The $\mathrm{Ba}$ contents are for the most part low, between 0.01 and 0.08 apfu on an 8 cation basis, except in a narrow interior growth zone that appears bright in BSE images (Zone B, see below). The Ba content in these zones range from 0.18 to 0.38 apfu. With the exception of $\mathrm{Ba}$, the other analysed cations occur only in trace amounts.

The epidote in the study area is strongly zoned, and this zoning is visible both in transmitted light microscopy and in BSE images. The typical zoning pattern in epidote from the study area is shown in table 6.3 and figures 6.8 and 6.9. Epidote with this zonation pattern also occur as inclusions inside garnet porphyroblasts.

The compositions vary between different zones in epidotes (Fig. 6.9) with a decrease in $\mathrm{Fe}^{3+}$ at the most extreme rim (zone D) from core zones A, B and C. This zoning pattern is compared to other studies of Haast Schist in the discussion section of this chapter.

\subsubsection{Biotite}

Although textural evidence such as later biotite infilling pull-aparts and rimming biotite porphyroblasts provides evidence of a protracted biotite growth history (Fig. 6.10), the biotite compositions in greyschists from the study area vary little, and show no correlation with either distance from the Alpine Fault or with specific biotite textures. The compositions are presented (Fig. 6.11) in an ideal biotite plane (Guidotti, 1984). 
Figure 6.7. BSE image of a dark grey albite porphyroblast overgrown by lighter grey oligoclase on the rim tips (DMNR-07).

Figure 6.8. BSE and schematic images of epidote porphyroblasts. a) Zoning textures of epidote represented by 4 zones, A-D (DMNR-01). b) Epidote inclusions in garnet and in the rock matrix have comparable zoning (DMNR-05).
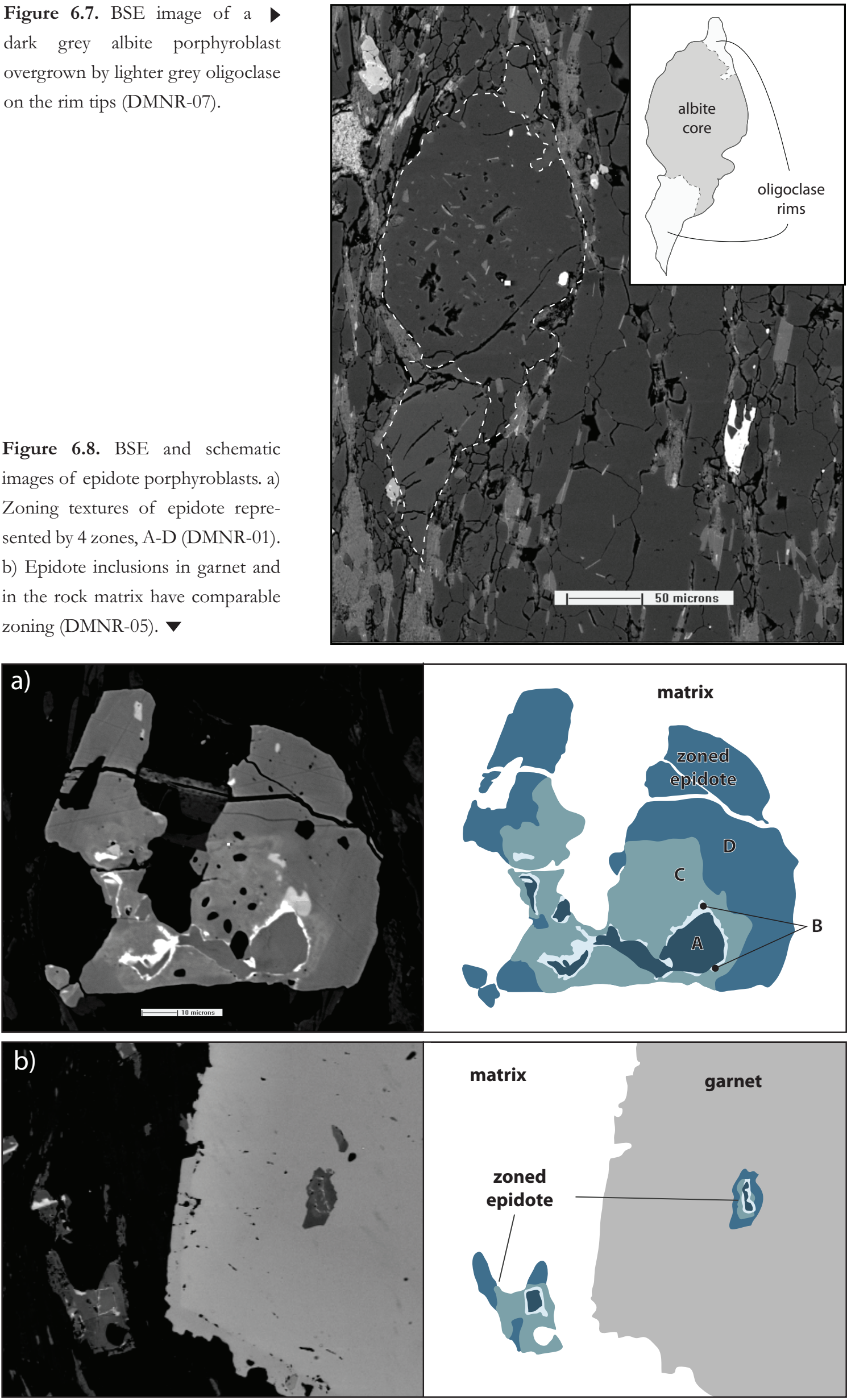


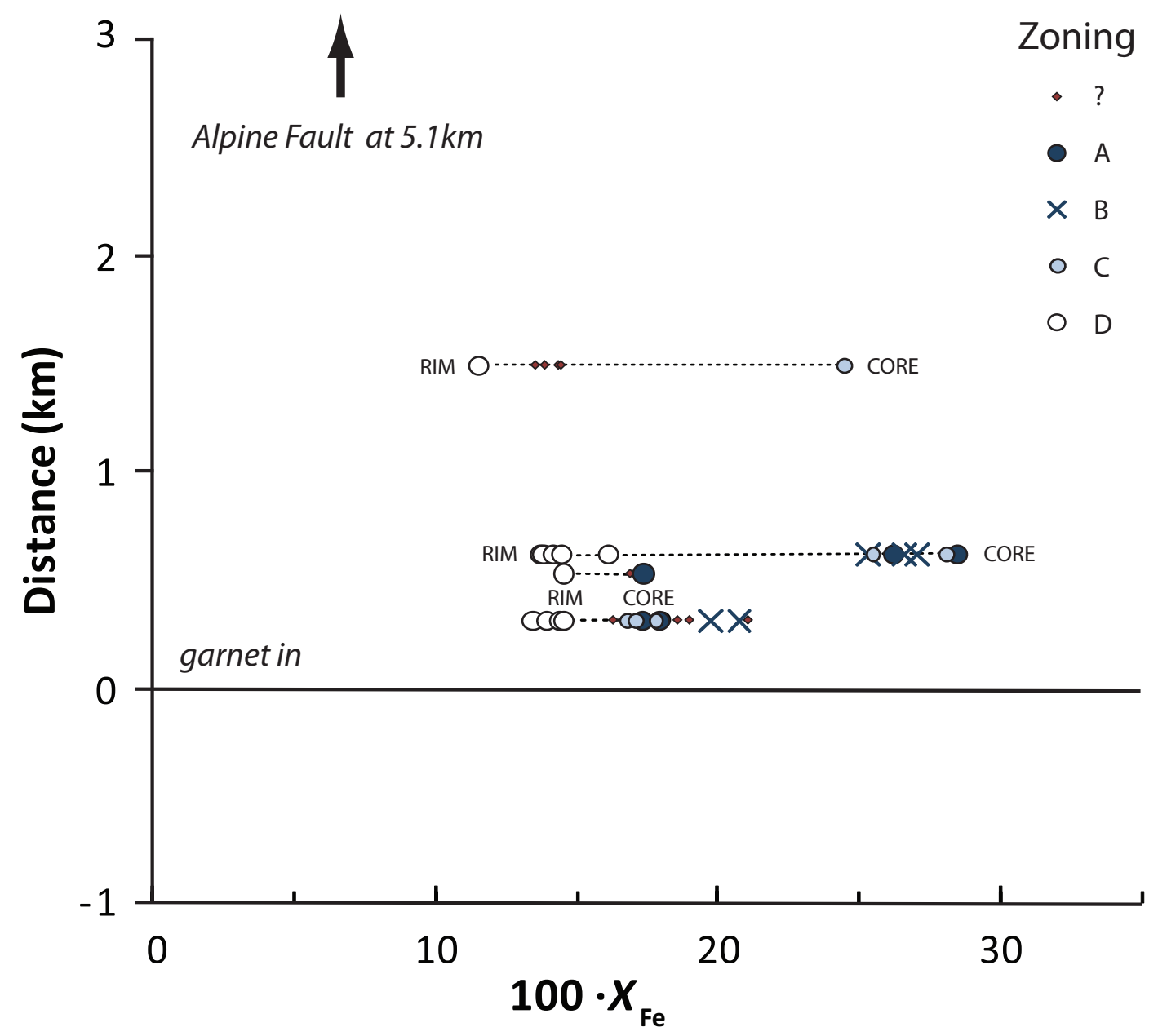

Figure 6.9. Epidote $100 \cdot X_{\mathrm{Fe}}$ compositions plotted against map distance from the garnet-in isograd to the Alpine Fault. ? denotes zone of analysis point unknown. Dashed lines connect cores and rim analyses of individual epidotes within a sample.

\begin{tabular}{cccc}
\hline & \multicolumn{1}{c}{$\boldsymbol{X}_{\mathrm{ep}}$} & $100 \cdot \boldsymbol{X}_{\mathrm{Fe}}$ & $\mathrm{Ba}(\mathrm{apfu})$ \\
\hline Zone A & $0.5-0.85$ & $17.4-28.4$ & $0.00-0.01$ \\
Zone B & $0.61-0.77$ & $19.8-27.1$ & $0.18-0.38$ \\
Zone C & $0.49-0.84$ & $16.8-28.2$ & $0.01-0.08$ \\
Zone D & $0.34-0.46$ & $11.54-16.2$ & $0.00-0.02$ \\
\hline
\end{tabular}

Table 6.3. Epidote zone compositions. $\mathrm{Xep}=\left(\mathrm{Fe}^{3+} /\left(\mathrm{Fe}^{3+}+\mathrm{Al}+\mathrm{Cr}^{3+}-2\right)\right)(\mathrm{Franz} \& \mathrm{Liebscher}, 2004)$ and 100•XFe $\left(100\left(\mathrm{Fe}^{3+} / \mathrm{Fe}^{3+}+\mathrm{Al}\right)\right)($ Grapes \& Hoskin, 2004). 

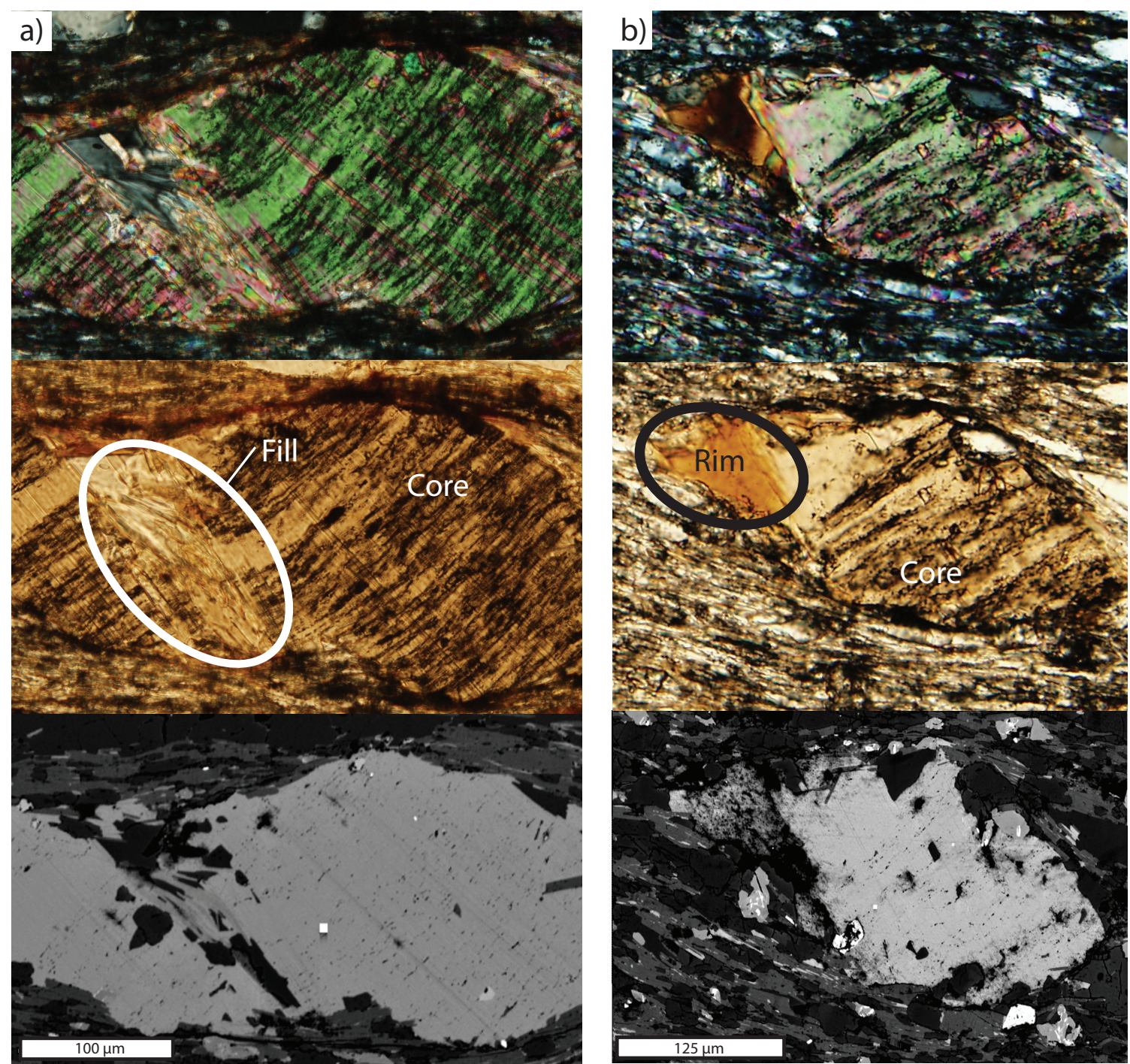

Figure 6.10. Biotite core, rim and fill textures shown in crossed polarised light (top), plane-polarised light (middle) and BSE imaging (bottom) of DMNR-05. Note how the cleavage in the cores of the biotite porphyroblasts are at a different angle to the external foliation. N.B. - the fill in a) is partially replaced by chlorite in the top half (marked by the black-grey area in cross-polarised light) therefore analyses were conducted in the lower half where biotite is not intergrown with chlorite. 


\subsubsection{Ilmenite \& Titanite}

Results of analyses of ilmenite and titanite are presented in appendix A3.6 and table 6.2. Ilmenite in greyschist from the study area occurs as elongate porphyroblasts that are often rimmed by titanite (Fig. 6.12). The ilmenite contains minor amounts of Mn (0.05 apfu), for analyses normalised on a 2 cation basis. Titanite (sphene) is present as porphyroblasts and overgrowths of ilmenite. The chemical formula of titanite can be described as:

$$
\mathrm{Ca}\left(\mathrm{Ti}>>\mathrm{Al} . \mathrm{Fe}^{3+}\right)(\mathrm{O}>>\mathrm{OH}, \mathrm{F})\left(\mathrm{SiO}_{4}\right)
$$

The six analyses of titanite from two samples of greyschist were slightly aluminous, with 0.060.11apfu. Traces of Na, Ba \& Mn may be substituted on the Ca site at levels typically 0.01 apfu or less. Porphyroblasts and overgrowth textures have no significant differences in composition.

\subsubsection{Chlorite}

The chlorite in the greyschist from the study area is slightly Fe-rich, with $\mathrm{Fe} /(\mathrm{Fe}+\mathrm{Mg})=0.55-0.59$, and low in $\mathrm{Mn}$ (0-0.04 apfu, for a formula normalised to 10 cations). Like biotite, chlorite is compositionally quite uniform. The chlorite compositions are similar to analyses of chlorite from medium-low grade metamorphosed pelites (Laird, 1988) (Fig. 6.13).

\subsubsection{Apatite}

Trace amounts of fluorine-rich apatite occur in most samples in the matrix and as inclusions in garnet. Results of analyses of apatite are presented in appendix 3.6 and table 6.2.

\subsection{Discussion}

\subsubsection{Garnet}

Prograde garnet growth zoning of garnet from the Newton Range for the most part involves the progressive replacement of $\mathrm{MnO}$ and/or $\mathrm{CaO}$ by $\mathrm{FeO}$ from core to rim (as $\mathrm{MgO}$ is in low concentrations $(<0.5 \%)$ and near constant, $\mathrm{Fe} /(\mathrm{Fe}+\mathrm{Mg})$ also increases). Samples with the highest whole rock $\mathrm{MnO} \mathrm{wt}^{\%} \%$ have garnet cores higher in $\mathrm{MnO}$ (Figs. 6.1, 6.2, 6.3 \& 6.4), reflecting 


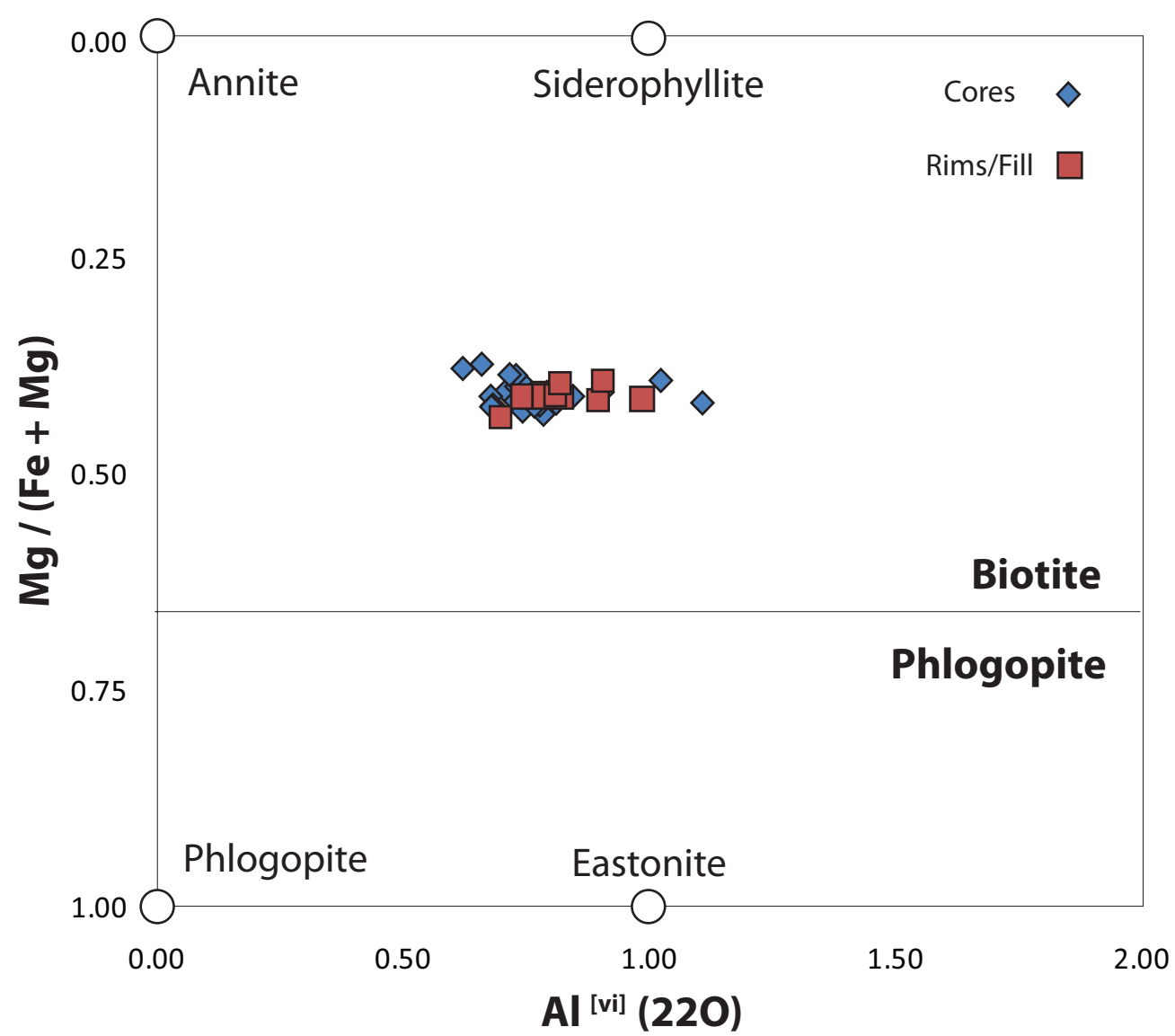

Figure 6.11. Biotite compositions plotted on the ideal biotite plane (Guidotti, 1984). Core and rim/ fill compositions are much the same in composition.

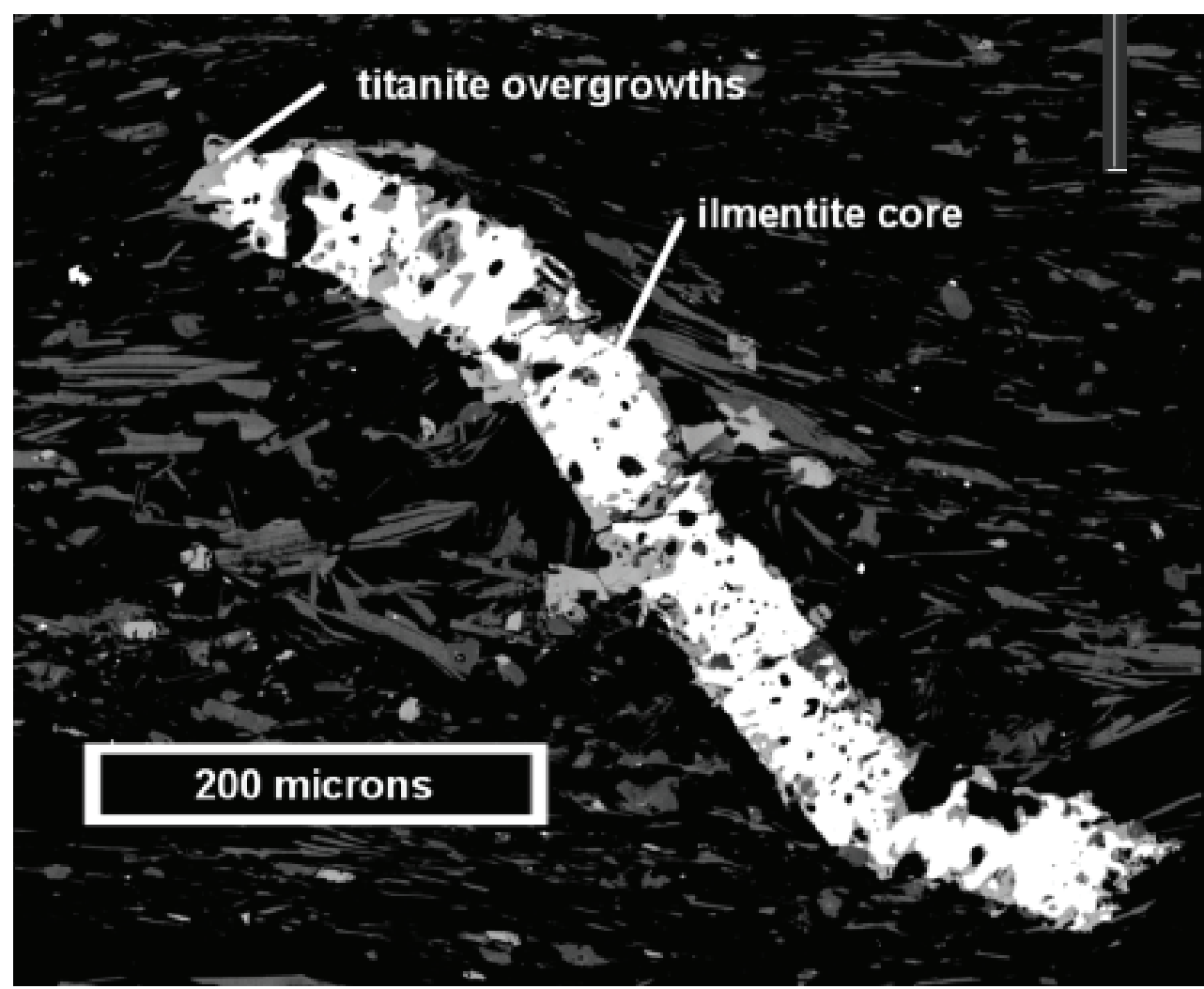

Figure 6.12. BSE image of an ilmenite porphyroblast overgrown by titanite (DMNR-20). 

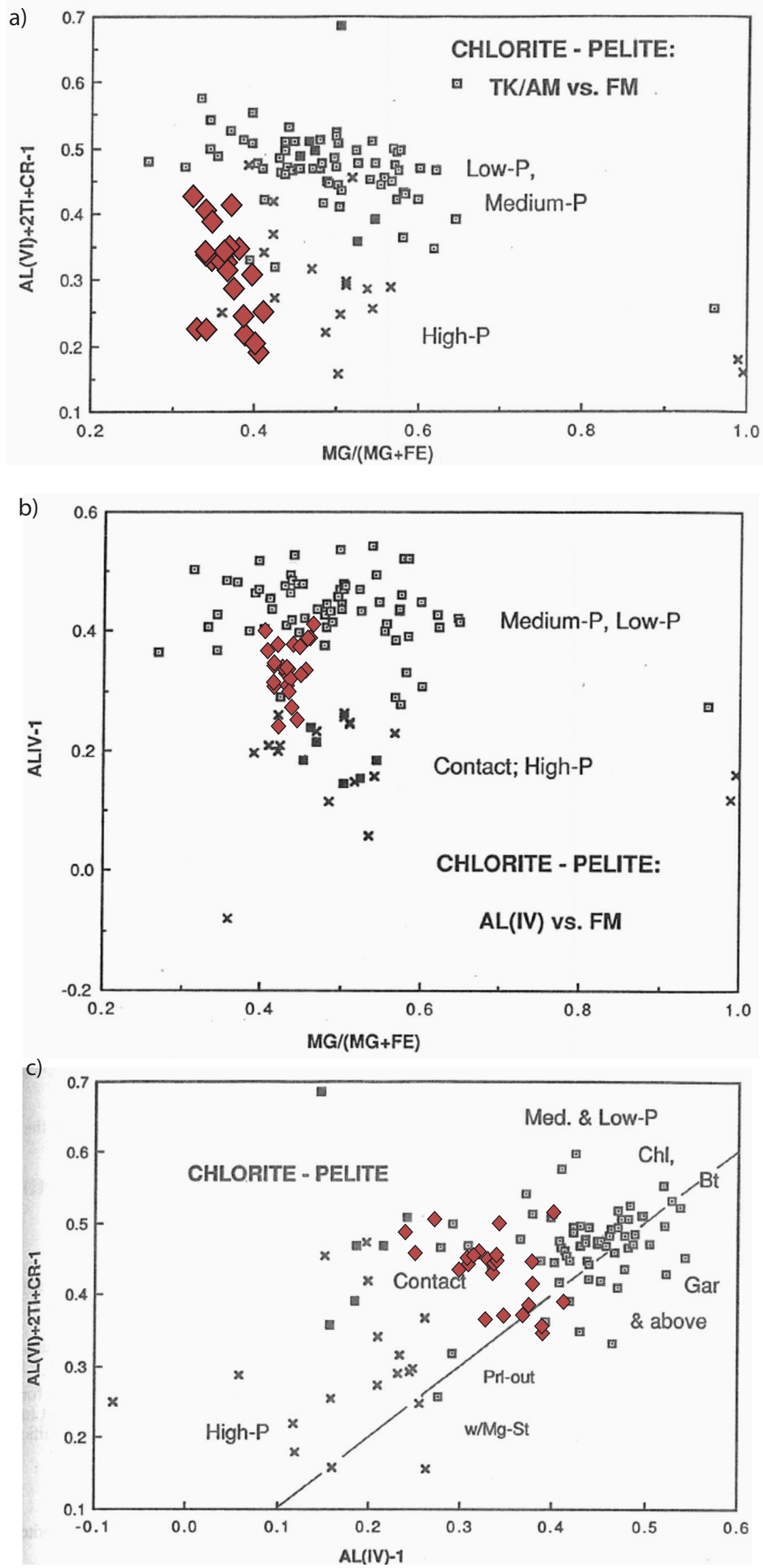

Figure 6.13. Chlorite compositions plotted on diagrams of metamorphosed pelite modified from Laird (1988). Newton Range chlorite analyses are red diamonds. 
incipient growth of garnet at lower P-T conditions (Symmes \& Ferry, 1992). In many samples, the composition of garnet does not vary much throughout a transect. This is interpreted to reflect garnet growth for a short period in the $P$ - $T$ history, hence different garnets from different samples represent growth during different parts of the $P-T$ path. Because of this, the linking of different parts of compositional garnet transects throughout separate samples as "stages" is more practical than assigning a "type" to a whole garnet as is done in other studies from the northern section of the Southern Alps (Storkey, 1999; Pepper, 2000; Williams, 2006).

\section{Stages 1-4}

Stage 1 only occurs in sample DMNR-27, with the high MnO content reflecting garnet growth at low P-T conditions (Symmes \& Ferry, 1992). A prograde path is inferred from stage 1 to stage 2 as $\mathrm{MnO}$ gradually decreases towards the rim. The abrupt decrease of $\mathrm{CaO}$ marks stage 3 . A decrease in $\mathrm{CaO}$ can be attributed to continued garnet growth following the appearance of oligoclase (more calcic plagioclase), and the necessary partitioning of some Ca into oligoclase. This stage shows an important shift from garnet growing synchronously with albite to garnet growing with a higher P-T oligoclase phase late in the metamorphic history. This part of the metamorphic history is discussed further in the chapter seven.

Stage 4 is an overgrowth on some stage 3 garnet rims and is similar in composition (with slightly less $\mathrm{CaO}$ ) to stage 2 garnets, suggesting a return to synchronous garnet-albite growth (no oligoclase). This means garnet growth is either occurring during post peak metamorphic decompression or during another metamorphic event. Either way, the absence of oligoclase suggests this overgrowth is occurring at lower temperatures than stage 3. As the decompressional path in Alpine Schists in the northern section of the Southern Alps is tangential to water isopleths (i.e. the rock is no longer dehydrating), it is probable that garnet growth is not occurring at this time (Vry, et al., 2008). The increase of $\mathrm{CaO}$ on some garnet rims may be attributed to a mylonitic overprint as suggested by Upton, (1995) and Vry et al., (2004). Garnet growth during the late Cenozoic metamorphic event is recorded in a garnet from mylonitised Alpine Schist $\sim 35 \mathrm{~km}$ southeast of Hokitika with an approximate age of $6.4 \pm 2.4 \mathrm{Ma}$ (using calculated $P-T$ conditions of garnet growth and a constant uplift rate along a $45^{\circ}$ dipping Alpine Fault plane) (Vry, et al., 2004).

Stage 4 does not seem to rely on any particular whole rock composition nor occurs in garnets closest to the Alpine Fault, as would be expected for a "mylonitic" overprint. The three samples showing stage 4 are located adjacent to the Pounamu Ultramafic Belt (PUB) and garnet-in isograd, 
$\sim 8 \mathrm{~km}$ southeast of the Alpine Fault. Samples are within $100 \mathrm{~m}$ of one another and are close to bands of altered greenschist and quartz veins up to $1 \mathrm{~m}$ thick, oriented sub-parallel to the dominant greyschist foliation. The source of these quartz veins may be metamorphic dehydration reactions during exhumation of the rocks, probably during the late Cenozoic uplift of the Southern Alps (see Vry, et al., 2009). The growth of stage 4 garnet rims may be evidence of metasomatic processes occurring at depth late in the metamorphic history, with mobilisation of $\mathrm{MnO}$ from nearby $\mathrm{MnO}$ rich greenschist facilitating overgrowth of selected garnets proximal to the $\mathrm{MnO}$ source. More in depth study must be completed to further establish such a hypothesis.

\section{Garnet Compositions in Alpine \& Otago Schist}

The range of garnet compositions are generally comparable to previous analyses of garnet from Haast Schist samples, in particular those from fairly low-grade (greenschist facies and greenschistamphibolite transition) occurrences. The most detailed study of garnets in the region splits garnets into three types - A, B and C (Williams, 2006) (Fig. 6.14b) and the different garnet stages identified in this study can be identified in these three types. Type A garnets have stages $1 \& 2$, type B garnets have stage 2 and type $C$ garnets have stages 2, 3 and 4. Williams, (2006) notes the dominant control on the type of garnet is whole rock chemistry, with type A garnets having the highest whole-rock $\mathrm{MnO}$ composition, an observation which also applies to the Newton Range where rocks with higher bulk rock $\mathrm{MnO}$ (such as DMNR-27) contain garnets with higher MnO core compositions (stage 1).

High $\mathrm{MnO}$ (stage 1 and 2) garnet have similar compositions (with lower $\mathrm{CaO} \& \mathrm{MnO}$ and higher $\mathrm{FeO} \& \mathrm{MgO}$ ) to garnet found in the Otago Schist (Brown, 1967) and the Haast Schist (White, 1996). Stage 3 garnet are similar in composition to: type 2 Haast Schist garnet (White, 1996); Alpine Schist garnet (Cooper, 1974); but are slightly more Mn rich than garnet from higher grade garnetoligoclase facies Alpine Schists (Grapes \& Watanabe, 1994). Garnet in mylonitised Alpine Schist $\sim 35 \mathrm{~km}$ east-southeast of Hokitika (Vry, et al., 2004) has a compositional pattern similar to garnet from this study $(\mathrm{CaO}$ gradually decreases towards the rim and increases sharply at the most extreme rim). Core compositions (Zone 1 dated using Sm-Nd methods at $97.8 \pm 8.1 \mathrm{Ma}$ ) from Vry et al., (2004) have compositions similar to stage 2 garnet from the Newton Range. Although the composition of garnet cores and the general zoning pattern are similar, the composition of $\mathrm{MnO}$ shows a different pattern. $\mathrm{MnO}$ from Vry et al., (2004) gradually drops toward the rim from $\sim 8 \mathrm{wt} \%$ to $<0.5 \mathrm{wt} \%$, compositions far lower than found in this study (lowest $\mathrm{MnO} \sim 6 \mathrm{wt} \%$ ) therefore dated garnet zones (Vry, et al., 2004) cannot directly be applied to garnet from this study. 

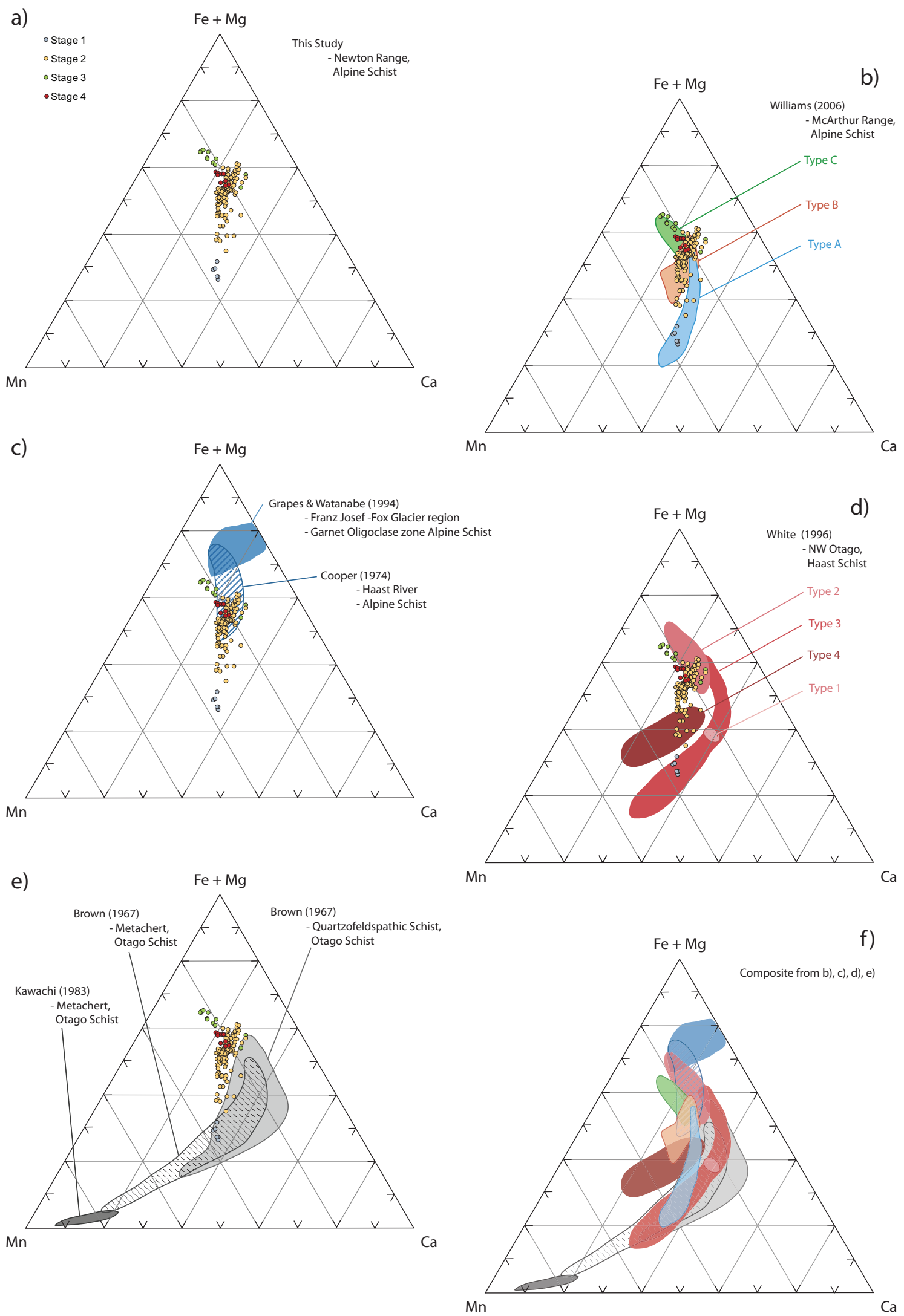

Figure 6.14. Ternary diagrams of garnet compositions. a) Composition of different garnet stages (this study). b) Garnet types from (Williams, 2006). c) Garnet compositional fields for Alpine Schists (Cooper, 1974; Grapes \& Watanabe, 1994). d) Garnet types of the Haast Schist (White, 1996). Note Type 4 garnets are of Aspiring lithological association, not Torlesse sediments. e) Otago Schist fields for metachert (Brown, 1967; Kawachi, 1975) and quartzofeldspathic schist (Brown, 1967). f) All field from b) - e) combined. 


\section{Stage 0 Cores}

The irregular composition of stage 0 cores signifies a phase of garnet growth before the dominant porphyroblast growth event (Alpine Schist metamorphism). Therefore the cores may be from a previous event (Otago Schist) or detrital in origin (Torlesse terrane) with preferential nucleation occurring later in the history at stage 1 or 2 . Both of these options are explored with respect to the low and high $\mathrm{MnO}$ stage 0 cores.

The stage 0 core with low $\mathrm{MnO}$ (DMNR-27) has a composition similar to some detrital garnet found in Torlesse terrane sediments from the South Island (Yokoyama, 1994) and group in garnet sources of calc-silicate and amphibolite grade quartzofeldspathic rocks (Grapes, et al., 2001) (Fig. $6.15 \mathrm{a} \& \mathrm{~b}$ ). This composition also plots near compositions of higher grade Otago Schist (Brown, 1967; White, 1996) (Fig. 6.14d). As DMNR-27 is relatively high in whole-rock MnO (0.18 wt\%), initial garnet nucleation should accordingly occur with high $\mathrm{MnO}$ core compositions. As this is not the case with the stage 0 core, it is likely that this core is detrital in origin.

High $\mathrm{MnO}$ stage 0 cores from samples DMNR-80 and 90 do neither plot near any detrital garnet compositions, or Torlesse terrane source garnet compositions (Yokoyama, 1994; Smale, 1997; Grapes, et al., 2001), so it is unlikely that these cores are detrital. However, these cores do have similar compositions to high MnO garnet from the Otago Schist (Brown, 1967; White, 1996) and the most $\mathrm{MnO}$ rich garnets from the McArthur Range (Williams, 2006), therefore the potential sources of these stage 0 cores are the Otago Schist or earliest Alpine Schist events. As these samples are relatively low in bulk rock $\mathrm{MnO}(0.05-0.06 \mathrm{wt} \%)$, the nucleation of $\mathrm{MnO}$ rich garnets from this bulk rock composition is unlikely. So if these cores are deemed to be from an early metamorphic event, the bulk rock composition may have been different at the time of initial garnet nucleation.

A possibility is that localised, sparse, thin lenses of $\mathrm{MnO}$ rich sediment (possibly metachert like composition) or localised $\mathrm{MnO}$ rich minerals (e.g. chlorite) may have been part of the sedimentary protolith. This could allow garnet nucleation to occur at lower $P$-T conditions with higher $\mathrm{MnO}$ compositions than expected through analysis of whole-rock chemistry alone. The small size of the garnet cores may also reflect the small quantity of $\mathrm{MnO}$ rich source material, where garnets would cease growth once the $\mathrm{MnO}$ reservoir was depleted and would also account for why these localised $\mathrm{MnO}$ sources are longer evident in the rock. As stages 1, 2 and 3 are interpreted to have grown during the Alpine Schist event, a gradual transition in composition may be expected from stage 0 to stage 1 (or 2) if garnet growth is during the same event. However, the sharp transition from stage 0 to stage 1 (or 2) may suggest these garnet cores grew during the earlier Otago Schist event and not 
a)
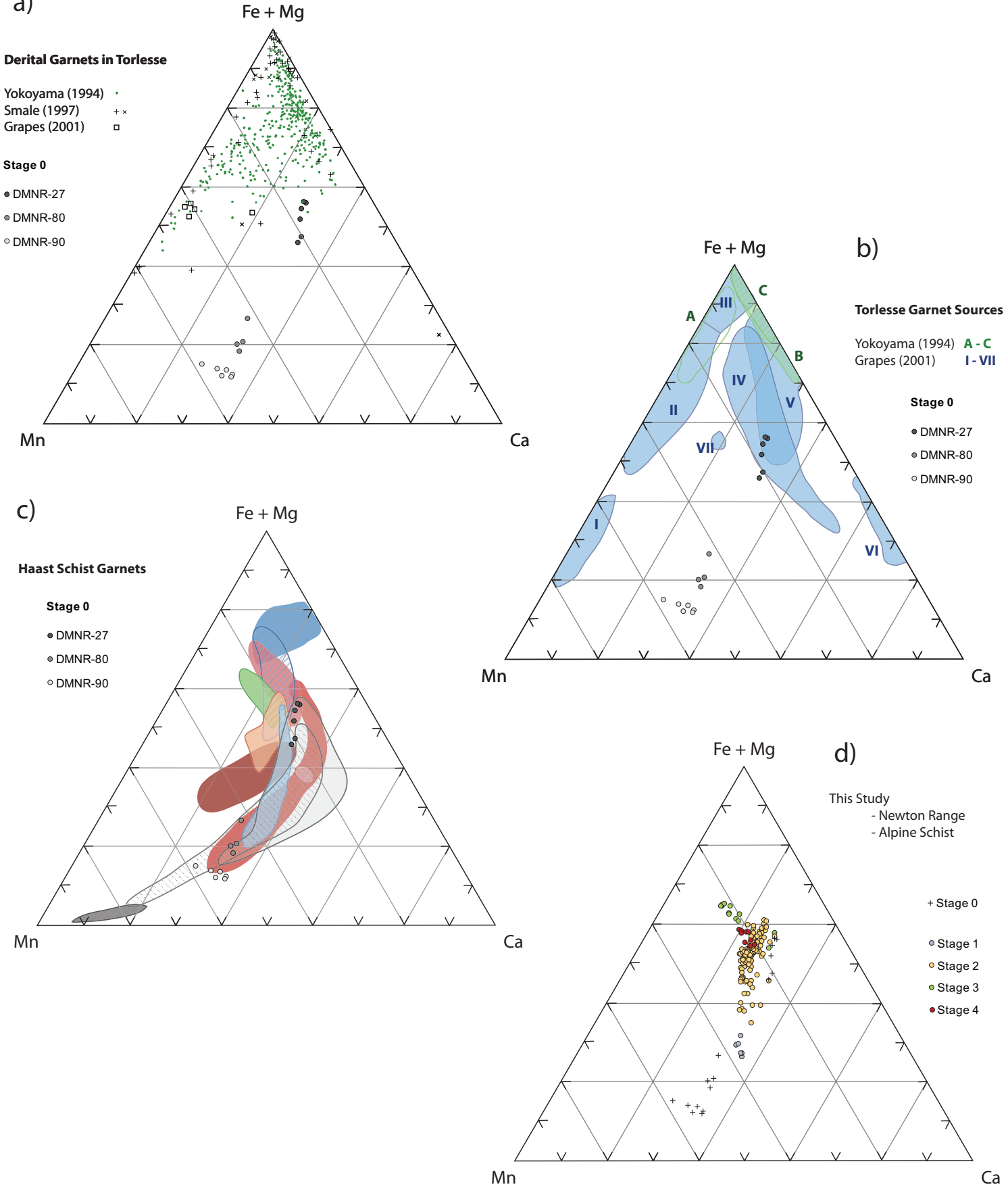

Figure 6.15. Ternary diagram for garnet compositions of stage 0 low $\mathrm{MnO}$ (DMNR-27) and high $\mathrm{MnO}$ (DMNR $80 \&$ 90) garnet cores. a) Stage 0 cores plotted against detrital garnets found in Torlesse sediments from the Kaimanawa Ranges, Wellington and the South Island respectively (Grapes, et al., 2001; Smale, 1997; Yokoyama, 1994). b) Possible source rocks for detrital garnets in Torlesse sediments. (Yokoyama, 1994): A Granite in Westland; B - High-grade rocks in the Antarctic; C - Frazer Gneiss. (Grapes, et al., 2001): I - granite pegmatites; II - primary magmatic/muscovite-bearing granites; III - cordierite-bearing granites/migmatities; IV - calc silicate rocks; V - amphibolite grade quartzofeldspathic rocks; VI - secondary garnet after prehnite/pumpellyite in granitoids; VII - tonalite gneiss. 
during the early Alpine Schist event. Although beyond the scope of this study, diffusion modelling across stage $0 /$ stage 1 boundaries may allow insights into the time between the different growth stages, and hence may allow insights into the timing of core growth.

\subsubsection{Plagioclase}

In many rocks metamorphosed to greenschist-amphibolite facies conditions, two different sodic plagioclases (albite and oligoclase) coexist, and appear to have crystallised contemporaneously or with a core/rim relationship (e.g. Evans, 1964; Crawford, 1966; Cooper, 1972; Carpenter, 1981; Maruyama, et al., 1982; Grapes \& Otsuki, 1983). The miscibility gap is due to the presence of an asymmetrical solvus with a steeper limb along the high-Na (albite) side, such that with increasing temperature the anorthite content of the oligoclase decreases while that of the albite remains relatively constant (Fig. 6.16). This is termed the peristerite solvus, or peristerite gap, and is an expression of the energetics of increasing Al/Si order in albite (Carpenter, 1994). During progressive metamorphism, albite and oligoclase coexist, and the anorthite content of the oligoclase decreases until temperatures near the crest of the solvus are attained and plagioclase with compositions bridging the peristerite gap grow (Evans, 1964; Crawford, 1966; Cooper, 1972; Maruyama, et al., 1982; Grapes \& Otsuki, 1983).

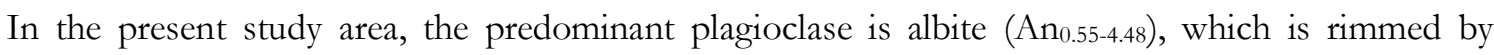
oligoclase $\left(\mathrm{An}_{18-25}\right)$ on the tips of many porphyroblasts (Fig. 6.7). Samples containing plagioclase with compositions spanning the miscibility gap occur in both the lowest grade garnet-bearing samples and also higher grade samples more proximal to the Alpine Fault, suggesting that the crest of the solvus approximately coincides with the lowest temperatures at which garnet appears in greyschists of ordinary bulk composition $\left(\sim 500-525^{\circ} \mathrm{C}\right.$, see chapter seven). The textures of oligoclase on albite can be thin, patchy and uneven, and this introduces the plagioclase results may be mixed analyses resulting from beam overlap. However, it its highly unlikely that all of the plagioclase compositions that span the miscibility gap could be mixed analyses, as the analytic spots were all carefully selected using BSE imaging. The simplest interpretation, and one that is consistent with the available data, is that in the Newton Range the first appearance of garnet in greyschist rocks of ordinary bulk composition, approximately coincides with temperatures near the crest of the peristerite solvus.

Grapes \& Otsuki (1983) observed a peristerite gap in garnet grade schists in the Franz-Josef Fox Glacier region, gradually becoming less distinguishable closer to the Alpine Fault and eventually 


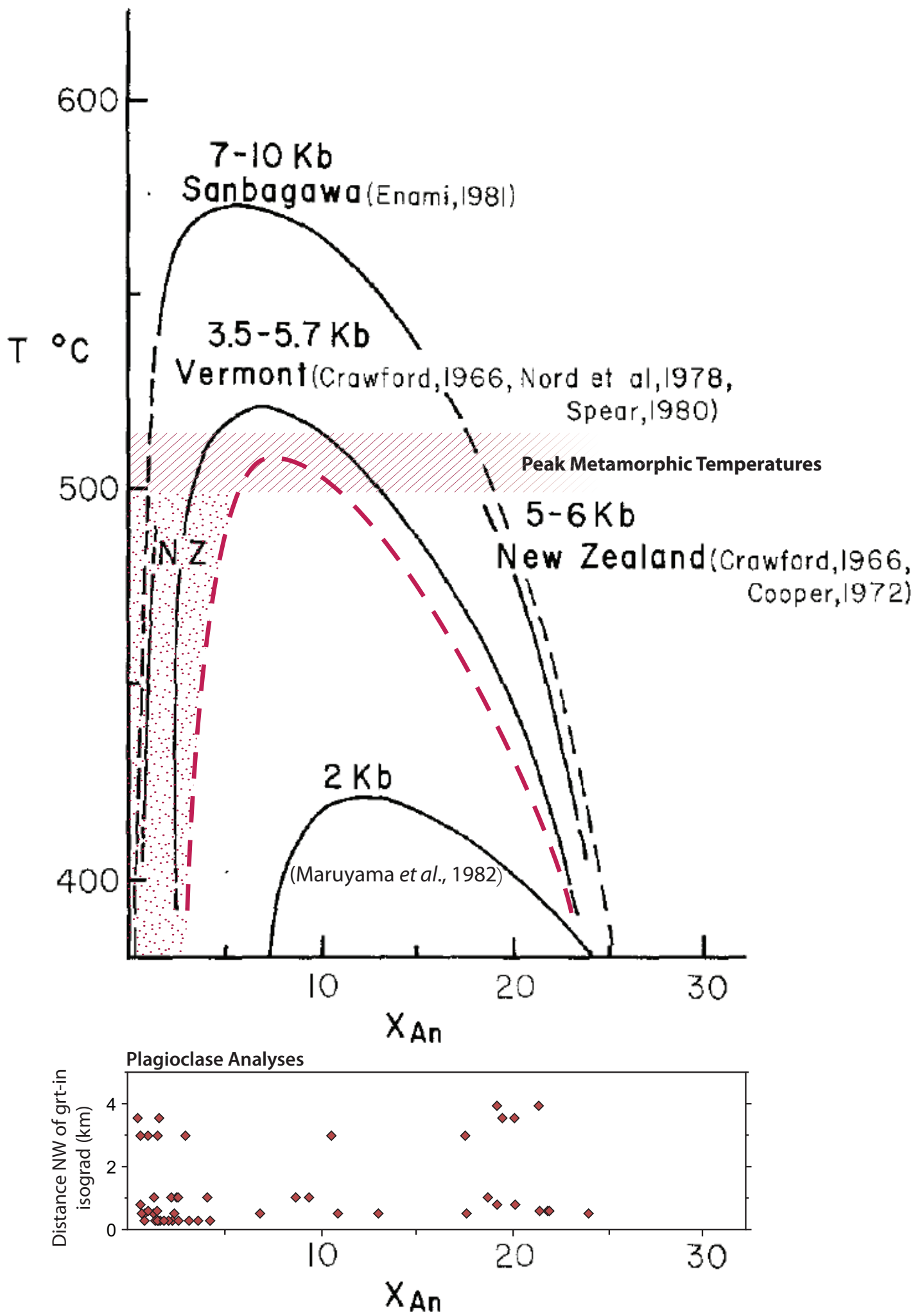

Figure 6.16. Schematic plagioclase $X_{\mathrm{An}}$ - temperature solvus (dashed red line) plotted against other plagioclase solvuses modified from (Maruyama et al., 1982). Red, diagonally striped area is the peak metamorphic temperatures obtained using THERMOCALC (chapter seven). Oligoclase compositions are interpreted to have grown at these temperatures. Dotted area shows where $<\mathrm{Ab}_{5}$ albite compositions may grow prior to peak metamorphic conditions. Plagioclase analyses show no relation show to metamorphic grade (increasing distance from grt-in isograd). Alpine Fault is $\sim 5.1 \mathrm{~km}$ northwest of the grt-in isograd 
disappearing at the garnet-oligoclase zone where oligoclase is the only plagioclase phase. Plagioclase compositions in this study seem to have no correlation to distance from the Alpine Fault with plagioclase overgrown by rims of albite (An 0.7-9.4) and oligoclase (An 10.6-23.9) located in the same rocks as the first appearance of garnet. A peristerite gap was also not observed in greyschists $\sim 7 \mathrm{~km}$ to the north-northeast in the McArthur Range (Williams, 2006). For the peristerite gap not to be apparent at peak metamorphic conditions in this study, the $\mathrm{X}_{\mathrm{Ab}}$ - temperature solvus must differ in shape to the Franz-Josef-Fox Glacier region. Figure 6.16 (modified from Maruyama et al., (1982)) shows a schematic minimum temperature solvus for the Newton Range compared to other studies containing peristerite gaps. The lower solvus allows compositions of $\mathrm{An}_{6-13}$ to grow at peak metamorphic temperatures of $\sim 500^{\circ} \mathrm{C}$, temperatures at which a peristerite gap is observed in the Franz Josef-Fox Glacier region.

Most of the garnet growth history (stages $1 \& 2$ ) is interpreted to occur synchronously with albite with stage 3 of garnet growth showing a gradual decrease in $\mathrm{CaO}$, representing synchronous growth with oligoclase. This pattern differs to the Franz Josef-Fox Glacier region where the appearance of oligoclase precedes garnet (Grapes \& Watanabe, 1994). The implications of this are further discussed in chapters seven and eight.

\subsubsection{Muscovite}

Muscovite compositions from the Newton Range are different in composition to other muscovite found in the Alpine Schist (Fig. 6.17). Si is higher, and $\mathrm{Ti}$ and $\mathrm{Al}$ are lower in abundance to other samples of Alpine and Otago Schist, with compositions grouping on the edge of the Otago Schist field and between the Alpine Schist and Otago Schist fields outlined by Little et al., (1999). The estimated closure temperature for muscovite in the Haast Schist is between $302-375^{\circ} \mathrm{C}$ (Little, et al., 1999), temperatures well below peak metamorphic temperatures of garnet growth from this study of $\sim 500^{\circ} \mathrm{C}$ (see chapter seven). This suggests the last event to reset the composition of muscovite reached metamorphic conditions more similar to the parts of the Otago Schist than the traditional Alpine Schist in the Franz-Josef Fox Glacier region. It is not inferred that muscovite compositions reflect Otago Schist metamorphism. 

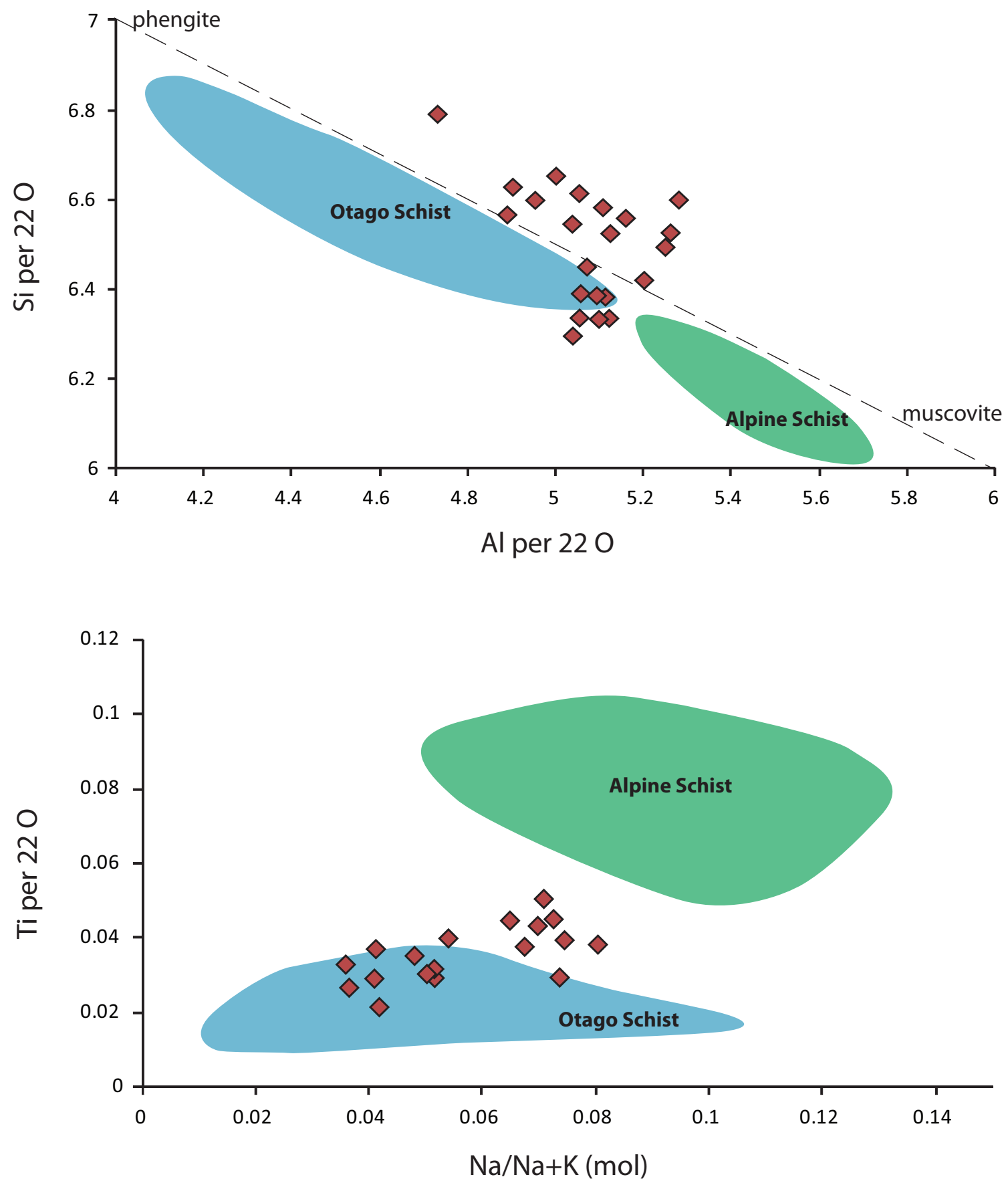

Figure 6.17. Muscovite compositions plotted over Otago and Alpine Schist fields from Little, et al. (1999). 


\subsubsection{Epidote}

The zoning pattern of epidote cores and rims shows a multistage epidote growth history. Four zones (A-D) are presented in figures $6.9 \&$ 6.18. Cores (zone A) have high iron contents $\left(100 \cdot \boldsymbol{X}_{\mathrm{Fe}}\right.$ 17.4-28.4). These are typically overgrown by thin irregular halos of $\mathrm{Ba}$ rich epidote with a wide range in composition $\left(100 \cdot \boldsymbol{X}_{\mathrm{Fe}} 10-28\right)$. Zone $\mathrm{C}$ has a similar composition to zone $\mathrm{A}$, but is slightly lighter in BSE imaging and sometimes has lower totals $\left(\sim 96 \mathrm{wt}^{\mathrm{o}} \%\right)$. This may suggest enrichment of REE, unable to be analysed on the microprobe. A fourth stage epidote (zone D) has lower iron compositions $\left(100 \cdot \boldsymbol{X}_{\mathrm{Fe}} 11.5-16.2\right)$ epidote. The general core-rim pattern of decreasing $100 \cdot \boldsymbol{X}_{\mathrm{Fe}}$ is similar to selected epidote textures found in both Otago and Alpine Schists, however, no mention of Ba rich overgrowths has been identified in any study of epidotes from the Haast Schist.

Epidotes in metabasites from the Haast Schist (Cooper, 1972) show a marked decrease in $100 \cdot \boldsymbol{X}_{\mathrm{Fe}}$ at the rim and are comparable in composition to the Newton Range epidotes (Fig. 6.18). This zoning pattern ceases at higher grades than chlorite zone schists. A similar decreasing $100 \cdot \boldsymbol{X}_{\mathrm{Fe}}$ core-rim pattern is also seen in weakly schistose pumpellyite facies rocks in the upper Wakitipu, Otago (Kawachi, 1975), and is also inferred by retardation measurements in lowest grade greenschist facies metagreywackes in Dansey Pass, Otago (Bishop, 1972). Grapes \& Watanabe (1984) recorded the compositional variation of epidote in Alpine Schists in detail and discovered five distinct epidote generations generally showing a pattern of decreasing $100 \cdot \boldsymbol{X}_{\mathrm{Fe}}$ from core to rim. These generations become less distinguishable at higher grades after the first appearance of oligoclase. Zone iii) of epidote growth from Grapes \& Watanabe (1984) is rich in Sr, a composition not identified in the Newton Range.

Figure 6.18. Epidote $100 \cdot \boldsymbol{X}_{\mathrm{Fe}}$ compositions plotted against metamorphic grade (distance in $\mathrm{km}$ ). a) Epidotes of Quartzofeldspathic Alpine Schist plotted against structural distance from the biotite isograd. Epidote generations are numbered 1 through 5 with increasing temperature. Symbols: open squares = first generation; filled and open triangles $=$ second and third (Sr-rich) generations, respectively; filled circles $=$ fourth generation rims on earlier generations; open circles = fourth generation weakly zoned to homogeneous individual grains; filled diamonds = fifth generation (see Grapes \& Hoskin, (2004) for explanation). In the greenschist facies chlorite and biotite-albite zones, solid lines define a composition gap between second-third generation and fourth generation epidote, while dashed lines define compositional limits for various epidote generations. (Grapes \& Watanabe, 1994) from (Grapes \& Hoskin, 2004). b) Epidote $100 \cdot \boldsymbol{X}_{\mathrm{Fe}}$ plotted against distance from the garnet in isograd. Note the Alpine Fault is $\sim 9 \mathrm{~km}$ NE of the garnet in isograd in the Newton Range. Analyses on porphyroblasts with cores and rims are plotted respectively as filled and open circles and a connecting dotted line. All other analyses are red diamonds. c) Metabasite epidote from the Haast Schist (left) and Otago Schist (right). Data from (Brown, 1967) and presented in (Grapes \& Hoskin, 2004). C and R reflect core and rim analyses respectively. Dashed lines mark the minimum $100 \cdot \boldsymbol{X}_{\mathrm{Fe}}$ composition. 


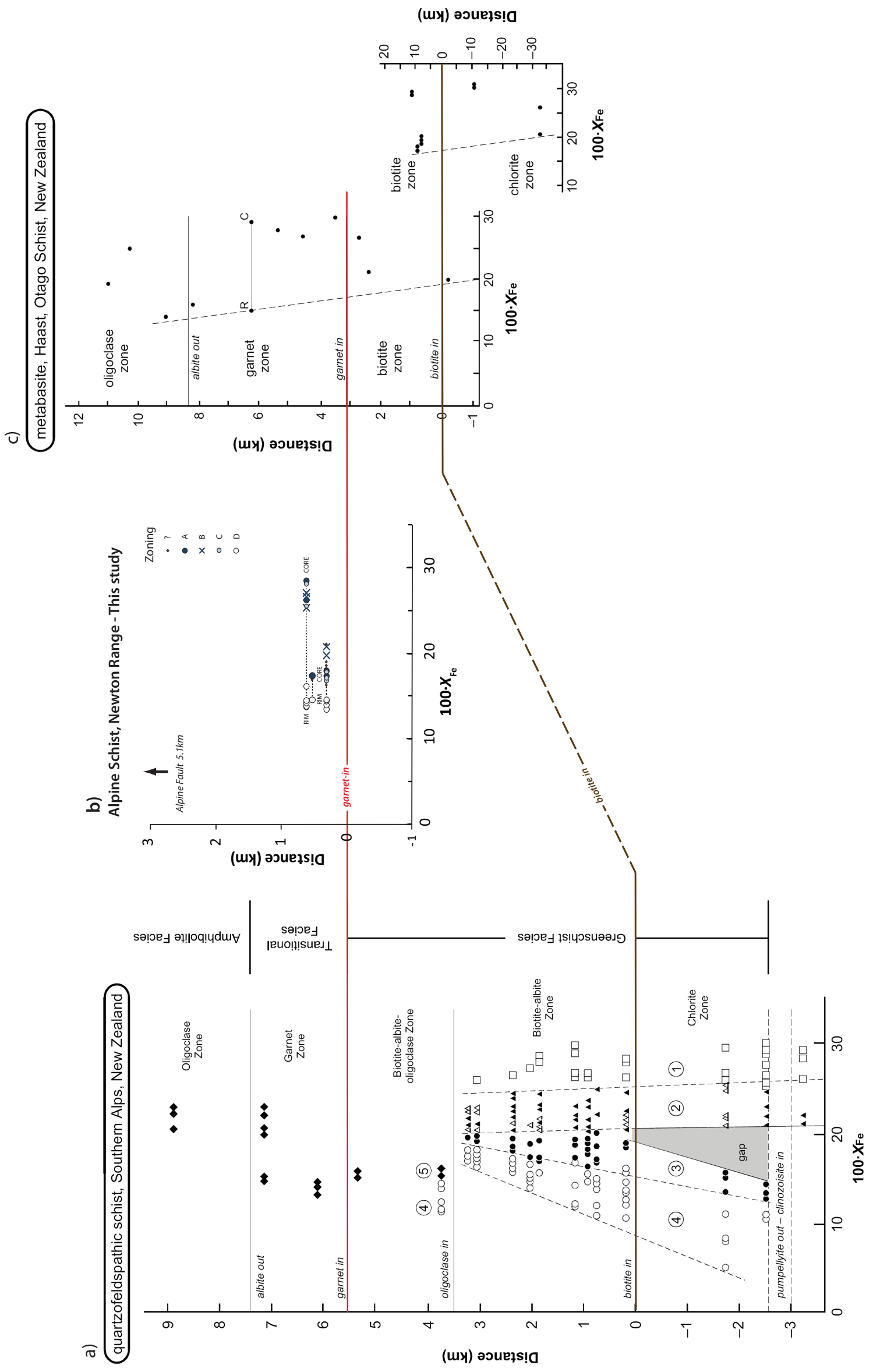

Figure 6.18. Epidote 100. $X_{\mathrm{Fe}}$ compositions plotted against metamorphic grade. See caption on previous page. 
The core-rim zoning pattern can be seen in BSE imaging of epidote grains in the schist matrix as well as inclusions in garnet porphyroblasts (Fig. 6.8). This means all epidote growth has occurred before garnet growth, possibly reflecting why a core-rim composition discrepancy is seen in this study, but not in other Alpine Schists found westward of the garnet-in isograd (Grapes \& Watanabe, 1984). As epidote is often replaced by oligoclase (Grapes \& Hoskin, 2004) the absence of a dominant oligoclase phase in the Newton Range may allow preservation of early stage epidote in these garnet grade rocks.

The $\mathrm{Ba}$ rich zone $\mathrm{B}$ may reflect a pulse of $\mathrm{Ba}$ rich fluid early in the metamorphic history, as $\mathrm{Ba}$ is a fluid mobile element. Another option could be the breakdown of a Ba rich mineral phase. However this is unlikely to occur at low grades as the only Ba rich mineral phase in the Alpine Schist is mica from high grade amphibolite facies metacherts (Grapes, 1993). Epidotes in the study area are interpreted to have formed at low grades with core-rim $100 \cdot \boldsymbol{X}_{\mathrm{Fe}}$ zonation similar to both low grade Alpine and Otago Schists. It is not possible to attribute epidote growth to either event without further study of lower grade schists (biotite and chlorite zone) from the Newton Range.

\subsubsection{Biotite}

Biotite compositions are a mix of the four biotite endmembers presented by Guidotti, (1984) (Fig. 6.11) and show no significant change in composition between biotite rim/fill and core textures. Figure 6.8 shows representative biotite core-rim (a), and core-fill (b) textures.

Temperatures obtained using the $\mathrm{Ti}$ in biotite thermometer (Henry, et al., 2005) range from $~ 540$ $630^{\circ} \mathrm{C}$ and show no real relationship to biotite texture or distance from the Alpine Fault (Fig. 6.19). This thermometer requires: 1) the presence of ilmenite, quartz, graphite and aluminous minerals; 2 ) biotite compositions in the range of $X_{\mathrm{Mg}}=0.275-1.0$ and Ti 0.04-0.6 apfu; and 3) a rock pressure range of 4-6kbar. The temperatures obtained using this thermometer are higher than the peak estimated temperatures for garnet growth $\left(\sim 500^{\circ} \mathrm{C}\right)$, therefore the results are deemed inconsistent and are not used for interpretation of the $P$-T history. These high temperatures relate to high $\mathrm{Ti}$ compositions, a possible reflection that metagreywackes (these rocks) behave differently than traditional pelites when metamorphosed. Another contributing factor to the higher than expected temperatures may be the lack of aluminous minerals such as staurolite, cordierite or $\mathrm{Al}_{2} \mathrm{SiO}_{5}$ polymorphs. A lack of these minerals increases the Ti concentration in biotite (Henry, et al., 2005) which would result in higher than expected temperatures. 
a)

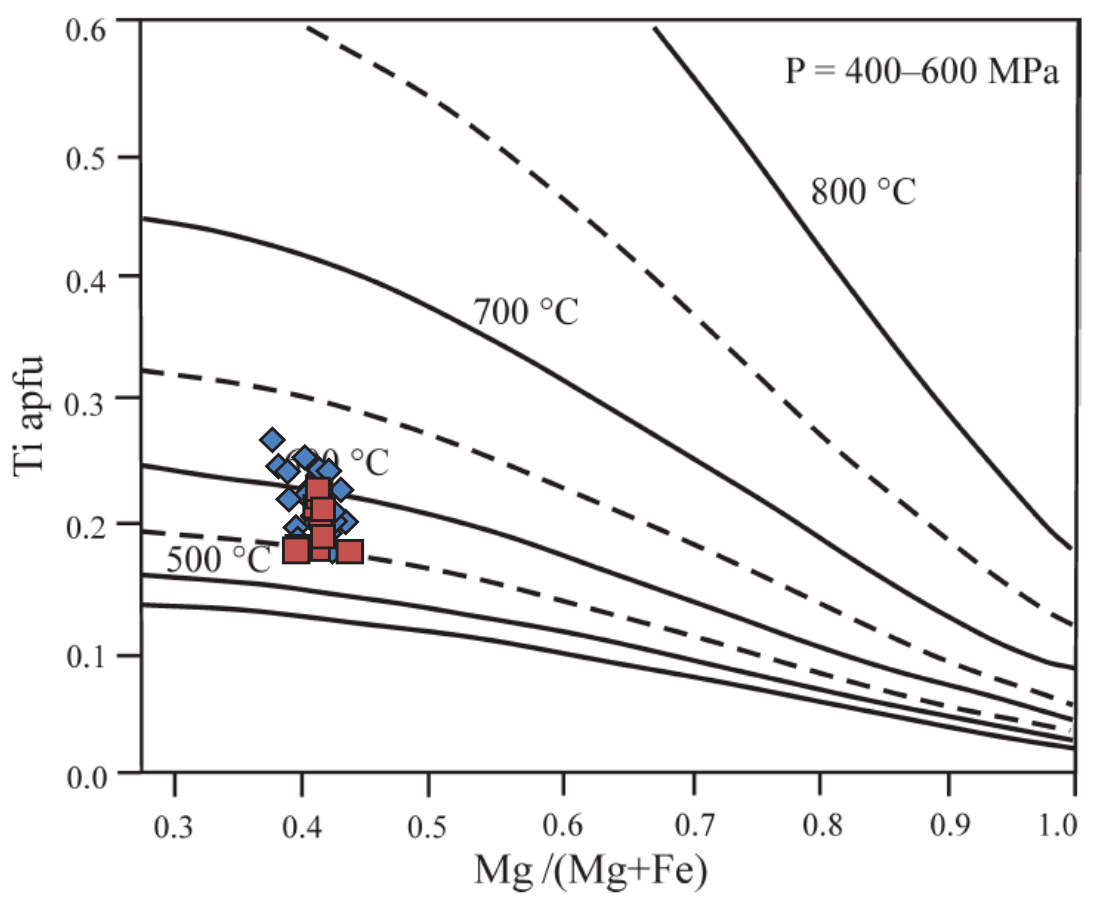

b)

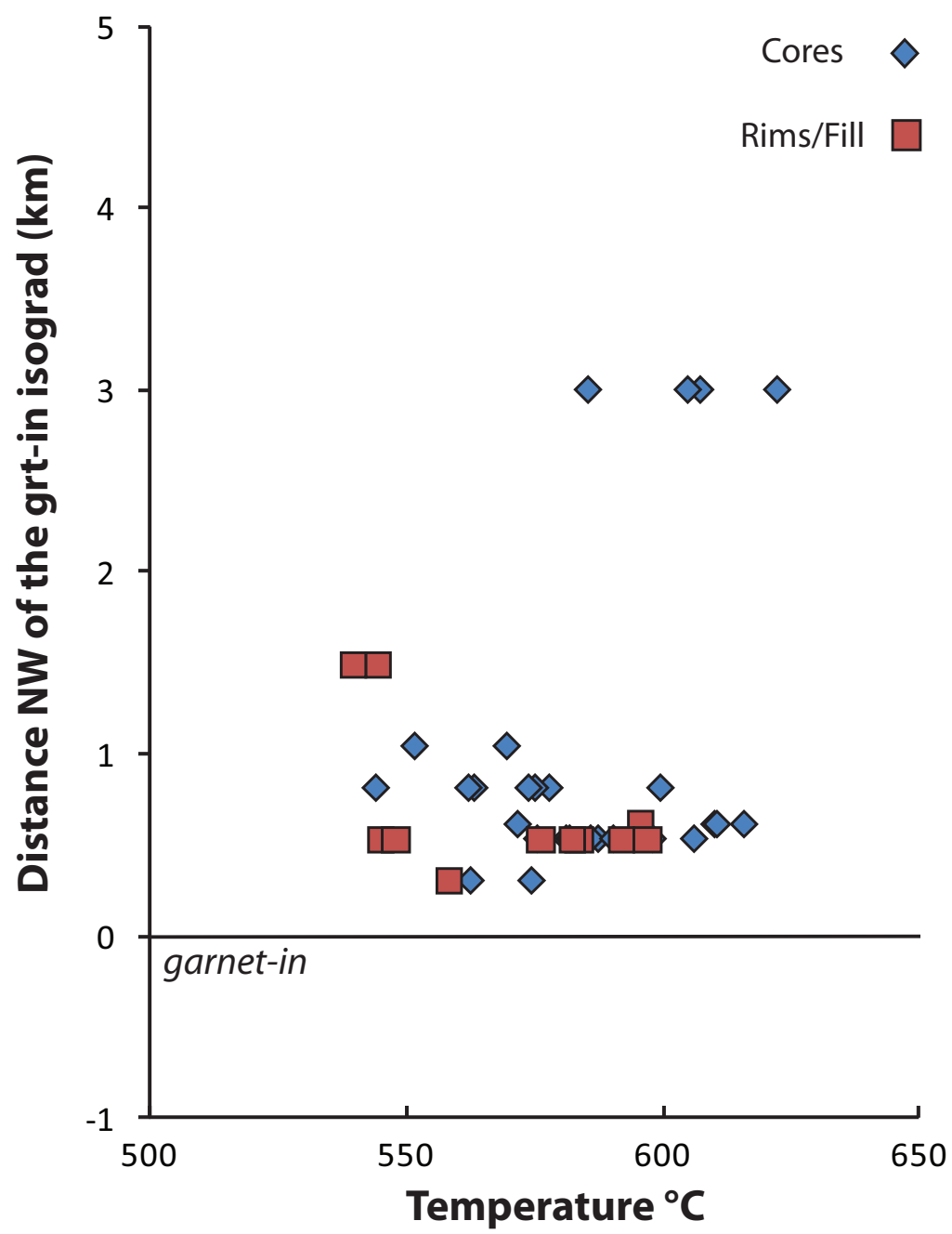

Figure 6.19. a) Biotite $\mathrm{Ti}(\mathrm{apfu})$ vs. $\mathrm{Mg} /(\mathrm{Mg}+\mathrm{Fe})$ compositions plotted on the $\mathrm{Ti}$ in biotite geothermometer from (Henry, et al., 2005). Note how rim/fill textures group similar to biotite cores. b) Temperature plotted against map distance from the Alpine Fault. 


\subsubsection{Ilmenite \& Titanite}

Titanite and ilmenite are both Ti bearing mineral phases and hence titanite rimming ilmenite is identified as a replacement texture. This indicates metamorphic conditions changed at some point in the metamorphic history allowing titanite to grow in some samples.

\subsubsection{Chlorite}

Chlorite compositions presented in figure 6.13 plot near analysed chlorite from regional medium and low-P metamorphic pelites. This reflects the expected conditions for chlorite growth in the Alpine Schist. Two geothermometers (Cathelineau, 1988; Jowett, 1991) yield results ranging from $\sim 335-400^{\circ} \mathrm{C}$ (Fig. 6.20 ). These temperatures probably represent re-equilibration of chlorite during late stage decompression and exhumation in the late Cenozoic, as it seems all chlorite yields similar temperatures regardless of distance from the Alpine Fault.

\subsection{Conclusion}

The different mineral compositions and mineral compositional zoning in greyschist from the Newton Range show a complex history, with minerals growing under changing $P$ - $T$ conditions at different parts of the metamorphic history.

Possible relict Otago Schist garnet cores mark the earliest part of the metamorphic history of greyschist from the Newton Range. Muscovite compositions suggest the last event to reset the composition of muscovite was the Alpine Schist event but at metamorphic conditions more similar to the Otago Schist than the traditional Alpine Schist metamorphism in the Franz-Josef Fox Glacier region. Zoned epidotes grew before garnet and have a compositional zoning pattern similar to both low grade Otago and Alpine Schist. The dominant mineral growth event is the Alpine Schist event, with differing compositions of garnet and plagioclase, growing at different stages in the metamorphic history. The most recent metamorphic event to have affected these rocks is related to the late Cenozoic uplift of the Southern Alps, possibly represented by stage 4 garnet rims. Compositions of lower grade, more open structured minerals such as chlorite and biotite and possibly muscovite have most probably been chemically reset by this event, erasing any evidence of the complex growth history. 


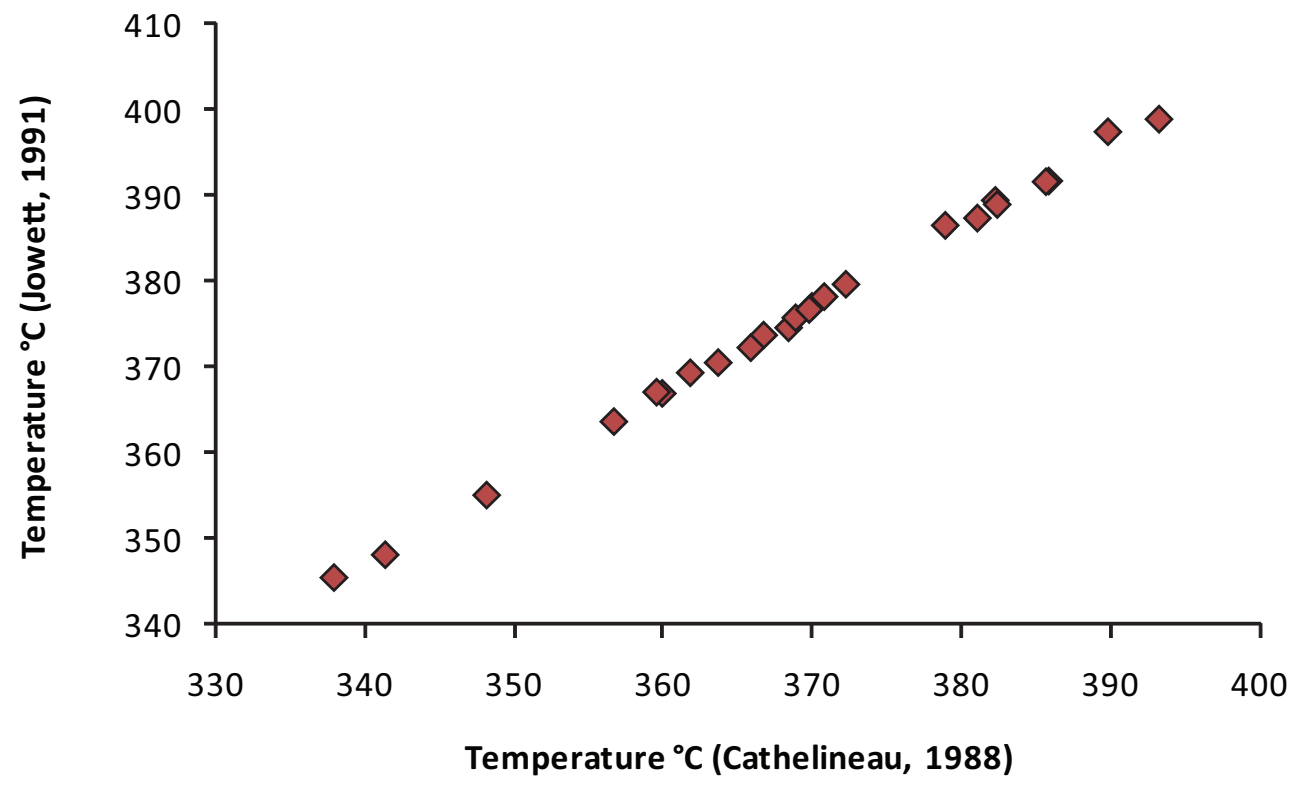

Figure 6.20. Two chlorite geothermometers group between $\sim 335-400^{\circ} \mathrm{C}$ (Cathelineau, 1988; Jowett, 1991). 


\section{Chapter Seven}

\section{THERMOCALC \& P-TPATHS}

\subsection{Introduction}

In this chapter pressure-temperature $(P-T)$ pseudosections and detailed $P-T$ paths are presented for nine greyschist samples from the Newton Range, Southern Alps, New Zealand.

P-T pseudosections show the multivariant phase relationships for a chosen rock composition as a function of pressure and temperature. In other words, the diagrams show what mineral assemblages should develop and be stable in a rock at particular metamorphic pressure and temperature conditions. The use of $P-T$ pseudosections to describe the metamorphic history of specific samples relies on the assumption that all of the minerals within each sample grew in equilibrium, both with each other and with the bulk-rock composition. The diagrams are calculated by forward modelling, beginning from the whole-rock major element data for the selected sample, normalised to molar proportions of each oxide, and using chemical activity-composition models for the various phases (minerals, fluid) together with a dataset containing internally-consistent thermodynamic data for all the phases considered. Activity-composition models are a set of parameters that describe the distribution of elements between compositional end-members of minerals and mineral interaction energies. Mineral activity-composition models must be selected for each mineral modelled in the $P$ - $T$ pseudosections that best describe the variation in analysed mineral compositions for a particular suite of samples.

The method has the potential to yield a good representation of the actual metamorphic record preserved in a rock, the successfulness of which depends on the initial choices of the number of chemical components to be considered and the sophistication of activity-composition models for the phases examined. The results of $P-T$ pseudosection calculations pertain to a wider range of conditions than just those at which the minerals currently present in the rock grew (most likely the peak metamorphic assemblage), and so have the potential to yield otherwise-unobtainable insights into metamorphic conditions and processes. 
As a part of the pseudosection calculations, THERMOCALC generates predictions about the compositions and modal proportions of the various phases in each assemblage field, and how those compositions and proportions change in response to changes in pressure and temperature. The results can be plotted as contours (composition or mode isopleths) on a pseudosection. The boundaries between mineral assemblage fields are located where a mineral either first appears, or disappears in $P$-T space (i.e., at a zero-mode isopleth, where the modal proportion of a mineral is zero).

If a correlation can be made between the predicted and measured mineral compositions, then the two lines of evidence can be used together to extract $P$ - $T$ estimates for each mineral analysis. Compositionally zoned minerals thus potentially contain, in the details of their chemistry, a detailed record of the changing P-T conditions during the mineral growth history. In this chapter individual analyses along compositional transects of zoned garnets are used together with the predicted compositional isopleths, to derive detailed metamorphic $P$ - $T$ paths for the garnet growth history.

\subsubsection{Samples}

The map locations of the nine garnet-bearing greyschist samples are shown in figure 7.1. Samples were selected to show a wide range in whole-rock chemistry and garnet compositions and to contain a mineral assemblage $\mathrm{q}+\mathrm{bi}+\mathrm{mu}+\mathrm{chl}+\mathrm{ab}+\mathrm{g}+\mathrm{ep}+\mathrm{ilm} \pm \mathrm{ttn}$, that (without titanite) has been previously shown to yield geologically reasonable $P-T$ pseudosections and successful $P$ - $T$ path interpretations for Alpine Schist greyschist (Vry, et al., 2008). Studied samples were specifically selected to contain no calcite and little or no graphite, in order to undertake $P$ - $T$ pseudosection calculations using the simplifying assumption that the fluid phase consisted of pure $\mathrm{H}_{2} \mathrm{O}$. All indications are that the Alpine Schist metamorphism involved an extremely water-rich metamorphic fluid (Yardley, 1982; Holm, et al., 1989; Craw \& Norris, 1993; Smith \& Yardley, 1999), a useful observation, as considering a mixed $\mathrm{H}_{2} \mathrm{O}-\mathrm{CO}_{2}$ fluid introduces considerable extra complexity into the pseudosection calculations and their interpretation (Vry, pers. comm., 2010).

\subsection{Methods}

The $P$-T pseudosection diagrams were calculated in the 11-component system MnNCKFMASHTO ( $\mathrm{MnO}, \mathrm{Na}_{2} \mathrm{O}, \mathrm{CaO}, \mathrm{FeO} \mathrm{MgO} \mathrm{Al}_{2} \mathrm{O}_{3}, \mathrm{SiO}_{2}, \mathrm{H}_{2} \mathrm{O}, \mathrm{TiO}_{2}, \mathrm{O}$ ) using the computer program THERMOCALC v. 3.33 and the internally-consistent thermodynamic dataset 5.5 (revised version of 


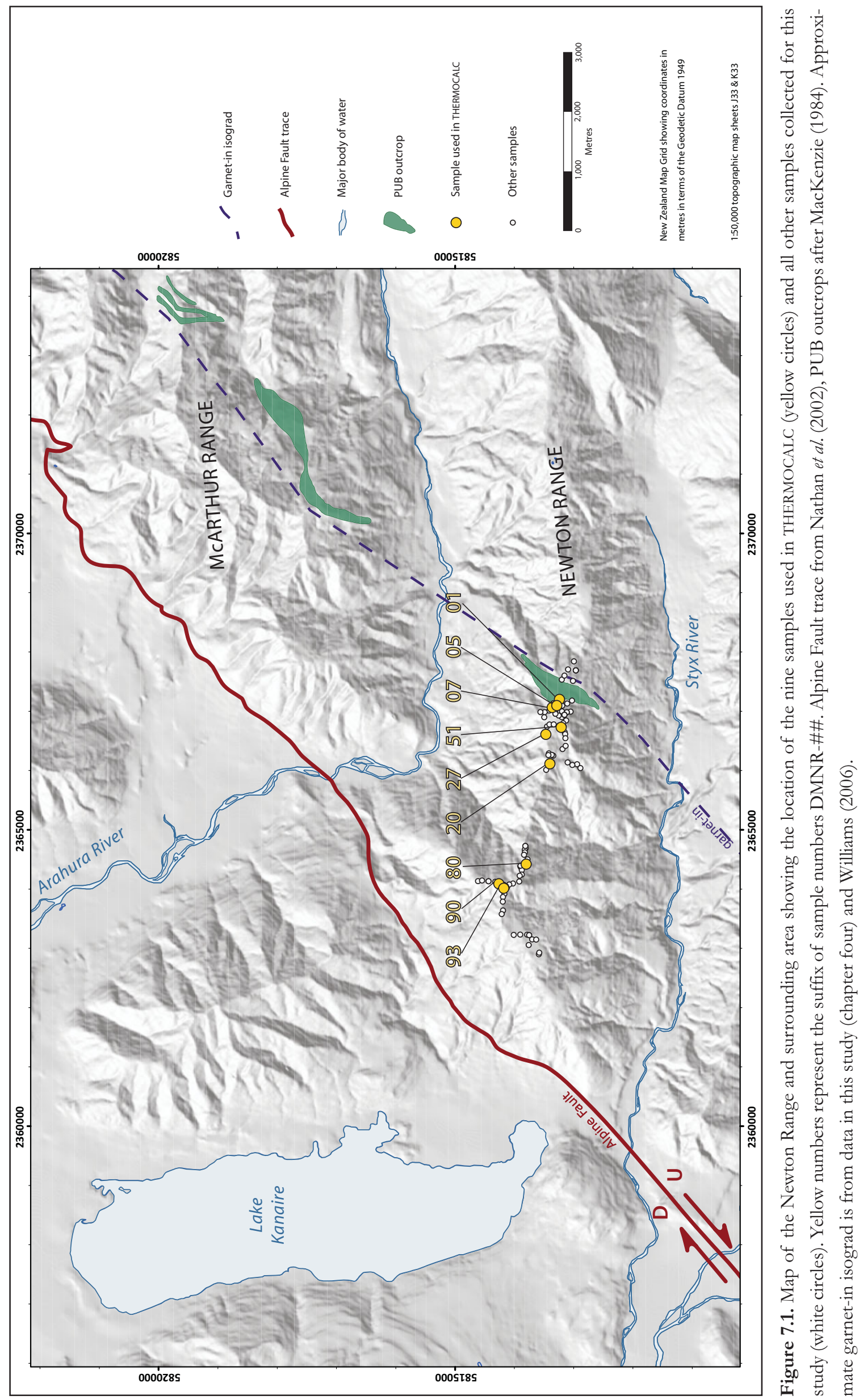


Holland \& Powell (1998). The P-T pseudosections were calculated with water, quartz, ilmenite and muscovite in excess, for $0.5-12 \mathrm{kbar}$ and $300-700^{\circ} \mathrm{C}$, using the activity-composition models presented in appendices A4.1 and A4.2. Abbreviations for minerals in this chapter are those used in the THERMOCALC program (appendix A4.3). The P-T paths were calculated following previouslydeveloped methods (Williams, 2006; Vry, et al., 2008), which will be described in more detail in a later section of this chapter. Electron microprobe analyses of garnet were carried out using wavelength dispersive methods at Victoria University of Wellington (for a full description of methods see chapter six). Detailed analytical transects across multiple garnets within each sample were performed in order to document, as fully as possible, the range of garnet compositions within each sample, and to identify the analysis that was closest to the garnet core in each transect.

Porphyroblasts with low internal diffusivity, such as garnet, effectively lock in elements during their growth, thereby changing the remaining "effective" bulk-rock composition for subsequent parts of the mineral growth history (Marmo, et al., 2002; Evans, 2004). As the garnets in the studied samples are small $(<1 \mathrm{~mm})$ and typically low in abundance, the effects of their growth on the effective bulkrock compositions can reasonably be assumed to be negligible. Therefore no corrections were applied for changes in the effective bulk-rock composition due to fractionation of elements during garnet growth.

\section{$\mathrm{FeO} \& \% \mathrm{O}$}

The whole-rock major element oxide data ( $\mathrm{wt} \%$ oxides from XRF results (chapter five)) was converted into molar proportions on an L.O.I. free basis for input into THERMOCALC (tables 7.1 \& 7.2). Whole-rock XRF results present total $\mathrm{Fe}_{\text {as }} \mathrm{Fe}^{3+}$, listed as $\mathrm{wt} \% \mathrm{Fe}_{2} \mathrm{O}_{3}$, whereas total iron is input into THERMOCALC as $\mathrm{Fe}^{2+}$, entered as mole $\% \mathrm{FeO}_{\text {total }}$. The XRF data must therefore be converted, after which a correction (the input parameter $\% \mathrm{O}$ ) is applied, to account for the minor $\mathrm{Fe}^{3+}$ present in a rock. This correction is necessary in order to include $\mathrm{Fe}^{3+}$-bearing minerals such as epidote, which typically occurs in small amounts in Alpine Schist greyschist at relevant P-T conditions. The amount of $\mathrm{Fe}^{3+}$ and the presence or absence of epidote both affect the stability limits of mineral assemblage fields of interest; for example, increases in $\mathrm{Fe}^{3+}$ cause the zero-mode isopleth for garnet to shift to higher pressures and temperatures. All of the $P-T$ pseudosections presented in this chapter were calculated using $\% \mathrm{O}=0.05$. The results have thus been obtained by methods consistent with those used by Vry et al., (2008), and should be directly comparable with results obtained in that earlier study. 


\begin{tabular}{|c|c|c|c|c|c|c|c|c|c|}
\hline $\begin{array}{c}\text { Sample } \\
\text { DMNR-\#\# }\end{array}$ & 01 & 05 & 07 & 20 & 27 & 51 & 80 & 90 & 93 \\
\hline \multicolumn{10}{|c|}{ Major element oxide concentration ( $w \mathrm{t} \%$ ) } \\
\hline $\mathrm{SiO}_{2}$ & 78.04 & 62.44 & 67.64 & 66.79 & 66.25 & 64.83 & 75.45 & 76.83 & 81.06 \\
\hline $\mathrm{Al}_{2} \mathrm{O}_{3}$ & 11.38 & 18.36 & 15.80 & 15.46 & 15.28 & 16.85 & 12.13 & 11.72 & 9.69 \\
\hline $\mathrm{Fe}_{2} \mathrm{O}_{3 \text { total }}$ & 2.22 & 5.57 & 4.56 & 6.18 & 6.12 & 5.25 & 3.09 & 2.46 & 2.13 \\
\hline $\mathrm{MgO}$ & 0.75 & 1.80 & 1.49 & 1.87 & 1.85 & 1.84 & 1.00 & 0.83 & 0.70 \\
\hline $\mathrm{MnO}$ & 0.03 & 0.06 & 0.05 & 0.12 & 0.18 & 0.09 & 0.03 & 0.05 & 0.03 \\
\hline $\mathrm{TiO}_{2}$ & 0.39 & 0.79 & 0.66 & 0.69 & 0.82 & 0.72 & 0.42 & 0.40 & 0.31 \\
\hline $\mathrm{Na}_{2} \mathrm{O}$ & 3.30 & 3.13 & 2.97 & 2.19 & 2.21 & 2.72 & 3.08 & 3.67 & 2.95 \\
\hline $\mathrm{CaO}$ & 0.71 & 1.36 & 1.21 & 1.38 & 1.74 & 1.47 & 0.75 & 0.96 & 0.59 \\
\hline $\mathrm{K}_{2} \mathrm{O}$ & 1.62 & 3.98 & 3.27 & 2.87 & 3.04 & 3.85 & 2.35 & 1.75 & 1.45 \\
\hline $\mathrm{SO}_{3}$ & $<0.01$ & $<0.01$ & $<0.01$ & $<0.01$ & n.a. & n.a. & n.a. & n.a. & n.a. \\
\hline $\mathrm{P}_{2} \mathrm{O}_{5}$ & 0.07 & 0.17 & 0.13 & 0.14 & 0.15 & 0.17 & 0.09 & 0.09 & 0.06 \\
\hline LOI & 1.26 & 2.28 & 1.95 & 2.18 & 2.04 & 1.82 & 1.23 & 0.94 & 0.93 \\
\hline SUM & 99.75 & 99.93 & 99.71 & 99.86 & 99.69 & 99.60 & 99.60 & 99.70 & 99.90 \\
\hline
\end{tabular}

Table 7.1. Whole-rock major element oxide (wt \%) XRF data of greyschists used to make $P$-T pseudosections. Not analysed $=$ n.a. Sample locations in figure 7.1.

\begin{tabular}{|c|c|c|c|c|c|c|c|c|c|}
\hline $\begin{array}{c}\text { Sample } \\
\text { DMNR-\#\# }\end{array}$ & 01 & 05 & 07 & 20 & 27 & 51 & 80 & 90 & 93 \\
\hline \multicolumn{10}{|c|}{ MnNCKFMASHTO input to THERMOCALC (molar proportions wt $\%$ ) } \\
\hline $\mathrm{SiO}_{2}$ & 84.14 & 71.3 & 75.81 & 72.53 & 74.34 & 73.25 & 82.08 & 82.8 & 86.23 \\
\hline $\mathrm{Al}_{2} \mathrm{O}_{3}$ & 7.23 & 12.36 & 10.44 & 11.43 & 10.11 & 11.22 & 7.78 & 7.45 & 6.08 \\
\hline $\mathrm{FeO}_{\text {total (calc.) }}$ & 1.80 & 4.79 & 3.85 & 4.87 & 5.17 & 4.46 & 2.53 & 2.00 & 1.71 \\
\hline $\mathrm{MgO}$ & 1.21 & 3.06 & 2.49 & 2.93 & 3.09 & 3.10 & 1.62 & 1.33 & 1.11 \\
\hline $\mathrm{MnO}$ & 0.03 & 0.06 & 0.05 & 0.12 & 0.17 & 0.09 & 0.03 & 0.05 & 0.03 \\
\hline $\mathrm{TiO}_{2}$ & 0.32 & 0.68 & 0.56 & 0.63 & 0.69 & 0.61 & 0.34 & 0.32 & 0.25 \\
\hline $\mathrm{Na}_{2} \mathrm{O}$ & 3.45 & 3.46 & 3.23 & 3.68 & 2.40 & 2.98 & 3.25 & 3.83 & 3.04 \\
\hline $\mathrm{CaO}$ & 0.71 & 1.39 & 1.25 & 1.54 & 1.85 & 1.51 & 0.74 & 1.02 & 0.58 \\
\hline $\mathrm{K}_{2} \mathrm{O}$ & 1.11 & 2.90 & 2.34 & 2.26 & 2.18 & 2.77 & 1.63 & 1.20 & 0.98 \\
\hline$\% \mathrm{O}$ & 0.05 & 0.05 & 0.05 & 0.05 & 0.05 & 0.05 & 0.05 & 0.05 & 0.05 \\
\hline
\end{tabular}

Table 7.2. Whole-rock major element oxide (molar proportion, LOI free) data used for input into THERMOCALC to make $P-T$ pseudosections. $\mathrm{No} \mathrm{P}_{2} \mathrm{O}_{5}$ or $\mathrm{SO}_{3}$ is included in the THERMOCALC input. Use of \%O discussed in text. 


\section{$\mathbf{P}_{2} \mathrm{O}_{5}$ and $\mathrm{CaO}$}

As apatite $\left(\mathrm{Ca}_{5}\left(\mathrm{PO}_{4}\right)_{3}(\mathrm{~F}, \mathrm{OH}, \mathrm{Cl})\right.$ is the sole phosphate mineral in the greyschists from the Newton Range, the amount of $\mathrm{P}_{2} \mathrm{O}_{5}(<0.2 \mathrm{wt} \%)$ in each whole-rock analysis will be proportional to the amount of apatite. Therefore, for input into THERMOCALC, $\mathrm{P}_{2} \mathrm{O}_{5}$ was subtracted from each wholerock composition, together with sufficient $\mathrm{CaO}$ to form apatite.

\subsection{Results}

\subsubsection{P-T Pseudosections}

P-T pseudosections of nine samples from the Newton Range are shown in figures 7.2, 7.3, 7.4 \& 7.5. The position of mineral assemblage stability fields change in $P-T$ space with varying whole-rock composition, with some zero-mode isopleths moving with enrichment of particular elements. With increasing whole-rock $\mathrm{MnO}$ content, garnet becomes stable at lower pressures and temperatures, (garnet zero-mode isopleth shifts to lower P-T conditions), increasing the size of the g-bi-chl-ab-ep field. This can be seen in sample DMNR-27 which has $0.18 \mathrm{wt} \% \mathrm{MnO}$ and a large g-bi-chl-ab-ep field. Other samples range in $\mathrm{wt} \% \mathrm{MnO}$ from 0.03 - 0.12 and have smaller g-bi-chl-ab-ep fields (in order of increasing size: DMNR-01, 80, 07, 05, 93, 51, 90, 20). Another mineral with significant changes in $P-T$ space with changing whole-rock composition is albite, which becomes stable at higher temperatures with increasing $\mathrm{Na}_{2} \mathrm{O}$ (DMNR 07, 80, 90 \& 93). The plagioclase zero-mode isopleth is effectively fixed, and does not change in position between different $P$ - $T$ pseudosections. Figure 7.2 includes labelled mineral assemblage stability fields (a), and fields coloured for variance (b).

For visual clarity the fields in figures 7.3, 7.4 \& 7.5 are unlabelled and unshaded, with the exception of the g-bi-chl-ab-ep (mu-q-ilm- $\mathrm{H}_{2} \mathrm{O}$ ) field, as it is the most important stability field for this study (dominant metamorphic mineral assemblage).

Metamorphic temperatures of the Alpine Schist in north Westland were not hot enough for a Cabearing plagioclase (oligoclase) to become the sole plagioclase stable in the rock, instead both albite and oligoclase were stable at peak metamorphic temperatures. As albite is stable at lower temperatures with increasing amounts of $\mathrm{Na}_{2} \mathrm{O}$ in the whole-rock composition, and the samples in this study have relatively high $\mathrm{Na}_{2} \mathrm{O}(2.21-3.67 \mathrm{wt} \%)$, temperatures above $550^{\circ} \mathrm{C}$ would be required before rocks could develop albite-free mineral assemblages. The high-temperature limit of the shaded g-bi-chl-ab-ep field is located at $\sim 500^{\circ} \mathrm{C}$ and $7 \mathrm{kbar}$, where the plagioclase and paragonite (or 

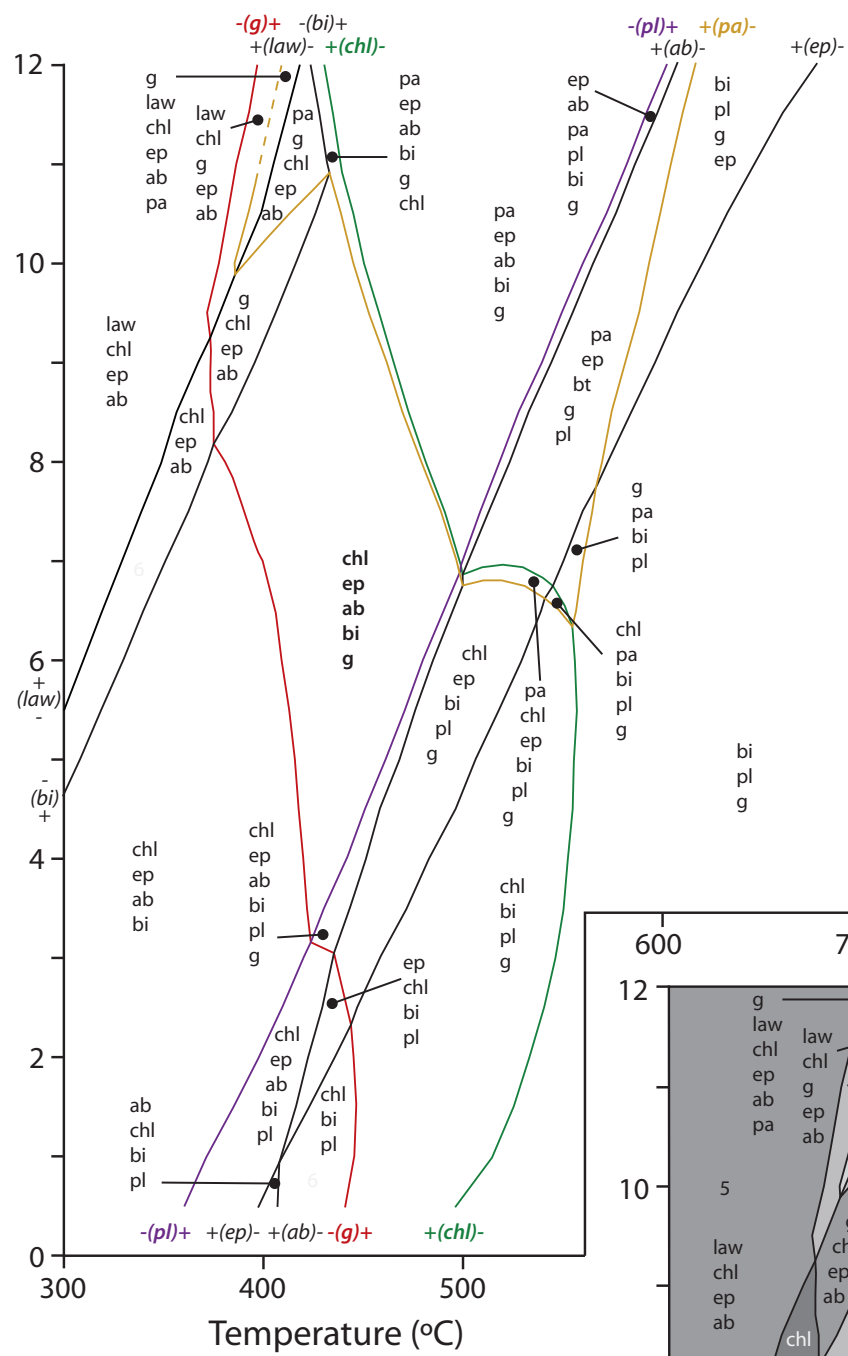

DMNR-27

MnNCKFMASHTO

$0.05 \% \mathrm{O}$

$0.19 \mathrm{wt} \% \mathrm{MnO}$

$2.21 \mathrm{wt} \% \mathrm{Na}_{2} \mathrm{O}$

$+\mathrm{q}+\mathrm{ilm}+\mathrm{mu}+\mathrm{H}_{2} \mathrm{O}$

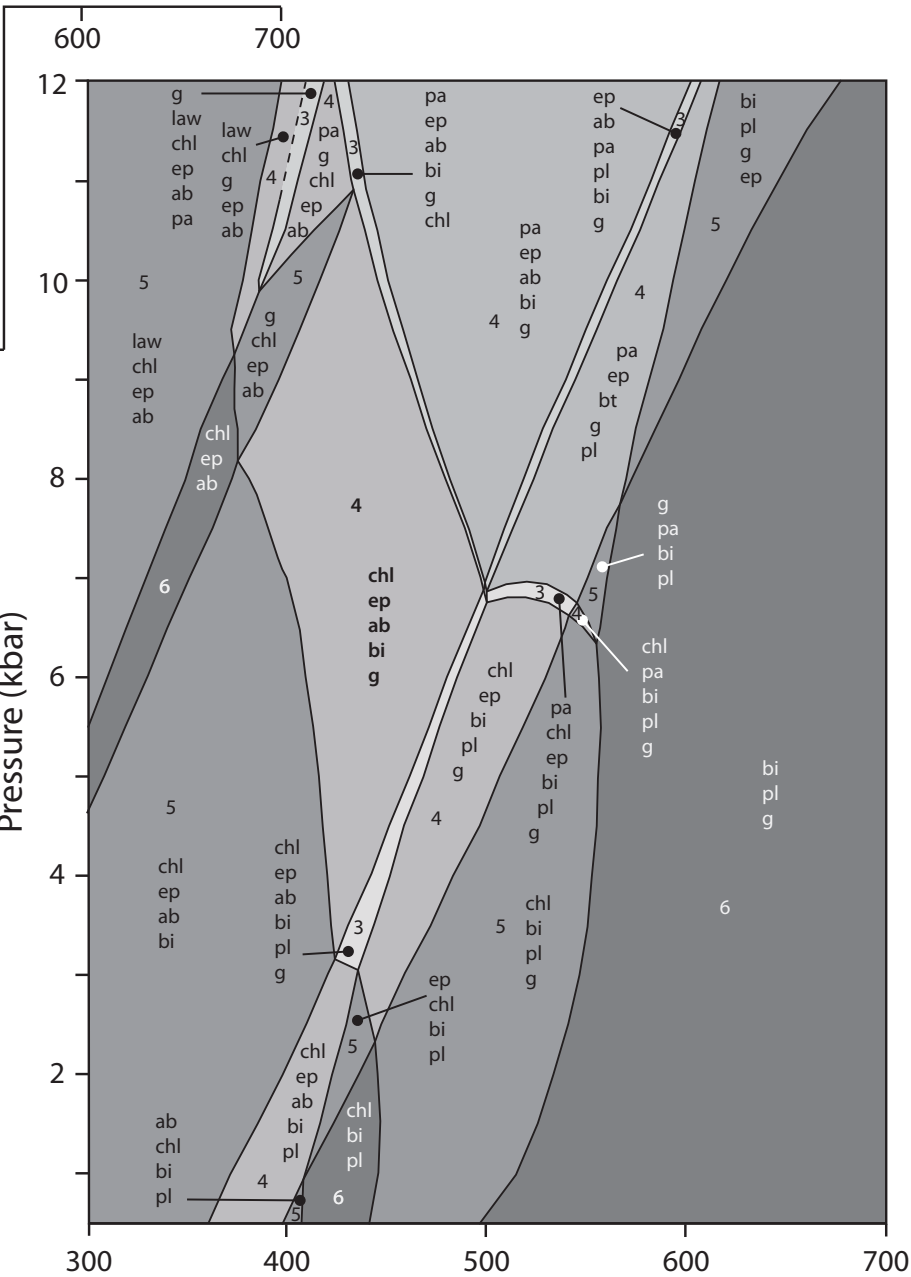

Figure 7.2. 11-component P-T pseudosections for DMNR-27. a) Labelled mineral assemblages. The zeromode isopleth of each mineral phase is labelled with a + and - to show which side of the line a mineral is stable $(+)$ and unstable (-) in P-T space. b) P-T pseudosection with shaded and numbered areas to indicate the variance of the mineral assemblage field. Dashed line denotes an estimated metastable extension of a reaction line. 
DMNR-27

MnNCKFMASHTO

$0.05 \% \mathrm{O}$

$0.19 \mathrm{wt} \% \mathrm{MnO}$

$2.21 \mathrm{wt} \% \mathrm{Na}_{2} \mathrm{O}$

$+\mathrm{q}+\mathrm{ilm}+\mathrm{mu}+\mathrm{H}_{2} \mathrm{O}$
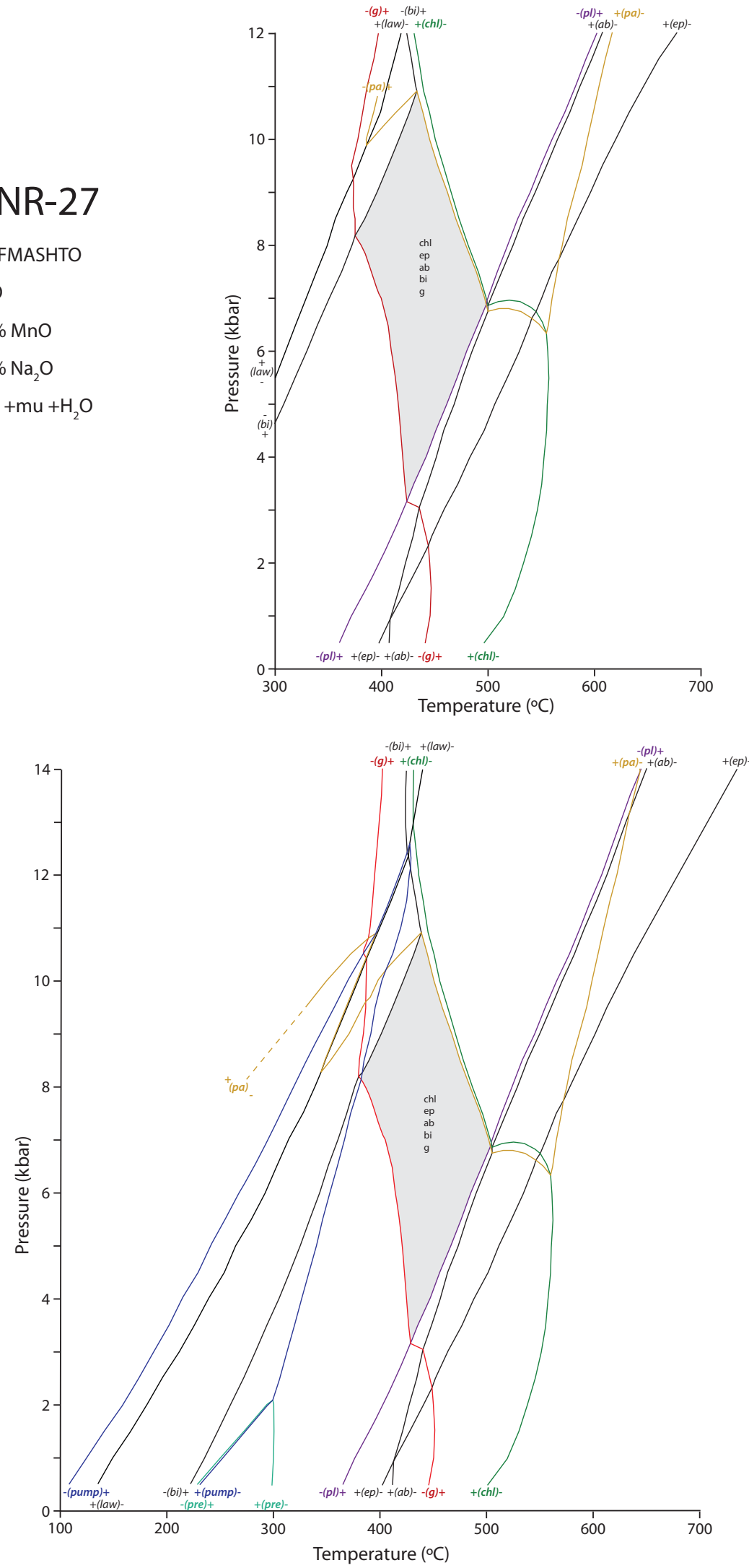

Figure 7.3. 11-component $P-T$ pseudosections for sample DMNR-27. The zero modal isopleth of each mineral phase is labelled with a + and - to show which side of the line a mineral is stable $(+)$ and unstable $(-)$ in $P-T$ space. The shaded field represents the dominant mineral assemblage in the rock. a) $P-T$ pseudosection with the same mineral assemblage as figure 7.3. b) $P$-T pseudosection including low temperature mineral phases prehnite and pumpellyite. 
a)
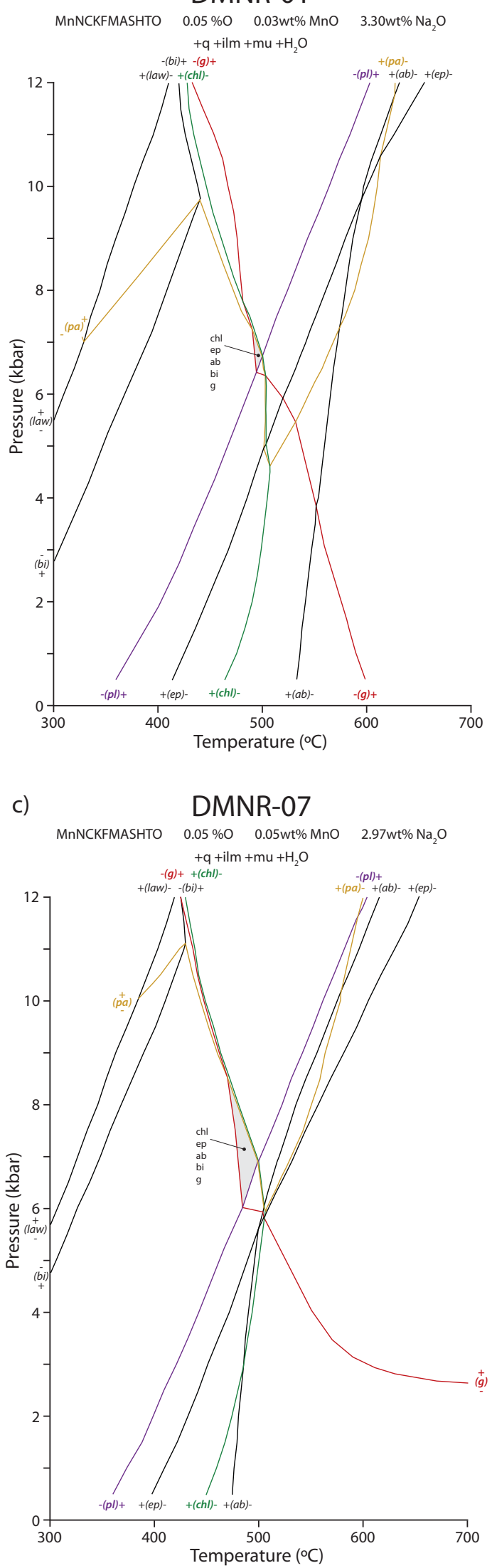

b)

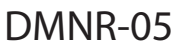

MnNCKFMASHTO $\quad 0.05 \% \mathrm{O} \quad 0.06 \mathrm{wt} \% \mathrm{MnO} \quad 3.13 \mathrm{wt} \% \mathrm{Na}_{2} \mathrm{O}$ $+\mathrm{q}+\mathrm{ilm}+\mathrm{mu}+\mathrm{H}_{2} \mathrm{O}$

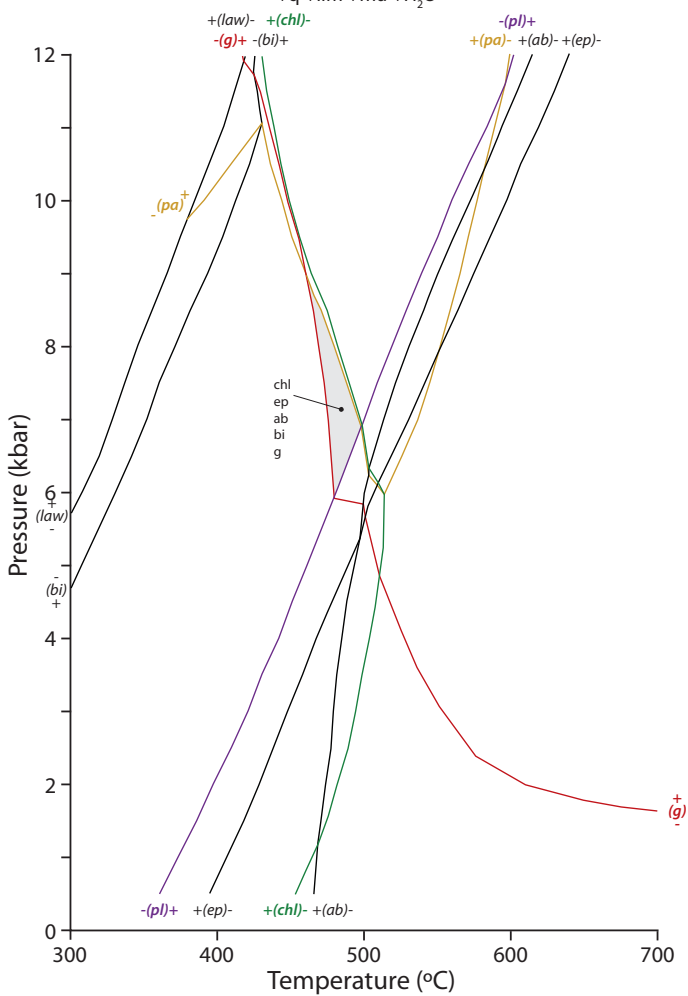

d)

DMNR-20
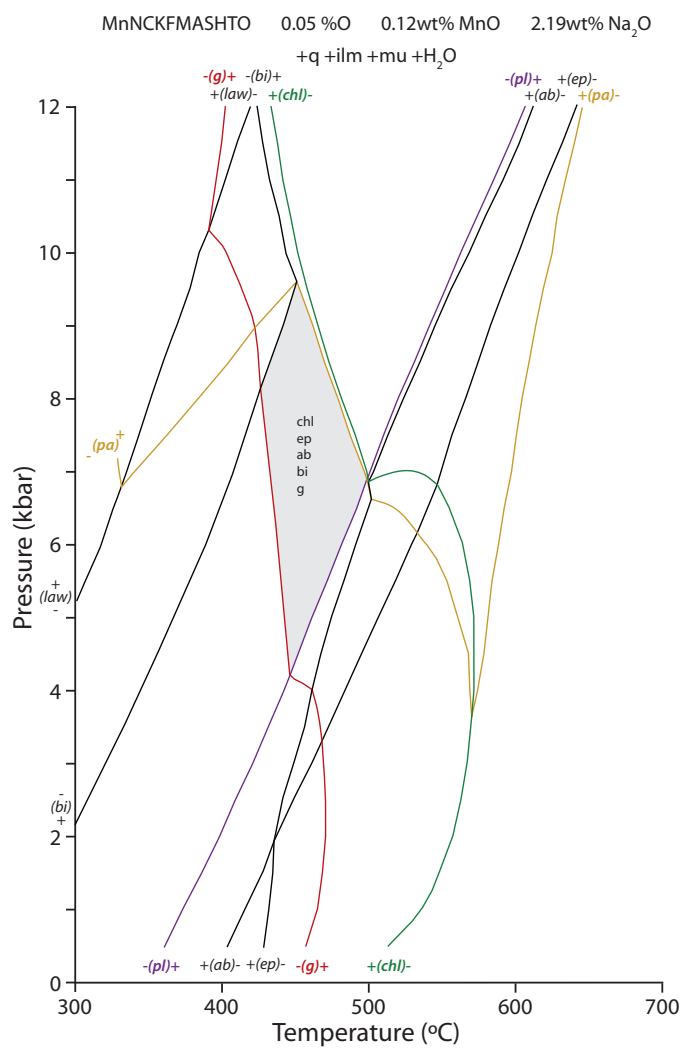

Figure 7.4. 11-component P-T pseudosections for samples DMNR-01 (a), 05 (b), 07 (c) \& 20 (d). The zero modal isopleth of each mineral phase is labelled with a + and - to show which side of the line a mineral is stable (+) and unstable (-) in P-T space. The shaded field represents the dominant mineral assemblage in the rock. 
a)

DMNR-51

MnNCKFMASHTO $\quad 0.05 \% \mathrm{O} \quad 0.09 \mathrm{wt} \% \mathrm{MnO} \quad 2.21 \mathrm{wt} \% \mathrm{Na}_{2} \mathrm{O}$ $+\mathrm{q}+\mathrm{ilm}+\mathrm{mu}+\mathrm{H}_{2} \mathrm{O}$

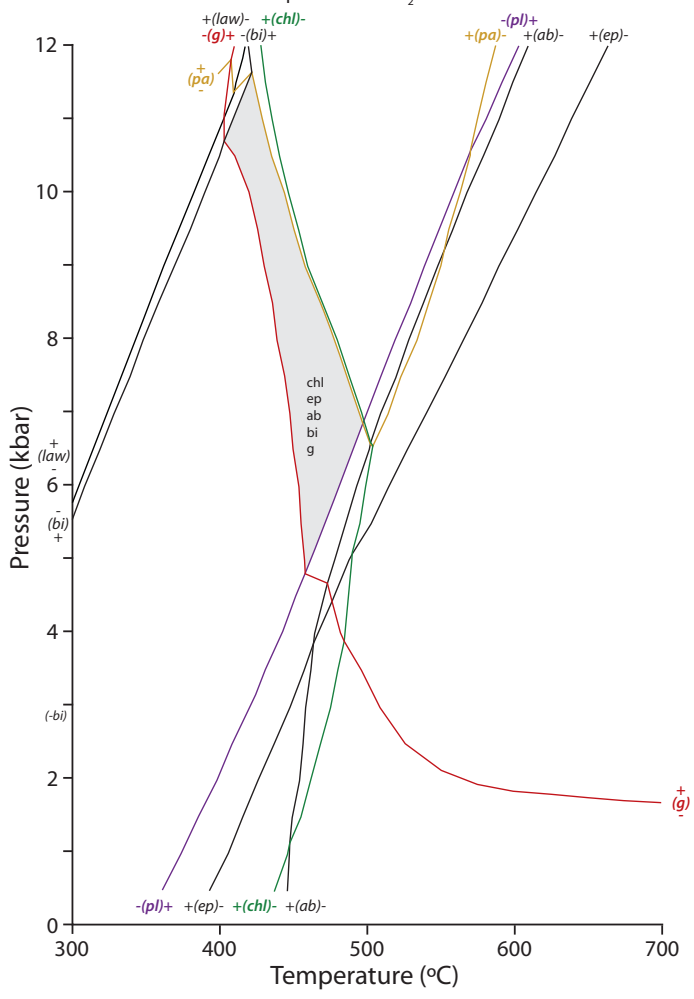

C)
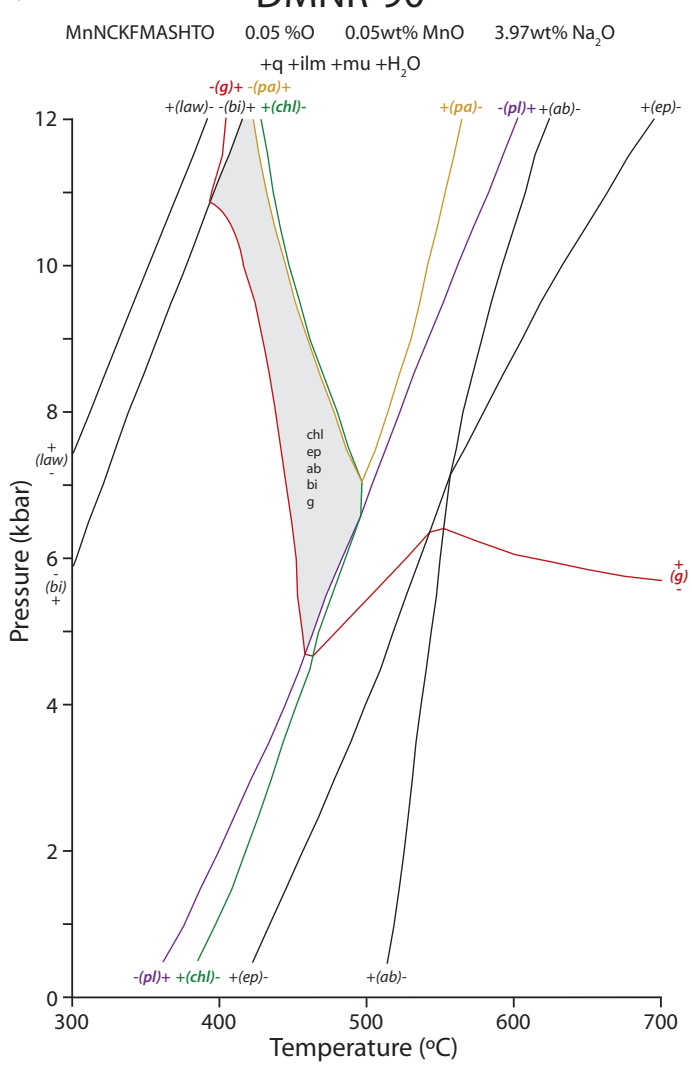

b)

DMNR-80

MnNCKFMASHTO $\quad 0.05 \% \mathrm{O} \quad 0.03 \mathrm{wt} \% \mathrm{MnO} \quad 3.08 \mathrm{wt} \% \mathrm{Na}_{2} \mathrm{O}$ $+\mathrm{q}+\mathrm{ilm}+\mathrm{mu}+\mathrm{H}_{2} \mathrm{O}$

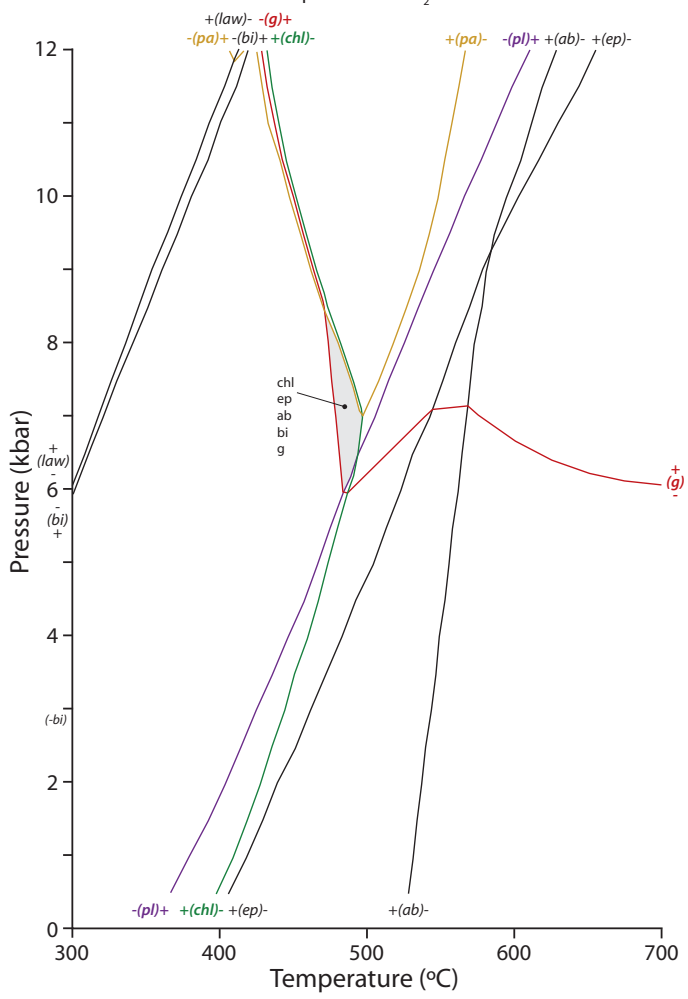

d)
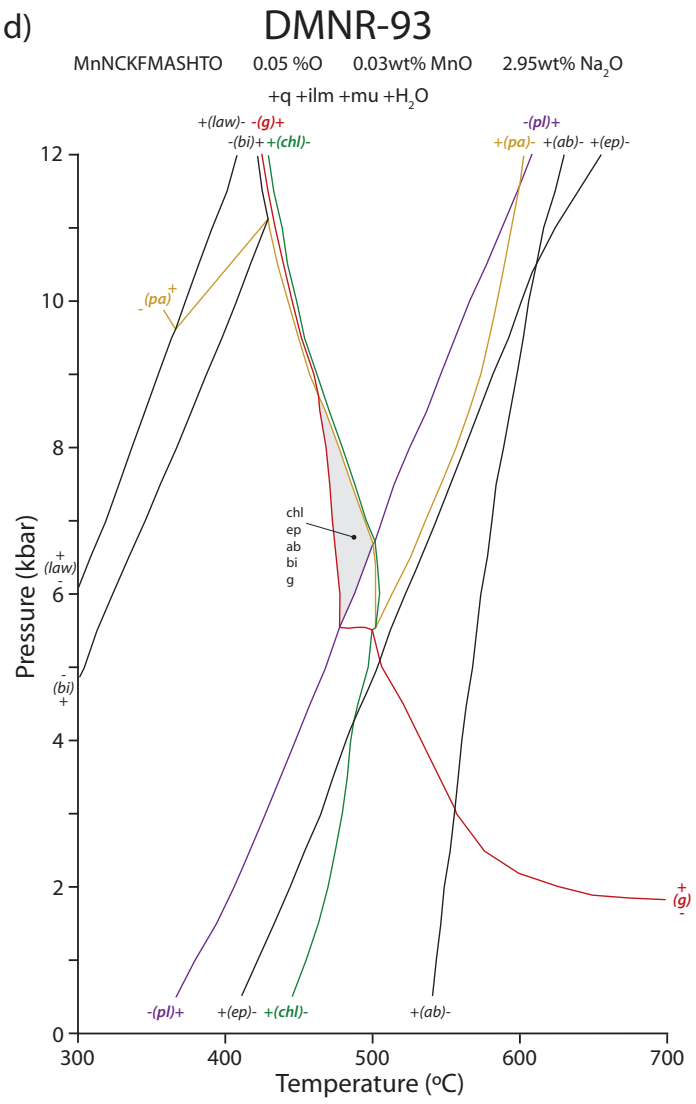

Figure 7.5. 11-component P-T pseudosections for samples DMNR-51 (a), 80 (b), 90 (c) \& 93 (d). The zero modal isopleth of each mineral phase is labelled with a + and - to show which side of the line a mineral is stable $(+)$ and unstable (-) in P-T space. The shaded field represents the dominant mineral assemblage in the rock. 
chlorite) zero-mode isopleths intersect. The location of this high-temperature limit differs slightly from sample to sample, as the location of the zero-mode isopleth for both paragonite and chlorite is dependent on the bulk rock composition (see Figs. 7.2 - 7.5).

In the $P$-T pseudosection diagrams for many of the studied samples, the zero-mode isopleth for paragonite is untraceable at higher pressures in the stability field of lawsonite. This is because pumpellyite (not modelled) becomes stable at such conditions. Pumpellyite is not found in greenschist facies Alpine Schist and is not modelled to reduce unnecessary complexity in the pseudosections. An example of a P-T pseudosection containing prehnite and pumpellyite shows intersection of the pumpellyite zero-mode isopleth with the g-bi-chl-ab-ep field at lower blueschist facies metamorphic conditions (Fig. 7.3b).

\subsubsection{Plagioclase Compositions}

The modelling of two plagioclase phases, albite (the pure $\mathrm{Na}$ endmember species) and plagioclase (Ca-bearing) in THERMOCALC, takes into account the possibility that Alpine Schist can contain either albite or oligoclase, or both, within a single sample. At greenschist facies conditions, albite is typically the first metamorphic plagioclase to appear, and is first joined by, and eventually replaced by, a more calcic plagioclase with increasing metamorphic grade (Grapes \& Otsuki, 1983). On a P-T pseudosection diagram, these changes correspond to a $P-T$ path crossing the plagioclase zero-mode isopleth (pl-in line) and eventually crossing the albite zero-mode isopleth (ab-out line).

Oligoclase (defined as a Ca-bearing plagioclase of composition $\mathrm{An}_{10}$ to $\mathrm{An}_{30}$ ) rims some albite porphyroblasts in the studied samples from the Newton Range. Based on the information presented above, this indicates that on a $P-T$ pseudosection, the $P-T$ path should at some stage cross the plagioclase zero-mode isopleth, into an assemblage where plagioclase and albite coexist. This observed change in plagioclase composition should also be expressed as a drop in $\mathrm{CaO}$ on some garnet rims.

\subsubsection{Garnet Compositions}

Garnet in Alpine Schist greyschist has a general formula (Ca, $\mathrm{Fe}, \mathrm{Mn}, \mathrm{Mg}){ }_{3} \mathrm{Al}_{2} \mathrm{Si}_{3} \mathrm{O}_{12}$ signifying that garnet composition is not fixed, but can vary within compositional limits. These are traditionally described in terms of solid solution between four main compositional endmembers: spessartine 
( $\left.\mathrm{Mn}_{3} \mathrm{Al}_{2} \mathrm{Si}_{3} \mathrm{O}_{12}\right)$; grossular $\left(\mathrm{Ca}_{3} \mathrm{Al}_{2} \mathrm{Si}_{3} \mathrm{O}_{12}\right)$; almandine $\left(\mathrm{Fe}_{3} \mathrm{Al}_{2} \mathrm{Si}_{3} \mathrm{O}_{12}\right)$; and pyrope $\left(\mathrm{Mg}_{3} \mathrm{Al}_{2} \mathrm{Si}_{3} \mathrm{O}_{12}\right)$. Alternatively, compositions can be described using terms that can be contoured using THERMOCALC, provided that the garnet activity-composition model used involves the above four endmember species. These alternative terms are: $\mathrm{m}(\mathrm{g})$, the mole fraction of spessartine $\left(\mathrm{Mn} /\left(\mathrm{Mn}+\mathrm{Ca}+\mathrm{Fe}_{\text {total }}+\mathrm{Mg}\right)\right) ; \mathrm{z}(\mathrm{g})$, the mole fraction of grossular $\left(\mathrm{Ca} /\left(\mathrm{Mn}+\mathrm{Ca}+\mathrm{Fe}_{\text {total }}+\mathrm{Mg}\right)\right)$, and $\mathrm{x}(\mathrm{g})$, the ratio of almandine and pyrope, $\left(\mathrm{Fe}_{\text {total }} /\left(\mathrm{Fe}_{\text {total }}+\mathrm{Mg}\right)\right)$.

Garnet has the potential to preserve a record of the progressive evolution of metamorphic conditions during the garnet growth history in compositional zoning. This is mainly due to the slow rates of $\mathrm{Fe}, \mathrm{Mg}, \mathrm{Mn}$ and $\mathrm{Ca}$ diffusion in garnet at temperatures below $\sim 700^{\circ} \mathrm{C}$ (Tracy, 1982; Spear, 1988; Chakraborty \& Ganguly, 1992). Diffusion rates become exponentially slower with decreasing temperature (i.e. diffusion rates in garnet are very slow at greenschist facies conditions). The metamorphic mineral assemblages in greyschist samples from the Newton Range are consistent with most garnet growth taking place at greenschist facies conditions. In the following sections of this chapter, the compositional growth zoning in garnet-in samples from the Newton Range is used together with $P-T$ pseudosection results for the same rock samples, to investigate the local metamorphic $P$-T record.

As garnets from Alpine Schist greyschist in north Westland typically have very low MgO contents $(<1 \mathrm{wt} \%)$, the $\mathrm{Fe} /(\mathrm{Fe}+\mathrm{Mg})$ values are all very high $(>0.92)$ and do not vary much throughout a garnet zoning profile. See chapter six for a full description of garnet compositional zoning. Although $\mathrm{Fe} /(\mathrm{Fe}+\mathrm{Mg})$ data from garnet is ordinarily considered essential for most traditional geothermobarometry studies, for the samples studied here, $\mathrm{Fe} /(\mathrm{Fe}+\mathrm{Mg})$ is not a useful parameter for indicating $P$ - $T$ conditions or changes in $P$-T conditions.

\section{Calculated garnet composition isopleths}

In a perfect world there would be an exact correlation between the measured garnet composition data and the predicted compositions obtained based on the results of P-T pseudosection calculations, with the calculated isopleths for the measured garnet composition all intersecting at a point on the $P-T$ pseudosection diagram. This intersection of measured and predicted compositions should also lie within a predicted mineral assemblage field that is appropriate for the sample, based on the results of petrographic observations. In most cases the field should be that of the dominant metamorphic mineral assemblage (q-bi-mu-chl-ab-g-ep-ilm). The composition isopleths for the firstgrown garnet (garnet core composition (excluding stage 0 cores)) should also intersect at the garnet 
zero-mode isopleth. Stage 0 cores are small garnet cores with compositions that are anomalous in respect to the surrounding garnet and do not reflect progressive metamorphism during the Alpine Schist event (see chapter six). Hence they cannot be used to construct P-T paths (see discussion section). Samples DMNR-01, $05 \& 07$ contain garnet with stage 4 garnet rims, the origin of which are not fully understood (possibly a late Cenozoic overprint - see chapter six), but based on the calculated garnet composition isopleths, the P-T conditions of these rims does not appear to be interpretable in terms of a simple continuous $P-T$ path. Therefore stage 4 rims are not used in the calculation of $P-T$ paths.

The $\mathrm{m}(\mathrm{g})$ composition isopleths for measured $X_{\text {sps }}$ garnet core compositions generally intersect the garnet zero-mode isopleth along the boundary of the dominant metamorphic mineral assemblage. However, $z(\mathrm{~g})$ isopleths for the corresponding measured $X_{\mathrm{grs}}$ core compositions do not intersect the garnet zero-mode isopleth. Therefore, as the composition isopleths do not intersect at, or close to, an appropriate location, a $P-T$ path cannot be calculated directly from measured garnet compositions. The methods used to estimate a $P$ - $T$ path are described in the following section.

\subsubsection{P-T Path Construction}

P-T paths show the relative rate of heating vs. burial of rocks during metamorphism and are an integral part in deciphering tectonic processes of orogens. If paths with different rates of heaving vs. burial and/or peak metamorphic conditions are found within a single orogen, important insights regarding variability of crustal-scale metamorphic processes can be drawn. In this study $P-T$ paths are produced by matching compositional analyses of garnet to predicted garnet compositions, calculated using THERMOCALC.

As the $\mathrm{m}(\mathrm{g})$ (i.e. $X_{\mathrm{sps}}$ ) composition isopleth intersects the garnet zero-mode isopleth along the boundary of the stability field containing the dominant mineral assemblage, and the $z(g)$ (i.e. $\left.X_{\text {grs }}\right)$ composition isopleth does not, it is probable that the $\mathrm{z}(\mathrm{g})$ isopleth is in error. As suggested by Vry et al. (2008), the amount of $\mathrm{CaO}$ available for garnet growth in the studied samples is probably being overestimated by THERMOCALC due to initial assumptions made in order to undertake the P-T pseudosection calculations. Those assumptions, that albite (Na-plagioclase) is a pure endmember species, and that no carbonate was ever present, are simplifications. At present, it is necessary to assume that albite is pure in order to calculate $P$-T pseudosections that show both albite and a more calcic plagioclase, but the albite in samples from the Newton Range contains small amounts of Ca, and so is not an endmember composition (see chapter six). In addition, it is quite possible that some 
calcite might have been present in at least some samples during some stage of the metamorphic history (see chapter six). If a $P$-T path is to be extracted from the existing analytical data and modelling results, some correction will be required. The approach used here is to calculate an $X_{\text {grs }}$ "offset", as explained in the following sections and in figure 7.6.

\section{$P$-T Path Calculation - Method A}

The measured $X_{\mathrm{sps}}$ composition of the innermost garnet core is matched to the corresponding predicted $\mathrm{m}(\mathrm{g})$ composition on the garnet zero-mode isopleth on the $P-T$ pseudosection. This is the starting point for the $P-T$ path. The predicted $\mathrm{z}(\mathrm{g})$ composition at this point does not match the analysed garnet $X_{\mathrm{grs}}$ composition so an offset is calculated by taking the difference between the measured $X_{\mathrm{grs}}$ and the predicted $\mathrm{z}(\mathrm{g})$ from the starting point $\left(\mathrm{z}(\mathrm{g})\right.$ - measured $X_{\mathrm{grs}}=X_{\mathrm{grs}}$ offset). This offset is then added to the measured $X_{\mathrm{grs}}$ of each analysis in the garnet transect (up to 50 points) to create the "used $X_{\mathrm{grs}}$ " values (measured $X_{\mathrm{grs}}+X_{\mathrm{grs}}$ offset $=$ used $X_{\mathrm{grs}}$ ). These used $X_{\mathrm{grs}}$ values are matched with the measured $X_{\mathrm{sps}}$ compositions and plotted on predicted garnet composition isopleths on the $P-T$ pseudosection. When these points are joined together in sequence from core to rim, they form an interpreted $P-T$ path.

\section{$P$-T Path Calculation - Method B}

If the $P$-T paths calculated using method $A$ are located at significantly higher pressures than those obtained from other nearby samples, a secondary method can sometimes be used. Method B is only applicable when the analysed garnets show an abrupt rimward drop in $\mathrm{CaO}$, most simply interpreted as a result of from continued garnet growth after a second, Ca-bearing plagioclase becomes stable and begins to grow. In P-T space, this drop in $\mathrm{CaO}$ should coincide with the P-T path crossing the plagioclase zero-mode isopleth (pl-in line) within the stability field of garnet, from which point $\mathrm{Ca}$ is partitioned into oligoclase, resulting in a reduction of the total Ca available in the bulk-rock from which garnet can grow. $P-T$ paths created using method A from garnets which have a rimward drop in $\mathrm{CaO}$ generally cross the plagioclase zero-mode isopleth as $\mathrm{CaO}$ begins to abruptly decrease.

Method B changes the point for the $X_{\mathrm{grs}}$ offset calculation to the plagioclase zero-mode isopleth (pl) instead of the garnet zero-mode isopleth $(\mathrm{g})$. The measured $X_{\mathrm{sps}}$ value is matched to the predicted $\mathrm{m}(\mathrm{g})$ value at the point along the garnet transect at which Ca begins to drop, and the $X_{\text {grs }}$ offset is calculated at this point, in the same way as before $\left(\mathrm{z}(\mathrm{g})\right.$ - measured $X_{\mathrm{grs}}=X_{\mathrm{grs}}$ offset), (measured $X_{\mathrm{grs}}$ 
a)

Garnet 1

No Ca drop at rim

(stages $1 \& 2$ )

1.Schematic compositional zoning profile
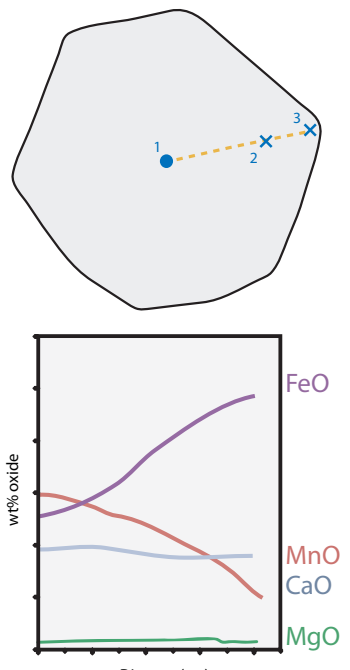

Distance $(\mu \mathrm{m})$

2. Example Xgrs offset calculation

\begin{tabular}{|c|c|c|c|}
\hline Point & 1 & 2 & 3 \\
\hline $\begin{array}{c}\text { Measured } \\
\text { Xsps }\end{array}$ & 0.3 & 0.2 & 0.1 \\
\hline $\begin{array}{c}\text { Measured } \\
\text { Xgrs }\end{array}$ & 0.3 & 0.25 & 0.2 \\
\hline$z(g)$ & 0.4 & & \\
\hline $\begin{array}{c}\text { Xgrs } \\
\text { *offset }\end{array}$ & 0.1 & 0.1 & 0.1 \\
\hline $\begin{array}{l}\text { Used } \\
\text { Xgrs } \\
\end{array}$ & 0.4 & 0.35 & 0.3 \\
\hline
\end{tabular}

${ }^{*} X \mathrm{grs}$ Offset $=\mathrm{z}(\mathrm{g})_{\text {point1 }}-$ Measured grrs $_{\text {point1 }}$

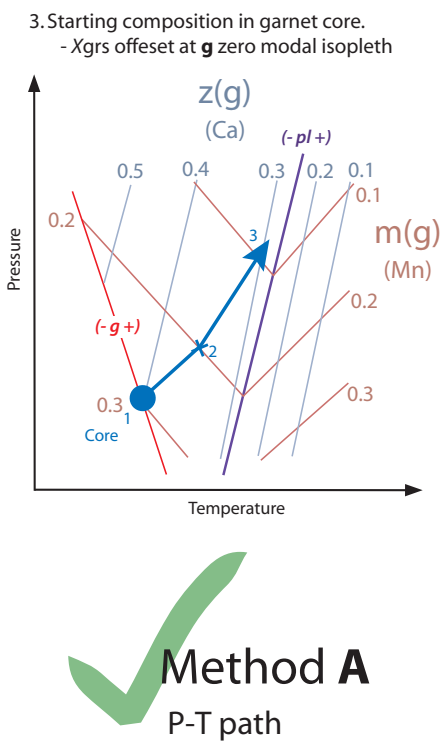

b)

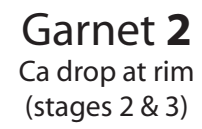

1.Schematic compositional zoning profile
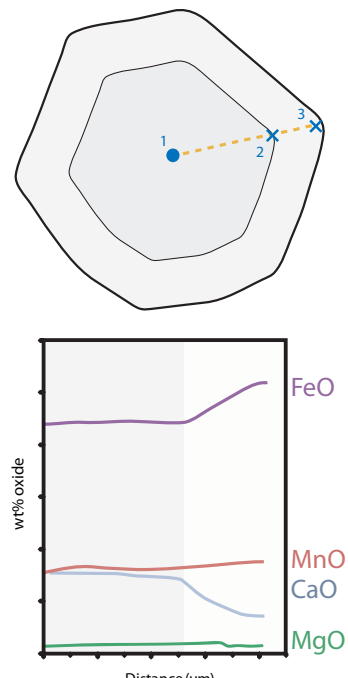

2. Example Xgrs offset calculation

\begin{tabular}{|c|c|c|c|}
\hline Point & 1 & 2 & 3 \\
\hline $\begin{array}{c}\text { Measured } \\
\text { Xsps }\end{array}$ & 0.2 & 0.1 & 0.12 \\
\hline $\begin{array}{c}\text { Measured } \\
\text { Xgrs }\end{array}$ & 0.2 & 0.15 & 0.05 \\
\hline z(g) & 0.55 & 0.35 & 0.35 \\
\hline $\begin{array}{c}\text { Xgrs } \\
\text { *offset }\end{array}$ & 0.35 & 0.35 \\
\hline $\begin{array}{c}\text { Used } \\
\text { Xgrs }\end{array}$ & 0.55 & 0.5 & 0.45 \\
\hline
\end{tabular}

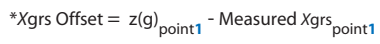

3. Starting composition in garnet core gives an anomalous P-T path,
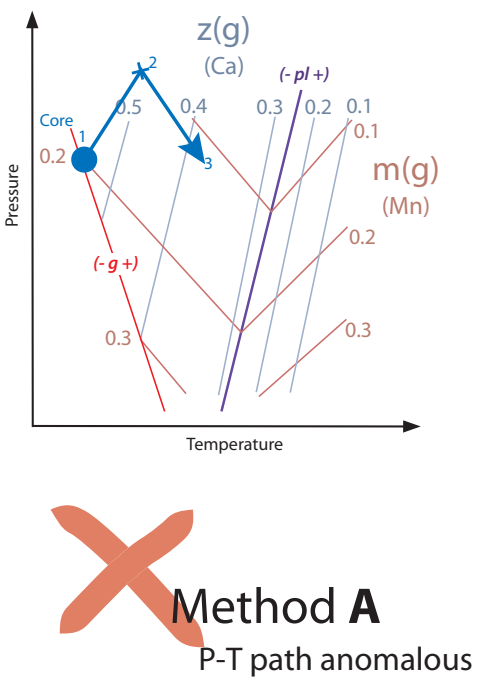

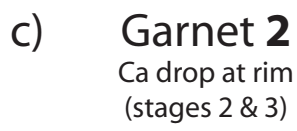

1.Schematic compositional zoning profile
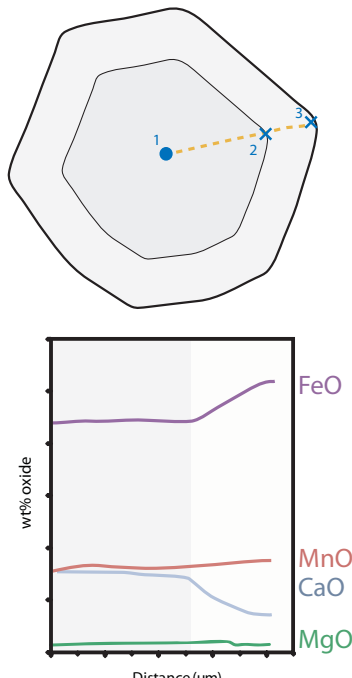

2. Example Xgrs offset calculation

\begin{tabular}{|c|c|c|c|}
\hline Point & 1 & $2(\mathrm{pl})$ & 3 \\
\hline $\begin{array}{c}\text { Measured } \\
\text { Xsps }\end{array}$ & 0.2 & 0.1 & 0.12 \\
\hline $\begin{array}{c}\text { Measured } \\
\text { Xgrs }\end{array}$ & 0.2 & 0.15 & 0.05 \\
\hline z(g) & 0.25 & 0.1 \\
\hline $\begin{array}{c}\text { Xgrs } \\
\text { *offset }\end{array}$ & 0.1 & 0.1 & 0.15 \\
\hline $\begin{array}{c}\text { Used } \\
\text { Xgrs }\end{array}$ & 0.3 & 0.25 & 0.15 \\
\hline
\end{tabular}

${ }^{*} X$ grs Offset $=z(g)_{\text {point2(pl) }}{ }^{- \text {Measured } X g r s}{ }_{\text {point2(pl) }}$

3. Starting composition from Ca-drop in grt transect - Xgrs offset at pl zero modal isopleth

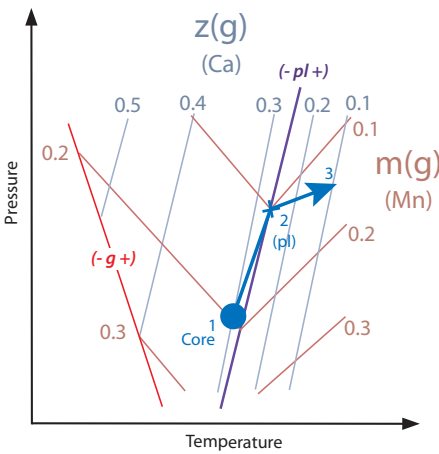

\section{Method B}

P-T path crosses $\mathrm{pl}$

Figure 7.6. Schematic examples of methods used to calculate $P$ - $T$ paths (explained further in text). a) Successful use of Method A - measured core Xsps composition of "garnet 1" (point 1) plotted on the grt zero-mode isopleth. b) Anomalously high-pressure P-T path of "garnet 2" using Method A. c) Method B can be used to plot a P-T path for "garnet 2" with reasonable P-T conditions. The measured Xsps composition at Ca-drop (point 2) is plotted on the pl zero-mode isopleth instead of the $\mathrm{g}$ zero-mode isopleth. 
$+X_{\mathrm{grs}}$ offset $=$ used $X_{\mathrm{grs}}$. The matched measured $X_{\mathrm{sps}}$ and used $X_{\mathrm{grs}}$ compositions are then plotted on composition isopleths in the $\mathrm{g}$ stability field. Method B produces $P-T$ paths that are located within error of paths obtained by method A for nearby samples.

P-T paths are created using method B for DMNR-05 \& 07, as they are the only samples which have anomalous paths created using method $\mathrm{A}$ and that have garnet showing a rimward drop in $\mathrm{CaO}$. Other samples with anomalously high pressure $P-T$ paths do not show changes in garnet composition which reflect the inception of a new mineral phase (i.e. $P$ - $T$ path does not cross a zeromode isopleth such as the pl-in line). Sample DMNR-01 \& 27 contain garnet with a roimward drop in Ca but plot successfully with method A (no titanite in rock). If method B is used for these two samples, the $P$ - $T$ paths generated are within error of ones created using method A.

\subsubsection{P-T Path Results}

$P-T$ paths are presented in figures 7.7, 7.8, 7.9, 7.10 and 7.11, overlain on previously presented $P-T$ pseudosections. Also shown are back-scattered electron (BSE) images and compositional transects of the garnets the $P-T$ paths are taken from. Garnet compositions vary sample to sample but the composition of garnet cores within an individual sample rarely varies (excluding stage 0 cores), meaning one path is representative of the sample. DMNR-27 shows the longest path of any sample starting at $\sim 3.5 \mathrm{kbar}$ and $425^{\circ} \mathrm{C}$, increasing to $\sim 6.75 \mathrm{kbar}$ and $500^{\circ} \mathrm{C}$. Four other samples have shorter paths (DMNR 01, 05, 07, and 80) with conditions of $\sim 6.25-7.5 \mathrm{kbar}$ and $475-525^{\circ} \mathrm{C}$, similar to the end of the DMNR-27 path.

Four samples (DMNR 20, 51, $90 \&$ 93) have P-T paths that plot at much higher pressures than the other four $P$ - $T$ paths. The anomalous paths, colour coded red in the composite $P$ - $T$ path in figure 7.12, are not deemed to be representative of the real $P-T$ path for the Newton Range (explained further in the discussion section). All other $P-T$ paths (coloured green) group similarly at near peak metamorphic pressures and show a slight isobaric increase in temperature $\left(\sim 25^{\circ} \mathrm{C}\right)$ as the $P-T$ path crosses the plagioclase zero-mode isopleth $(\mathrm{pl})$. This change into the plagioclase stability field is represented in garnets containing a rimward drop in Ca (stage 3 garnet composition: chapter six) providing a handy link between modelled mineral assemblages and compositional observations. Most of the calculated P-T paths cross into the stability field of paragonite (Na-rich mica) at peak pressures although no mica with a paragonite-like composition is observed in any sample. 
a)

DMNR-01 ${ }^{\mathrm{A}}$
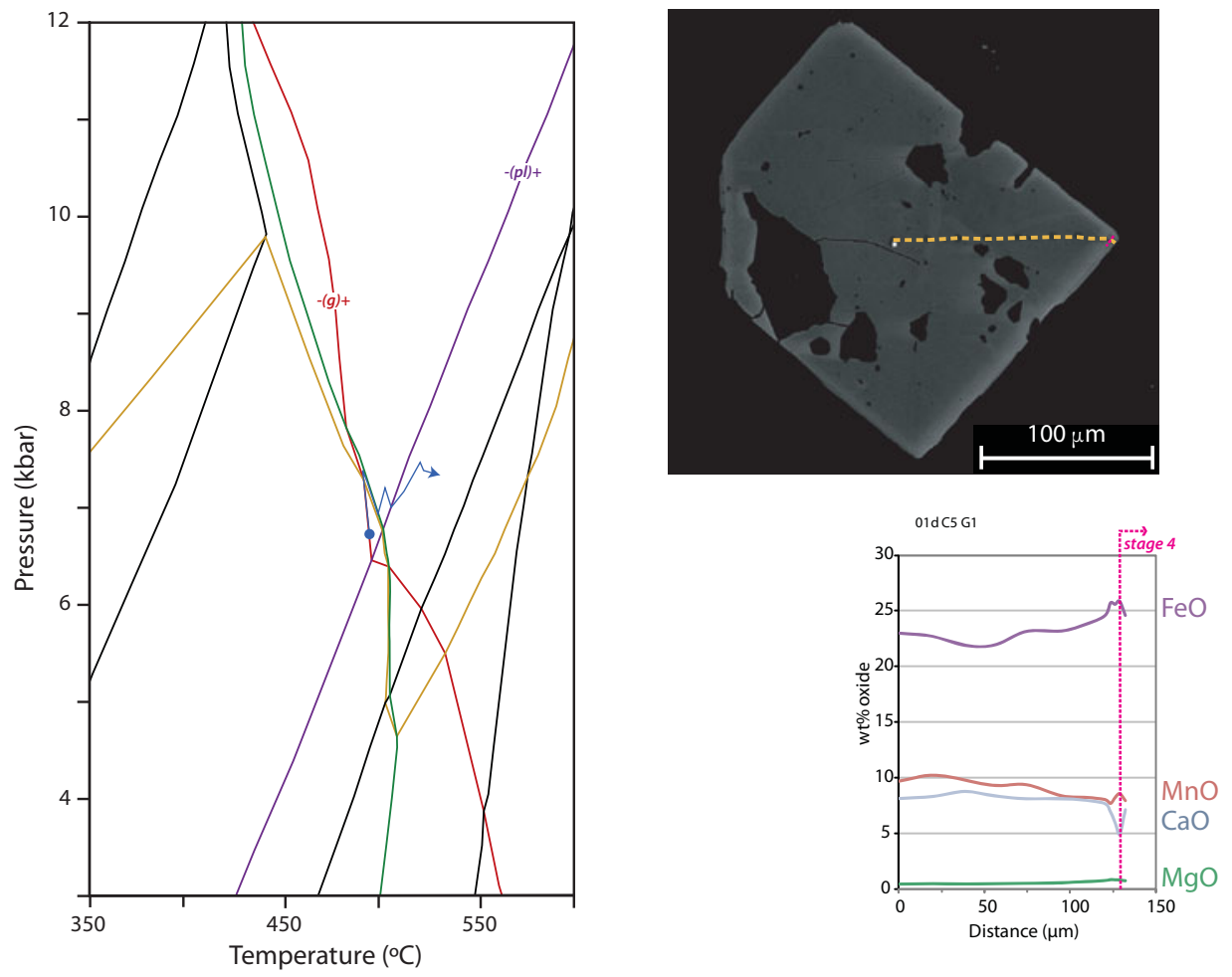

b) DMNR-05
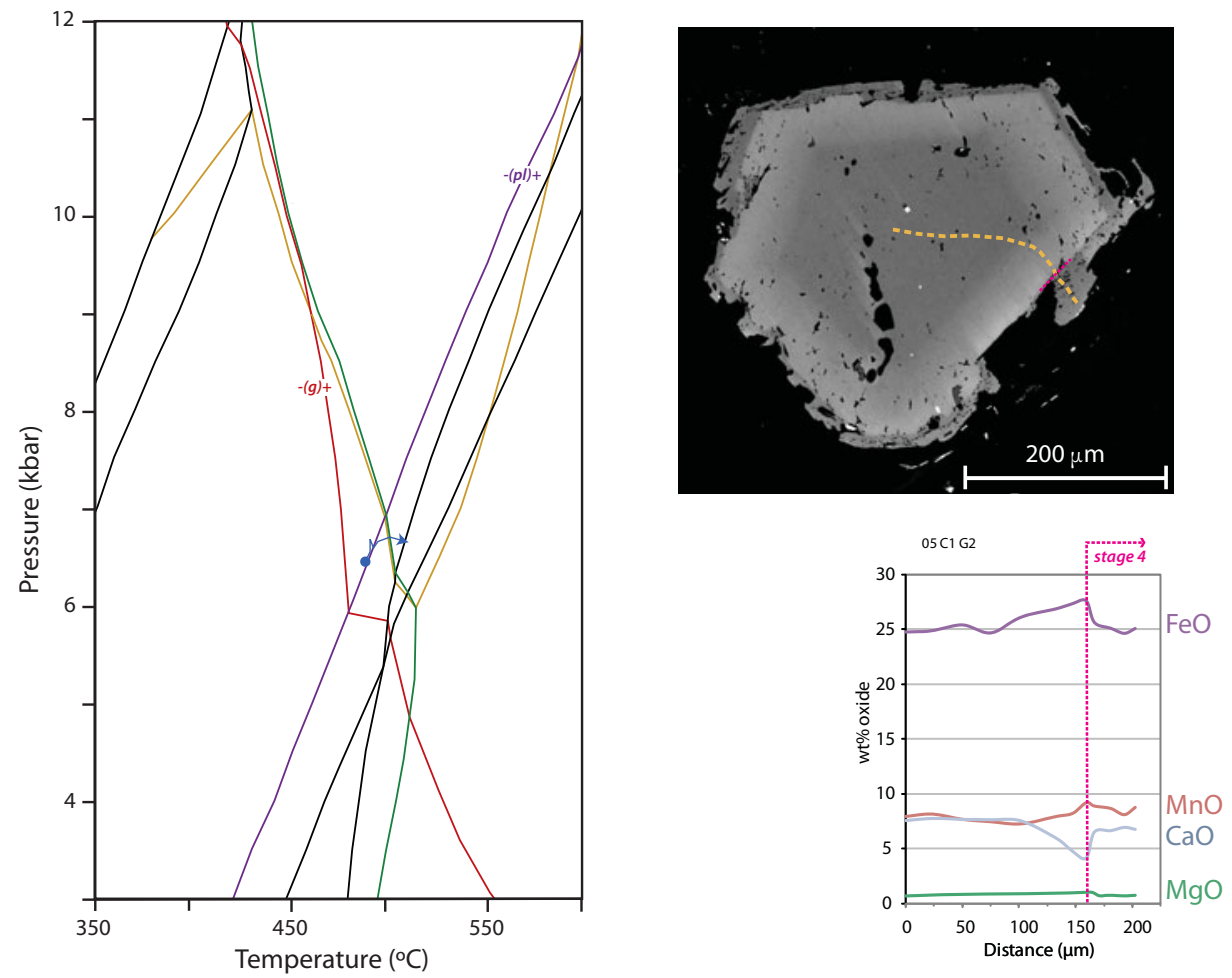

Figure 7.7. 11-component $P-T$ pseudosections with $P-T$ paths (blue line) overlain for samples DMNR-01 (a) and 05 (b). Compositional transect and back-scattered electron image of the garnet used to calculate the P-T path. The start (filled circle) and end (arrow) of the P-T path represent the core and rim of the garnet transect respectively. The pink dashed line denotes a stage 4 (see text) rim not used in calculation of the $P-T$ path. Labels of zero modal isopleths can be seen in figures $7.3 \mathrm{a}$ ) and b). ${ }^{\mathbf{A}}$ Method A used to calculate P-T path. ${ }^{\mathbf{B}}$ Method B used to calculate $P-T$ path. 
a) $\mathrm{DMNR}-07^{\mathrm{B}}$
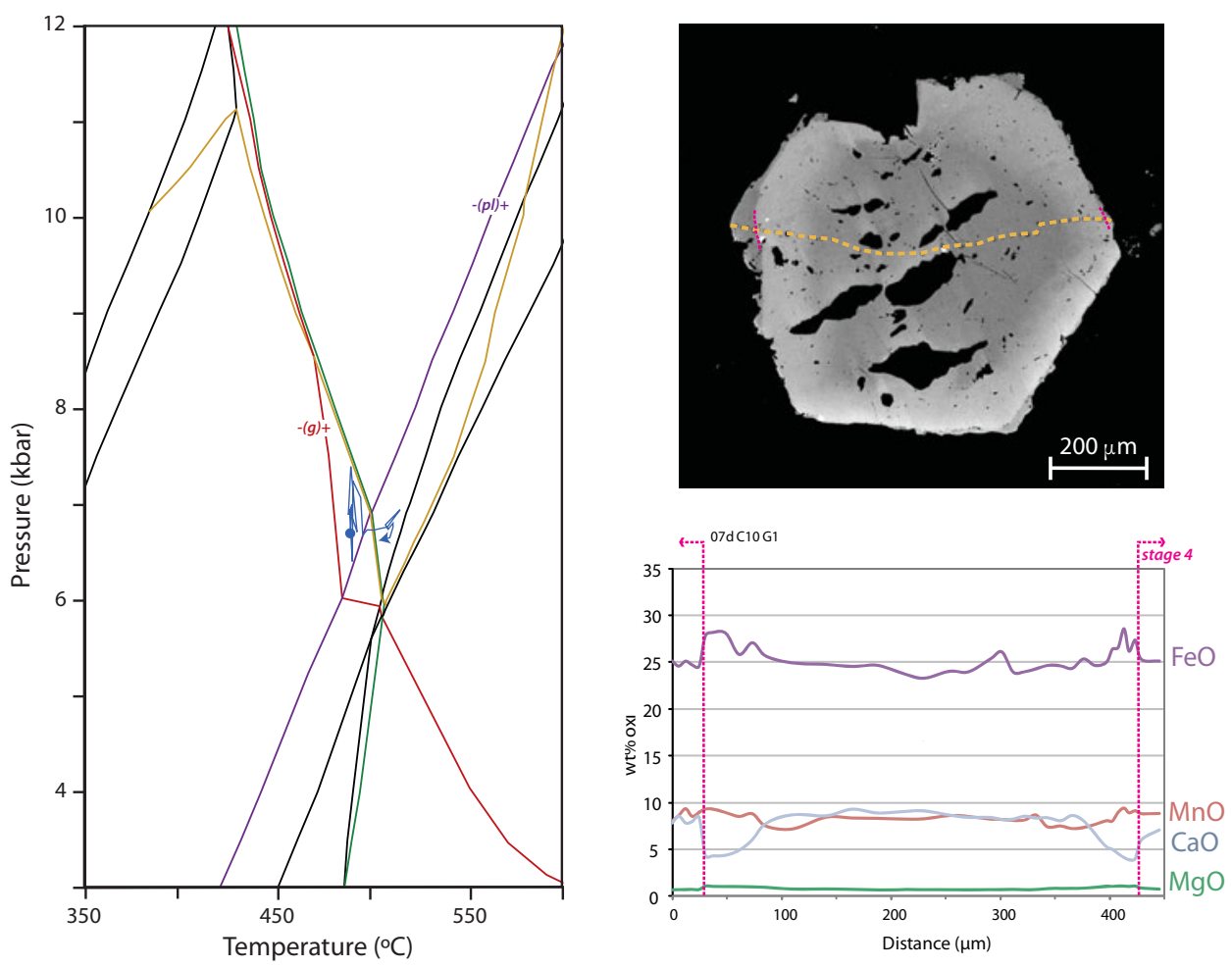

b) $\mathrm{DMNR}-20^{\mathrm{A}}$
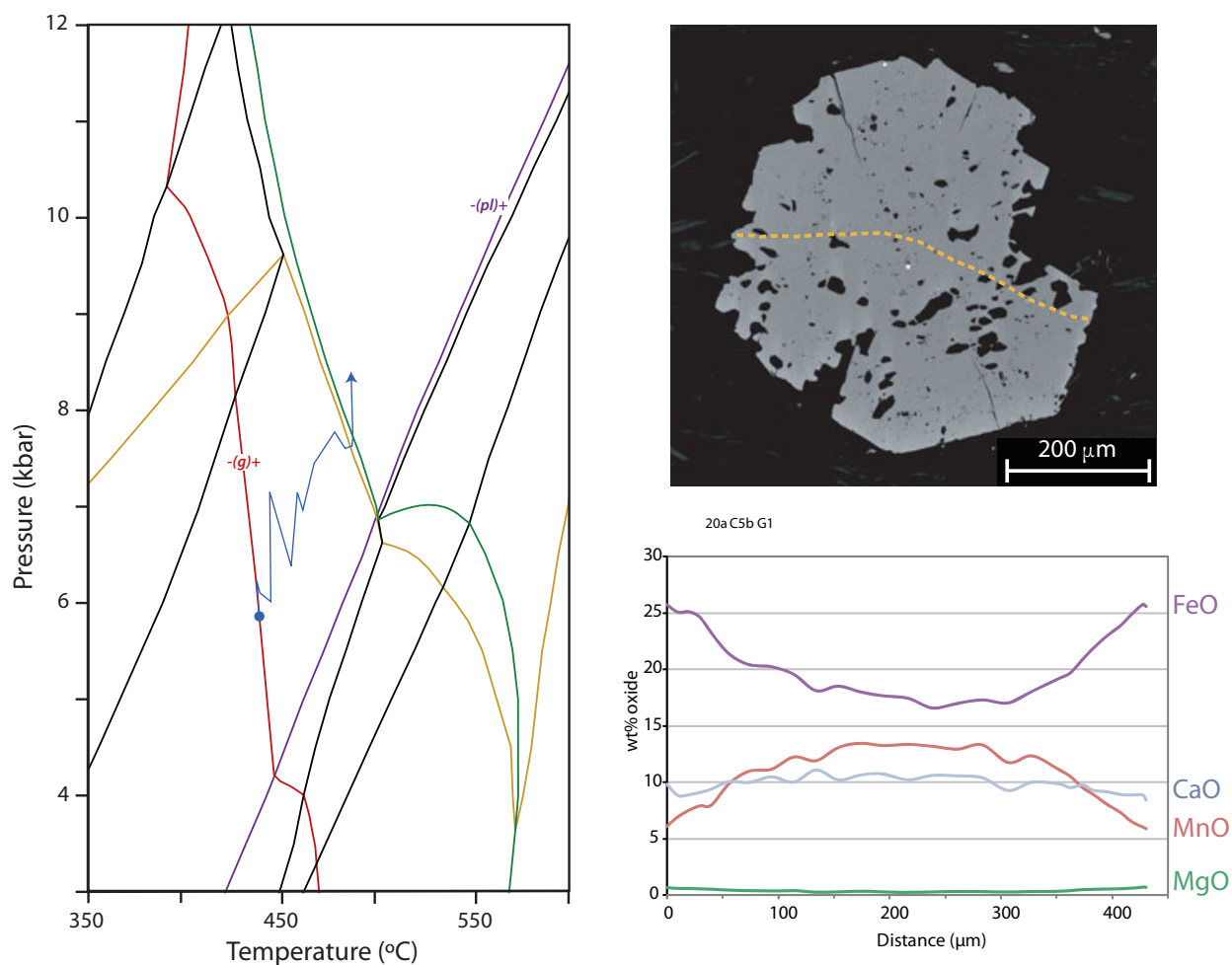

Figure 7.8. 11-component $P-T$ pseudosections with $P$-T paths (blue line) overlain for samples DMNR-07 (a) and 20 (b). Compositional transect and back-scattered electron image of the garnet used to calculate the P-T path. The start (filled circle) and end (arrow) of the $P$-T path represent the core and rim of the garnet transect respectively. The pink dashed line denotes a stage 4 (see text) rim not used in calculation of the $P$ - T pathLabels of zero modal isopleths can be seen in figures $7.3 \mathrm{c}$ ) and d). ${ }^{\mathbf{A}}$ Method A used to calculate $P-T$ path. ${ }^{\mathbf{B}}$ Method B used to calculate $P$ - $T$ path. 
a)

DMNR-27 ${ }^{\mathrm{A}} 1$

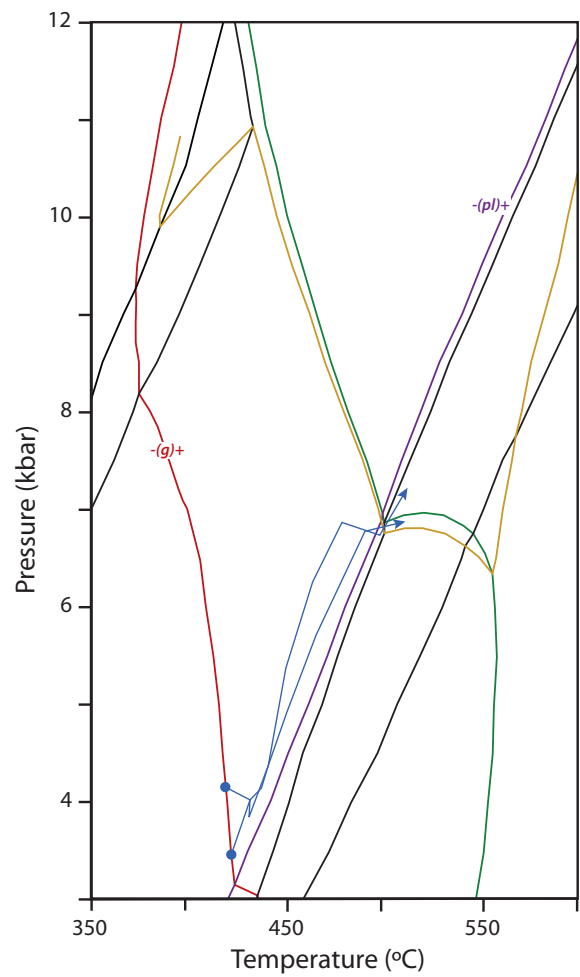

b) $\mathrm{DMNR}-51^{\mathrm{A}}$

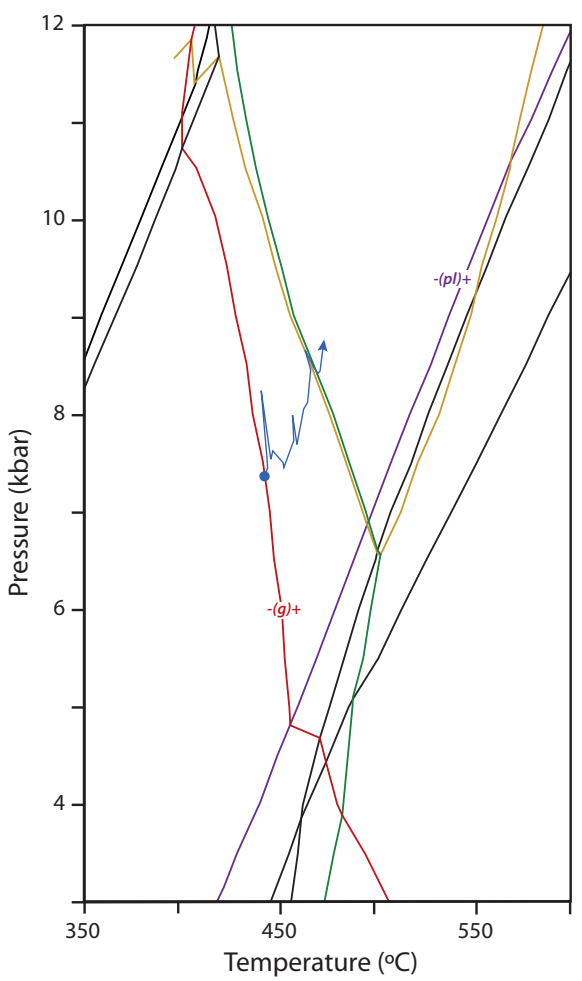

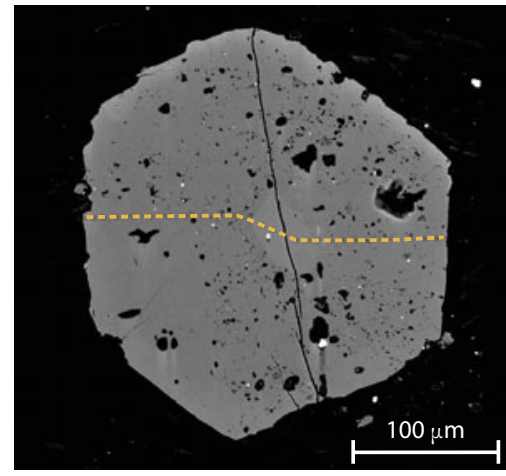

7C1 G
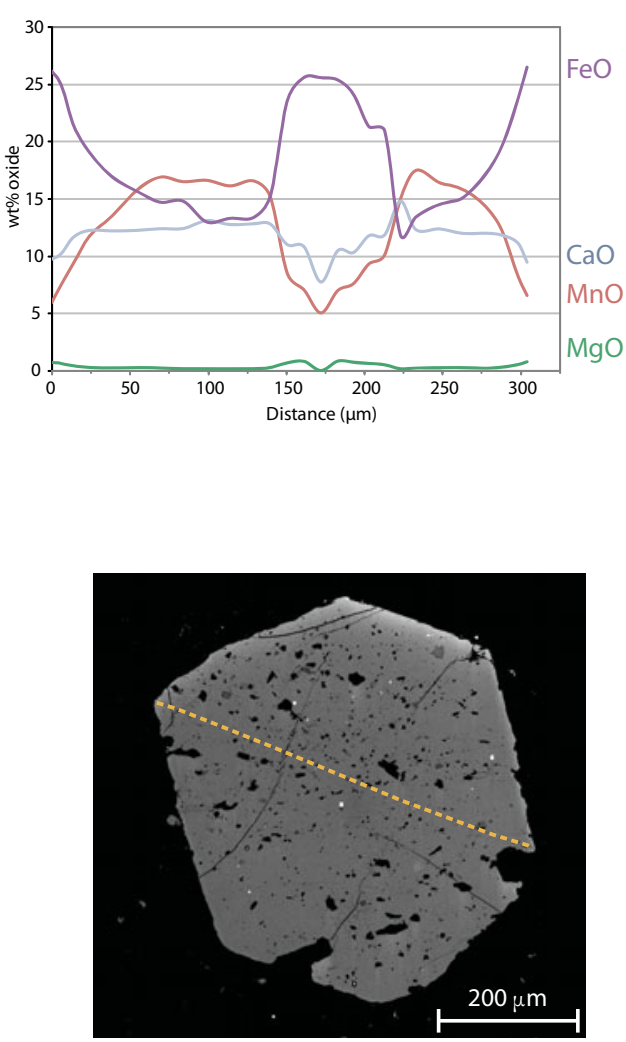

$51 \mathrm{C3G}$

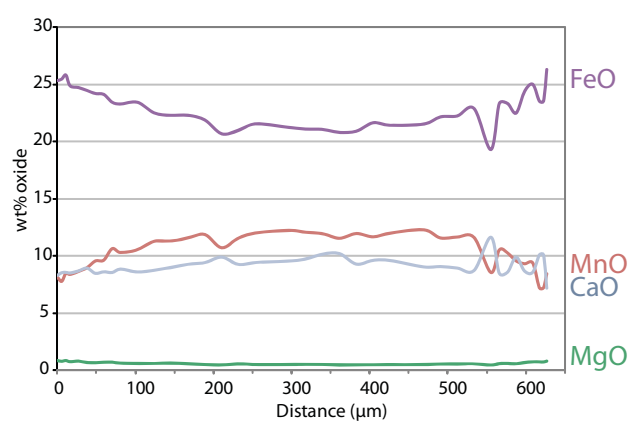

Figure 7.9. 11-component $P-T$ pseudosections with $P$ - $T$ paths (blue line) overlain for samples DMNR-27 (a) and 51 (b). Compositional transect and back-scattered electron image of the garnet used to calculate the P-T path. The start (filled circle) and end (arrow) of the $P-T$ path represent the core and rim of the garnet transect respectively. Labels of zero modal isopleths can be seen in figures 7.5 a) and 7.4 a). ${ }^{\mathbf{A}}$ Method A used to calculate P-T path. ${ }^{1}$ Anomalous (stage 0 ) core composition not used for $P-T$ path as it is not part of the same metamorphic event as the rest of the transect. 
a) DMNR-80 1
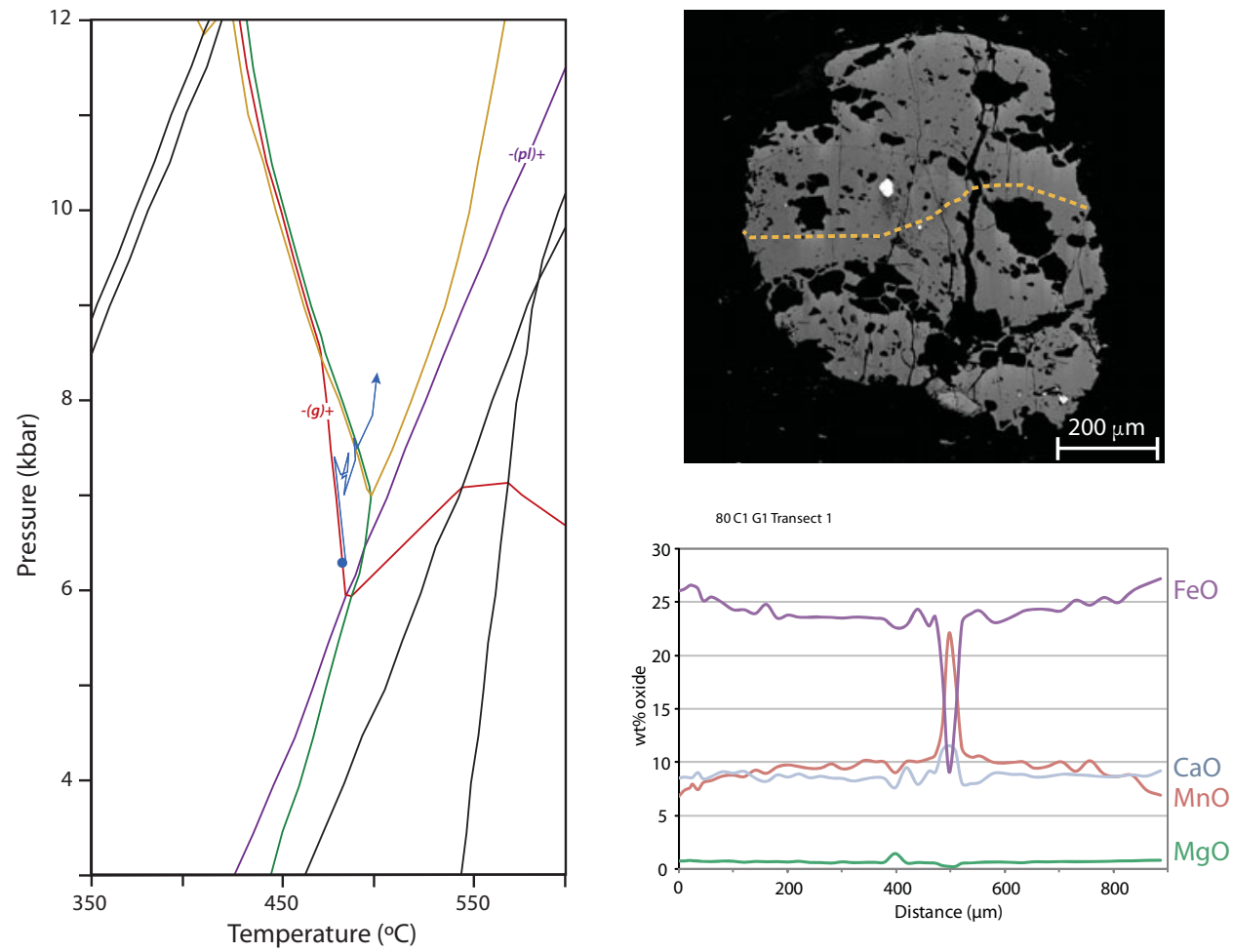

b) DMNR-93 ${ }^{\mathrm{A}}$
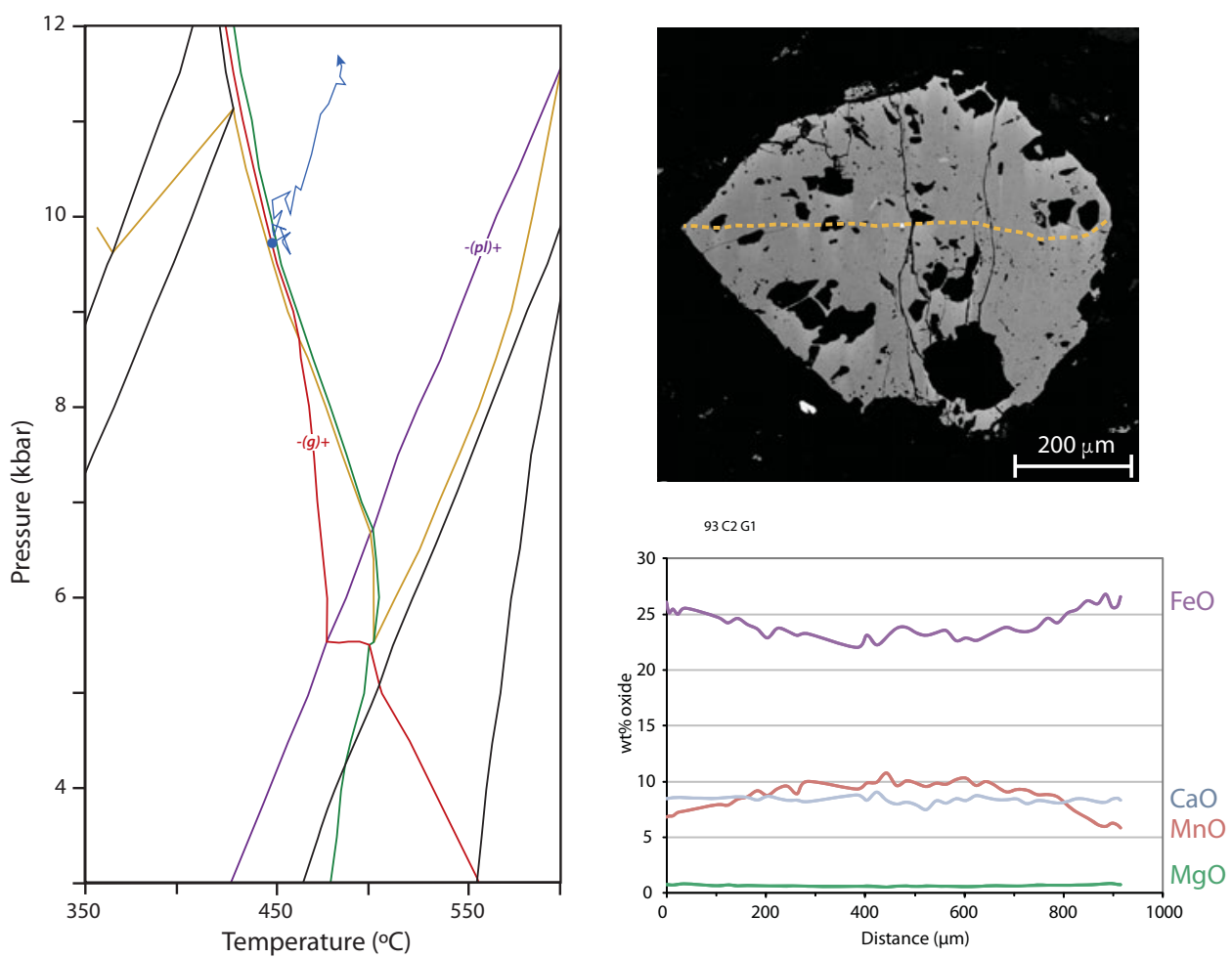

Figure 7.10. 11-component P-T pseudosections with $P-T$ paths (blue line) overlain for samples DMNR-80 (a) and 93 (b). Compositional transect and back-scattered electron image of the garnet used to calculate the P-T path. The start (filled circle) and end (arrow) of the P-T path represent the core and rim of the garnet transect respectively. Labels of zero modal isopleths can be seen in figures $7.4 \mathrm{~b}$ ) and d). ${ }^{\mathbf{A}}$ Method A used to calculate P-T path. ${ }^{1}$ Anomalous (stage 0 ) core composition not used for $P-T$ path as it is not part of the same metamorphic event as the rest of the transect. 
The interpreted P-T path for the Newton Range (Fig. 7.12) shows an overall pattern of increasing pressure and temperature with albite as the only plagioclase phase present for most of the $P-T$ history. Peak metamorphic conditions (when garnet stops growing) are estimated to be at $P_{\max }$ and $T_{\max }$, where the $P-T$ path increases in temperature from $\sim 500-525^{\circ} \mathrm{C}$ crossing the plagioclase zeromode isopleth at $\sim 6.75 \mathrm{kbar}$. No evidence for garnet growth during the decompression section of the $P-T$ path is evident in Newton Range, unlike the case in the McArthur Range, $\sim 7 \mathrm{~km}$ to the northeast (Williams, 2006; Vry, et al., 2008).

\subsection{Discussion}

\subsubsection{P-T paths}

P-T pseudosection calculations have the potential to yield a far more complete interpretation of a metamorphic history than can be obtained using traditional geothermometers and barometers. The majority of traditional geobarometers involve the partitioning of $\mathrm{Ca}$ between garnet and a calcic plagioclase, and are unusable if albite (near-endmember Na-plagioclase) is the sole plagioclase phase stable in the rock, as is the case for most of the metamorphic history of the Alpine Schist in the Newton Range.

The general pattern for the Newton Range $P$ - $T$ path is increasing pressure and temperature, with peak metamorphic conditions where oligoclase was able to grow synchronously with albite. The lack of continued garnet growth during decompression suggests that either of two processes occurred: option 1: dehydration reactions were no longer occurring in the rock, effectively locking the peak mineral assemblage; or option 2: the effective bulk rock composition in a chemically complex mineral assemblage did not allow garnet to continue growing past $P_{\max }$. Schematic decompression paths for both options are represented by the dashed arrows in the composite P-T path (Fig. 7.12).

A path decreasing in temperature during decompression (option 1) would explain lack of continued mineral growth as the amount of fluid available during retrograde evolution is a dominant control on mineral reactions (Guiraud, et al., 2001; Vry, et al., 2008). In this case the P-T path would cool with decompression, running tangential to water isopleths.

A path continuing to increase in temperature after $P_{\max }$ is another option, such as in $P$ - $T$ paths from the nearby McArthur Range (Williams, 2006; Vry, et al., 2008). This section of the P-T path may not be apparent in these rocks because of a lack of local element-availability, meaning garnet may not have the bulk rock composition to grow with that particular mineral assemblage, at those P-T 
DMNR-90 1

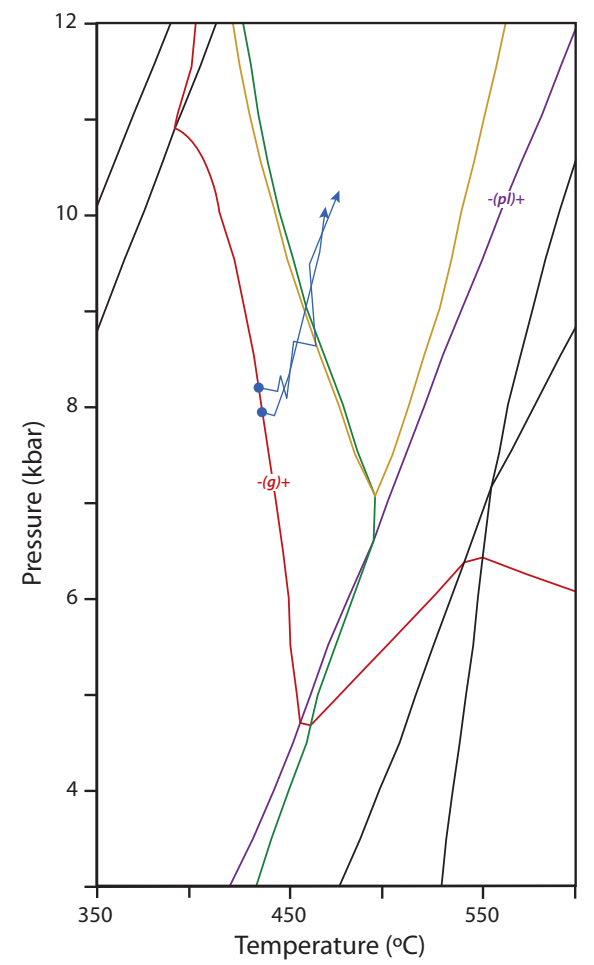

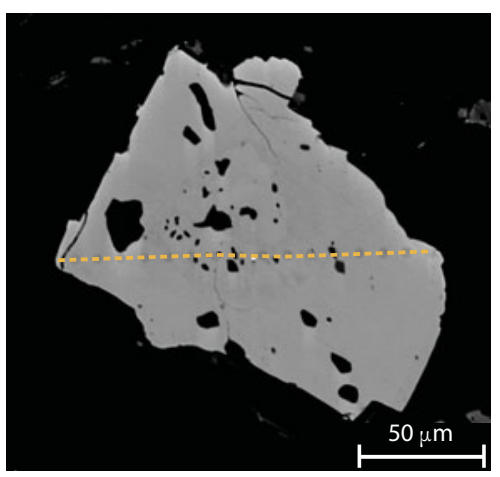

$90 \mathrm{C1G}$

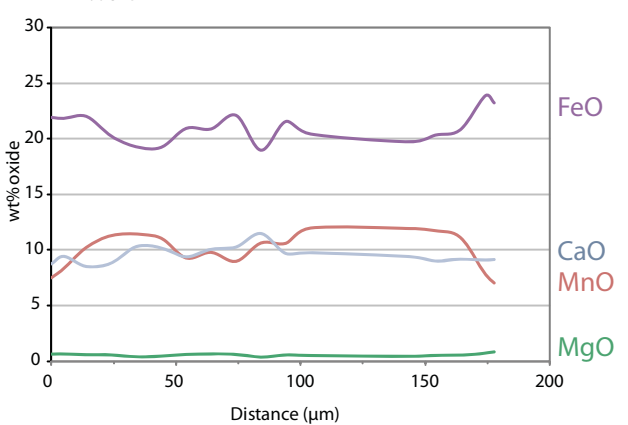

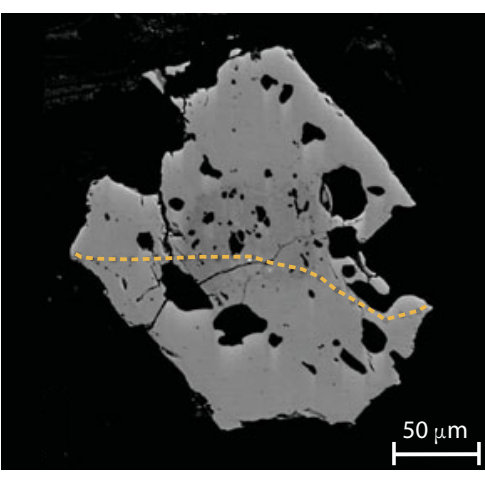

$90 \mathrm{C} 3 \mathrm{G} 1$

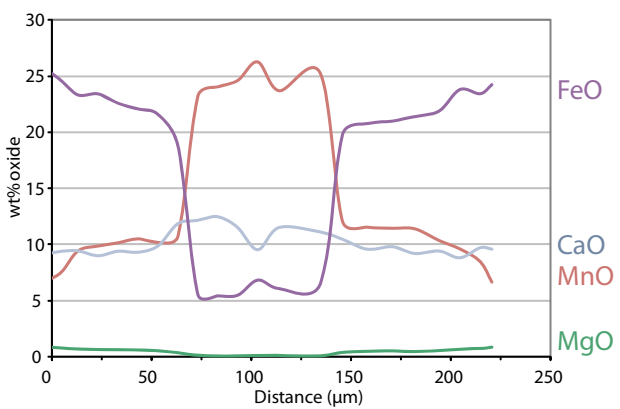

Figure 7.11. 11-component P-T pseudosection with P-T path (blue line) overlain for samples DMNR-90. Compositional transects and back-scattered electron images of the garnet used to calculate the P-T path are shown below. The transect to the right has an anomalous (stage 0) core composition so is not used for the P-T path as it is not part of the same metamorphic event as the rest of the transect. Note how the core composition of $90 \mathrm{C} 1 \mathrm{G} 1$ (left) is the same as the composition of 90 C3 G1 (right) directly outside the stage 0 core. The start (filled circle) and end (arrow) of the P-T path represent the core and rim of the garnet transect respectively. Labels of zero modal isopleths can be seen in figures $7.4 \mathrm{c}$ ). ${ }^{\mathbf{A}}$ Method A used to calculate $P-T$ path. 


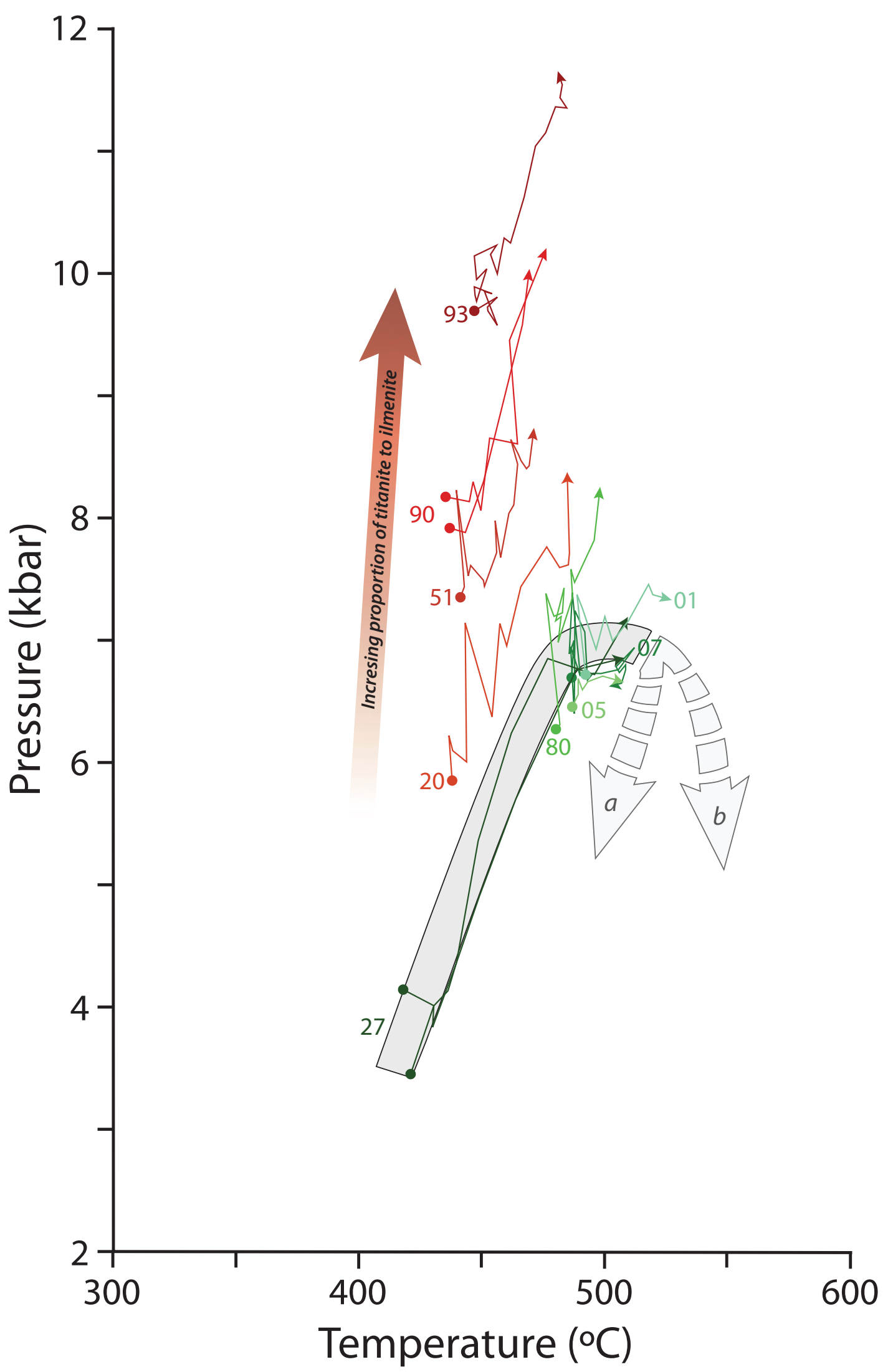

Figure 7.12 Summary of P-T paths for all nine samples. Green coloured paths represent ones used for the interpreted P-T path (light grey). Red paths are deemed too high pressure (explained in text) and are discarded. Thick red arrow signifies higher pressure paths have increasing amounts of titanite in propotion to ilmentite. Dashed grey lines with arrows represent possible post-peak metamorphism a) cooling and b) heating, decompression paths. 
conditions. However, in this study minimal variation in garnet composition within single thin sections was observed, in contrast to the McArthur Range where different garnets from different parts of the same thin-section differed in composition, yielding different parts of the P-T path depending on the composition of the layer they grew in (Williams, 2006).

\section{Effect of Titanite}

A major problem with using THERMOCALC on north Westland metagreywackes is the occurrence of the Ti and Ca-bearing mineral titanite (sphene). Metamorphosed greywacke is complicated in its chemistry, and therefore potentially difficult to model using THERMOCALC, and in the past THERMOCALC modelling of rocks that contained only ilmenite have been successful (Vry, et al., 2008). At present, calculated mineral phase equilibria involving titanite are plagued by uncertainties, mainly attributable to the following causes: a detailed solid solution model of titanite is not available for rocks of such composition, and titanite stability is also extremely sensitive to slight variations in fluid composition in a water-rich $\mathrm{H}_{2} \mathrm{O}-\mathrm{CO}_{2}$ fluid (Vry pers. comm, 2010); hence it is preferable if samples analysed in THERMOCALC contain ilmenite as the only Ti-bearing mineral phase.

Titanite is common in metamorphosed greyschist at low metamorphic grade, and is replaced by ilmenite at higher grade. The fact that titanite rims some ilmenite porphyroblasts in this study, and that both titanite and ilmenite porphyroblasts are stable in the same samples at lower grade, shows titanite has a complex relationship with other minerals. Hence there are still serious gaps in the understanding of the multivariant phase relationships in greyschist rocks containing titanite. As the $P-T$ pseudosection diagrams presented consider only ilmenite, and not titanite, rutile, pumpellyite, or amphiboles, some of the phase relationships shown may be metastable with respect to other phases.

An associated problem is that titanite partitions $\mathrm{Ca}$ from the bulk-rock meaning that in rocks containing titanite, the compositions of other Ca-bearing mineral phases will be incorrectly modelled. Such a problem exists with garnet, where the $\mathrm{m}(\mathrm{g})$ and $\mathrm{z}(\mathrm{g})$ composition isopleths are offset making it difficult to match measured mineral compositions to compositions calculated using THERMOCALC. In this study the more titanite and less ilmenite the rock has, the higher pressure the $P-T$ path is (Figs. $7.12 \&$ 7.13). Garnet core $X_{\text {sps }}$ compositions and matched $\mathrm{m}(\mathrm{g})$ values, plot at high pressures on the garnet zero-mode isopleth when titanite is present. DMNR-93 has almost all ilmenite replaced by titanite and has the most anomalous $P-T$ path whereas DMNR-20 contains a dominant ilmenite Ti-bearing phase but has rims of titanite (Fig. 7.13). This shows that even small amounts of titanite can still affect the $P-T$ path. 
Estimating $P-T$ paths from rocks containing titanite is not successful at present, and may require a revised titanite mineral activity-composition model. Successful modelling of titanite may never be possible if the effect of unquantifiable changing fluid composition is important in such rocks.

\subsubsection{Comparisons with Other Studies}

Rocks now exposed in the McArthur Range $\sim 7 \mathrm{~km}$ to the north experienced a $P-T$ path located at slightly higher pressures and lower temperatures than the rocks in the Newton Range (Williams, 2006; Vry, et al., 2008) (Fig. 7.14). The P-T path for the McArthur Range samples increases in pressure in the albite stability field and sharply transitions into a decompressional path at $8.5 \mathrm{kbar}$ with minimal increase in temperature during decompression $\left(>25^{\circ} \mathrm{C}\right.$ over $\left.\sim 2 \mathrm{kbar}\right)$. The path crosses into the $\mathrm{pl}$ stability field during this decompression as opposed to crossing at $P_{\max }$ as in the present study. The implication is that there is along-strike variability in the $P$-T history of the Alpine Schist, even over short distances.

Peak metamorphic conditions for garnet-oligoclase grade Alpine Schist in the Franz Josef-Fox Glacier region are considerably higher than this study, with upper estimates of $9.2 \mathrm{kbar}$ and $620^{\circ} \mathrm{C}$, and garnet stably coexisting with oligoclase without albite. $T_{\max }$ was probably attained during decompression (Grapes, 1995). The Otago Schist was formed at higher pressures and lower temperatures than the Alpine Schist and represents an earlier metamorphic event with the highestgrade rocks developing $\mathrm{g}+\mathrm{bi}+\mathrm{ab}+\mathrm{chl}+\mathrm{q}+$ mus $+\mathrm{ep}+\mathrm{ttn}$ epidote assemblages at peak temperatures of $350-400^{\circ} \mathrm{C}$ and pressures of $\sim 8-10 \mathrm{kbar}$ (Mortimer, 2000).

The $P$-T path from Newton Range shows peak metamorphism occurred at shallower depths than the Otago Schist and highest grade Alpine Schist from the Franz Josef-Fox Glacier region. Temperatures of peak metamorphism $\left(\sim 500^{\circ} \mathrm{C}\right)$ are higher than the Otago Schist and lower than Alpine Schist from the Franz Josef-Fox Glacier region. A southward increase in the peak metamorphic temperatures attained is tentatively suggested by this study. Such variations in metamorphic conditions and $P-T$ paths could be expected in a long $(>450 \mathrm{~km})$ variably exhumed orogen, such as the Southern Alps (Suggate, 1963; Grapes, 1995; Walcott, 1998). 

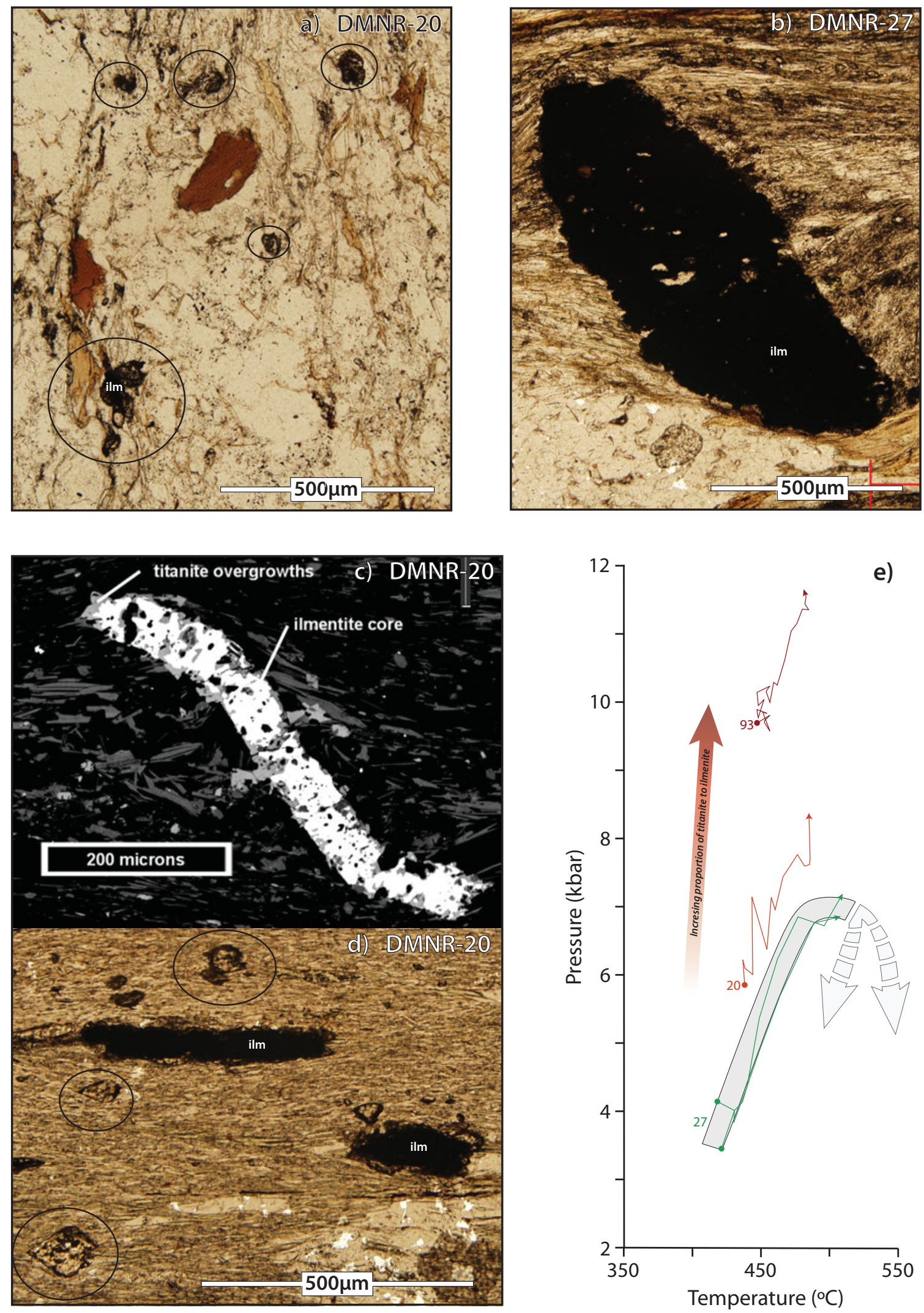

Figure 7.13. Photos and P-T paths of DMNR 93, $20 \& 27$ showing how the amount of titanite effects the $P-T$ path. Circled minerals are titanite, ilm denotes ilmenite porphyroblasts. a) Photomicrograph (ppl) of DMNR-93 showing small anhedral titanite replacing ilmenite. b) Photomicrograph (ppl) of DMNR-27 showing a large ilmenite porphyroblast and no titanite. c) BSE image and d) photomicrograph (ppl) of DMNR-20 showing titanite overgrowing ilmenite porphyroblasts. e) P-T paths of DMNR 93, 20 \& 27. 


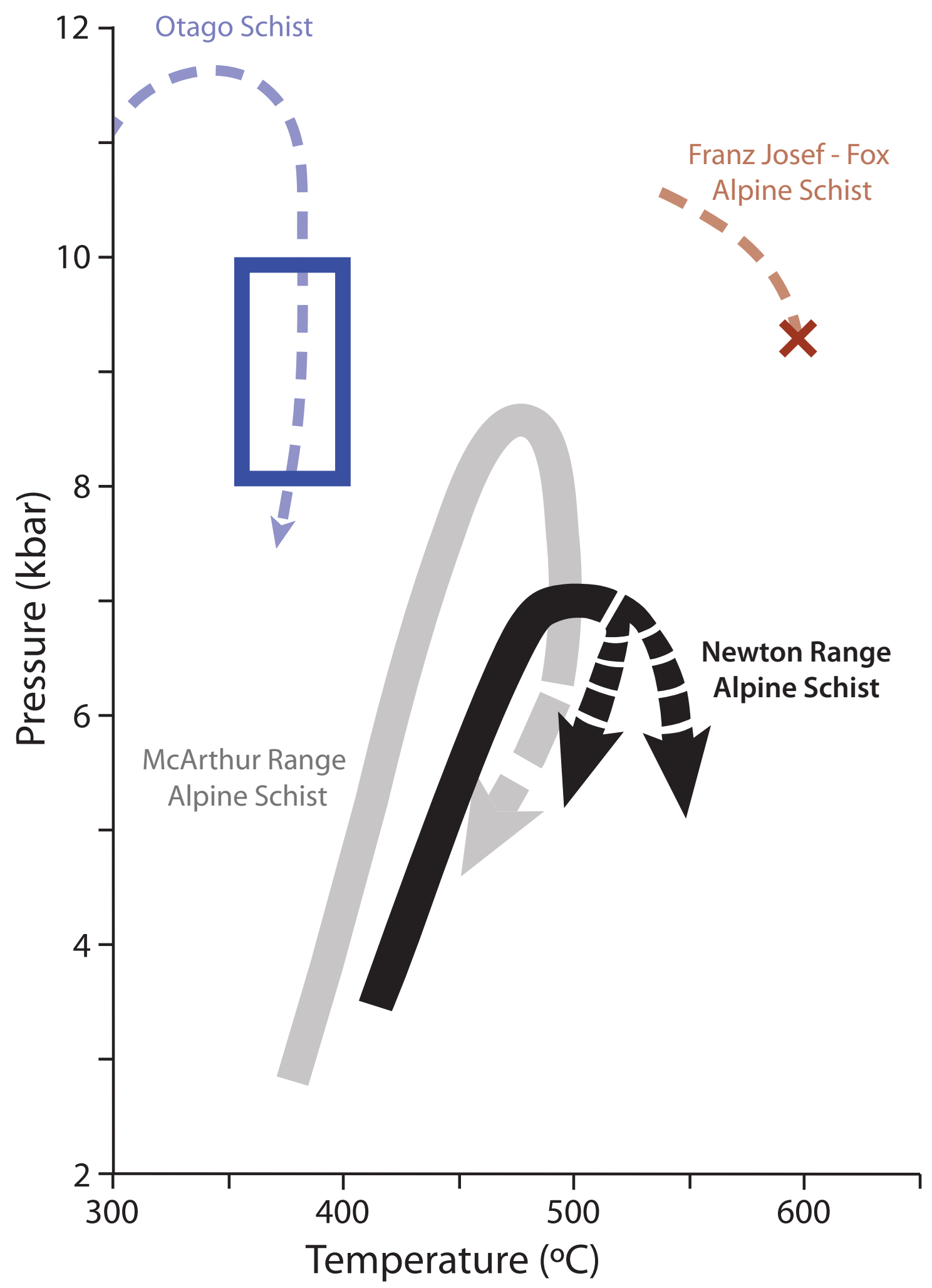

Figure 7.14. Summary of P-T paths for different parts of the Haast Schist. Black line is from this study (fig. 7.11). Grey line is from the McArthur Range (Vry et al., 2008) with the dashed arrow reflecting a possible postpeak $P-T$ path. The red cross shows $P-T$ estimates of peak meatmorphic conditions of garnet-oligoclase grade Alpine Schist in the Franz Josef-Fox glacier region of $9.2 \mathrm{kbar} \& 620^{\circ} \mathrm{C}$ (Grapes, 1995). The blue box shows P-T estimates of peak metamorphic conditions of the Otago Schist of $8-10 \mathrm{kbar}$ and $350-400^{\circ} \mathrm{C}$ (Mortimer, 2000). The dashed red and blue lines represent possible P-T paths modified after Mortimer (2000) and Grapes (1995). 


\subsubsection{Anomalous Garnet Cores}

There are two types of strange garnet cores (stage 0) in greyschist from the Newton Range, with starkly different compositions to the overgrowing garnet, representing earlier growth at different conditions to most of garnet in the Newton Range (see chapter six). One core is anomalously low in MnO (DMNR-27), and two are anomalously high in MnO (DMNR-80 \& 90). These cores are of interest as the Haast Schist has a complex polymetamorphic history, therefore interpreting the source of these cores could give insights into the early metamorphic history of the Haast Schist or the sedimentary protolith.

\section{Low MnO Cores}

One low $\mathrm{MnO}$ stage 0 core is present in Alpine Schist from the Newton Range. This core has a $X_{\mathrm{sps}}$ composition that does not plot at any point along the garnet zero-mode isopleth in the P-T pseudosection for DMNR-27. This means they are unlikely to have grown during the initial garnet growth history. As no garnets with such compositions have been observed in Otago Schist (Brown, 1967; Kawachi, 1975; White, 1996) (see chapter six), a different source of the garnet core is likely. The most likely source is a detrital garnet grain which has been preferentially nucleated upon during Alpine Schist metamorphism. Some detrital garnets grains in Torlesse terrane greywackes have similar compositions (Yokoyama, 1994; Smale, 1997). P-T estimates of this core cannot be obtained, as if it is detrital, it grew in a rock with different mineral assemblages and a different bulk-rock composition.

\section{High MnO}

High $\mathrm{MnO}$ cores have extremely high $X_{\mathrm{sps}}$ compositions that do not plot on the garnet zero-mode isopleths at normal temperatures (below $600^{\circ} \mathrm{C}$ ). In addition, cores with such compositions can only grow with an effective bulk-rock composition high in $\mathrm{MnO}$ (localised metachert lenses in the rock since recrystallized into the rock may be a potential compositional source) and as a result, the current whole-rock chemistry may not be representative of the effective bulk-rock composition in from which a stage 0 garnet core grew. It is conceivable that during an earlier (possibly Otago Schist) event, a small garnet grew in a localised Mn-rich layer, and not elsewhere in the rock. When the rock was subjected to Alpine Schist metamorphism, garnet grew throughout the sample, and would have preferentially nucleated on any garnet that was relict from a previous event. However, 
the possible Otago Schist source of high $\mathrm{MnO}$ stage 0 garnet cores cannot be fully investigated until Otago Schist is modelled using THERMOCALC.

The different metamorphic history of the Otago Schist (higher P, lower T) means the mineral assemblages and fluid composition modelled with THERMOCALC will be significantly different to the Alpine Schist. So to be able to fully understand and model the P-T conditions of the high $\mathrm{MnO}$ stage 0 garnet cores, further investigation is needed regarding the relationships between different mineral assemblages (i.e. containing titanite and ilmenite), and variable fluid composition (mixed $\mathrm{H}_{2} \mathrm{O} \& \mathrm{CO}_{2}$ ). If such modelling is ever possible, mineral assemblages and fluid compositions used for Otago Schist samples (with similar garnet and bulk-rock compositions) could be used to create P-T pseudosections from DMNR-80 \& 90 (hosts of high MnO stage 0 cores). This could yield insights into $P-T$ conditions of the polymetamorphic history of the Haast Schist within a single sample, however, a significant amount of new research would have to done to make any of this even attemptable, yet alone possible.

\subsection{Conclusion}

The whole-rock $\mathrm{MnO}$ composition has a dominant effect on the size of the garnet stability field and also the $P-T$ conditions at which garnets can begin to grow. This means longer $P-T$ paths starting at lower $P$ - $T$ conditions can be extracted from samples with high $\mathrm{MnO}$. The $P-T$ path for the Newton Range starts at $\sim 3.5 \mathrm{kbar}$ and $425^{\circ} \mathrm{C}$ in the g-bi-chl-ab-ep field and increases to peak metamorphic conditions of $\sim 7 \mathrm{kbar}$ and $500-525^{\circ} \mathrm{C}$ in the g-bi-chl-ab-ep-pl field. The end of $P$-T paths in the Newton Range reflect that peak metamorphic conditions occur at $P_{\max }$ and possibly $T_{\max }$, depending on whether garnet growth ceased because of: a lack of local element-availability (heating path after $\left.P_{\text {max }}\right)$ or; a cessation in dehydration reactions (cooling path after $P_{\text {max }}$ ). Metagreywackes containing titanite will not lend themselves to studies using THERMOCALC until a revised titanite activitycomposition model is created and/or the effects of carbonate minerals and mixed $\mathrm{H}_{2} \mathrm{O}-\mathrm{CO}_{2}$ fluids are better understood. Until such a time, samples containing garnets showing a drop in Ca (partitioning into plagioclase) can be modelled using method B, presented for the first time in this chapter. 
Chapter Eight

\section{SUMMARY \& SUGGESTIONS FOR FUTURE RESEARCH}

\subsection{Introduction}

This chapter summarises ideas developed in chapters three, four, five, six and seven, and draws comparisons to the geological and tectonic framework produced by previous studies of the Alpine Schist. Brief conclusions and ideas for future research are presented at the end of this chapter.

By comparing the petrography, structural fabrics, whole rock chemistry and metamorphic P-T estimates for samples of Alpine Schist from the Newton Range with previous studies of Alpine Schist from other locations in the Southern Alps, notably the Franz Josef-Fox Glacier region, a more complete picture of the metamorphic history of the Alpine Schist can be gained. Until recently it has been assumed that the Alpine Schist was relatively homogeneous along strike of the Alpine Fault (in terms of terrane affinity, mineral assemblages and the $P-T$ history), and results of metamorphic studies in the Franz Josef-Fox Glacier region were broadly applied to Alpine Schist throughout the Southern Alps. By comparing the results of this study with those further south, along strike variability of Alpine Schist, and insights into metamorphic history of the northern section of the Southern Alps are revealed.

\subsection{Terrane Affinity}

Greyschist in the Newton Range is interpreted to be the metamorphosed equivalent of older Torlesse (Rakaia) terrane sediments that were most probably deposited in the late Triassic off the Gondwana supercontinent in a borderland basin setting along a trench slope, as part of a developing accretionary prism complex (see chapter four). This interpretation is made from the use of multielement discrimination plots (Roser \& Korsch, 1988; Mortimer \& Roser, 1992; Roser, et al., 1993) where whole-rock compositions have depressed ratios of $\mathrm{Ti} / \mathrm{Zr}$ and $\mathrm{V} / \mathrm{La}$ and elevated ratios of $\mathrm{Th} / \mathrm{Sc}$ and $\mathrm{Ce} / \mathrm{Sc}$ compared to samples from the Caples and Maitai terranes. Greyschist in the 
Newton Range is similar in composition to those in the nearby McArthur Range (Williams, 2006), where a Torlesse derived greyschist protolith was also suggested.

On the basis of major and trace element analyses, greenschist is inferred to be strongly related to the Pounamu Ultramafic Belt (PUB), possibly representing narrow slices of (PUB) pods. Greenschist samples from the Newton Range are more ultramafic in composition, with elevated $\mathrm{Cr}$ and $\mathrm{Ni}$ compared to other recent analyses of greenschist/metabasite in north Westland (Storkey, 1999; Williams, 2006). No evidence of the Aspiring lithologic association is evident in the Newton Range, as has been inferred in areas close to the Alpine Fault elsewhere in north Westland (Grapes, 1999; Dixon, 2001).

\subsection{Petrography \& Mineral Chemistry}

Petrographic observations of the Alpine Schist greyschist in the Newton Range show a dominant mineral assemblage of:

$$
\mathrm{Qtz}+\mathrm{Ms}+\mathrm{Bt} \pm \mathrm{Chl} \pm \mathrm{Ep} \pm \mathrm{Pl} \pm \mathrm{Ilm} \pm \mathrm{Ttn} \pm \mathrm{Grt} \pm \mathrm{Zrn} \pm \operatorname{Tur} \pm \mathrm{Ap} \pm \mathrm{Cal}
$$

Core to rim compositional zonation of epidote is apparent, showing an overall decrease in $100 \cdot \boldsymbol{X}_{\mathrm{Fe}}$ from core to rim, akin to epidote from low grade Otago and Alpine Schist (Grapes \& Hoskin, 2004). Epidote porphyroblasts have the same zonation when occurring as porphyroblasts and as inclusions in garnet, signifying that most epidote growth occurred before garnet growth. Interestingly, epidote in garnet grade rocks from the Franz Josef-Fox Glacier region lack the same zonation patterns, possibly due to the replacement of epidote by oligoclase (Ca-bearing plagioclase) (Grapes \& Hoskin, 2004). The predominance of albite (Na-bearing plagioclase) in schist from the Newton Range may allow for the preservation of early epidote zonation textures in these garnet grade rocks. Irregular $\mathrm{Ba}$ rich halos (up to $11.5 \mathrm{wt} \%$ ) are observed overgrowing epidote cores, possibly reflecting a pulse of a $\mathrm{Ba}$ rich fluid at some point in the early metamorphic history. No such overgrowth of epidote has been reported elsewhere in the Haast Schist.

Ilmenite and titanite vary in abundance throughout the Newton Range. In low grade samples both large elongate ilmenite and large euhedral titanite porphyroblasts are present. With increasing metamorphic grade titanite occurs as finer anhedral porphyroblasts as well as forming on the rims of ilmenite porphyroblasts. In the highest grade rocks, titanite and ilmenite decrease in abundance and often occur as sporadic ilmenite cores overgrown by anhedral titanite. Hydrous, open structured minerals (biotite, chlorite and muscovite) are relatively homogenous between samples, even when 
the textures preserve clear evidence that the minerals have a polymetamorphic history (core vs. rim/infill). This suggests that metamorphic temperatures were high enough to homogenise the mineral compositions, possibly during the late Cenozoic metamorphic event.

Garnet growth was synchronous with albite for much of the garnet growth history. Late in the porphyroblast growth history a second, more Ca-rich plagioclase (oligoclase) phase became stable, evident by oligoclase rims on albite porphyroblasts and a rimward decrease in $\mathrm{CaO}$ in some garnets. The implications for this are that the metamorphic mineral growth history of the Alpine Schist in the Newton Range differs from that in the Franz Josef-Fox Glacier region, where oligoclase appears geographically eastward (lower grade) of the garnet-in isograd, and is the sole plagioclase phase in high grade Alpine Schist. Figure 8.1 schematically shows how the dissimilarities in the location and sequence of mineral isograds between the northern and central sections of the Southern Alps may be explained by the different peak metamorphic conditions attained (when porphyroblasts ceased growth).

\section{Garnet Stages}

Garnets from greyschist in the Newton Range show core-to-rim patterns of compositional zoning. Zones of comparable compositions are linked between samples and represent different stages of garnet growth (see chapter six). Stage 0 garnet cores are anomalous in composition with respect to the overgrowing garnet rims. This suggests that growth during the Alpine Schist event has preferentially nucleated upon relict, pre-metamorphic high $\mathrm{MnO}$ (possibly relict Otago Schist) cores and a low $\mathrm{MnO}$ detrital core. To the author's knowledge, this is the first observation of what are probably overgrown detrital garnet cores, in the Alpine Schist.

Stages 1 and 2 are characterised by progressive decreases in $\mathrm{MnO}$ and increases in $\mathrm{FeO}$ and are related to prograde, rimward garnet growth prior to the appearance of oligoclase. The boundary between stages 1 and 2 are defined where garnet has equal amounts of $\mathrm{MnO}$ and $\mathrm{FeO}$. Stage 3 is represented by a relative drop in $\mathrm{CaO}$, reflecting the appearance and growth of oligoclase late in the garnet growth history.

Stage $4 \mathrm{CaO}$-rich garnet rims occur only in samples proximal to the PUB. Such rims have in the past been interpreted as mylonitic overgrowths associated with metamorphism the late Cenozoic. As samples containing garnet with stage 4 rims do not show a correlation to metamorphic grade (as one would expect for a mylonitic overprint), a different mechanism for rim growth, other than purely 
a)

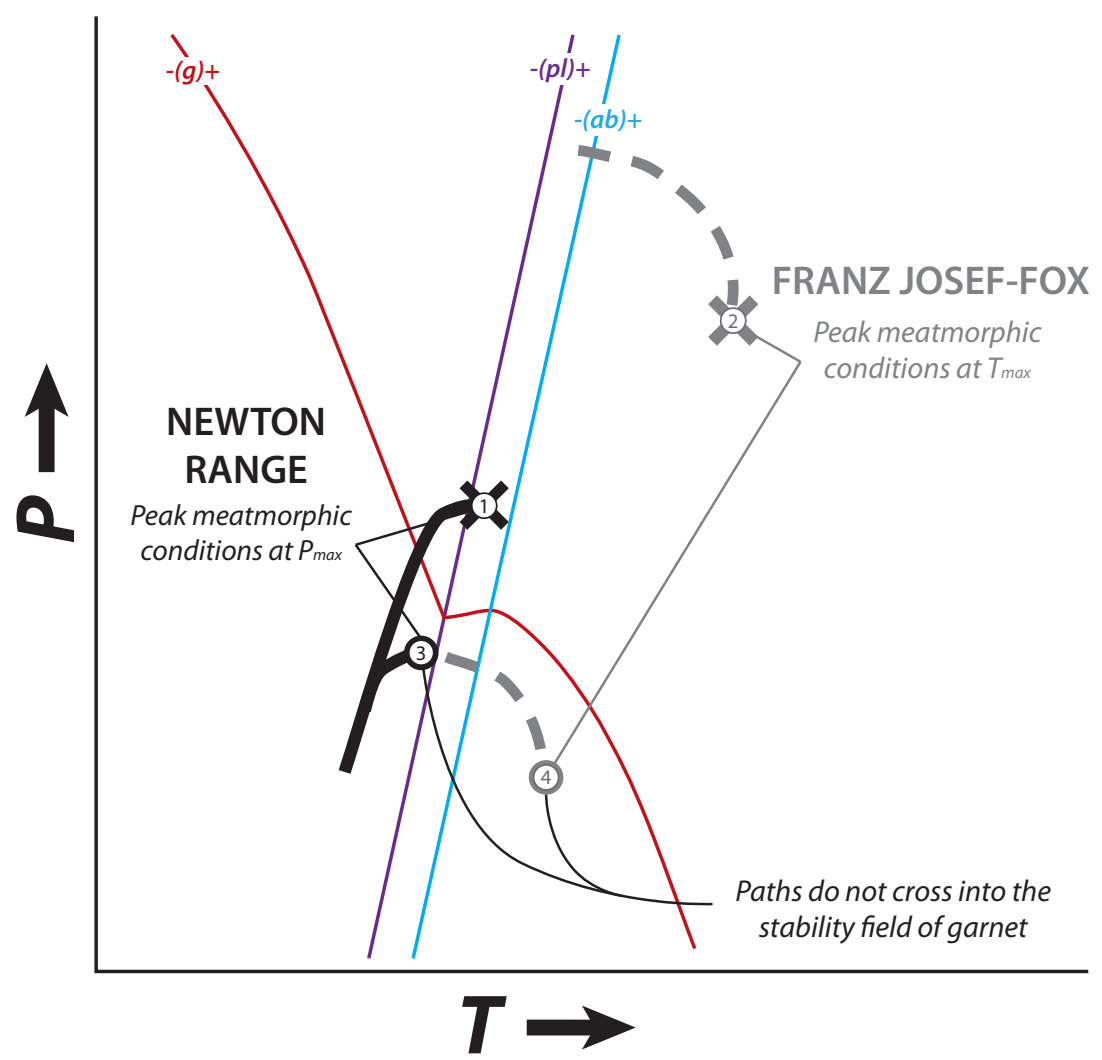

b)

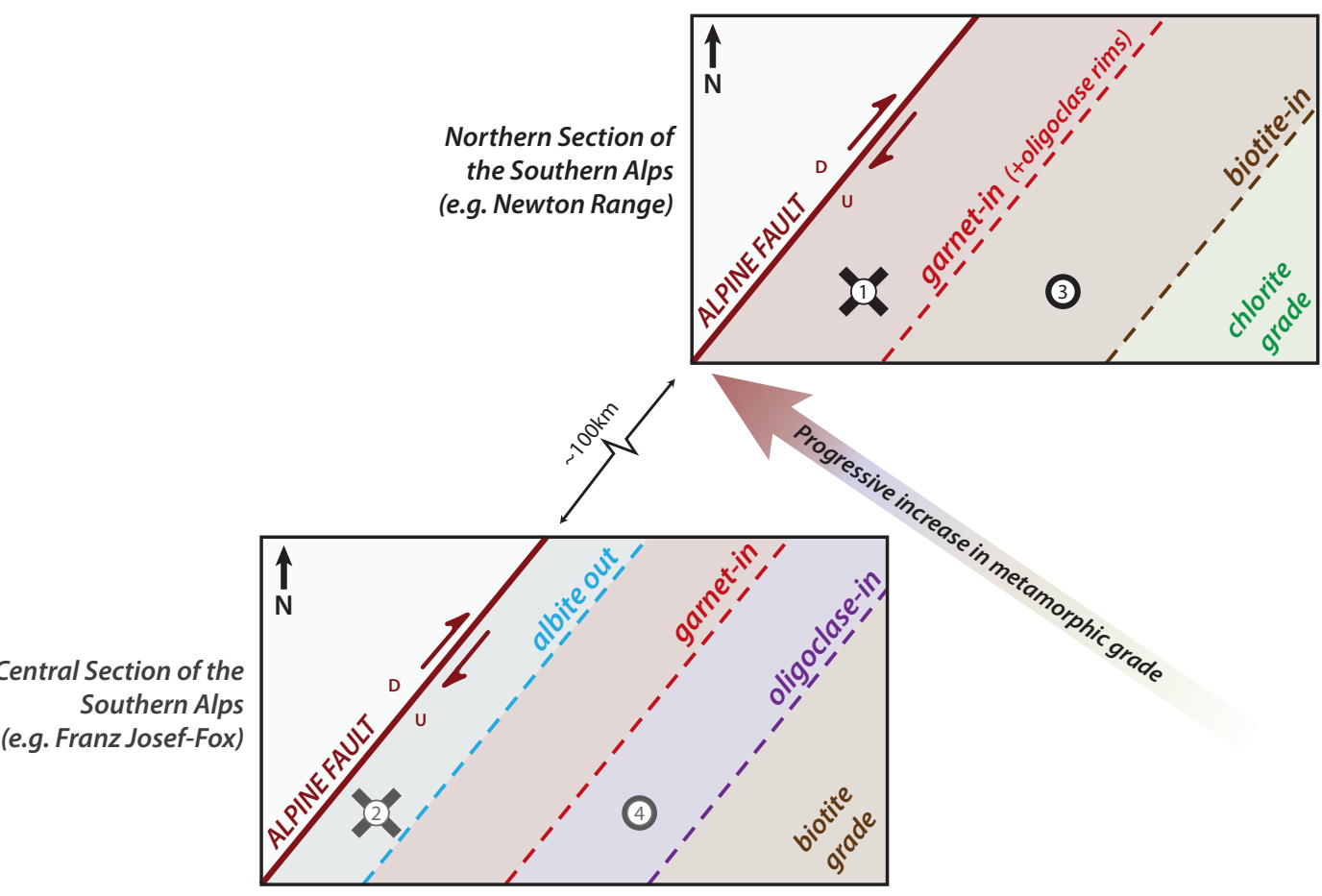

Figure 8.1. Schematic diagrams showing how different $P-T$ paths, and different peak metamorphic condtions may control the dominant mineral assemblage in a rock and associated mineral isograds. a) Highly simplified $P-T$ pseudosection with schematic $P$-T paths for: (1) peak conditions in the Newton Range; (2) peak conditions in the Franz Josef-Fox glacier region; (3) low grade rocks with no garnet or oligoclase; and (4) low grade rocks with oligoclase but no garnet. b) Simplified map view of differing mineral isograds for the northern and central sections of the Southern Alps, resulting from the different $P$-T paths in a). The location of mineral isograds depends on the peak conditions reached and whether these conditions are at $P_{\max }$ or $T_{\max }$ Grey and black crosses and circles represent exhumed rocks corresponding to the different peak metamorphic conditions in a). 
mylonitic growth, must be invoked. Samples containing stage 4 rims are located within 100m of one another and are close to bands of altered greenschist and quartz veins up to $\sim 1 \mathrm{~m}$ thick oriented subparallel to the dominant greyschist foliation. The growth of stage 4 garnet rims may be evidence of metasomatic processes occurring at depth late in the metamorphic history, with mobilisation of elements (Mn, Fe, Ca) from nearby greenschist facilitating overgrowth of selected garnets.

More in depth study of samples from other locations within the Alpine Schist would be required to confirm the above hypotheses regarding stage 0 and stage 4 garnet.

\section{Greenschist}

The mineral assemblage for greenschist from the Newton Range is:

$$
\mathrm{Chl}+\mathrm{Amp}+\mathrm{Ep}+\mathrm{Bio}+\mathrm{Qtz} \pm \mathrm{Ilm} \pm \mathrm{Ttn} \pm \mathrm{Cal} \pm \mathrm{Mag} \pm \mathrm{Pl} \pm \text { Tur }
$$

The minerals present in greenschist are comparable to those reported for other greenschist/metabasite from throughout the Haast Schist, but the relative abundance of these minerals is different. Greenschist samples from the Newton Range are notable for the abundance of amphibole and epidote and an overwhelming lack of garnet. This most likely reflects the more ultramafic bulk-rock composition from which the minerals grew (PUB sourced), compared with other Aspiring/Torlesse sourced greenschist/metabasite from elsewhere in the Southern Alps.

\subsection{Structure}

The structural fabric of Alpine Schist in the Newton Range is dominantly planar with only 7\% of samples showing a visible crenulation of this planar fabric. Rocks increase in textural grade with increasing proximity to the Alpine Fault from biotite-albite grade TZ2b schist in the lowest grade samples to garnet-albite-oligoclase TZ4 schist in the highest grade samples. The zone of intermediate TZ3 schist is far more extensive when the thickness of white mica is used as a TZ proxy (chapter four), compared to the thickness of segregated quartz layers (chapter three). This shows the relationship between segregated quartz layers and white mica thickness is not the same as in other areas of the Haast Schist, where both white mica and segregated quartz layers coincide with textural zones boundaries (Turnbull, et al., 2001). 
Evidence for the development of metamorphic fabrics that are closely comparable to those from the well studied Franz Josef-Fox Glacier region (Little, et al., 2002a; Little, et al., 2002b) are present in the form of: S0/S1 - isoclinally folded layers and boudined lenses of equigranular quartz; S2 dominant planar foliation reinforced during D3; and S3 - represented by the rare crenulation of the planar S2 fabric. This suggests the structure of the Newton Range is comparable to the main planar zone from the Franz Josef-Fox Glacier region, where the orientation of S2 was relatively homogeneous (with respect to the eastern and western folded zones) and was steepened prior to D3.

The growth of garnet over the planar reinforced S2 fabric, as well as curved inclusion trail patterns that continue into the exterior foliation, suggest that the relative timing of garnet growth was late D2 or early D3.

Weak SC'-type shear bands in the NW section show a general top to the west-northwest bulk shear direction. The common occurrence of microscale SC'-type shear bands in the NW section are indicators of a possible eastward extension of a distal mylonite zone into non-mylonitic Alpine Schist. Shear-sense in the SE section is much more complicated where rigid-body rotation of inequant porphyroblasts to different angles within the same sample signifies a large component of pure shear.

The presence of brittle-style mesoscopic folds implies that post metamorphic deformation of the schist has occurred, possibly in the latest stages of compression and uplift of the Southern Alps along the Alpine Fault. The proximity of these mesoscopic folds to the PUB, as well as inferred surrounding macroscopic folding in the SE section, suggest the PUB may play some part in the deformation of the surrounding schist, possibly due to the inherent rheological differences between the two rock types.

With the limited structural data obtained in this study, the relationship between, and timing of, shearing and macroscopic folding cannot be fully explained.

\subsection{P-TConditions}

The probable $P$-T path for Alpine Schist in the Newton Range starts at $\sim 3.5 \mathrm{kbar} / 425^{\circ} \mathrm{C}$ in the g-bichl-ab-ep field, and increases to peak metamorphic conditions of $\sim 7 \mathrm{kbar} / 500-525^{\circ} \mathrm{C}$ in the g-bi-chlab-ep-pl field. These peak metamorphic conditions are considerably lower than those reported for rocks from the Franz Josef-Fox Glacier region, where peak conditions reached $9.2 \mathrm{kbar}$ and $620^{\circ} \mathrm{C}$. 
Metamorphic temperatures are slightly higher than rocks of comparable grade in the McArthur Range ( $\sim 7 \mathrm{~km}$ to the northeast). This tentatively suggests a progressive southward increase in peak metamorphic temperatures of Alpine Schist in the Southern Alps. The cessation of garnet growth (prior to the development of stage 4 Ca-rich overgrowths), is interpreted to have occurred near $P_{\max }$. $P_{\max }$ may or may not have coincided with $T_{\max }$, depending on whether garnet growth ceased because of a local lack in the availability of some key element, or a cessation in dehydration reactions (cooling decompression path after $P_{\max }$ ) (see chapter seven).

The estimated P-T path for Alpine Schist from the Newton Range shows a steep pressure increase over a narrow range of metamorphic temperatures $\left(<100^{\circ} \mathrm{C}\right)$, and begins at low pressures and moderate temperatures of $3.5 \mathrm{kbar} / 425^{\circ} \mathrm{C}$, in contrast to a $P-T$ path starting at $0 \mathrm{kbar}$ and $0^{\circ} \mathrm{C}$ (i.e. Grapes, 1995). This suggests the rocks were already at crustal depths and had previously been heated prior to the Alpine Schist event. It is possible that metamorphism of the Alpine Schist involved re-metamorphism of rocks that were previously metamorphosed in the earlier Otago Schist event), and subsequently uplifted/decompressed to higher levels in the crust (but not fully exposed).

\subsection{Variations in Metamorphic Grade - Tectonic Implications}

Observations of the petrography, structural fabrics and mineral chemistry of schist in this study show that rocks in the Newton Range represent lower grade Alpine Schist than that exposed in the well studied Franz Josef-Fox Glacier region. The northern section of the Southern Alps has long been known to contain lower grade rocks, exhumed from shallower depths in the crust along the Alpine Fault. This is reflected by a northward decrease in slip rates along the Alpine Fault from: 8$12 \mathrm{~mm} / \mathrm{yr}$ in the central Southern Alps; to $6-8 \mathrm{~mm} / \mathrm{yr}$ in areas immediately south of the Newton Range; to $\sim 3 \mathrm{~mm} / \mathrm{yr}$ at the intersection of the Hope Fault and Alpine Fault $(\sim 25 \mathrm{~km}$ to the northeast) where $\sim 52 \%$ of the Alpine Fault motion is partitioned into the Marlborough Fault System (MFS) (Yetton \& Nobes, 1998; Norris \& Cooper, 2001; Langridge, et al., 2010).

As the southern most extent of the MFS intersects the Alpine Fault in the area immediately surrounding the Newton Range (Newton Fault, Hura Fault, Kelly Fault, Hope Fault - see Fig. 8.2a), the exhumation history of the Newton Range has an added component of complexity with respect to the central Southern Alps. An expression of this complexity is the disparity between $P-T$ paths from this study and the McArthur Range. $P_{\max }$ in the Newton Range is $\sim 6.75 \mathrm{kbar}$, whereas the McArthur Range the crest of the $P-T$ path is at $\sim 8.5 \mathrm{kbar}$. The Newton Range has slightly higher temperatures $\left(\sim 25^{\circ} \mathrm{C}\right)$ at $P_{\max }$. Such differences in $P_{\max }$ are within error but relative differences are 
likely to be meaningful as whole-rock compositions are comparable between studies and the same analytical facility (VUW) and THERMOCALC activity-composition models were used. This means a mechanism is required to allow for the varied exhumation of schist between ranges. Two possibilities are: 1. motion on the Alpine Fault has a slightly less dip-slip (possibly more strike-slip) component adjacent to the Newton Range compared to the McArthur Range, a possible result of localised steepening and/or bending of the Alpine Fault footwall ramp (see Little, et al. (2005)) or a greater proportion of fault segments with an oblique thrust motion compared to dextral strike-slip motion. 2. Faults from the MFS bounding the Newton and McArthur Ranges play a part in the exhumation history, with differential uplift of the McArthur Range along these faults has resulted in the exhumation of rocks from deeper crustal levels. Both of these ideas are summarised in figure $8.2 \mathrm{~b} \& \mathrm{c})$.

However interpretations regarding either of these possibilities have inherent drawbacks: 1 . slip data for the Alpine Fault is not available for the foot of the McArthur and Newton Ranges (heavily vegetated and rugged terrain), and no structural data set exists that could serve to explain subsurface bending/steepening of the footwall ramp and; 2. nearby strands of the MFS have a predominantly dextral strike-slip sense and have negligible components of shortening (Langridge, et al., 2010) so differential uplift of the McArthur Range on any of these faults is unlikely. Perhaps the main point is that the Alpine Schist has a complex exhumation history, that at present cannot be entirely explained using quaternary fault slip-rates and an incomplete regional structural dataset. The reasons behind localised varied levels of exhumation are obviously complex and beyond the scope of this current study.

\subsection{Future Research}

The large scale of this study leaves some interpretations open for discussion and some questions unanswered, leaving scope for future research.

1. Multiple generations of quartz veins in the Newton Range show evidence for a complex, multistage fluid flow history. Full scale structural mapping of the extent of $\sim 1 \mathrm{~m}$ thick quartz veins and studies of fluid inclusions, and/or Ti in quartz thermometry could yield insights into the timing, composition, source and P-T conditions of fluid flow. Drilling of a core though such veins, and sampling at regular intervals along the core might allow changes in temperature/composition of the fluid flow to be assessed. It would also be of interest to compare the other generations of veins in the Alpine Schist. 

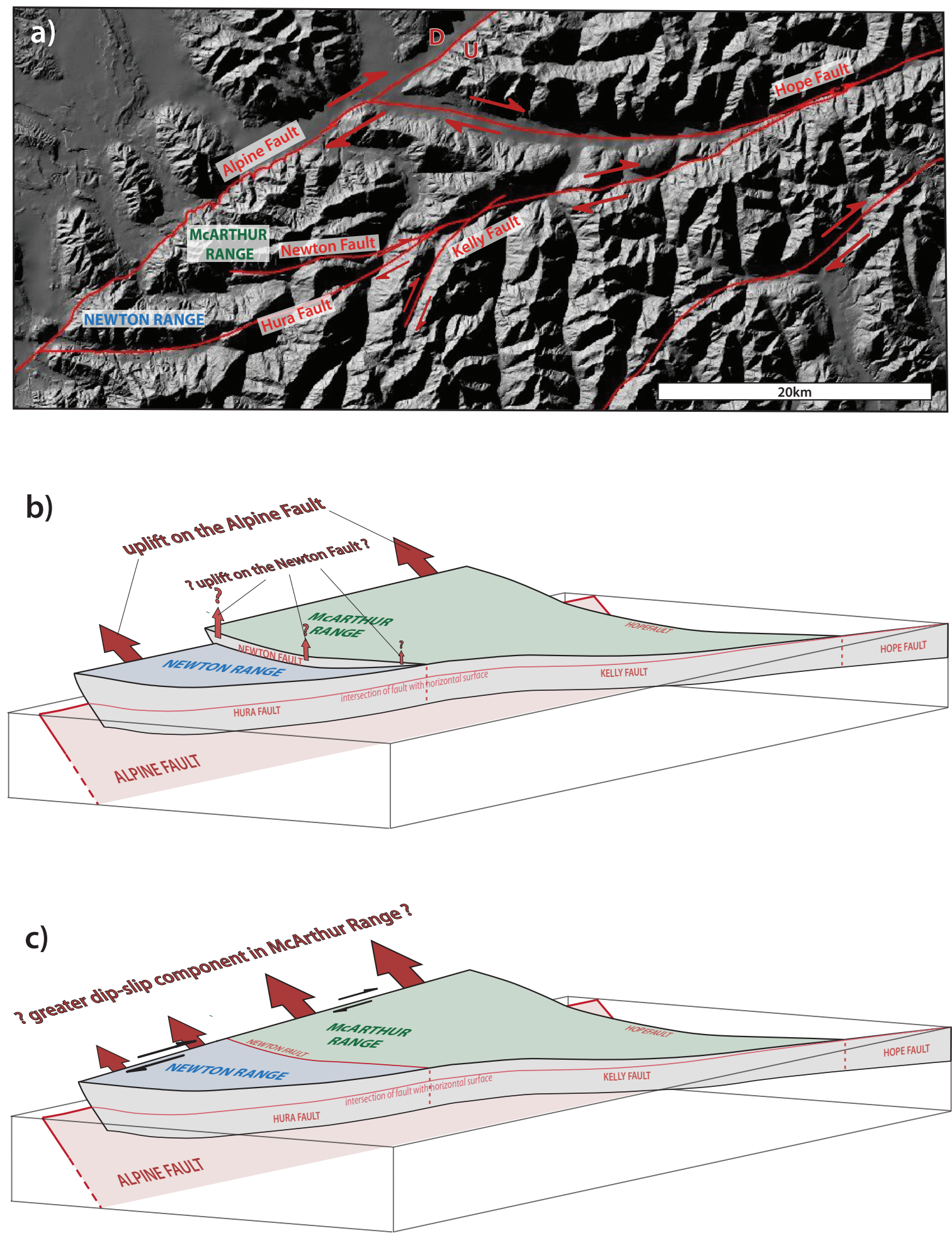

Figure 8.2. a) Map of active faults in the area surrounding the Newton Range. b) \& c) Schematic threedimensional diagrams showing mechanims for exhumation of rocks from deeper crustal levels in the nearby McArthur Range. b) Differential uplift on the Newton Fault (located between the Newton and McArthur Ranges), c) Uplift on the Alpine Fault, but a more dip-slip motion partitioned to the McArthur Range. 
2. Anomalous garnet cores (stage 0 ) are an interesting find in this study. The source of the cores may be interpreted if diffusion studies were carried out along the stage boundaries to interpret the relative timing between the cessation of stage 0 growth and growth of the surrounding garnet. Such information could yield further insights regarding the a) detrital, b) Otago Schist event, or c) early Alpine Schist event source of these cores.

3. If high $\mathrm{MnO}$ stage 0 cores are Otago Schist event in origin, studies using THERMOCALC on Otago Schist rocks with similar garnet compositions may allow insights into multi stage metamorphism of the Haast Schist. Comparing the composition of other zoned minerals such as epidote to such Otago Schist samples will also enable interpretation of the source of such minerals as early Alpine or, Otago Schist.

In saying this, such modelling will only occur when a better understanding of how titanite behaves in such whole-rock compositions and the effect of $\mathrm{XCO}_{2}$ of the stability of Cabearing mineral phases. At present, inroads are being made into such problems (Vry, pers. comm., 2010).

4. Further mapping and sampling of the PUB in the Newton Range may allow insights into the tectonic history of the PUB as a whole, and the possible effect PUB pods have on late stage deformation of the surrounding schist. Numerical/tectonic modelling may be an option for assessing these things.

5. The lack of evidence for the Aspiring lithologic association in the Newton Range means further mapping and sampling of schist throughout the Southern Alps could supply information regarding the continuity of the Aspiring lithologic association from the Franz Josef-Fox Glacier region to north Westland.

6. SC'-type shear bands observed in the NW section of the Newton Range could be of interest in future studies regarding the westward extent of the distal mylonite zone. As the angle of C' bands relative to the shear zone boundary $(S)$ is a product of the relative amounts of pure and simple shear, the C' shear bands occurring in rocks on the edges of the Alpine Fault shear zone may be important with regards to the initial inception angle of the SC'-type shear bands, and the associated roles of pure and simple shear during the late Cenozoic. Such a study would require a transect of samples to be collected towards the mylonite zone, possible locations of which could be in the streams draining the NW section, i.e. Mt Brown Creek. 
7. This study leaves the door open for other studies of the P-T path of Alpine Schist in the Southern Alps between north Westland and the Franz Josef-Fox Glacier region. Such studies should be able to quantify the southward increase in peak metamorphic temperatures proposed by this study. Future work could investigate the cause of the difference in $P$-T paths i.e. the effect of the Marlborough Fault System, the effect of heating by a previous metamorphic event (Otago Schist), or along strike differences in geothermal gradient along the Alpine Fault. 


\section{REFERENCES}

Adams, C., Bishop, D. \& Gabites, J., 1985. Potassium-argon age studies of a low-grade, progressively metamorphosed greywacke sequence, Dansey Pass, South Island, New Zealand. Journal of the Geological Society, 142(2), 339 .

Adams, C. J., Beek, R. J. \& Campbell, H. J., 2007a. Characterisation and origin of New Zealand nephrite jade using its strontium isotopic signature. Lithos, 97(3-4), 307-322.

Adams, C. J., Campbell, H. J., Graham, I. J. \& Mortimer, N., 1998. Torlesse, Waipapa and Caples suspect terranes of New Zealand: Integrated studies of their geological history in relation to neighbouring terranes. Episodes, 21(4), 235-240.

Adams, C. J., Campbell, H. J. \& Griffin, W. L., 2007b. Provenance comparisons of Permian to Jurassic tectonostratigraphic terranes in New Zealand: perspectives from detrital zircon age patterns. Geological Magazine, 144(4), 701-729.

Adams, C. J. \& Graham, I. J., 1996. Metamorphic and tectonic geochronology of the Torlesse Terrane, Wellington, New Zealand. New Zealand Journal of Geology and Geophysics, 39, 157-180.

Armbruster, T., Bonazzi, P., Akasaka, M., Bermanec, V., Chopin, C., Giere, R., Heuss-Assbichler, S., Liebscher, A., Menchetti, S., Pan, Y. M. \& Pasero, M., 2006. Recommended nomenclature of epidote-group minerals. European Journal of Mineralogy, 18(5), 551-567.

Barnes, P. \& Korsch, R., 1990. Structural analysis of a middle Cretaceous accretionary wedge, Wairarapa, New Zealand. New Zealand Journal of Geology and Geophysics, 33(2), 355-375.

Barnes, P. M., Sutherland, R. \& Delteil, J., 2005. Strike-slip structure and sedimentary basins of the southern Alpine Fault, Fiordland, New Zealand. Geological Society of America Bulletin, 117(3-4), 411-435.

Beck, A. C., 1965. Arahura River Copper. New Zealand Journal of Geology and Geophysics, 8, 1233-1238.

Bell, J. \& Fraser, C., 1906. The geology of the Hokitika sheet, north Westland Quadrangle. New Zealand Geological Survey Bulletin, 1, 101.

Bell, T., 1985. Deformation partitioning and porphyroblast rotation in meta-morphic rocks: a radical reinterpretation. Journal of Metamorphic Geology, 3(2), 109-118.

Berryman, K., Beanland, S., Cooper, A., Cutten, H., Norris, R. \& Wood, P., 1992. The Alpine Fault, New Zealand: variation in Quaternary structural style and geomorphic expression. Annales Tectonicae, 6, 126-163. 
Bhatia, M. R. \& Crook, K. A. W., 1986. Trace element characteristics of graywackes and tectonic setting discrimination of sedimentary basins. Contributions to Mineralogy and Petrology, 92(2), 181-193.

Bishop, D., Bradshaw, J. \& Landis, C., 1985. Provisional terrane map of South Island, New Zealand. Tectonostratigraphic terranes. Houston, Texas. Circum-Pacific Council for Energy and Mineral Resources Earth Science Series, 1, 515-521.

Bishop, D. G., 1972. Progressive metamorphism from prehnite-pumpellyite to greenschist facies in the Dansey Pass area, Otago, New Zealand. Geological Society of America Bulletin, 83(11), 3177-3198.

Bradshaw, J., Andrews, P. \& Adams, C., 1981. Carboniferous to Cretaceous on the Pacific margin of Gondwana: the Rangitata phase of New Zealand. Gondwana Five, 217-221.

Brown, E. H., 1967. The greenschist facies in part of eastern Otago, New Zealand. Contributions to Mineralogy and Petrology, 14(4), 259-292.

Burton, K. W., 1986. Garnet-quartz intergrowths in graphitic pelites; the role of the fluid phase. Mineralogical Magazine, 50, Part 4(358), 611-620.

Campbell, J. D. \& Warren, G., 1965. Fossil localities of the Torlesse Group in the South Island. Transactions of the Royal Society of New Zealand: Botany, 3(8), 99-137.

Cande, S. C. \& Stock, J. M., 2004. Pacific-Antarctic-Australia motion and the formation of the Macquarie Plate. Geophysical Journal International, 157(1), 399-414.

Carpenter, M., 1994. Subsolidus phase relations of the plagioclase feldspar solid solution. NATO ASI Series C Mathematical and Physical Sciences-Advanced Study Institute, 421, 221-270.

Carpenter, M. A., 1981. A conditional spinodal within the peristerite miscibility gap of plagioclase feldspars. American Mineralogist, 66(5-6), 553-560.

Cathelineau, M., 1988. Cation site occupancy in chlorites and illites as a function of temperature. Clay Minerals, 23(4), 471-485.

Cavanagh, M., 2004. Metamorphism of the Alpine Schist, Griffin Range, northern Westland, New Zealand. Unpub. MSc. Thesis, Victoria University of Wellington, Wellington

Chakraborty, S. \& Ganguly, J., 1992. Cation diffusion in aluminosilicate garnets: experimental determination in spessartine-almandine diffusion couples, evaluation of effective binary diffusion coefficients, and applications. Contributions to Mineralogy and Petrology, 111(1), 74-86.

Chamberlain, C. P., Zeitler, P. K. \& Cooper, A. F., 1995. Geochronologic constraints of the uplift and metamorphism along the Alpine Fault, South Island, New Zealand. New Zealand Journal of Geology and Geophysics, 38(4), 515-523. 
Coggon, R. \& Holland, T. J. B., 2002. Mixing properties of phengitic micas and revised garnet-phengite thermobarometers. Journal of Metamorphic Geology, 20(7), 683-696.

Coleman, R., 1966. New Zealand serpentinites and associated metasomatic rocks. New Zealand Geological Survey Bulletin, 76.

Coombs, D. S., Landis, C. A., Hada, S., Ito, M., Roser, B. P., Suzuki, T. \& Yoshikura, S., 2000. The Chrystalls Beach-Brighton block, southeast Otago, New Zealand: Petrography, geochemistry, and terrane correlation. New Zealand Journal of Geology and Geophysics, 43(3), 355-372.

Cooper, A. \& Lovering, J., 1970. Greenschist amphiboles from Haast River, New Zealand. Contributions to Mineralogy and Petrology, 27(1), 11-24.

Cooper, A. F., 1972. Progressive metamorphism of metabasic rocks from the Haast Schist group of southern New Zealand. Journal of Petrology, 13(3), 457-492.

Cooper, A. F., 1974. Multiphase deformation and its relationship to metamorphic crystallization at Haast River, South Westland, New Zealand. New Zealand Journal of Geology and Geophysics, 17(4), 855-\&.

Cooper, A. F., 1976. Concentrically zoned ultramafic pods from Haast Schist zone, South Island, New Zealand. New Zealand Journal of Geology and Geophysics, 19(5), 603-623.

Cooper, A. F., Barreiro, B. A., Kimbrough, D. L. \& Mattinson, J. M., 1987. Lamprophyre dike intrusion and the age of the Alpine fault, New Zealand. Geology, 15(10), 941-944.

Cooper, A. F. \& Reay, A., 1983. Lithology, field relationships, and structure of the Pounamu Ultramafics from the Whitcombe and Hokitika Rivers, Westland, New Zealand. New Zealand Journal of Geology and Geophysics, 26(4), 359-\&.

Craw, D., 1984. Lithologic variations in Otago Schist, Mt Aspiring area, northwest Otago, New Zealand. New Zealand Journal of Geology and Geophysics, 27(2), 151-166.

Craw, D. \& Norris, R., 1993. Grain boundary migration of water and carbon dioxide during uplift of garnetzone Alpine Schist, New Zealand. Journal of Metamorphic Geology, 11, 371-378.

Crawford, M. L., 1966. Optical properties of metamorphic albite. American Mineralogist, 51(3-4), 523-\&.

Deer, W. A., Howie, R. A., Zussman, J., 1966. An introduction to the rock-forming minerals /W.A. Deer, R.A. Howne, J. Zussman. Longmans, London.

DeMets, C., Gordon, R., Argus, D. \& Stein, S., 1994. Effect of recent revisions to the geomagnetic reversal time scale on estimates of current plate motions. Geophysical Resarch Letters, 21(2), 191-2.

Dickinson, W. R., Beard, L. S., Brakenridge, G. R., Erjavec, J. L., Ferguson, R. C., Inman, K. F., Knepp, R. A., Lindberg, F. A. \& Ryberg, P. T., 1983. Provenance of North American Phanerozoic sandstones in relation to tectonic setting. Geological Society of America Bulletin, 94(2), 222-235. 
Dixon, M. R., 2001. An interpretation of the metamorphic history of the Alpine Schist of northern Westland. Unpub. MSc. Thesis, Victoria University of Wellington, Wellington.

Evans, B. W., 1964. Coexisting albite + oligoclase in some schists from New Zealand. American Mineralogist, 49(1-2), 173-\&.

Evans, T. P., 2004. A method for calculating effective bulk composition modification due to crystal fractionation in garnet-bearing schist: implications for isopleth thermobarometry. Journal of Metamorphic Geology, 22(6), 547-557.

Foley, L. A., Orr, T. O. H. \& Korsch, R. J., 1988. Environments of formation of lithologic associations in the Torlesse accretionary wedge, Tararua Range, New Zealand. New Zealand Journal of Geology and Geophysics, 31(2), 167-181.

George, A. D., 1992. Deposition and deformation of an Early Cretaceous trench-slope basin deposit, Torlesse terrane, New Zealand. Geological Society of America Bulletin, 104(5), 570-580.

Grapes, R., 1995. Uplift and exhumation of Alpine schist, Southern Alps, New Zealand: thermobarometric constraints. New Zealand Journal of Geology and Geophysics, 38, 525-534.

Grapes, R. \& Otsuki, M., 1983. Peristerite compositions in quartzofeldspathic schists, Franz Josef-Fox Glacier Area, New Zealand. Journal of Metamorphic Geology, 1(1), 47-61.

Grapes, R. \& Palmer, K., 1982. X-ray fluorescence major and trace element analyses of metabasites, Southern Alps, New Zealand. Department of Geology Publication, Victoria University of Wellington, 24.

Grapes, R. \& Palmer, K., 1984. Magma type and tectonic setting of metabasites, Southern Alps, New Zealand, using immobile elements. New Zealand Journal of Geology and Geophysics, 27(1), 21-25.

Grapes, R., Roser, B. \& Kashai, K., 2001. Composition of monocrystalline detrital and authigenic minerals, metamorphic grade, and provenance of Torlesse and Waipapa graywacke, central North Island, New Zealand. International Geology Review, 43(2), 139-175.

Grapes, R. \& Watanabe, T., 1984. Al-Fe ${ }^{3+}$ And Ca-Sr ${ }^{2+}$ Epidotes In Metagreywacke-Quartzofeldspathic Schist, Southern Alps, New Zealand. American Mineralogist, 69(5-6), 490-498.

Grapes, R. \& Watanabe, T., 1992. Metamorphism and uplift of Alpine Schist is the Franz Josef-Fox Glacier area of the Southern Alps, New Zealand. Journal of Metamorphic Geology, 10(2), 171-180.

Grapes, R. H., 1993. Barian mica And distribution of barium in metacherts and quartzofeldspathic schists, Southern Alps, New Zealand. Mineralogical Magazine, 57(387), 265-272.

Grapes, R. H., 1999. Geochemical affinity and volatile content of the Alpine Schist: some implications for Cenozioc prograde metamorphism and eletrical conductivity. In: Research Report '99, pp. 56-58, School of Earth Sciences, Victoria University of Wellington 
Grapes, R. H. \& Hoskin, P. W. O., 2004. Epidote group minerals in low-medium pressure metamorphic terranes. Epidotes, 56, 301-345.

Grapes, R. H. \& Watanabe, T., 1994. Mineral composition variation in Alpine Schist, Southern Alps, New Zealand: Implications for recrystallization and exhumation. The Island Arc, 3(3), 163-181.

Gray, D. \& Foster, D., 2004. 40Ar/39Ar thermochronologic constraints on deformation, metamorphism and cooling/exhumation of a Mesozoic accretionary wedge, Otago Schist, New Zealand. Tectonophysics, 385(1-4), $181-210$.

Gregg, D. R., 1964. Sheet 18 - Hurunui. In: Geological Map of New Zealand 1:250,000, New Zealand Department of Scientific and Industrial Research, Wellington

Guidotti, C. V., 1984. Micas in metamorphic rocks. Reviews in Mineralogy and Geochemistry, 13(1), 357-467.

Guiraud, M., Powell, R. \& Rebay, G., 2001. $\mathrm{H}_{2} \mathrm{O}$ in metamorphism and unexpected behaviour in the preservation of metamorphic mineral assemblages. Journal of Metamorphic Geology, 19(4), 445-454.

Henry, D. J., Guidotti, C. V. \& Thomson, J. A., 2005. The Ti-saturation surface for low-to-medium pressure metapelitic biotites: Implications for geothermometry and Ti-substitution mechanisms. American Mineralogist, 90(2-3), 316-328.

Holcombe, R. \& Little, T., 2001. A sensitive vorticity gauge using rotated porphyroblasts, and its application to rocks adjacent to the Alpine Fault. New Zealand. Journal of Structural Geology, 23, 979-989.

Holcombe, R. J., 2009. GeoCalculator v4.9.2. Available from: http://www.holcombe.net.au/software.

Holland, T. \& Powell, R., 1998. An internally consistent thermodynamic data set for phases of petrological interest. Journal of Metamorphic Geology, 16, 309-344.

Holland, T. \& Powell, R., 2003. Activity-composition relations for phases in petrological calculations: an asymmetric multicomponent formulation. Contributions to Mineralogy and Petrology, 145(4), 492-501.

Holm, D., Norris, R. \& Craw, D., 1989. Brittle and ductile deformation in a zone of rapid uplift: Central Southern Alps, New Zealand. Tectonics, 8(2), 153-168.

Ireland, T. R., 1981. The geology of the Diedrich Range. Unpub. B.Sc. Honours Thesis, University of Otago, Dunedin.

Ireland, T. R., Reay, A. \& Cooper, A. F., 1984. The Pounamu Ultramafic Belt in the Diedrich Range, Westland, New Zealand. New Zealand Journal of Geology and Geophysics, 27(3), 247-256.

Jowett, E. C., 1991. Fitting iron and magnesium into the hydrothermal chlorite geothermometer. GAC/MAC/SEG Joint Annual Meeting (Toronto, May 27-29, 1991) Program with Abstracts, 16(A62). 
Kawachi, Y., 1975. Pumpellyite-actinolite and contiguous facies metamorphism in part of upper Wakatipu District, South Island, New Zealand. New Zealand Journal of Geology and Geophysics, 18(3), 401-441.

Kleffmann, S., Davey, F., Melhuish, A., Okaya, D., Stern, T. \& Team, S., 1998. Crustal structure in the central South Island, New Zealand, from the Lake Pukaki seismic experiment. New Zealand Journal of Geology and Geophysics, 41(1), 39-49.

Koons, P. O., 1978. The Pounamu Ultramafics: A study of metasomatism. Unpub. M.Sc. Thesis, University of Otago, Dunedin.

Korsch, R. \& Wellman, H., 1988. The geological evolution of New Zealand and the New Zealand region. The Oceanic Basins and Margins. The Pacific Ocean, 7, 411-482.

Kretz, R., 1983. Symbols for rock-forming minerals. American Mineralogist, 68(1-2), 277.

Kurz, G. A. \& Northrup, C. J., 2008. Structural analysis of mylonitic rocks in the Cougar Creek Complex, Oregon-Idaho using the porphyroclast hyperbolic distribution method, and potential use of SC'-type extensional shear bands as quantitative vorticity indicators. Journal of Structural Geology, 30(8), 1005-1012.

Laird, J., 1988. Chlorites; metamorphic petrology. Reviews in Mineralogy and Geochemistry, 19(1), 405-453.

Langridge, R. M., Villamor, P., Basili, R., Almond, P., Martinez-Diaz, J. J. \& Canora, C., 2010. Revised slip rates for the Alpine fault at Inchbonnie: Implications for plate boundary kinematics of South Island, New Zealand. Lithosphere, 2(3), 139-152.

Leverenz, A., 2000. Trench-sedimentation versus accreted submarine fan--an approach to regional-scale facies analysis in a Mesozoic accretionary complex: "Torlesse" terrane, northeastern North Island, New Zealand. Sedimentary Geology, 132(1-2), 125-160.

Little, T., Cox, S., Vry, J. \& Batt, G., 2005. Variations in exhumation level and uplift rate along the oblique-slip Alpine fault, central Southern Alps, New Zealand. Geological Society of America Bulletin, 117(5-6), 707.

Little, T. \& Jones, A., 1998. Seven million years of strike-slip and related off-fault deformation, northeastern Marlborough fault system, South Island, New Zealand. Tectonics, 17(2), 285-302.

Little, T. A., Holcombe, R. J. \& Ilg, B. R., 2002a. Ductile fabrics in the zone of active oblique convergence near the Alpine Fault, New Zealand: identifying the neotectonic overprint. Journal of Structural Geology, 24(1), 193-217.

Little, T. A., Holcombe, R. J. \& Ilg, B. R., 2002b. Kinematics of oblique collision and ramping inferred from microstructures and strain in middle crustal rocks, central Southern Alps, New Zealand. Journal of Structural Geology, 24(1), 219-239. 
Little, T. A., Mortimer, N. \& McWilllams, M., 1999. An episodic Cretaceous cooling model for the OtagoMarlborough Schist, New Zealand, based on Ar-40/Ar-39 white mica ages. New Zealand Journal of Geology and Geophysics, 42(3), 305-325.

MacKenzie, I. F., 1984. Final report on exploration licence 33195, Whitcombe River, Westland, New Zealand. In: Mineral Report Series MR1398, CRA Exploration Co. Ltd

MacKinnon, T. \& Howell, D., 1984. Turbidite facies in an ancient subduction complex: Torlesse terrane, New Zealand. Geo-Marine Letters, 3(2), 211-216.

MacKinnon, T. C., 1983. Origin of the Torlesse terrane and coeval rocks, South Island, New Zealand. Geological Society of America Bulletin, 94(8), 967-985.

Marmo, B., Clarke, G. \& Powell, R., 2002. Fractionation of bulk rock composition due to porphyroblast growth: effects on eclogite facies mineral equilibria, Pam Peninsula, New Caledonia. Journal of Metamorphic Geology, 20(1), 151-165.

Maruyama, S., Liou, J. G. \& Suzuki, K., 1982. The peristerite gap in low-grade metamorphic rocks. Contributions to Mineralogy and Petrology, 81(4), 268-276.

Mason, B., 1962. Metamorphism in the southern Alps of New Zealand. Bulletin of the American Museum of Natural History, 123, 217-248.

McClintock, M. K. \& Cooper, A. F., 2003. Geochemistry, mineralogy, and metamorphic history of kyaniteorthoamphibole-bearing Alpine Fault mylonite, South Westland, New Zealand. New Zealand Journal of Geology and Geophysics, 46(1), 47-62.

McKay, A., 1893. Geological explorations of the northern part of Westland. New Zealand Mines Department Report C, 3, 132-186.

Morgan, P., 1908. The Geology of the Mikonui Subdivision, North Westland. New Zealand Geological Survey Bulletin, 6.

Mortimer, N., 1993a. Metamorphic zones, terranes, and Cenozoic faults in the Marlborough Schist, New Zealand. New Zealand Journal of Geology and Geophysics, 36(3), 357-368.

Mortimer, N., 1993b. Jurassic tectonic history of the Otago schist, New Zealand. Tectonics, 12(1), 237-244.

Mortimer, N., 2000. Metamorphic discontinuities in orogenic belts: example of the garnet-biotite-albite zone in the Otago Schist, New Zealand. International Journal of Earth Sciences, 89(2), 295-306.

Mortimer, N. \& Cooper, A. F., 2004. U-Pb and Sm-Nd ages from the Alpine Schist, New Zealand. New Zealand Journal of Geology and Geophysics, 47(1), 21-28. 
Mortimer, N. \& Johnston, M., 1990. Discovery of a new Rangitata structure offset by the Alpine Fault: enigmatic $350 \mathrm{~km}$-long synform within the Caples-Pelorus terrane. Geological Society of New Zealand Miscellaneous Publication 50A, 99.

Mortimer, N. \& Roser, B. P., 1992. Geochemical evidence for the position of the Caples-Torlesse boundary in the Otago Schist, New Zealand. Journal of the Geological Society, 149, 967-977.

Nathan, S., 1976. Geochemistry of the Greenland Group (Early Ordovician), New Zealand. NZJ Geol. Geophys, 19(5), 683-706.

Nathan, S., Rattenbury, M. \& Suggate, R., 2002. Geology of the Greymouth area 1:250,000. Institute of Geological and Nuclear Sciences.

New Zealand Geological Survey, 1972. Geological Map of New Zealand 1:1,000,000, South Island (1st Edn), Department of Scientific \& Industrial Research, Wellington

Norris, R., Koons, P. \& Cooper, A., 1990. The obliquely-convergent plate boundary in the South Island of New Zealand: implications for ancient collision zones. Journal of Structural Geology, 12(5-6), 715-725.

Norris, R. J. \& Cooper, A. F., 1995. Origin of small-scale segmentation and transpressional thrusting along the Alpine fault, New Zealand. Geological Society of America Bulletin, 107(2), 231-240.

Norris, R. J. \& Cooper, A. F., 2001. Late Quaternary slip rates and slip partitioning on the Alpine Fault, New Zealand. Journal of Structural Geology, 23(2-3), 507-520.

Norris, R. J. \& Craw, D., 1987. Aspiring terrane: an oceanic assemblage from New Zealand and its implications for Mesozoic terrane accretion in the southwest Pacific. In: Terrane Accretion and Orogenic Belts (eds E. C. Leitche \& E. Scheibner), pp. 169-177, American Geophysical Union Geodynamics Series.

Parish, R., 1998. Metamorphism of the Alpine Schist in the north Westland region. Unpub. B.Sc. Honours Thesis, Victoria University of Wellington, Wellington.

Pearce, J. \& Cann, J., 1973. Tectonic setting of basic volcanic rocks determined using trace element analyses. Earth and Planetary Science Letters, 19(2), 290-300.

Pepper, A., 2000. Metamorphism and Fluid Processes in the Mylonitised Alpine Schist, South East of Hokitika, South Island, New Zealand. Unpub. B.Sc. Honours Thesis, Victoria University of Wellington, Wellington.

Reay, A. \& Cooper, A., 1984. The Pounamu Ultramafic Belt, an ophiolite within the Torlesse Terrane, New Zealand. Ofioliti, 9, 135-144.

Roser, B. \& Coombs, D., 2005. Geochemistry of the Willsher Group, southeast Otago, New Zealand, and comparison with the Murihiku and Dun Mountain-Maitai terranes. New Zealand Journal of Geology and Geophysics, 48, 415-434. 
Roser, B. P., Coombs, D. S., Korsch, R. J. \& Campbell, J. D., 2002. Whole-rock geochemical variations and evolution of the arc-derived Murihiku Terrane, New Zealand. Geological Magazine, 139(6), 665-685.

Roser, B. P. \& Cooper, A. F., 1990. Geochemisty and terrane affiliation of Haast Schist from the western Southern Alps, New Zealand. New Zealand Journal of Geology and Geophysics, 33(1), 1-10.

Roser, B. P. \& Korsch, R. J., 1986. Determination of tectonic setting of sandstone mudstone suites using $\mathrm{SiO} 2$, content and $\mathrm{K} 2 \mathrm{O} / \mathrm{Na} 2 \mathrm{O}$ ratio. Journal of Geology, 94(5), 635-650.

Roser, B. P. \& Korsch, R. J., 1988. Provenance signatures of sandstone-mudstone suites determined using discriminant function analysis of major element data. Chemical Geology, 67(1-2), 119-139.

Roser, B. P., Mortimer, N., Turnbull, I. M. \& Landis, C. A., 1993. Geology and geochemistry of the Caples Terrane, Otago, New Zealand: compositional variations near a Permo-Triassic arc margin. In: South Pacific Sedimentary Basins (ed P. F. Ballance) Sedimentary Basins of The World, pp. 119-139, Elsevier, Amsterdam.

Sibson, R., White, S. \& Atkinson, B., 1981. Structure and distribution of fault rocks in the Alpine Fault Zone, New Zealand. Geological Society London Special Publications, 9(1), 197.

Smale, D., 1997. Heavy minerals in the Torlesse Terrane of the Wellington area, New Zealand. New Zealand Journal of Geology and Geophysics, 40(4), 499-506.

Smith, M. \& Yardley, B., 1999. Fluid evolution during metamorphism of the Otago Schist, New Zealand: (I) Evidence from fluid inclusions. Journal of Metamorphic Geology, 17(2).

Spear, F., 1988. Metamorphic fractional crystallization and internal metasomatism by diffusional homogenization of zoned garnets. Contributions to Mineralogy and Petrology, 99(4), 507-517.

Storkey, A., 1999. Metamorphism of the Alpine Schist in northern Central Westland, New Zealand. Unpub. B.Sc. Honours Thesis, Victoria University of Wellington, Wellington.

Suggate, R., 1963. The Alpine Fault. Transactions of the Royal Society of New Zealand, 2, 105-129.

Sutherland, R., 1995. The Australia-Pacific boundary and Cenozoic plate motions in the SW Pacific: Some constraints from Geosat data. Tectonics, 14(4), 819-831.

Sutherland, R., 1999. Cenozoic bending of New Zealand basement terranes and Alpine Fault displacement: a brief review. New Zealand Journal of Geology and Geophysics, 42(2), 295-301.

Sutherland, R., Berryman, K. \& Norris, R., 2006. Quaternary slip rate and geomorphology of the Alpine fault: Implications for kinematics and seismic hazard in southwest New Zealand. Geological Society of America Bulletin, 118(3-4), 464-474.

Sutherland, R. \& Norris, R., 1995. Late Quaternary displacement rate, paleoseismicity, and geomorphic evolution of the Alpine Fault: evidence from Hokuri Creek, South Westland, New Zealand. New Zealand Journal of Geology and Geophysics, 38(4), 419-430. 
Symmes, G. H. \& Ferry, J. M., 1992. The effect of whole-rock MnO content on the stability of garnet in pelitic schists during metamorphism. Journal of Metamorphic Geology, 10(2), 221-237.

Taylor, S., 1955. The origin of some New Zealand metamorphic rocks as shown by their major and trace element composition. Geochimica et Cosmochimica Acta, 8(4), 182-197.

Thurlow, C., 1999. Matamorphism and deformation of the Alpine Schist, Kokatahi River, Westland, New Zealand. Unpub. B.Sc. Honours Thesis, Victoria University of Wellington, Wellington.

Tracy, R., 1982. Compositional zoning and inclusions in metamorphic minerals. Reviews in Mineralogy and Geochemistry, 10(1), 355.

Turnbull, I., 1979. Petrography of the Caples terrane of the Thomson Mountains, northern Southland, New Zealand. New Zealand Journal of Geology and Geophysics, 22(6), 709-27.

Turnbull, I. M., Mortimer, N. \& Craw, D., 2001. Textural zones in the Haast Schist - a reappraisal. New Zealand Journal of Geology and Geophysics, 44(1), 171-183.

Upton, P., 1995. Mechanics, reaction and fluid flow associated with continental collision along the Alpine Fault, Southern Alps, New Zealand. Unpub. Ph.D. Thesis, University of Otago, Dunedin.

Vance, D. \& Holland, T., 1993. A detailed isotopic and petrological study of a single garnet from the Gassetts Schist, Vermont. Contributions to Mineralogy and Petrology, 114(1), 101-118.

Vry, J., Storkey, A. \& Harris, C., 2001. Role of fluids in the metamorphism of the Alpine Fault Zone, New Zealand. Journal of Metamorphic Geology, 19(1), 21-31.

Vry, J. K., Baker, J., Maas, R., Little, T. A., Grapes, R. \& Dixon, M., 2004. Zoned (Cretaceous and Cenozoic) garnet and the timing of high grade metamorphism, Southern Alps, New Zealand. Journal of Metamorphic Geology, 22(3), 137-157.

Vry, J. K., Powell, R., Golden, K. M. \& Petersen, K., 2009. The role of exhumation in metamorphic dehydration and fluid production. Nature Geoscience, 3(1), 31-35.

Vry, J. K., Powell, R. \& Williams, J., 2008. Establishing the P-T path for Alpine Schist, Southern Alps near Hokitika, New Zealand. Journal of Metamorphic Geology, 26(1), 81-97.

Walcott, R., 1998. Modes of oblique compression: Late Cenozoic tectonics of the South Island of New Zealand. Reviews of Geophysics, 36(1), 1-26.

Wandres, A. M., Bradshaw, J. D., Weaver, S., Maas, R., Ireland, T. \& Eby, N., 2004. Provenance of the sedimentary Rakaia sub-terrane, Torlesse Terrane, South Island, New Zealand: the use of igneous clast compositions to define the source. Sedimentary Geology, 168(3-4), 193-226.

Warren, G., 1967. Sheet 17 - Hokitika. In: Geological Map of New Zealand 1:250,000, New Zealand Department of Scientific and Industrial Research, Wellington 
Wellman, H., 1955. New Zealand Quaternary tectonics. Geologische Rundschau, 43, 248-257.

Wellman, H., 1979. An uplift map for the South Island of New Zealand, and a model for uplift of the Southern Alps. Royal Society of New Zealand Bulletin, 19, 13-20.

White, P. \& Holland, W., 2002. The effect of $\mathrm{TiO}_{2}$ and $\mathrm{Fe}_{2} \mathrm{O}_{3}$ on metapelitic assemblages at greenschist and amphibolite facies conditions: mineral equilibria calculations in the system $\mathrm{K}_{2} \mathrm{O}-\mathrm{FeO}-\mathrm{MgO}-\mathrm{Al}_{2} \mathrm{O}_{3}-\mathrm{SiO}_{2}-$ $\mathrm{H}_{2} \mathrm{O}-\mathrm{TiO}_{2}-\mathrm{Fe}_{2} \mathrm{O}_{3}$. Journal of Metamorphic Geology, 18(5), 497-511.

White, S., 1996. Composition and zoning of garnet and plagioclase in Haast Schist, northwest Otago, New Zealand: Implications for progressive regional metamorphism. New Zealand Journal of Geology and Geophysics, 39(4), 515-531.

Williams, J. E., 2006. The garnet-albite-biotite zone and evidence for high P/T metamorphism of the Alpine Schist, McArthur Range, Southern Alps, New Zealand. Unpub. M.Sc. Thesis, Victoria University of Wellington, Wellington.

Winchester, J. \& Floyd, P., 1976. Geochemical magma type discrimination: application to altered and metamorphosed basic igneous rocks. Earth and Planetary Science Letters, 28(3), 459-469.

Wysoczanski, R. J., Gibson, G. M. \& Ireland, T. R., 1997. Detrital zircon age patterns and provenance in late Paleozoic-early Mesozoic New Zealand terranes and development of the paleo-Pacific Gondwana margin. Geology, 25(10), 939-942.

Yardley, B., 1982. The early metamorphic history of the Haast Schists and related rocks of New Zealand. Contributions to Mineralogy and Petrology, 81(4), 317-327.

Yetton, M., 2000. The probability and consequences of the next Alpine Fault earthquake, South Island, New Zealand. Unpub. Ph.D. Thesis, University of Canterbury, Christchurch.

Yetton, M. \& Nobes, D., 1998. Recent vertical offset and near-surface structure of the Alpine Fault in Westland, New Zealand, from ground penetrating radar profiling. New Zealand Journal of Geology and Geophysics, 41(4), 485-492.

Yokoyama, k., 1994. Preliminary study of the sandstones in the Torlesse terrane, New Zealand. Geoscience reports of Shizuoka University, 20, 63-70. 
STRUCTURAL OBSERVATION \& SAMPLE LOCATION DATA

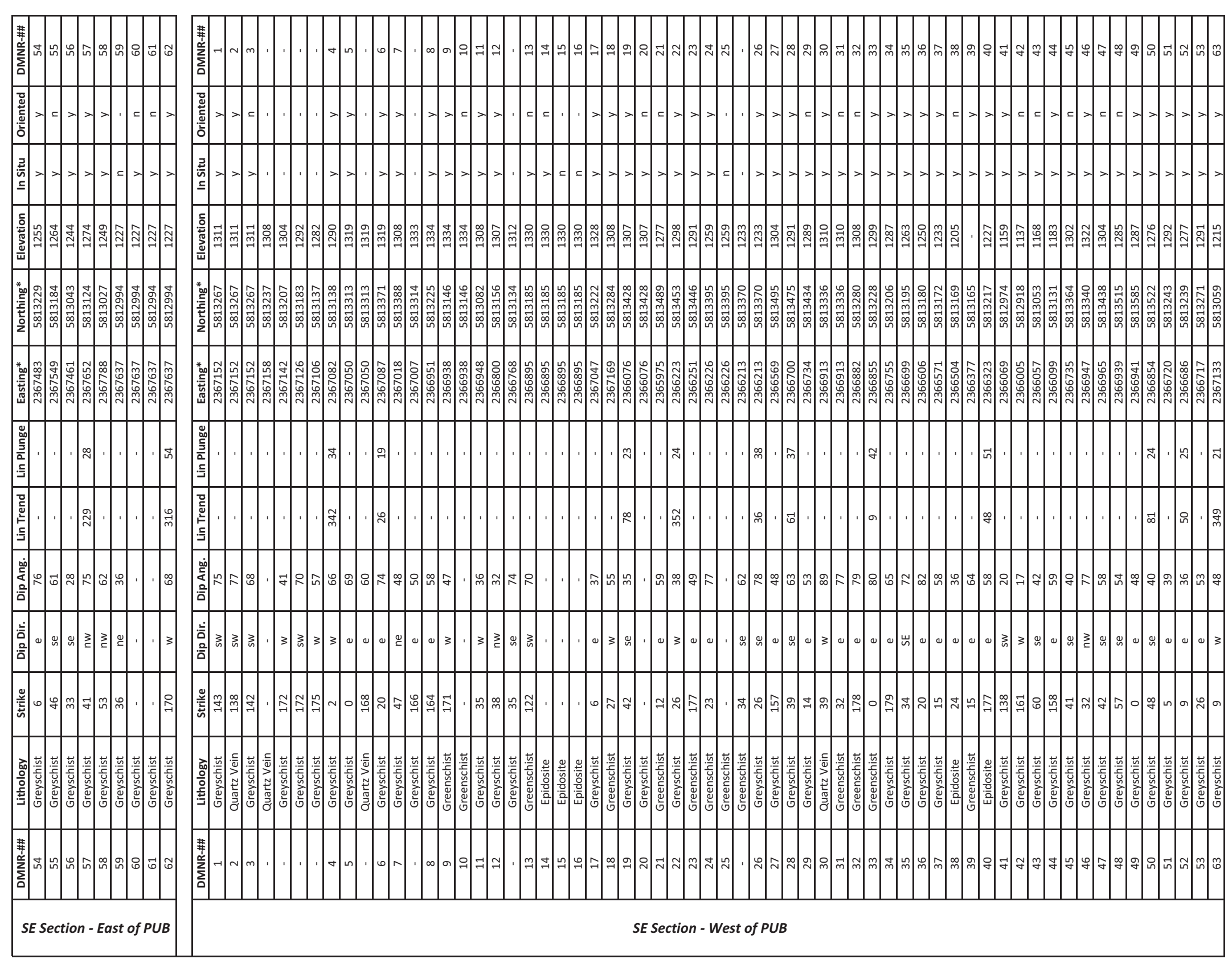

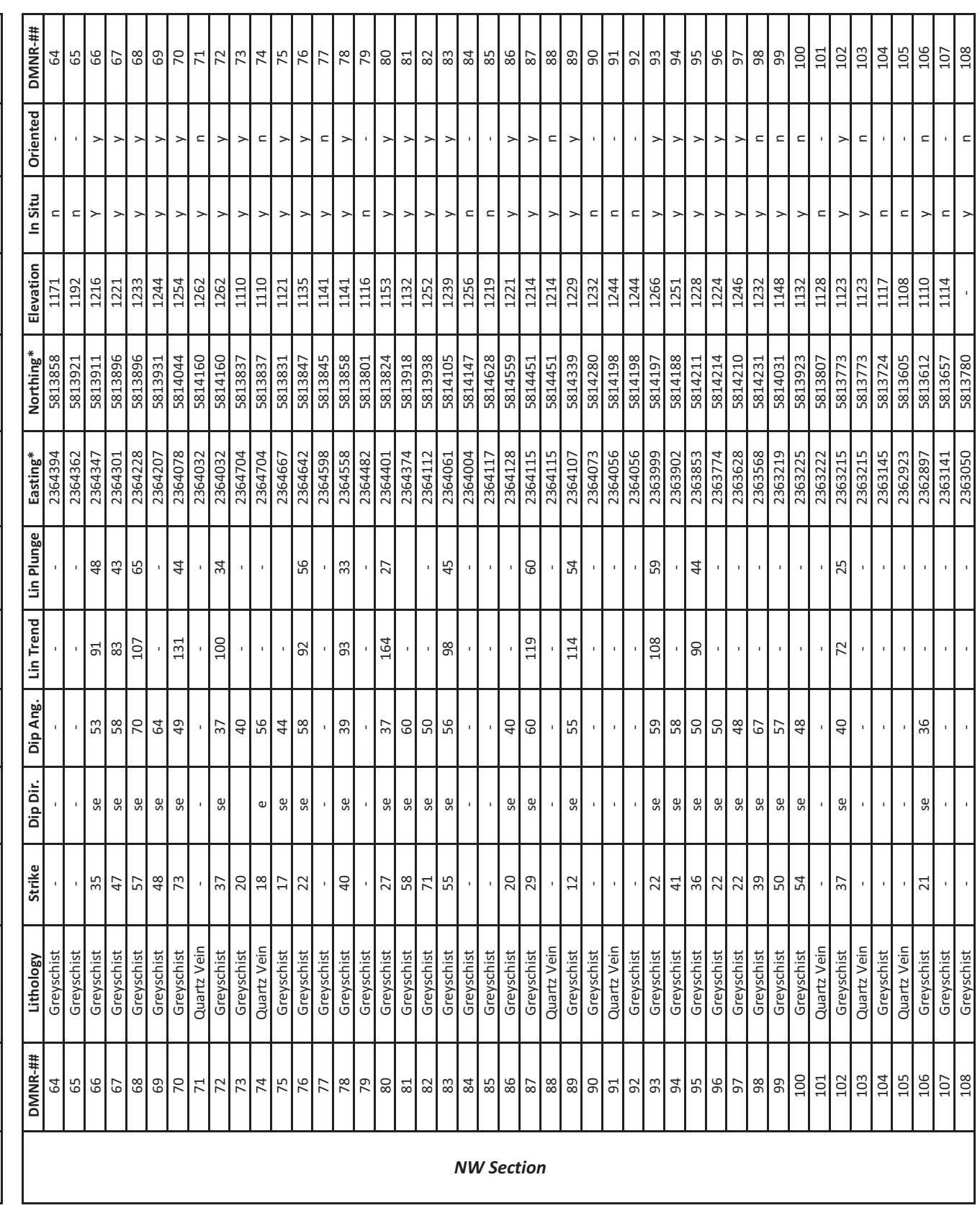


Appendix A1.2

\section{OUTCROP-SCALE FOLD AND FAULT DATA}

OUTCROP SCALE FOLDS

\begin{tabular}{|c|c|c|c|c|c|c|c|c|c|c|}
\hline Fold No. & Lithology & Easting* & Northing* & Elv. (m) & Strike & Dip Dir. & Dip & Limb Notes & Hinge T & Hinge $P$ \\
\hline \multirow{3}{*}{1} & \multirow{3}{*}{ Greyschist } & \multirow{3}{*}{2367152} & \multirow{3}{*}{5813267} & \multirow{3}{*}{1311} & 142 & sw & 68 & TOP LIMB & \multirow[b]{2}{*}{142} & \multirow{3}{*}{1} \\
\hline & & & & & & & & & & \\
\hline & & & & & 325 & se & 12 & BOTTOM LIMB & & \\
\hline \multirow{5}{*}{2} & \multirow{5}{*}{ Greenschist } & \multirow{5}{*}{2366207} & \multirow{5}{*}{5813357} & \multirow{5}{*}{1225} & 54 & se & 26 & TOP LIMB & \multirow{3}{*}{216} & \multirow{3}{*}{9} \\
\hline & & & & & & & & & & \\
\hline & & & & & 31 & nw & 60 & MIDDLE LIMB & & \\
\hline & & & & & & & & & 30 & 1 \\
\hline & & & & & 28 & se & 26 & BOTTOM LIMB & & \\
\hline \multirow{5}{*}{3} & \multirow{5}{*}{ Greenschist } & \multirow{5}{*}{2366205} & \multirow{5}{*}{5813314} & \multirow{5}{*}{1202} & 35 & nw & 18 & TOP LIMB & & \\
\hline & & & & & & & & & 34 & \multirow[t]{2}{*}{0} \\
\hline & & & & & 33 & se & 32 & MIDDLE LIMB & \multirow[b]{2}{*}{47} & \\
\hline & & & & & & & & & & 8 \\
\hline & & & & & 68 & nw & 22 & BOTTOM LIMB & & \\
\hline \multirow{7}{*}{4} & \multirow{7}{*}{ Greyschist } & \multirow{7}{*}{2366571} & \multirow{7}{*}{5813172} & \multirow{7}{*}{1233} & 352 & $\mathrm{e}$ & 36 & TOP LIMB & & \\
\hline & & & & & & & & & 15 & 16 \\
\hline & & & & & 200 & $w$ & 73 & 2ND LIMB & & \\
\hline & & & & & & & & & 9 & 32 \\
\hline & & & & & 301 & $\mathrm{e}$ & 34 & 3RD LIMB & & \\
\hline & & & & & & & & & 31 & 34 \\
\hline & & & & & 206 & $\mathrm{e}$ & 82 & BOTTOM LIMB & & \\
\hline
\end{tabular}

OUTCROP SCALE FAULT

\begin{tabular}{|c|c|c|c|c|c|c|c|c|}
\hline Fault No. & Lithology & Easting* & Northing* & Elevation \\
\hline $\mathbf{1}$ & Fault & 2364704 & 5813837 & 1110 \\
\hline
\end{tabular}

* New Zealand Map Grid coordinates in metres in terms of the Geodetic Datum 1949 
Appendix A2.1

MINERAL ASSEMBLAGE INFORMATION
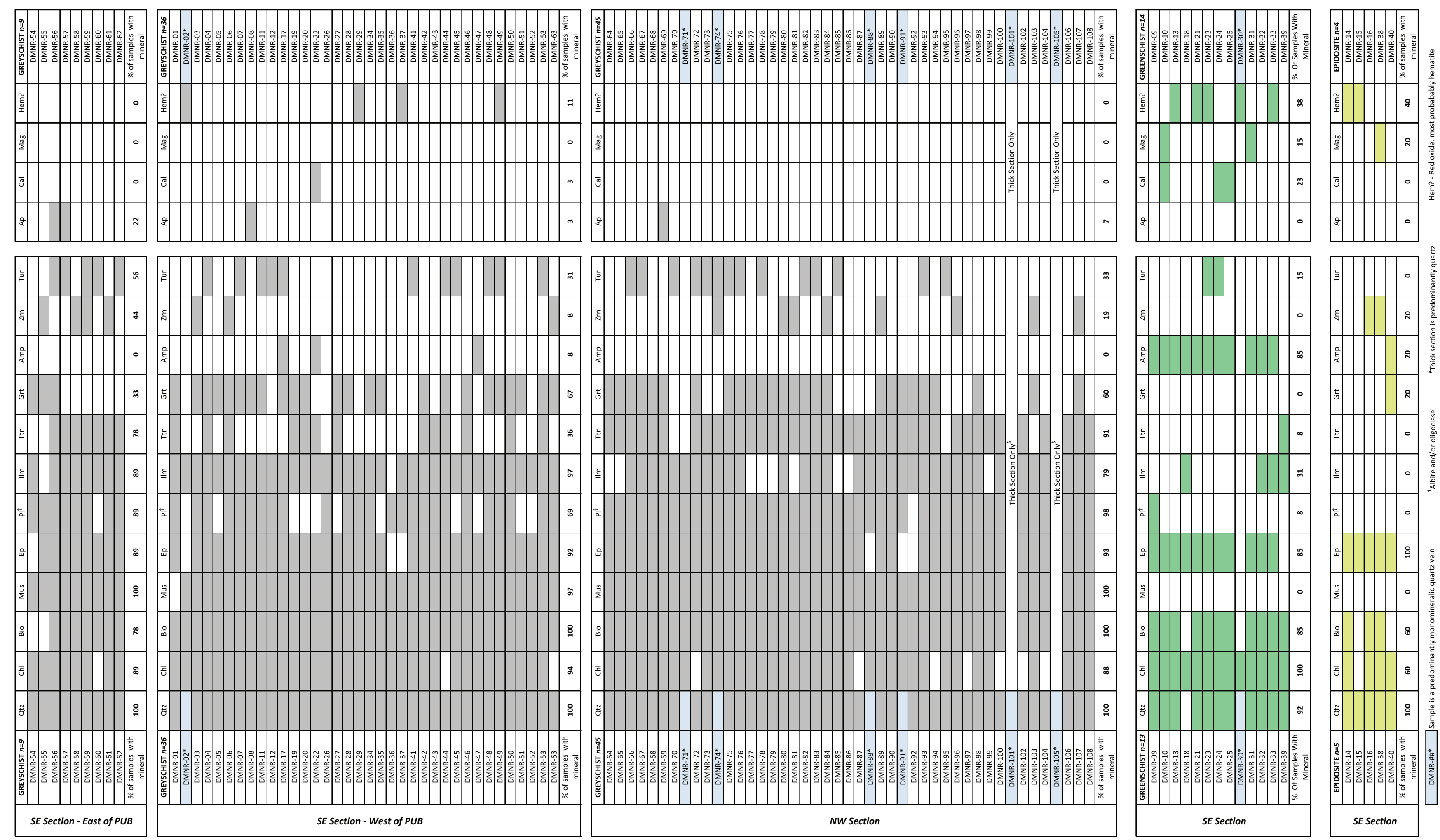

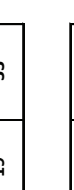
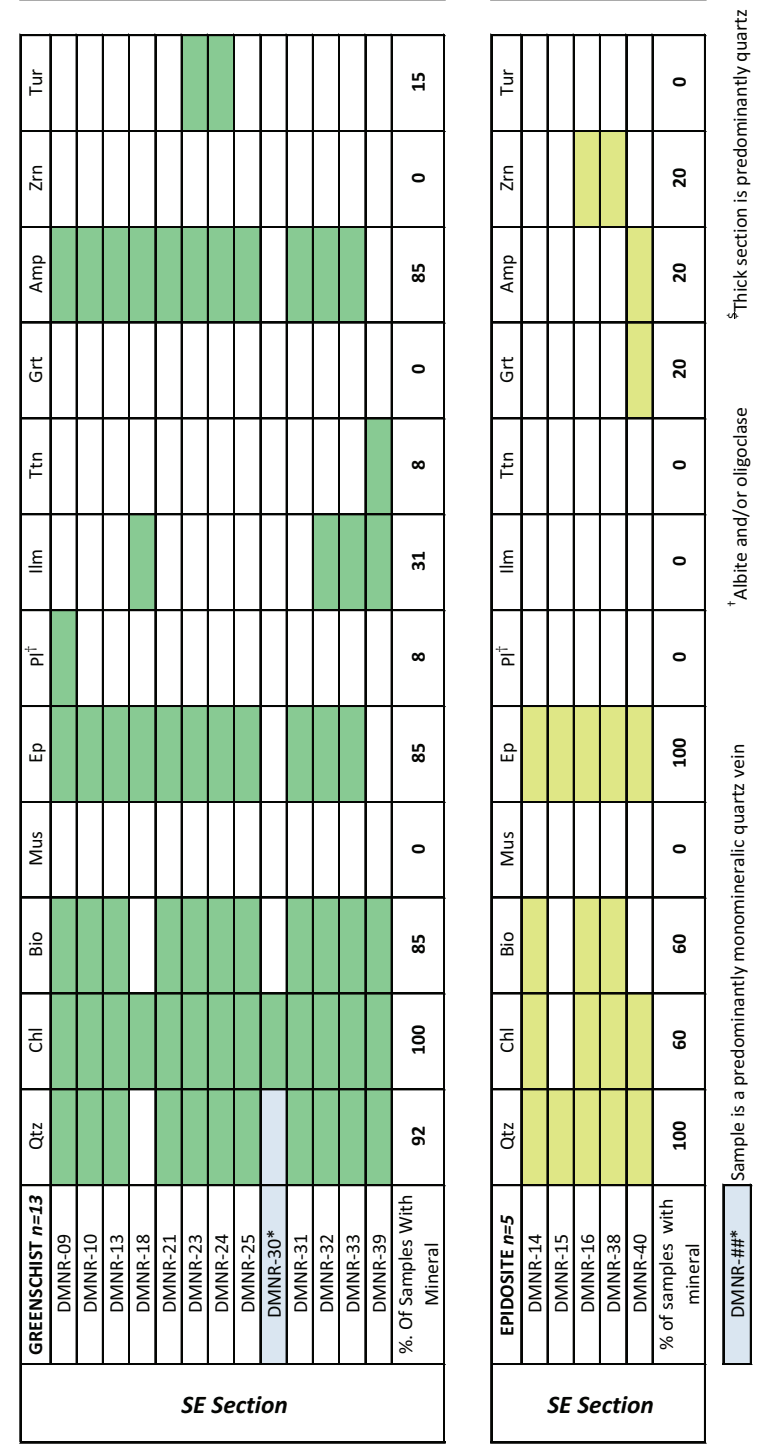
Appendix A2.2

ORIENTATION OF SC'-TYPE SHEAR BANDS

\begin{tabular}{|c|c|c|c|c|}
\hline \multirow{7}{*}{ 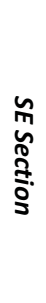 } & Sample No. & \multicolumn{3}{|c|}{ Foliaiton (S) Orientation } \\
\hline & DMNR-\#\# & Strike & Dip Dir. & Dip Ang. \\
\hline & 1 & 143 & sw & 75 \\
\hline & 4 & 182 & w & 66 \\
\hline & 17 & 6 & $\mathrm{e}$ & 37 \\
\hline & 28 & 39 & $\mathrm{se}$ & 63 \\
\hline & 36 & 20 & $\mathrm{e}$ & 82 \\
\hline
\end{tabular}

\begin{tabular}{|c|c|c|c|c|c|}
\hline \multicolumn{2}{|c|}{ SC'-type shear band pitch } & \multicolumn{2}{c|}{ C' band orientation } & Sample No. \\
\hline $\begin{array}{c}\text { "d" section } \\
\text { from up dip dir. }\end{array}$ & $\begin{array}{c}\text { "st" section } \\
\text { from sth end of strike }\end{array}$ & Strike & Dip Dir. & Dip Ang. & DMNR-\#\# \\
\hline- & 150 & \multicolumn{2}{|c|}{ No C' bands in "d" section } & $\mathbf{1}$ \\
\hline- & 149 & No C' bands in "d" section & $\mathbf{4}$ \\
\hline- & 21 & No C' bands in "d" section & $\mathbf{1 7}$ \\
\hline- & 15 & No C' bands in "d" section & $\mathbf{2 8}$ \\
\hline- & 27 & No C' bands in "d" section & $\mathbf{3 6}$ \\
\hline
\end{tabular}

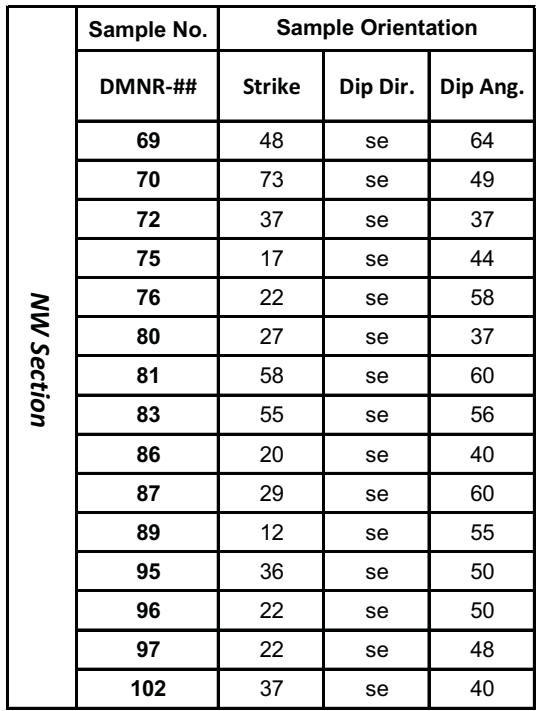

\begin{tabular}{|c|c|c|c|c|c|c|}
\hline \multicolumn{2}{|c|}{ SC'-type shear band pitch } & \multicolumn{3}{c|}{ C' band orientation } & Sample No. \\
\hline $\begin{array}{c}\text { "d" section } \\
\text { from up dip dir. }\end{array}$ & $\begin{array}{c}\text { "st" section } \\
\text { from sth end of strike }\end{array}$ & Strike & Dip Dir. & Dip Ang. & DMNR-\#\# \\
\hline 18 & 27 & 82 & s & 51 & $\mathbf{6 9}$ \\
\hline 18 & 24 & 112 & s & 38 & $\mathbf{7 0}$ \\
\hline 17 & - & \multicolumn{4}{|c|}{ No C' bands in "st" section } & $\mathbf{7 2}$ \\
\hline 24 & 33 & 77 & s & 36 & $\mathbf{7 5}$ \\
\hline 27 & - & \multicolumn{2}{|c|}{ No C' bands in "st" section } & $\mathbf{7 6}$ \\
\hline 29 & 17 & 90 & s & 17 & $\mathbf{8 0}$ \\
\hline 23 & 13 & 77 & s & 38 & $\mathbf{8 1}$ \\
\hline 23 & 33 & 103 & s & 44 & $\mathbf{8 3}$ \\
\hline 33 & 32 & 97 & s & 29 & $\mathbf{8 6}$ \\
\hline 30 & 21 & 62 & s & 35 & $\mathbf{8 7}$ \\
\hline 28 & 23 & 51 & s & 33 & $\mathbf{8 9}$ \\
\hline 32 & 23 & 86 & s & 27 & $\mathbf{9 5}$ \\
\hline 24 & 15 & 52 & s & 29 & $\mathbf{9 6}$ \\
\hline 29 & 21 & 68 & s & 26 & $\mathbf{9 7}$ \\
\hline 19 & 16 & 73 & s & 26 & $\mathbf{1 0 2}$ \\
\hline
\end{tabular}


Appendix Three

\title{
MINERAL CHEMISTRY ANALYSES
}

\author{
A3.1: $\quad$ Garnet \\ A3.2: $\quad$ Plagioclase \\ A3.3: $\quad$ Muscovite \\ A3.4: $\quad$ Epidote \\ A3.5: Biotite \\ A3.6: Titanite, Ilmenite, Apatite \\ A3.7: $\quad$ Chlorite
}




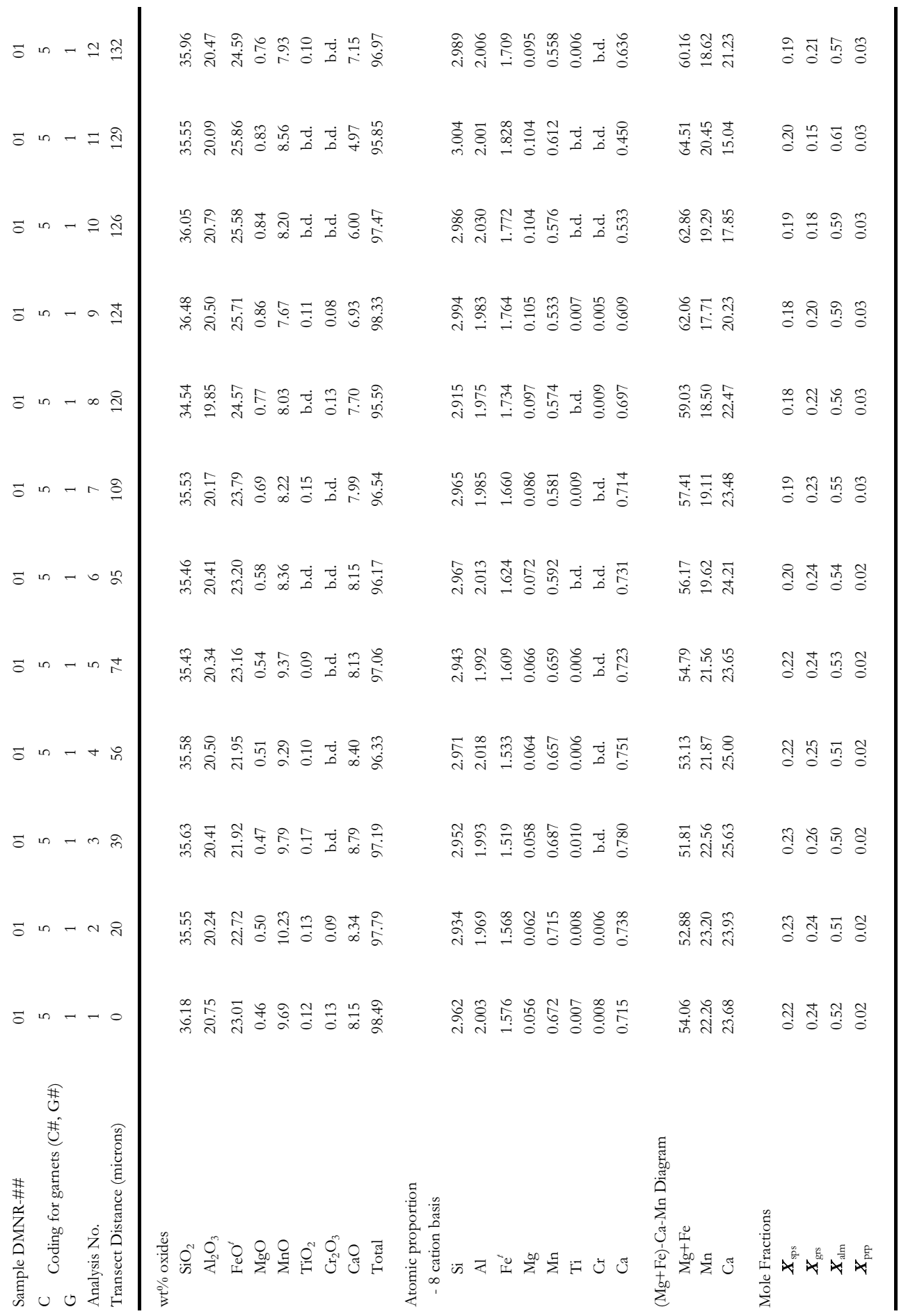




\begin{tabular}{|c|c|c|c|c|}
\hline ถู $-\alpha=$ ปี & 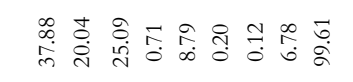 & 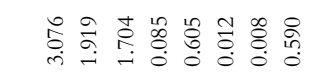 & 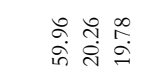 & वें 공 ing \\
\hline $\mathscr{8}-\alpha \cong \stackrel{9}{2}$ & 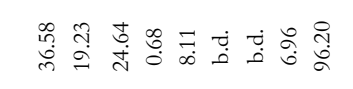 & 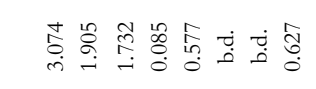 & 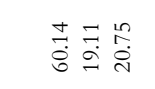 & 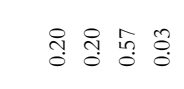 \\
\hline 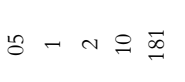 & 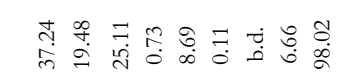 & 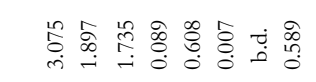 & 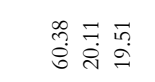 & 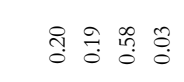 \\
\hline 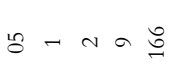 & 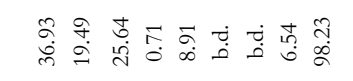 & 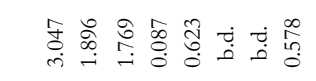 & 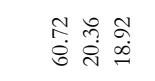 & 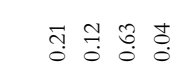 \\
\hline แू $-\alpha \infty$ î & 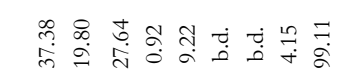 & 总 & 员 & 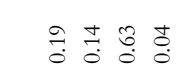 \\
\hline 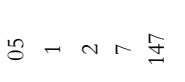 & 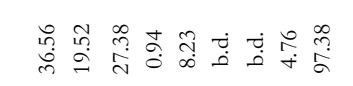 & 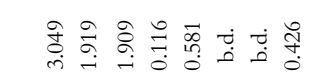 & 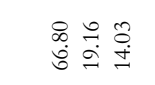 & 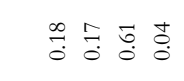 \\
\hline 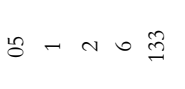 & 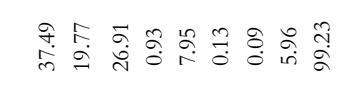 & 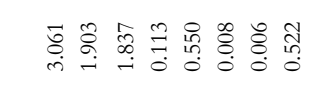 & 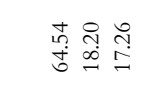 & 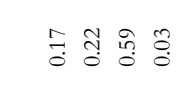 \\
\hline 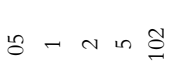 & 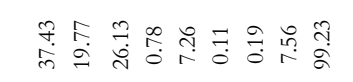 & 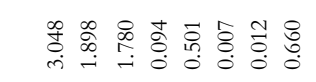 & 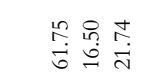 & 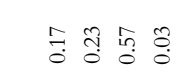 \\
\hline $\operatorname{son}-4+\frac{5}{n}$ & 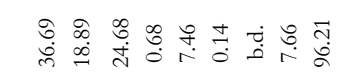 & 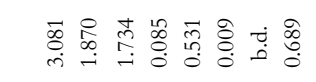 & 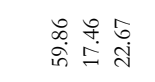 & $\stackrel{\infty}{0}$ 공 \\
\hline$n-\alpha m$ in & 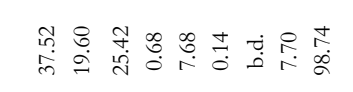 & 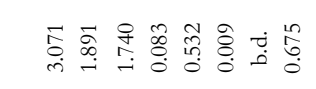 & 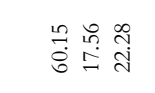 & 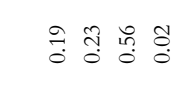 \\
\hline $8-a v i$ & 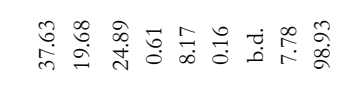 & 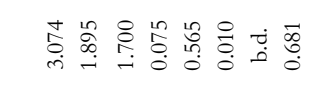 & 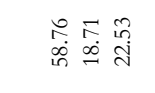 & $\stackrel{\infty}{\circ}$ 종 in \\
\hline$g-4-0$ & 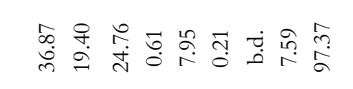 & 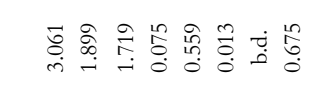 & 过 辇 & 웅 तี่ \\
\hline 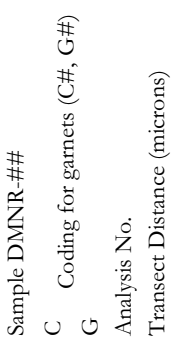 & 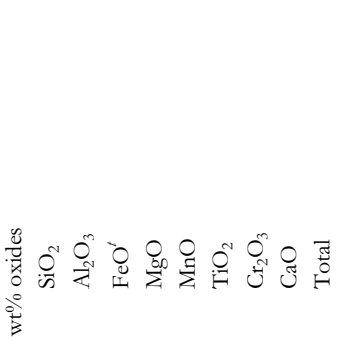 & 总 & 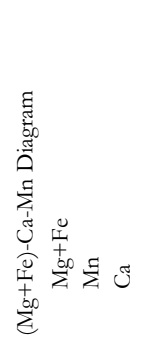 & 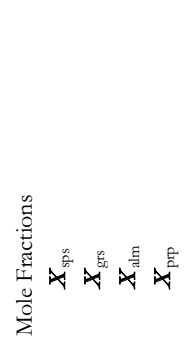 \\
\hline
\end{tabular}




\begin{tabular}{|c|c|c|c|c|}
\hline 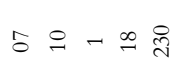 & 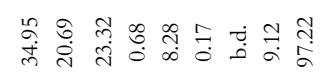 & 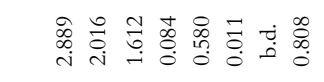 & 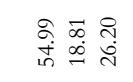 & 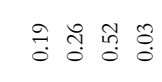 \\
\hline 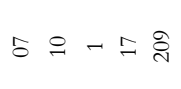 & 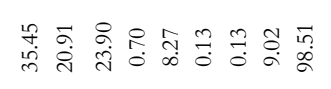 & 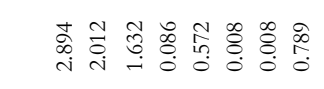 & 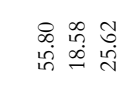 & 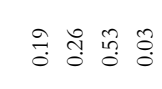 \\
\hline$b \cong-\infty$ & 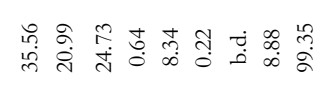 & 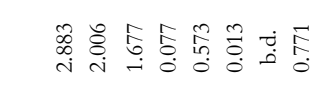 & 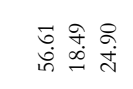 & 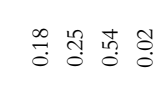 \\
\hline$b=-\ln$ & 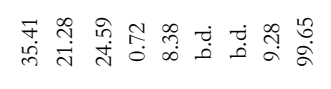 & 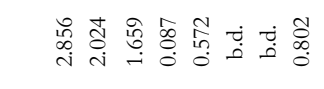 & 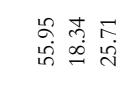 & 융 용 \\
\hline$b \because- \pm d$ & 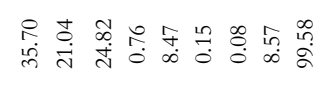 & 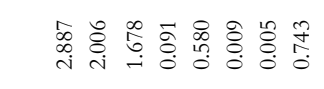 & 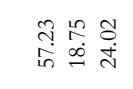 & केषे \\
\hline 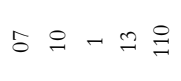 & 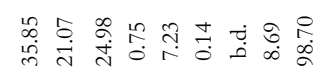 & 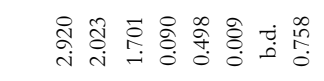 & 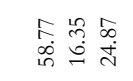 & 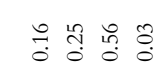 \\
\hline 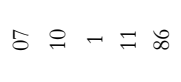 & 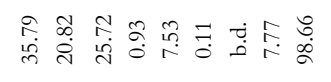 & 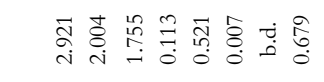 & 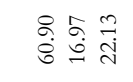 & 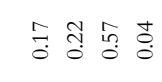 \\
\hline$b \div-\circ ?$ & 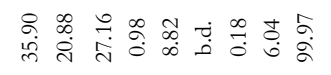 & 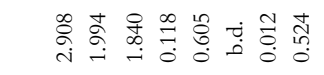 & 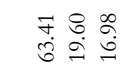 & 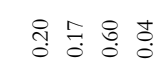 \\
\hline$b \div-a b$ & 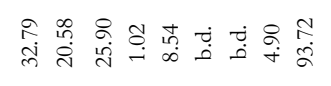 & 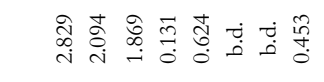 & 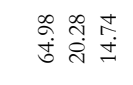 & శ్ \\
\hline $5 \&-\infty g$ & 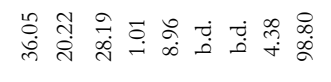 & 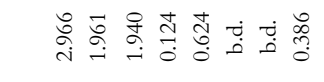 & 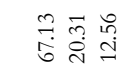 & శ్తి \\
\hline$=\subseteq-r i$ & 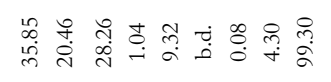 & 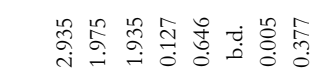 & 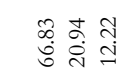 & 공 용 용 \\
\hline$\varepsilon \circ-0 \%$ & 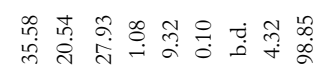 & 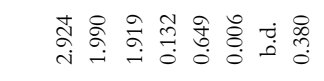 & 会 & 겅 궁 용 范 \\
\hline$\rho \subseteq-$ 的 & 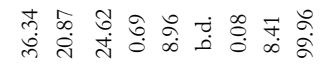 & 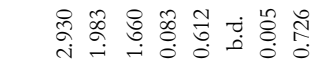 & 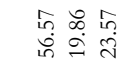 & 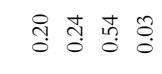 \\
\hline$\varepsilon \odot-+\stackrel{\infty}{\longrightarrow}$ & 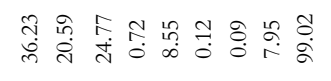 & 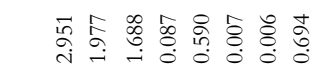 & 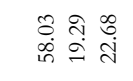 & 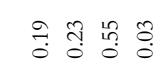 \\
\hline 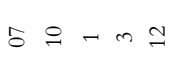 & 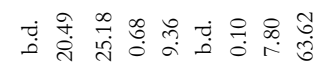 & تُ & 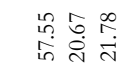 & 공 त్తి \\
\hline$g \circ-a 0^{2}$ & 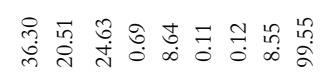 & 龵合 & 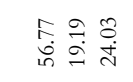 & 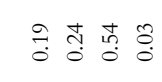 \\
\hline$\varepsilon \circ--0$ & 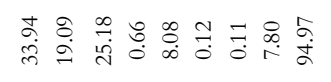 & 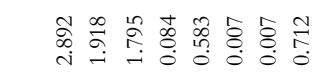 & 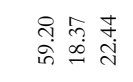 & $\stackrel{\infty}{\circ}$ 궁 \\
\hline 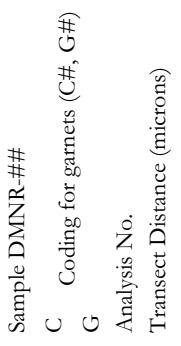 & $\begin{array}{l}b \\
0 \\
0\end{array}$ & 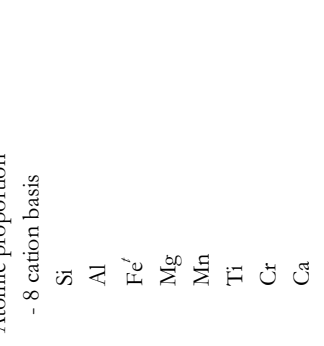 & 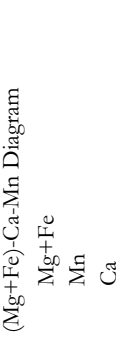 & 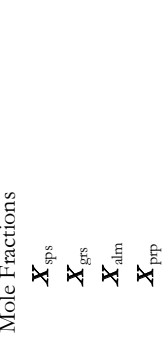 \\
\hline
\end{tabular}




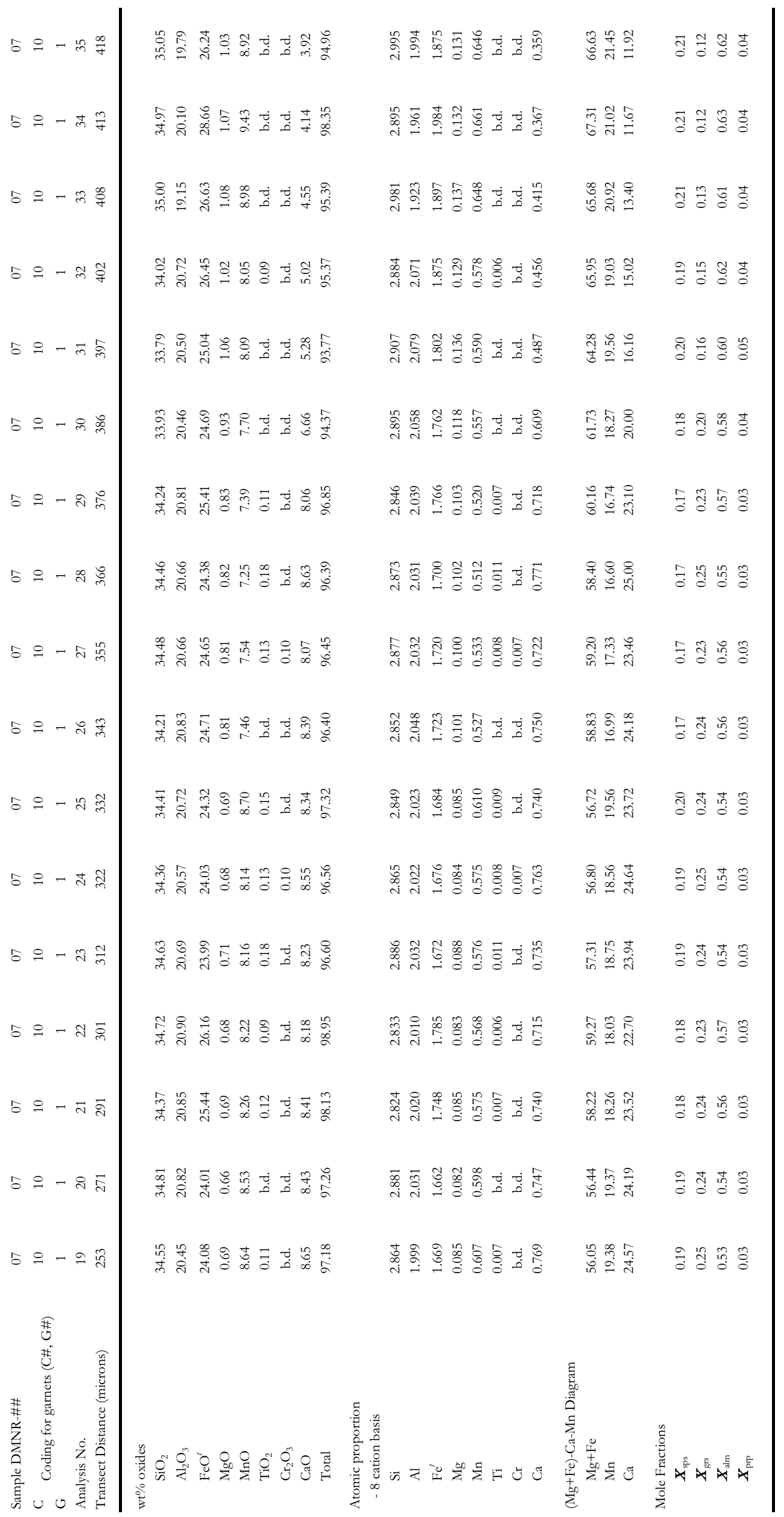




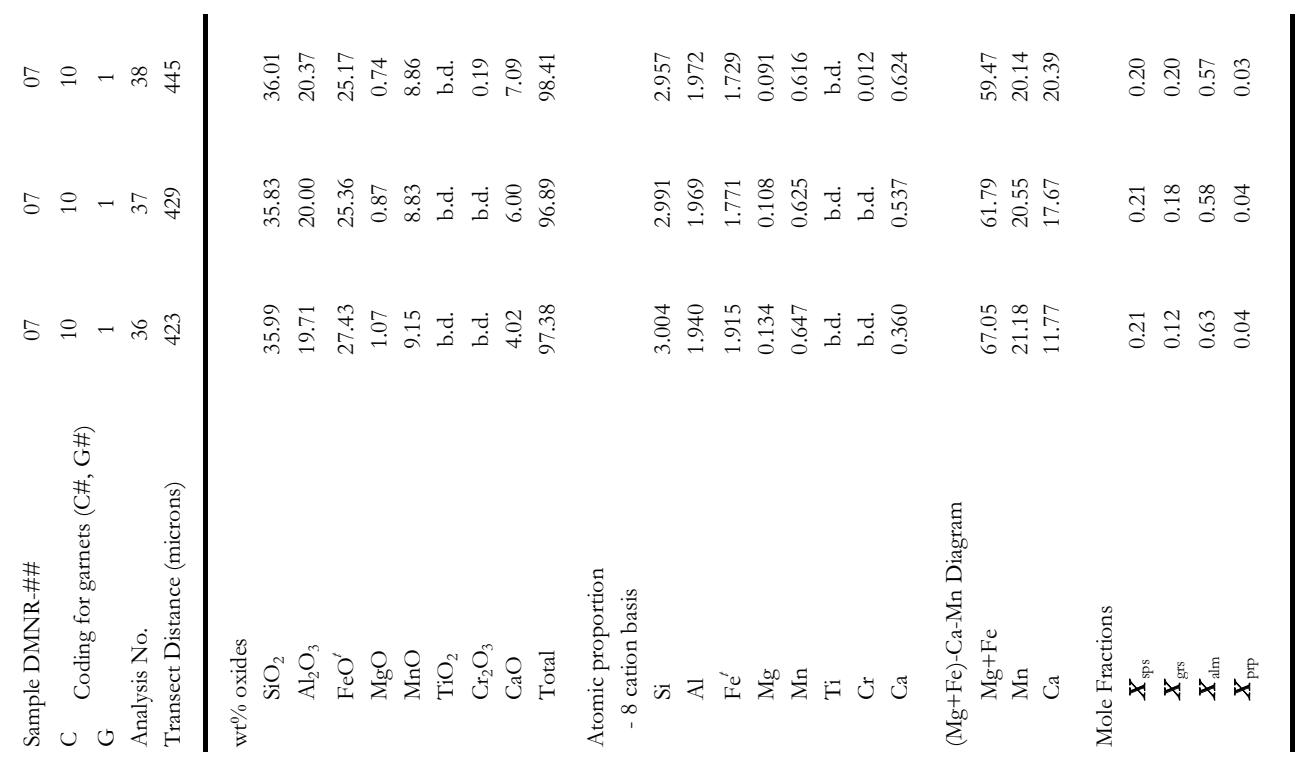




\begin{tabular}{|c|c|c|c|c|}
\hline व की & 志芯号 & 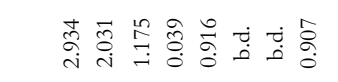 & 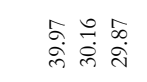 & वृ. \\
\hline 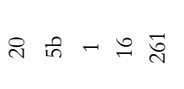 & 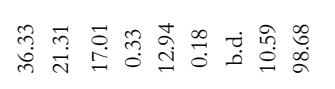 & 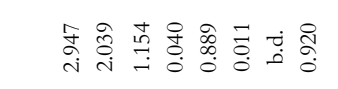 & 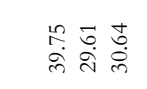 & 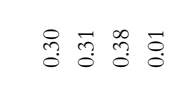 \\
\hline in $-\stackrel{\text { nิ }}{\text { aे }}$ & 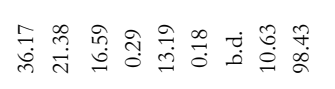 & 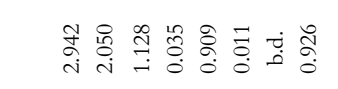 & 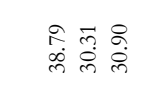 & 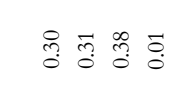 \\
\hline in - \pm ते & 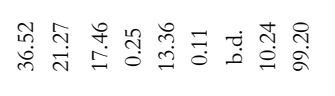 & 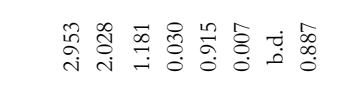 & 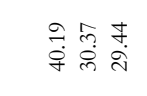 & 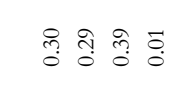 \\
\hline की -2 व & 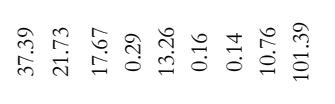 & 品 & 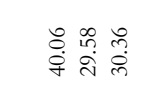 & ळై \\
\hline in $-\simeq$ & 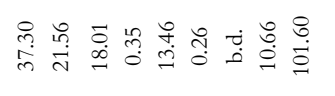 & 辛 & 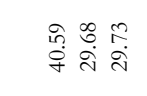 & 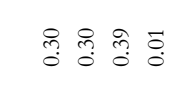 \\
\hline in - 苟 & 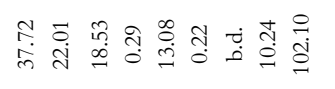 & 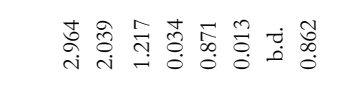 & 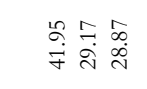 & 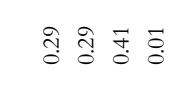 \\
\hline in $-\circ \stackrel{+}{=}$ & 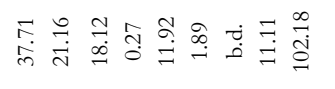 & 员 & 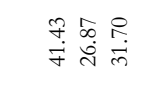 & 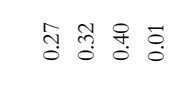 \\
\hline$\vec{x}$ in $-a \pm$ & 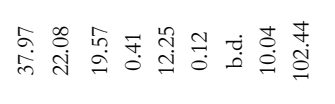 & 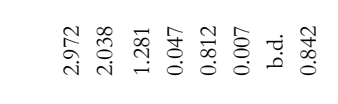 & 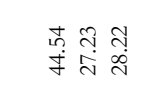 & 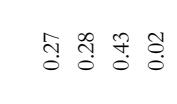 \\
\hline$i_{\text {in }}-\infty$ t & 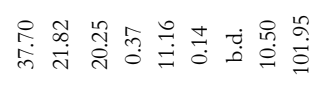 & 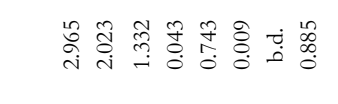 & 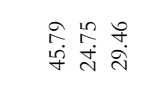 & 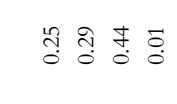 \\
\hline रो & 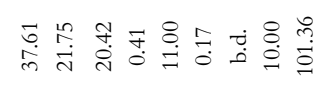 & 号过 & 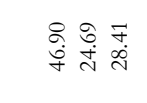 & 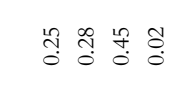 \\
\hline 2 in -0 in & 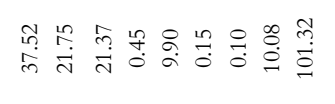 & 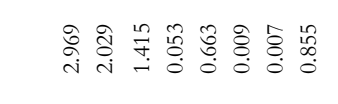 & 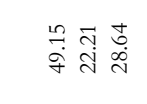 & สี่ \\
\hline in & 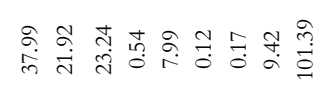 & 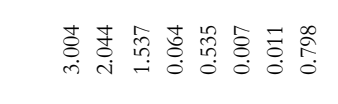 & 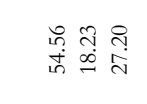 & $\stackrel{\infty}{0}$ 덩 용 웅 \\
\hline $\overrightarrow{\text { in }}-+8$ & 公号 & 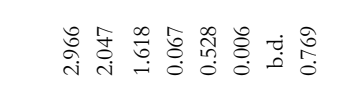 & 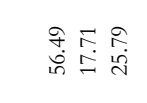 & 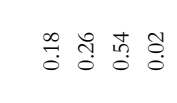 \\
\hline वे की $-m$ वे & 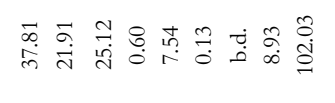 & 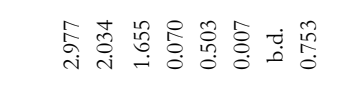 & 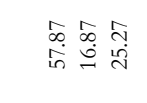 & 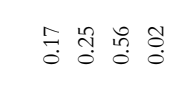 \\
\hline ते in $-\alpha ?$ & 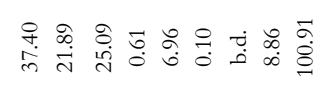 & 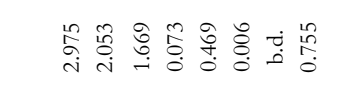 & 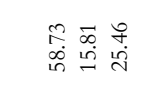 & 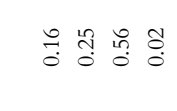 \\
\hline तो in -70 & 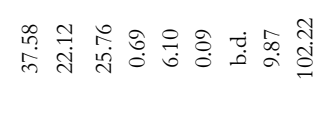 & 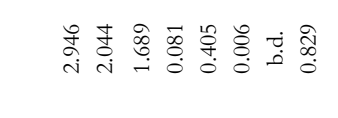 & 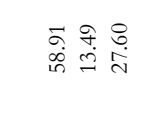 & 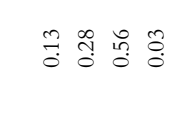 \\
\hline 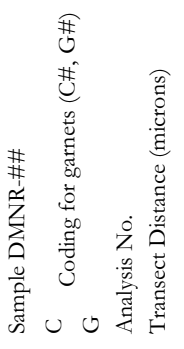 & 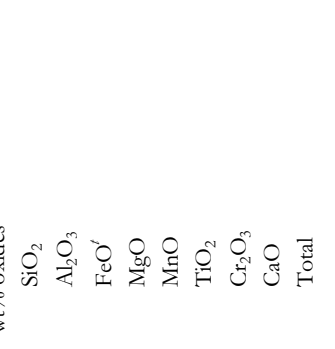 & 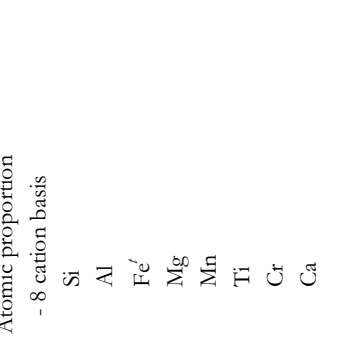 & 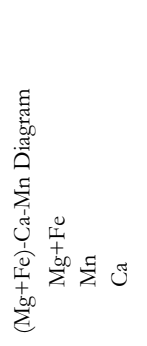 & 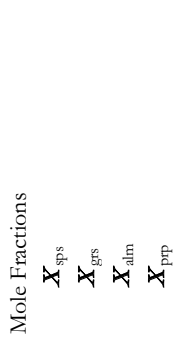 \\
\hline
\end{tabular}




\begin{tabular}{|c|c|c|c|c|}
\hline$\stackrel{\sim}{\text { in }}-\stackrel{\infty}{\text { r }}$ & 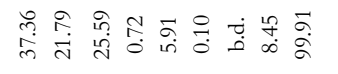 & 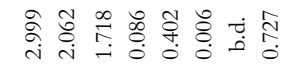 & 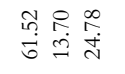 & 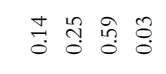 \\
\hline ते ही - ה & 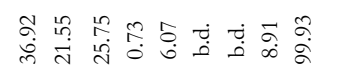 & 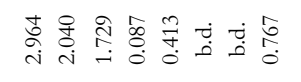 & 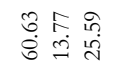 & 声 듕 \\
\hline 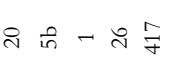 & 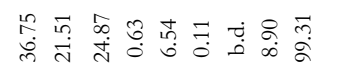 & 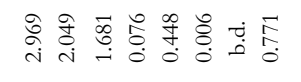 & 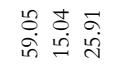 & 늉 용 융 \\
\hline 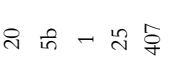 & 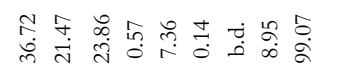 & 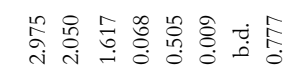 & 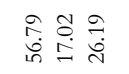 & 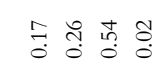 \\
\hline वे की - ते & 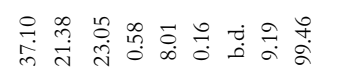 & 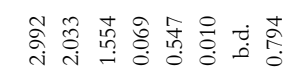 & 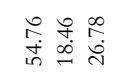 & 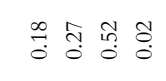 \\
\hline ते & 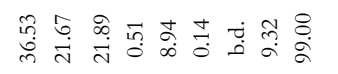 & 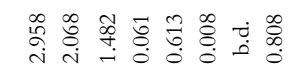 & 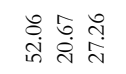 & 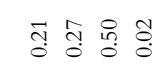 \\
\hline तो की - त 总 & 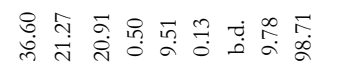 & 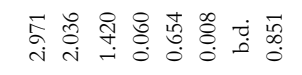 & 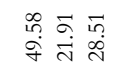 & 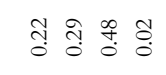 \\
\hline वे की $-\vec{\lambda}$ & 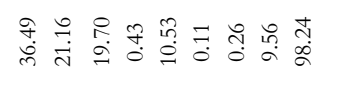 & 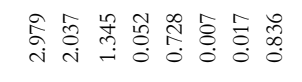 & 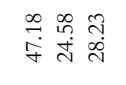 & গุiñ \\
\hline 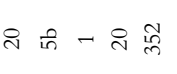 & 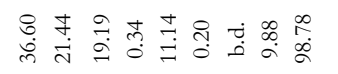 & 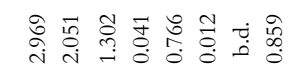 & 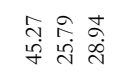 & 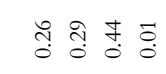 \\
\hline 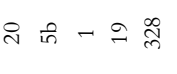 & 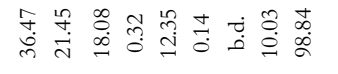 & 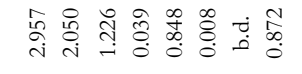 & 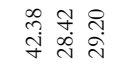 & 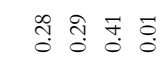 \\
\hline ㅇ & 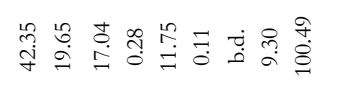 & 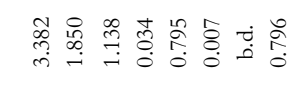 & 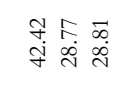 & 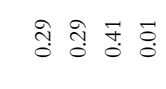 \\
\hline 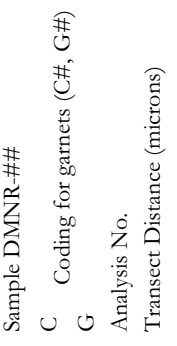 & 00 & . & 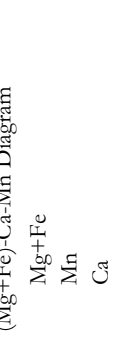 & 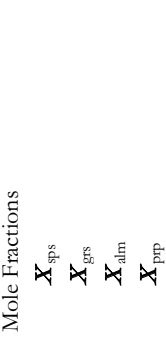 \\
\hline
\end{tabular}




\begin{tabular}{|c|c|c|c|c|}
\hline 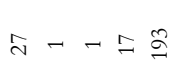 & 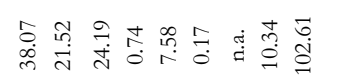 & 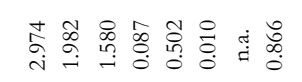 & 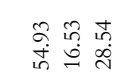 & 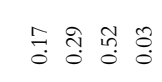 \\
\hline ¿ $-\underset{\infty}{\infty}$ & 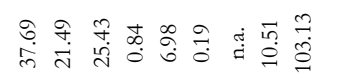 & 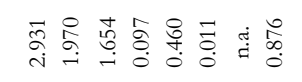 & 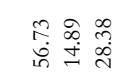 & 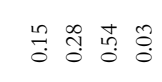 \\
\hline$\overline{4}--\sqrt{2}$ & 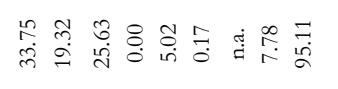 & 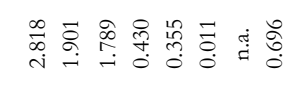 & 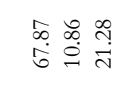 & 궁 त् \\
\hline $\bar{\lambda}- \pm \underline{\Xi}$ & 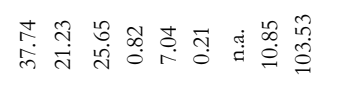 & 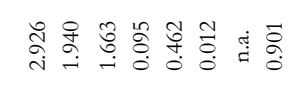 & 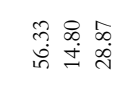 & 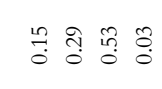 \\
\hline$\vec{a}-a \underline{n}$ & 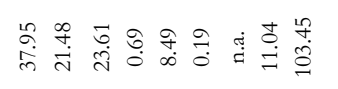 & 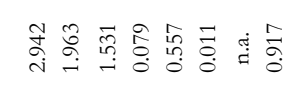 & 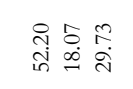 & 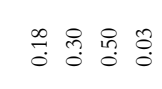 \\
\hline 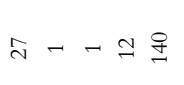 & 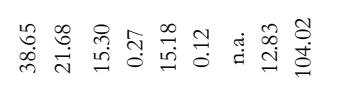 & 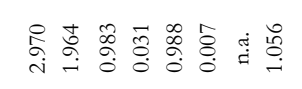 & 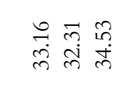 & 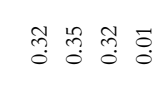 \\
\hline$\hat{\imath}--=\grave{\jmath}$ & 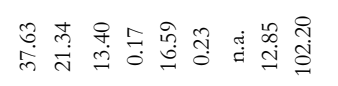 & 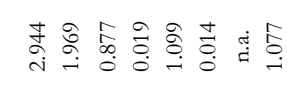 & 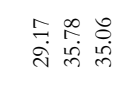 & 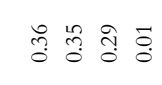 \\
\hline $\bar{n}-\rho \stackrel{\Xi}{=}$ & 范苛 & 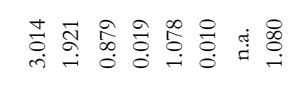 & 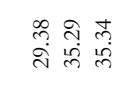 & ณृ \\
\hline$\pi-a g$ & 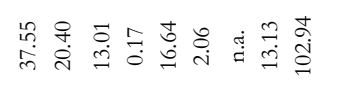 & 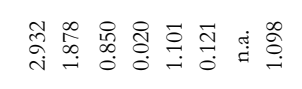 & 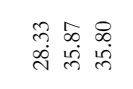 & 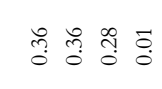 \\
\hline$\tilde{N}-\infty \infty_{\infty}^{+}$ & 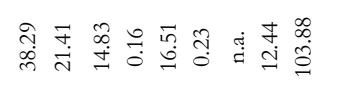 & 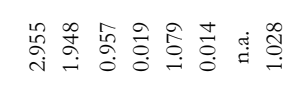 & 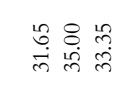 & مै \\
\hline sta & 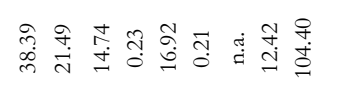 & 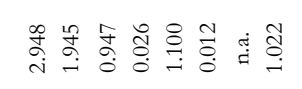 & 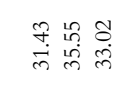 & 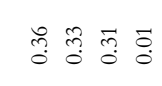 \\
\hline$\hat{4}--0$ 呙 & 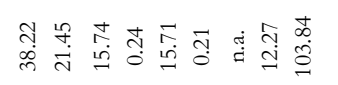 & 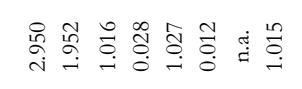 & 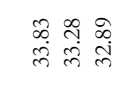 & 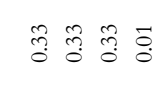 \\
\hline $\bar{\lambda}-\operatorname{in} \bar{m}$ & 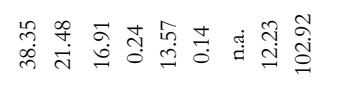 & 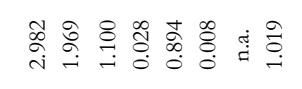 & 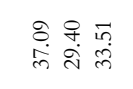 & 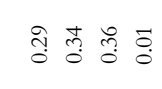 \\
\hline A $-A$ t & 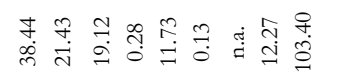 & 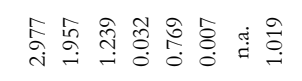 & 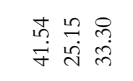 & 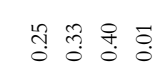 \\
\hline$s-m \pm$ & 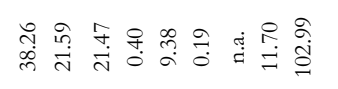 & 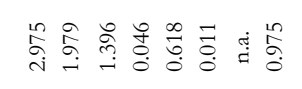 & 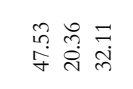 & 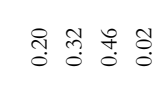 \\
\hline$a-40$ & 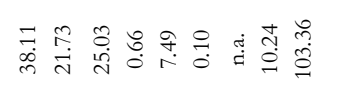 & 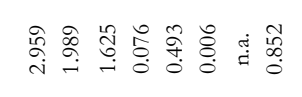 & 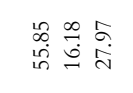 & 잉 文 \\
\hline$\hat{\lambda}-x_{0}$ & 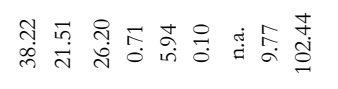 & 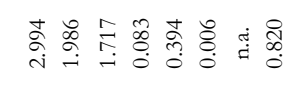 & 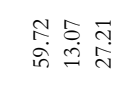 & 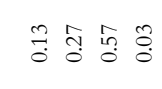 \\
\hline 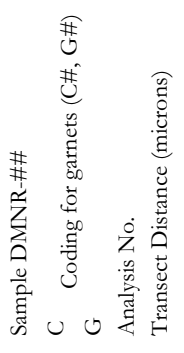 & $\approx 0$ & 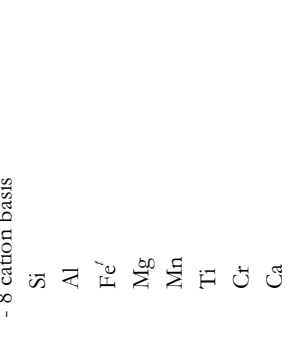 & 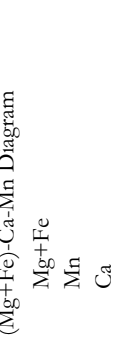 & 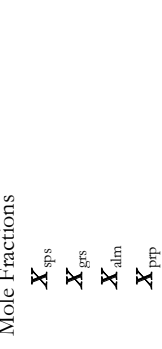 \\
\hline
\end{tabular}




\begin{tabular}{|c|c|c|c|c|}
\hline$\hat{\lambda}--\hat{\lambda}$ & 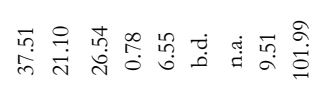 & 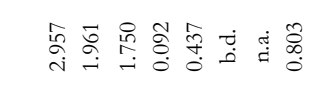 & $\begin{array}{l}\text { ñ } \\
\text { in } \\
\text { in }\end{array}$ & ț 웡 in \\
\hline 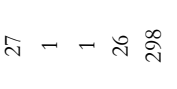 & 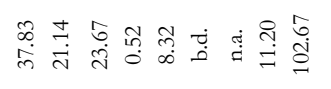 & 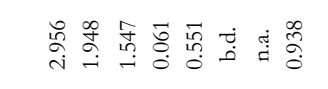 & 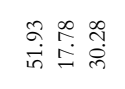 & 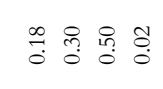 \\
\hline ㄱ- & 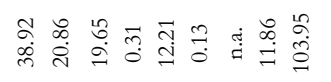 & 菺 吕 & 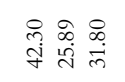 & 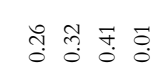 \\
\hline$\hat{a}--\vec{d} \stackrel{\infty}{i}$ & 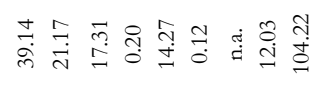 & 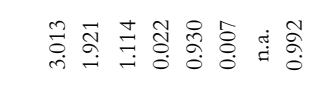 & 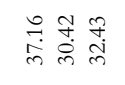 & 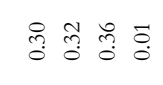 \\
\hline $4--28$ & مَ & 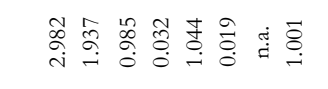 & 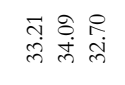 & 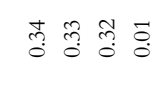 \\
\hline$\hat{\lambda}-\lambda \stackrel{d}{d}$ & 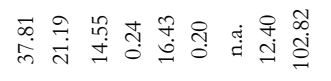 & 虽先 & 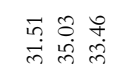 & 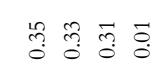 \\
\hline $\bar{a}--\bar{\lambda}$ & 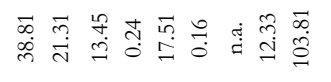 & 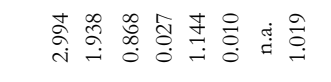 & 구요 & గై \\
\hline ๘- - & 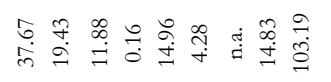 & 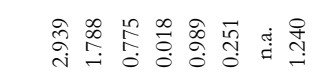 & 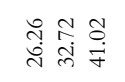 & 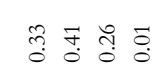 \\
\hline $\bar{\lambda}-2 \frac{\vec{\lambda}}{2}$ & 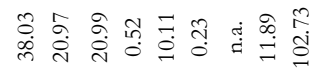 & 厼 & 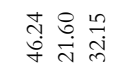 & 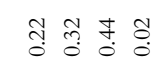 \\
\hline 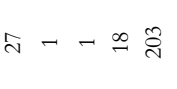 & 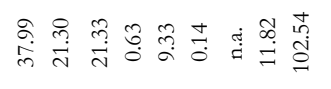 & 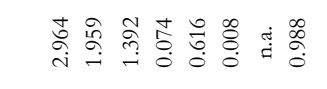 & 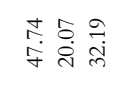 & 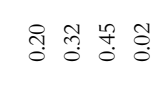 \\
\hline 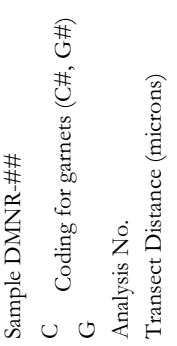 & $\begin{array}{ll}0 \\
0 \\
0\end{array}$ & 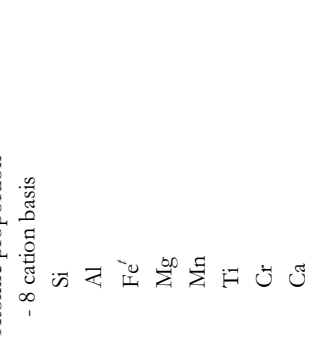 & 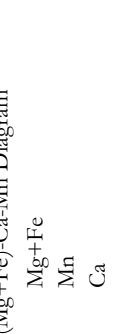 & 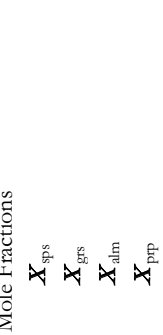 \\
\hline
\end{tabular}




\begin{tabular}{|c|c|c|c|c|}
\hline [n & 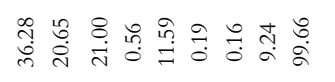 & 岂 & 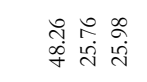 & శ్రి \\
\hline $\overrightarrow{i n} n-\stackrel{\circ}{\circ}$ & 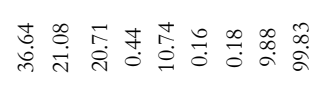 & 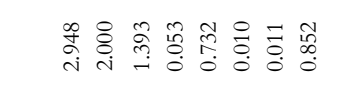 & 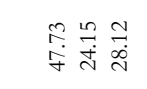 & đ্่ \\
\hline in $n-\stackrel{n}{\sim} \stackrel{\infty}{\longrightarrow}$ & 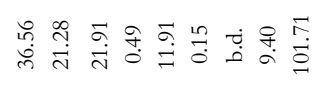 & 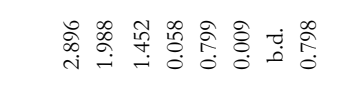 & 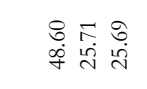 & 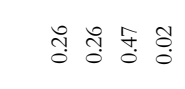 \\
\hline in $n- \pm 5$ & 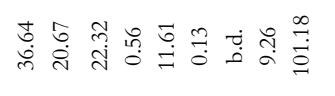 & 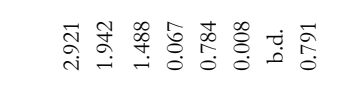 & 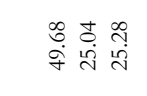 & 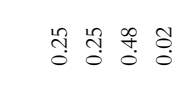 \\
\hline in $n-2$ 尔 & 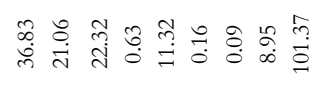 & 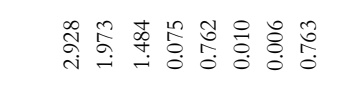 & 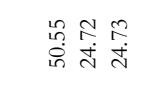 & นึ่ \\
\hline in $n-\simeq$ I & 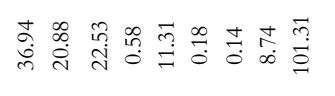 & 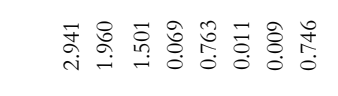 & 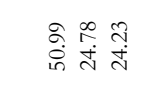 & 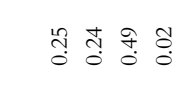 \\
\hline 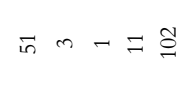 & 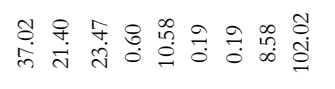 & 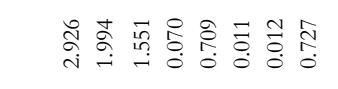 & 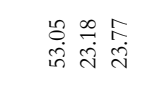 & 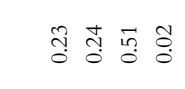 \\
\hline$\vec{n} m-\odot \vec{\infty}$ & 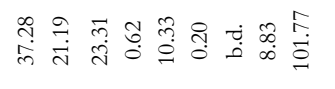 & 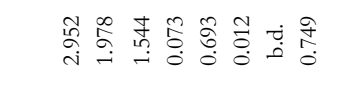 & 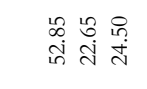 & તุ่ \\
\hline in $n-a p$ & 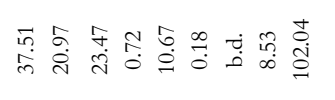 & 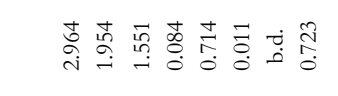 & 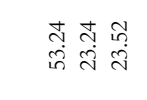 & đֶ: \\
\hline in $n-\infty$ in & 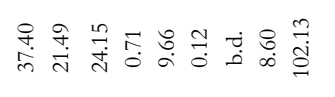 & 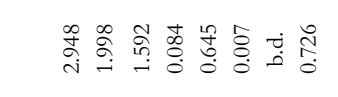 & 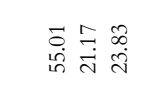 & 공 공 정 \\
\hline in & 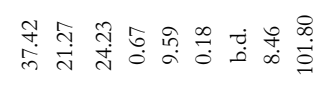 & 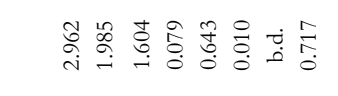 & 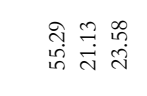 & 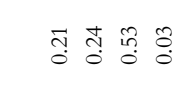 \\
\hline$\vec{n} n-\infty \infty$ & 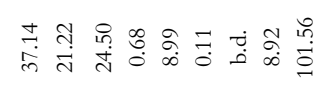 & 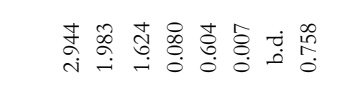 & 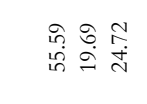 & 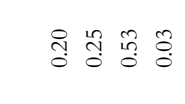 \\
\hline in $n-\min$ & 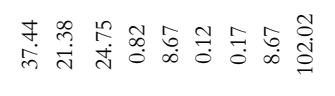 & 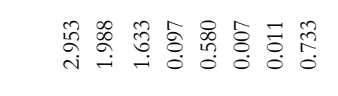 & 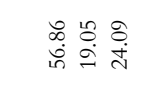 & 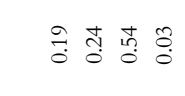 \\
\hline inn $\rightarrow+0$ & 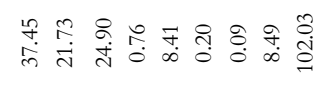 & 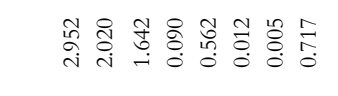 & 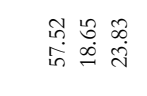 & 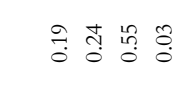 \\
\hline का & 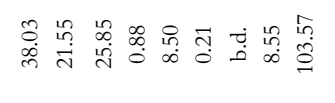 & 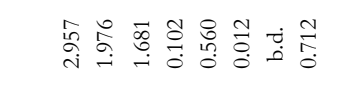 & 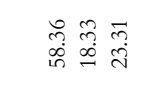 & 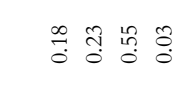 \\
\hline$\vec{n} n-a$ in & 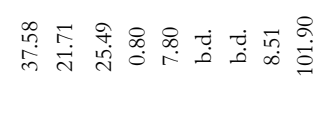 & 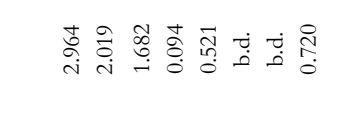 & $\begin{array}{l}\infty \\
\infty \\
\infty \\
\infty \\
i \\
i\end{array}$ & 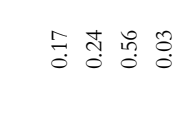 \\
\hline in & 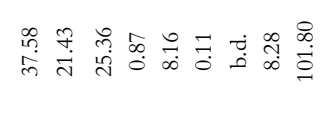 & 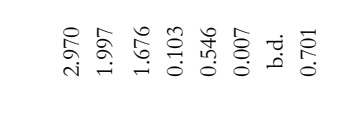 & 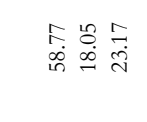 & 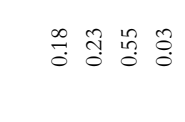 \\
\hline 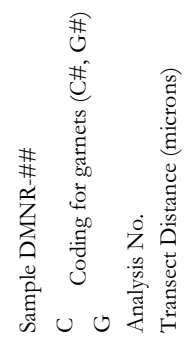 & 范 & 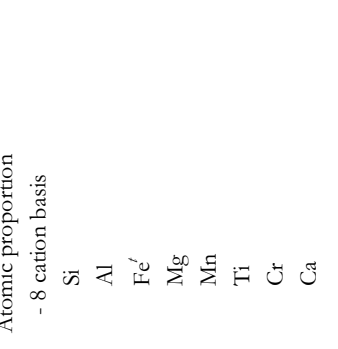 & 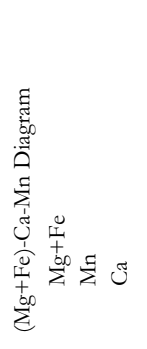 & 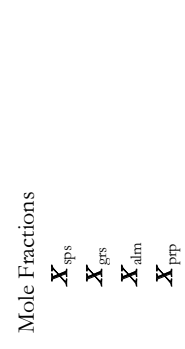 \\
\hline
\end{tabular}




\begin{tabular}{|c|c|c|c|c|}
\hline in & 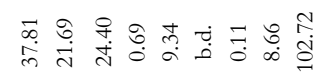 & 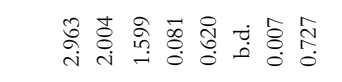 & 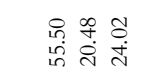 & 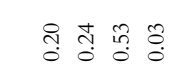 \\
\hline$m-m$ & 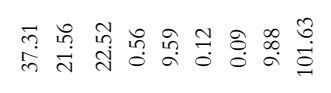 & 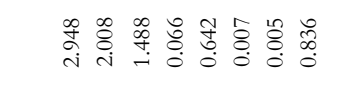 & 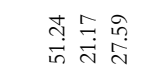 & 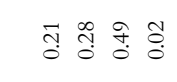 \\
\hline$\vec{n} m-\dot{m}$ in & 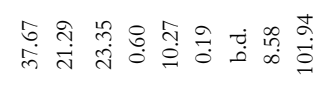 & 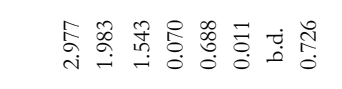 & 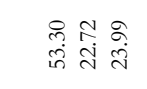 & 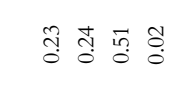 \\
\hline$\vec{n} m-m$ & مै & 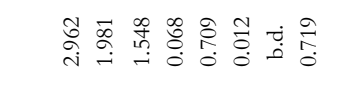 & 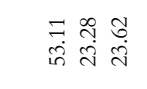 & 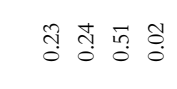 \\
\hline$\vec{n} m-\sqrt[m]{\text { 品 }}$ & 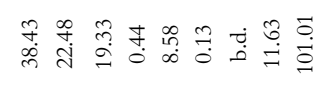 & 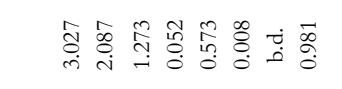 & 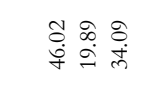 & 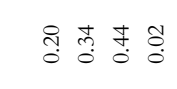 \\
\hline$\vec{n} n-\vec{m}$ & 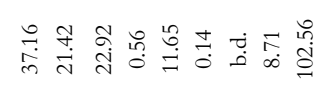 & 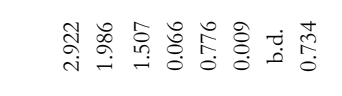 & 总足希 & 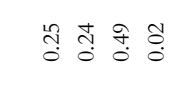 \\
\hline$n m-8 \approx$ & 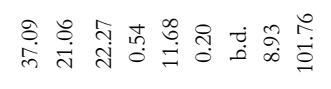 & 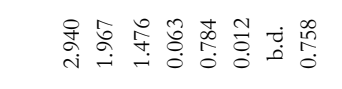 & 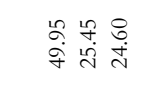 & 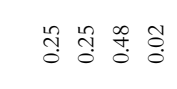 \\
\hline în - ते & 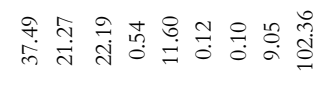 & 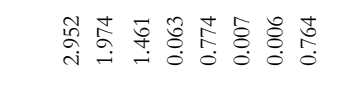 & 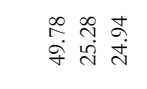 & 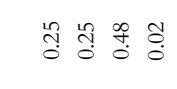 \\
\hline 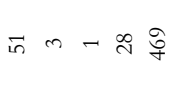 & 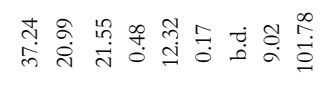 & 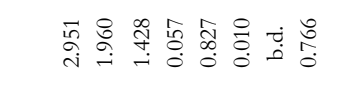 & 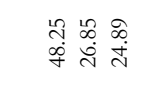 & 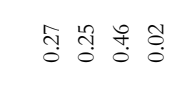 \\
\hline$\vec{n} m-\stackrel{d}{q}$ & 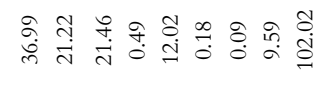 & 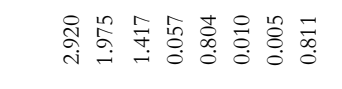 & 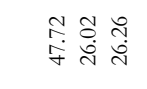 & 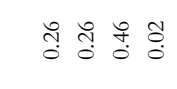 \\
\hline$\vec{n} m-$ 朵㐋 & 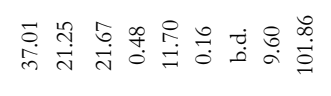 & 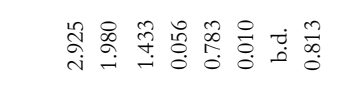 & 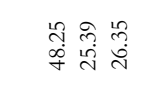 & 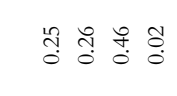 \\
\hline in $n-\underset{d}{\infty}$ & 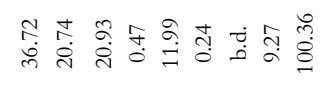 & 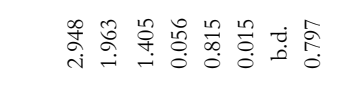 & 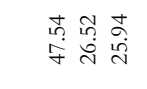 & 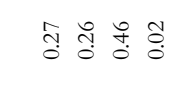 \\
\hline$\vec{n} m-\sqrt[\lambda]{0}$ & 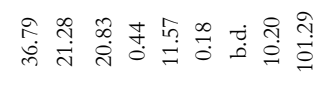 & 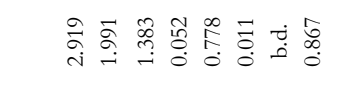 & 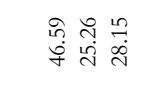 & 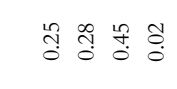 \\
\hline जि & 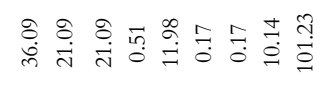 & 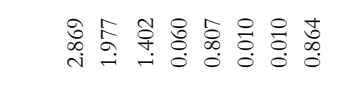 & 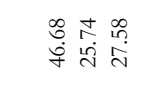 & đ̊ำ \\
\hline$\vec{n} m-\vec{\lambda} \stackrel{\infty}{m}$ & 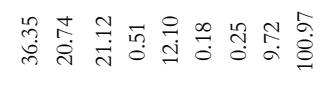 & 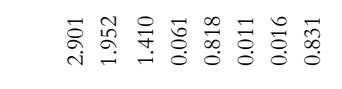 & 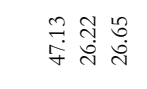 & 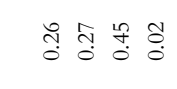 \\
\hline किm-8ิ & 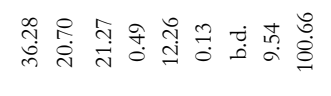 & 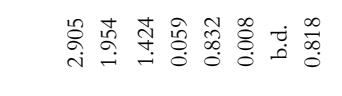 & 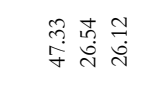 & 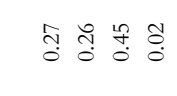 \\
\hline in & 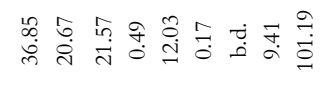 & 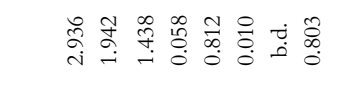 & 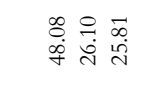 & 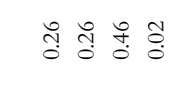 \\
\hline 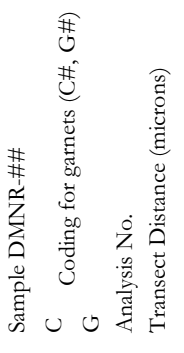 & 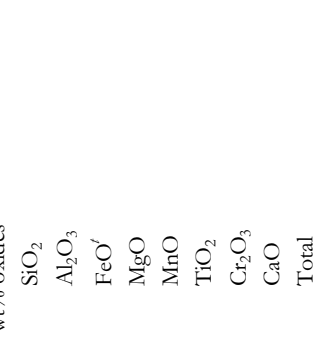 & 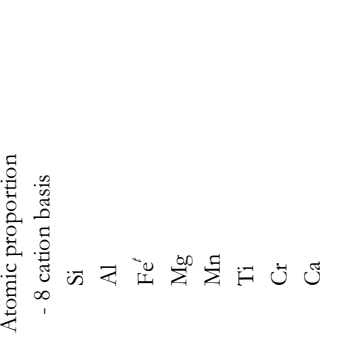 & 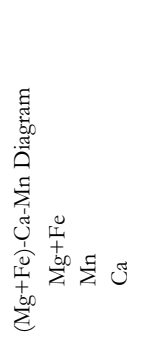 & 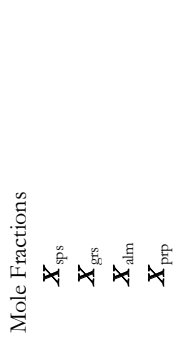 \\
\hline
\end{tabular}




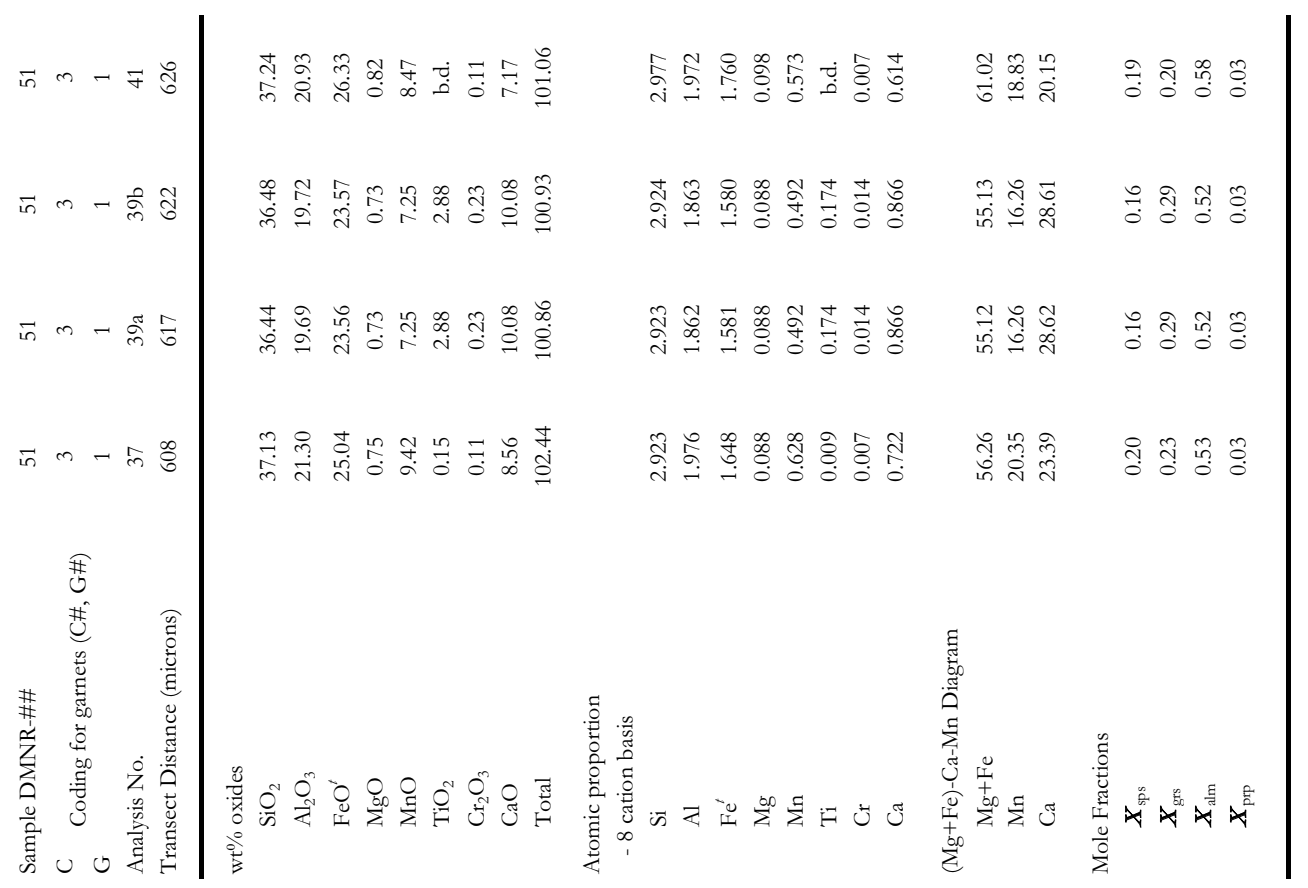




\begin{tabular}{|c|c|c|c|c|}
\hline$\infty-\cdots \sqrt{\circ}$ & 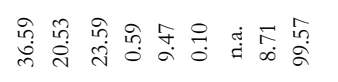 & 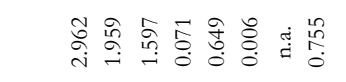 & רิ & 공 송 종 \\
\hline 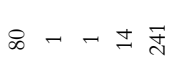 & 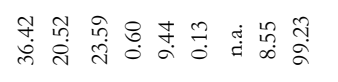 & 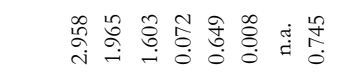 & 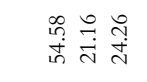 & 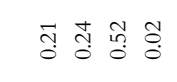 \\
\hline$\infty-\cdots \bar{d}$ & 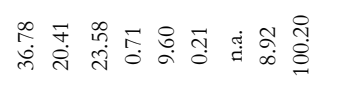 & 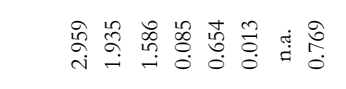 & 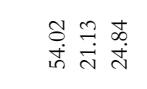 & त्र \\
\hline$\infty--\simeq \overline{\text { ก }}$ & 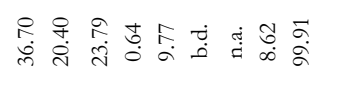 & 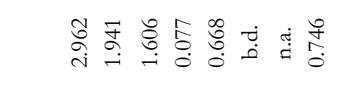 & 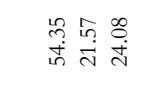 & ปู \\
\hline$\infty-\neg \vec{\infty}$ & 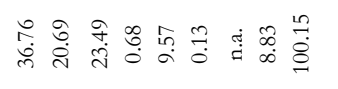 & 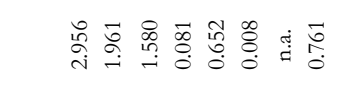 & 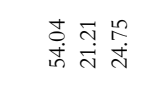 & तु \\
\hline 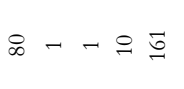 & 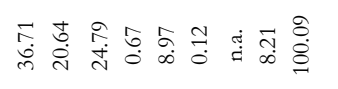 & 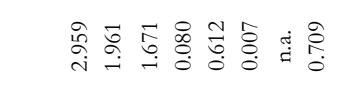 & 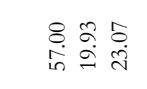 & तิำ สู่ \\
\hline$\varnothing--\sigma \exists$ & 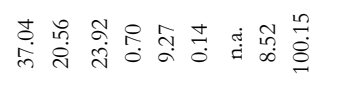 & 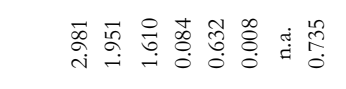 & 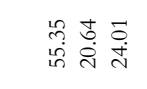 & 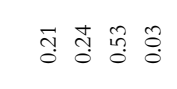 \\
\hline$\infty--\infty \vec{\beth}$ & 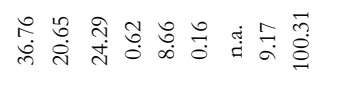 & 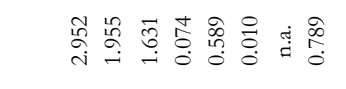 & 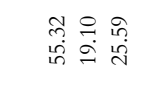 & 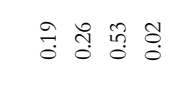 \\
\hline 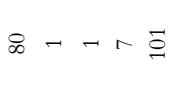 & 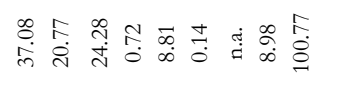 & 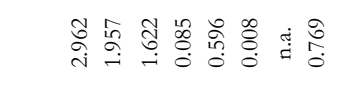 & 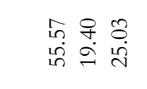 & 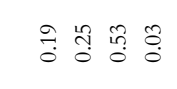 \\
\hline$\infty-\infty \bar{\infty}$ & 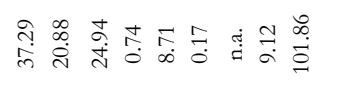 & 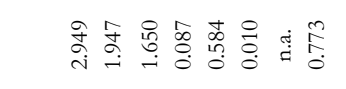 & 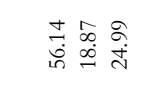 & 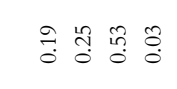 \\
\hline$\infty-\ldots$ in & 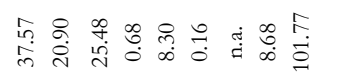 & 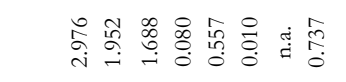 & 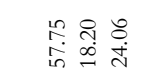 & 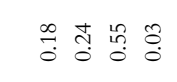 \\
\hline$\Phi-r+2$ & 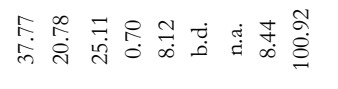 & 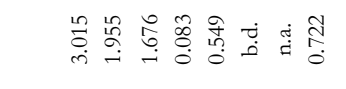 & 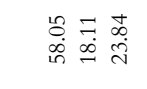 & 文 范 $\stackrel{n}{0} \stackrel{0}{0} \stackrel{0}{0}$ \\
\hline$\infty--m$ & 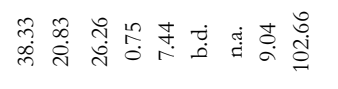 & 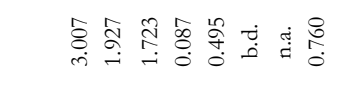 & 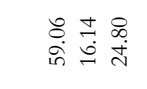 & 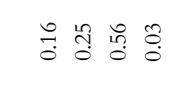 \\
\hline $8-a \stackrel{4}{\infty}$ & 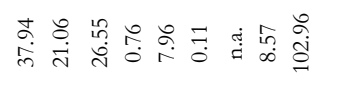 & 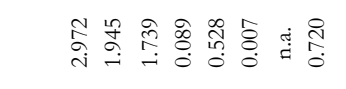 & 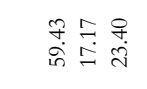 & 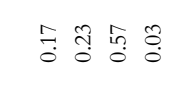 \\
\hline$\infty-\because \bar{\lambda}$ & 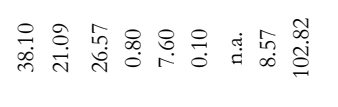 & 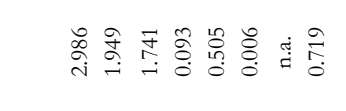 & 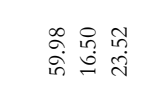 & 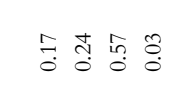 \\
\hline$\infty-\cdots=$ & 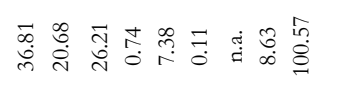 & 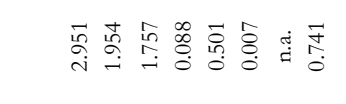 & 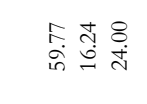 & 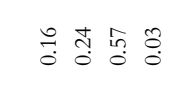 \\
\hline$\infty--\cong 0$ & 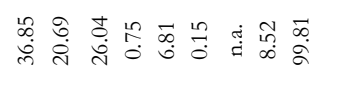 & 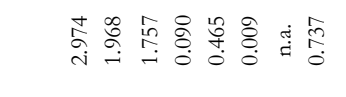 & 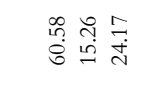 & 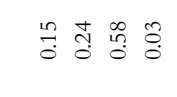 \\
\hline 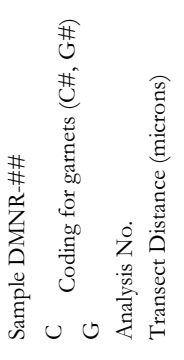 & 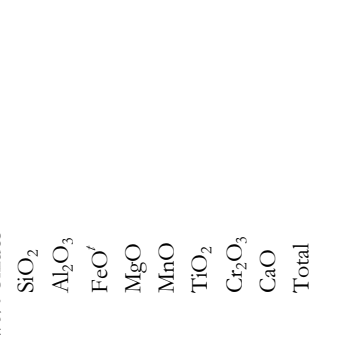 & 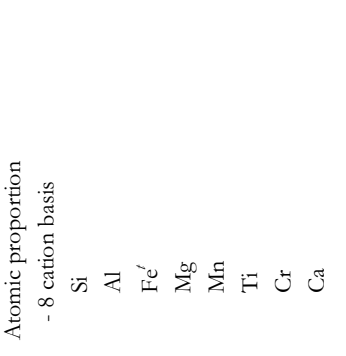 & 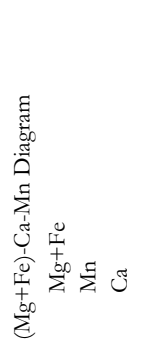 & 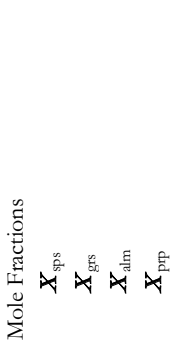 \\
\hline
\end{tabular}




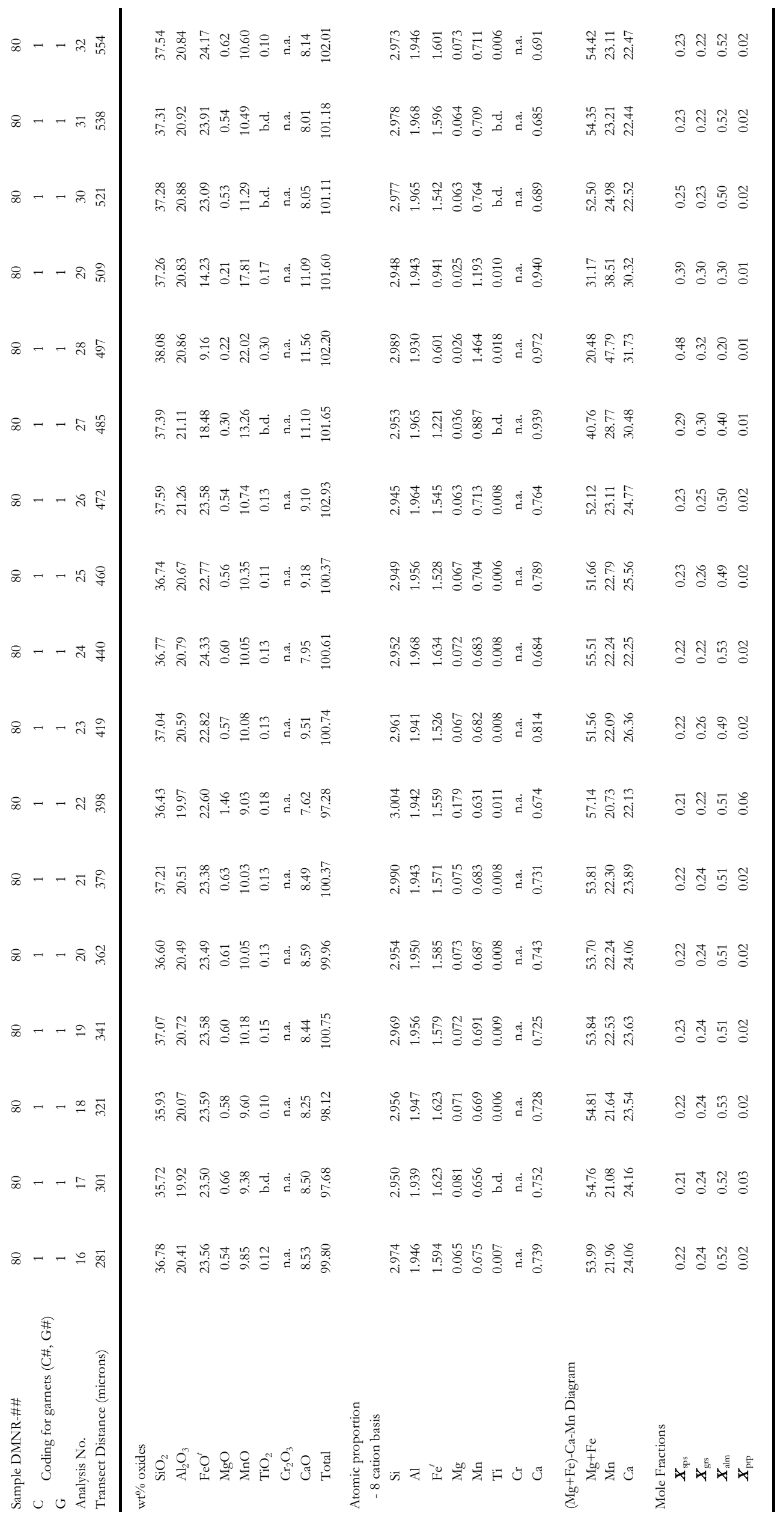




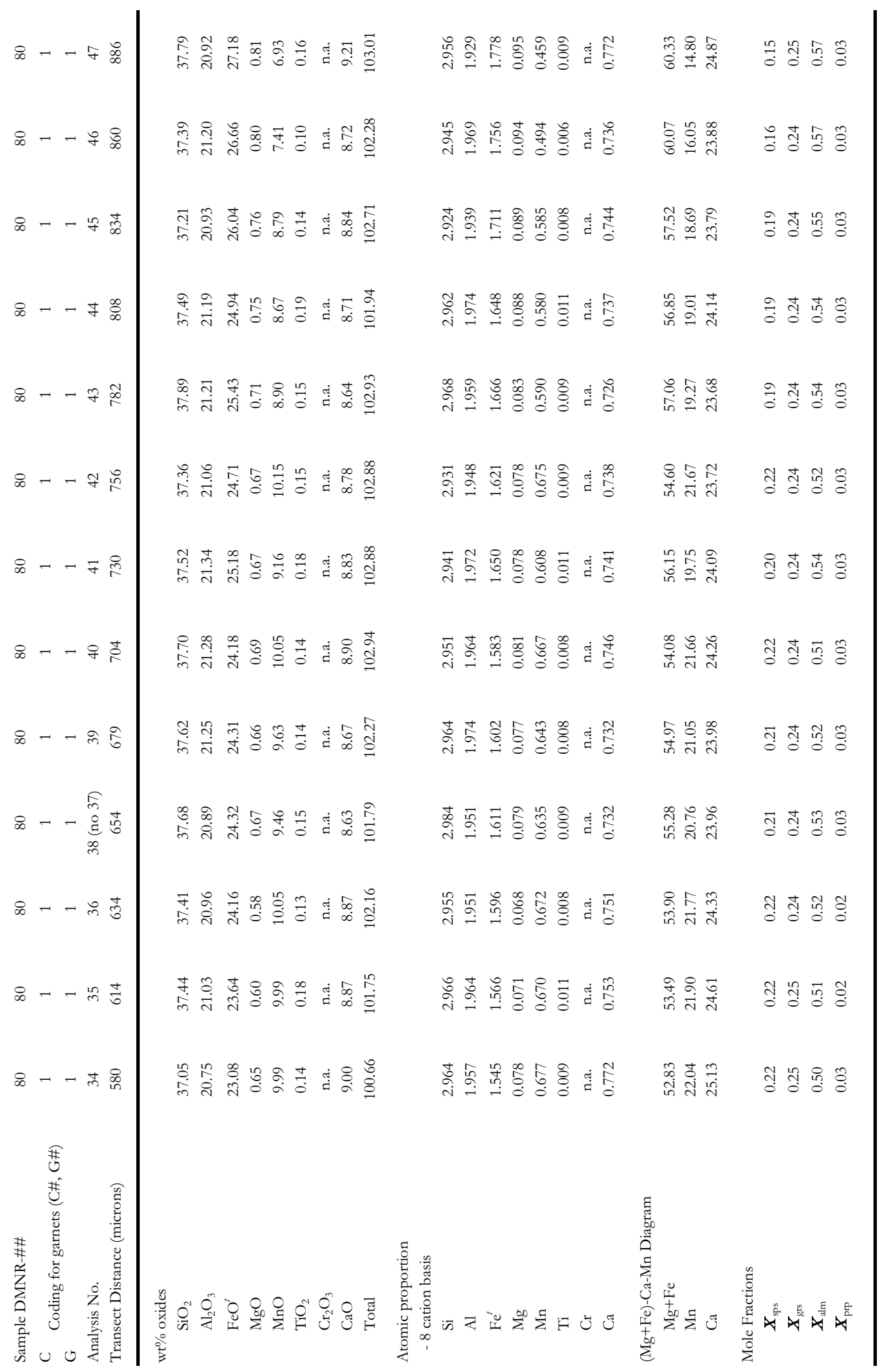




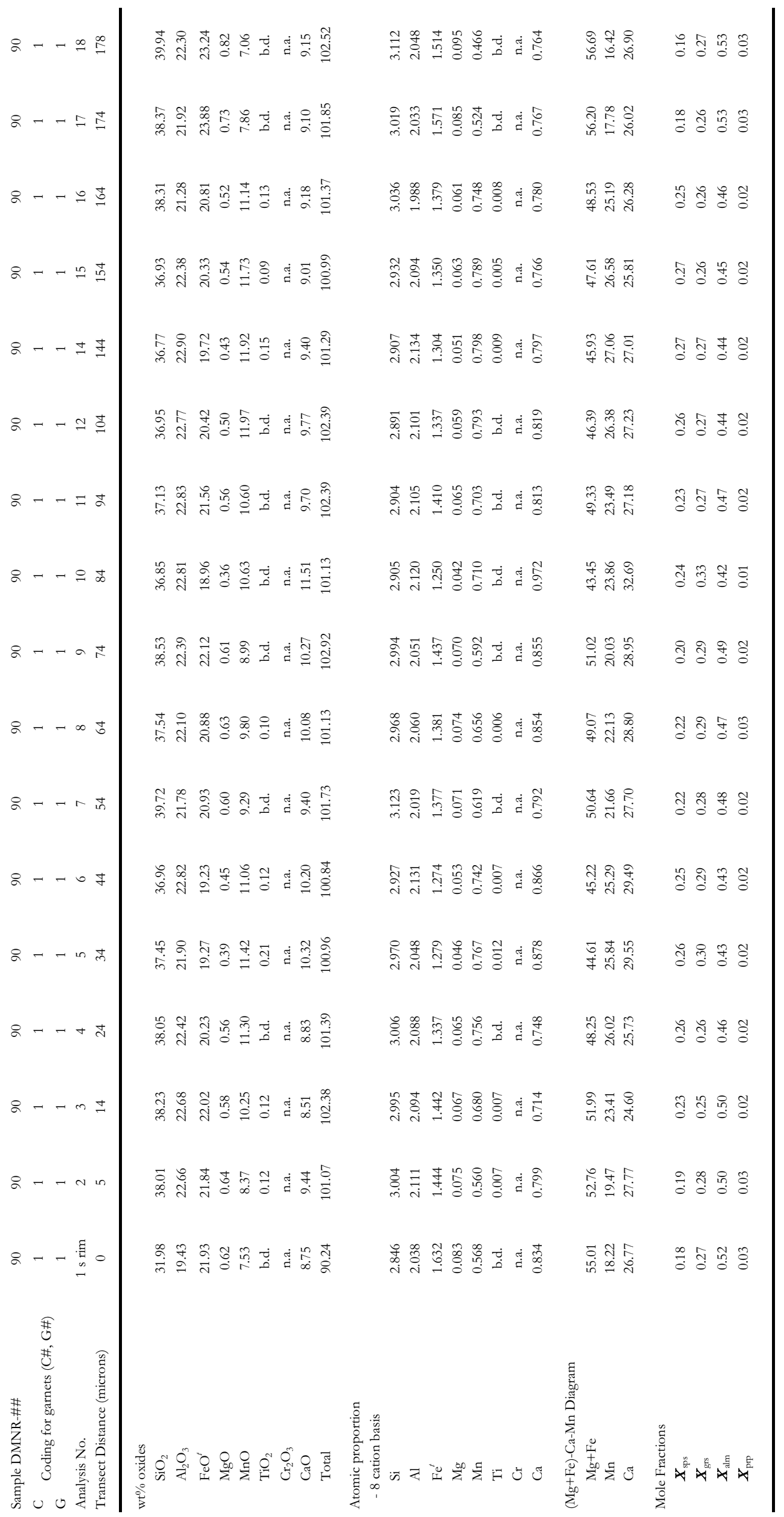




\begin{tabular}{|c|c|c|c|c|}
\hline $2 m-E=5$ & 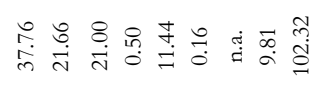 & 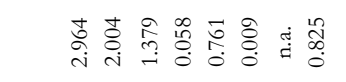 & 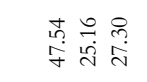 & 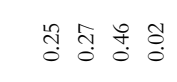 \\
\hline \&n-욤 & 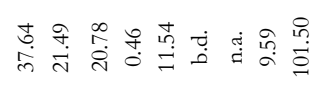 & 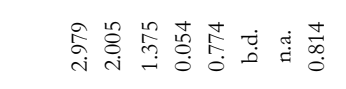 & 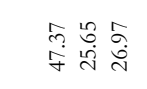 & 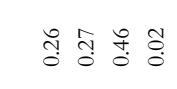 \\
\hline $8 m-n$ & 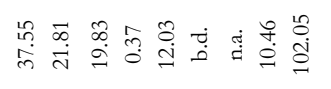 & 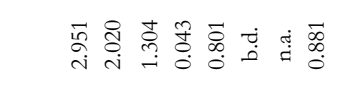 & 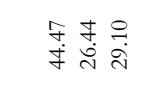 & 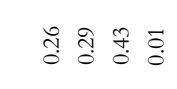 \\
\hline \&n-士志 & 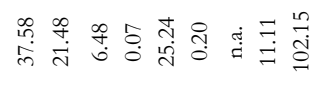 & 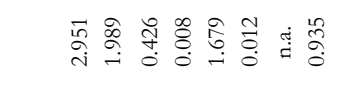 & 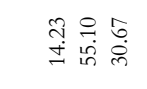 & 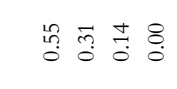 \\
\hline$\therefore m-2 \stackrel{t}{=}$ & 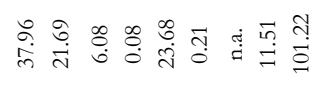 & 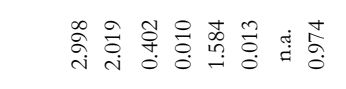 & 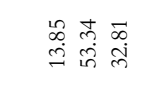 & กู่ \\
\hline$\& m-\simeq \stackrel{\varrho}{=}$ & 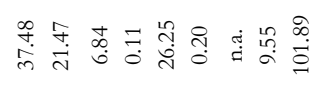 & 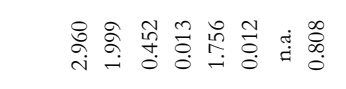 & 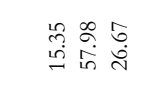 & $\stackrel{\infty}{\leftrightarrow}$ \\
\hline$\therefore n-z a$ & 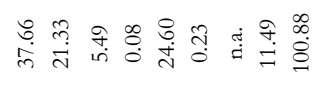 & 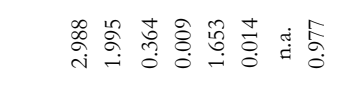 & 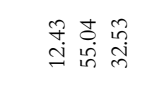 & 惩 \\
\hline $2 m-\odot \infty$ & 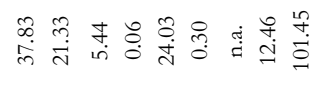 & 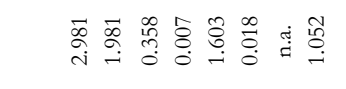 & 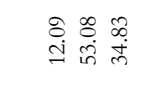 & กี่ \\
\hline$a m-a n$ & 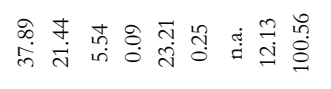 & 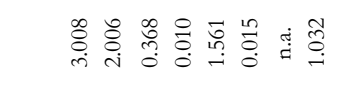 & 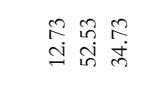 & ก̂. \\
\hline $2 n-\infty \beta$ & 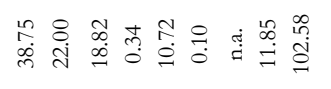 & 苛 完 苻 & 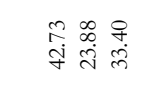 & 荙 \\
\hline$\therefore m-r$ in & 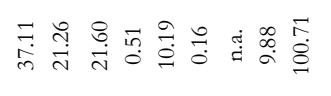 & 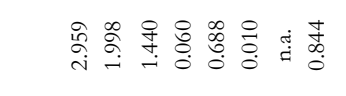 & 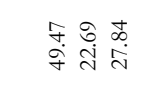 & તุ่ \\
\hline $8 m-0 q$ & 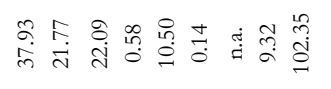 & 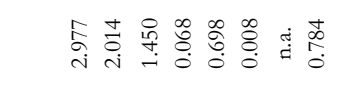 & 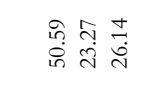 & 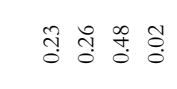 \\
\hline $2 m-\ln m$ & 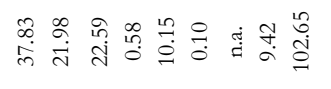 & 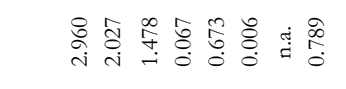 & 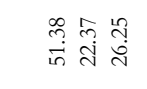 & 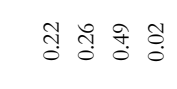 \\
\hline $8 m-+\infty$ & 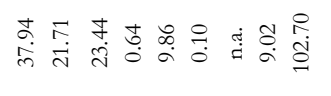 & 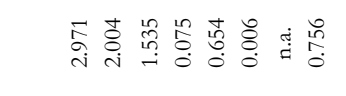 & 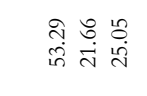 & đ્ำ \\
\hline $2 n-m n$ & 岩 号 & 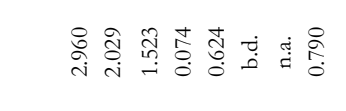 & लिं & 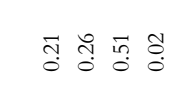 \\
\hline $8 m-4$ in & 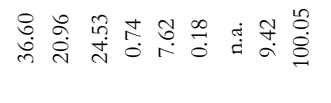 & 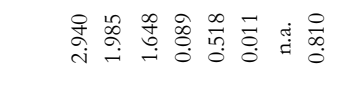 & 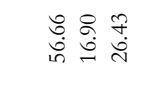 & 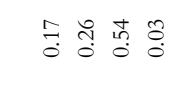 \\
\hline \&の一酋。 & 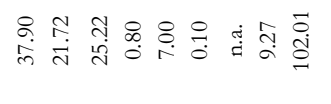 & 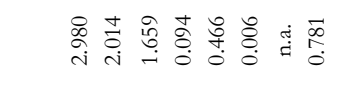 & 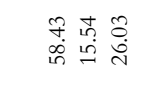 & $\stackrel{ }{\circ} \stackrel{0}{0} \stackrel{n}{0} \stackrel{n}{0} \stackrel{0}{0}$ \\
\hline 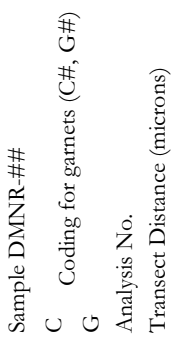 & के & 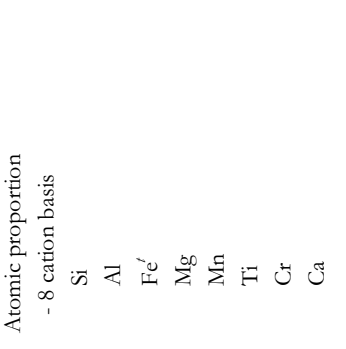 & 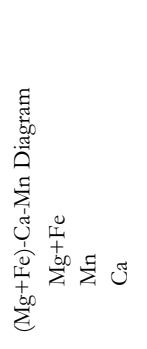 & 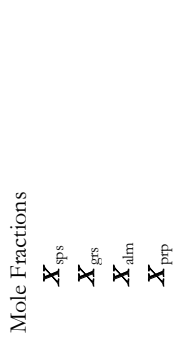 \\
\hline
\end{tabular}




\begin{tabular}{|c|c|c|c|c|}
\hline 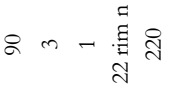 & 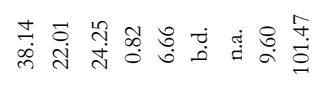 & 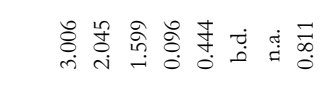 & 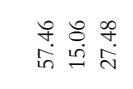 & 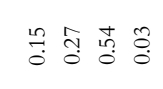 \\
\hline $8 m-\overline{4} \stackrel{n}{a}$ & 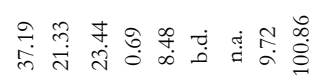 & 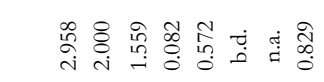 & 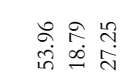 & 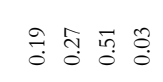 \\
\hline $8 m-\frac{4}{7}$ & 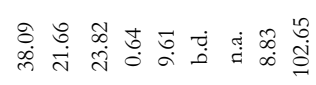 & 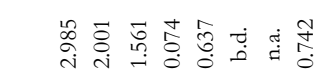 & 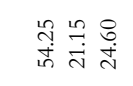 & तี่ \\
\hline$\& m-2 \pm$ & 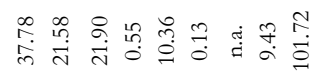 & 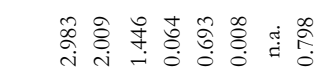 & 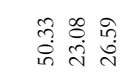 & 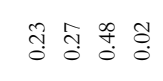 \\
\hline \&n- $\stackrel{\infty}{\sim}$ & 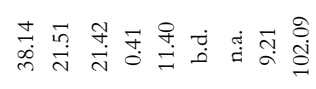 & 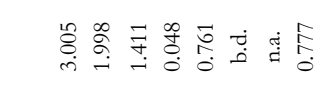 & 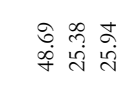 & 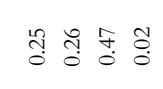 \\
\hline 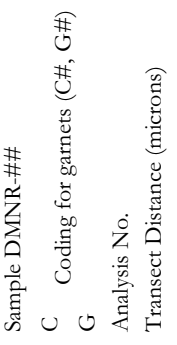 & $\begin{array}{lll}0 \\
0\end{array}$ & 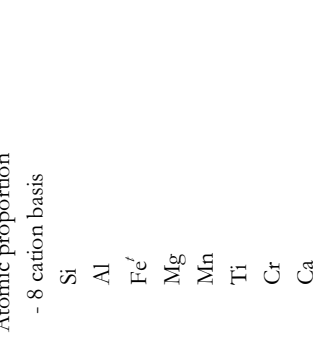 & 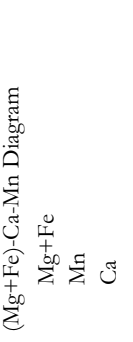 & 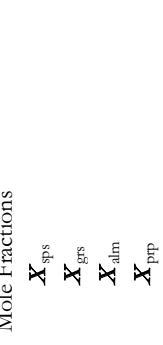 \\
\hline
\end{tabular}




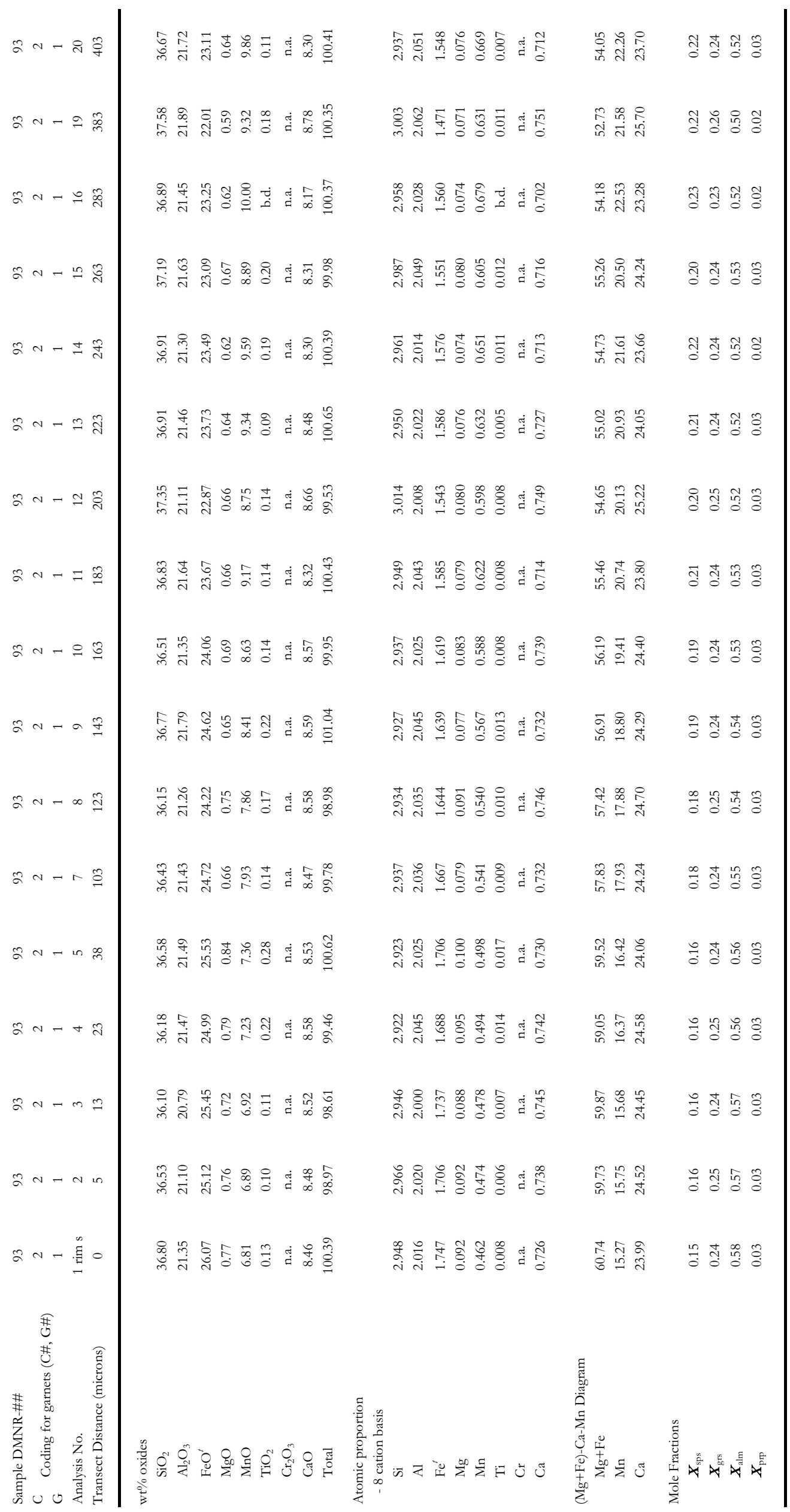




\begin{tabular}{|c|c|c|c|c|}
\hline gat a 的早 & 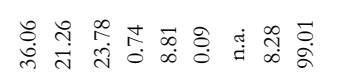 & 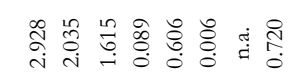 & đี่ & 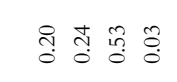 \\
\hline$g a-m$ & 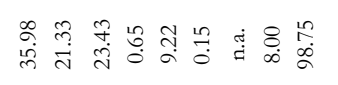 & 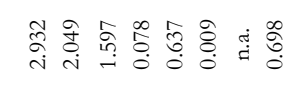 & 总 & तี่ \\
\hline ñ $N-m$ & 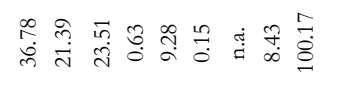 & 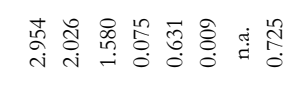 & 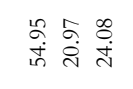 & तु \\
\hline হぇ & 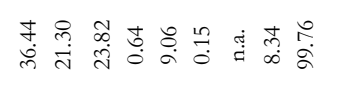 & 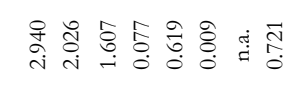 & 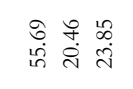 & 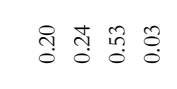 \\
\hline ñ $\sim$ m & 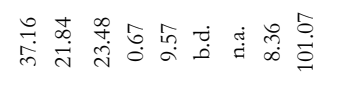 & 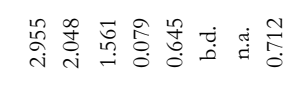 & 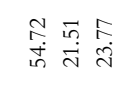 & ปู่ \\
\hline న $\sim-\tilde{m}$ & 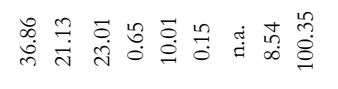 & 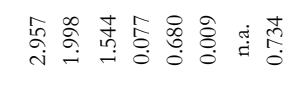 & 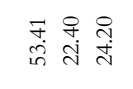 & ปิ \\
\hline ूn & 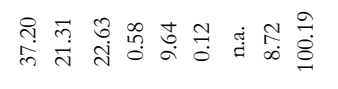 & 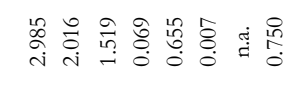 & 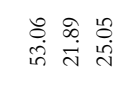 & 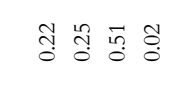 \\
\hline nn & 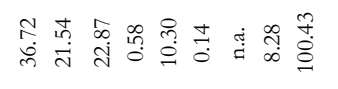 & 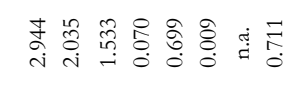 & 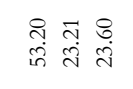 & 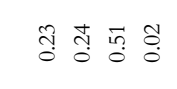 \\
\hline 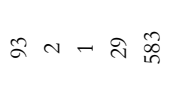 & 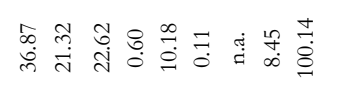 & ơ⿱ & 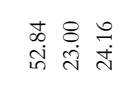 & 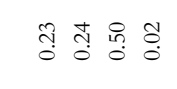 \\
\hline$\Re \sim-\infty$ & 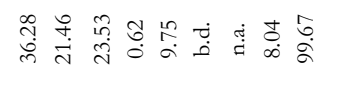 & 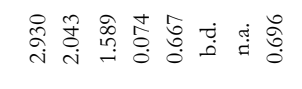 & 常 & ปี สู่ \\
\hline תar & 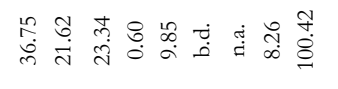 & 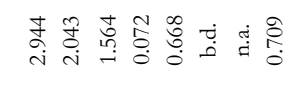 & 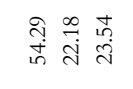 & ปู่ ป⿱一兀 \\
\hline 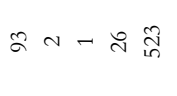 & 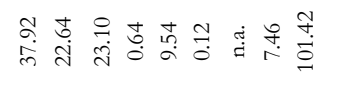 & 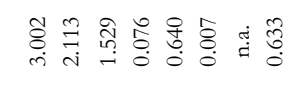 & 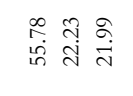 & 종 สู่ \\
\hline ฉָ & 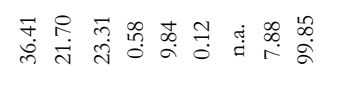 & 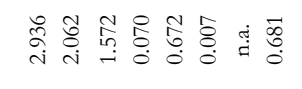 & $\begin{array}{ll}0 \\
0 \\
0 \\
0 \\
0\end{array}$ & สู่ สู่ \\
\hline 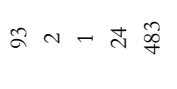 & 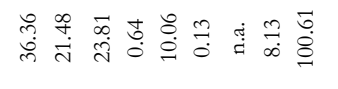 & 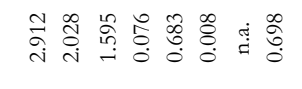 & 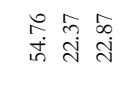 & สู สู่ \\
\hline man-a d & 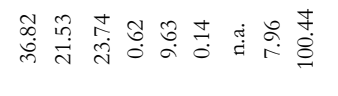 & 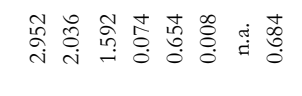 & 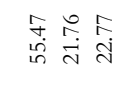 & สุ่ \\
\hline$g u-4 \frac{7}{2}$ & 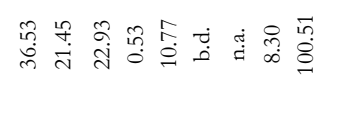 & 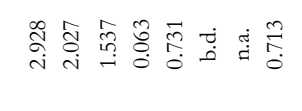 & i⿱ & ปี่ तึ่ \\
\hline 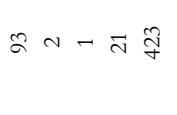 & స్ల్ & 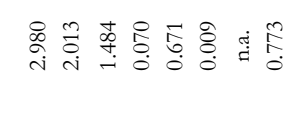 & 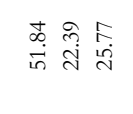 & 공 귱 : \\
\hline 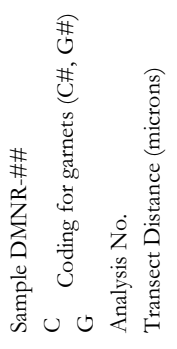 & $\approx 0$ & 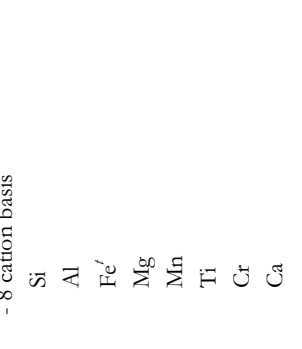 & 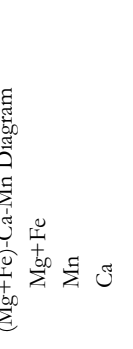 & 惫 \\
\hline
\end{tabular}




\begin{tabular}{|c|c|c|c|c|}
\hline תaー子去 & 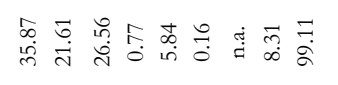 & 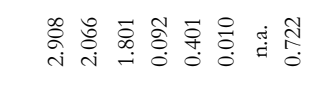 & 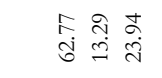 & 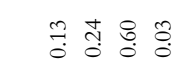 \\
\hline 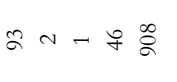 & 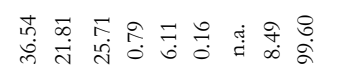 & 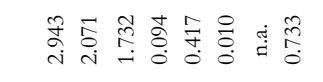 & 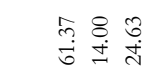 & 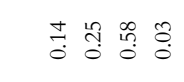 \\
\hline 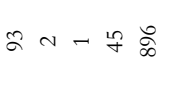 & 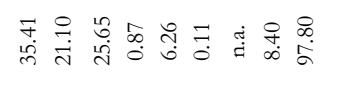 & 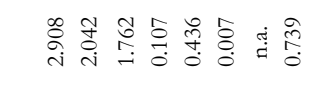 & 导勇労 & 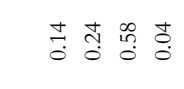 \\
\hline$\Omega \sim-ま \underset{\infty}{\$}$ & 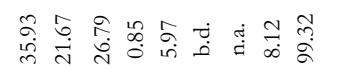 & 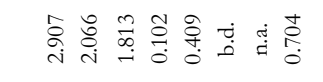 & 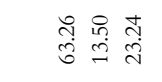 & 苛 \\
\hline 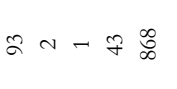 & 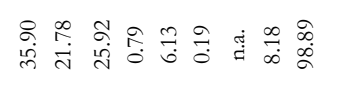 & 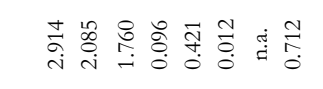 & 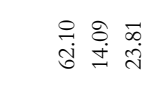 & 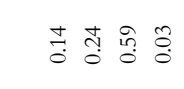 \\
\hline 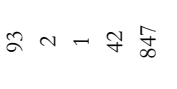 & 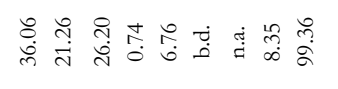 & 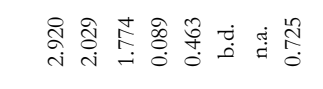 & 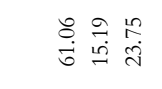 & 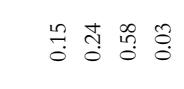 \\
\hline$\Omega a-F \bar{\infty}$ & 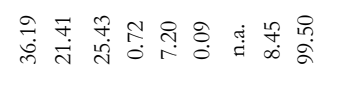 & 芯 & 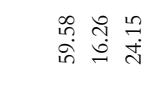 & 융 đa \\
\hline 凤n- & 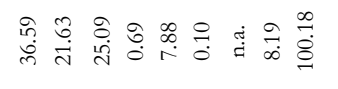 & 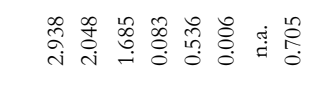 & 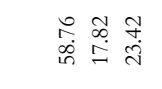 & 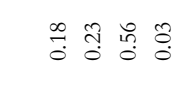 \\
\hline$\approx n-\infty \bar{\infty}$ & 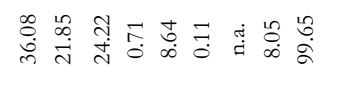 & 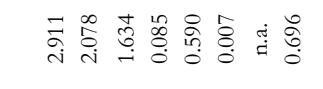 & 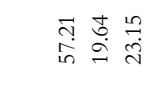 & 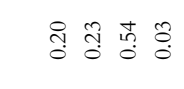 \\
\hline $2 a-\infty$ & 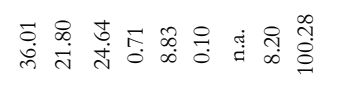 & 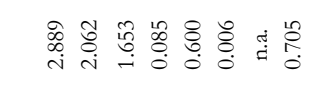 & 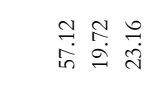 & శ్తి శ్రి \\
\hline 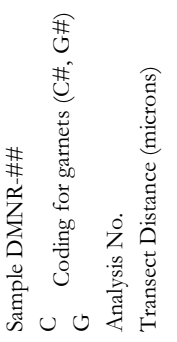 & 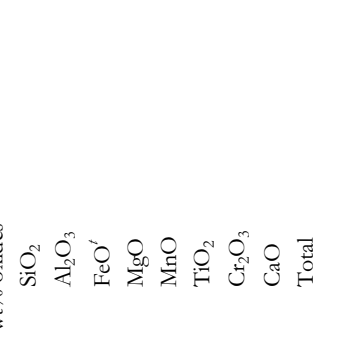 & 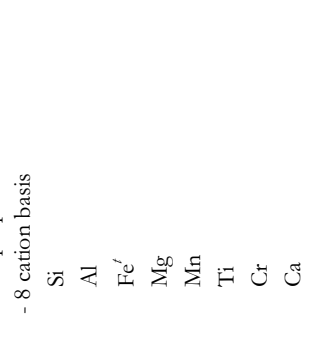 & 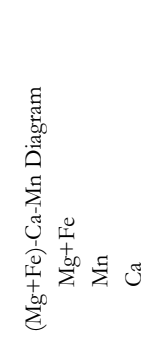 & 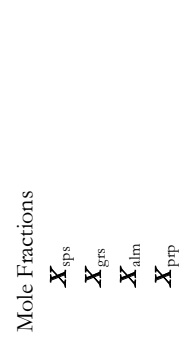 \\
\hline
\end{tabular}




\begin{tabular}{|c|c|c|c|c|}
\hline 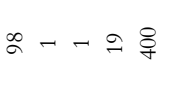 & 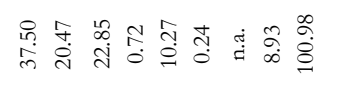 & 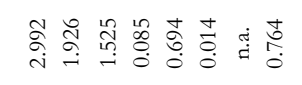 & 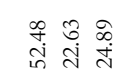 & สุ่ \\
\hline$\stackrel{\infty}{\infty}-\infty \stackrel{t}{=}$ & 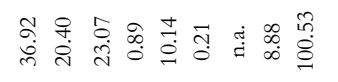 & 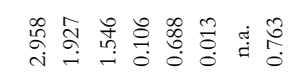 & 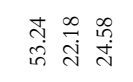 & 종 중 융 \\
\hline$\infty$ & 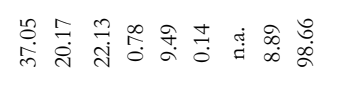 & 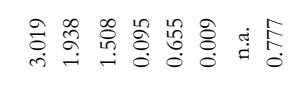 & 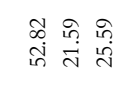 & ปูำ \\
\hline$\stackrel{\infty}{\infty}-\stackrel{m}{m}$ & 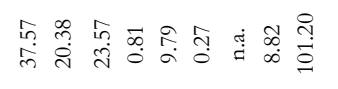 & 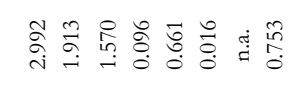 & 总导管 & त్ \\
\hline 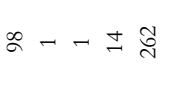 & 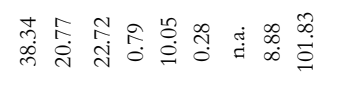 & 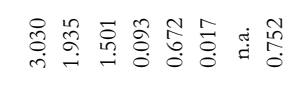 & 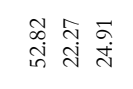 & 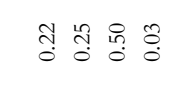 \\
\hline$\stackrel{\infty}{\infty}-\simeq \stackrel{4}{\sim}$ & 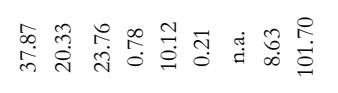 & 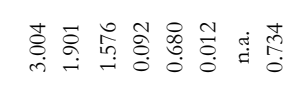 & 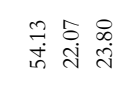 & 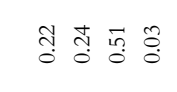 \\
\hline$\infty--=\infty$ & 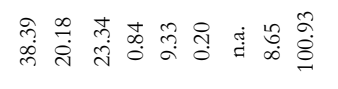 & 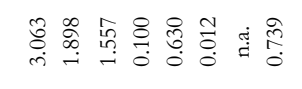 & 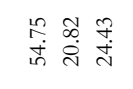 & 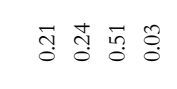 \\
\hline$\infty--\circ]$ & 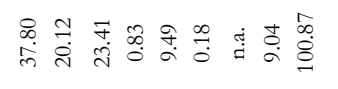 & 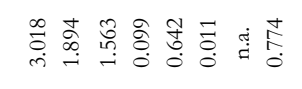 & 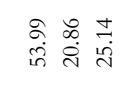 & तु \\
\hline$\stackrel{\infty}{\infty}-\infty \stackrel{\circ}{2}$ & 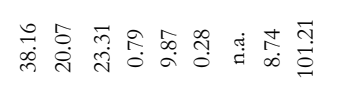 & 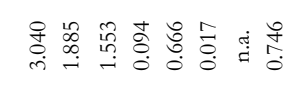 & 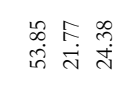 & 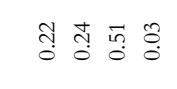 \\
\hline 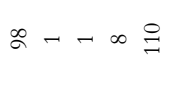 & 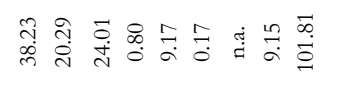 & 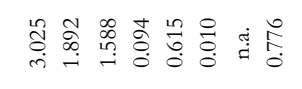 & 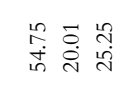 & ชิ \\
\hline$\infty-\neg n$ & 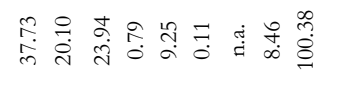 & 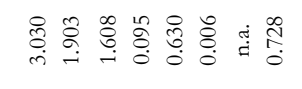 & 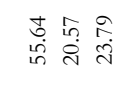 & 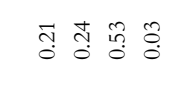 \\
\hline$\infty--\infty 8$ & 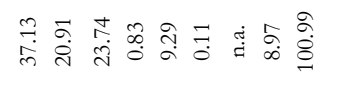 & 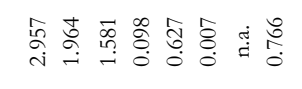 & 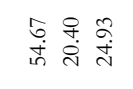 & 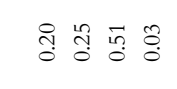 \\
\hline$\infty-\ldots$ in & 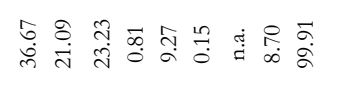 & 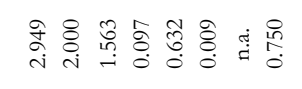 & 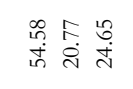 & 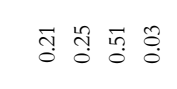 \\
\hline$\stackrel{\infty}{\infty}++\infty$ & 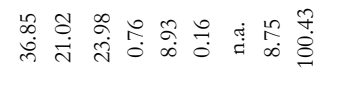 & 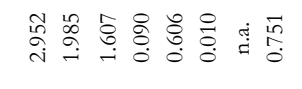 & 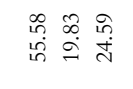 & 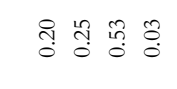 \\
\hline$\infty--m$ व & 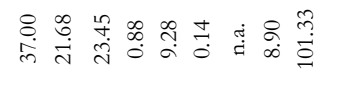 & 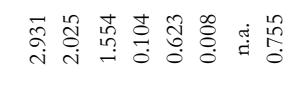 & 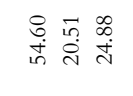 & त्व \\
\hline 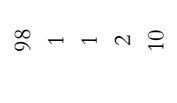 & 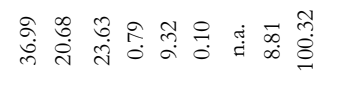 & 总总苫 & 融 & 겅 ํㅗㅇ 종 \\
\hline$\infty-\cdots+$ & 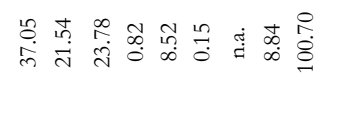 & 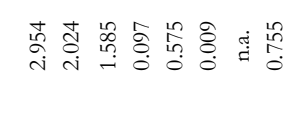 & 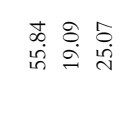 & 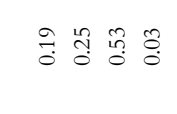 \\
\hline 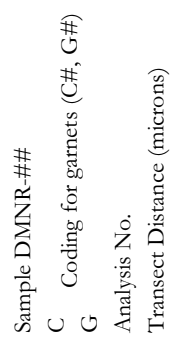 & $=0$ & 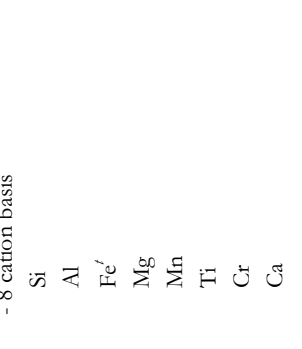 & 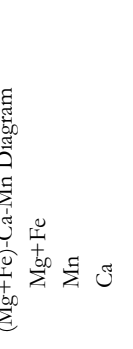 & 惫 \\
\hline
\end{tabular}




\begin{tabular}{|c|c|c|c|c|}
\hline$\infty--\infty$ & 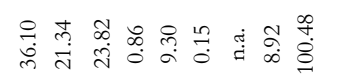 & 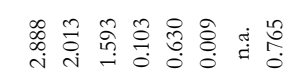 & 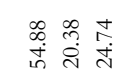 & 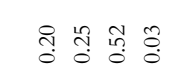 \\
\hline 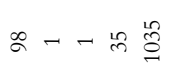 & 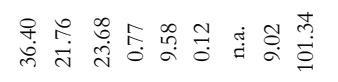 & 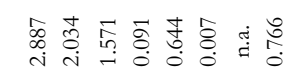 & 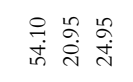 & त्व \\
\hline$\stackrel{\infty}{\infty}-$ + & 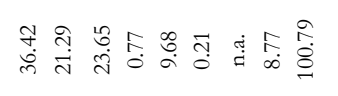 & 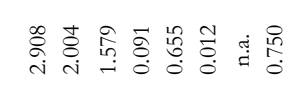 & 至 & 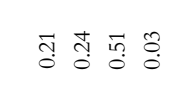 \\
\hline$\infty-\infty \propto$ & 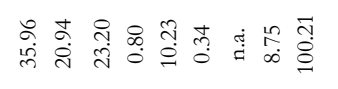 & 品哭 命 & 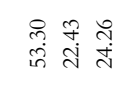 & 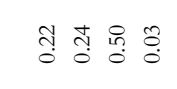 \\
\hline$\infty-\cdots \infty$ & 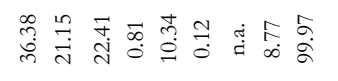 & 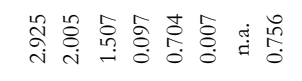 & 节 & 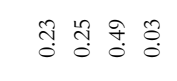 \\
\hline$\infty--\bar{\infty}$ & 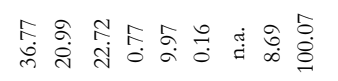 & 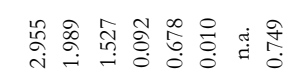 & 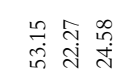 & 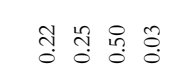 \\
\hline$\infty-\infty \infty_{\infty}^{\infty}$ & 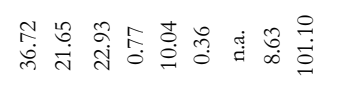 & 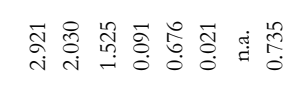 & 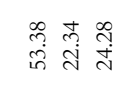 & สู ปู่ \\
\hline 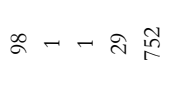 & 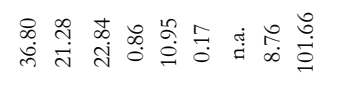 & 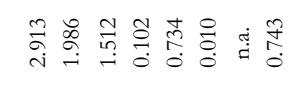 & 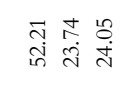 & 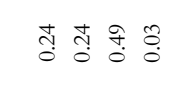 \\
\hline$\stackrel{\infty}{a}-\infty \stackrel{\infty}{i}$ & مُ & 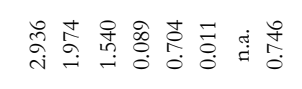 & 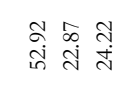 & 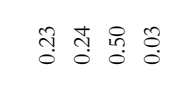 \\
\hline$\infty$ & 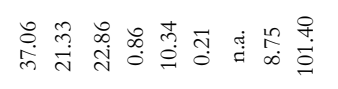 & 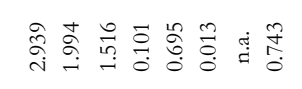 & 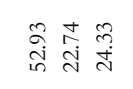 & તิ: \\
\hline$\infty--\infty$ & $\begin{array}{l}\infty \\
0 \\
0 \\
0\end{array}$ & 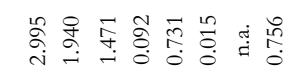 & 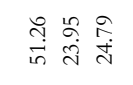 & 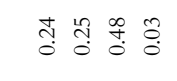 \\
\hline $2--125$ & 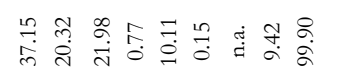 & 怘 & 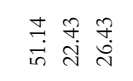 & 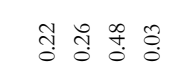 \\
\hline 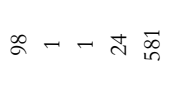 & 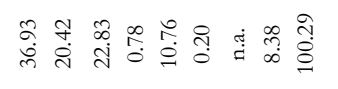 & 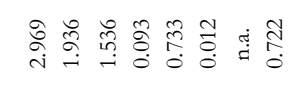 & 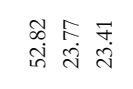 & ป⿱艹 \\
\hline$\infty-\infty i$ & 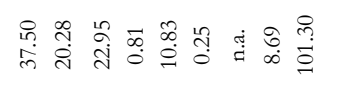 & 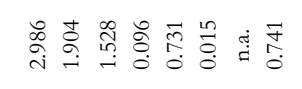 & 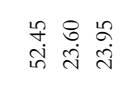 & 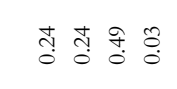 \\
\hline 舟- & 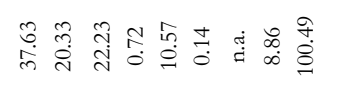 & 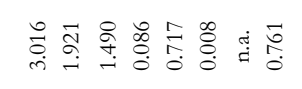 & 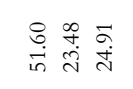 & తึ่ \\
\hline 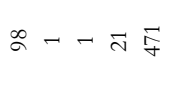 & 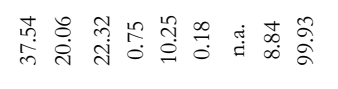 & 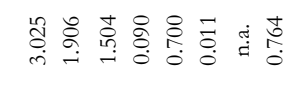 & 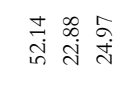 & 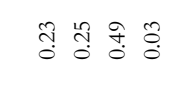 \\
\hline œ- - ণ ণ্ণ & 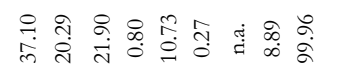 & 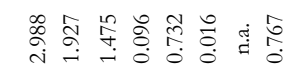 & 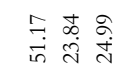 & 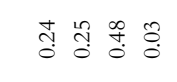 \\
\hline 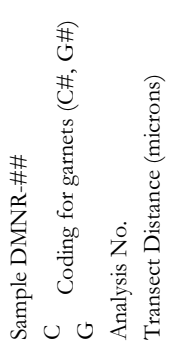 & $\approx C$ & 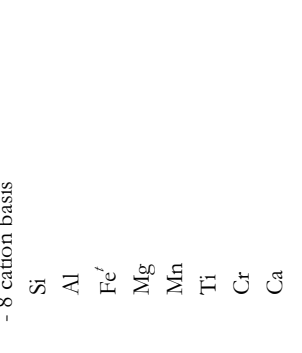 & 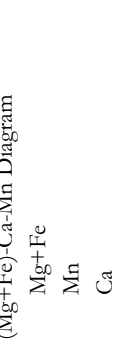 & 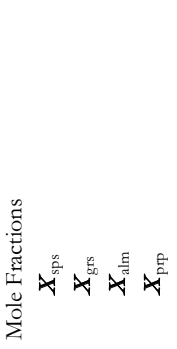 \\
\hline
\end{tabular}




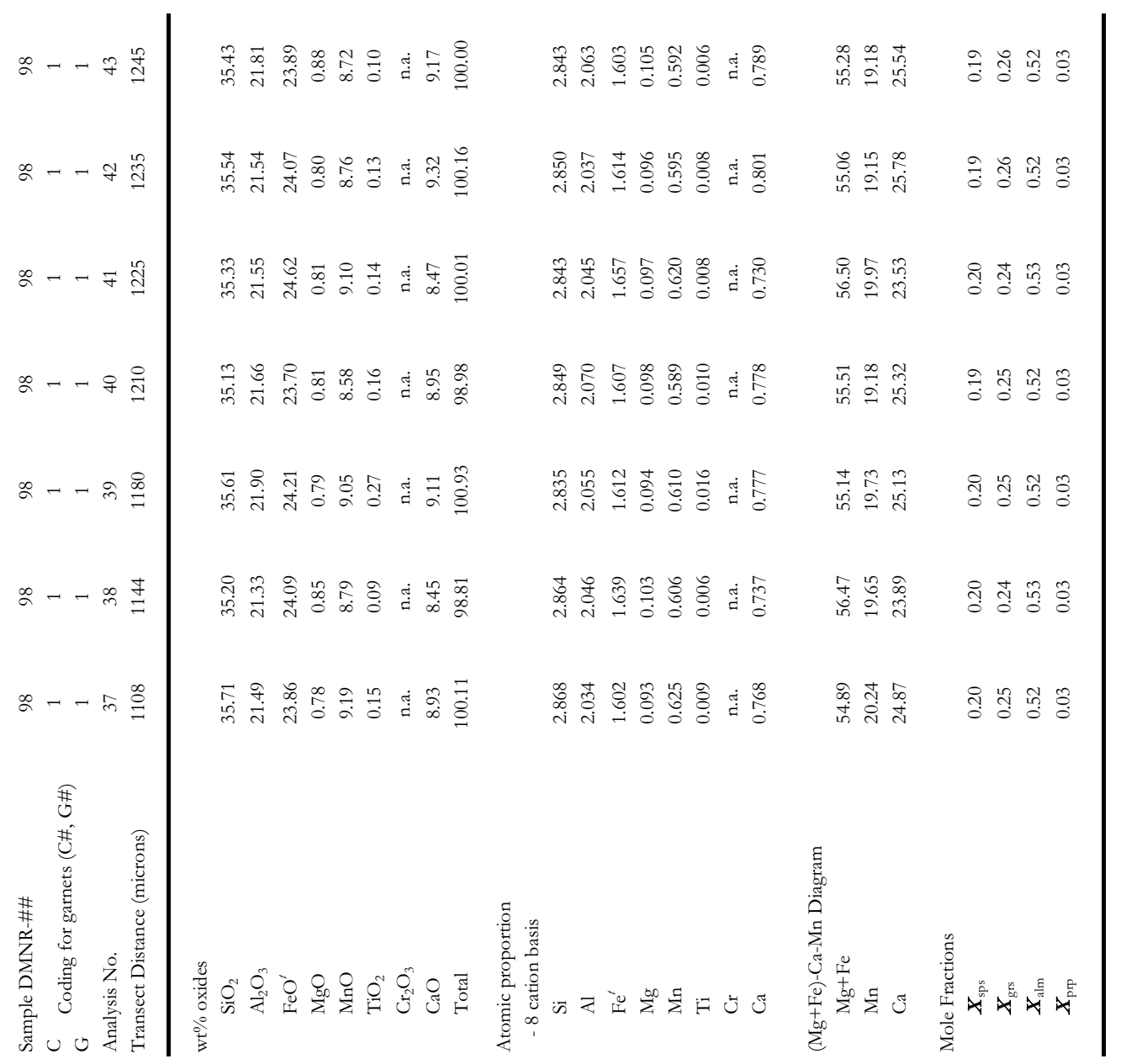




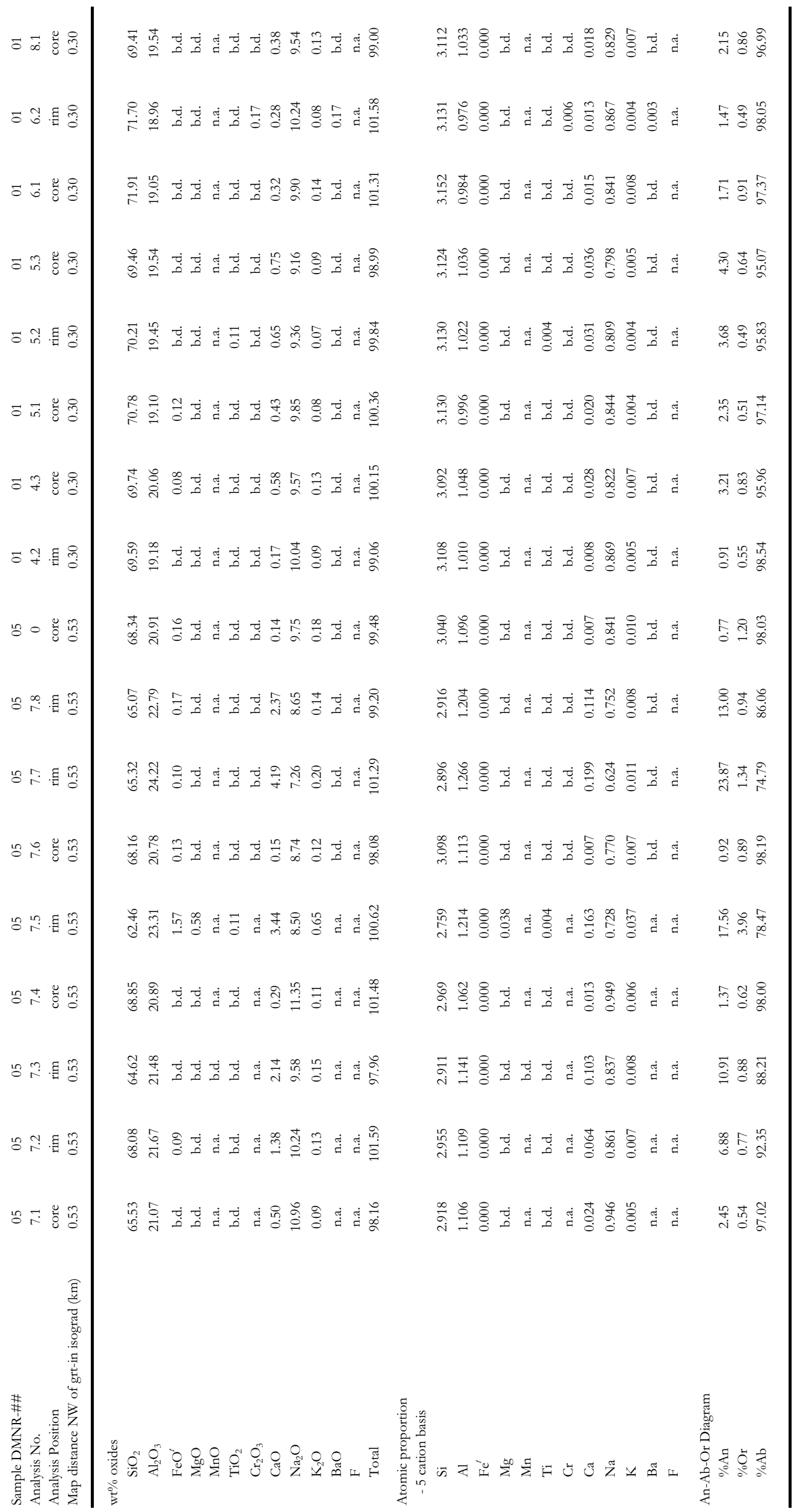




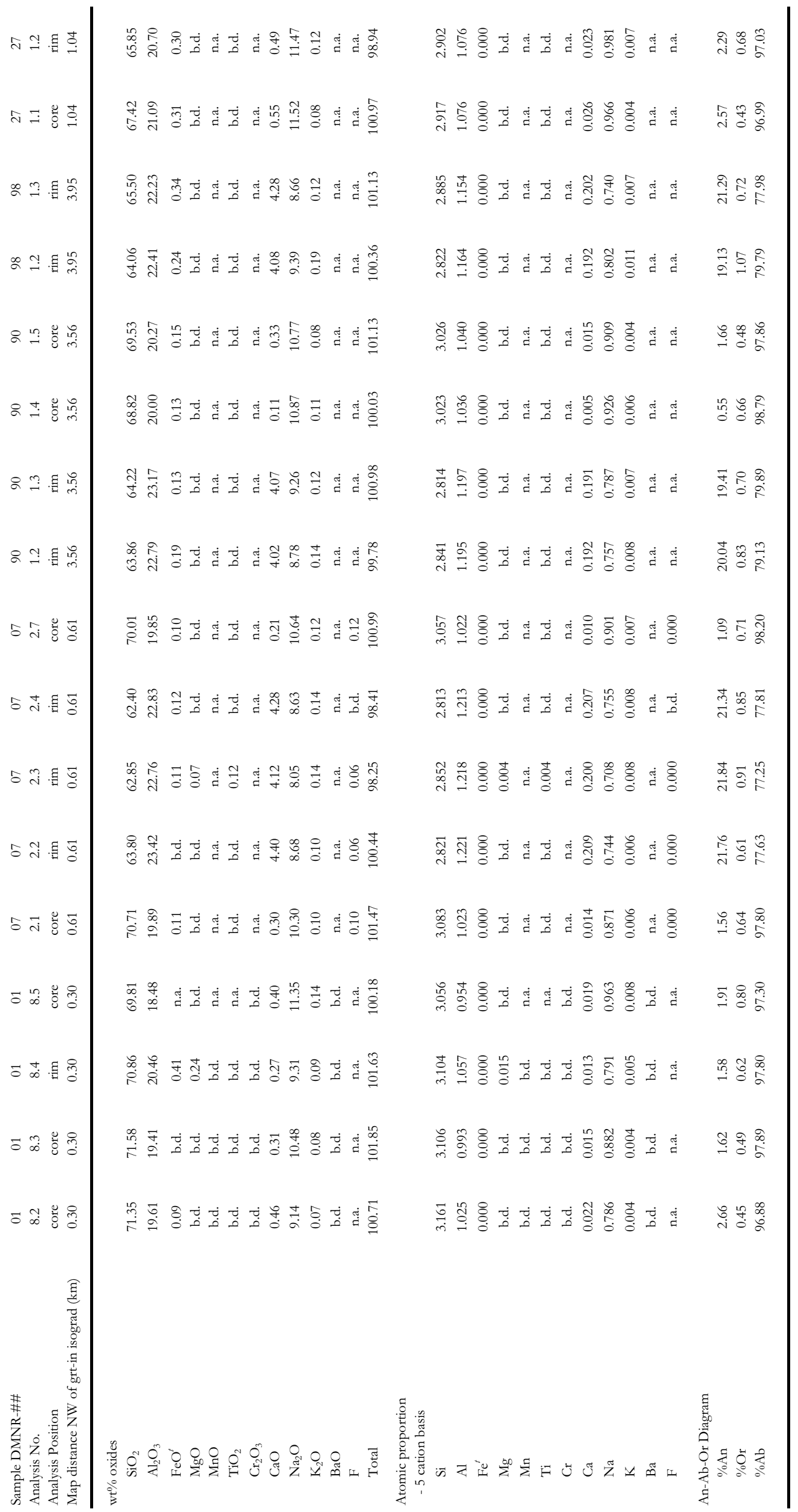




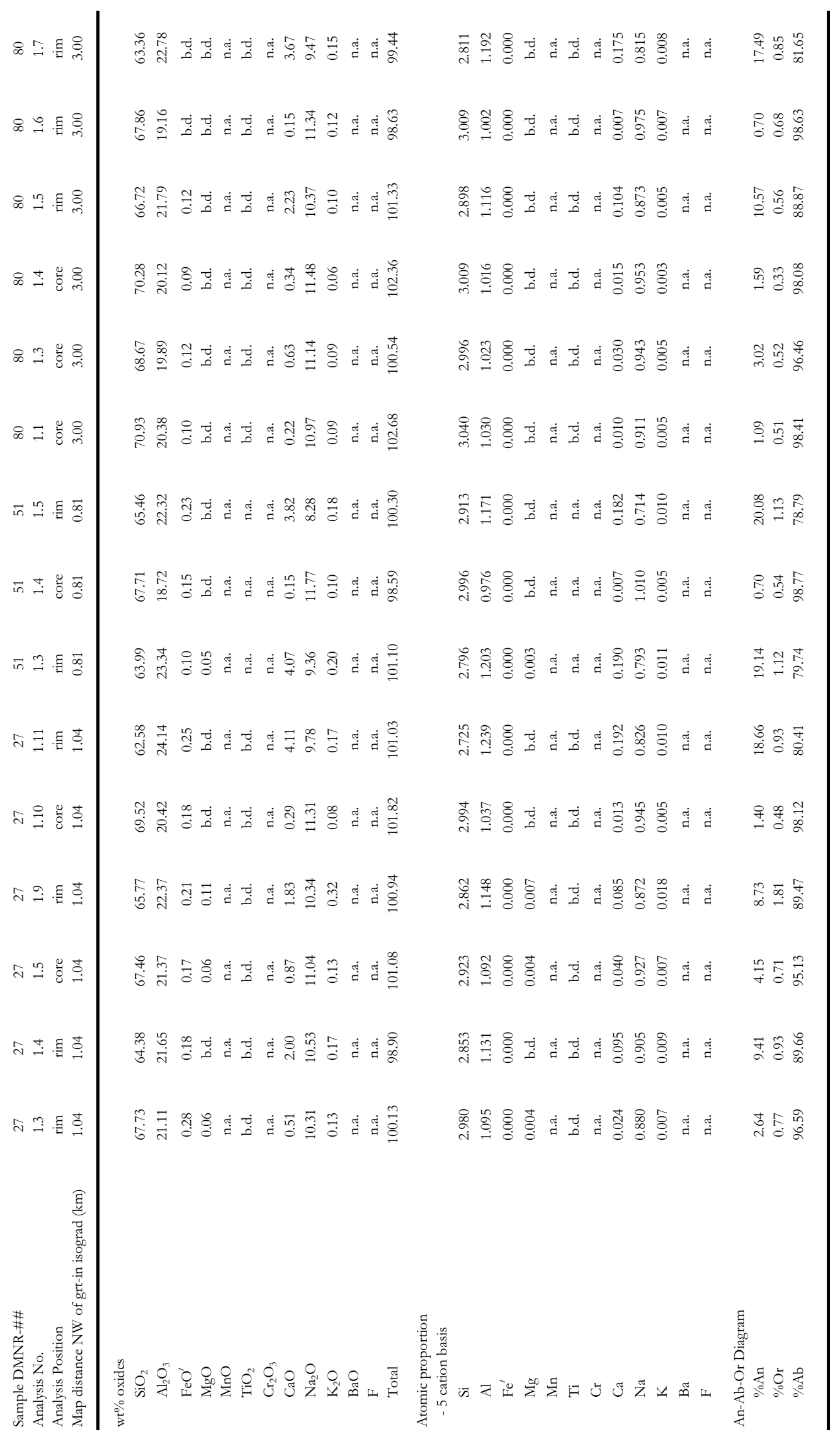




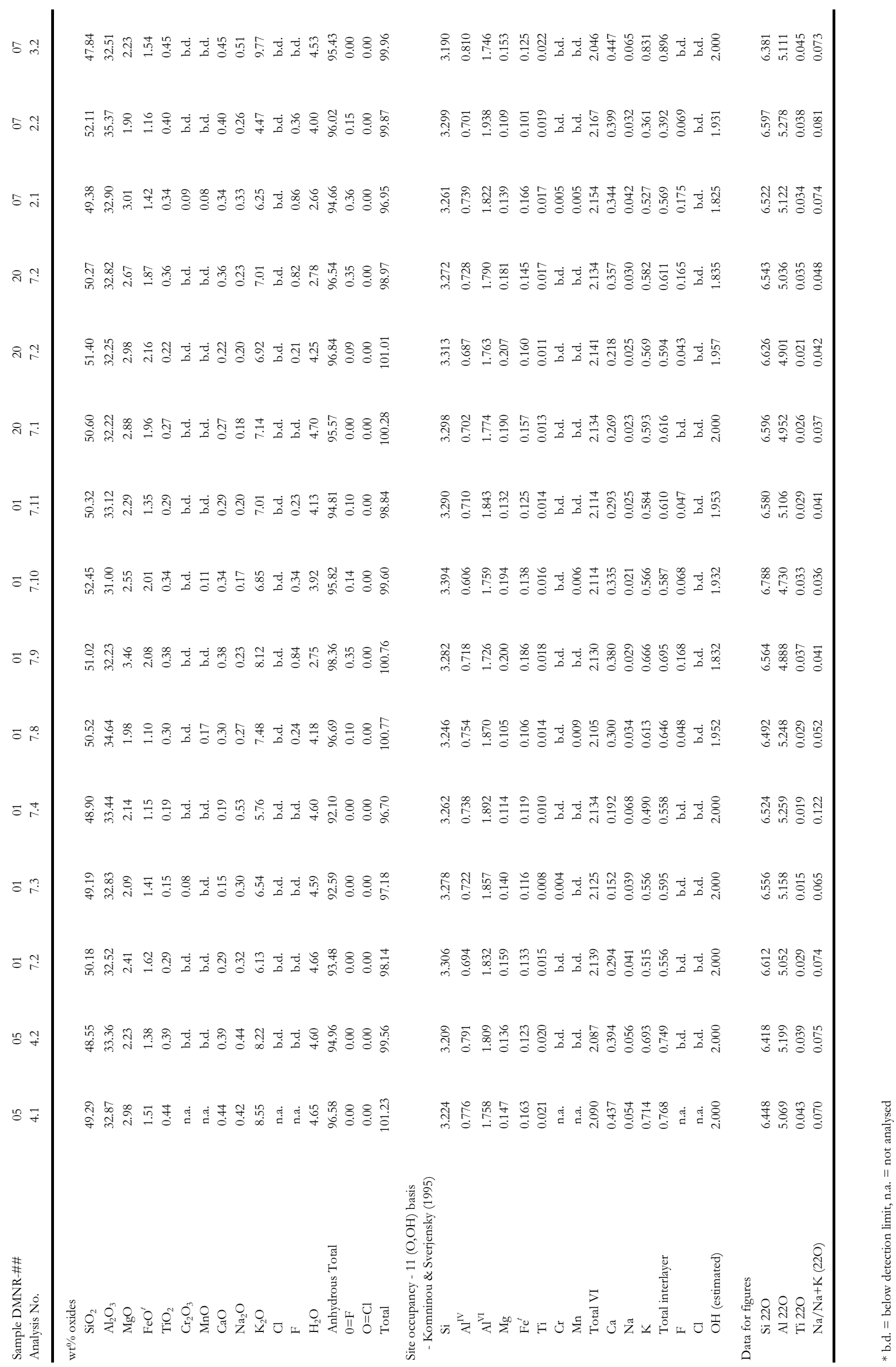




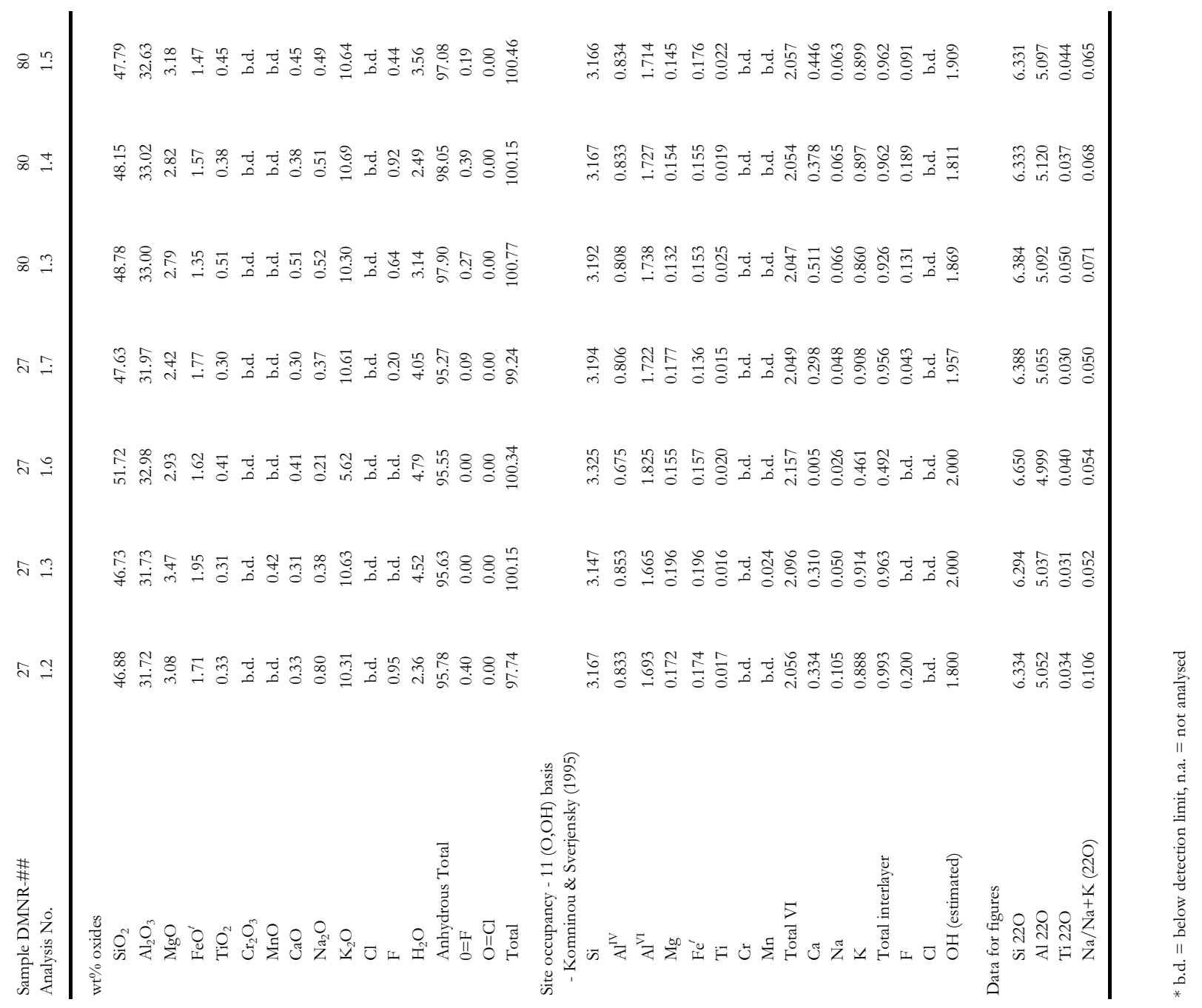




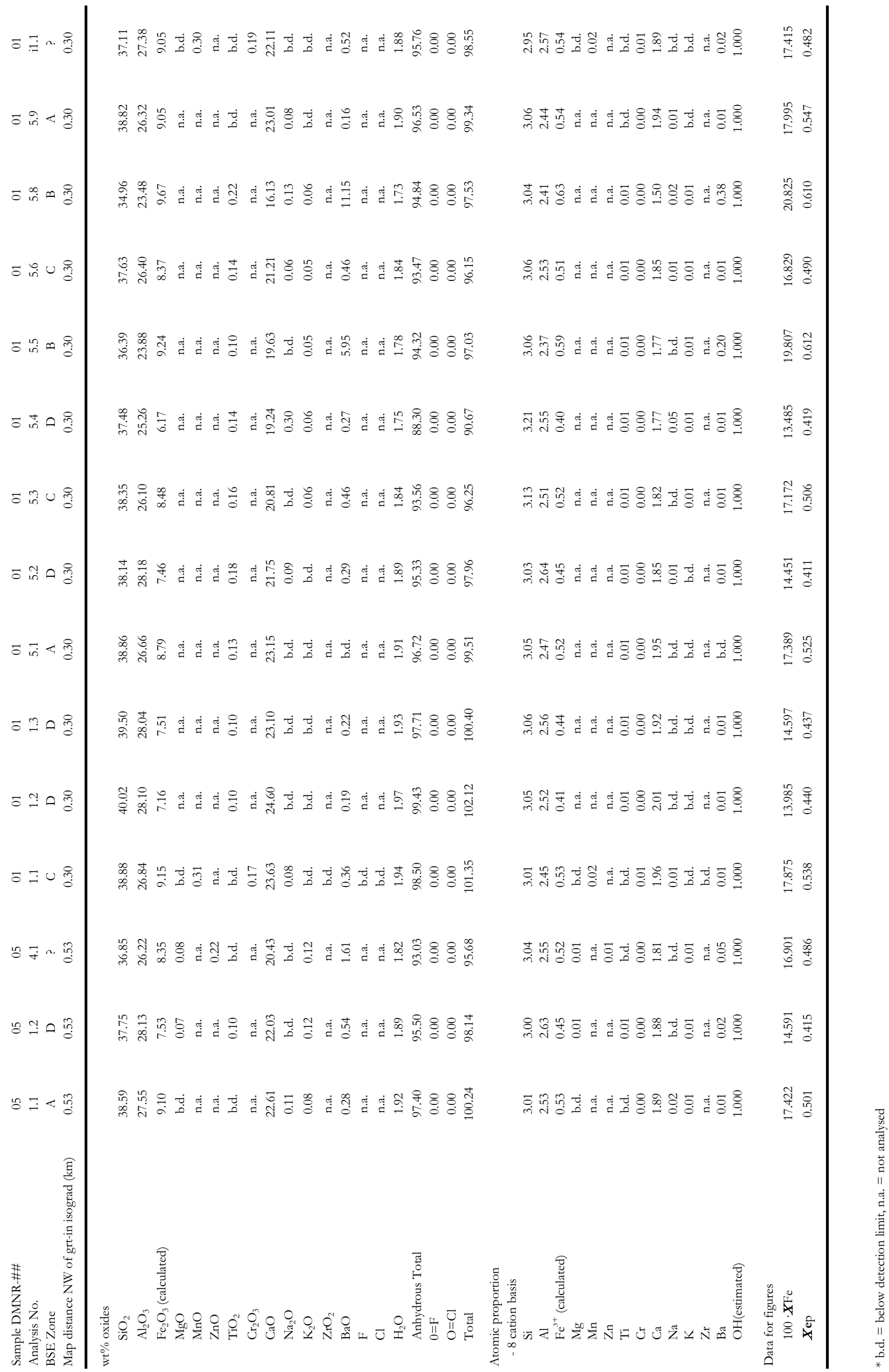




\begin{tabular}{|c|c|c|c|}
\hline b & 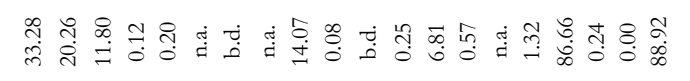 & भُ & 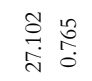 \\
\hline 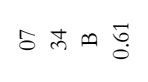 & 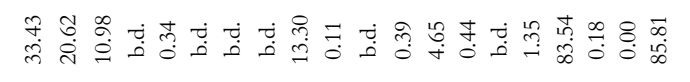 & 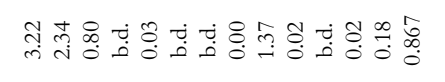 & 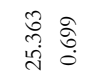 \\
\hline $5 \approx \infty \stackrel{\overrightarrow{0}}{0}$ & 品 숑 & 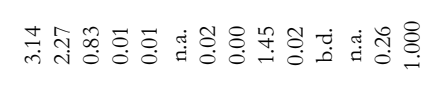 & \&: \\
\hline$\vec{b} \approx<\overrightarrow{0}$ & 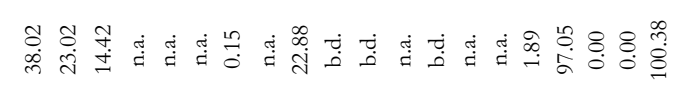 & 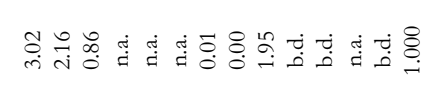 & 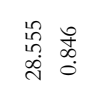 \\
\hline 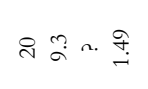 & 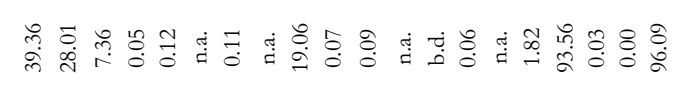 & 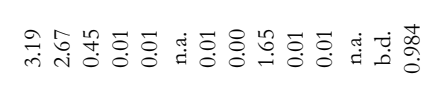 & 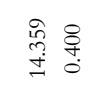 \\
\hline \& & 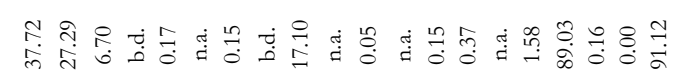 & 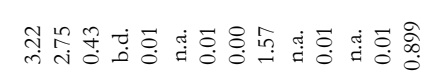 & 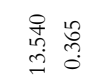 \\
\hline 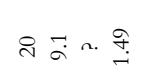 & 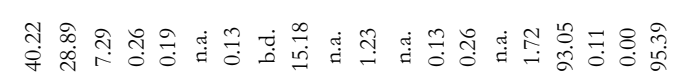 & 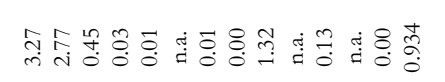 & 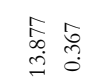 \\
\hline 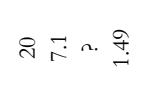 & 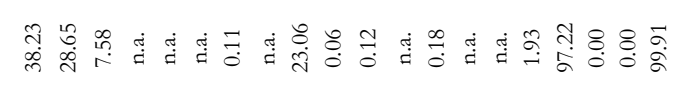 & 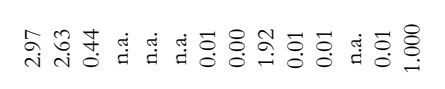 & 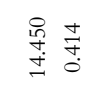 \\
\hline \& & 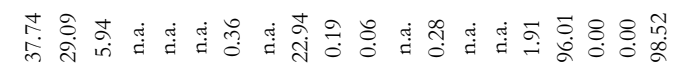 & 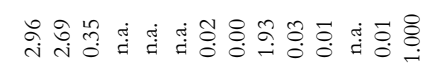 & 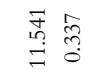 \\
\hline 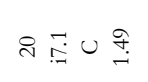 & 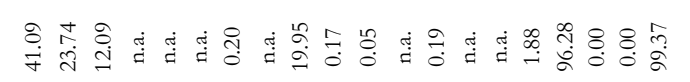 & ભ & 窟点 \\
\hline 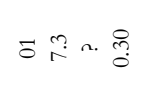 & 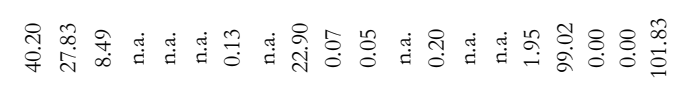 & 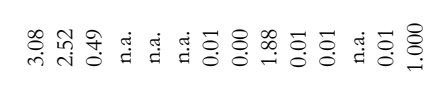 & 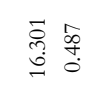 \\
\hline$\Xi \stackrel{1}{\pi} n \cdot \frac{8}{0}$ & 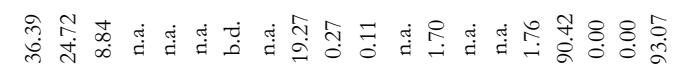 & ğ & 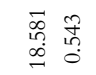 \\
\hline 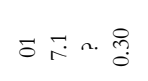 & 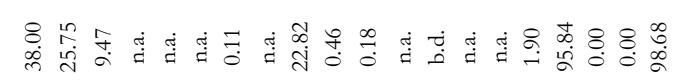 & 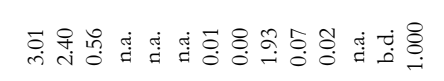 & 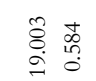 \\
\hline$\Xi \stackrel{?}{=} \cdots \stackrel{8}{8}$ & 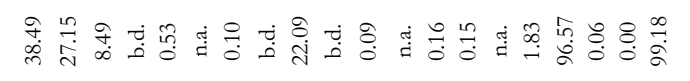 & 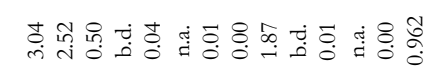 & 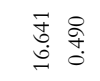 \\
\hline 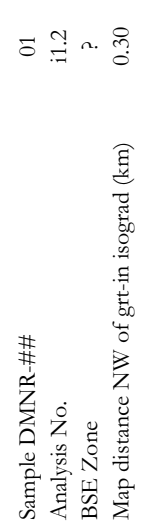 & 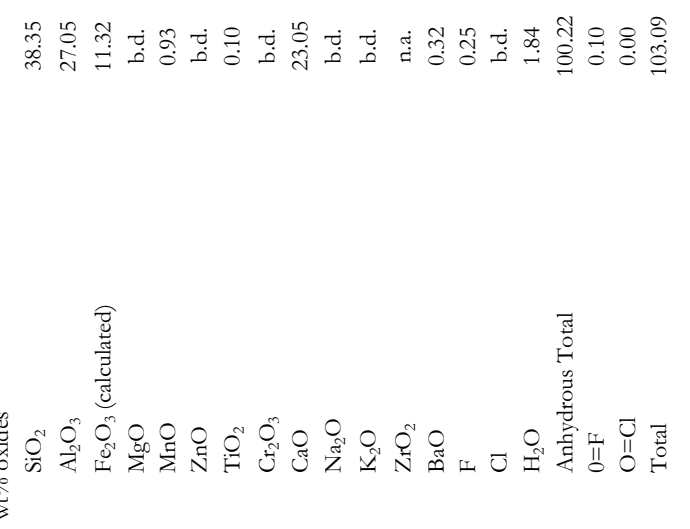 & 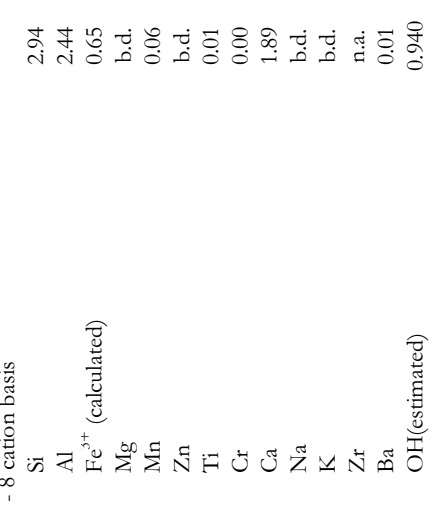 & 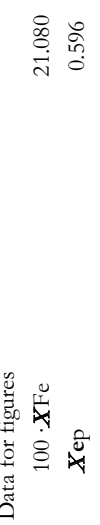 \\
\hline
\end{tabular}




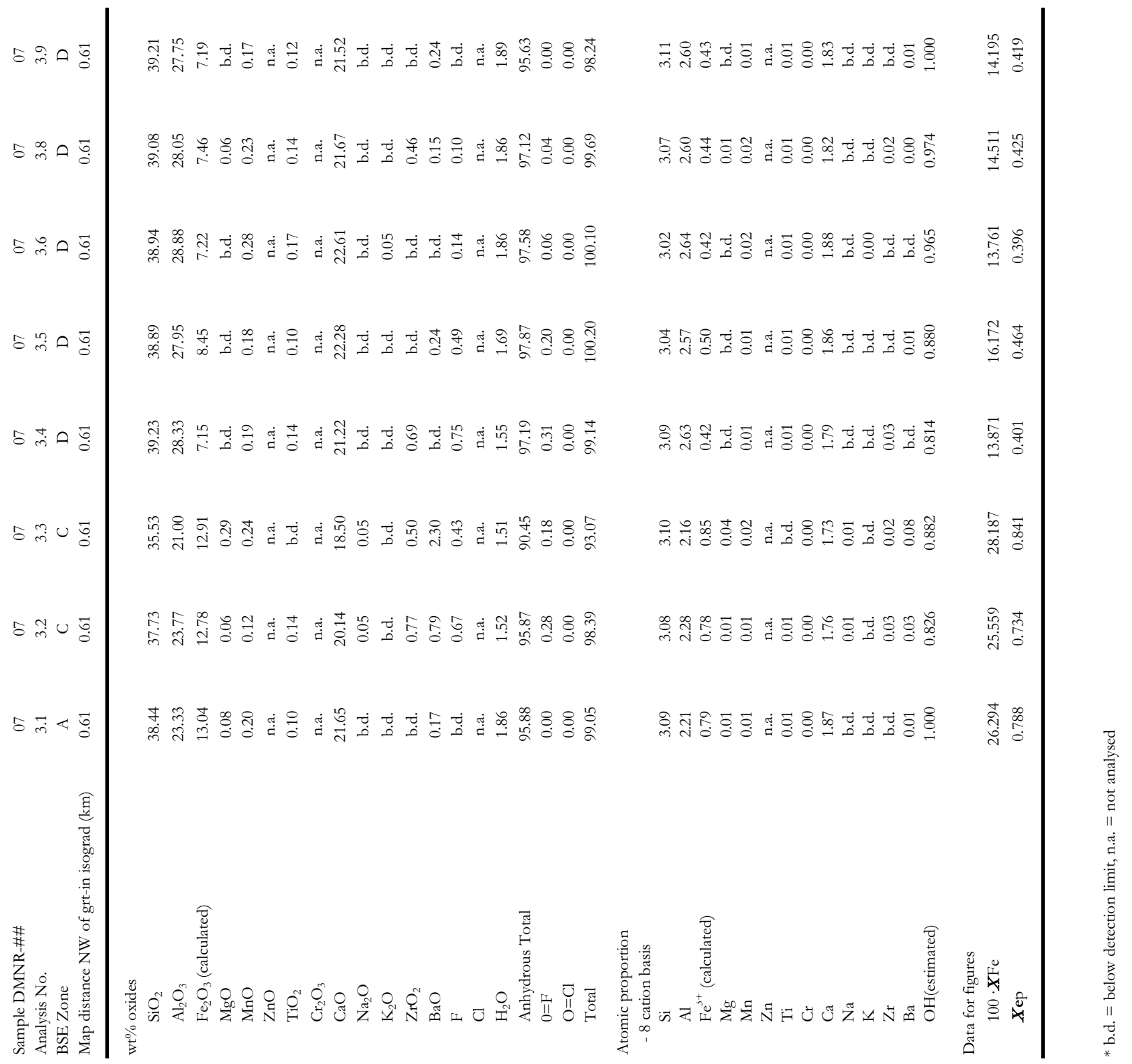




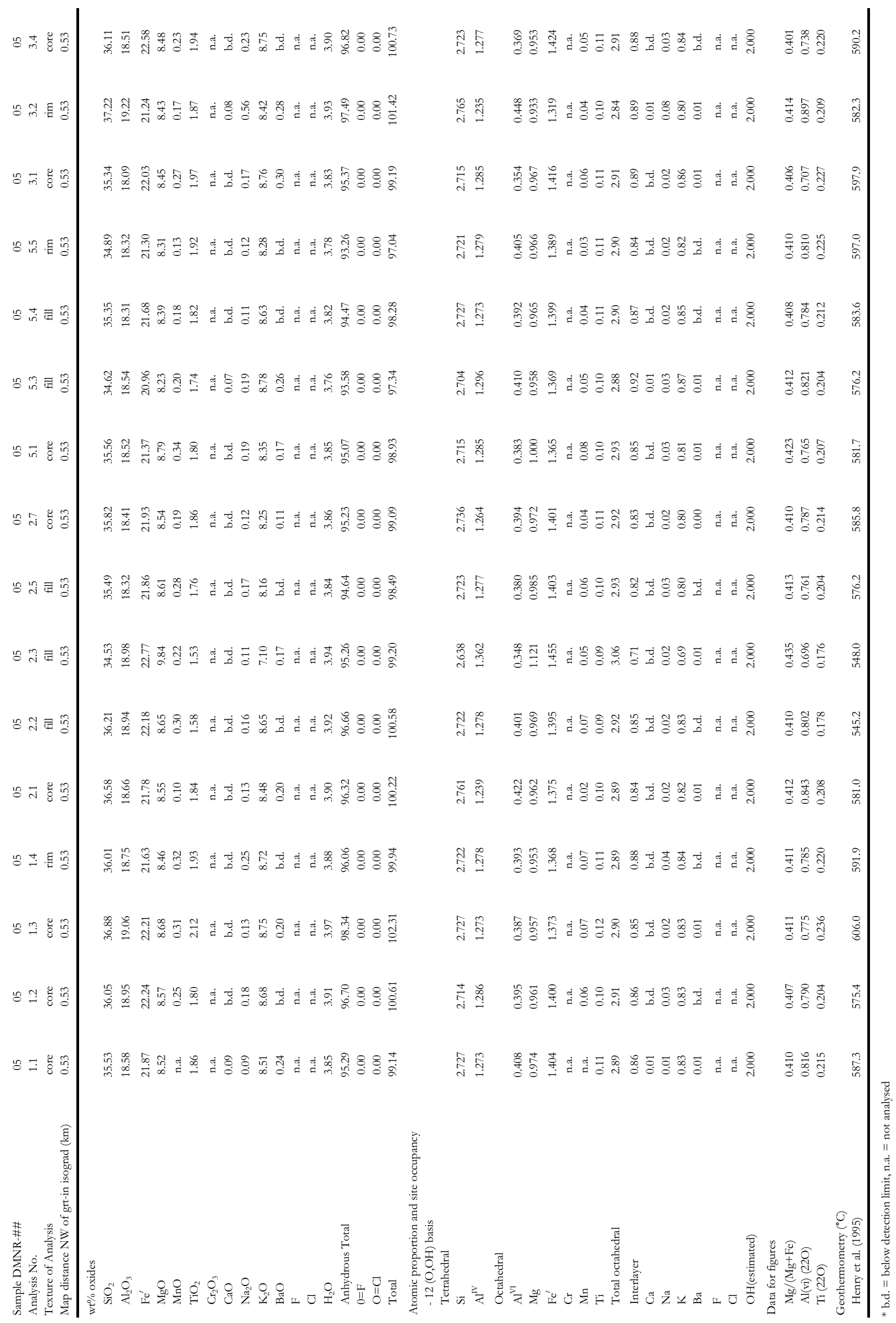




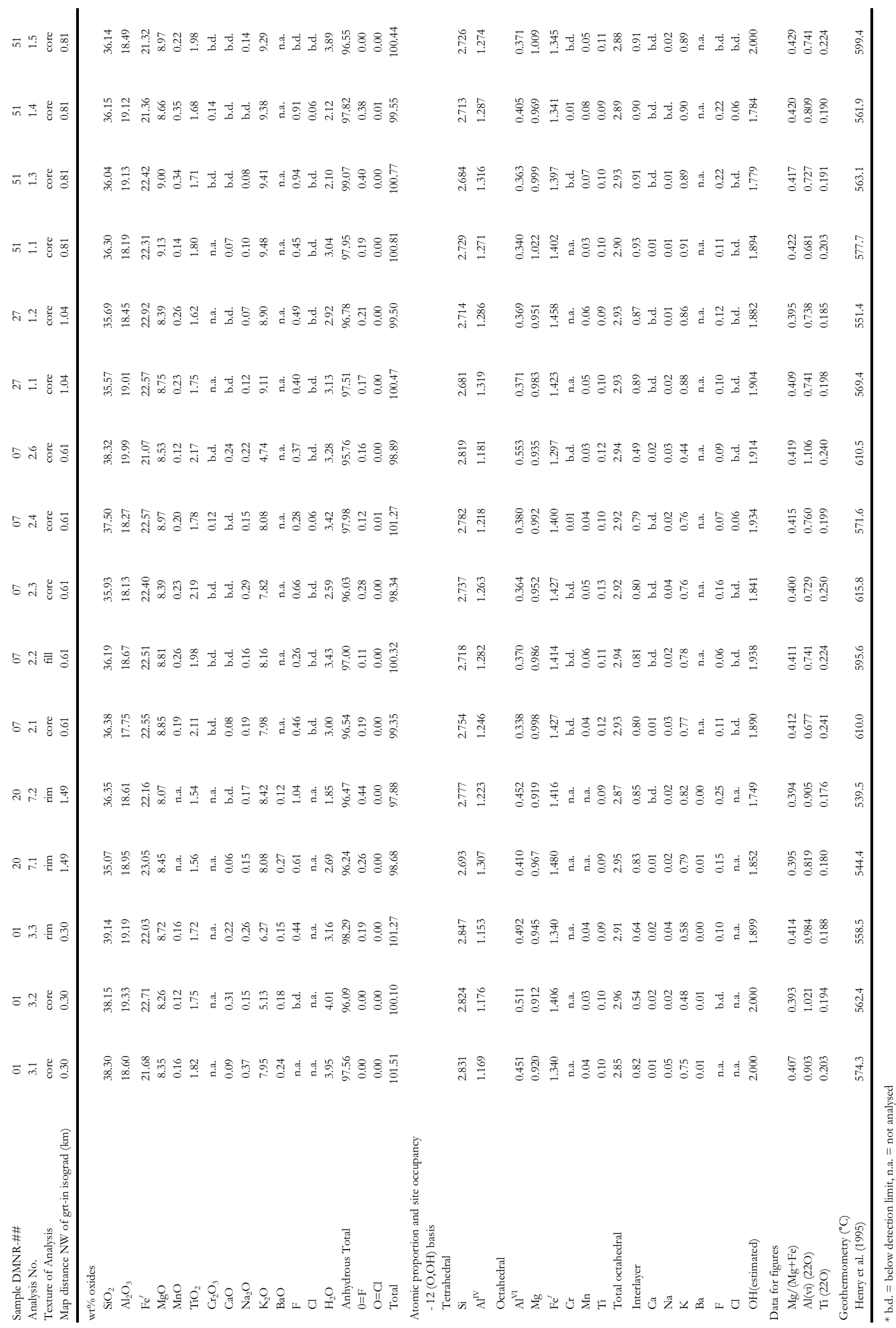




\begin{tabular}{|c|c|c|c|c|c|}
\hline$\varnothing \cong$ & 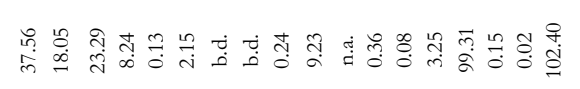 & 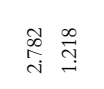 & 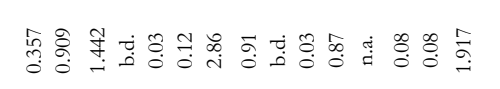 & 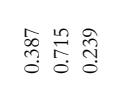 & \\
\hline 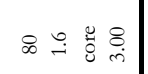 & 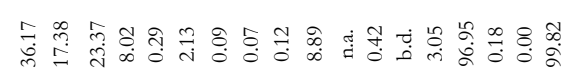 & 党 & 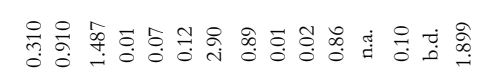 & 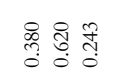 & \\
\hline 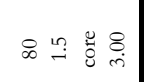 & 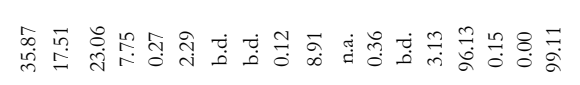 & 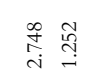 & 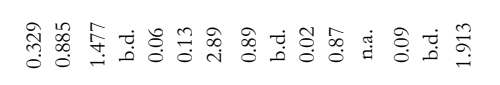 & 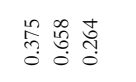 & तु่ \\
\hline$\infty \cong$ & 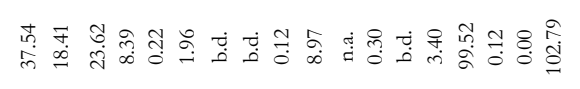 & 劳 & 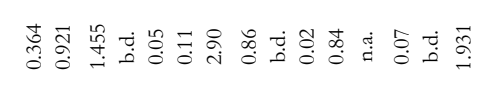 & $\begin{array}{l}\infty \\
\infty \\
\substack{D \\
0} \\
0\end{array}$ & 承 \\
\hline 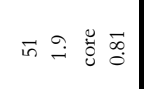 & 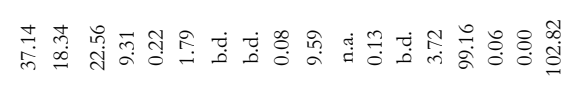 & 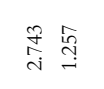 & 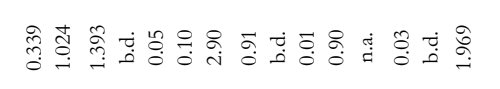 & 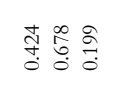 & in \\
\hline 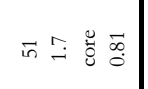 & 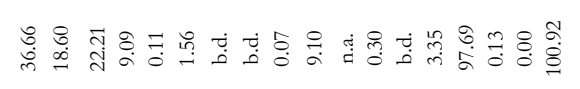 & 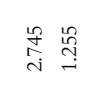 & 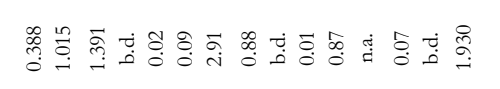 & 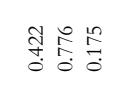 & 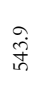 \\
\hline 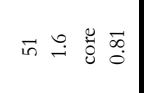 & 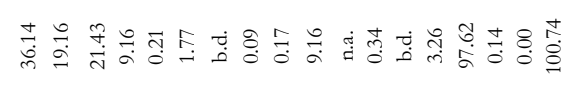 & 芳商 & 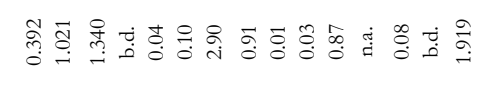 & 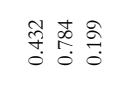 & \\
\hline 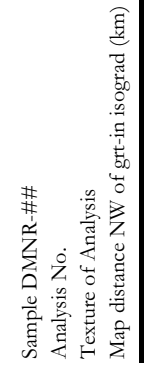 & 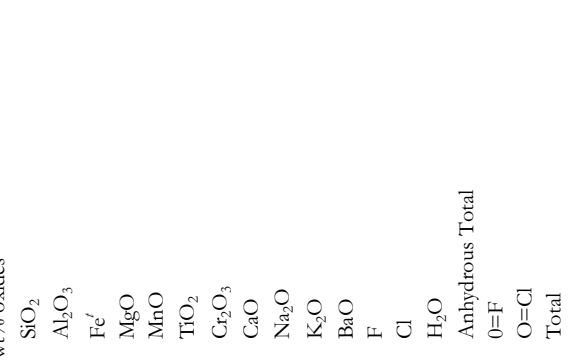 & & 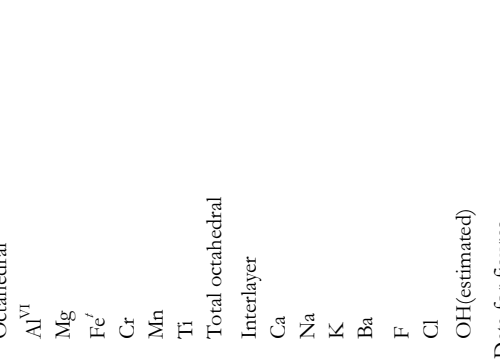 & 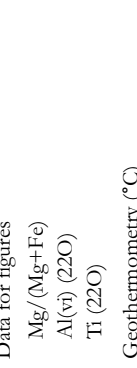 & \\
\hline
\end{tabular}




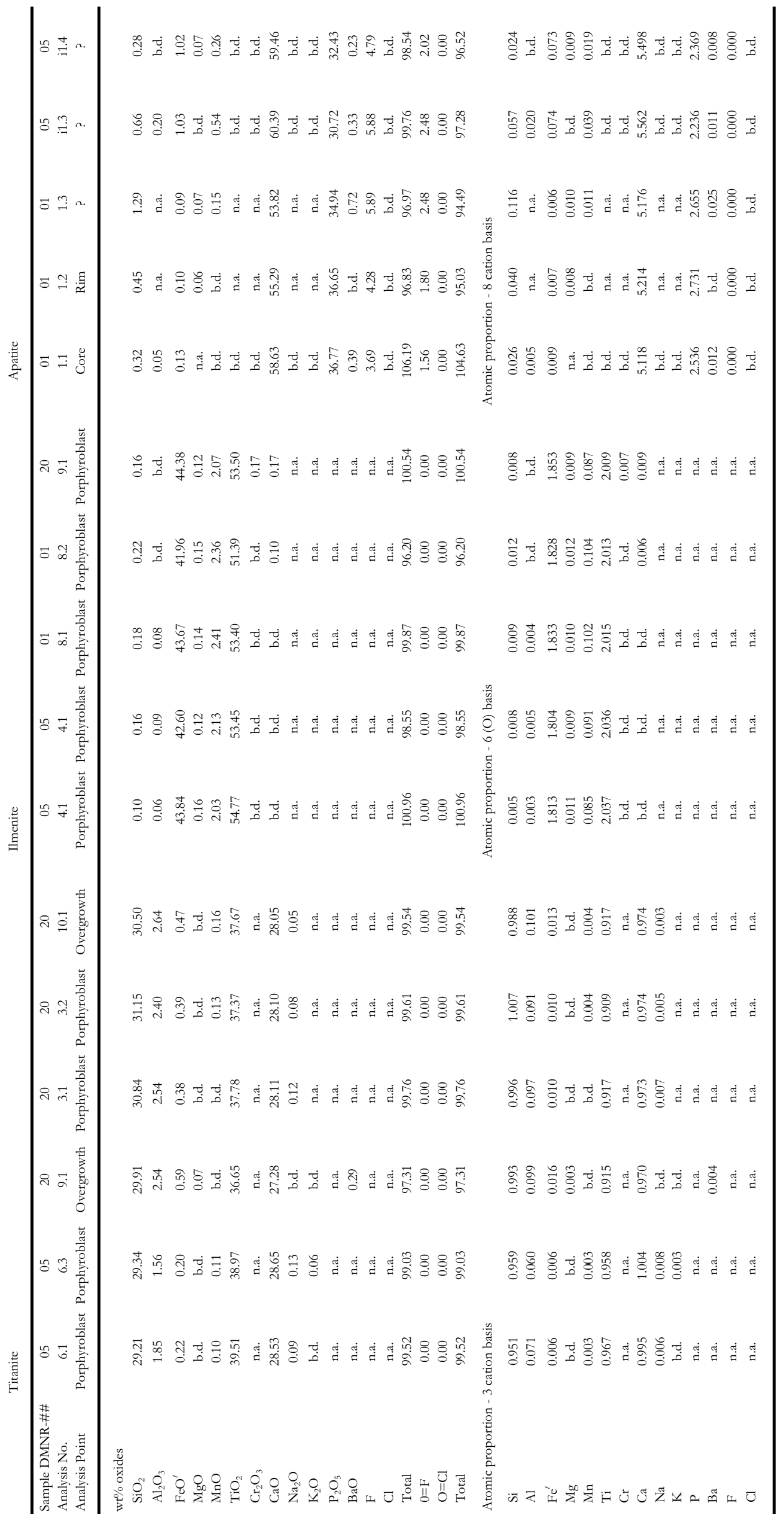




\begin{tabular}{|c|c|c|c|c|}
\hline I & 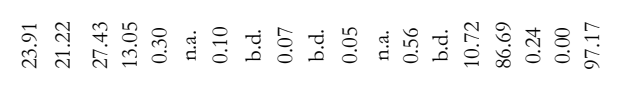 & 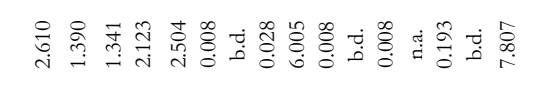 & 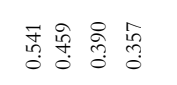 & $\begin{array}{l}0 \\
\infty \\
\infty \\
\infty\end{array}$ \\
\hline & 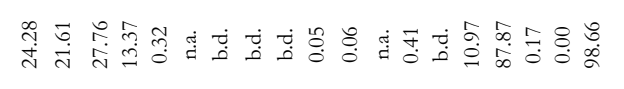 & 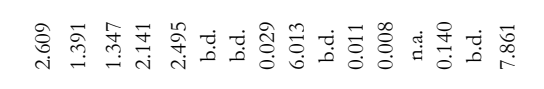 & 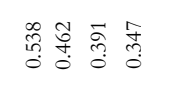 & \\
\hline & 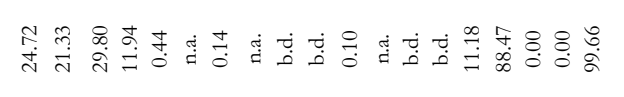 & 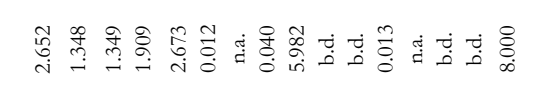 & 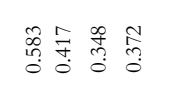 & 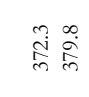 \\
\hline $\overrightarrow{\mathrm{i}}$ & 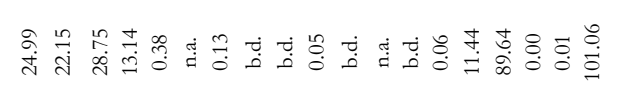 & 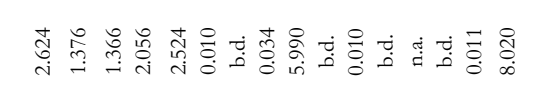 & 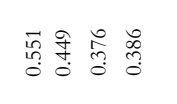 & 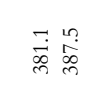 \\
\hline $\overrightarrow{\mathrm{i}}$ & 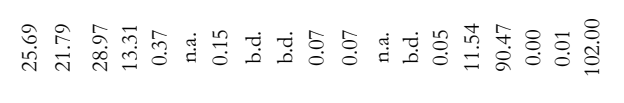 & 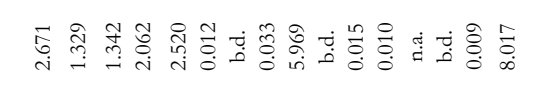 & 品拿 商 & 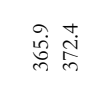 \\
\hline 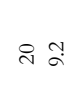 & 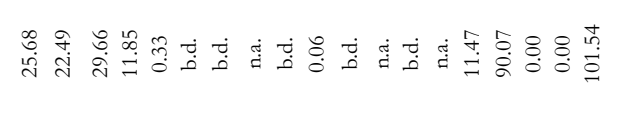 & 劳 & 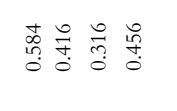 & 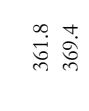 \\
\hline$\vec{a}$ & 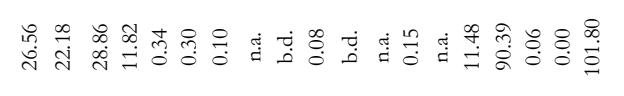 & 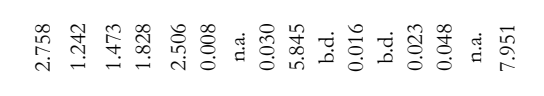 & 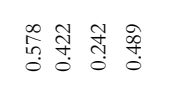 & 宰 \\
\hline$F$ & 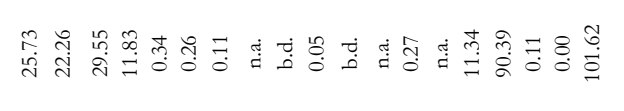 & 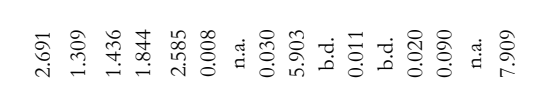 & 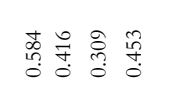 & 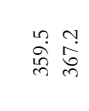 \\
\hline ? & 商 & 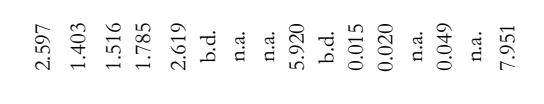 & 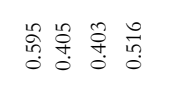 & $\begin{array}{ll}\infty & 0 \\
0 \\
0 \\
\infty\end{array}$ \\
\hline$\rightarrow$ & 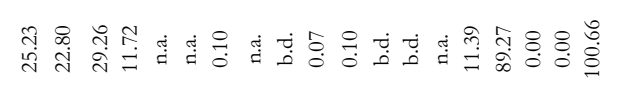 & 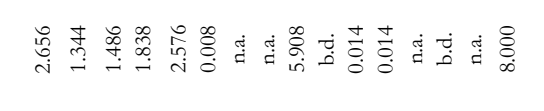 & 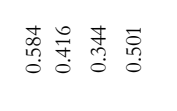 & 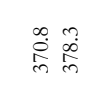 \\
\hline$\stackrel{t}{r}$ & 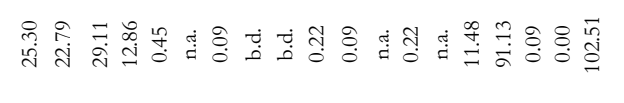 & 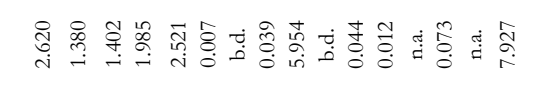 & 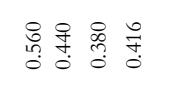 & 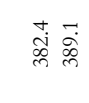 \\
\hline$\stackrel{9}{n}$ & 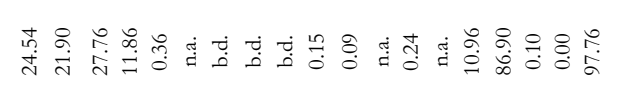 & 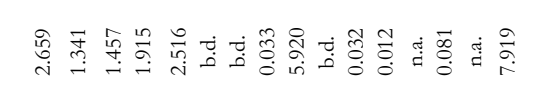 & 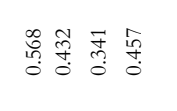 & 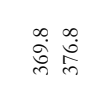 \\
\hline$\stackrel{7}{\pi}$ & 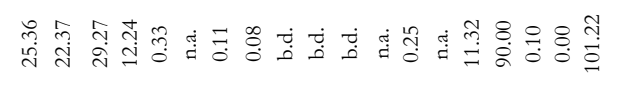 & 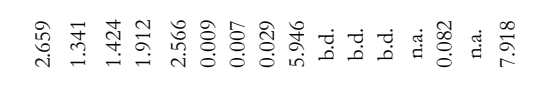 & 超然表亭 & 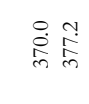 \\
\hline$\underset{n}{F}$ & 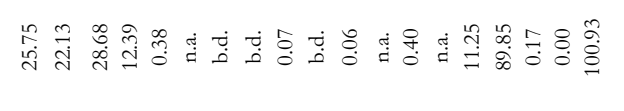 & 总 & 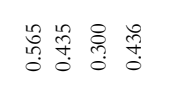 & 总商 \\
\hline$\Rightarrow$ & 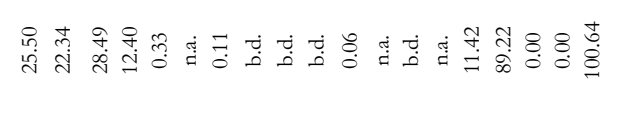 & 点 & 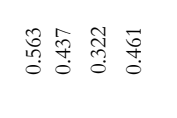 & 焉总 \\
\hline 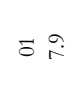 & 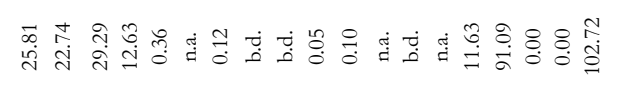 & 엉 & 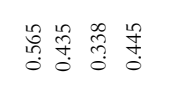 & 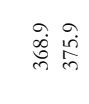 \\
\hline n? & 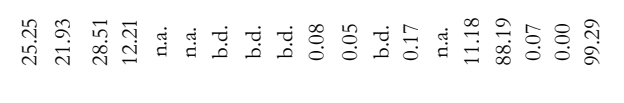 & 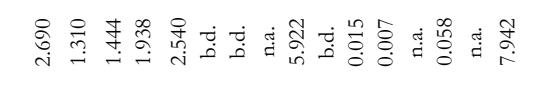 & 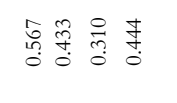 & 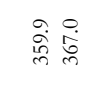 \\
\hline & 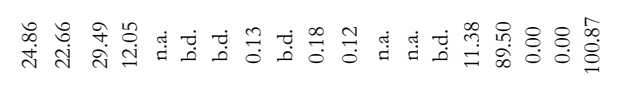 & శ్రి & 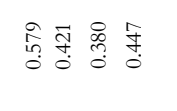 & 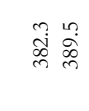 \\
\hline$\sum_{\substack{\infty \\
\frac{0}{0}}}^{\infty}$ & 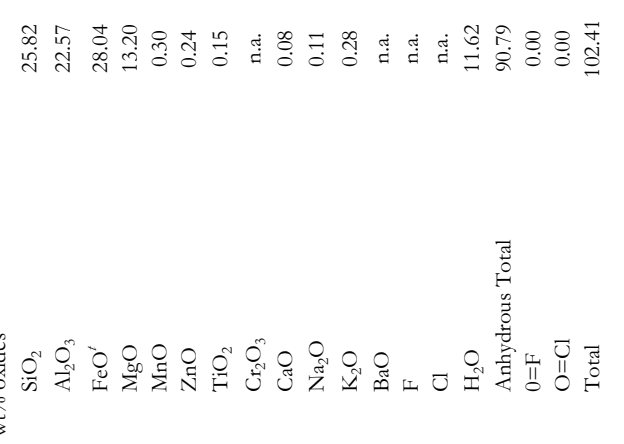 & 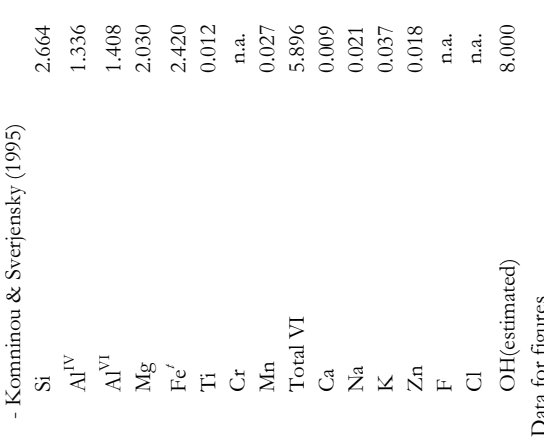 & 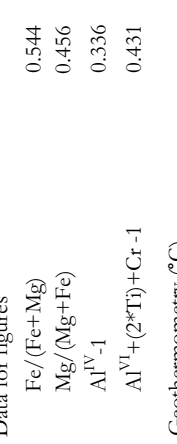 & 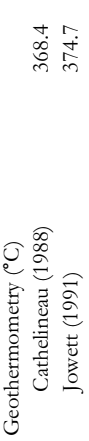 \\
\hline
\end{tabular}


Appendix A4.1

\section{ACTIVITY-COMPOSITION MODELS}

Pure Phases

Quartz

Albite

Lawsonite

Prehnite (only used for DMNR-27)

$\mathrm{H}_{2} \mathrm{O}$

Chlorite

(NKFMASHTO)

(Coggon \& Holland, 2002)

\section{Muscovite}

NKFMASH

(Coggon \& Holland, 2002)

Paragonite

NKFMASH

(Coggon \& Holland, 2002)
(White \& Holland, 2002)

\section{Epidote}

3 Endmember (clinozoisite, $\mathrm{Al}$ epidote, $\mathrm{Fe}$ epidote)

(Holland \& Powell, 1998)?

\section{Garnet}

$\mathrm{Fe}, \mathrm{Mg}, \mathrm{Mn}, \mathrm{Ca}$

Non-ideality grossular \& pyrope (Vance \& Holland, 1993)

Non-ideality grossular \& pyrope (Holland \& Powell, 1998)

\section{Ilmenite}

Ideal solution of ilmenite $\left(\mathrm{FeTiO}_{3}\right)$ and pyrophanite (MnTiO3)

\section{Plagioclase}

$\mathrm{Na}+\mathrm{Ca}$

(Holland \& Powell, 2003)

\section{Biotite}

KFMASHTO
Pumpellyite (only used for DMNR-27)

$\mathrm{Mg}+\mathrm{Fe}$ 
Appendix A4.2

\section{ACTIVITY-COMPOSITION MODEL INPUT FILE}

$\%$ MnNaCaKFMASHTO, no mixed fluid; using pure $\mathrm{H} 2 \mathrm{O}$ instead $\%$ no cc, dol, sph, magnetite, $\mathrm{co}_{2}$

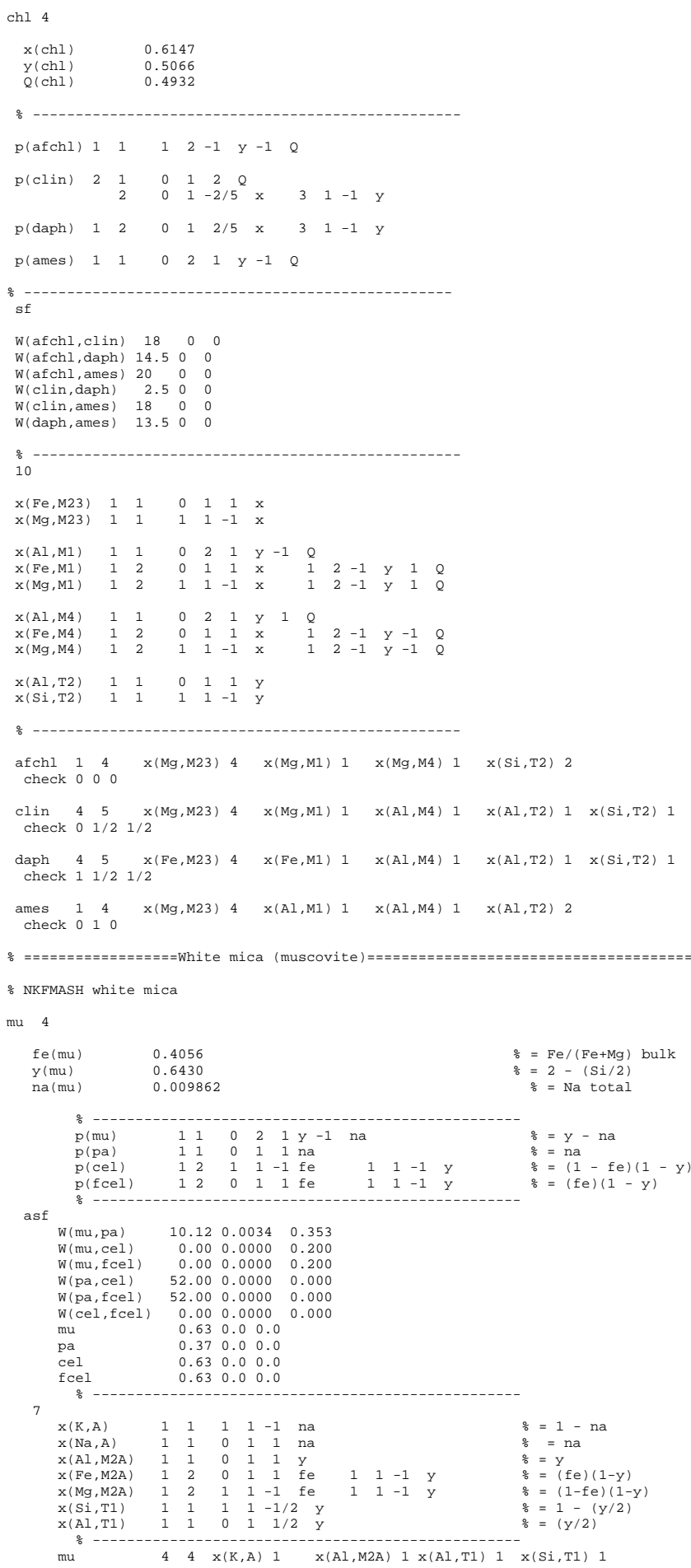




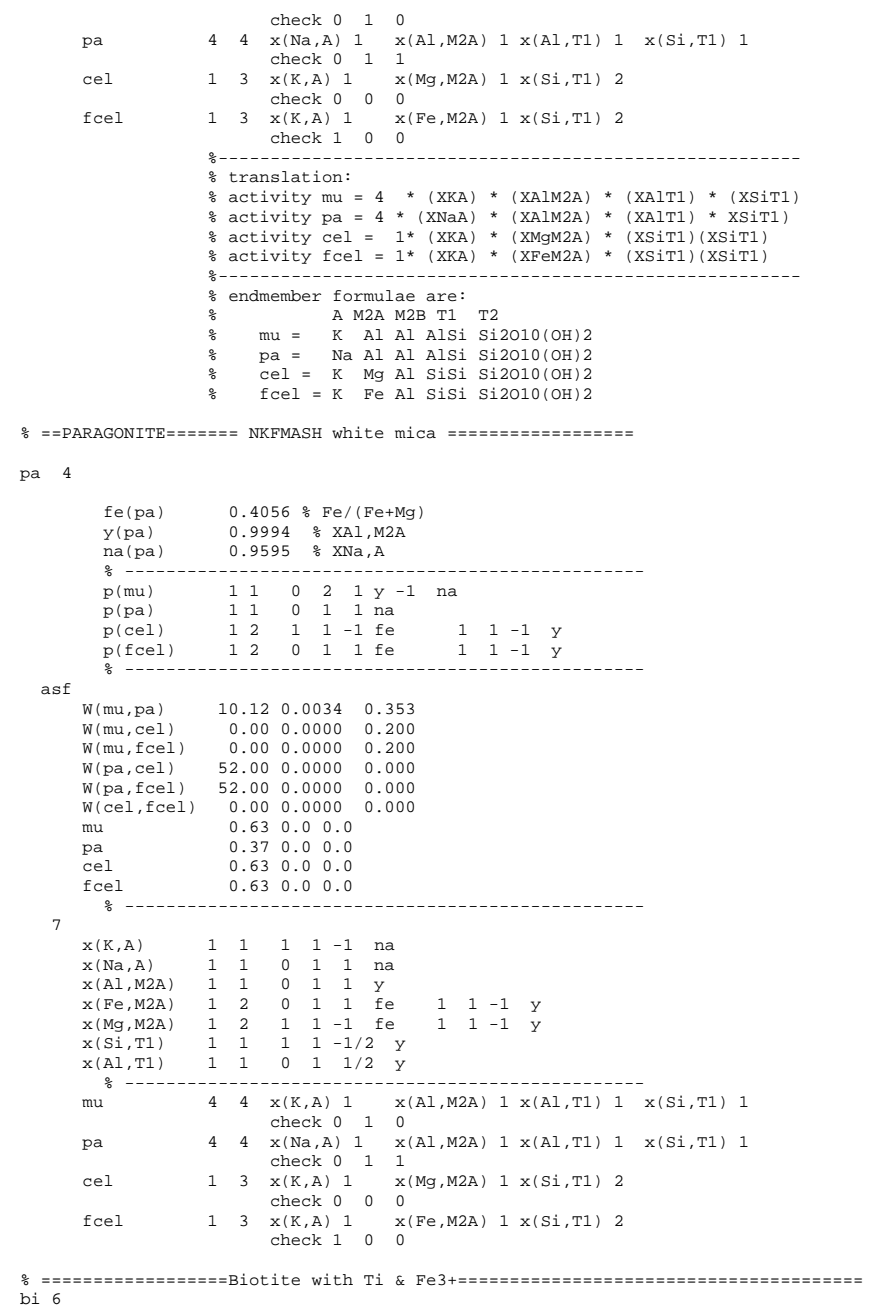

$\%===$
bi 6

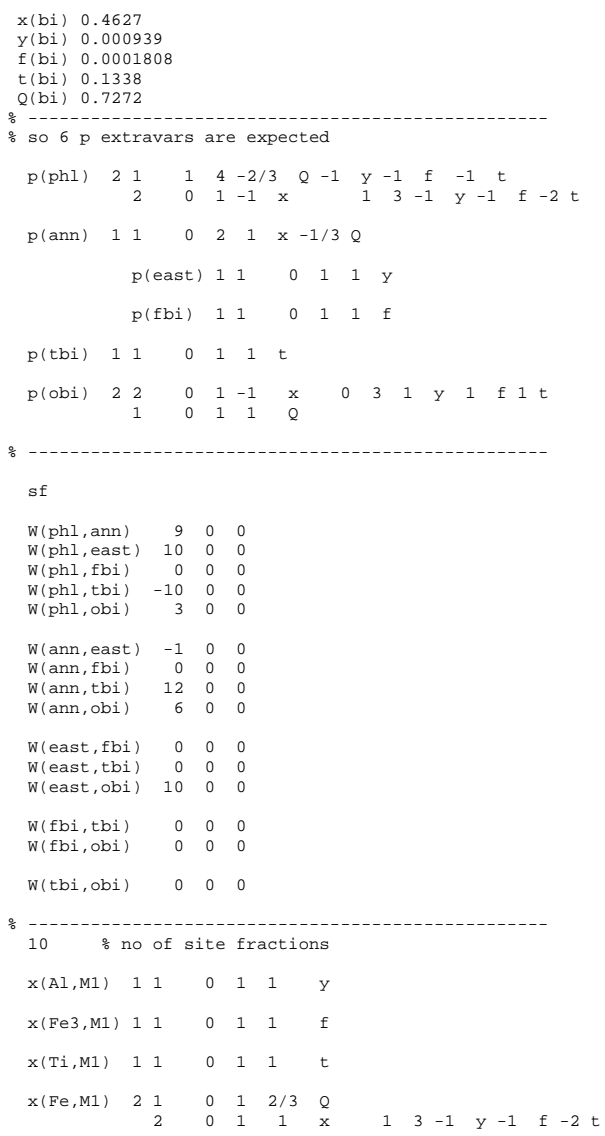




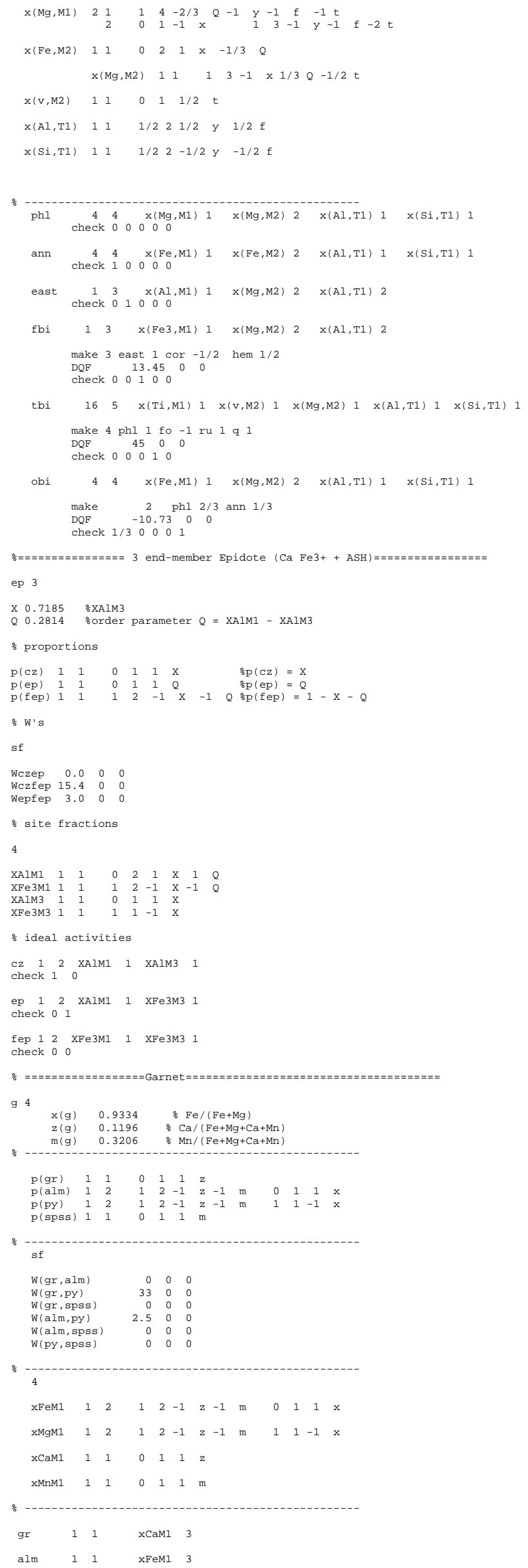




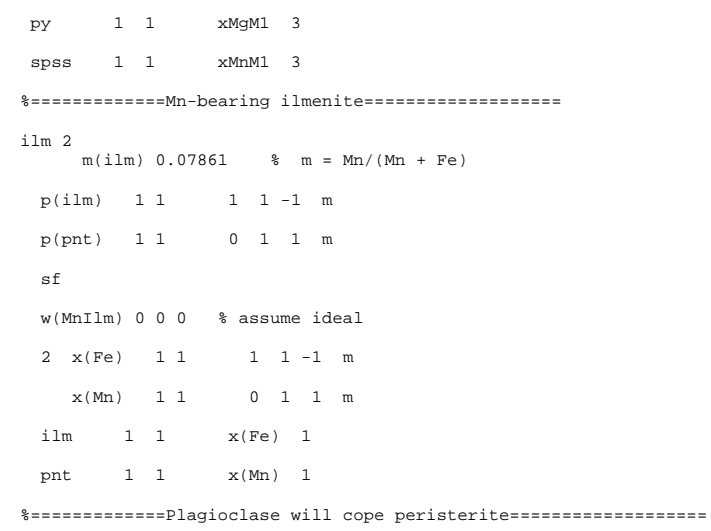

$\%$ from ternary plag mode for Cbar1 ASF

pl 2

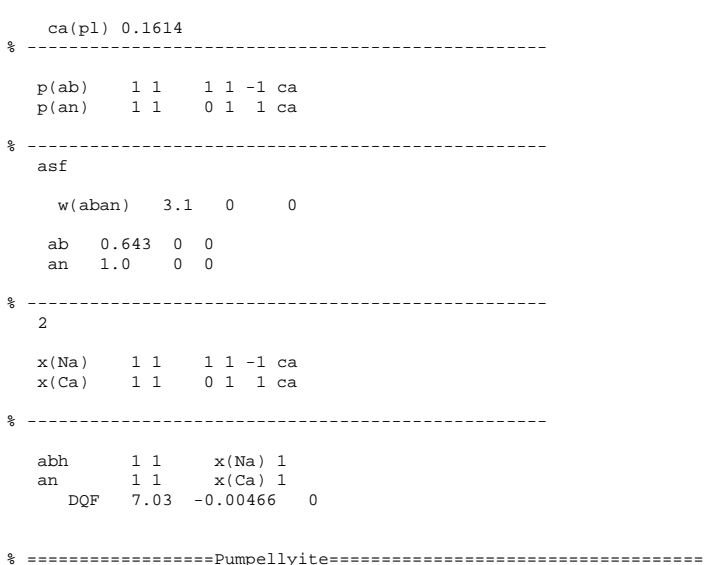

pump 2
$\times$ (pump) 0.76

$\mathrm{p}$ (m) $\begin{array}{lllllllll} & 1 & 1 & 1 & -1 & -1\end{array}$

ideal

$2 \times(\mathrm{Mg}) \quad 1 \quad 1 \quad 1 \quad 1 \quad-1 \times$

$x(\mathrm{Fe}) 1100111 \times$

pump $11 \times \times(\mathrm{Mg}) 1$

nake 3 pump 1 mctd -1 fctd 1

DQF 800

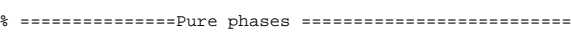

q ab law pre $\mathrm{H} 20 \%$ ab, with $\mathrm{pl}$ above, allows peristerite to be handled

$\%$ NOTE: $\quad C$ is in list of mineral abbreviations but is not in the pdata dataset

$\%$ so currently can't do graphite or graphite out, or graphite reduction of $\mathrm{Fe} 3+$ 
Appendix A4.3

\section{CHAPTER SEVEN MINERAL ABBREVIATIONS}

$\begin{array}{ll}\text { Albite } & \mathrm{ab} \\ \text { Biotite } & \mathrm{bi} \\ \text { Chlorite } & \mathrm{chl} \\ \text { Epidote } & \mathrm{ep} \\ \text { Garnet } & \mathrm{g} \\ \text { Ilmenite } & \mathrm{ilm} \\ \text { Lawsonite } & \mathrm{law} \\ \text { Muscovite } & \mathrm{mu} \\ \text { Paragonite } & \mathrm{pa} \\ \text { Plagioclase } & \mathrm{pl} \\ \text { Prehnite } & \mathrm{pre} \\ \text { Pumpellyite } & \mathrm{pump} \\ \text { Quartz } & \mathrm{q} \\ \text { Water } & \mathrm{H}{ }_{2} \mathrm{O}\end{array}$

